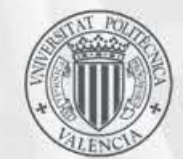

UNIVERSITAT POLITECCNICA DE VALÈNCIA
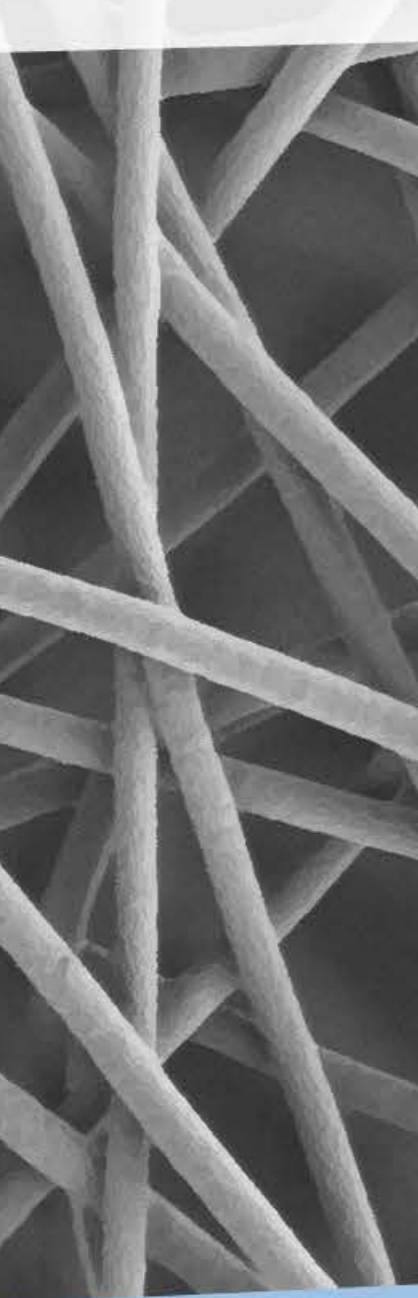

Development, characterisation and validation of functionalised polymer-based materials for smart applications

O. Gil-Castell

A. Ribes-Greus

J.D. Badia

July, 2018 


\section{Development, characterisation and validation of} functionalised polymer-based materials for smart applications

Submitted by:

$$
\text { Óscar Gil Castell, M. Sc. }
$$

Supervisors:

Amparo Ribes Greus, Ph. D.

José David Badia Valiente, Ph. D. 

Diu la creença popular que les energies -tant del pensament propi, com del cosmos- t'ajuden a aconseguir allò que et proposes o desitges $i$, majoritàriament, tendeix a ser útil i positiu.

Serà això cert?

Popular belief affirms that energies - both own thinking and from the cosmos- help you to achieve what you propose or desire, and most of all, tend to be useful and positive.

Is this true? 



\section{DECLARATION}

Amparo Ribes Greus, Professor at the Department of Heat Engines and Motors and researcher at the Institute of Technology of Materials of the Universitat Politècnica de València, and José David Badia Valiente, Assistant Professor at the Department of Chemical Engineering of the School of Engineering of the Universitat de València,

Certify that,

This work that has been carried out and presented by M. Sc. Óscar Gil Castell in partial fulfilment of the requirements for the Degree of Doctor of Philosophy in Engineering and Industrial Production with International mention, has been developed under our supervision and direction in the laboratories of the Group of Functionalisation, Degradation and Recycling of Polymer Materials at the Institute of Technology of Materials, as well as in the laboratories of the Department of Technology of Fibres and Polymers of the School of Engineering Sciences in Chemistry, Biotechnology and Health of the Kungliga Tekniska Högskolan (KTH), Stockholm, Sweden.

For the record, we sign this document in Valencia, May 2018. 



\section{Abstract}

The understanding of new materials and methodologies have led to an exponential progress of polymer science. Recent advances in polymer modification and processing techniques have endorsed amazing functionalities to cover the features required in specific applications. The aim of this thesis was to develop appropriate research strategies of functionalisation of polymers based on a multi-stage scheme, involving the design, processing, characterisation, and validation to meet the requisites of specific durability and service life. This methodology was applied to provide alternative solutions that respond to service requirements in several applications, such as photo-stabilisation of polyolefins for outdoor applications, polyelectrolyte membranes for fuel cells, and scaffolds for tissue engineering.

The functionalisation of polymers was performed by macromolecular modification, blending, and combination with micro and nanoparticles. Processing techniques such as solvent-casting, hot-melt extrusion, compression moulding and electrospinning permitted to obtain specific physico-chemical features, which were determined by spectroscopy, chromatography, microscopy and thermal analysis. In addition, a validation procedure was performed by means of real or simulated service conditions, which helped assess the suitability of the functionalised polymer-based materials.

In the field of the photo-stabilisation of polyolefins, polydisperse silicon particles provided high stability to raw non-additivated polypropylene (PP) against sunlight irradiation in terms of appearance, thermal stability and mechanical properties.

In order to design polyelectrolytes for fuel cells, the cross-linking and sulfonation of poly(vinyl alcohol) (PVA) with sulfosuccinic acid (SSA) was considered. The combination with graphene oxide (GO) and chitosan (CS) was also explored. The new functionalised films or nanofibrous polyelectrolytes, offered dimensional and thermal stability under service conditions, were electric insulators, and revealed promising performance in terms of proton conductivity.

Functionalised blended scaffolds of polycaprolactone (PCL) and gelatin (Ge) were obtained for tissue engineering. The control of the dissolution time into a formic/acetic acid hydrolytic solvent prior to electrospinning permitted to obtain tailored scaffolds, in terms of nanofibrous morphology, physico-chemical performance and biocompatibility. The scaffolds with balanced ratios of $\mathrm{PCL} / \mathrm{Ge}$ promoted in vitro cell adhesion and proliferation, as well as suited appropriate durability under in vitro conditions and during the in vivo implantation. 


\section{RESUM}

L'estudi de nous materials i metodologies ha resultat en un progrés exponencial de la ciència de polímers. Els recents avanços en la modificació d'aquests materials, juntament amb l'ús de noves tècniques de processat, han aportat extraordinàries funcionalitats per afrontar les necessitats requerides en aplicacions específiques. En aquest sentit, l'objectiu de la present tesi fou desenvolupar l'estratègia d'investigació adequada per a la funcionalització de polímers, basada en un esquema de múltiples etapes, implicant el disseny, processat, caracterització i validació del compliment dels requisits de durabilitat específica i vida útil. Aquesta metodologia es va aplicar per aportar solucions alternatives en aplicacions com la foto-estabilització de poliolefines exposades a l'aire lliure, el desenvolupament de membranes de polielectròlits per a piles de combustible i de bastides per a enginyeria de teixits.

La funcionalització dels polímers es va realitzar mitjançant tècniques de modificació macromolecular, mescla, i combinació amb micro i nanopartícules. Es van considerar tècniques de processat com la dissolucióabocament, l'extrusió per fusió en calent, l'emmotllament per compressió i l'electrofilat, les quals van permetre obtenir característiques fisicoquímiques específiques, que es van avaluar mitjançant tècniques d'espectroscòpia, cromatografia, microscòpia i anàlisi tèrmic. A més, es van realitzar els procediments de validació en condicions de servei reals o simulades, que van permetre avaluar la idoneïtat dels materials desenvolupats.

En el camp de la foto-estabilització de poliolefines, l'addició de micropartícules de silici polidispers va proporcionar una elevada estabilitat al polipropilè (PP) sense additivar davant de la irradiació solar, en termes d’aparença, estabilitat tèrmica i propietats mecàniques.

En el disseny de polielectròlits per a piles de combustible, es va considerar el entrecreuament i sulfonació de poli(alcohol vinílic) (PVA) amb àcid sulfosuccínic (SSA). També es va estudiar la combinació amb òxid de grafè (GO) i quitosà (CS). Tant els nous films funcionalitzats com els polielectròlits nanofibrosos, mostraren estabilitat dimensional i tèrmica en condicions de servei, foren aïllants elèctrics i revelaren un rendiment prometedor en termes de conductivitat protònica.

Es van obtenir bastides funcionalitzades per a enginyeria de teixits a partir de la mescla de policaprolactona (PCL) i gelatina (Ge). El control del temps de dissolució en un dissolvent hidrolític d'àcid fòrmic/acètic abans de l'electrofilat va permetre obtenir bastides amb característiques a mida, en termes de morfologia, comportament fisicoquímic i biocompatibilitat. Les bastides amb proporcions equilibrades de PCL i Ge van promoure l'adhesió i proliferació cel·lular in vitro, així com una durabilitat adequada en condicions in vitro i durant la implantació in vivo. 


\section{RESUMEN}

El estudio de nuevos materiales y metodologías ha resultado en un progreso exponencial de la ciencia de polímeros. Los recientes avances en la modificación de estos materiales, junto con el uso de técnicas de procesado novedosas, han aportado extraordinarias funcionalidades para afrontar las necesidades requeridas en aplicaciones específicas. En ese sentido, el objetivo de la presente tesis fue desarrollar la estrategia de investigación adecuada para la funcionalización de polímeros, basada en un esquema de múltiples etapas, implicando el diseño, procesado, caracterización y validación del cumplimiento de los requisitos de durabilidad específica y vida útil. Esta metodología se aplicó para aportar soluciones alternativas para aplicaciones como la foto-estabilización de poliolefinas al aire libre, el desarrollo de membranas de polielectrolitos para pilas de combustible y de andamios para ingeniería de tejidos.

La funcionalización de los polímeros se realizó mediante técnicas de modificación macromolecular, mezclado, y combinación con micro y nanopartículas. Se consideraron técnicas de procesado como la disoluciónvertido, la extrusión por fusión en caliente, el moldeo por compresión y el electrohilado, las cuales permitieron obtener características fisicoquímicas específicas, que se evaluaron mediante técnicas de espectroscopia, cromatografía, microscopía y análisis térmico. Además, se realizaron los procedimientos de validación en condiciones de servicio reales o simuladas, que permitieron evaluar la idoneidad de los materiales desarrollados.

En el campo de la foto-estabilización de poliolefinas, la adición de micropartículas de silicio polidisperso proporcionó una elevada estabilidad al polipropileno (PP) sin aditivar frente a la irradiación solar, en términos de apariencia, estabilidad térmica y propiedades mecánicas.

En el diseño de polielectrolitos para pilas de combustible, se consideró el entrecruzado y sulfonación de poli(alcohol vinílico) (PVA) con ácido sulfosuccínico (SSA). También se estudió la combinación con óxido de grafeno (GO) y quitosano (CS). Tanto los nuevos films funcionalizados como los polielectrolitos nanofibrosos, mostraron estabilidad dimensional y térmica en condiciones de servicio, fueron aislantes eléctricos y revelaron un rendimiento prometedor en términos de conductividad protónica.

Se obtuvieron andamios funcionalizados para ingeniería de tejidos a partir de la mezcla de policaprolactona (PCL) y gelatina (Ge). El control del tiempo de disolución en un disolvente hidrolítico de ácido fórmico/acético antes del electrohilado permitió obtener andamios con características a medida, en términos de morfología, comportamiento físicoquímico y biocompatibilidad. Los andamios con proporciones equilibradas de PCL y Ge promovieron la adhesión y proliferación celular in vitro, así como una durabilidad adecuada en condiciones in vitro y durante la implantación in vivo. 


\section{SAMMANFATTNING}

Forskning om nya material och metoder har lett till en exponentiell utveckling av polymervetenskap. Nyligen gjorda framsteg inom modifierings- och bearbetningstekniker av polymerer har möjliggjort nya funktioner för att använda i specifika applikationer. Syftet med denna avhandling var att utveckla lämpliga forskningsstrategier för funktionalisering av polymerer, baserad på ett flerstegssystem, som omfattar konstruktion, bearbetning, karakterisering och validering för att uppfylla krav i hållbarhet och livslängd. Denna metodik applicerades för att tillhandahålla alternativa lösningar som uppfyller krav på tjänster inom flera tillämpningar, till exempel fotostabilisering av polyolefiner i utomhustillämpningar, polyelektrolytiska membran för bränsleceller och strukturer för vävnadsteknik.

Funktionaliseringen av polymerer gjordes av makromolekylär modifiering, blandning och i kombination med mikro- och nanopartiklar. Bearbetningstekniker, till exempel lösningsmedelsgjutning, smältsträngssprutning, formpressning och elektrospinning tillät fysiokemiska funktioner som faststäldes med spektroskopi, kromatografi, mikroskopi och termisk analys. Dessutom utfördes en valideringsprocedur i reell eller simulerad omgivning, vilket bidrog till att bedöma lämpligheten hos de funktionaliserade polymerbaserade materialen.

Fotostabilisering av polyolefiner genom tillägg av polydispergerade kiselpartiklar gav hög stabilitet till polypropen (PP) utan tillsatser, mot strålning av soljus med avseende på utseende, termisk stabilitet och mekaniska egenskaper.

I syfte att utforma polyelektrolyter för bränsleceller, övervägdes tvärbinding och sulfonering av poly (vinylalkohol) (PVA) med sulfosuccinsyra (SSA). Kombinationen grafenoxid (GO) och kitosan (CS) undersöktes också. Nya funktionaliserade nanofibrösa filmer eller polyelektrolyter, gav termisk och dimensionsstabilitet, agerade som elektriska isolatorer och uppvisade lovande resultat i protonledningsförmåga.

Funktionaliserade blandade strukturer av polykaprolakton (PCL) och gelatin (Ge) erhölls för vävnadsteknik. Kontroll av upplösningstiden till ett hydrolytiskt lösningsmedel i myr/ättiksyra innan electrospinning tillät att få skräddarsydda strukturer, i nanofibrös morfologi, fysiokemiska prestanda och biokompatibilitet. Strukturerna med balanserade förhållanden av PCL/Ge främjade in vitro celladhesion och proliferation, liksom lämplig hållbarhet under in vitro-förhållandenoch under implantation in vivo. 


\section{TABLE OF CONTENTS}

Abstract

Resum

III

Resumen

$\mathrm{V}$

Sammanfattning

VII

Table of contents

IX

\section{Chapter 1. Motivation, aim and overview}

1.1. Motivation and aim

1.2. Overview

1.3. References of Chapter 1

1.4. Contributions of Chapter 1

Contribution 1.1. Long-term properties and end-of-life of

2.1. Experimental strategy

2.2. Materials and reagents

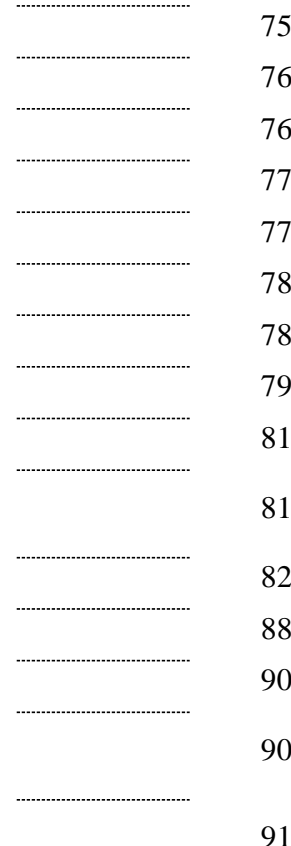

2.2.1. Polymers

2.2.2. Reagents and solvents

2.2.3. Obtaining of silicon microparticles

77

2.2.4. Sulfonation of poly(vinyl alcohol) (PVA)

2.2.5. Obtaining of graphene oxide (GO)

2.2.6. Sulfonation of graphene oxide (GO)

2.3. Processing techniques

2.3.1. Photo-stabilised polyolefins for outdoor applications

2.3.2. Polyelectrolyte membranes for fuel cells

2.3.3. Scaffolds for tissue engineering

2.4. Analytical techniques and calculation methods

2.4.1. Chemical structure. Fourier transform infrared spectroscopy (FT-IR)

2.4.2. Molar mass. Size exclusion chromatography (SEC) 
2.4.3. Surface morphology. Field emission scanning electron microscopy (FE-SEM)

2.4.4. Thermal properties. Differential scanning calorimetry (DSC)

2.4.5. Thermal and thermo-oxidative stability. Thermogravimetric analysis (TGA)

2.4.6. Thermo-mechanical properties. Dynamicmechanic-thermal analysis (DMTA)

2.4.7. Dielectric properties. Dielectric-thermal impedance spectrometry (DETA)

2.5. Validation of photo-stabilised polyolefins for outdoor applications

2.5.1. Accelerated sunlight irradiation procedure

2.6. Validation of polyelectrolyte membranes for fuel cells

2.6.1. Ethanol permeability

2.6.2. Swelling and solution uptake

2.6.3. Behaviour under simulated service conditions

2.6.4. Direct ethanol fuel cell (DEFC) test

2.7. Validation of scaffolds for tissue engineering

2.7.1. Hydrophilicity. Contact angle

2.7.2. Biocompatibility

2.7.3. In vitro hydrolytic degradation in physiologic conditions

2.8. References of Chapter 2

\section{Chapter 3.}

3.1.

\section{Photo-stabilised
applications}

Polyolefin degradation: polypropylene (PP) as a model case

3.2. Ultraviolet stabilisation of polypropylene (PP)

3.2.1. Radical scavengers

3.2.2. Hydroperoxide decomposers

3.2.3. Deactivators/energy quenchers

3.2.4. UV light absorbers

3.2.5. UV light screeners

3.3. Silicon microparticles as novel ultraviolet stabilisers

3.4. References of Chapter 3 
3.5. Contributions of Chapter 3

Contribution 3.1. Novel silicon microparticles to improve

Chapter 4. Polyelectrolyte membranes for fuel cells

4.1. Proton exchange fuel cells fed with alcohols

4.2. Poly(vinyl alcohol) (PVA)-based polyelectrolyte membranes

4.2.1. Nanocomposite PVA-based polyelectrolytes

4.2.2. Blended PVA-CS polyelectrolytes

4.3. References of Chapter 4

4.4. Contributions of Chapter 4

Contribution 4.1. Functionalised poly(vinyl alcohol)/ graphene oxide membranes for energy applications

Contribution 4.2. Crosslinked sulfonated poly(vinyl alcohol)/ graphene oxide electrospun nanofibres as polyelectrolytes

Contribution 4.3. Crosslinked chitosan/poly(vinyl alcohol)-based membranes for proton exchange polyelectrolytes

\section{Chapter 5. Scaffolds for tissue engineering}

5.1. Tissue engineering

5.2. Polymer-based functionalised scaffolds

5.2.1. Poly(lactide-co-glycolide) (PLGA)

5.2.2. Polycaprolactone (PCL)

5.2.3. Polyhydroxybutyrate (PHB)

5.2.4. Polydioxanone (PDO)

5.2.5. Gelatin (Ge)

5.3. References of Chapter 5

5.4. Contributions of Chapter 5

Contribution 5.1. In vitro validation of biomedical polyester-

based scaffolds: poly(lactide-co-glycolide) as model-case

Contribution 5.2. Comparison of in vitro hydrolytic degradation patterns of short-term and long-term polyester-based electrospun scaffolds

Contribution 5.3. Effect of the dissolution time into an acid hydrolytic solvent to tailor electrospun nanofibrous polycaprolactone scaffolds 
Contribution 5.4. Tailored electrospun nanofibrous

polycaprolactone/gelatin scaffolds into an acid hydrolytic solvent

system

Contribution 5.5. Validation of tailored electrospun nanofibrous

polycaprolactone/gelatin based scaffolds

Chapter 6. Conclusions and future work

\section{Glossaries}

Abbreviations

Symbols

Other contributions

Journal articles

Conference contributions

459

Scientific divulgation articles 


\section{CHAPTER 1.}

Motivation, aim and

\section{overview}




\subsection{Motivation AND Aim}

The polymer science development along the last decades has contributed not only to challenge the classical materials such as wood or metals in several applications, but also to speed up the conception of new products, which have contributed to spread the range of human activities.

The polymer technology is an intrinsically heterogeneous, transversal and multidisciplinary science, and include a broad spectrum of processes and phenomena, comprising the chemistry, physics, biology, materials science and engineering fields.

The functionalisation of polymers has been practised since their earliest origin in order to achieve new requirements for novel applications. In general, the polymer modification usually pursues the endorsement of new features such as physico-chemical performance, environmental stability, physical responses, biocompatibility or degradability, among others. Several functionalisation strategies have been proposed along the last years. Generally, polymer modification can be performed either by means of chemical or physical routes. The molecular modification of polymers can be achieved by grafting, crosslinking, copolymerisation or irradiation. As well, the blending of the polymer materials and its combination with particles or reinforcements has brought new opportunities in different fields. These external agents could be organic or inorganic phases, including either particles or fibres.

Recent advances in polymer modification have resulted in new amazing functionalities. Nevertheless, regardless the progress in the polymer science along the last decades, there is still an enormous field to exploit with many interesting opportunities. This, along with the progresses in the processing techniques of polymer materials, endorsed new features required in specific applications. In this context, the study and understanding of new materials and methodologies have led to an exponential progress and expansion of the polymer science.

The development of new functionalised materials for smart applications is, however, usually developed following a chaotic pathway, in which frequently, accomplishing all of the features required for a given application is the only output taken into account. Unfortunately, getting a perfect design in the first trial is not the common result. When nonsatisfactory response is found in materials submitted to service conditions, inaccurate decisions are generally considered. The research of new and different materials or alternative processing techniques is often examined instead of looking for design modifications or functionalisation strategies that could resolve some of the resulting concerns. If the design of a given 
product is robust enough, it must be deeply evaluated through verification and validation processes and subsequently necessarily modified to achieve the desired qualities and behaviour during application [1].

The evaluation process must be carried out as a verification and validation procedure, which is concerned with demonstrating the consistency and completeness of design with respect to the application needs, according to the scheme represented in Figure 1.1. According to this flux diagram, each version of the product may be built, verified in terms of the design features and validated against the application requirements. The design to validation is the process in which the product is evaluated during or at the end of the development stage, to ensure that the obtained device satisfies the specification for the end application [2]. In this sense, the objective is to gain knowledge on how design solutions can be improved and optimised, according to the validation requirements [3].



Figure 1.1. Design, verification and validation diagram.

At this point, it is important to differentiate between the verification and validation concepts, as defined in the ISO9001 in Section 8.3 (Design and development of products and services) [4]. On the one hand, the verification is strictly referred to the confirmation by examination and evaluation of objective evidence that the design output -product specification- meets all the design inputs -technical report according to application needs-. On the other hand, the design validation means the examination and evaluation of objective evidence to confirm that the final product meets the application needs and intended use. While the verification procedure should answer to the question "Are you building it right?", the validation study should be expressed by the question "Are you building the right thing?" [5].

The design can be validated by analysing different product attributes, which are connected to the application needs, design objectives and available resources. Experiencing design and predicting the response 
during service life may contribute to get a better solution for a given requirement. Accordingly, understanding the different stages of the design and characterisation process as a verification procedure is important for creating successful solutions.

In the engineering and scientific field, the design verification and validation procedures are usually delimited by quality standardised tests, according to international norms. In this sense, results obtained for a given application can be evaluated under defined operation conditions -real or simulated-. Therefore, this analysis include the study of the variation of the properties of the product as a function of their life cycle, subjected to the application environment. The main advantage of the standardised analyses is the possibility to obtain comparable and reproducible results to that found in the literature and stablish a concrete assessment for a given application. Accordingly, the verification and validation results can be widely compared regardless the laboratory or technician that has performed the verification and validation standardised procedures. Some of these validation strategies in the field of polymer science were reviewed in Contribution 1.1. Long-term properties and end-of-life of polymers from renewable resources [6], appended to the end of this chapter. In summary, successful design verification and validation consists in identifying the right application needs, designing the right product, assessing all risks and verifying that the product meets all the requirements [7].

Functionalised polymeric materials can be used for several industrial applications, including stabilisation against degradation, energy related applications, and tissue engineering, among others. Each application requires specific characteristics and further service life behaviour. In this sense, the present work focuses on the development and validation of functionalised polymer-based devices for smart applications under a multidisciplinary perspective. The general aim of this thesis was therefore to design and develop appropriate strategies of functionalisation of polymers according to the foreseen performance required to meet with the outcome-oriented conditions and requisites of durability of the polymers in each application.

Accordingly, the establishment of a comprehensive designing methodology for obtaining, characterising and validating these devices for its application in outdoor technologies, energy and biomedicine was considered essential for the progress in these fields, which is represented in Figure 1.1. 


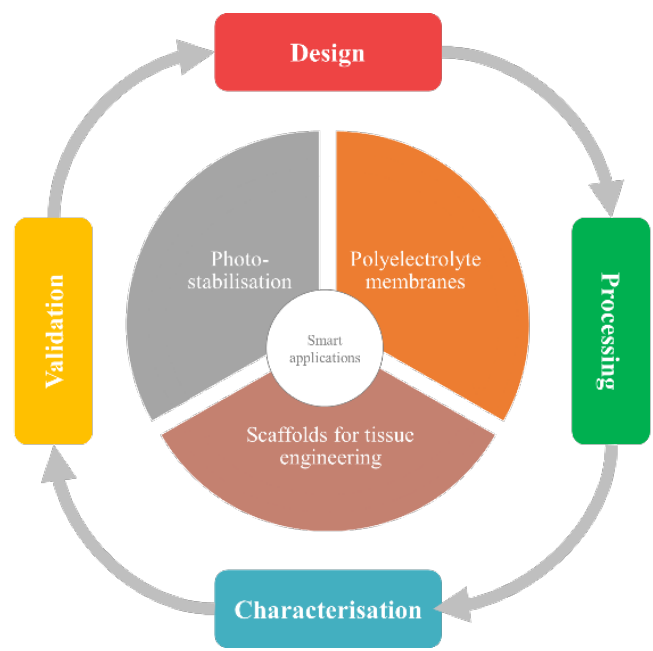

Figure 1.1. Methodology for the design, processing, characterisation and validation of the polymer-based materials.

In particular, given the three different applications focused in this thesis, the specific aims of design of functionalisation were defined as follows:

- To assess the additivation of polypropylene with silicon microparticles to avoid photo-degradation caused by sunlight irradiation at outdoor conditions.

- To design and functionalise poly(vinyl alcohol)-based membranes with enhanced dimensional stability, reduced crossover and increased proton conductivity as polyelectrolytes in fuel cells.

- To obtain and validate tailored functionalised polyester-based scaffolds with controlled performance and biocompatibility for tissue engineering purposes. 


\subsection{OVERVIEW}

The text was structured in different chapters, in which the following topics were addressed.

Chapter 1. Motivation and overview included the inspiration and objective, along with the outline of the thesis. As well, a contribution was proposed, as a review of the long-term evaluation and end-of-life procedures as validation strategies in the polymer field.

Contribution 1.1. Long-term properties and end-of-life of polymer from renewable resources

Chapter 2. Experimental methodologies for the development, characterisation and validation involved the description of the materials and laboratory procedures considered along the thesis.

Chapter 3. Photo-stabilised polyolefins for outdoor applications described the state of the art of the polymer UV-stabilisation and the results obtained for a commodity material widely used in outdoor applications such as the polypropylene. The work in this chapter was reported in Contribution 3.1.

Contribution 3.1. Novel silicon microparticles to improve sunlight stability of raw polypropylene

Chapter 4. Polyelectrolyte membranes for fuel cells dealt with the background of fuel cell technology and included the results of the development and validation of new polyelectrolytes as alterative membranes in fuel cells. The work in this chapter was distributed in Contributions 4.1, 4.2 and 4.3.

Contribution 4.1. Functionalised poly(vinyl alcohol)/graphene oxide membranes for energy applications

Contribution 4.2. Crosslinked sulfonated poly(vinyl alcohol)/ graphene oxide electrospun nanofibres as polyelectrolytes

Contribution 4.3. Crosslinked chitosan/poly(vinyl alcohol)-based proton exchange polyelectrolyte membranes

Chapter 5. Scaffolds for tissue engineering included the state of the art of the scaffold development for tissue engineering strategies along with the results obtained in this field. The progress in this chapter was reflected in Contributions 5.1 to 5.5 .

Contribution 5.1. In vitro validation of biomedical polyester-based scaffolds: poly(lactide-co-glycolide) as model-case 
Contribution 5.2. Comparison of in vitro hydrolytic degradation patterns of short-term and long-term polyester-based electrospun scaffolds

Contribution 5.3. Effect of the dissolution time into an acid hydrolytic solvent to tailor electrospun nanofibrous polycaprolactone scaffolds

Contribution 5.4. Tailored electrospun nanofibrous polycaprolactone/ gelatin scaffolds into an acid hydrolytic solvent system

Contribution 5.5. Validation of tailored electrospun nanofibrous polycaprolactone/gelatin based scaffolds

Chapter 6. Conclusions and future work summarised the most relevant deductions and inferences along with the indications for subsequent studies in the different research lines of this thesis. 


\subsection{REFERENCES OF CHAPTER 1}

[1] CQE Academy, "Design Verification \& Validation for Quality Engineers," Design Verification and Validation, 2018. [Online]. Available: http://www.cqeacademy.com/cqe-body-of-knowledge/product-processdesign/design-verification/. [Accessed: 24-Mar-2018].

[2] M. Hammar, "ISO 9001 Design Verification vs Design Validation,” ISO 9001 Knowledge base - 9001Academy, 2018. [Online]. Available: https://advisera.com/9001academy/knowledgebase/iso9001-designverification-vs-design-validation/. [Accessed: 24-Mar-2018].

[3] Guru99, "Learn Design Validation,” Guru99, 2018. [Online]. Available: https://www.guru99.com/learn-design-validation.html. [Accessed: 24-Mar2018].

[4] I. O. for S. ISO, "ISO 9001:2015 Quality management systems -Requirements,” 2015.

[5] Jon Speer, "The Beginner's Guide to Design Verification and Design Validation for Medical Devices,” Greenlight Guru, 2015. [Online]. Available: https://www.greenlight.guru/blog/design-verification-and-design-validation. [Accessed: 24-Mar-2018].

[6] J. D. Badia, O. Gil-Castell, and A. Ribes-Greus, "Long-term properties and end-of-life of polymers from renewable resources,” Polym. Degrad. Stab., vol. 137, pp. 35-57, 2017.

[7] V. Sastri, “Design Validation and Regulatory Requirements,” Medical Design Briefs, $2017 . \quad$ [Online]. Available: https://www.medicaldesignbriefs.com/component/content/article/mdb/feature s/26238. [Accessed: 24-Mar-2018]. 


\subsection{CONTRIBUTIONS OF CHAPTER 1}

The design of new polymer-based products, from the classical concept of sustainability, must meet the requirements in several axes. While the economic aspect provide value in terms of business growth, positioning and competitiveness, the social one responds to a need of society; and the environmental requires a contribution to care for the environment where social and economic activities take place. In the conception of a plastic, the design is based on the interrelation between the material chosen, and its intrinsic properties; the transformation process, with its process windows; and the destination application, with its requirements and benefits. Thus, from the confluence of the prism of sustainability and the prism of design for the generation of new product, the dichotomy arises between the terms durability and degradation, supposedly antagonistic. However, for the development of new plastic products, the perspective of the service-life must be considered, before, during and after service. The pre-service life takes into account, during the design stage, the adequacy of properties, features, requirements, functionalities, specifications, characteristics or indications at time 0 . Life in service, on the other hand, adds not only the time variable to the equation, but it includes the interaction between the product and the conditions of application. Finally, in the post-service life, the elimination and valorisation of the product are balanced, after fulfilling its function, with the aim of reducing the impact. Figure 1.2 represents the service-life vs valorisation correlation in terms of durability and degradation, respectively.

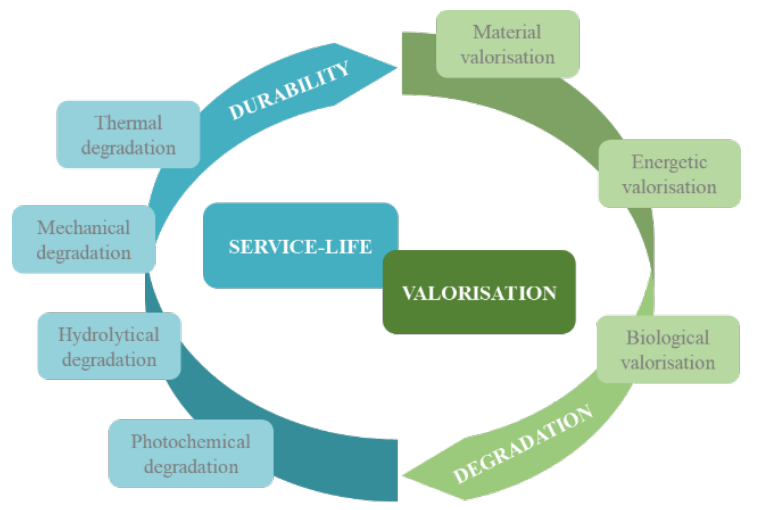

Figure 1.2. Service-life vs. valorisation assessment in terms of durability and degradation, respectively.

The approach in this field was disserted in:

Contribution 1.1. Long-term properties and end-of-life of polymers from renewable resources. 


\section{Contribution 1.1.}

Long-term properties and end-of-life of polymers from renewable resources

J.D. Badia, O. Gil-Castell, A. Ribes-Greus. Long-term properties and endof-life of polymers from renewable resources. Polymer Degradation and Stability 2017;137:25-57

This is an open-access version, according to:

http://www.sherpa.ac.uk/romeo/issn/0141-3910/

Full text available at:

http://www.sciencedirect.com/science/article/pii/S0141391017300022

DOI:

http://dx.doi.org/10.1016/j.polymdegradstab.2017.01.002 


\title{
Long-term properties and end-of-life of polymers from renewable resources
}

\author{
J.D. Badia ${ }^{1,2, *}$, O. Gil-Castell ${ }^{1}$, A. Ribes-Greus ${ }^{1}$ \\ ${ }^{1}$ Instituto de Tecnología de Materiales. Universitat Politècnica de València. Camí de Vera, s/n, \\ 46022 València, Spain \\ ${ }^{2}$ Departament d’Enginyeria Química. Escola Tècnica Superior d’Enginyeria. Universitat de \\ València. Av. de la Universitat, s/n, 46100, Burjassot, Spain \\ ${ }^{*}$ Corresponding Author \\ J.D. Badia \\ jdbadia@itm.upv.es
}




\title{
Long-term properties and end-of-life of polymers from renewable resources
}

\author{
J.D. Badia, O. Gil-Castell, A. Ribes-Greus
}

\begin{abstract}
The long-term properties and end-of-life of polymers are not antagonist issues. They actually are inherently linked by the duality between durability and degradation. The control of the service-to-disposal pathway at useful performance, along with low-impact disposal represents an added-value. Therefore, the routes of design, production, and discarding of bio-based polymers must be carefully strategized. In this sense, the combination of proper valorisation techniques, i.e. material, energetic and/or biological at the most appropriate stage should be targeted. Thus, the consideration of the end-of-life of a material for a specific application, instead of the end-of-life of a material should be the fundamental focus. This review covers the key aspects of lab-scale techniques to infer the potential of performance and valorisation of polymers from renewable resources as a key gear for sustainability.
\end{abstract}

\section{Keywords}

long-term properties; durability; stability; end-of-life; degradation; material valorisation; energetic valorisation; biological valorisation; biobased polymers; renewable resources;

\section{Highlights}

- $\quad$ The long-term properties and the end-of-life of polymers are not antagonist issues.

- The duality between durability and degradation is key for the sustainable design.

- Design, production, valorisation and disposal of bio-based polymers are strategic.

- End-of-life of a material for an application, instead of end-of-life of a material.

- Material, energetic and biological valorisations must be smartly combined. 


\section{List of abbreviatons}

AFM

AIDS

ASTM

ATP

DETA

DMTA

DSC

EN

FTIR

GC

GPC

HV

ISO

LCA

LMWC

MALDI-TOF-

MS

MODA

NMR

OIT

PBAT

PBF

PBS

PCL

PE

PET

PGA

PHAs

PHB

PHBV

PHV

PLA

PLGA

PP

PVA

PVC
Atomic Force Microscopy

Acquired Immune Deficiency Syndrome

American Society for Testing Materials

Adenosine Triphosphate

Dielectric Thermal Analysis

Dynamic Mechanical-Thermal Analysis

Differential Scanning Calorimetry

European Standards Organisation

Fourier Transformed Infrared Spectroscopy

Gas Chromatography

Gel Permeation Chromatography

Hydroxyvalerate

International Standard Organisation

Life Cycle Assessments

Low Molecular Weight Compounds

Matrix-Assisted Laser Desorption-Ionization Time-of-Flight

Mass Spectrometry

Microbial Oxidative Degradation Analyser

Nuclear Magnetic Resonance

Oxidation Induction Time

Poly(butylene adipate terephthalate)

Poly(butylene fumarate)

Poly(butylene succinate)

Polycaprolactone

Polyethylene

Poly(ethylene terephtalate)

Poly(glycolic acid)

Polyhydroxyalkanoates

Polyhydroxybutirate

Poly(hydroxybutyrate-co-valerate)

Polyhydroxyvalerate

Poly(lactic acid)

Poly(lactic-co-glycolic acid)

Poly(propylene)

Poly(vinyl alcohol)

Poly(vinyl chloride) 
PS Polystyrene

PSW Plastic Solid Waste

SEM Scanning Electron Microscopy

TE-EC End-Chain Transesterifications

TE-MC Middle-Chain Transesterifications

TEM Transmission Electron Microscopy

TGA Thermogravimetric Analysis

TPS Thermoplastic Starch

UV Ultraviolet 


\section{Sustainability of polymers from renewable resources}

Plastics currently account for about $20 \%$ by volume of municipal solid waste. Even more, they are not only generating so much waste, but are also becoming extinct due to finite petroleum-based reserves. It is estimated that the global resources of oil, natural gas and coal are limited and the economic impact could be exhausted in a near future, as prices will rise as these resources are more limited [1]. Due to the oscillation of oil prices and the problem of the accumulation of waste, which has led to hard environmental policies, polymers from renewable resources may become a sustainable solution. Actually, this market has experienced a high expansion, being the focus of lots of research studies [2], in many sectors of application, such as food packaging, agriculture and biomedicine, among other.

Food packaging applications aim at substitute traditional polymers [3], [4] by bio-based polymers such as poly(lactic acid) (PLA) [5]-[8] or polyhydroxyalkanoates (PHA) [9], [10] , along with other polymers [11][13], blends [14]-[16], or nanocomposites [17]-[31]. The focus is devoted to the combination of appropriate processability, good durability [32]-[34] barrier properties [24], [35]-[40] and tuned biodegradability [33], [41][46], as well as to add value with natural additives [47], the combination of coatings [35], [36], [48]-[58] and multilayers [31], [37], [38], [59]-[65], or even the production of edible [57], [58], [66]-[74] or active properties [75]-[87]. Agricultural applications consider the use of polymers from renewable resources as films for mulching and protection [88]-[92], drug delivery [93]-[103] or goods as twines, strings, filaments and clips [104]. Biomedical applications based on polymers from renewable resources [105], [106] are based on their biodegradability and biocompatibility with low-impact form substance after degradation [107]-[109], for applications such as tissue engineering [110]-[121], which ensure cell proliferation [119], [122]-[128], controlled drug delivery [129]-[142], wound dressing [117], [143]-[163]. In all cases, polymers require a tuned balance between their performance during service life, and their degradation behaviour after use, that is, between the long-term properties and their end-of-life. Nevertheless, polymers from renewable resources still involve relatively high production costs and, frequently, they show underperformed properties for each application in contrast to their petroleum-based counterparts. In addition, concerns are growing into the society about the use of long-life polymers in products in which a short-life is expected. Therefore, there is an engagement to base the research in appropriate production-service-waste management mainstreams on an equitable commitment of the three pillars of sustainability, i.e. People (social pillar), Planet (environmental pillar) and Profit (economic pillar) [164]. 
Specifically, the sustainability of polymers from renewable resources, i.e. bio-based polymers, is a topic which has been approached from several perspectives due to its importance and impact on wealth, environment and technological development [165]-[170]. Due to their high potential of replacement of petroleum-based polymers, the design, use and disposal routes of bio-based polymers must be carefully strategized in order to ensure appropriate service conditions and adequate valorisation and/or elimination after their service-life [171]. In addition, these processes have to be economically efficient, energetically affordable and environmentally friendly. Thus, the concepts of applications, long-term properties and endof-life of bio-based polymers have to be constantly linked, as shown in Figure 1.

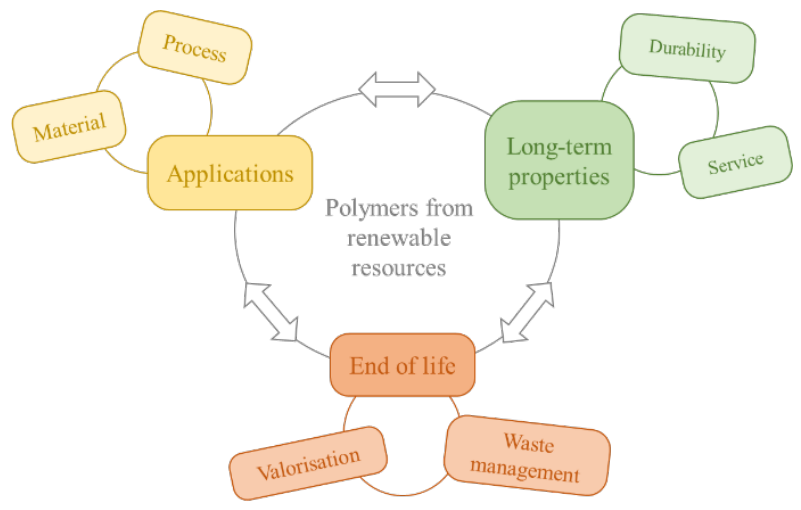

Figure 1. Perspective of this review: interlinked approach of applications, long-term properties and end-of-life of bio-based polymers.

The applications of bio-based polymers are inherent to both the choice of suitable materials and their particular obtaining process to ensure the expected performance during service, which is related to their long-term properties. This combination of process and performance must be efficiently balanced, to guarantee correct end-of-life of the bio-based goods, not only understood as the disposal and reintegration of carbon source into the life cycle, but also from the point of view of its possible valorisations into feedstock, the same or different materials and/or energy. In this sense, in this review, the long-term properties of polymers are approached from the point of view of the durability facing different degrading agents such as temperature, sun light or humidity. The three following sections are devoted to material, energetic and biological valorisations, as alternatives to extend the value of polymers, depending on the expected performance and end-of-life opportunities. Finally, a list of different opportunities to foster the background of a correct alignment between long-term properties and end-of-life is proposed, in order to 
contribute to the field of sustainable design of polymers from renewable resources.

\section{Long-term properties and end-of-life of polymers}

The terms durability and degradation, as well as long-term properties and end-of-life are inherently linked. The emphasis on each term will be showed depending on the focus of the analysis under consideration. Whether the conservation of the high-level performance of bio-based polymers is aimed, the preservation of its durability will determine the improvement of long-term properties. On the contrary, if the elimination of plastic waste after discarding is sought, monitoring and favouring the most effective degradation pathway will be focused. However, both ideas are not antagonist. In fact, both must be considered together at the steps of design or choice of appropriate materials for specific applications. A correct balance between an appropriate durability of a plastic good and a simple end-of-life pathway without energetic or environmental impact should be addressed. Even more, the consideration of the end-of-life of a material for an application, instead of the end-of-life of a material should be kept in mind in order to favour second-life uses, and thus enlarge its service-life, giving an extra value to this material. Sending discarded material to downgraded applications, combine them with other materials to upgrade them, obtaining energy, feedstock or recover the carbon sources by biological methods should be considered as added-value alternatives for bio-based polymers.

Different strategies to simulate service-life conditions, and thus focus on the durability of the materials, or to simulate different valorisation options, therefore aiming the degradation pathways, can be taken into account, as schematised in Figure 2.

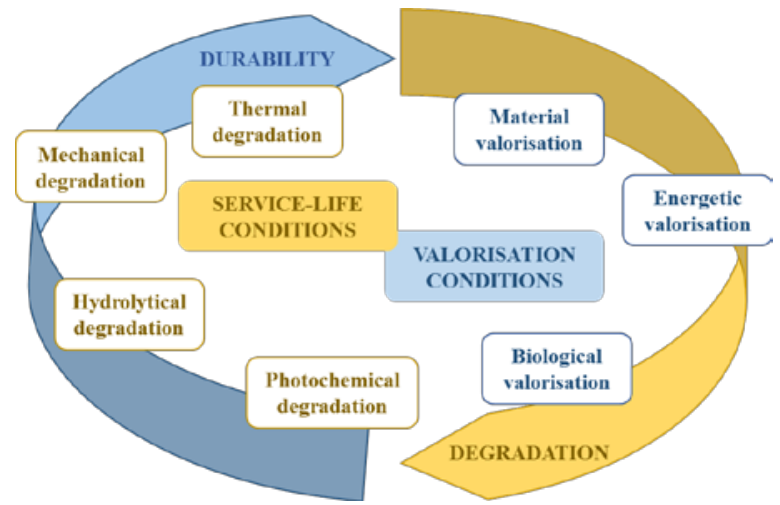

Figure 2. Types of durability and degradation studies summarised in this review.

The physico-chemical properties of bio-based materials subjected to different service-life or valorisation conditions must be followed in order 
to respectively evaluate, on the one hand, the preservation of performance or, on the other hand, to monitor the extent of degradation to ensure correct valorisation. In this sense, as shown in Figure 3, the evaluation of properties goes from micro-approach, i.e., structure-morphology, to macro-response, i.e. mechanical, thermal or rheological properties, connecting with the application at the durability stage, and with the surroundings and impact on environment and human health with the analysis of release of low-molecular weight compounds, at the degradation stage.

Structural and morphological observation by means of techniques such as Gel Permeation Chromatography (GPC) [172], Matrix-Assisted Laser Desorption-Ionization Time-of-Flight Mass Spectrometry (MALDI-TOFMS) [173]-[175], Nuclear Magnetic Resonance (NMR) [176], or FourierTransform Infrared Spectrometry (FTIR) [177] are used for determining the molar-mass distributions and to identify the chemical nature of the polymer chains and/or their chemical groups. As well, micrographic techniques such as Scanning/Transmission Electron Microscopy (SEM/TEM) or Atomic Force Microscopy (AFM) allow the observation of the topology of polymers as well as the analysis of interfaces in blends or composites [178]. In addition, Differential Scanning Calorimetry (DSC) can be used to determine the main thermal properties and the balance between crystalline and mobile and rigid amorphous fractions [179], [180]. As well, Dielectric Thermal Analysis (DETA) and Dynamic-Mechanical Thermal Analysis (DMTA) is of great importance to test the segmental rearrangements and dynamic fragility of polymers [181]-[184], which modifications are not perceptible by other macroscopic techniques.

The macroscopic response, in terms of rheological, thermal and mechanical performance is of great importance and currently the focus of most reports, due to the technology-driven and market-pulling of applications for biobased polymers. The mechanical characterization of the stress and strain at break or impact to check the resistance of second-life applications is fundamental. The control of the rheological properties in order to assure proper flow during processing, as well as the study of the stability indicators such as the Oxidation Induction Time (OIT) or the Temperature of Oxidation ( $\mathrm{T}_{\mathrm{Ox}}$ ), the thermal and thermo-oxidative decomposition temperatures or the melting temperatures are of immediate application and use in industrial quality labs to infer the necessary processing windows. In addition, those polymers designed for specific applications need specific analyses which may inform about the suitability of these materials to be used in second-life applications or should be sent to other valorisation routes. This could be the case of polymers used for packaging, which need gas transmission experiments [185]-[187]. As well, those used in electrical or insulating applications may rely on dielectric characterisation [181]. 
Moreover, for those which serve in contact with food or in aggressive environments, the ecotoxicity should be assessed [188]-[190]. Finally, for those applications in contact with humans, animals, plants or to be used in cosmetics, food packaging or as drugs carriers, for example, the controlled extraction and identification of low molecular weight compounds has to be considered [191], [192].

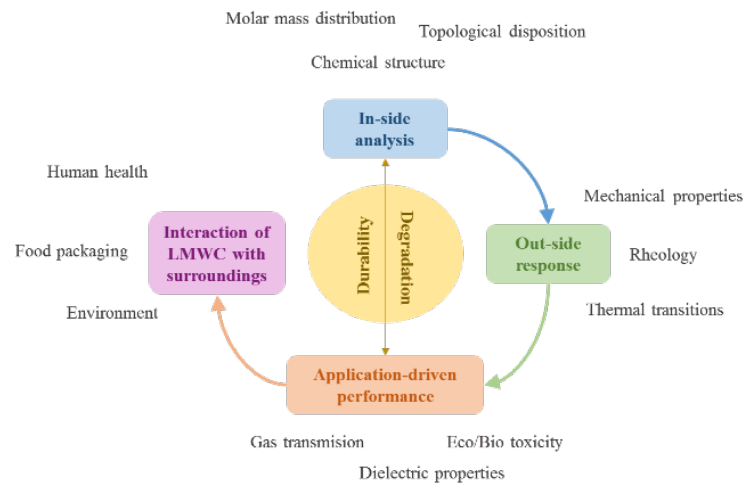

Figure 3. Analytical strategies to monitor durability or degradation.

\section{Durability and simulation of service conditions}

Bio-based polymers are subjected to different service conditions, which can be more or less aggressive depending on their application, being thus exposed to some degrading factors which individually or in combination can affect their physico-chemical properties, and thus the durability of their properties. In general terms, the types of degradation can be thermal, hydrolytic/chemolytic, photochemical or mechanical. In order to simulate the performance of these materials under these conditions, different normalised and accelerated protocols can be applied.

\subsection{Thermal degradation}

Thermal degradation comprises the negative response, i.e., loss of properties, due to the subjection of bio-based materials to specific temperatures during extended time. In general terms, one must differ between (i) thermal degradation at temperatures below the glass transition temperature, which can induce structural rearrangements know as physical ageing [193]-[195]; (ii) thermal degradation at temperatures between the glass transition temperature and the melting temperature, which can provoke from loss of dimensions due to flow of material to crystallisation processes or starting of thermal decomposition of low molecular weight additives; (iii) thermal degradation at temperatures above the melting temperature and below the decomposition onset temperature, which will be extremely important to know to ensure processability of second-life biobased goods, or (iv) thermal degradation above thermal decomposition, 
which is treated as energetic valorisation option in section 5. In order to test the thermal degradation of bio-based polymers, different methodologies can be used. On the one hand, the use of ovens permits the analysis of every type of thermal degradation, preferably those without decomposition, and then evaluate degradation by analysis of molar masses and physico-chemical properties. Differential Scanning Calorimetry (DSC) is interesting to test thermal degradation at temperatures up to the melting temperature, as well as to monitor degradation by means of indicators such as the glass transition temperature, the degree of crystallinity, the crystallisation and cold-crystallisation temperatures or the crystallinity degree. However, it is not advisable to induce thermal degradation at temperatures below the glass transition by DSC due to the high consumption of time. The use of Dynamic Mechanical Thermal Analysis (DMTA) is suitable to test the impact of thermal degradation until temperatures far below the melting temperature on mechanical properties by means of creep experiments. Finally, the use of Thermogravimetric Analysis (TGA) is essential to test the thermal decomposition of polymerbased materials, both under inert or oxidative conditions. Some studies have been reported for neat [196], [197] and reprocessed [198] PLA, PLAbased composites [199]-[202], PHAs [203], PCL [204], polyester-based blends [205] or starch-based blends [206], among others.

\subsection{Hydrolytic and hydrothermal degradation}

Hydrolysis of ester linkages is one of the most established types of biobased polymer degradation, and therefore most of bio-absorbable polymers for biomedical applications are based on polyesters. There are two main ways by which biopolymers can be hydrolyzed, passively by chemical hydrolysis, or actively by enzymatic reaction. The latter method is more important for naturally occurring polymers such as polysaccharides and PHAs [207]. PLA and PGA degrade by simple hydrolysis of the ester bond and do not require the presence of enzymes to catalyse hydrolysis [208]. The hydrolysis of ester linkages occurs through a series of overlapping stages, progressively reducing the molar mass and thus affecting to the macroscopic physico-chemical properties. Simulation of service-life conditions of biomedical materials usually follows the ISO10993-13:2010 normative [209]. Shortly, materials are exposed to the analytic medium, which can be water, phosphate buffer solution or human fluid simulants, during different times at $37{ }^{\circ} \mathrm{C}$, to mimic human conditions. The monitoring of degradation can be followed both in the liquid and in the solid fractions. Several reports for PLA [210]-[213], PCL [214], PHAs [215], poly(butylene fumarate) (PBF) [216], or copolyesters [217] can be found in literature, among others.

For non-biomedical purposes, modified water absorption protocols such as the ISO62:2008 [218] can be used to induce accelerated hydrothermal 
degradation on polymers. In this sense, both agents, water and temperature can sinergically act to simulate real service conditions. This has been reported for neat [219], [220] and reprocessed PLA [221], [222], PHAs [223], [224], PCL, and blends [225] or composites such as PLA/sisal [226], [227], PHBV/sisal [228], or poly(butylene sebacate) (PBS)/montmorillonite [229], among others.

\subsection{Mechanical degradation}

Bio-based polymers can be subjected to several types of mechanical solicitations during processing, storage and use. These mechanical stresses can be tensile, compressive, shearing or bending, in the form of vibrations, agitations, grinding or hard extrusion.

The basic phenomenon involved when subjecting the polymer to very powerful shearing forces is the breakage of the macromolecule. Mechanical degradation reduces the average molecular weight of the polymer [230]. Although mechanical factors are not predominant during biodegradation, they can activate or accelerate it [208]. In order to simulate mechanical degradation, common experiments of fatigue or creep can be performed on polymers by DMTA [184], which not only serve for classical mechanical analysis, but also gives the chance of applying several vibrating frequencies and combine them with thermal effect.

\subsection{Photochemical degradation}

Photodegradation of polymers is induced by the action of light, due to UV absorption, mainly by carbonyl groups of polyesters [231]. Photodegradation mechanisms are mainly expressed by the Norrish reactions that transform the polymers by photoionization (Norrish I) and chain scission (Norrish II) [232]. Photodegradation can conduce to Norrish reactions and/or cross-linking reactions, or oxidative processes [233]. Polymers such as PLA or PCL [234] have shown Norrish-type photodegradation, whereas others such as Poly(butyrate adipate terephthalate) (PBAT) or Ecoflex ${ }^{\circledR}$ have shown main routes of crosslinking and chain scission [235], [236].

Photodegradation and sunlight oxidation test protocols are practices such as ASTM D5071 with Xenon lamps [237], ASTM D5208 with fluorescence lamps [238], or ASTM D5272 for outdoor conditions [239] are preferably used for exposing a plastic to some form of radiation and subsequently measuring the loss of any property, usually molar mass and mechanical properties, such as tensile or impact resistances or show the performance of additives to protect them such as $\mathrm{ZnO}$ [240], Si colloids [241] and other stabilizers to prevent them from degradation [242]. These techniques allow setting not only UV wavelengths, but also temperatures, day-night cycles, or controlled floating, rain or humidity. Some studies 
have been reported for neat PLA [196] and composites [243]-[245], PHAs [246]-[248], PCL [234], starch-based blends [249], [250] or cellulose [251], [252], among others.

\section{Material valorisation of biopolymers}

Short-time applications from bio-based and biodegradable plastics have attracted much interest in different industrial, social and economic sectors [253]. It is known that bio-based materials are suitable for biological waste treatment such as composting, thus having a great potential to contribute to the reduction of the amount of waste sent to landfill and generating valuable soil improvers, which is of great importance for industries, governments and consumers [254]. However, the presumably high amount of bio-based plastic waste surpassing the capability of composting facilities has to be taken into account [255]. Actually, including the end-of-life stage in Life Cycle Assessments (LCA) provides more comprehensive life pathways for bio-based polymers, but simultaneously introduces greater amounts of uncertainty and variability. Although there is little life-cycle data available on the impacts of different ways of disposal, it has been argued that it would be critical for future sustainability assessments [256], [257]. The necessary implementation of operation units during the dismantling process, new separation technologies, and the logistics of handling additional streams of materials will require significant study, development, and monitoring in order to develop robust and effective recovery methods [258]. In this sense, to explore the chances to enhance the valorisation of bioplastic-based goods, by means of mechanical recycling would be advisable to explore the possibilities of extending their service lives before finally discarding them to bio-disposal facilities [259], [260].

Mechanical recycling represents one of the most cost-effective methodologies, though recycled materials are usually directed to downgraded applications, due to the inherent thermo-mechanical degradation affecting its mechanical, thermal and rheological performance [261]. During re-processing, polymers are subjected to the synergic influence of degrading agents such as oxygen, UV-light, mechanical stresses, temperature and water, which, separately or in combination, during its material loop (synthesis-processing-service-life-discardingrecovery), results in chemical and physical changes that alter their stabilization mechanisms and long-term properties [262], [263]. Degradation usually provokes a reduction of physical properties and functional quality of polymers and, hence, reprocessed products of high confidence are difficult to obtain. Traditional simulation of mechanical recycling by multiple processing and service-life by accelerated thermal ageing was previously developed for commodities such as PE [264], PP [265], poly(styrene) (PS) [191], [192], poly(vinyl chloride) (PVC) [266] or 
PET [179], [267]-[269], among others. Concerning bio-based polymers, the main effort has been dedicated to PLA in great extension, and other materials such as PHAs [270]-[272], poly(caprolactone) [273] or biocomposites with matrixes of PLA or thermoplastic starch (TPS) [274].

The mechanical recycling of PLA has been approached in lab-scale studies by means of multiple injection [183], [275]-[277] and extrusion [278][281] steps, and the recyclates characterized in terms of structural and morphological analysis rheological, thermal and mechanical properties, release of low molecular weight compounds (LMWC) [282], and application-driven techniques such as mass-transport [221] or dielectric properties [181]. A review devoted to the mechanical recycling of PLA [261] showed that, in general terms, reprocessing of PLA was responsible for a decrease in molecular weight, modification of thermal properties and crystallization kinetics, dynamic fragility or permeation performance, among other parameters [261]. As a general idea, PLA could be reprocessed without losing most of its properties up to 2 cycles, but this affirmation strongly depends on the PLA grade used and the care during reprocessing. Studies focused on the characterization of multi-injected PCL have revealed that PCL technological waste is suitable to be reused as an additive to a neat polymer [273]. Regarding PHAs, their performance of mechanical recycling was tested during successive injection [270], [271] and extrusion cycles [272], showing successive diminution of molecular weight after increasing cycles, with its consequent decrease in mechanical properties.

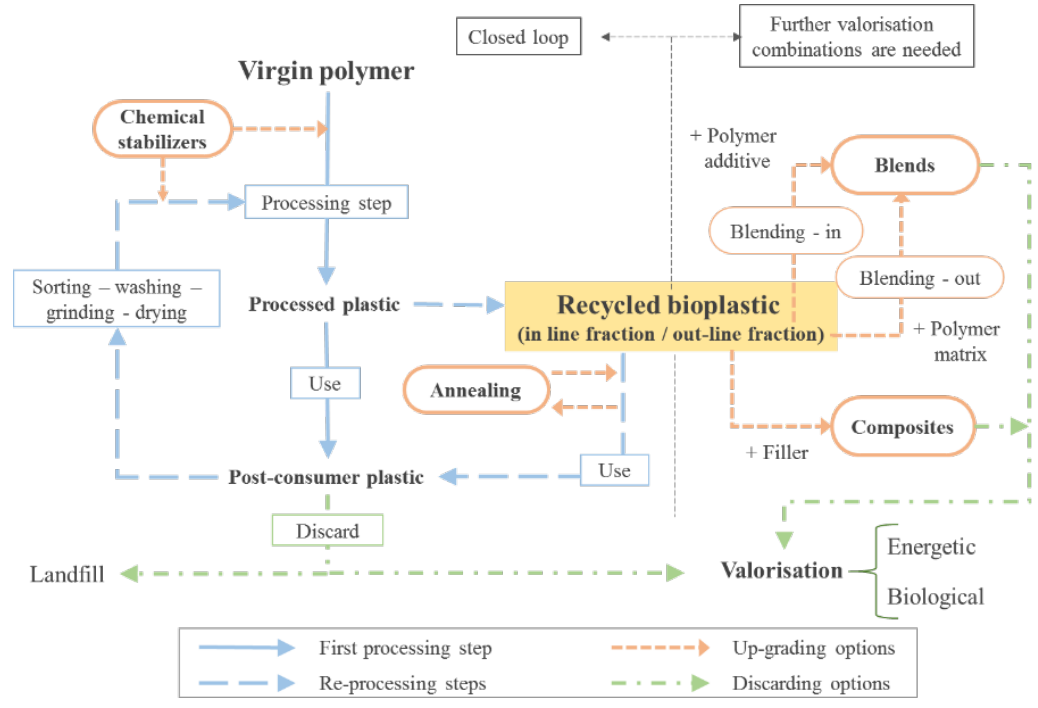

Figure 4. Scheme of material valorisation through mechanical recycling and upgrading options. 
Figure 4 shows a schematic material flow from virgin to recycled polymer in a closed loop, i.e. within the same polymer fraction, or in combination with other material, which hinders the continuation of material flow inside the mechanical recycling loop and thus suggests the design for further valorization. Due to degradation during re-processing, the performance of bioplastics is usually downgraded and thus several strategies to improve and upgrade materials can be followed. This is the case of the application of physical treatments such as annealing to increase young modulus and yield strength of PLA [275], [283] or the use of chemical stabilizers such as tropolone, quinones or irgafos/irganox during processing to prevent transesterification [284], [285]. Other options include the blending of recycled polymers with other ones that can act as plasticizers or tougheners (blending - in) [277], [286]-[288], or the use of recycled bioplastics as value-added modifiers for other plastic matrixes (blending - out) [289][291]. The case of the combination of PLA and PHBV is remarkable [272]. The effects of 6 recycling cycles on the structure and properties of neat PHBV, neat PLA and PHBV/PLA (50/50 wt\%) blends elaborated by injection moulding were investigated. In contrast to PLA, PHBV seems to be relatively more sensitive to the thermomechanical degradation, where the presence of PLA in the PHBV-PLA blend tends to partially prevent the degradation of PHBV. Even more, it was suggested that the recyclability of PHBV/PLA blends was affordable after several reprocessing cycles, since the values of mechanical properties remained at the original level, as well as the molar mass slightly reduced [272]. Other studies focused on blends such as that of PLA/TPS have shown worsening of the thermal properties as a function of reprocessing cycles, especially for those with high concentration of TPS [292].

Finally, the option of compositing recycled bioplastics following the same compositing routes as for neat polymers may also provide with upgraded performance. Lopez et al. studied the recycling ability of biodegradable matrices such as PLLA and Mater-Bi and their cellulose-reinforced composites in a plastic recycling stream [293]. In the same direction, the behaviour of polylactide/flax composites was evaluated after several recycling cycles [294]. Moreover, polylactide-recycled wood fibre composites were prepared and characterised by Pilla et al [295]. Other applications of reused natural fibre reinforced composites such as in polymer mortars were considered by Grozdanov et al [296].

Once the extent of material valorisation has been exhausted, there are still possibilities to make profit from bioplastics without the need of sending them to landfilling. This is the case of energetic or biological valorisation, as shown in the next sections. 


\section{Energetic Valorisation of Biopolymers}

Energetic valorisation is compressed under the term chemical recycling, which covers both chemical methods to recover feedstock from wastes and thermolytic processes to obtain energy. Figure 5 shows the relationship between these technologies put in practice.

Feedstock valorisation refers to advanced technological processes which convert plastic materials into smaller molecules, usually liquids or gases, which are suitable for being used as a feedstock for the production of new petrochemicals and plastics. The technology behind its success is the depolymerisation -both chemically and thermally driven- process that can result in a profitable and sustainable industrial scheme, providing a high product yield and minimum waste [297]. However, for the case of bioplastics, the effort in recovering monomers could be more expensive and harmful for the environment than just obtaining them as raw material. Concerning the energy balance and costs, these processes lay between remelting and combustion [298]. In fact, chemical recycling options could be suitable when the amount of wastes surpass the capabilities of biological valorisation facilities. More literature of feedstock recycling can be found in terms of chemically-driven obtaining of lactic acid by hydrolysis of PLA [299]-[301] and thermally-driven obtaining of L-L-lactide from PLA [302]-[304] or vinyl monomers from PHAs [3]. It must be pointed out that feedstock recycling might be particularly interesting for blends of biopolymers with commodities when high performance at service conditions is no more expected, especially for those difficult to separate mechanically, or those which have different thermal decomposition profiles. This could be the case of blends of PHBV/PE [305], PLA/PET [306], PLA/PE [307], [308] or PLA/PBS [309].

Energetic valorisation implies thermal cracking of waste to produce energy in the form of heat, which may be converted into steam and further to electricity by a conventional thermoelectric plant. Polymer-based materials possess a very high calorific value when burned, especially when considering that they are derived from crude oil. Since the heating value of plastics is high, they make a convenient energy source, such as heating oil and coal [310]. Thermolytic processes consider pyrolysis, gasification, combustion, liquid-gas hydrogenation, viscosity breaking, steam or catalytic cracking, and the use of plastic solid waste as a reducing agent in blast furnaces [311]. 


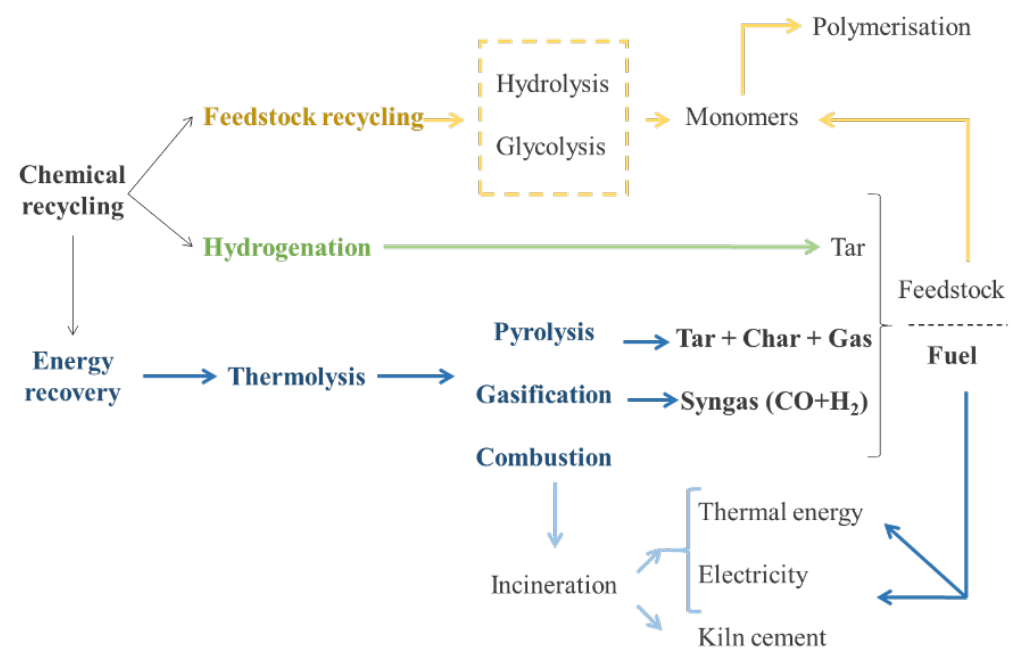

Figure 5. Chemical recycling options. Detail of thermolytic processes for energetic valorisation. Redrawn from ref [255].

Not only healthy monomer fractions can be recovered up to $60 \%$ [312], but also valuable petrochemicals can be produced, such as gases (hydrocarbons), tars (waxes and liquids very high in aromatic content) and chars (carbon black and/or activated carbon). However, one must consider that, in general, post-consumer plastic waste consists of a variety of long chain polymer molecules, chemical contaminants and hetero-atoms such as chlorine, oxygen or nitrogen. Physical impurities like fillers, pigments or adhered dirt are present as well as larger inorganic material, arising from incomplete sorting. In order to use this waste as feedstock for new plastics or fuel components, the following problems need to be overcome [313]: (i) Larger inorganic particles have to be discharged from the process in order to prevent the process to be blocked by, as well as to avoid the erosion of pipes and pumps; (ii) Inorganic particles have to be mechanically separated; (iii) Long polymer chains have to be cracked; and (iv) Heteroatoms need to be chemically separated.

\subsection{Pyrolysis, gasification or combustion}

Pyrolysis has the ability to produce high calorific value gas by thermal cracking in inert atmospheres at temperatures up to $800^{\circ} \mathrm{C}$ [313]. The solid char can be used in-site to release its energy content by further thermal processes or used off-site to valorise its inorganic residues in further applications. In contrast to other thermolytic technologies, pyrolysis has the advantages of being less energy consumer, using low pressures and preventing the generation of pollutants [311], [313]. Examples of pyrolysis for Plastic Solid Waste (PSW) [312], biomass [314] or rubbers [315] have been reported. Of all the biopolymers investigated, PHB is the most 
promising material, followed by aliphatic-aromatic copolyesters, PLAbased polymers, potato starch, corn starch and starch based biopolymers in order of decreasing profits [208], [316]-[319].

Gasification operates at temperatures up to $1300{ }^{\circ} \mathrm{C}$ and use controlled addition of oxygen as reagent [313]. It mainly produces syngas, which is a mixture of carbon monoxide and hydrogen, which can be used as fuel, substituting natural gas. Additionally, a significant amount of char is produced which has to be further treated. If this inorganic ash is bounded into a glassy matrix, it can be used as a component in concrete or mortar due to its high acid resistance [313]. As well, the emission of pollutants is reduced due to the use of high temperatures and low oxygen partial pressure in its operational parameters [313]. Some applications of gasification of conventional plastic fractions have been developed for PVC [320], PP [321] or PET [322], as well as for bio-based polymers such as PLA and others [323]-[325].

Incineration involves the combustion of polymer wastes to obtain mainly carbon dioxide, water and inorganic ashes. Despite the unpopular not-inmy-backyard syndrome, its use as centralized alternative for landfill could be significant, considering that the technologies of control of pollutants are efficient enough. In fact, it could be advisable for not-recoverable plastics coming from biomedical applications, drugs, hazardous-goods packaging, electronics or highly contaminated plastics. The inorganic fraction of the waste, if any, is essentially mineralised in an inert slag that can be used in cement kilns for materials for construction of roads.

\subsection{Tests to approach the pyrolysis and combustion of bioplastics}

Appropriate design and scale are of paramount importance when it comes to thermal treatment plants. Thermolysis behaviour in laboratory scale enables the assessment of a number of important parameters, such as thermal stability temperature of polymers, thermal kinetics, activation energy assessment or product formation [311].

To design a chemical reactor, the expression for the decomposition rate must be ascertained. Assuming the reaction is known not to be elementary, the search for a mechanism that describes the reaction taking place or use experimental data directly must be aimed. Mechanisms can be hypothesized as the sum of a series of elementary reactions with intermediates. Using methods developed by physical chemists, whether the proposed mechanism fits the actual experimental evidence can be hypothesized. Systems kinetics will not only develop appropriate models that will predict systems products and their interaction, but through solving the derived mathematical expressions, they will predict the product interaction behaviour. This will assist in reducing side reactions and undesired by-products on an industrial scale. Developing rate expressions 
of the materials being treated will then be utilized in determining the optimum unit operation to be used and its required supply of power and proper media of operation, in the case of pyrolysis, the sufficient amount of inert atmosphere in the pyrolyser or the ratio of steam to oxygen in a gasifier [326].

In the attempt of developing a model for thermal and thermo-oxidative decompositions in full-scale systems, the main purpose is to describe the behaviour of polymers in terms of intrinsic kinetics, in which heat and mass transfer limitations are not included. General kinetic models are proposed in literature for plastics and biomasses [327]. These models do not take into account the rigorous and exhaustive description of the chemistry of thermal decomposition of polymers and describe the process by means of a simplified reaction pathway. Each single reaction step considered is representative of a complex network of reactions [328].

Pyrolysis is usually the first process in a thermal plant. This could be approached via the understanding of the systems kinetics by Thermogravimetric Analysis (TGA) and scale pilots, using inert atmospheres such as $\mathrm{Ar}$ or $\mathrm{N}_{2}$. Combustion/Gasification systems can also be approached by using $\mathrm{O}_{2}$ or mixtures of $\mathrm{N}_{2} / \mathrm{O}_{2}$ rich in the $\mathrm{O}_{2}$ phase [311] - Therefore, TGA stands out as fast, cost-effective and reliable characterization technique to ascertain a deeper knowledge about the ongoing thermal and thermo-oxidative decomposition of plastics. Completing this experimental technique with a proper theoretical modelfitting methodology is commonly used for the study of kinetic parameters such as the apparent activation energy $E a$, the pre-exponential factor $A$ and the reaction model $f(\alpha)$, which yield the so-called kinetic triplet [329], [330]. The hyphenation with techniques such as GC-MS or FT-IR for identification and quantification of gases [331], as well as the use of 2Dcorrelation spectroscopy to set the sequences of release of gases complete the analysis [330], [332], [333]. These parameters are essential to further optimise the design of the thermal valorisation processes in computer simulation software to achieve a better understanding of the process to obtain the optimum operational parameters in a thermal equipment [329], [334].

\subsection{Thermal decomposition studies of bioplastics}

Applications of TGA to model thermal decomposition of bioplastics are reported for PHAs [203], [335]-[340], PLA [276], [333], [341]-[343], PCL [344]-[348], celluloses [349]-[352], and chitosan [353], among others.

Studies on PHAs showed that their thermal decomposition occurred through a simple reaction mechanism [335]. This supported the hypothesis that the controlling step was the depolymerization of the macromolecular 
chains. The results clearly indicated an increase in activation energy with increasing hydroxyvalerate content.

Concerning decomposition of PLA, Kopinke and Mackenzie [354], [355] surveyed previous studies and concluded that the thermal decomposition of PLA is mainly driven by transesterification and homolytic reactions, as shown in Figure 6 and Figure 7, respectively and, with minor participation, catalyser (Sn)-based depolymerization or cis-elimination.



Figure 6. Transesterification reactions of thermal decomposition of PLA, as adapted from [356]. Note that R is an undefined PLA chain fraction.

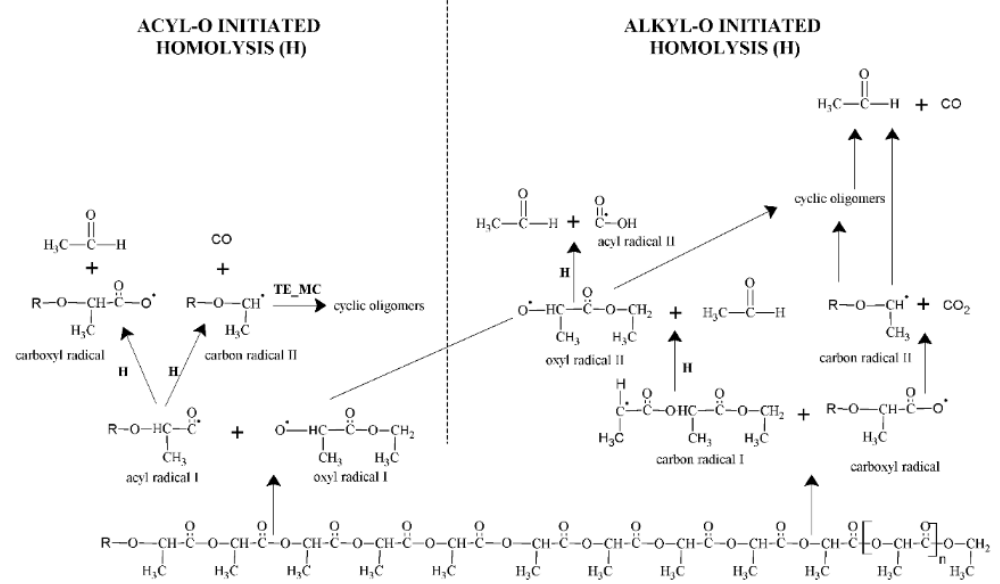

Figure 7. Homolytic reactions of thermal decomposition of PLA, as adapted from [354]. Reproduced with permission from [255]. Note that R is an undefined PLA chain fraction. TE-MC stands for middle-chain transesterifications. 
Combinations of valorisation procedures of PLA have been considered. This is the case of the thermal simulation of the decomposition process of recycled PLA [333]. It was found that PLA, as well as its successive recyclates, described a mass-loss profile driven by one decomposition stage in inert conditions and two in oxidizing conditions. In both cases, the first step could be ascribed to the pyrolysis of the backbone. The second mass-loss step under $\mathrm{O}_{2}$ was related to the decomposition of the remaining char, representing a $\sim 2 \%$ of mass. The mathematical description of the kinetics allows technicians to use mechanically-recycled PLA as raw PLA in thermally-driven energetic valorisation facilities.

The thermal decomposition of PCL was investigated in bulk and solution by Sivalingam and Madras [344]. They found that the polymer degrades by random chain scission and specific chain end scission in solution and bulk, respectively. The activation energy of the processes, determined from the temperature dependency of the rate coefficients, was found to be significantly higher than that of the degradation in solution. The use of several strategies to modulate and tune the thermal decomposition of biopolymers such as PCL are of great importance, as demonstrated by Albertsson et al., who enhanced the degradation of PCL through the incorporation of recycled oxidized model polyethylene powder as a filler in polyethylene/polycaprolactone blends [357].

The thermal decomposition of cellulose over the wide range of mass loss is essentially the same in both air and nitrogen. At the beginning of the decomposition, oxygen interacts only with surface cellulose, resulting in only $\cong 3 \%$ of mass loss. The two-phase model of cellulose was proposed to explain all observable phenomena related to both the pyrolysis and the oxidative decomposition. According to the report of Mamleev et al. [349], the decomposition occurred through a migration of chain ends from the phase of polymer cellulose into the phase of products, i.e. char, gases and high-boiling tar.

\section{Biological valorisation of biopolymers}

In contrast to previous sections, this one deals with the valorisation of plastics from the point of view of the reincorporation of polymers into the Carbon cycle under biotic conditions. The design of plastic materials from renewable resources for high-consume applications such as packaging or agricultural mulches moves towards the design of sustainable polymers with controlled degradability and enhanced bio-reintegration. Cradle-tocradle design enables the establishment of completely beneficial industrial systems driven by the synergistic search of positive economic, environmental and social goals by enabling a perpetual flow within both biological and technical metabolisms [358]. Although certain biodegradable polymers can be used in long-term applications, the 
commercialization of these materials is continuously increasing in markets for products that have a short lifetime. Biodegradable polymers are much beneficial when they can actually biodegrade in the environment [25]. Thus, the understanding of the degradation mechanisms, as well as the standard methodologies to test the biodegradability of natural polymers by microorganisms and enzymes should open new prospects in the field of biodegradable plastics [359].

\subsection{Steps of biodegradation}

Biodegradation of plastics occurs through non-competitive and likelycoincident stages, which erode and disintegrate the polymeric segments by depolymerisation, being the cleavage chains reintegrated into the carbon cycle by assimilation and mineralisation in the media. Three main stages can thus be distinguished: deterioration, fragmentation and assimilation.

The deterioration of biopolymers could proceed through bulk or surface erosion [359]. In the case of bulk erosion, fragments are lost from the entire polymer mass and the molar mass decreases due to bond cleavage. This breakage is provoked by chemicals such as $\mathrm{H}_{2} \mathrm{O}$, acids, bases, transition metals and radicals, but not by enzymes, since they are too large to penetrate throughout the matrix framework. In the case of surface erosion, matter is lost but there is no relevant change in the molar mass. One should note that if the diffusion of chemicals throughout the material is faster than the cleavage of polymer bonds, the polymer undergoes bulk erosion. In contrasts, if the cleavage of bonds is faster than the diffusion of chemicals, the process occurs mainly at the surface of the matrix.

The fragmentation of biopolymers is considered when low molecular weight molecules are found within the media [359]. The fragmentation is a lytic phenomenon necessary for the subsequent assimilation of the broken polymeric chains into the surrounding environment. Fragmentation is fundamentally an electron transfer process [360]. Biological energy is obtained through the oxidation of reduced materials, where the enzymes catalyse the electron transfer. The loss of oxygen induces a change in the activity and composition of the soil microbial population. Facultative anaerobic organisms can use oxygen, when it is present, or can switch to alternative electron acceptors, such as nitrates and sulphates [360].

The assimilation is the unique event in which there is a real integration of atoms from fragments of polymeric materials inside microbial cells, ending up in mineralisation [233], [361]. This integration brings to microorganisms the necessary sources of energy, electrons and elements such as carbon, nitrogen, oxygen, phosphorus, or sulphur, among others, for the formation of the cell structure. Assimilation allows microorganisms to grow and reproduce consuming nutrient substrate, i.e, polymer segments, from the environment. Monomers surrounding the microbial 
cells must go through the cellular membranes to be assimilated. Inside the cells, the transported molecules are usually oxidised through catabolic pathways conducing to the production of adenosine triphosphate (ATP) and constitutive elements of cells structure. The existence of appropriate micro-organisms to synthesize the specific enzymes required to depolymerize and mineralize the targeted polymer is essential. Actually, these two steps in the biodegradation process may not involve the same microorganism. Naturally occurring polymers, such as polysaccharides, proteins, and cellulose, are easily biodegraded since many microorganisms that produce the enzymes required to metabolize these compounds are readily available in nature [362].

Depending on the microbial abilities to grow in aerobic or anaerobic conditions, there exist three essential catabolic pathways to produce the energy to maintain cellular activity, structure and reproduction [363][365]:

(i) In the case of aerobic respiration, numerous microorganisms are able to use oxygen as the final electron acceptor. These microorganisms need substrates that are oxidised into the cell. Firstly, basic catabolic pathways (e.g. glycolysis, $\beta$-oxidation, aminoacids catabolic reactions, and purine and pyrimidine catabolism) produce a limited quantity of energy. Secondly, more energy is then produced by the oxidative phosphorylations performed by electron transport systems that reduce oxygen to water.

(ii) During anaerobic respiration, several microorganisms are unable to use oxygen as the final electron acceptor. However, they can perform complete oxidation by adapted electron transport in membrane systems. They use final electron acceptors other than oxygen, such as like $\mathrm{NO}_{3}{ }^{-}, \mathrm{SO}_{4}{ }^{2-}, \mathrm{CO}_{2}, \mathrm{Fe}^{3+}$ or fumarate. The result is also the synthesis of more ATP molecules than in an incomplete oxidation.

(iii) Fermentation, an incomplete oxidation pathway, is a way to produce energy when the microorganisms lack of electron transport systems and are unsuitable to use oxygen or other exogenous mineral molecules as final electron acceptors. In this case, endogenous organic molecules synthesised by the cell itself are used as final electron acceptors. The products of fermentation can be mineral and/or organic molecules excreted into the environment, such as $\mathrm{CO}_{2}$, ethanol, lactate, acetate or butanediol. Frequently, these molecules can be used as carbon sources by other organisms, since they still have a reduction power. 


\subsection{Requirements for biodegradation}

The study of the biodegradation mechanisms should contribute to further developments of the next generation of materials having a high environmental acceptability and recyclability, which would become a powerful tool for the sustainable design of polymers from renewable resources [366]. The requirements for biodegradation of polymers at the fragmentation stage are related to the nature and morphology of the polymer and to the environment of biodegradation, in terms of abiotic and biotic conditions [25].

(i) Concerning the nature of the polymer [367], it must contain cleavable polymer groups, liable to enzymatic hydrolysis or oxidation. The balance among hydrophilicity and hydrophobicity will determinate the velocity of chain scission, being as well faster the lower the molecular weight of the polymers is.

(ii) Regarding the morphology, the amorphous regions are more susceptible to degradation both by enzymatic and non-enzymatic hydrolysis, ascribed to the ease of water penetration into the polymer matrix [366]. Thus, the lack of branching and lower crystallinity enhance biodegradability.

(iii) A well-tuned environment where the specific microorganisms can flourish is essential to assure proper biodegradation. Abiotic factors include appropriate temperature range, presence of $\mathrm{H}_{2} \mathrm{O}$, nature and level of salts, action of oxygen to perform from aerobic to anaerobic modes, trace metals, $\mathrm{pH}$, environmental stability, flux, or pressure [368]. The biotic factors concern the action of specific enzymes, which are catalytic proteins that decrease the level of activation energy of molecules favouring chemical reactions [361].

Several enzymes can be found depending on the class of groups preferred during a given chemical reaction: oxidoreductases, transferases, hydrolases, lyases, isomerases or ligases. Enzymatic hydrolysis and oxidation are the main fragmentation pathways.

(i) The enzymatic hydrolysis is mainly concerned by enzymes that belong to hydrolases, such as cellulases, amylases or cutinases, which are readily synthesised by soil microorganisms to hydrolyse natural abundant polymers like cellulose, starch or cutin. Regarding polyesters, lipases and esterases are responsible for the hydrolysis of ester, carbonate, amide and glycosidic linkages [369].

(ii) When the scission reactions by specific enzymes are difficult, e.g. due to crystalline area, hydrophobic zones and steric hindrances, enzymatic oxidation can be implicated [370]. Such is the case of mono-oxygenases and di-oxygenases, like oxidoreductases, which 
incorporate, one and two oxygen atoms respectively, forming alcohol or peroxyl groups that are more easily fragmentable. Other transformations are catalysed by peroxidases leading to smaller molecules. They are hemoproteins, enzymes containing a prosthetic group with an iron atom that can be electron donor or acceptor, i.e. act in both reduced or oxidative ways. Peroxidases catalyse reactions between a peroxyl molecule, e.g. $\mathrm{H}_{2} \mathrm{O}_{2}$ and organic peroxide, and an electron acceptor group as phenol, phenyl, amino, carboxyl, thiol or aliphatic unsaturation [233]. Polymers such as PE, natural and polyisoprene rubbers, lignin and coal are first subjected to biological oxidation by oxidoreductases, such as oxygenases, monooxygenases, peroxidases and oxidases in the biodegradation process [366]. It should be stressed that, though crystalline structures and highly organised molecular networks such as cellulose-based polymer are not favourable to the enzymatic attack, several soil decomposers, particularly fungi, are able to produce $\mathrm{H}_{2} \mathrm{O}_{2}$ to catalyse the fragmentation [233].

\subsection{Standardized methods of analysis}

Studies aimed to enhance the suitability and the reproducibility of laboratory methods to assess the biodegradation of polymers are in continuous progression [371]. This is due to the fact that some operative difficulties can arise during the performance of the tests, thus affecting the accuracy of the measurements as based on the monitoring of suited parameters of choice, as well as the outstanding number of new and structurally different renewable polymer materials [188].

Studies are usually performed under land or water conditions. Landfills, compost or soils are used to simulate degradation under land, whereas sewage, marine water or sludge are used to simulate aqueous conditions. All environments furnish different rates of degradation. In fact, it is possible that some polymers that are degradable in one environment may or may not degrade in another environment. In-land experiments might show difficulties during the performance of tests designed to assess the extent of biodegradation as $\mathrm{CO}_{2}$ release or $\mathrm{O}_{2}$ uptake in the presence of media such as mature compost. In contrast, the tests carried out in aqueous media are considered easier to set up and generally more reproducible, but are not significant for simulating conditions of buried plastics.

The biodegradation kinetics of a test material under in-land conditions can be influenced by the concentration of the material in the solid medium, as well as by the nature of the microbial populations, whereas the test results might vary significantly depending upon the test duration and a reference material designed in the standard test specifications [188]. A critical discussion has argued that the technical specifications should be rephrased 
in a unique, condensed and practical norm, in order to avoid confusion between the available normative from different certification agencies with very close characteristics [372].

Several analytical strategies can be considered to test biodegradation of polymers from renewable resources, depending on the stage focused on: deterioration or assimilation.

(i) Polymer deterioration can be tested by several methods such as the evaluation of macroscopic modifications in the materials, such as roughening of the surface, formation of holes and cracks, changes in colour or development of microorganisms over the surface [373][375]. There exist normalised tests to estimate the deterioration by the colonisation of microorganisms on Petri dishes [376]. A positive result of the test is considered as an argument indicating the consumption of the polymer by the microbial species. This way, different microscopy techniques [234], [377]-[379] are used to refine the analysis, along with the study of changes in mechanical, rheological or thermal properties [341], [380]-[382]. In particular, the measurement of the weight loss is frequently used for the estimation of biodegradability, but actually it may not be really representative of a material biodegradability, since this loss of weight can be due to the vanishing of volatile and soluble impurities [226], [228].

(ii) Polymer assimilation is generally estimated by standardised respirometric methods [383], which mainly consist in measuring the consumption of oxygen or the evolution of carbon dioxide or methane, depending on the respirometric mode. The decrease of oxygen is detected by the diminution of the pressure and may be fully automated. The experiment can be conducted with oxygen limitation or not. In anaerobic conditions, gases are released and the augmentation of the pressure is then measured. The identification of the evolved gases is performed by gas chromatography (GC), infrared analysis (FTIR) [374] or titration [384], [385] . Failure in one test does not necessarily exclude biodegradation, but it merely indicates that under the environmental conditions and/or the timeframe where the experiment was conducted, no or incomplete biodegradation occurred. Thus, more than one test method is usually needed to entirely assess biodegradability.

Table 1 shows a summary of the application of different standards from the American Society for Testing and Materials (ASTM), European Standards Organisation (EN) and International Organization for Standardization (ISO), respectively, on different polymers from renewable resources of the families of polyesters and polysaccharides. 
Table 1. Studies based on ASTM, EN and ISO standards on different polymers from renewable resources.

\begin{tabular}{|c|c|c|c|c|c|c|c|c|}
\hline \multirow{2}{*}{ Organisation } & \multirow{2}{*}{ Code } & \multirow{2}{*}{ Title } & \multicolumn{6}{|c|}{ Material } \\
\hline & & & PLA & PCL & PHAs & Cellulose & Lignin & Starch \\
\hline \multirow{4}{*}{ ASTM } & D5209 & $\begin{array}{l}\text { Standard test method for determining the aerobic } \\
\text { biodegradation of plastic materials in the presence } \\
\text { of municipal sewage sludge }\end{array}$ & [386] & - & [387], [388] & - & - & - \\
\hline & D5338 & $\begin{array}{l}\text { Standard test method for determining aerobic } \\
\text { biodegradation of plastic materials under } \\
\text { controlled composting conditions, incorporating } \\
\text { thermophilic temperatures }\end{array}$ & $\begin{array}{l}{[190],} \\
{[389]-[391]}\end{array}$ & [392] & - & - & [393], [394] & - \\
\hline & D5526 & $\begin{array}{l}\text { Standard test method for determining anaerobic } \\
\text { biodegradation of plastic materials under } \\
\text { accelerated landfill conditions }\end{array}$ & [395] & [395] & - & - & - & - \\
\hline & D5988 & $\begin{array}{l}\text { Standard test method for determining aerobic } \\
\text { biodegradation of plastic materials in soil }\end{array}$ & [389] & - & $\begin{array}{l}\text { [248], [396], } \\
\text { [397] }\end{array}$ & [398] & [396] & [102], [399] \\
\hline EN & 14046 & $\begin{array}{l}\text { Packaging - Evaluation of the ultimate aerobic } \\
\text { biodegradability and disintegration of packaging } \\
\text { materials under controlled composting conditions } \\
\text { - Method by analysis of released carbon dioxide }\end{array}$ & - & - & - & [400], [401] & - & - \\
\hline \multirow{2}{*}{ ISO } & 14852 & $\begin{array}{l}\text { Determination of the ultimate aerobic } \\
\text { biodegradability of plastic materials in an aqueous } \\
\text { medium - Method by analysis of evolved carbon } \\
\text { dioxide }\end{array}$ & [402]-[404] & $\begin{array}{l}{[403],[405],} \\
{[406]}\end{array}$ & [403], [404] & [407], [408] & [409] & $\begin{array}{l}\text { [402], [406], } \\
{[410]}\end{array}$ \\
\hline & 14855 & $\begin{array}{l}\text { Determination of the ultimate aerobic } \\
\text { biodegradability of plastic materials under } \\
\text { controlled composting conditions - Method by } \\
\text { analysis of evolved carbon dioxide }\end{array}$ & $\begin{array}{l}{[190],[391]} \\
{[402]} \\
{[411]-[422]}\end{array}$ & $\begin{array}{l}\text { [412], [416], } \\
{[423]}\end{array}$ & [424], [425] & $\begin{array}{l}\text { [401], [419], } \\
{[422],[426]}\end{array}$ & - & $\begin{array}{l}\text { [413], [417], } \\
{[419],} \\
{[427]-[430]}\end{array}$ \\
\hline
\end{tabular}




\begin{tabular}{|c|c|c|c|c|c|c|c|c|}
\hline \multirow{2}{*}{ Organisation } & \multirow{2}{*}{ Code } & \multirow{2}{*}{ Title } & \multicolumn{6}{|c|}{ Material } \\
\hline & & & PLA & PCL & PHAs & Cellulose & Lignin & Starch \\
\hline & 16929 & $\begin{array}{l}\text { Plastics - Determination of the degree of } \\
\text { disintegration of plastic materials under defined } \\
\text { composting conditions in a pilot-scale test }\end{array}$ & - & - & [425] & - & - & [431] \\
\hline & 17556 & $\begin{array}{l}\text { Plastics - Determination of the ultimate aerobic } \\
\text { biodegradability of plastic materials in soil by } \\
\text { measuring the oxygen demand in a respirometer } \\
\text { or the amount of carbon dioxide evolved }\end{array}$ & - & - & [397] & - & [409] & - \\
\hline & 20200 & $\begin{array}{l}\text { Plastics - Determination of the degree of } \\
\text { disintegration of plastic materials under simulated } \\
\text { composting conditions in a laboratory-scale test }\end{array}$ & $\begin{array}{l}\text { [35], [185], } \\
\text { [432]-[438] }\end{array}$ & [439] & $\begin{array}{l}\text { [185], [432], } \\
{[433]}\end{array}$ & [436], [437] & - & - \\
\hline Review & 50 & ]$,[233],[256],[370],[371],[440]-[451]$ & & & & & & \\
\hline
\end{tabular}




\subsection{Biodegradation under in-land conditions}

In-land biodegradation experiments mainly comprise biotic in-soil and incompost studies [450]. In vitro degradation studies based on the application of microorganisms such as fungi or bacteria are of high interest to tune the binomial soil-bioplastic. Fungal organisms such as Aspergillus niger, Aspergillus flavus, Chaetomium globosum and Penicillium funiculosum, as well as bacterial standards such as Pseudomonas aeruginosa are suggested in some test protocols according to international standards, and evaluated for growth on suitable plastics, thus correlating them with the susceptibility of the plastic to biodegradation [452], [453]. A list of different microorganisms that have been shown able to degrade different groups of plastics can be found in literature [370]. Compostability covers not only naturally-occurring disintegration and biodegradation understood as the lytic action of microorganisms, but also the application of an accelerated process to favour the conversion of plastics into $\mathrm{CO}_{2}, \mathrm{H}_{2} \mathrm{O}$ and cell biomass, with no toxicity [454]. For that reason, high temperature, humidity and aeration systems are used, while the compost proceeds through an initial mesophilic phase, a subsequent thermophilic phase and a final maturation phase.

\subsubsection{Aerobic Studies}

There are several standardized methods to control and determine aerobic biodegradability and disintegration of plastic materials. Among them, the ISO 14855 is one of the most used norms. This ISO standard specifies a method for determining the ultimate aerobic biodegradability of the plastics, under controlled composting conditions by measuring the amount of carbon dioxide generated and the degree of disintegration of the material at the end of the assay. The test material is exposed to an inoculum derived from compost. Composting takes place in an environment in which temperature, ventilation and humidity are controlled. The test method is designed to provide the percentage of conversion of carbon in the test material that generated carbon dioxide as well as the conversion speed. The method applies to several kinds of materials. For plastic materials from renewable resources, several studies have been published. The most studied materials are those that involve degradation of PLA and its derivatives. In this sense, Kunioka et al. proposed the use of PLA powders as the reference test materials for the ISO 14855 methods [415]. They selected mechanical crushing at low temperature of polymer pellets using dry ice for powder production. The degree of biodegradation for this PLA powder was approximately $91 \%$ for 35 days. Moreover, they studied the biodegradation of PLA samples in different shapes [412]. Their studies found that biodegradabilities of polymer pellets, polymer films, polymer products and polymer composites in controlled compost could be evaluated according to ISO 14855-2. Final degrees of biodegradation and 
biodegradation curves of samples prepared from biodegradable polymers with various shapes showed almost the same tendency. However, Kale et al. studied the biodegradability of PLA bottles in real and simulated composting conditions [190]. They found that biodegradation matched well with theoretical degradation and biodegradation mechanisms; however, some variability existed in both conditions, suggesting that the standard methodologies are limited to the plastic material and not to the whole package. On the other hand, Pantani et al. studied the influence of crystallinity on the biodegradation rate of injection-moulded PLA [391]. As expected, the crystallinity was found to decrease the PLA degradation rate. The dense structure of the initially crystalline sample was more impermeable to the enzymatic attach and to oligomer diffusion.

Other kind of biodegradable bio-based materials have been studied such as PHAs, PCL, cellulose or starch based materials. For PHBV films, Weng et al. worked on the influence of the chemical structure [424]. They compared the degradation behaviour of the homopolymer (PHB) as starting material with copolymer PHBV with several amounts of hydroxyvalerate (HV) units. They found that the higher the presence of HV was, the faster the biodegradation ocurred. Moreover, they performed a comparison of the biodegradation in both pilot scale and laboratory scale tests following the ISO14855 standard [425]. The PHBV film was completely disintegrated in the pilot-scale composting test, while the degree of biodegradation was $81 \%$ in the laboratory-scale control composting test. Thus, degradation in a semi-real environment at pilot-scale is suggested to be similar while slightly faster than under the standard guidelines.

The biodegradabilities of cellulose, PCL and PLA powders in a controlled compost at $58{ }^{\circ} \mathrm{C}$ were also investigated according to the ISO14855 standard [412]. Polymer powder samples were obtained from PCL pellets and PLA pellets by mechanically crushing and sieving. The biodegradations of the samples were measured by the Microbial Oxidative Degradation Analyser (MODA). The reproducibility and repeatability of the biodegradation tests using MODA were confirmed for cellulose powders as the reference material, PCL powders and PLA powders.

\subsubsection{Anaerobic Studies}

Anaerobic conditions are important for different end-of-life in-land scenarios, such as landfills and anaerobic digestion systems, which are tackled in the section of degradation under liquid media. Conditions in landfills vary considerably in terms of geography, age of waste or management practices [455]. The potential production of $\mathrm{CH}_{4}$ has been approached in literature from the point of view of greenhouse gas monitoring and, as an added-value alternative, due to its promising performance as a source of energy [456]. In this line, most lab-scale studies 
have been focused on celluloses and hemicelluloses, due to the traditional presence of paper and cardboard in landfills [457]. Since anaerobic microorganisms have a much limited set of enzymes than under the presence of oxygen, and the energy benefit is lower without presence of $\mathrm{O}_{2}$, the rates of degradation are normally lower [458]. Concerning plastic waste, few examples can be highlighted for PLA [386], [459], PHAs [445], PCL [459]-[461], starch/PCL [459], PBAT [459], PBS [461]. It was found that PHB was degraded anaerobically more rapidly than the copolyester PHBV, when tested with either mixed cultures or a single strained isolate, whereas PCL tended to degrade slower than the natural polyesters PHB and PHBV [460]. As well, it was reported that PLA can be considered as a compostable material, being stable during use at mesophilic temperatures, but rapidly degrading during waste disposal in compost or anaerobic treatment facilities. Actually, the biodegradation of PLA was much faster in anaerobic solid state conditions than in aerobic aquatic conditions [386]. Other study showed that anaerobic bacteria degraded PCL-starch blend, showing an $83 \%$ biodegradability for 139 days, although its biodegradation rate was relatively slow compared to that of cellulose used as a reference material. Conversely, PBS was barely degraded under anaerobic conditions, with only $2 \%$ biodegradability in 100 days [461].

\subsection{Biodegradation in aqueous conditions}

The study of biodegradation of plastics under liquid environments has to be considered from a double point of view. On the one hand, the design of novel materials to prevent wastes from ships and offshore platforms under seas and oceans, and on the other hand as a faster comparing methodology to test biodegradability of bioplastics. This could be the case of fishery equipment to be biodegradable to reduce harmful impact to sea life if lost during fishing [458].

Different studies have been performed for polymers such as PLA [395], PCL [395], PHB [462] or PBS [462]. In particular, it has been shown that the biodegradability of PCL and PLA powders under aquatic conditions can be tested with sludges at thermophilic conditions $\left(\sim 55^{\circ} \mathrm{C}\right)$. The biodegradability of PCL was 92\% in the diluted sludge [395]. Other studies at mesophilic conditions $\left(\sim 37^{\circ} \mathrm{C}\right)$ showed that bioplastics could be ranked as PHB $>>$ PLA > PCL in terms of anaerobic biodegradation rate, relating it to the detection of the same eubacteria. On the contrary, PBS could not be anaerobically biodegraded by the sludge used in this study [462]. For PHAs, an experiment on PHBV and PE-Starch blends in a freshwater environment showed steady degradation rates of 10-20 mg per day for PHBV even under relatively extreme conditions. Conversely, PE-Starch blends showed no degradation after one year [463]. It was also shown that degradation of PHBV occurred most rapidly in anaerobic sewage sludge, then estuarine sediment, aerobic sewage, soil, and finally in seawater [464]. 
Concerning microorganisms, it was found that Pseudoalteromonas could be isolated as predominant PHBV-degrading bacterium from a tropical marine environment [465].

\section{Concluding remarks}

Due to their high potential of replacement of petroleum-based polymers, the design, use and disposal routes of bio-based polymers must be carefully strategized in order to ensure appropriate service conditions and adequate valorisation and/or elimination after their service-life. In this sense, the long-term properties and end-of-life of polymers are not antagonist issues, since both are inherently linked by the duality between durability and degradation.

Despite certain biodegradable polymers could be used in long-term applications, the commercialization of bio-based plastics is continuously increasing in markets for products that have a short lifetime. The technological efforts in adding value to these plastic goods are therefore misused. The consideration of the end-of-life of a material for an application, instead of the end-of-life of a material could be therefore kept in mind in order to favour second-life uses, and thus enlarge their servicelives.

Concerning durability, performance tests can be designed to experimentally simulate individual or synergic effects of degrading agents such as temperature, water, chemicals, mechanical stresses or sun light. The control of physico-chemical properties must be monitored in a frommicro-to-macro approach, in order to connect structure to behaviour and, therefore, help decide further steps in the application-to-disposal pathway. Regarding degradation at the end-of-life stage, material, energetic and biological valorisations should be carefully combined. This field is still a matter of interest and offers a wide field of opportunities, as suggested hereby:

(i) Material valorisation would benefit from more specialised sorting technologies for plastic waste, so as the reuse before recycling might be enhanced, as well as the recycled fractions offer more homogeneity in their compositions. As well, the options of using additivities, blending and/or compositing to upgrade recycled plastics should foresee the following steps of valorisation and/or disposal. Finally, one should consider that, during real recycling, plastic fractions would be commingled and previously subjected to degrading agents during service life. More standardisation and realscale studies should therefore be performed for recycled materials, since most are currently run at lab conditions by multiple reprocessing with individual polymers. 
(ii) Energetic/Feedstock valorisation could be prioritised after material valorisation when the obtaining of chemicals is relevant and/or the biological facilities cannot cover the treatment of bio-based wastes. Nowadays the studies are devoted, on the one hand, to the analysis of the solid-state thermal and thermo-oxidative kinetics at lab conditions and, on the other hand, to the obtaining of calorific values of bio-based polymers at pilot-scale. In order to link labs with realscale applications, a current challenge would be to connect, via computer simulation, solid-state kinetics with operational units such as pyrolysers or gasifiers. The optimisation of working parameters would produce more complete thermal transformation, therefore with higher thermal efficiency and lower emission of gases. This connection would release useful information to set up standards, which may help homogenise the studies and benchmark the applicability of energetic/feedstock valorisation for bio-based polymers.

(iii) Biological valorisation to reintegrate sources into the $\mathrm{C}$ cycle is essential for bio-based polymers, obviously for controlled management of wastes via current facilities such as composters and, even more, to ensure the lowest impact of non-controlled disposed bio-based goods. Due to the environmental concern and deep knowledge of the different stages of biodegradation through deterioration, fragmentation and assimilation, and the different media of degradation both aqueous and in-land environments, the amount of standards are sometimes very similar, which complicates the choice of the most appropriate one to certify biodegradation. Therefore, and effort in unifying the standards of certification of biodegradation remains a challenge. As well, the proliferation and optimisation of specific composting facilities for bio-based plastics would help clarify the disposal pathways and therefore reduce the impact of treatment of these wastes.

In conclusion, the balance between the long-term properties and the endof-life of bio-based polymers is key to set up a design for sustainability. A smart combination of the routes of production, valorisation and disposal might lead to reduce the environmental impact and gear bio-based polymers towards added-value applications.

\section{Acknowledgements}

The authors acknowledge the Spanish Ministry of Economy and Competitiveness for the projects POLYCELL (ENE2014-53734-C2-1-R) and TETRA-SEC (UPOV13-3E-1947). The Spanish Ministry of Education, Culture and Sports is thanked for the FPU grant of O. GilCastell (FPU13/01916). Generalitat Valenciana is recognized for the 
BIOARMED project (APOSTD/2014/041) for J.D. Badia. Universitat de València and Hospital Universitari i Politècnic La Fe are thanked for the funding of the project 57-DERMASAFE-MOLINS-ONTORIA-2015-A.

\section{References}

[1] M. Tolinski, “Towards a Peaceful Coexistence between Bio-based and Fossil Fuel-based Plastics,” in Plastics and Sustainability, John Wiley \& Sons, Inc., 2011, pp. i-xv.

[2] J. P. Greene, "Sustainable Plastic Products," in Sustainable Plastics, John Wiley \& Sons, Inc., 2014, pp. 145-186.

[3] H. Ariffin, H. Nishida, M. A. Hassan, and Y. Shirai, "Chemical recycling of polyhydroxyalkanoates as a method towards sustainable development,” Biotechnol. J., vol. 5, no. 5, pp. 484-492, May 2010.

[4] C. J. M. Lagarón, S. M. Martínez, and R. A. López, "Procedimiento de obtencion de una pelicula multicapa con alta barrera, película, material y uso en envases, ingeniería de tejidoso y en un biopoliéster.” Google Patents, 07-Feb-2013.

[5] P. Capra, B. Briasco, M. Sorrenti, L. Catenacci, M. Sachet, and P. Perugini, "Preliminary evaluation of packaging-content interactions: Mechanical and physicochemical characterization of polylactide bottles,” J. Appl. Polym. Sci., vol. 131, no. 7, pp. 1-10, 2014 .

[6] S. Slomkowski, S. Penczek, and A. Duda, "Polylactides-an overview," Polym. Adv. Technol., vol. 2014, no. February, 2014.

[7] N. Burgos, V. P. Martino, and A. Jiménez, "Characterization and ageing study of poly(lactic acid) films plasticized with oligomeric lactic acid,” vol. 98, no. 2, pp. 651658, Feb. 2013.

[8] M. Ceraulo, M. C. Mistretta, F. P. La Mantia, and L. Botta, "Rheological behaviour, filmability and mechanical properties of biodegradable polymer films,” 2014, vol. 1599, pp. 510-513.

[9] M. J. Fabra, A. Hambleton, P. Talens, F. Debeaufort, A. Chiralt, and A. Voilley, “Aroma Barrier Properties of Sodium Caseinate-Based Films,” Biomacromolecules, vol. 9, no. 5, pp. 1406-1410, May 2008.

[10] M. J. Fabra, P. Talens, and A. Chiralt, “Tensile properties and water vapor permeability of sodium caseinate films containing oleic acid-beeswax mixtures,” J. Food Eng., vol. 85, no. 3, pp. 393-400, Apr. 2008.

[11] W. Phetwarotai, P. Potiyaraj, and D. Aht-Ong, "Characteristics of biodegradable polylactide/gelatinized starch films: Effects of starch, plasticizer, and compatibilizer," J. Appl. Polym. Sci., vol. 126, no. S1, pp. E162-E172, Oct. 2012.

[12] M. A. Shirai, M. V. E. Grossmann, S. Mali, F. Yamashita, P. S. Garcia, and C. M. O. Müller, "Development of biodegradable flexible films of starch and poly(lactic acid) plasticized with adipate or citrate esters.," Carbohydr. Polym., vol. 92, no. 1, pp. 19-22, Jan. 2013.

[13] Z. Xiong, Y. Yang, J. Feng, X. Zhang, C. Zhang, Z. Tang, and J. Zhu, "Preparation and characterization of poly(lactic acid)/starch composites toughened with epoxidized soybean oil.," Carbohydr. Polym., vol. 92, no. 1, pp. 810-6, Jan. 2013.

[14] I. Armentano, E. Fortunati, N. Burgos, F. Dominici, F. Luzi, S. Fiori, A. Jiménez, K. Yoon, J. Ahn, S. Kang, J. M. Kenny, A. Jim??nez, K. Yoon, J. Ahn, S. Kang, and J. M. Kenny, "Processing and characterization of plasticized PLA/PHB blends for biodegradable multiphase systems,” Express Polym. Lett., vol. 9, no. 7, pp. 583-596, 2015.

[15] I. Armentano, E. Fortunati, N. Burgos, F. Dominici, F. Luzi, S. Fiori, A. Jiménez, K. Yoon, J. Ahn, S. Kang, and J. M. Kenny, "Bio-based PLA_PHB plasticized blend films: Processing and structural characterization,” LWT - Food Sci. Technol., vol. 64, no. 2, pp. 980-988, 2015.

[16] M. P. Arrieta, M. D. Samper, J. López, and A. Jiménez, "Combined Effect of Poly(hydroxybutyrate) and Plasticizers on Polylactic acid Properties for Film Intended for Food Packaging,” J. Polym. Environ., vol. 22, no. 4, pp. 460-470, Nov. 2014.

[17] A. Jiménez and R. A. Ruseckaite, “Nano-Biocomposites for Food Packaging,” Green 
Energy Technol., vol. 50, pp. 393-408, 2012.

[18] S. Sinha Ray and M. Okamoto, "Polymer/layered silicate nanocomposites: a review from preparation to processing,” Prog. Polym. Sci., vol. 28, no. 11, pp. 1539-1641, Nov. 2003.

[19] M. Avella, J. J. De Vlieger, M. E. Errico, S. Fischer, P. Vacca, and M. G. Volpe, "Biodegradable starch/clay nanocomposite films for food packaging applications," Food Chem., vol. 93, no. 3, pp. 467-474, Dec. 2005.

[20] J. Huang, C. He, X. Liu, J. Xu, C. S. S. Tay, and S. Y. Chow, "Organic-inorganic nanocomposites from cubic silsesquioxane epoxides: direct characterization of interphase, and thermomechanical properties,” Polymer (Guildf)., vol. 46, no. 18, pp. 7018-7027, Aug. 2005.

[21] V. P. Cyras, L. B. Manfredi, M.-T. Ton-That, and A. Vázquez, "Physical and mechanical properties of thermoplastic starch/montmorillonite nanocomposite films," Carbohydr. Polym., vol. 73, no. 1, pp. 55-63, Jul. 2008.

[22] R. Zhao, P. Torley, and P. Halley, "Emerging biodegradable materials: starch- and protein-based bio-nanocomposites,” J. Mater. Sci., vol. 43, no. 9, pp. 3058-3071, 2008.

[23] O. V. López, L. A. Castillo, M. A. García, M. A. Villar, and S. E. Barbosa, "Food packaging bags based on thermoplastic corn starch reinforced with talc nanoparticles," Food Hydrocoll., vol. 43, pp. 18-24, Jan. 2015.

[24] S. Dash and S. K. Swain, "Synthesis of thermal and chemical resistant oxygen barrier starch with reinforcement of nano silicon carbide.," Carbohydr. Polym., vol. 97, no. 2, pp. 758-63, Sep. 2013.

[25] K. Dean, L. Yu, G. Madras, M. Bhattacharya, R. L. Reis, V. Correlo, L. Boesel, S. Matsumura, K. Dean, and L. Yu, Biodegradable Polymers for Industrial Applications. Elsevier, 2005.

[26] P. Chen and L. Zhang, "Interaction and Properties of Highly Exfoliated Soy Protein/Montmorillonite Nanocomposites,” Biomacromolecules, vol. 7, no. 6, pp. 17001706, Jun. 2006.

[27] J. Yu, G. Cui, M. Wei, and J. Huang, "Facile exfoliation of rectorite nanoplatelets in soy protein matrix and reinforced bionanocomposites thereof,” J. Appl. Polym. Sci., vol. 104, no. 5, pp. 3367-3377, Jun. 2007.

[28] N. Lavoine, C. Givord, N. Tabary, I. Desloges, B. Martel, and J. Bras, "Elaboration of a new antibacterial bio-nano-material for food-packaging by synergistic action of cyclodextrin and microfibrillated cellulose,” Innov. Food Sci. Emerg. Technol., vol. 26, pp. 330-340, Dec. 2014.

[29] J. J. Zhou, S. Y. Wang, and S. Gunasekaran, "Preparation and Characterization of Whey Protein Film Incorporated with TiO2 Nanoparticles,” J. Food Sci., vol. 74, no. 7, pp. N50-N56, Sep. 2009.

[30] L. Shi, J. Zhou, and S. Gunasekaran, "Low temperature fabrication of ZnO-whey protein isolate nanocomposite,” Mater. Lett., vol. 62, no. 28, pp. 4383-4385, Nov. 2008.

[31] F. Li, P. Biagioni, M. Finazzi, S. Tavazzi, and L. Piergiovanni, "Tunable green oxygen barrier through layer-by-layer self-assembly of chitosan and cellulose nanocrystals.," Carbohydr. Polym., vol. 92, no. 2, pp. 2128-34, Feb. 2013.

[32] B.-K. Chen, C.-C. Shih, and A. F. Chen, "Ductile PLA nanocomposites with improved thermal stability,” Compos. Part A Appl. Sci. Manuf., vol. 43, no. 12, pp. 2289-2295, Dec. 2012.

[33] C.-C. Chen, J.-Y. Chueh, H. Tseng, H.-M. Huang, and S.-Y. Lee, "Preparation and characterization of biodegradable PLA polymeric blends,” Biomaterials, vol. 24, no. 7, pp. 1167-1173, Mar. 2003.

[34] N. Peelman, P. Ragaert, A. Vandemoortele, E. Verguldt, B. De Meulenaer, and F. Devlieghere, "Use of biobased materials for modified atmosphere packaging of short and medium shelf-life food products," Innov. Food Sci. Emerg. Technol., vol. 26, pp. 319-329, Dec. 2014.

[35] P. Cinelli, M. Schmid, E. Bugnicourt, J. Wildner, A. Bazzichi, I. Anguillesi, and A. Lazzeri, "Whey protein layer applied on biodegradable packaging film to improve barrier properties while maintaining biodegradability,” Polym. Degrad. Stab., vol. 108, pp. 151-157, Oct. 2014.

[36] P. Lu, H. Xiao, W. Zhang, and G. Gong, "Reactive coating of soybean oil-based polymer 
on nanofibrillated cellulose film for water vapor barrier packaging.," Carbohydr. Polym., vol. 111, pp. 524-9, Oct. 2014.

[37] M. J. Fabra, A. Lopez-Rubio, and J. M. Lagaron, "High barrier polyhydroxyalcanoate food packaging film by means of nanostructured electrospun interlayers of zein,” Food Hydrocoll., vol. 32, no. 1, pp. 106-114, Jul. 2013.

[38] M. J. Fabra, A. López-Rubio, and J. M. Lagaron, “On the use of different hydrocolloids as electrospun adhesive interlayers to enhance the barrier properties of polyhydroxyalkanoates of interest in fully renewable food packaging concepts," Food Hydrocoll., vol. 39, pp. 77-84, Aug. 2014.

[39] R. G. Sinclair, "The Case for Polylactic Acid as a Commodity Packaging Plastic,” J. Macromol. Sci. Part A, vol. 33, no. 5, pp. 585-597, May 1996.

[40] L. Botta, R. Scaffaro, M. C. Mistretta, and F. P. La Mantia, "Biopolymer based nanocomposites reinforced with graphene nanoplatelets," in AIP Conference Proceedings, 2016, vol. 1736.

[41] C. Bastioli, V. Bellotti, and A. Montino, "Biodegradable polymeric compositions based on starch and thermoplastic polymers.” Google Patents, 03-Sep-1992.

[42] S. Jacobsen, H. G. Fritz, P. Degée, P. Dubois, and R. Jérôme, "Polylactide (PLA)—a new way of production,” Polym. Eng. Sci., vol. 39, no. 7, pp. 1311-1319, Jul. 1999.

[43] S. Jacobsen and H. G. Fritz, "Filling of poly(lactic acid) with native starch,” Polym. Eng. Sci., vol. 36, no. 22, pp. 2799-2804, Nov. 1996.

[44] M. F. F. Koenig and S. J. J. Huang, "Biodegradable blends and composites of polycaprolactone and starch derivatives,” Polymer (Guildf)., vol. 36, no. 9, pp. 18771882, Apr. 1995.

[45] E.-S. Park, M.-N. Kim, and J.-S. Yoon, "Grafting of polycaprolactone onto poly(ethylene-co-vinyl alcohol) and application to polyethylene-based bioerodable blends,” J. Polym. Sci. Part B Polym. Phys., vol. 40, no. 22, pp. 2561-2569, Nov. 2002.

[46] H. Tsuji and T. Yamada, "Blends of aliphatic polyesters. VIII. Effects of poly(L-lactideco-e-caprolactone) on enzymatic hydrolysis of poly(L-lactide), poly( $\varepsilon$-caprolactone), and their blend films,” J. Appl. Polym. Sci., vol. 87, no. 3, pp. 412-419, Jan. 2003.

[47] A. Valdés, A. C. Mellinas, M. Ramos, M. C. Garrigós, and A. Jiménez, "Natural additives and agricultural wastes in biopolymer formulations for food packaging," vol. 2, no. FEB. Frontiers Media S. A, 2014.

[48] C. F. Struller, P. J. Kelly, and N. J. Copeland, "Aluminum oxide barrier coatings on polymer films for food packaging applications,” Surf. Coatings Technol., vol. 241, pp. 130-137, Feb. 2014.

[49] V. Guazzotti, S. Limbo, L. Piergiovanni, R. Fengler, D. Fiedler, and L. Gruber, “A study into the potential barrier properties against mineral oils of starch-based coatings on paperboard for food packaging," Food Packag. Shelf Life, vol. 3, pp. 9-18, Mar. 2015.

[50] P. Appendini and J. H. Hotchkiss, "Review of antimicrobial food packaging," Innov. Food Sci. Emerg. Technol., vol. 3, no. 2, pp. 113-126, Jun. 2002.

[51] R. Nigmatullin, F. Gao, and V. Konovalova, "Polymer-layered silicate nanocomposites in the design of antimicrobial materials,” J. Mater. Sci., vol. 43, no. 17, pp. 5728-5733, 2008.

[52] P. Persico, V. Ambrogi, C. Carfagna, P. Cerruti, I. Ferrocino, and G. Mauriello, "Nanocomposite polymer films containing carvacrol for antimicrobial active packaging,” Polym. Eng. Sci., vol. 49, no. 7, pp. 1447-1455, Jul. 2009.

[53] P. Suppakul, J. Miltz, K. Sonneveld, and S. W. Bigger, “Active Packaging Technologies with an Emphasis on Antimicrobial Packaging and its Applications,” J. Food Sci., vol. 68, no. 2, pp. 408-420, Mar. 2003.

[54] T. M. de Oliveira, N. de Fátima Ferreira Soares, R. M. Pereira, and K. de Freitas Fraga, "Development and evaluation of antimicrobial natamycin-incorporated film in gorgonzola cheese conservation,” Packag. Technol. Sci., vol. 20, no. 2, pp. 147-153, Mar. 2007.

[55] J. P. P. Kerry, M. N. O’Grady, S. A. A. Hogan, M. N. O’Grady, and S. A. A. Hogan, "Past, current and potential utilisation of active and intelligent packaging systems for meat and muscle-based products: A review,” Meat Sci., vol. 74, no. 1, pp. 113-130, Sep. 2006.

[56] M. del R. Moreira, M. Pereda, N. E. Marcovich, and S. I. Roura, “Antimicrobial 
Effectiveness of Bioactive Packaging Materials from Edible Chitosan and Casein Polymers: Assessment on Carrot, Cheese, and Salami,” J. Food Sci., vol. 76, no. 1, pp. M54-M63, Jan. 2011.

[57] X. Liu, Q. Sun, H. Wang, L. Zhang, and J.-Y. J.-Y. Wang, "Microspheres of corn protein, zein, for an ivermectin drug delivery system.," Biomaterials, vol. 26, no. 1, pp. 109-15, Jan. 2005.

[58] R. Shukla and M. Cheryan, "Zein: the industrial protein from corn,” Ind. Crops Prod., vol. 13, no. 3, pp. 171-192, May 2001.

[59] A. González and C. I. Alvarez Igarzabal, "Soy protein - Poly (lactic acid) bilayer films as biodegradable material for active food packaging," Food Hydrocoll., vol. 33, no. 2, pp. 289-296, Dec. 2013.

[60] S. Tripathi, G. K. Mehrotra, and P. K. Dutta, "Preparation and physicochemical evaluation of chitosan/poly(vinyl alcohol)/pectin ternary film for food-packaging applications,” Carbohydr. Polym., vol. 79, no. 3, pp. 711-716, Feb. 2010.

[61] S. Alix, A. Mahieu, C. Terrie, J. Soulestin, E. Gerault, M. G. J. Feuilloley, R. Gattin, V. Edon, T. Ait-Younes, and N. Leblanc, "Active pseudo-multilayered films from polycaprolactone and starch based matrix for food-packaging applications,” Eur. Polym. J., vol. 49, no. 6, pp. 1234-1242, Jun. 2013.

[62] C.-H. Gu, J.-J. Wang, Y. Yu, H. Sun, N. Shuai, and B. Wei, "Biodegradable multilayer barrier films based on alginate/polyethyleneimine and biaxially oriented poly(lactic acid).," Carbohydr. Polym., vol. 92, no. 2, pp. 1579-85, Feb. 2013.

[63] M. Smolander and Q. Chaudhry, "Chapter 6 Nanotechnologies in Food Packaging,” in Nanotechnologies in Food, The Royal Society of Chemistry, 2010, pp. 86-101.

[64] J. M. Lagarón, E. Giménez, B. Altava, V. Del-Valle, and R. Gavara, "Characterization of extruded ethylene-vinyl alcohol copolymer based barrier blends with interest in food packaging applications,” Macromol. Symp., vol. 198, no. 1, pp. 473-482, Aug. 2003.

[65] D. R. Paul and C. B. Bucknall, Polymer blends. New York: John Wiley \& Sons Inc, 2000.

[66] C. Mellinas, A. Valdés, M. Ramos, N. Burgos, M. Del Carmen Garrigós, and A. Jiménez, “Active edible films: Current state and future trends,” J. Appl. Polym. Sci., vol. 133, no. 2, Jan. 2016.

[67] H. M. C. Azeredo, L. H. C. Mattoso, D. Wood, T. G. Williams, R. J. Avena-Bustillos, and T. H. McHugh, "Nanocomposite Edible Films from Mango Puree Reinforced with Cellulose Nanofibers,” J. Food Sci., vol. 74, no. 5, pp. N31-N35, Jun. 2009.

[68] K. S. Miller and J. M. Krochta, "Oxygen and aroma barrier properties of edible films: A review,” Trends Food Sci. Technol., vol. 8, no. 7, pp. 228-237, Jul. 1997.

[69] N. Burgos, A. Valdés, and A. Jiménez, "Valorization of Agricultural Wastes for the Production of Protein-Based Biopolymers,” J. Renew. Mater., vol. 4, no. 3, pp. 165177, Jun. 2016.

[70] T. Janjarasskul, K. Tananuwong, and J. M. Krochta, "Whey Protein Film with Oxygen Scavenging Function by Incorporation of Ascorbic Acid,” J. Food Sci., vol. 76, no. 9, pp. E561-E568, Nov. 2011.

[71] E. P. Winters and D. L. Deardorff, "Zein as a film-type coating for medicinal tablets," J. Am. Pharm. Assoc., vol. 47, no. 8, pp. 608-612, Aug. 1958.

[72] J. W. Lawton, “Zein: A History of Processing and Use,” Cereal Chem. J., vol. 79, no. 1, pp. 1-18, Jan. 2002.

[73] J. P. Maran, V. Sivakumar, R. Sridhar, and K. Thirugnanasambandham, "Development of model for barrier and optical properties of tapioca starch based edible films.," Carbohydr. Polym., vol. 92, no. 2, pp. 1335-47, Feb. 2013.

[74] I. Belyamani, F. Prochazka, and G. Assezat, "Production and characterization of sodium caseinate edible films made by blown-film extrusion,” J. Food Eng., vol. 121, pp. 3947, Jan. 2014.

[75] D. K. R. Robinson and M. J. Morrison, "Nanotechnologies for Food Packaging: Reporting the Science and Technology Research Trends,” 2010.

[76] D. Salarbashi, S. Tajik, M. Ghasemlou, S. Shojaee-Aliabadi, M. Shahidi Noghabi, and R. Khaksar, "Characterization of soluble soybean polysaccharide film incorporated essential oil intended for food packaging.," Carbohydr. Polym., vol. 98, no. 1, pp. 112736, Oct. 2013. 
[77] M. Ramos, A. Jiménez, M. Peltzer, and M. C. Garrigós, "Development of novel nanobiocomposite antioxidant films based on poly (lactic acid) and thymol for active packaging.,” Food Chem., vol. 162, pp. 149-55, Nov. 2014.

[78] A. Beltrán, A. J. M. Valente, A. Jiménez, and M. C. Garrigós, "Characterization of poly( $\varepsilon$-caprolactone)-based nanocomposites containing hydroxytyrosol for active food packaging,” J. Agric. Food Chem., vol. 62, no. 10, pp. 2244-2252, Mar. 2014.

[79] N. Lavoine, I. Desloges, and J. Bras, "Microfibrillated cellulose coatings as new release systems for active packaging.,” Carbohydr. Polym., vol. 103, pp. 528-37, Mar. 2014.

[80] S. K. Pankaj, C. Bueno-Ferrer, N. N. Misra, L. O’Neill, A. Jiménez, P. Bourke, and P. J. Cullen, "Surface, thermal and antimicrobial release properties of plasma-treated zein films,” J. Renew. Mater., vol. 2, no. 1, pp. 77-84, Mar. 2014.

[81] R. Scaffaro, L. Botta, A. Maio, M. C. Mistretta, and F. P. La Mantia, "Effect of graphene nanoplatelets on the physical and antimicrobial properties of biopolymer-based nanocomposites,” Materials (Basel)., vol. 9, no. 5, p. 351, 2016.

[82] J. H. Han, C. H. L. Ho, and E. T. Rodrigues, "Intelligent packaging," in Innovations in Food Packaging, J. H. Han, Ed. Elsevier, 2005.

[83] K. L. Yam, P. T. Takhistov, and J. Miltz, "Intelligent Packaging: Concepts and Applications,” J. Food Sci., vol. 70, no. 1, pp. R1-R10, Jan. 2005.

[84] P. Dallas, J. Tucek, D. Jancik, M. Kolar, A. Panacek, and R. Zboril, "Magnetically Controllable Silver Nanocomposite with Multifunctional Phosphotriazine Matrix and High Antimicrobial Activity,” Adv. Funct. Mater., vol. 20, no. 14, pp. 2347-2354, Jul. 2010.

[85] D. Cui, F. Tian, S. R. Coyer, J. Wang, B. Pan, F. Gao, R. He, and Y. Zhang, "Effects of Antisense-Myc-Conjugated Single-Walled Carbon Nanotubes on HL-60Cells,” $J$. Nanosci. Nanotechnol., vol. 7, no. 4-5, pp. 1639-1646, 2007.

[86] B. Pan, D. Cui, Y. Sheng, C. Ozkan, F. Gao, R. He, Q. Li, P. Xu, and T. Huang, "Dendrimer-modified magnetic nanoparticles enhance efficiency of gene delivery system,” Cancer Res., vol. 67, no. 17, pp. 8156-8163, 2007.

[87] V. A. Pereira, I. N. Q. de Arruda, and R. Stefani, “Active chitosan/PVA films with anthocyanins from Brassica oleraceae (Red Cabbage) as Time-Temperature Indicators for application in intelligent food packaging,” Food Hydrocoll., vol. 43, pp. 180-188, Jan. 2015.

[88] S. Guilbert and Ensa, "Biodegradable polymers in agricultural applications," in Biodegradable polymers for industrial applications, R. Smith, Ed. .

[89] G. Scarascia-Mugnozza, E. Schettini, G. Vox, M. Malinconico, B. Immirzi, and S. Pagliara, "Mechanical properties decay and morphological behaviour of biodegradable films for agricultural mulching in real scale experiment,” Polym. Degrad. Stab., vol. 91, no. 11, pp. 2801-2808, Nov. 2006.

[90] R. Costa, A. Saraiva, L. Carvalho, and E. Duarte, "The use of biodegradable mulch films on strawberry crop in Portugal,” Sci. Hortic. (Amsterdam)., vol. 173, pp. 65-70, Jun. 2014.

[91] G. Borreani and E. Tabacco, "Bio-based biodegradable film to replace the standard polyethylene cover for silage conservation.,” J. Dairy Sci., vol. 98, no. 1, pp. 386-94, Jan. 2015.

[92] D. Briassoulis, "Analysis of the mechanical and degradation performances of optimised agricultural biodegradable films,” Polym. Degrad. Stab., vol. 92, no. 6, pp. 1115-1132, Jun. 2007.

[93] N. Gontard and S. Guilbert, "Bio-packaging: technology and properties of edible and/or biodegradable material of agricultural origin,” in Food Packaging and Preservation, M. Mathlouthi, Ed. Glasgow: Blackie Academic \& Professional, 1994, pp. 159-181.

[94] S. Guilbert and B. Cuq, "Protein as raw material for biodegradable products," in Handbook of Biodegradable Polymers, C. Bastioli, Ed. London: Rapra tech. LTD, 2005.

[95] A. Gennadios and T. High, "Edible coatings and films based on proteins," in Edible Coating and Films to Improve Food Quality, J. Krochta, E. Baldwin, and M. NisperosCarriedo, Eds. Lancaster: Technomic Publishing Co. Inc., 1994.

[96] S. Guilbert, N. Gontard, M. Morel, P. Claier, V. Micard, and A. Redl, "Formation and properties of wheat gluten films and coatings,” in Protein-based Films and Coatings, A. Gennadios, Ed. Boca Raton: CRC Press, 2002, pp. 69-122. 
[97] S. Guilbert, A. Redl, and M. H. Morel, "Method for preparing composite materials containing natural binders.” Google Patents, 17-Jun-2008.

[98] F. Chen, X. Monnier, M. Gällstedt, U. W. Gedde, and M. S. Hedenqvist, "Wheat gluten/chitosan blends: A new biobased material,” vol. 60, pp. 186-197, 2014.

[99] L. Ao, L. Qin, H. Kang, Z. Zhou, and H. Su, "Preparation, properties and field application of biodegradable and phosphorus-release films based on fermentation residue,” Int. Biodeterior. Biodegradation, vol. 82, pp. 134-140, Aug. 2013.

[100] B. Singh, D. K. Sharma, R. Kumar, and A. Gupta, "Development of a new controlled pesticide delivery system based on neem leaf powder.,” J. Hazard. Mater., vol. 177, no. 1-3, pp. 290-9, May 2010.

[101] S. Kumar, G. Bhanjana, A. Sharma, M. C. Sidhu, and N. Dilbaghi, "Synthesis, characterization and on field evaluation of pesticide loaded sodium alginate nanoparticles.," Carbohydr. Polym., vol. 101, pp. 1061-7, Jan. 2014.

[102] A. Chevillard, H. Angellier-Coussy, V. Guillard, N. Gontard, and E. Gastaldi, "Investigating the biodegradation pattern of an ecofriendly pesticide delivery system based on wheat gluten and organically modified montmorillonites,” Polym. Degrad. Stab., vol. 97, no. 10, pp. 2060-2068, Oct. 2012.

[103] A. Chevillard, H. Angellier-Coussy, V. Guillard, N. Gontard, and E. Gastaldi, "Controlling pesticide release via structuring agropolymer and nanoclays based materials,” J. Hazard. Mater., vol. 205-206, pp. 32-39, Feb. 2012.

[104] A. K. Lau, W. W. Cheuk, and K. V Lo, "Degradation of greenhouse twines derived from natural fibers and biodegradable polymer during composting.,” J. Environ. Manage., vol. 90, no. 1, pp. 668-71, Jan. 2009.

[105] E. Chiellini, "Bioactive polymeric materials in biomedical and pharmaceutical applications-A story ongoing for decades-),” Polimery/Polymers, vol. 58, no. 9, pp. 631640, 2013.

[106] D. Puppi, F. Chiellini, M. Dash, and E. Chiellini, "Biodegradable polymers for biomedical applications,” Nova Science Publishers, Inc., 2011, pp. 545-604.

[107] B. Guo, L. Glavas, and A.-C. Albertsson, "Biodegradable and electrically conducting polymers for biomedical applications,” Prog. Polym. Sci., vol. 38, no. 9, pp. 1263-1286, Sep. 2013.

[108] A. W. Lloyd, "Interfacial bioengineering to enhance surface biocompatibility,” Med. Device Technol., vol. 13, pp. 18-21, 2002.

[109] A. Göpferich, "Mechanisms of polymer degradation and erosion,” Biomaterials, vol. 17, no. 2, pp. 103-114, Jan. 1996.

[110] R. Langer, "Biomaterials in Drug Delivery and Tissue Engineering: One Laboratory's Experience,” Acc. Chem. Res., vol. 33, no. 2, pp. 94-101, Feb. 2000.

[111] A. Atala, "Tissue Engineering and Regenerative Medicine: Concepts for Clinical Application,” Rejuvenation Res., vol. 7, no. 1, pp. 15-31, May 2004.

[112] F. J. O’Brien, "Biomaterials \& scaffolds for tissue engineering,” Mater. Today, vol. 14, no. 3, pp. 88-95, Mar. 2011.

[113] A. J. R. Lasprilla, G. A. R. Martinez, B. H. Lunelli, A. L. Jardini, R. M. Filho, and F. R. Lasprilla AJR, Martinez GAR, Lunelli BH, Jardini AL, "Poly-lactic acid synthesis for application in biomedical devices - a review.,” Biotechnol. Adv., vol. 30, no. 1, pp. 3218, Jan. 2012.

[114] M. Smiga-Matuszowicz, B. Janicki, K. Jaszcz, J. Łukaszczyk, M. Kaczmarek, M. Lesiak, A. L. Sieroń, W. Simka, M. Mierzwiński, and D. Kusz, "Novel bioactive polyester scaffolds prepared from unsaturated resins based on isosorbide and succinic acid.,” Mater. Sci. Eng. C. Mater. Biol. Appl., vol. 45, pp. 64-71, Dec. 2014.

[115] P. B. Malafaya, G. A. Silva, R. L. Reis, and R. R. Malafaya PB, Silva GA, "Naturalorigin polymers as carriers and scaffolds for biomolecules and cell delivery in tissue engineering applications.,” Adv. Drug Deliv. Rev., vol. 59, no. 4-5, pp. 207-33, May 2007.

[116] E. M. Fernandes, R. A. Pires, J. F. Mano, and R. L. Reis, "Bionanocomposites from lignocellulosic resources: Properties, applications and future trends for their use in the biomedical field,” Prog. Polym. Sci., vol. 38, no. 10-11, pp. 1415-1441, Oct. 2013.

[117] I.-Y. Kim, S.-J. Seo, H.-S. Moon, M.-K. Yoo, I.-Y. Park, B.-C. Kim, and C.-S. Cho, "Chitosan and its derivatives for tissue engineering applications.," Biotechnol. Adv., vol. 
26, no. 1, pp. 1-21, Jan. 2008.

[118] F. Croisier and C. Jérôme, “Chitosan-based biomaterials for tissue engineering,” Eur. Polym. J., vol. 49, no. 4, pp. 780-792, Apr. 2013.

[119] W. Friess and M. Schlapp, "Sterilization of gentamicin containing collagen/PLGA microparticle composites.,” Eur. J. Pharm. Biopharm., vol. 63, no. 2, pp. 176-87, Jun. 2006.

[120] C. E. Tanase and I. Spiridon, "PLA/chitosan/keratin composites for biomedical applications.,” Mater. Sci. Eng. C. Mater. Biol. Appl., vol. 40, pp. 242-7, Jul. 2014.

[121] M. C. Serrano, M. C. Gutiérrez, and F. del Monte, "Role of polymers in the design of 3D carbon nanotube-based scaffolds for biomedical applications,” Prog. Polym. Sci., vol. 39, no. 7, pp. 1448-1471, Jul. 2014.

[122] P. Pooyan, R. Tannenbaum, and H. Garmestani, "Mechanical behavior of a cellulosereinforced scaffold in vascular tissue engineering.," J. Mech. Behav. Biomed. Mater., vol. 7, pp. 50-9, Mar. 2012.

[123] D. Yuan, C. Xu, Z. Chen, and Y. Chen, "Crosslinked bicontinuous biobased polylactide/natural rubber materials: Super toughness, 'net-like'-structure of NR phase and excellent interfacial adhesion,” Polym. Test., vol. 38, pp. 73-80, Sep. 2014.

[124] A. Masek and M. Zaborski, "ENR/PCL Polymer biocomposites from renewable resources,” Comptes Rendus Chim., vol. 17, no. 9, pp. 944-951, Sep. 2014.

[125] L. L. Hench, "Bioceramics,” J. Am. Ceram. Soc., vol. 81, no. 7, pp. 1705-1728, Jul. 1998.

[126] A. M. A. Ambrosio, J. S. Sahota, Y. Khan, and C. T. Laurencin, "A novel amorphous calcium phosphate polymer ceramic for bone repair: I. Synthesis and characterization,” J. Biomed. Mater. Res., vol. 58, no. 3, pp. 295-301, Jan. 2001.

[127] S.-S. Kim, M. Sun Park, O. Jeon, C. Yong Choi, and B.-S. Kim, "Poly(lactide-coglycolide)/hydroxyapatite composite scaffolds for bone tissue engineering.," Biomaterials, vol. 27, no. 8, pp. 1399-409, Mar. 2006.

[128] B. Damadzadeh, H. Jabari, M. Skrifvars, K. Airola, N. Moritz, and P. Vallittu, "Effect of ceramic filler content on the mechanical and thermal behaviour of poly-l-lactic acid and poly-l-lactic-co-glycolic acid composites for medical applications,” J. Mater. Sci. Mater. Med., vol. 21, no. 9, pp. 2523-2531, 2010.

[129] S. Y. Kim and Y. M. Lee, "Taxol-loaded block copolymer nanospheres composed of methoxy poly(ethylene glycol) and poly(e-caprolactone) as novel anticancer drug carriers,” Biomaterials, vol. 22, no. 13, pp. 1697-1704, Jul. 2001.

[130] K. Lee, H. Chung, S. Im, Y. Park, C. Kim, S.-B. Kim, S. Rha, M. Lee, and J. Ro, "Multicenter phase II trial of Genexol-PM, a Cremophor-free, polymeric micelle formulation of paclitaxel, in patients with metastatic breast cancer," Breast Cancer Res. Treat., vol. 108, no. 2, pp. 241-250, 2008.

[131] L. Mu and S. . Feng, "A novel controlled release formulation for the anticancer drug paclitaxel (Taxol®): PLGA nanoparticles containing vitamin E TPGS,” J. Control. Release, vol. 86, no. 1, pp. 33-48, Jan. 2003.

[132] C. Coester, J. Kreuter, H. von Briesen, and K. Langer, "Preparation of avidin-labelled gelatin nanoparticles as carriers for biotinylated peptide nucleic acid (PNA)," Int. J. Pharm., vol. 196, no. 2, pp. 147-149, Mar. 2000.

[133] C. Damgé, P. Maincent, and N. Ubrich, "Oral delivery of insulin associated to polymeric nanoparticles in diabetic rats.,” J. Control. Release, vol. 117, no. 2, pp. 163-70, Feb. 2007.

[134] A. A. Date, M. D. Joshi, and V. B. Patravale, "Parasitic diseases: Liposomes and polymeric nanoparticles versus lipid nanoparticles.,” Adv. Drug Deliv. Rev., vol. 59, no. 6, pp. 505-21, Jul. 2007.

[135] P. Calvo, B. Gouritin, I. Brigger, C. Lasmezas, J.-P. Deslys, A. Williams, J. P. Andreux, D. Dormont, and P. Couvreur, "PEGylated polycyanoacrylate nanoparticles as vector for drug delivery in prion diseases,” J. Neurosci. Methods, vol. 111, no. 2, pp. 151-155, Sep. 2001.

[136] E. Leo, B. Brina, F. Forni, and M. A. Vandelli, "In vitro evaluation of PLA nanoparticles containing a lipophilic drug in water-soluble or insoluble form.," Int. J. Pharm., vol. 278, no. 1, pp. 133-41, Jun. 2004.

[137] R. C. Mundargi, V. R. Babu, V. Rangaswamy, P. Patel, and T. M. Aminabhavi, 
"Nano/micro technologies for delivering macromolecular therapeutics using poly(D,Llactide-co-glycolide) and its derivatives.," J. Control. Release, vol. 125, no. 3, pp. 193209, Feb. 2008.

[138] M. . Hans and A. . Lowman, "Biodegradable nanoparticles for drug delivery and targeting,” Curr. Opin. Solid State Mater. Sci., vol. 6, no. 4, pp. 319-327, Aug. 2002.

[139] C. Gómez-Gaete, N. Tsapis, M. Besnard, A. Bochot, and E. Fattal, "Encapsulation of dexamethasone into biodegradable polymeric nanoparticles.,” Int. J. Pharm., vol. 331, no. 2, pp. 153-9, Mar. 2007.

[140] Q. Cheng, J. Feng, J. Chen, X. Zhu, and F. Li, "Brain transport of neurotoxin-I with PLA nanoparticles through intranasal administration in rats: a microdialysis study," Biopharm. Drug Dispos., vol. 29, no. 8, pp. 431-439, Nov. 2008.

[141] J. K. Oh, D. I. Lee, and J. M. Park, "Biopolymer-based microgels/nanogels for drug delivery applications,” Prog. Polym. Sci., vol. 34, no. 12, pp. 1261-1282, Dec. 2009.

[142] N. Rescignano, E. Fortunati, S. Montesano, C. Emiliani, J. M. Kenny, S. Martino, and I. Armentano, "PVA bio-nanocomposites: a new take-off using cellulose nanocrystals and PLGA nanoparticles.,” Carbohydr. Polym., vol. 99, pp. 47-58, Jan. 2014.

[143] R. Jayakumar, M. Prabaharan, P. T. Sudheesh Kumar, S. V Nair, and H. Tamura, "Biomaterials based on chitin and chitosan in wound dressing applications.," Biotechnol. Adv., vol. 29, no. 3, pp. 322-37, Jan. 2011.

[144] C. M. Zelen, T. E. Serena, and D. E. Fetterolf, "Dehydrated human amnion/chorion membrane allografts in patients with chronic diabetic foot ulcers: A long-term followup study,” Wound Med., vol. 4, pp. 1-4, 2014.

[145] J. Shores, G. Allen, and S. Cupta, "Skin substitutes and alternatives: a review," Adv. Skin Wound Care, vol. 20, no. 9, pp. 493-508, 2007.

[146] P. Bruin, M. F. Jonkman, H. J. Meijer, and A. J. Pennings, "A new porous polyetherurethane wound covering,” J. Biomed. Mater. Res., vol. 24, no. 2, pp. 217-226, Feb. 1990.

[147] K. Matsuda, S. Suzuki, N. Isshiki, K. Yoshioka, T. Okada, and Y. Ikada, "Influence of glycosaminoglycans on the collagen sponge component of a bilayer artificial skin," Biomaterials, vol. 11, no. 5, pp. 351-355, Jul. 1990.

[148] S. Suzuki, K. Matsuda, N. Isshiki, Y. Tamada, and Y. Ikada, "Experimental study of a newly developed bilayer artificial skin,” Biomaterials, vol. 11, no. 5, pp. 356-360, Jul. 1990 .

[149] H. Nagahama, N. Nwe, R. Jayakumar, S. Koiwa, T. Furuike, and H. Tamura, "Novel biodegradable chitin membranes for tissue engineering applications," Carbohydr. Polym., vol. 73, no. 2, pp. 295-302, Jul. 2008.

[150] H. Nagahama, T. Kashiki, N. Nwe, R. Jayakumar, T. Furuike, and H. Tamura, "Preparation of biodegradable chitin/gelatin membranes with GlcNAc for tissue engineering applications,” Carbohydr. Polym., vol. 73, no. 3, pp. 456-463, Aug. 2008.

[151] N. L. B. M. Yusof, A. Wee, L. Y. Lim, and E. Khor, "Flexible chitin films as potential wound-dressing materials: Wound model studies,” J. Biomed. Mater. Res. Part A, vol. 66A, no. 2, pp. 224-232, Aug. 2003.

[152] P. R. Marreco, P. da L. Moreira, S. C. Genari, and Â. M. Moraes, "Effects of different sterilization methods on the morphology, mechanical properties, and cytotoxicity of chitosan membranes used as wound dressings," J. Biomed. Mater. Res. Part B Appl. Biomater., vol. 71B, no. 2, pp. 268-277, Nov. 2004.

[153] R. Jayakumar, N. Nwe, S. Tokura, and H. Tamura, "Sulfated chitin and chitosan as novel biomaterials.,” Int. J. Biol. Macromol., vol. 40, no. 3, pp. 175-81, Feb. 2007.

[154] R. Jayakumar, N. Nwe, H. Nagagama, T. Furuike, and H. Tamura, "Synthesis, Characterization and Biospecific Degradation Behavior of Sulfated Chitin," Macromol. Symp., vol. 264, no. 1, pp. 163-167, Mar. 2008.

[155] R. Jayakumar, V. V Divya Rani, K. T. Shalumon, P. T. S. Kumar, S. V Nair, T. Furuike, and H. Tamura, "Bioactive and osteoblast cell attachment studies of novel alpha- and beta-chitin membranes for tissue-engineering applications.,” Int. J. Biol. Macromol., vol. 45, no. 3, pp. 260-4, Oct. 2009.

[156] K. Madhumathi, N. S. Binulal, H. Nagahama, H. Tamura, K. T. Shalumon, N. Selvamurugan, S. V Nair, and R. Jayakumar, "Preparation and characterization of novel beta-chitin-hydroxyapatite composite membranes for tissue engineering applications.," 
Int. J. Biol. Macromol., vol. 44, no. 1, pp. 1-5, Jan. 2009.

[157] Y. Har-el, J. A. Gerstenhaber, R. Brodsky, R. B. Huneke, and P. I. Lelkes, "Electrospun soy protein scaffolds as wound dressings: Enhanced reepithelialization in a porcine model of wound healing,” Wound Med., vol. 5, pp. 9-15, Jun. 2014.

[158] K. Muramatsu, S. Masuda, Y. Yoshihara, and A. Fujisawa, "In vitro degradation behavior of freeze-dried carboxymethyl-chitin sponges processed by vacuum-heating and gamma irradiation,” Polym. Degrad. Stab., vol. 81, no. 2, pp. 327-332, Jan. 2003.

[159] A. Portero, D. Teijeiro-Osorio, M. J. Alonso, and C. Remuñán-López, "Development of chitosan sponges for buccal administration of insulin,” Carbohydr. Polym., vol. 68, no. 4, pp. 617-625, Apr. 2007.

[160] H. Ueno, T. Mori, and T. Fujinaga, "Topical formulations and wound healing applications of chitosan,” Adv. Drug Deliv. Rev., vol. 52, no. 2, pp. 105-115, Nov. 2001.

[161] M. N. . Ravi Kumar, "A review of chitin and chitosan applications," React. Funct. Polym., vol. 46, no. 1, pp. 1-27, Nov. 2000.

[162] R. A. A. Muzzarelli, "Chitins and chitosans for the repair of wounded skin, nerve, cartilage and bone,” Carbohydr. Polym., vol. 76, no. 2, pp. 167-182, Mar. 2009.

[163] H. Tamura, T. Furuike, S. V. Nair, and R. Jayakumar, "Biomedical applications of chitin hydrogel membranes and scaffolds,” Carbohydr. Polym., vol. 84, no. 2, pp. 820-824, Mar. 2011.

[164] R. B. Gibson, "Specification of sustainability-based environmental assessment decision criteria and implications for determining 'significance' in environmental assessment," Canadian Environmental Assessment Agency., 2000.

[165] M. Lindblad, Y. Liu, A.-C. Albertsson, E. Ranucci, and S. Karlsson, "Polymers from Renewable Resources,” in Degradable Aliphatic Polyesters SE - 5, vol. 157, Springer Berlin Heidelberg, 2002, pp. 139-161.

[166] E. Chiellini, F. Chiellini, and P. Cinelli, "Polymers from Renewable Resources,” in Degradable Polymers SE - 7, G. Scott, Ed. Springer Netherlands, 2002, pp. 163-233.

[167] C. K. Williams and M. A. Hillmyer, "Polymers from Renewable Resources: A Perspective for a Special Issue of Polymer Reviews,” Polym. Rev., vol. 48, no. 1, pp. 110, Feb. 2008.

[168] C. Chassenieux, D. Durand, P. Jyotishkumar, and S. Thomas, "Biopolymers: State of the Art , New Challenges , and Opportunities,” in Handbook of Biopolymer-Based Materials: From Blends and Composites to Gels and Complex Networks, P. J. S. Thomas, D. Durand, C. Chassenieux, Ed. Weinheim, Germany: Wiley-VCH Verlag GmbH \& Co. KGaA, 2013, pp. 1-6.

[169] G. E. Luckachan and C. K. S. Pillai, "Biodegradable Polymers- A Review on Recent Trends and Emerging Perspectives,” J. Polym. Environ., vol. 19, no. 3, pp. 637-676, 2011.

[170] T. Iwata, "Biodegradable and bio-based polymers: Future prospects of eco-friendly plastics,” Wiley-VCH Verlag, Mar. 2015.

[171] C. R. Álvarez-Chávez, S. Edwards, R. Moure-Eraso, and K. Geiser, "Sustainability of bio-based plastics: General comparative analysis and recommendations for improvement,” J. Clean. Prod., vol. 23, no. 1, pp. 47-56, 2012.

[172] N. P. Cheremisinoff, "Chromatographic techniques,” in Polymer Characterization, Elsevier, 1996, pp. 1-15.

[173] R. Liyanage and J. O. Lay, “An Introduction to MALDI-TOF MS,” in Identification of Microorganisms by Mass Spectrometry, John Wiley \& Sons, Inc., 2005, pp. 39-60.

[174] S. Dopico-García, A. Ares-Pernas, J. Otero-Canabal, M. Castro-López, J. M. LópezVilariño, V. González-Rodríguez, and M. J. Abad-López, "Insight into industrial PLA aging process by complementary use of rheology, HPLC, and MALDI,” Polym. Adv. Technol., vol. 24, no. 8, pp. 723-731, 2013.

[175] P. Rizzarelli and S. Carroccio, "Modern mass spectrometry in the characterization and degradation of biodegradable polymers," Anal. Chim. Acta, vol. 808, pp. 18-43, 2014.

[176] N. P. Cheremisinoff, "Elemental and structural characterization tests," in Polymer Characterization, Elsevier, 1996, pp. 43-81.

[177] N. P. Cheremisinoff, "Chemical analysis of polymers," in Polymer Characterization, Elsevier, 1996, pp. 97-103.

[178] N. P. Cheremisinoff, "Microscopy for polymer characterization," in Polymer 
Characterization, Elsevier, 1996, pp. 25-41.

[179] J. D. Badia, E. Strömberg, S. Karlsson, and A. Ribes-Greus, "The role of crystalline, mobile amorphous and rigid amorphous fractions in the performance of recycled poly (ethylene terephthalate) (PET),” Polym. Degrad. Stab., vol. 97, no. 1, pp. 98-107, Jan. 2012.

[180] D. Newman, E. Laredo, A. Bello, A. Grillo, J. L. Feijoo, and A. J. Muller, "Molecular mobilities in biodegradable poly(DL-lactide)/poly(epsilon-caprolactone) blends," Macromolecules, vol. 42, no. 14, pp. 5219-5225, 2009.

[181] J. D. Badia, L. Monreal, V. Sáenz de Juano-Arbona, and A. Ribes-Greus, "Dielectric spectroscopy of recycled polylactide,” Polym. Degrad. Stab., vol. 107, pp. 21-27, Sep. 2014.

[182] S. A. Cruz and M. Zanin, "Dielectric strength of the blends of virgin and recycled HDPE,” J. Appl. Polym. Sci., vol. 91, no. 3, pp. 1730-1735, 2004.

[183] J. D. Badia, E. Strömberg, S. Karlsson, and A. Ribes-Greus, "Material valorisation of amorphous polylactide. Influence of thermo-mechanical degradation on the morphology, segmental dynamics, thermal and mechanical performance," Polym. Degrad. Stab., vol. 97, no. 4, pp. 670-678, Apr. 2012.

[184] J. D. Badia, L. Santonja-Blasco, A. Martínez-Felipe, and A. Ribes-Greus, "Dynamic Mechanical Thermal Analysis of Polymer Blends,” in Characterization of Polymer Blends: Miscibility, Morphology and Interfaces, S. Thomas, Y. Grohens, and P. Jyotishkumar, Eds. Weinheim, Germany: Wiley-VCH, 2015, pp. 365-392.

[185] M. P. Arrieta, E. Fortunati, F. Dominici, E. Rayón, J. López, and J. M. Kenny, "PLAPHB/cellulose based films: Mechanical, barrier and disintegration properties," Polym. Degrad. Stab., vol. 107, pp. 139-149, Sep. 2014.

[186] H. Larsen and K. H. Liland, "Determination of O2 and CO2 transmission rate of whole packages and single perforations in micro-perforated packages for fruit and vegetables," J. Food Eng., vol. 119, no. 2, pp. 271-276, Nov. 2013.

[187] S. F. Mexis and M. G. Kontominas, "Effect of oxygen absorber, nitrogen flushing, packaging material oxygen transmission rate and storage conditions on quality retention of raw whole unpeeled almond kernels (Prunus dulcis)," LWT - Food Sci. Technol., vol. 43, no. 1, pp. 1-11, Jan. 2010.

[188] A. Krzan, S. Hemjinda, S. Miertus, A. Corti, and E. Chiellini, "Standardization and certification in the area of environmentally degradable plastics,” Polym. Degrad. Stab., vol. 91, no. 12, pp. 2819-2833, Dec. 2006.

[189] J. Sarasa, J. M. Gracia, and C. Javierre, "Study of the biodisintegration of a bioplastic material waste.,” Bioresour. Technol., vol. 100, no. 15, pp. 3764-8, Aug. 2009.

[190] G. Kale, R. Auras, S. P. Singh, and R. Narayan, "Biodegradability of polylactide bottles in real and simulated composting conditions,” Polym. Test., vol. 26, no. 8, pp. 10491061, Dec. 2007.

[191] F. Vilaplana, A. Ribes-Greus, and S. Karlsson, "Chromatographic pattern in recycled high-impact polystyrene (HIPS) - Occurrence of low molecular weight compounds during the life cycle,” Polym. Degrad. Stab., vol. 95, no. 2, pp. 172-186, 2010.

[192] F. Vilaplana, M. Martínez-Sanz, A. Ribes-Greus, and S. Karlsson, "Emission pattern of semi-volatile organic compounds from recycled styrenic polymers using headspace solid-phase microextraction gas chromatography-mass spectrometry,” J. Chromatogr. A, vol. 1217, no. 3, pp. 359-367, 2010.

[193] J. M. Hutchinson, "Physical aging of polymers," Prog. Polym. Sci., vol. 20, no. 4, pp. 703-760, 1995.

[194] L. C. E. Struik, "The mechanical and physical ageing of semicrystalline polymers: 1," Polymer (Guildf)., vol. 28, no. 9, pp. 1521-1533, 1987.

[195] L. C. E. Struik, "The mechanical behaviour and physical ageing of semicrystalline polymers: 2,” Polymer (Guildf)., vol. 28, no. 9, pp. 1534-1542, 1987.

[196] L. Santonja-Blasco, A. Ribes-Greus, and R. G. Alamo, "Comparative thermal, biological and photodegradation kinetics of polylactide and effect on crystallization rates," Polym. Degrad. Stab., vol. 98, no. 3, pp. 771-784, Mar. 2013.

[197] J. D. Badía, L. Santonja-Blasco, R. Moriana, and A. Ribes-Greus, “Thermal analysis applied to the characterization of degradation in soil of polylactide: II. On the thermal stability and thermal decomposition kinetics,” Polym. Degrad. Stab., vol. 95, no. 11, pp. 
2192-2199, 2010.

[198] J. D. Badia, L. Santonja-Blasco, A. Martí-nez-Felipe, A. Ribes-Greus, A. MartínezFelipe, and A. Ribes-Greus, "Reprocessed polylactide: studies of thermo-oxidative decomposition.,” Bioresour. Technol., vol. 114, no. 0, pp. 622-8, Jun. 2012.

[199] J. Li, W. Zheng, L. Li, Y. Zheng, and X. Lou, "Thermal degradation kinetics of gHA/PLA composite,” Thermochim. Acta, vol. 493, no. 1-2, pp. 90-95, Sep. 2009.

[200] N. Najafi, M. C. Heuzey, P. J. Carreau, and P. M. Wood-Adams, "Control of thermal degradation of polylactide (PLA)-clay nanocomposites using chain extenders,” Polym. Degrad. Stab., vol. 97, no. 4, pp. 554-565, Apr. 2012.

[201] A. Araújo, G. Botelho, M. Oliveira, and A. V. Machado, "Influence of clay organic modifier on the thermal-stability of PLA based nanocomposites,” Appl. Clay Sci., vol. 88, pp. 144-150, 2014.

[202] B. S. Bouakaz, I. Pillin, A. Habi, and Y. Grohens, "Synergy between fillers in organomontmorillonite/graphene-PLA nanocomposites,” Appl. Clay Sci., vol. 116, pp. 69-77, 2015.

[203] E. Hablot, P. Bordes, E. Pollet, and L. Avérous, "Thermal and thermo-mechanical degradation of poly(3-hydroxybutyrate)-based multiphase systems,” Polym. Degrad. Stab., vol. 93, no. 2, pp. 413-421, Feb. 2008.

[204] J. P. Mofokeng and A. S. Luyt, "Morphology and thermal degradation studies of meltmixed poly(lactic acid) (PLA)/poly( $\varepsilon$-caprolactone) (PCL) biodegradable polymer blend nanocomposites with TiO2 as filler,” Polym. Test., vol. 45, pp. 93-100, Aug. 2015.

[205] M. A. Abdelwahab, A. Flynn, B. Sen Chiou, S. Imam, W. Orts, and E. Chiellini, "Thermal, mechanical and morphological characterization of plasticized PLA-PHB blends,” Polym. Degrad. Stab., vol. 97, no. 9, pp. 1822-1828, Sep. 2012.

[206] V. A. Alvarez and A. Vázquez, "Thermal degradation of cellulose derivatives/starch blends and sisal fibre biocomposites,” Polym. Degrad. Stab., vol. 84, no. 1, pp. 13-21, Apr. 2004.

[207] T. Tanaka and T. Iwata, "Physical Properties, Structure Analysis, and Enzymatic Degradation of Poly[(R)-3-hydroxybutyrate-co-(R)-3-hydroxyvalerate] Films and Fibers,” in Degradable Polymers and Materials: Principles and Practice, 2nd ed., ACS Symposium Series, 2012, pp. 171-185.

[208] M. Niaounakis, Biopolymers Reuse, Recycling, and Disposal. Elsevier, 2013.

[209] “ISO 10993-13. Biological evaluation of medical devices.” 2010.

[210] S. K. Saha and H. Tsuji, "Effects of molecular weight and small amounts of d-lactide units on hydrolytic degradation of poly(l-lactic acid)s,” Polym. Degrad. Stab., vol. 91, no. 8, pp. 1665-1673, Aug. 2006.

[211] J. S. Wiggins, M. K. Hassan, K. A. Mauritz, and R. F. Storey, "Hydrolytic degradation of poly(d,l-lactide) as a function of end group: Carboxylic acid vs. hydroxyl,” Polymer (Guildf)., vol. 47, no. 6, pp. 1960-1969, Mar. 2006.

[212] A. Jaszkiewicz, A. Bledzki, and A. Meljon, "Impact of Humid Environment on Structural and Mechanical Properties of Biobased Polylactide,” Int. Polym. Process., vol. 30, no. 4, pp. 522-527, 2015.

[213] V. Arias, A. Höglund, K. Odelius, and A. C. Albertsson, "Tuning the degradation profiles of poly(L-lactide)-based materials through miscibility,” Biomacromolecules, vol. 15, no. 1, pp. 391-402, Jan. 2014.

[214] O. Gil-Castell, J. D. D. Badia, E. Strömberg, S. Karlsson, and A. Ribes-Greus, "Effect of the dissolution time into an acid hydrolytic solvent to tailor electrospun nanofibrous polycaprolactone scaffolds,” Eur. Polym. J., vol. 87, pp. 174-187, 2017.

[215] C. Y. Tang, D. Z. Chen, T. M. Yue, K. C. Chan, C. P. Tsui, and P. H. F. Yu, "Water absorption and solubility of PHBHV/HA nanocomposites,” Compos. Sci. Technol., vol. 68, no. 7-8, pp. 1927-1934, Jun. 2008.

[216] S. W. Liu-chun Zheng Chun-cheng Li, Dong Zhang, Yao-nan Xiao, Guo-hu Guan, Wenxiang Zhu, "Hydrothermal Aging Behavior of Poly(butylene fumarate)," Acta Polymerica Sinica, vol. 0, no. 12. pp. 1622-1628.

[217] V. Arias, P. Olsén, K. Odelius, A. Höglund, and A.-C. Albertsson, "Selective degradation in aliphatic block copolyesters by controlling the heterogeneity of the amorphous phase,” Polym. Chem., vol. 6, no. 17, pp. 3271-3282, Apr. 2015.

[218] “ISO 62:2008. Plastics - Determination of water absorption.” 2008. 
[219] C. S. Proikakis, N. J. Mamouzelos, P. A. Tarantili, and A. G. Andreopoulos, "Swelling and hydrolytic degradation of poly(d,l-lactic acid) in aqueous solutions," Polym. Degrad. Stab., vol. 91, no. 3, pp. 614-619, Mar. 2006.

[220] M. Deroiné, A. Le Duigou, Y.-M. Corre, P.-Y. Le Gac, P. Davies, G. César, and S. Bruzaud, "Accelerated ageing of polylactide in aqueous environments: Comparative study between distilled water and seawater,” Polym. Degrad. Stab., vol. 108, pp. 319329, Oct. 2014.

[221] J. D. Badia, L. Santonja-Blasco, A. Martínez-Felipe, and A. Ribes-Greus, "Hygrothermal ageing of reprocessed polylactide," Polym. Degrad. Stab., vol. 97, no. 10, pp. 1881-1890, Oct. 2012.

[222] F. R. Beltrán, V. Lorenzo, M. U. de la Orden, and J. Martínez-Urreaga, "Effect of different mechanical recycling processes on the hydrolytic degradation of poly(l-lactic acid),” Polym. Degrad. Stab., vol. 133, pp. 339-348, 2016.

[223] M. Deroiné, A. Le Duigou, Y.-M. Corre, P.-Y. Le Gac, P. Davies, G. César, and S. Bruzaud, “Accelerated ageing and lifetime prediction of poly(3-hydroxybutyrate-co-3hydroxyvalerate) in distilled water,” Polym. Test., vol. 39, pp. 70-78, Oct. 2014.

[224] X. Li, K. L. Liu, M. Wang, S. Y. Wong, W. C. Tjiu, C. Bin He, S. H. Goh, and J. Li, "Improving hydrophilicity, mechanical properties and biocompatibility of poly[(R)-3hydroxybutyrate-co-(R)-3-hydroxyvalerate] through blending with poly[(R)-3hydroxybutyrate]-alt-poly(ethylene oxide).," Acta Biomater., vol. 5, no. 6, pp. 2002-12, Jul. 2009.

[225] V. Berthé, L. Ferry, J. C. Bénézet, and A. Bergeret, “Ageing of different biodegradable polyesters blends mechanical and hygrothermal behavior,” Polym. Degrad. Stab., vol. 95, no. 3, pp. 262-269, Mar. 2010.

[226] O. Gil-Castell, J. D. D. Badia, T. Kittikorn, E. Strömberg, A. Martínez-Felipe, M. Ek, S. Karlsson, and A. Ribes-Greus, "Hydrothermal ageing of polylactide/sisal biocomposites. Studies of water absorption behaviour and Physico-Chemical performance,” Polym. Degrad. Stab., vol. 108, pp. 212-222, Oct. 2014.

[227] O. Gil-Castell, J. D. D. Badia, T. Kittikorn, E. Strömberg, M. Ek, S. Karlsson, A. RibesGreus, E. Strömberg, M. Ek, S. Karlsson, and A. Ribes-Greus, "Impact of hydrothermal ageing on the thermal stability, morphology and viscoelastic performance of PLA/sisal biocomposites,” Polym. Degrad. Stab., vol. 132, pp. 87-96, Mar. 2016.

[228] J. D. Badia, T. Kittikorn, E. Strömberg, L. Santonja-Blasco, A. Martínez-Felipe, A. Ribes-Greus, M. Ek, and S. Karlsson, "Water absorption and hydrothermal performance of PHBV/sisal biocomposites,” Polym. Degrad. Stab., vol. 108, pp. 166-174, Oct. 2014.

[229] Y. J. Phua, W. S. Chow, and Z. A. Mohd Ishak, "The hydrolytic effect of moisture and hygrothermal aging on poly(butylene succinate)/organo-montmorillonite nanocomposites,” Polym. Degrad. Stab., vol. 96, no. 7, pp. 1194-1203, Jul. 2011.

[230] M. Oliveira, E. Santos, A. Araújo, G. J. M. Fechine, A. V. Machado, and G. Botelho, "The role of shear and stabilizer on PLA degradation," Polym. Test., vol. 51, pp. 109116, 2016.

[231] J. L. Gardette, A. Rivaton, and S. Therias, "Photodegradation Processes In Polymeric Materials,” in Photochemistry and Photophysics of Polymer Materials, John Wiley and Sons, 2010, pp. 569-601.

[232] S. Al-Malaika, C. Hewitt, and H. H. Sheena, "Photodegradable Polymers," in Photochemistry and Photophysics of Polymer Materials, John Wiley and Sons, 2010, pp. 603-626.

[233] N. Lucas, C. Bienaime, C. Belloy, M. M. Queneudec, F. F. Silvestre, and J.-E. J. E. Nava-Saucedo, "Polymer biodegradation: mechanisms and estimation techniques.," Chemosphere, vol. 73, no. 4, pp. 429-42, Sep. 2008.

[234] H. Tsuji, Y. Echizen, and Y. Nishimura, "Photodegradation of biodegradable polyesters: A comprehensive study on poly(l-lactide) and poly(ع-caprolactone),” Polym. Degrad. Stab., vol. 91, no. 5, pp. 1128-1137, May 2006.

[235] T. Kijchavengkul, R. Auras, M. Rubino, M. Ngouajio, and R. T. Fernandez, "Assessment of aliphatic-aromatic copolyester biodegradable mulch films. Part I: field study.," Chemosphere, vol. 71, no. 5, pp. 942-53, Mar. 2008.

[236] T. Kijchavengkul, R. Auras, M. Rubino, M. Ngouajio, and R. T. Fernandez, "Assessment of aliphatic-aromatic copolyester biodegradable mulch films. Part II: 

“ASTM D5071-06. Standard Practice for Exposure of Photodegradable Plastics in a Xenon Arc Apparatus.” 2013.

[238] “ASTM D5208-14. Standard Practice for Fluorescent Ultraviolet (UV) Exposure of Photodegradable Plastics.” 2014.

[239] “ASTM D5272-08. Standard Practice for Outdoor Exposure Testing of Photodegradable Plastics.” 2013.

[240] H. Zhao and R. K. Y. Y. Li, "A study on the photo-degradation of zinc oxide (ZnO) filled polypropylene nanocomposites,” Polymer (Guildf)., vol. 47, no. 9, pp. 3207-3217, Apr. 2006

[241] O. Gil-Castell, J. D. Badia, R. Teruel-Juanes, I. Rodriguez, F. Meseguer, and A. RibesGreus, "Novel silicon microparticles to improve sunlight stability of raw polypropylene,” Eur. Polym. J., vol. 70, pp. 247-261, 2015.

[242] P. Gijsman, "Photostabilisation of Polymer Materials," in Photochemistry and Photophysics of Polymer Materials, John Wiley and Sons, 2010, pp. 627-679.

[243] E. Olewnik-Kruszkowska, "Effect of UV irradiation on thermal properties of nanocomposites based on polylactide,” J. Therm. Anal. Calorim., vol. 119, no. 1, pp. 219-228, 2015.

[244] M. Gardette, S. Thérias, J. L. Gardette, M. Murariu, and P. Dubois, "Photooxidation of polylactide/calcium sulphate composites,” Polym. Degrad. Stab., vol. 96, no. 4, pp. 616623, 2011.

[245] L. Pérez Amaro, F. Cicogna, E. Passaglia, E. Morici, W. Oberhauser, S. Al-Malaika, N. T. Dintcheva, and S. Coiai, "Thermo-oxidative stabilization of poly(lactic acid) with antioxidant intercalated layered double hydroxides,” vol. 133, pp. 92-100, Nov. 2016.

[246] P. Scarfato, E. Avallone, D. Acierno, and P. Russo, "Optical and mechanical properties of UV-weathered biodegradable PHBV/PBAT nanocomposite films containing halloysite nanotubes,” in AIP Conference Proceedings, 2014, pp. 398-401.

[247] J. Park, W.-M. Choi, C.-S. Ha, W.-H. Kim, and W.-J. Cho, "Synthesis and controlled photo- and biodegradabilities of poly[(hydroxybutyrate -Co-hydroxyvalerate)-Gstyrene]," Macromol. Symp., vol. 130, no. 1, pp. 53-69, Apr. 1998.

[248] R. K. Sadi, G. J. M. Fechine, and N. R. Demarquette, "Photodegradation of poly(3hydroxybutyrate),” Polym. Degrad. Stab., vol. 95, no. 12, pp. 2318-2327, Dec. 2010.

[249] A. Copinet, C. Bertrand, A. Longieras, V. Coma, and Y. Couturier, "Photodegradation and Biodegradation Study of a Starch and Poly(Lactic Acid) Coextruded Material,” J. Polym. Environ., vol. 11, no. 4, pp. 169-179, 2003.

[250] N. T. Dintcheva, F. P. La Mantia, and R. Arrigo, "Natural compounds as light stabilizer for a starch-based biodegradable polymer,” vol. 34, no. 5, pp. 441-449, Jul. 2014.

[251] A. Morawski, E. Kusiak-Nejman, J. Przepiórski, R. Kordala, and J. Pernak, "CelluloseTiO2 nanocomposite with enhanced UV-Vis light absorption,” Cellulose, vol. 20, no. 3, pp. 1293-1300, 2013.

[252] H. Fan, G. Li, F. Yang, L. Yang, and S. Zhang, "Photodegradation of cellulose under UV light catalysed by TiO2,” J. Chem. Technol. Biotechnol., vol. 86, no. 8, pp. 11071112, Aug. 2011.

[253] K. Madhavan Nampoothiri, N. R. Nair, and R. P. John, "An overview of the recent developments in polylactide (PLA) research.,” Bioresour. Technol., vol. 101, no. 22, pp. 8493-501, Nov. 2010.

[254] I. Leceta, a. Etxabide, S. Cabezudo, K. de la Caba, and P. Guerrero, "Bio-based films prepared with by-products and wastes: environmental assessment,” J. Clean. Prod., vol. 64, pp. 218-227, Feb. 2014.

[255] J. D. Badía Valiente, "Strategies and analytical procedures for a sustainable plastic waste management. An application to poly (ethylene terephthalate) and polylactide in the packaging sector,” Universitat Politècnica de València, 2011.

[256] T. A. Hottle, M. M. Bilec, and A. E. Landis, "Sustainability assessments of bio-based polymers,” Polym. Degrad. Stab., vol. 98, no. 9, pp. 1898-1907, Sep. 2013.

[257] S. Papong, P. Malakul, R. Trungkavashirakun, P. Wenunun, T. Chom-In, M. Nithitanakul, and E. Sarobol, "Comparative assessment of the environmental profile of PLA and PET drinking water bottles from a life cycle perspective,” J. Clean. Prod., vol. 65, pp. 539-550, 2014. 
[258] J. a. Stagner, S. Tseng, and E. K. L. Tam, "Bio-Based Polymers and End-of-Life Vehicles,” J. Polym. Environ., vol. 20, no. 4, pp. 1046-1051, Jul. 2012.

[259] K. Hamad, M. Kaseem, and F. Deri, "Recycling of waste from polymer materials: An overview of the recent works,” Polym. Degrad. Stab., vol. 98, no. 12, pp. 2801-2812, Dec. 2013.

[260] P. Gijsman, "Review on the thermo-oxidative degradation of polymers during processing and in service,” E-Polymers, May 2008.

[261] J. D. Badia and A. Ribes-Greus, "Mechanical recycling of polylactide, upgrading trends and combination of valorization techniques,” Eur. Polym. J., vol. 84, pp. 22-39, 2016.

[262] F. Vilaplana and S. Karlsson, "Quality concepts for the improved use of recycled polymeric materials: A review,” Macromol. Mater. Eng., vol. 293, no. 4, pp. 274-297, 2008.

[263] X. Colin and A. Tcharkhtchi, "Thermal degradation of polymers during their mechanical recycling,” Nova Science Publishers, Inc., 2013, pp. 57-95.

[264] E. Strömberg and S. Karlssom, "The design of a test protocol to model the degradation of polyolefirts during eecycling and service life,” J. Appl. Polym. Sci., vol. 112, no. 3, pp. 1835-1844, 2009.

[265] E. Strömberg and S. Karlsson, "Photo- And thermo-oxidation of polypropylene, Recycled polypropylene and polylactide biocomposites in a microenvironment chamber,” Polym. from Renew. Resour., vol. 1, no. 1, pp. 1-15, 2010.

[266] N. Yarahmadi, I. Jakubowicz, and T. Gevert, "Effects of repeated extrusion on the properties and durability of rigid PVC scrap,” Polym. Degrad. Stab., vol. 73, no. 1, pp. 93-99, 2001.

[267] J. D. Badia, F. Vilaplana, S. Karlsson, and A. Ribes-Greus, “Thermal analysis as a quality tool for assessing the influence of thermo-mechanical degradation on recycled poly(ethylene terephthalate),” Polym. Test., vol. 28, no. 2, pp. 169-175, 2009.

[268] J. D. Badía, E. Strömberg, A. Ribes-Greus, and S. Karlsson, "A statistical design of experiments for optimizing the MALDI-TOF-MS sample preparation of polymers. An application in the assessment of the thermo-mechanical degradation mechanisms of poly (ethylene terephthalate).," Anal. Chim. Acta, vol. 692, no. 1-2, pp. 85-95, Apr. 2011.

[269] F. P. La Mantia and M. Vinci, "Recycling poly(ethylene terephthalate),” Polym. Degrad. Stab., vol. 45, no. 1, pp. 121-125, 1994.

[270] M. Zaverl, M. Ö. Seydibeyoğlu, M. Misra, and A. Mohanty, "Studies on recyclability of poly(hydroxybutyrate-co-valerate) bioplastic: Multiple melt processing and performance evaluations,” J. Appl. Polym. Sci., vol. 125, no. S2, pp. E324-E331, Sep. 2012.

[271] K. Moraczewski, "Influence of multiple processing on selected properties of poly(3hydroxybutyrate-co-4-hydroxybutyrate),” Polym. Adv. Technol., vol. 27, no. 6, pp. 733739, 2016.

[272] I. Zembouai, S. Bruzaud, M. Kaci, A. Benhamida, Y.-M. Corre, and Y. Grohens, "Mechanical Recycling of Poly(3-Hydroxybutyrate-co-3-Hydroxyvalerate)/Polylactide Based Blends,” J. Polym. Environ., vol. 22, no. 4, pp. 449-459, 2014.

[273] K. Moraczewski, “Characterization of multi-injected poly(E-caprolactone)," Polym. Test., vol. 33, pp. 116-120, 2014.

[274] A. Soroudi and I. Jakubowicz, "Recycling of bioplastics, their blends and biocomposites: A review,” Eur. Polym. J., vol. 49, no. 10, pp. 2839-2858, Oct. 2013.

[275] F. Carrasco, P. Pagès, J. Gámez-Pérez, O. O. Santana, and M. L. Maspoch, "Processing of poly(lactic acid): Characterization of chemical structure, thermal stability and mechanical properties,” Polym. Degrad. Stab., vol. 95, no. 2, pp. 116-125, Feb. 2010.

[276] F. Carrasco, P. Pagès, J. Gámez-Pérez, O. O. Santana, and M. L. Maspoch, "Kinetics of the thermal decomposition of processed poly(lactic acid),” Polym. Degrad. Stab., vol. 95, no. 12, pp. 2508-2514, Dec. 2010.

[277] C. Hopmann, S. Schippers, and C. H??fs, "Influence of recycling of poly(lactic acid) on packaging relevant properties,” J. Appl. Polym. Sci., vol. 132, no. 9, pp. 1-6, 2015.

[278] W. Sikorska, J. Richert, J. Rydz, M. Musioł, G. Adamus, H. Janeczek, and M. Kowalczuk, "Degradability studies of poly(l-lactide) after multi-reprocessing experiments in extruder,” Polym. Degrad. Stab., vol. 97, no. 10, pp. 1891-1897, Oct. 2012. 
[279] I. Pillin, N. Montrelay, A. Bourmaud, and Y. Grohens, "Effect of thermo-mechanical cycles on the physico-chemical properties of poly(lactic acid),” Polym. Degrad. Stab., vol. 93, no. 2, pp. 321-328, Feb. 2008.

[280] M. Żenkiewicz, J. Richert, P. Rytlewski, K. Moraczewski, M. Stepczyńska, and T. Karasiewicz, "Characterisation of multi-extruded poly(lactic acid)," Polym. Test., vol. 28, no. 4, pp. 412-418, Jun. 2009.

[281] B. Brüster, F. Addiego, F. Hassouna, D. Ruch, J.-M. Raquez, and P. Dubois, “Thermomechanical degradation of plasticized poly(lactide) after multiple reprocessing to simulate recycling: Multi-scale analysis and underlying mechanisms,” Polym. Degrad. Stab., vol. 131, pp. 132-144, 2016.

[282] J. D. Badía, E. Strömberg, A. Ribes-Greus, and S. Karlsson, “Assessing the MALDITOF MS sample preparation procedure to analyze the influence of thermo-oxidative ageing and thermo-mechanical degradation on poly (Lactide),” Eur. Polym. J., vol. 47, no. 7, pp. 1416-1428, Jul. 2011.

[283] L. Nascimento, J. Gamez-Perez, O. O. Santana, J. I. Velasco, M. L. Maspoch, and E. Franco-Urquiza, "Effect of the Recycling and Annealing on the Mechanical and Fracture Properties of Poly(Lactic Acid),” J. Polym. Environ., vol. 18, no. 4, pp. 654-660, 2010.

[284] F. Signori, M.-B. Coltelli, and S. Bronco, "Thermal degradation of poly(lactic acid) (PLA) and poly(butylene adipate-co-terephthalate) (PBAT) and their blends upon melt processing,” Polym. Degrad. Stab., vol. 94, no. 1, pp. 74-82, Jan. 2009.

[285] N. S. Q. S. Amorin, G. Rosa, J. F. Alves, S. P. C. Goncalves, S. M. M. Franchetti, and G. J. M. Fechine, "Study of Thermodegradation and Thermostabilization of Poly(lactide acid) Using Subsequent Extrusion Cycles,” J. Appl. Polym. Sci., vol. 131, no. 6.

[286] H. Liu and J. Zhang, "Research progress in toughening modification of poly(lactic acid),” J. Polym. Sci. Part B Polym. Phys., vol. 49, no. 15, pp. 1051-1083, Aug. 2011.

[287] R. Scaffaro, M. Morreale, F. Mirabella, and F. P. La Mantia, "Preparation and Recycling of Plasticized PLA,” Macromol. Mater. Eng., vol. 296, no. 2, pp. 141-150, Feb. 2011.

[288] R. Scaffaro, N. T. Dintcheva, R. Marino, and F. P. La Mantia, "Processing and Properties of Biopolymer/Polyhydroxyalkanoates Blends,” J. Polym. Environ., vol. 20, no. 2, pp. 267-272, Jun. 2012.

[289] K. Hamad, M. Kaseem, and F. Deri, "Effect of recycling on rheological and mechanical properties of poly(lactic acid)/polystyrene polymer blend,” J. Mater. Sci., vol. 46, no. 5, pp. 3013-3019, Dec. 2010.

[290] N. Yarahmadi, I. Jakubowicz, and J. Enebro, "Polylactic acid and its blends with petroleum-based resins: Effects of reprocessing and recycling on properties,” J. Appl. Polym. Sci., vol. 133, no. 36, Sep. 2016.

[291] F. P. La Mantia, L. Botta, M. Morreale, and R. Scaffaro, "Effect of small amounts of poly(lactic acid) on the recycling of poly(ethylene terephthalate) bottles," Polym. Degrad. Stab., vol. 97, no. 1, pp. 21-24, Jan. 2012.

[292] H. Sirin, B. Tuna, and G. Ozkoc, "The Effects of Thermomechanical Cycles on the Properties of PLA/TPS Blends,” Adv. Polym. Technol., vol. 33, no. S1, p. n/a-n/a, Dec. 2014.

[293] J. P. Lopez, J. Girones, J. A. Mendez, J. Puig, and M. A. Pelach, "Recycling Ability of Biodegradable Matrices and Their Cellulose-Reinforced Composites in a Plastic Recycling Stream,” J. Polym. Environ., vol. 20, no. 1, pp. 96-103, 2012.

[294] A. Le Duigou, I. Pillin, A. Bourmaud, P. Davies, and C. Baley, "Effect of recycling on mechanical behaviour of biocompostable flax/poly(l-lactide) composites," Compos. Part A Appl. Sci. Manuf., vol. 39, no. 9, pp. 1471-1478, Sep. 2008.

[295] S. Pilla, S. Gong, E. O’Neill, L. Yang, and R. M. Rowell, "Polylactide-recycled wood fiber composites,” J. Appl. Polym. Sci., vol. 111, no. 1, pp. 37-47, Jan. 2009.

[296] A. Grozdanov, M. Avella, A. Buzarovska, G. Gentile, and M. E. Errico, "Reuse of natural fiber reinforced eco-composites in polymer mortars,” Polym. Eng. Sci., vol. 50, no. 4, pp. 762-766, Apr. 2010.

[297] S. M. Al-Salem, P. Lettieri, and J. Baeyens, "Recycling and recovery routes of plastic solid waste (PSW): a review.,” Waste Manag., vol. 29, no. 10, pp. 2625-43, Oct. 2009.

[298] G. Fleischer, F. Habashi, G. Menges, B. Bilitewski, and U. Loll, "Waste, 5. Recycling," in Ullmann's Encyclopedia of Industrial Chemistry, Wiley-VCH Verlag GmbH \& Co. KGaA, 2000. 
[299] A.-F. F. Mohd-Adnan, H. Nishida, and Y. Shirai, "Evaluation of kinetics parameters for poly(l-lactic acid) hydrolysis under high-pressure steam,” Polym. Degrad. Stab., vol. 93, no. 6, pp. 1053-1058, Jun. 2008.

[300] H. Tsuji, H. Daimon, and K. Fujie, “A New Strategy for Recycling and Preparation of Poly(l-lactic acid): Hydrolysis in the Melt,” Biomacromolecules, vol. 4, no. 3, pp. 835840, May 2003.

[301] V. Piemonte, S. Sabatini, and F. Gironi, "Chemical Recycling of PLA: A Great Opportunity Towards the Sustainable Development?,” J. Polym. Environ., vol. 21, no. 3, pp. 640-647, 2013.

[302] Y. Fan, H. Nishida, T. Mori, Y. Shirai, and T. Endo, “Thermal degradation of poly(llactide): effect of alkali earth metal oxides for selective l,l-lactide formation,” Polymer (Guildf)., vol. 45, no. 4, pp. 1197-1205, Feb. 2004.

[303] Y. Liu, R. Wei, J. Wei, and X. Liu, “Thermal Degradation of Poly(L-lactide) with High Molecular Weight into L-Lactide,” Prog. Chem., vol. 20, no. 10, pp. 1588-1594, 2008.

[304] Y. Fan, H. Nishida, Y. Shirai, and T. Endo, "Control of racemization for feedstock recycling of PLLA,” Green Chem., vol. 5, no. 5, pp. 575-579, 2003.

[305] M. N. F. Norrrahim, H. Ariffin, M. A. Hassan, N. A. Ibrahim, and H. Nishida, "Performance evaluation and chemical recyclability of a polyethylene/poly(3hydroxybutyrate-co-3-hydroxyvalerate) blend for sustainable packaging," RSC Adv., vol. 3, no. 46, pp. 24378-24388, 2013.

[306] A. Carné Sánchez and S. R. Collinson, “The selective recycling of mixed plastic waste of polylactic acid and polyethylene terephthalate by control of process conditions,” Eur. Polym. J., vol. 47, no. 10, pp. 1970-1976, Oct. 2011.

[307] M. Omura, T. Tsukegi, Y. Shirai, H. Nishida, and T. Endo, “Thermal Degradation Behavior of Poly(Lactic Acid) in a Blend with Polyethylene,” Ind. Eng. Chem. Res., vol. 45, no. 9, pp. 2949-2953, Apr. 2006.

[308] G. Singh, H. Bhunia, A. Rajor, and V. Choudhary, "Thermal properties and degradation characteristics of polylactide, linear low density polyethylene, and their blends,” Polym. Bull., vol. 66, no. 7, pp. 939-953, 2011.

[309] Y. Tsuneizumi, M. Kuwahara, K. Okamoto, and S. Matsumura, "Chemical recycling of poly(lactic acid)-based polymer blends using environmentally benign catalysts,” Polym. Degrad. Stab., vol. 95, no. 8, pp. 1387-1393, Aug. 2010.

[310] E. Dirks, "Energy recovery from plastic waste in waste incineration plants,” in Recycling and Recovery of Plastics, J. Brandup, Ed. Hanser Verlag Publsh, 1996, pp. 746-769.

[311] S. M. Al-Salem, P. Lettieri, and J. Baeyens, "The valorization of plastic solid waste (PSW) by primary to quaternary routes: From re-use to energy and chemicals,” Prog. Energy Combust. Sci., vol. 36, no. 1, pp. 103-129, Feb. 2010.

[312] K. Smolders and J. Baeyens, "Thermal degradation of PMMA in fluidised beds.," Waste Manag., vol. 24, no. 8, pp. 849-57, Jan. 2004.

[313] J. Scheirs, "Feedstock recycling - pyrolysis, hydrogenation and gasification,” in Polymer recycling. Science, Technology and Applications, J. Scheirs, Ed. WileySeries in Polymer Science, 1998.

[314] M. Van de Velden, J. Baeyens, and I. Boukis, "Modeling CFB biomass pyrolysis reactors,” Biomass and Bioenergy, vol. 32, no. 2, pp. 128-139, Feb. 2008.

[315] S.-Y. Wu, M.-F. Su, and J. Baeyens, "The fluidized bed pyrolysis of shredded tyres: the influence of carbon particles, humidity, and temperature on the hydrodynamics," Powder Technol., vol. 93, no. 3, pp. 283-290, Oct. 1997.

[316] T. Cornelissen, M. Jans, M. Stals, T. Kuppens, T. Thewys, G. K. Janssens, H. Pastijn, J. Yperman, G. Reggers, S. Schreurs, and R. Carleer, "Flash co-pyrolysis of biomass: The influence of biopolymers,” J. Anal. Appl. Pyrolysis, vol. 85, no. 1, pp. 87-97, 2009.

[317] T. Cornelissen, M. Jans, J. Yperman, G. Reggers, S. Schreurs, and R. Carleer, "Flash co-pyrolysis of biomass with polyhydroxybutyrate: Part 1. Influence on bio-oil yield, water content, heating value and the production of chemicals,” Fuel, vol. 87, no. 12, pp. 2523-2532, 2008.

[318] T. Cornelissen, J. Yperman, G. Reggers, S. Schreurs, and R. Carleer, "Flash co-pyrolysis of biomass with polylactic acid. Part 1: Influence on bio-oil yield and heating value," Fuel, vol. 87, no. 7, pp. 1031-1041, 2008.

[319] T. Kuppens, T. Cornelissen, R. Carleer, J. Yperman, S. Schreurs, M. Jans, and T. 
Thewys, "Economic assessment of flash co-pyrolysis of short rotation coppice and biopolymer waste streams,” J. Environ. Manage., vol. 91, no. 12, pp. 2736-2747, 2010.

[320] C. Borgianni, P. De Filippis, F. Pochetti, and M. Paolucci, "Gasification process of wastes containing PVC,” Fuel, vol. 81, no. 14, pp. 1827-1833, Sep. 2002.

[321] R. Xiao, B. Jin, H. Zhou, Z. Zhong, and M. Zhang, “Air gasification of polypropylene plastic waste in fluidized bed gasifier,” Energy Convers. Manag., vol. 48, no. 3, pp. 778786, Mar. 2007.

[322] J. Matsunami, S. Yoshida, O. Yokota, M. Nezuka, M. Tsuji, and Y. Tamaura, "Gasification of waste tyre and plastic (PET) by solar thermomechanical process for solar energy utilization,” Sol. Energy, vol. 65, no. 1, pp. 21-23, Jan. 1999.

[323] A. Undri, L. Rosi, M. Frediani, and P. Frediani, "Conversion of poly(lactic acid) to lactide via microwave assisted pyrolysis,” J. Anal. Appl. Pyrolysis, vol. 110, pp. 55-65, 2014.

[324] M. P. Arrieta, F. Parres, J. López, and A. Jiménez, “Development of a novel pyrolysisgas chromatography/mass spectrometry method for the analysis of poly(lactic acid) thermal degradation products,” J. Anal. Appl. Pyrolysis, vol. 101, pp. 150-155, 2013.

[325] O. Drzyzga, O. Revelles, G. Durante-Rodríguez, E. Díaz, J. L. García, and A. Prieto, "New challenges for syngas fermentation: Towards production of biopolymers," $J$. Chem. Technol. Biotechnol., vol. 90, no. 10, pp. 1735-1751, 2015.

[326] A. Tukker, H. de Groot, L. Simons, and S. Wiegersma, "Chemical Recycling of Plastics Waste (PVC and other resins)," 1999.

[327] A. Khawan and D. R. Flangan, "Solid-State Kinetic Models : Basics and Mathematical Fundamentals,” J. Phys. Chem. B, vol. 110, no. 35, pp. 17315-17328, 2006.

[328] B. Wunderlich, Thermal analysis of polymeric materials. Berlin: Springer, 2005.

[329] C. Moliner, B. Bosio, E. Arato, and A. Ribes, "Thermal and thermo-oxidative characterisation of rice straw for its use in energy valorisation processes,” Fuel, vol. 180, pp. 71-79, Sep. 2016.

[330] J. D. Badia, A. Martinez-Felipe, L. Santonja-Blasco, and A. Ribes-Greus, "Thermal and thermo-oxidative stability of reprocessed poly(ethylene terephthalate),” J. Anal. Appl. Pyrolysis, vol. 99, pp. 191-202, Jan. 2013.

[331] W. Jin, D. Shen, Q. Liu, and R. Xiao, "Evaluation of the co-pyrolysis of lignin with plastic polymers by TG-FTIR and Py-GC/MS,” Polym. Degrad. Stab., vol. 133, pp. 6574, 2016.

[332] Y. Park, I. Noda, and Y. M. Jung, "Novel developments and applications of twodimensional correlation spectroscopy,” J. Mol. Struct., vol. 1124, pp. 11-28, 2016.

[333] J. D. Badia, L. Santonja-Blasco, A. Martínez-Felipe, and A. Ribes-Greus, “A methodology to assess the energetic valorization of bio-based polymers from the packaging industry: pyrolysis of reprocessed polylactide.,” Bioresour. Technol., vol. 111, pp. 468-75, May 2012.

[334] C. Moliner, K. Aguilar, B. Bosio, E. Arato, and A. Ribes, "Thermo-oxidative characterisation of the residues from persimmon harvest for its use in energy recovery processes,” Fuel Process. Technol., vol. 152, pp. 421-429, 2016.

[335] F. Carrasco, D. Dionisi, A. Martinelli, and M. Majone, "Thermal stability of polyhydroxyalkanoates,” J. Appl. Polym. Sci., vol. 100, no. 3, pp. 2111-2121, May 2006.

[336] H. Ariffin, H. Nishida, Y. Shirai, and M. A. Hassan, "Anhydride production as an additional mechanism of poly(3-hydroxybutyrate) pyrolysis,” J. Appl. Polym. Sci., vol. 111, no. 1, pp. 323-328, Jan. 2009.

[337] P. Bordes, E. Hablot, E. Pollet, and L. Avérous, "Effect of clay organomodifiers on degradation of polyhydroxyalkanoates,” Polym. Degrad. Stab., vol. 94, no. 5, pp. 789796, May 2009.

[338] M. Lai, J. Li, J. Yang, J. Liu, X. Tong, and H. Cheng, "The morphology and thermal properties of multi-walled carbon nanotube and poly(hydroxybutyrate-cohydroxyvalerate) composite,” Polym. Int., vol. 53, no. 10, pp. 1479-1484, Oct. 2004.

[339] P. Mousavioun, W. O. S. Doherty, and G. George, "Thermal stability and miscibility of poly(hydroxybutyrate) and soda lignin blends,” Ind. Crops Prod., vol. 32, no. 3, pp. 656-661, Nov. 2010.

[340] P. Mousavioun, W. O. S. Doherty, G. George, and P. Halley, “Thermal stability and 
miscibility of poly(hydroxybutyrate) and methanol-soluble soda lignin blends,” 2010.

[341] L. Santonja-Blasco, R. Moriana, J. D. Badía, and A. Ribes-Greus, "Thermal analysis applied to the characterization of degradation in soil of polylactide: I. Calorimetric and viscoelastic analyses,” Polym. Degrad. Stab., vol. 95, no. 11, pp. 2185-2191, Nov. 2010.

[342] I. E. Yuzay, R. Auras, H. Soto-Valdez, and S. Selke, "Effects of synthetic and natural zeolites on morphology and thermal degradation of poly(lactic acid) composites," Polym. Degrad. Stab., vol. 95, no. 9, pp. 1769-1777, Sep. 2010.

[343] N. Kameno, S. Yamada, T. Amimoto, K. Amimoto, H. Ikeda, and N. Koga, “Thermal degradation of poly(lactic acid) oligomer: Reaction mechanism and multistep kinetic behavior,” Polym. Degrad. Stab., vol. 134, pp. 284-295, 2016.

[344] G. Sivalingam and G. Madras, "Thermal degradation of poly (ع-caprolactone)," Polym. Degrad. Stab., vol. 80, no. 1, pp. 11-16, Jan. 2003.

[345] K. Chrissafis, G. Antoniadis, K. M. Paraskevopoulos, A. Vassiliou, and D. N. Bikiaris, "Comparative study of the effect of different nanoparticles on the mechanical properties and thermal degradation mechanism of in situ prepared poly( $\varepsilon$-caprolactone) nanocomposites,” Compos. Sci. Technol., vol. 67, no. 10, pp. 2165-2174.

[346] E.-C. Chen and T.-M. Wu, "Isothermal crystallization kinetics and thermal behavior of poly( $\varepsilon$-caprolactone)/multi-walled carbon nanotube composites," Polym. Degrad. Stab., vol. 92, no. 6, pp. 1009-1015, Jun. 2007.

[347] Y. Aoyagi, K. Yamashita, and Y. Doi, "Thermal degradation of poly[(R)-3hydroxybutyrate], poly[ع-caprolactone], and poly[(S)-lactide],” Polym. Degrad. Stab., vol. 76, no. 1, pp. 53-59, Jan. 2002.

[348] R. A. Ruseckaite and A. Jiménez, "Thermal degradation of mixtures of polycaprolactone with cellulose derivatives,” Polym. Degrad. Stab., vol. 81, no. 2, pp. 353-358, Jan. 2003.

[349] V. Mamleev, S. Bourbigot, and J. Yvon, "Kinetic analysis of the thermal decomposition of cellulose: The main step of mass loss,” J. Anal. Appl. Pyrolysis, vol. 80, no. 1, pp. 151-165, Aug. 2007.

[350] V. Mamleev, S. Bourbigot, and J. Yvon, "Kinetic analysis of the thermal decomposition of cellulose: The change of the rate limitation,” J. Anal. Appl. Pyrolysis, vol. 80, no. 1, pp. 141-150, Aug. 2007.

[351] D. K. Shen and S. Gu, "The mechanism for thermal decomposition of cellulose and its main products.,” Bioresour. Technol., vol. 100, no. 24, pp. 6496-504, Dec. 2009.

[352] V. Mamleev, S. Bourbigot, M. Le Bras, J. Yvon, and J. Lefebvre, “Model-free method for evaluation of activation energies in modulated thermogravimetry and analysis of cellulose decomposition,” Chem. Eng. Sci., vol. 61, no. 4, pp. 1276-1292, Feb. 2006.

[353] S. Arora, S. Lal, S. Kumar, M. Kumar, and M. Kumar, "Comparative degradation kinetic studies of three biopolymers: Chitin, chitosan and cellulose,” Arch. Appl. Sci. Res., vol. 3, no. 3, pp. 188-201, 2011.

[354] F.-D. Kopinke, M. Remmler, K. Mackenzie, M. Möder, and O. Wachsen, “Thermal decomposition of biodegradable polyesters-II. Poly(lactic acid),” Polym. Degrad. Stab., vol. 53, no. 3, pp. 329-342, Sep. 1996.

[355] F.-D. Kopinke and K. Mackenzie, "Mechanistic aspects of the thermal degradation of poly(lactic acid) and poly( $\beta$-hydroxybutyric acid),” J. Anal. Appl. Pyrolysis, vol. 40-41, pp. 43-53, May 1997.

[356] I. C. McNeill and H. A. Leiper, "Degradation studies of some polyesters and polycarbonates-2. Polylactide: Degradation under isothermal conditions, thermal degradation mechanism and photolysis of the polymer,” Polym. Degrad. Stab., vol. 11, no. 4, pp. 309-326, Jan. 1985.

[357] M. Michalak, M. Hakkarainen, and A. C. Albertsson, "Recycling Oxidized Model Polyethylene Powder as a Degradation Enhancing Filler for Polyethylene/Polycaprolactone Blends," ACS Sustain. Chem. Eng., vol. 4, no. 1, pp. 129-135, Jan. 2016.

[358] M. Braungart, W. McDonough, and A. Bollinger, "Cradle-to-cradle design: creating healthy emissions - a strategy for eco-effective product and system design,” J. Clean. Prod., vol. 15, no. 13-14, pp. 1337-1348, Sep. 2007.

[359] F. von Burkersroda, L. Schedl, A. Göpferich, and A. G. F. von Burkersroda, L. Schedl, "Why degradable polymers undergo surface erosion or bulk erosion," Biomaterials, vol. 23, no. 21, pp. 4221-4231, Nov. 2002. 
[360] E. S. Stevens, Green plastics: An introduction to the New Science of Biodegradable Plastics. Princeton University Press, 2001.

[361] I. Kyrikou and D. Briassoulis, "Biodegradation of Agricultural Plastic Films: A Critical Review,” J. Polym. Environ., vol. 15, no. 2, pp. 125-150, 2007.

[362] A. J. Anderson and E. A. Dawes, "Occurrence, metabolism, metabolic role, and industrial uses of bacterial polyhydroxyalkanoates.,” Microbiol. Rev., vol. 54, no. 4, pp. 450-472, 1990.

[363] R. Kleerebezem, M. C. van Loosdrecht, and M. C. van L. R. Kleerebezem, "Mixed culture biotechnology for bioenergy production,” vol. 18, no. 3, pp. 207-212, 2007.

[364] A. G. M.B. Pedersen, P. Gaudu, D. Lechardeur, M.-A. Petit, M. B. Pedersen, P. Gaudu, D. Lechardeur, M.-A. Petit, and A. Gruss, "Aerobic Respiration Metabolism in Lactic Acid Bacteria and Uses in Biotechnology,” Annu. Rev. Food Sci. Technol., vol. 3, no. 1, pp. 37-58, 2012.

[365] Q. H. Tran, G. Unden, and G. U. Q.H. Tran, "Changes in the proton potential and the cellular energetics of Escherichia coli during growth by aerobic and anaerobic respiration or by fermentation,” Eur. J. Biochem., vol. 251, no. 1-2, pp. 538-543, 1998.

[366] S. Matsumura, "Mechanism of biodegradation," in Biodegradable Polymers for Industrial Applications, R. Smith, Ed. Woodhead Publishing Limited, 2005, pp. 357410.

[367] J. P. Eubeler, M. Bernhard, and T. P. Knepper, "Environmental biodegradation of synthetic polymers II. Biodegradation of different polymer groups,” TrAC Trends Anal. Chem., vol. 29, no. 1, pp. 84-100, Jan. 2010.

[368] K. L. Pozna, L. Sciences, G. L. Pozna, and L. Sciences, "Polymer Biodegradation and Biodegradable Polymers - a Review Polymers Biodegradation and Biodegradable Polymers - a Review,” Polish J. Environ. Stud., vol. 19, no. 2, pp. 255-266, 2010.

[369] J. M. Anderson and M. S. Shive, "Biodegradation and biocompatibility of PLA and PLGA microspheres,” Adv. Drug Deliv. Rev., vol. 64, no. SUPPL., pp. 72-82, 2012.

[370] A. A. Shah, F. Hasan, A. Hameed, and S. Ahmed, "Biological degradation of plastics: a comprehensive review.,” Biotechnol. Adv., vol. 26, no. 3, pp. 246-65, Jan. 2008.

[371] J. P. Eubeler, S. Zok, M. Bernhard, and T. P. Knepper, "Environmental biodegradation of synthetic polymers I. Test methodologies and procedures,” TrAC Trends Anal. Chem., vol. 28, no. 9, pp. 1057-1072, Oct. 2009.

[372] D. Briassoulis, C. Dejean, and P. Picuno, “Critical Review of Norms and Standards for Biodegradable Agricultural Plastics Part I. Biodegradation in Soil,” J. Polym. Environ., vol. 18, no. 3, pp. 364-383, 2010.

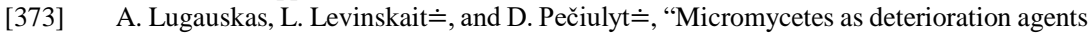
of polymeric materials,” Int. Biodeterior. Biodegradation, vol. 52, no. 4, pp. 233-242, Dec. 2003.

[374] D. N. Bikiaris, G. Z. Papageorgiou, and D. S. Achilias, "Synthesis and comparative biodegradability studies of three poly(alkylene succinate)s,” Polym. Degrad. Stab., vol. 91, no. 1, pp. 31-43, Jan. 2006.

[375] H.-S. Kim, H.-J. Kim, J.-W. Lee, and I.-G. Choi, "Biodegradability of bio-flour filled biodegradable poly(butylene succinate) bio-composites in natural and compost soil," Polym. Degrad. Stab., vol. 91, no. 5, pp. 1117-1127, May 2006.

[376] "ISO 11266. Soil quality - Guidance on laboratory testing for biodegradation of organic chemicals in soil under aerobic conditions.” 1994.

[377] M. Hakkarainen, "Rapid (bio)degradation of polylactide by mixed culture of compost microorganisms-low molecular weight products and matrix changes," Polymer (Guildf)., vol. 41, no. 7, pp. 2331-2338, Mar. 2000.

[378] M. S. Marqués-Calvo, M. Cerdà-Cuéllar, D. P. R. Kint, J. J. Bou, and S. Muñoz-Guerra, "Enzymatic and microbial biodegradability of poly(ethylene terephthalate) copolymers containing nitrated units,” Polym. Degrad. Stab., vol. 91, no. 4, pp. 663-671, Apr. 2006.

[379] S. Chanprateep, H. Shimizu, and S. Shioya, "Characterization and enzymatic degradation of microbial copolyester $\mathrm{P}(3 \mathrm{HB}-\mathrm{co}-3 \mathrm{HV})$ s produced by metabolic reaction model-based system,” Polym. Degrad. Stab., vol. 91, no. 12, pp. 2941-2950, Dec. 2006.

[380] K. Van de Velde and P. Kiekens, "Biopolymers: overview of several properties and consequences on their applications,” Polym. Test., vol. 21, no. 4, pp. 433-442, 2002.

[381] J. M. Morancho, X. Ramis, X. Fernández, A. Cadenato, J. M. Salla, A. Vallés, L. Contat, 
and A. Ribes, "Calorimetric and thermogravimetric studies of UV-irradiated polypropylene/starch-based materials aged in soil,” Polym. Degrad. Stab., vol. 91, no. 1, pp. 44-51, Jan. 2006.

[382] J. D. Badı and R. Moriana, "A Thermogravimetric Approach to Study the Influence of a Biodegradation in Soil Test to a Poly ( lactic acid ),” pp. 93-99, 2008.

[383] "ISO 14852. Determination of the ultimate aerobic biodegradability of plastic materials in an aqueous medium - Method by analysis of evolved carbon dioxide.” 1999.

[384] A. Calmon, L. Dusserre-Bresson, V. Bellon-Maurel, P. Feuilloley, and F. Silvestre, “An automated test for measuring polymer biodegradation,” Chemosphere, vol. 41, no. 5, pp. 645-651, Sep. 2000.

[385] J. S. P. Peltola, J. Juhanoja, and M. S. Salkinoja-Salonen, "Biodegradability and waste behavior of industrial wood-based construction materials," J. Ind. Microbiol. Biotechnol., vol. 24, no. 3, pp. 210-218, 2000.

[386] M. Itävaara, S. Karjomaa, and J.-F. Selin, "Biodegradation of polylactide in aerobic and anaerobic thermophilic conditions,” Chemosphere, vol. 46, no. 6, pp. 879-885, Feb. 2002.

[387] M.-N. Kim, A.-R. Lee, J.-S. Yoon, and I.-J. Chin, "Biodegradation of poly(3hydroxybutyrate), Sky-Green ${ }^{\circledR}$ and Mater-Bi ${ }^{\circledR}$ by fungi isolated from soils,” Eur. Polym. J., vol. 36, no. 8, pp. 1677-1685, Aug. 2000.

[388] S. O. Kulkarni, P. P. Kanekar, J. P. Jog, P. A. Patil, S. S. Nilegaonkar, S. S. Sarnaik, and P. R. Kshirsagar, "Characterisation of copolymer, poly (hydroxybutyrate-cohydroxyvalerate) (PHB-co-PHV) produced by Halomonas campisalis (MCM B-1027), its biodegradability and potential application.,” Bioresour. Technol., vol. 102, no. 11, pp. 6625-8, Jun. 2011.

[389] T. Apinya, N. Sombatsompop, and B. Prapagdee, "Selection of a Pseudonocardia sp. RM423 that accelerates the biodegradation of poly(lactic) acid in submerged cultures and in soil microcosms," Int. Biodeterior. Biodegradation, vol. 99, pp. 23-30, Apr. 2015.

[390] C. Chuensangjun, C. Pechyen, and S. Sirisansaneeyakul, "Degradation Behaviors of Different Blends of Polylactic Acid Buried in Soil,” Energy Procedia, vol. 34, pp. 7382, 2013.

[391] R. Pantani and A. Sorrentino, "Influence of crystallinity on the biodegradation rate of injection-moulded poly(lactic acid) samples in controlled composting conditions," Polym. Degrad. Stab., vol. 98, no. 5, pp. 1089-1096, May 2013.

[392] M. Avella, M. E. Errico, P. Laurienzo, E. Martuscelli, M. Raimo, and R. Rimedio, "Preparation and characterisation of compatibilised polycaprolactone/starch composites,” Polymer (Guildf)., vol. 41, no. 10, pp. 3875-3881, May 2000.

[393] M. Enamul Hoque, M. A. M. Aminudin, M. Jawaid, M. S. Islam, N. Saba, and M. T. Paridah, "Physical, mechanical, and biodegradable properties of meranti wood polymer composites,” Mater. Des., vol. 64, pp. 743-749, Dec. 2014.

[394] E. Schettini, G. Santagata, M. Malinconico, B. Immirzi, G. Scarascia Mugnozza, and G. Vox, "Recycled wastes of tomato and hemp fibres for biodegradable pots: Physicochemical characterization and field performance,” Resour. Conserv. Recycl., vol. 70, pp. 9-19, Jan. 2013.

[395] H. Yagi, F. Ninomiya, M. Funabashi, and M. Kunioka, “Anaerobic biodegradation tests of poly(lactic acid) and polycaprolactone using new evaluation system for methane fermentation in anaerobic sludge,” Polym. Degrad. Stab., vol. 94, no. 9, pp. 1397-1404, Sep. 2009.

[396] P. Mousavioun, G. A. George, and W. O. S. Doherty, "Environmental degradation of lignin/poly(hydroxybutyrate) blends,” Polym. Degrad. Stab., vol. 97, no. 7, pp. 11141122, Jul. 2012.

[397] L. Pérez Amaro, H. Chen, A. Barghini, A. Corti, and E. Chiellini, "High Performance Compostable Biocomposites Based on Bacterial Polyesters Suitable For Injection Molding and Blow Extrusion,” Chem. Biochem. Eng. Q., vol. 29, no. 2, pp. 261-274, 2015.

[398] S. Rimdusit, S. Jingid, S. Damrongsakkul, S. Tiptipakorn, and T. Takeichi, "Biodegradability and property characterizations of Methyl Cellulose: Effect of nanocompositing and chemical crosslinking,” Carbohydr. Polym., vol. 72, no. 3, pp. 
444-455, May 2008.

[399] A. Chevillard, H. Angellier-Coussy, B. Cuq, V. Guillard, G. César, N. Gontard, and E. Gastaldi, "How the biodegradability of wheat gluten-based agromaterial can be modulated by adding nanoclays,” Polym. Degrad. Stab., vol. 96, no. 12, pp. 2088-2097, Dec. 2011.

[400] J. V. L. Alvarez, M. A. Larrucea, P. A. Bermúdez, and B. L. Chicote, "Biodegradation of paper waste under controlled composting conditions.,” Waste Manag., vol. 29, no. 5, pp. 1514-9, May 2009.

[401] T. F. Fernandes, E. Trovatti, C. S. R. Freire, A. J. D. Silvestre, C. P. Neto, A. Gandini, and P. Sadocco, "Preparation and characterization of novel biodegradable composites based on acylated cellulose fibers and poly(ethylene sebacate),” Compos. Sci. Technol., vol. 71, no. 16, pp. 1908-1913, Nov. 2011.

[402] R. Gattin, A. Copinet, C. Bertrand, and Y. Couturier, "Biodegradation study of a starch and poly(lactic acid) co-extruded material in liquid, composting and inert mineral media,” Int. Biodeterior. Biodegradation, vol. 50, no. 1, pp. 25-31, Jul. 2002.

[403] W. Guo, J. Tao, C. Yang, Q. Zhao, C. Song, and S. Wang, "The rapid evaluation of material biodegradability using an improved ISO 14852 method with a microbial community,” Polym. Test., vol. 29, no. 7, pp. 832-839, Oct. 2010.

[404] Y. Zhou, Z. Huang, X. Diao, Y. Weng, and Y.-Z. Wang, "Characterization of the effect of REC on the compatibility of PHBH and PLA,” Polym. Test., vol. 42, pp. 17-25, Apr. 2015.

[405] R. Deng, Y. Chen, P. Chen, L. Zhang, and B. Liao, "Properties and biodegradability of water-resistant soy protein/poly( $\varepsilon$-caprolactone)/toluene-2,4-diisocyanate composites,” Polym. Degrad. Stab., vol. 91, no. 9, pp. 2189-2197, Sep. 2006.

[406] U. Pagga, A. Schäfer, R.-J. Müller, and M. Pantke, "Determination of the aerobic biodegradability of polymeric material in aquatic batch tests," Chemosphere, vol. 42, no. 3, pp. 319-331, Feb. 2001

[407] X. Qiu, S. Tao, X. Ren, and S. Hu, "Modified cellulose films with controlled permeatability and biodegradability by crosslinking with toluene diisocyanate under homogeneous conditions,” Carbohydr. Polym., vol. 88, no. 4, pp. 1272-1280, May 2012.

[408] C. Way, D. Y. Wu, K. Dean, and E. Palombo, "Design considerations for hightemperature respirometric biodegradation of polymers in compost,” Polym. Test., vol. 29, no. 1, pp. 147-157, Feb. 2010.

[409] J. S. Amaral, M. Sepúlveda, C. A. Cateto, I. P. Fernandes, A. E. Rodrigues, M. N. Belgacem, and M. F. Barreiro, "Fungal degradation of lignin-based rigid polyurethane foams,” Polym. Degrad. Stab., vol. 97, no. 10, pp. 2069-2076, Oct. 2012.

[410] S. Domenek, P. Feuilloley, J. Gratraud, M.-H. Morel, and S. Guilbert, "Biodegradability of wheat gluten based bioplastics.,” Chemosphere, vol. 54, no. 4, pp. 551-9, Jan. 2004.

[411] O. Cadar, M. Paul, C. Roman, M. Miclean, and C. Majdik, "Biodegradation behaviour of poly(lactic acid) and (lactic acid-ethylene glycol-malonic or succinic acid) copolymers under controlled composting conditions in a laboratory test system," Polym. Degrad. Stab., vol. 97, no. 3, pp. 354-357, Mar. 2012.

[412] M. Funabashi, F. Ninomiya, and M. Kunioka, "Biodegradability evaluation of polymers by ISO 14855-2.,” Int. J. Mol. Sci., vol. 10, no. 8, pp. 3635-54, Oct. 2009.

[413] R. Iovino, R. Zullo, M. A. Rao, L. Cassar, and L. Gianfreda, "Biodegradation of poly(lactic acid)/starch/coir biocomposites under controlled composting conditions,” Polym. Degrad. Stab., vol. 93, no. 1, pp. 147-157, Jan. 2008.

[414] H. J. Jeon and M. N. Kim, "Biodegradation of poly(l-lactide) (PLA) exposed to UV irradiation by a mesophilic bacterium,” Int. Biodeterior. Biodegradation, vol. 85, pp. 289-293, Nov. 2013.

[415] M. Kunioka, F. Ninomiya, M. Funabashi, and 2006. Kunioka, M., Ninomiya, F., Funabashi, M., "Biodegradation of poly(lactic acid) powders proposed as the reference test materials for the international standard of biodegradation evaluation methods," Polym. Degrad. Stab., vol. 91, no. 9, pp. 1919-1928, Sep. 2006.

[416] V. T. Phuong, M.-B. Coltelli, P. Cinelli, M. Cifelli, S. Verstichel, and A. Lazzeri, "Compatibilization and property enhancement of poly(lactic acid)/polycarbonate blends through triacetin-mediated interchange reactions in the melt,” Polymer (Guildf)., vol. 55, 
no. 17, pp. 4498-4513, Aug. 2014.

[417] Q. Shi, C. Chen, L. Gao, L. Jiao, H. Xu, and W. Guo, "Physical and degradation properties of binary or ternary blends composed of poly (lactic acid), thermoplastic starch and GMA grafted POE,” Polym. Degrad. Stab., vol. 96, no. 1, pp. 175-182, Jan. 2011.

[418] T. Kijchavengkul, R. Auras, M. Rubino, M. Ngouajio, and R. Thomas Fernandez, "Development of an automatic laboratory-scale respirometric system to measure polymer biodegradability,” Polym. Test., vol. 25, no. 8, pp. 1006-1016, Dec. 2006.

[419] T. Leejarkpai, U. Suwanmanee, Y. Rudeekit, and T. Mungcharoen, "Biodegradable kinetics of plastics under controlled composting conditions.,” Waste Manag., vol. 31, no. 6, pp. 1153-61, Jun. 2011.

[420] Y. Lemmouchi, M. Murariu, A. M. Dos Santos, A. J. Amass, E. Schacht, and P. Dubois, "Plasticization of poly(lactide) with blends of tributyl citrate and low molecular weight poly(d,l-lactide)-b-poly(ethylene glycol) copolymers,” Eur. Polym. J., vol. 45, no. 10, pp. 2839-2848, Oct. 2009.

[421] E. Petinakis, X. Liu, L. Yu, C. Way, P. Sangwan, K. Dean, S. Bateman, and G. Edward, "Biodegradation and thermal decomposition of poly(lactic acid)-based materials reinforced by hydrophilic fillers,” Polym. Degrad. Stab., vol. 95, no. 9, pp. 1704-1707, Sep. 2010.

[422] C. Way, K. Dean, D. Y. Wu, and E. Palombo, "Biodegradation of sequentially surface treated lignocellulose reinforced polylactic acid composites: Carbon dioxide evolution and morphology,” Polym. Degrad. Stab., vol. 97, no. 3, pp. 430-438, Mar. 2012.

[423] M. Kunioka, F. Ninomiya, and M. Funabashi, "Novel evaluation method of biodegradabilities for oil-based polycaprolactone by naturally occurring radiocarbon-14 concentration using accelerator mass spectrometry based on ISO 14855-2 in controlled compost,” Polym. Degrad. Stab., vol. 92, no. 7, pp. 1279-1288, Jul. 2007.

[424] Y.-X. Weng, X.-L. Wang, and Y.-Z. Wang, "Biodegradation behavior of PHAs with different chemical structures under controlled composting conditions," Polym. Test., vol. 30, no. 4, pp. 372-380, Jun. 2011.

[425] Y.-X. Weng, Y. Wang, X.-L. Wang, and Y.-Z. Wang, "Biodegradation behavior of PHBV films in a pilot-scale composting condition,” Polym. Test., vol. 29, no. 5, pp. 579587, Aug. 2010.

[426] C.-F. Kuan, C.-C. M. Ma, H.-C. Kuan, H.-L. Wu, and Y.-M. Liao, "Preparation and characterization of the novel water-crosslinked cellulose reinforced poly(butylene succinate) composites,” Compos. Sci. Technol., vol. 66, no. 13, pp. 2231-2241, Oct. 2006.

[427] Y.-L. Du, Y. Cao, F. Lu, F. Li, Y. Cao, X.-L. Wang, and Y.-Z. Wang, "Biodegradation behaviors of thermoplastic starch (TPS) and thermoplastic dialdehyde starch (TPDAS) under controlled composting conditions,” Polym. Test., vol. 27, no. 8, pp. 924-930, Dec. 2008.

[428] X. Zhang, Y. Gozukara, P. Sangwan, D. Gao, and S. Bateman, "Biodegradation of chemically modified wheat gluten-based natural polymer materials,” Polym. Degrad. Stab., vol. 95, no. 12, pp. 2309-2317, Dec. 2010.

[429] F. Xie, B. M. Flanagan, M. Li, P. Sangwan, R. W. Truss, P. J. Halley, E. V Strounina, A. K. Whittaker, M. J. Gidley, K. M. Dean, J. L. Shamshina, R. D. Rogers, and T. McNally, "Characteristics of starch-based films plasticised by glycerol and by the ionic liquid 1-ethyl-3-methylimidazolium acetate: a comparative study.," Carbohydr. Polym., vol. 111, pp. 841-8, Oct. 2014.

[430] H. Xiong, S. Tang, H. Tang, and P. Zou, "The structure and properties of a starch-based biodegradable film,” Carbohydr. Polym., vol. 71, no. 2, pp. 263-268, Jan. 2008.

[431] F. Jbilou, S. Galland, F. Ayadi, L. Belard, P. Dole, V. Desjardin, R. Bayard, and P. Degraeve, "Biodegradation of corn flour-based materials assessed by enzymatic, aerobic, and anaerobic tests: Influence of specific surface area,” Polym. Test., vol. 30, no. 1, pp. 131-139, Feb. 2011.

[432] M. P. Arrieta, E. Fortunati, F. Dominici, J. López, and J. M. Kenny, "Bionanocomposite films based on plasticized PLA-PHB/cellulose nanocrystal blends.,” Carbohydr. Polym., vol. 121, pp. 265-75, May 2015.

[433] M. P. Arrieta, J. López, E. Rayón, and A. Jiménez, “Disintegrability under composting 
conditions of plasticized PLA-PHB blends,” Polym. Degrad. Stab., vol. 108, pp. 307318, Oct. 2014.

[434] N. Bitinis, E. Fortunati, R. Verdejo, J. Bras, J. M. Kenny, L. Torre, and M. A. LópezManchado, "Poly(lactic acid)/natural rubber/cellulose nanocrystal bionanocomposites. Part II: properties evaluation.,” Carbohydr. Polym., vol. 96, no. 2, pp. 621-7, Jul. 2013.

[435] N. Bitinis, E. Fortunati, R. Verdejo, I. Armentano, L. Torre, J. M. Kenny, and M. Á. López-Manchado, "Thermal and bio-disintegration properties of poly(lactic acid)/natural rubber/organoclay nanocomposites,” Appl. Clay Sci., vol. 93-94, pp. 7884, May 2014.

[436] E. Fortunati, F. Luzi, D. Puglia, F. Dominici, C. Santulli, J. M. Kenny, and L. Torre, "Investigation of thermo-mechanical, chemical and degradative properties of PLAlimonene films reinforced with cellulose nanocrystals extracted from Phormium tenax leaves,” Eur. Polym. J., vol. 56, pp. 77-91, Jul. 2014.

[437] E. Fortunati, S. Rinaldi, M. Peltzer, N. Bloise, L. Visai, I. Armentano, A. Jiménez, L. Latterini, and J. M. Kenny, "Nano-biocomposite films with modified cellulose nanocrystals and synthesized silver nanoparticles.," Carbohydr. Polym., vol. 101, pp. 1122-33, Jan. 2014.

[438] M. Ramos, E. Fortunati, M. Peltzer, J. M. Kenny, and M. C. Garrigós, “Characterization and disintegrability under composting conditions of PLA-based nanocomposite films with thymol and silver nanoparticles,” Polym. Degrad. Stab., vol. 132, pp. 2-10, 2016.

[439] A. Valdés García, M. Ramos Santonja, A. B. Sanahuja, and M. del C. G. Selva, "Characterization and degradation characteristics of poly( $\varepsilon$-caprolactone)-based composites reinforced with almond skin residues,” Polym. Degrad. Stab., vol. 108, pp. 269-279, Oct. 2014.

[440] A. Ammala, S. Bateman, K. Dean, E. Petinakis, P. Sangwan, S. Wong, Q. Yuan, L. Yu, C. Patrick, and K. H. Leong, "An overview of degradable and biodegradable polyolefins,” Prog. Polym. Sci., vol. 36, no. 8, pp. 1015-1049, Aug. 2011.

[441] M. Avella, E. Bonadies, E. Martuscelli, and R. Rimedio, "European current standardization for plastic packaging recoverable through composting and biodegradation,” Polym. Test., vol. 20, no. 5, pp. 517-521, Jan. 2001.

[442] D. N. Bikiaris, "Nanocomposites of aliphatic polyesters: An overview of the effect of different nanofillers on enzymatic hydrolysis and biodegradation of polyesters," Polym. Degrad. Stab., vol. 98, no. 9, pp. 1908-1928, Sep. 2013.

[443] S. Chanprateep, "Current trends in biodegradable polyhydroxyalkanoates.," J. Biosci. Bioeng., vol. 110, no. 6, pp. 621-32, Dec. 2010.

[444] K. J. Edgar, C. M. Buchanan, J. S. Debenham, P. A. Rundquist, B. D. Seiler, M. C. Shelton, and D. Tindall, "Advances in cellulose ester performance and application," Prog. Polym. Sci., vol. 26, no. 9, pp. 1605-1688, Nov. 2001.

[445] E. F. Gómez and F. C. Michel, "Biodegradability of conventional and bio-based plastics and natural fiber composites during composting, anaerobic digestion and long-term soil incubation,” Polym. Degrad. Stab., vol. 98, no. 12, pp. 2583-2591, Dec. 2013.

[446] J.-D. Gu, "Microbiological deterioration and degradation of synthetic polymeric materials: recent research advances,” Int. Biodeterior. Biodegradation, vol. 52, no. 2, pp. 69-91, Sep. 2003.

[447] T. A. Hottle, M. M. Bilec, N. R. Brown, and A. E. Landis, "Toward zero waste: Composting and recycling for sustainable venue based events.," Waste Manag., Feb. 2015.

[448] R. Mohee, G. D. Unmar, A. Mudhoo, and P. Khadoo, "Biodegradability of biodegradable/degradable plastic materials under aerobic and anaerobic conditions.," Waste Manag., vol. 28, no. 9, pp. 1624-9, Jan. 2008.

[449] J. C. Philp, A. Bartsev, R. J. Ritchie, M.-A. Baucher, and K. Guy, "Bioplastics science from a policy vantage point.,” N. Biotechnol., vol. 30, no. 6, pp. 635-46, Sep. 2013.

[450] K. G. Satyanarayana, G. G. C. Arizaga, and F. Wypych, "Biodegradable composites based on lignocellulosic fibers-An overview,” Prog. Polym. Sci., vol. 34, no. 9, pp. 982-1021, Sep. 2009.

[451] H.-S. Yang, J.-S. Yoon, and M.-N. Kim, "Dependence of biodegradability of plastics in compost on the shape of specimens,” Polym. Degrad. Stab., vol. 87, no. 1, pp. 131-135, Jan. 2005. 
[452] “ASTM G21-13. Standard Practice for Determining Resistance of Synthetic Polymeric Materials to Fungi.” 2013.

[453] “ASTM G22-76(1996). Standard Practice for Determining Resistance of Plastics to Bacteria.” 1996.

[454] C. Li, J. Moore-Kucera, J. Lee, A. Corbin, M. Brodhagen, C. Miles, and D. Inglis, "Effects of biodegradable mulch on soil quality,” Appl. Soil Ecol., vol. 79, pp. 59-69, Jul. 2014.

[455] J. Hanson, N. Yeşiller, and N. Oettle, "Spatial and Temporal Temperature Distributions in Municipal Solid Waste Landfills,” J. Environ. Eng., vol. 136, no. 8, pp. 804-814, Nov. 2009.

[456] N. J. Themelis and P. A. Ulloa, "Methane generation in landfills,” Renew. Energy, vol. 32, no. 7, pp. 1243-1257, Jun. 2007.

[457] M. A. Barlaz, "Forest products decomposition in municipal solid waste landfills.," Waste Manag., vol. 26, no. 4, pp. 321-33, Jan. 2006.

[458] R.-J. Muller, "Biodegradation behavior of polymers in liquid environments," in Handbook of Biodegradable Polymers, C. Bastioli, Ed. London: Rapra tech. LTD, 2005.

[459] V. Massardier-Nageotte, C. Pestre, T. Cruard-Pradet, and R. Bayard, "Aerobic and anaerobic biodegradability of polymer films and physico-chemical characterization,” Polym. Degrad. Stab., vol. 91, no. 3, pp. 620-627, Mar. 2006.

[460] D.-M. Abou-Zeid, R.-J. Müller, and W.-D. Deckwer, "Degradation of natural and synthetic polyesters under anaerobic conditions,” J. Biotechnol., vol. 86, no. 2, pp. 113126, Mar. 2001.

[461] H. S. Cho, H. S. Moon, M. Kim, K. Nam, and J. Y. Kim, "Biodegradability and biodegradation rate of poly(caprolactone)-starch blend and poly(butylene succinate) biodegradable polymer under aerobic and anaerobic environment,” Waste Manag., vol. 31, no. 3, pp. 475-480, Mar. 2011.

[462] H. Yagi, F. Ninomiya, M. Funabashi, and M. Kunioka, "Mesophilic anaerobic biodegradation test and analysis of eubacteria and archaea involved in anaerobic biodegradation of four specified biodegradable polyesters,” Polym. Degrad. Stab., vol. 110, pp. 278-283, Dec. 2014.

[463] C. Hankermeyer and R. Tjeerdema, "Polyhydroxybutyrate: Plastic Made and Degraded by Microorganisms," in Reviews of Environmental Contamination and Toxicology SE 1, vol. 159, G. Ware, Ed. Springer New York, 1999, pp. 1-24.

[464] K. E. Gonda, D. Jendrossek, and H. P. Molitoris, "Fungal degradation of the thermoplastic polymer poly-ß-hydroxybutyric acid (PHB) under simulated deep sea pressure,” in Life at Interfaces and Under Extreme Conditions SE - 17, vol. 151, G. Liebezeit, S. Dittmann, and I. Kröncke, Eds. Springer Netherlands, 2000, pp. 173-183.

[465] T. Leathers, N. Govind, and R. Greene, "Biodegradation of Poly(3-hydroxybutyrate-co3-hydroxyvalerate) by a Tropical Marine Bacterium, Pseudoalteromonas sp. NRRL B30083,” J. Polym. Environ., vol. 8, no. 3, pp. 119-124, 2000. 


\section{CHAPTER 2。}

\section{Experimental}

methodologies for the

development,

characterisation and

\section{validation}




\subsection{EXPERIMENTAL STRATEGY}

The experimental strategy considered along this study is summarised in Figure 2.1. Four main stages were approached: membrane designing processing, characterisation and validation, which were interlinked and continuously reconsidered for a suitable approach of polymer-based material development for smart applications.

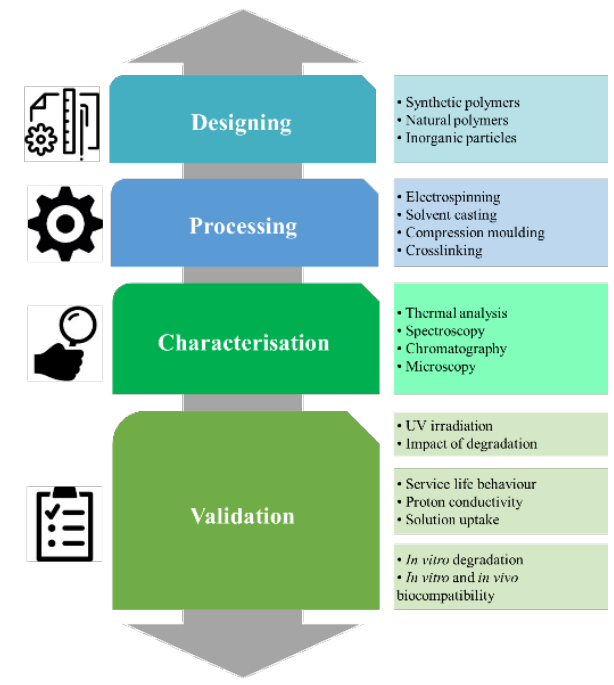

Figure 2.1. Experimental strategy based in four stages: designing, processing, characterisation and validation.

Firstly, membranes were designed according to literature and previous results of the research group, and then processed either by means of electrospinning, solvent casting, compression moulding, or a combination of them. Afterwards, the main physico-chemical properties of the membranes were assessed from different perspectives. Characterisation was performed in terms of chemical structure, molar mass, surface morphology, thermal properties, thermo-oxidative stability, thermomechanical properties or dielectric properties. Finally, a validation procedure for each application was carried out.

All of the experimental procedures described in this section were carried out at the Functionalisation, Degradation and Recycling of Polymer Materials Research Group (DREMAP) facilities of the Materials Technology Institute (ITM) in the Polytechnic University of Valencia (UPV), with the exception of those in which the place of execution or collaborative context is specified. 


\subsection{MATERIALS AND REAGENTS}

\subsubsection{Polymers}

Several commercial polymeric materials were used along this thesis. Table 2.1 gathers the polymer type and the acronym along with the manufacturer and reference.

Table 2.1. Polymeric materials considered along this thesis.

\begin{tabular}{|c|c|c|c|}
\hline Type & Acronym & Manufacturer & Reference \\
\hline Polypropylene & PP & Repsol YPF & $\begin{array}{l}\text { ISPLEN PP040 } \\
\text { G1E }\end{array}$ \\
\hline $\begin{array}{l}\text { Maleic anhydride grafted } \\
\text { polypropylene }\end{array}$ & MAH-PP & Eastman & G-3003 \\
\hline Poly(lactide-co-glycolide) & PLGA & \multirow{6}{*}{ Sigma-Aldrich } & Resomer RG505 \\
\hline Polydioxanone & PDO & & Resomer X \\
\hline Gelatin & $\mathrm{Ge}$ & & G2500 \\
\hline Poly(vinyl alcohol) & PVA & & 563900 \\
\hline Chitosan & $\mathrm{CS}$ & & 448869 \\
\hline \multirow{2}{*}{ Polycaprolactone } & \multirow{2}{*}{ PCL } & & 440744 \\
\hline & & Perstorp & CAPA 6800 \\
\hline $\begin{array}{l}\text { 50:50 DL-poly(lactide-co- } \\
\text { glycolide) }\end{array}$ & PLGA & Lactel & B6010-4 \\
\hline Polyhydroxybutyrate & PHB & Biomer & P209 \\
\hline
\end{tabular}




\subsubsection{Reagents and solvents}

The reagents and solvents used along this thesis are gathered in Table 2.2. All of them were used without further purification.

Table 2.2. Reagents and solvents considered along this thesis.

\begin{tabular}{|c|c|}
\hline Type & Manufacturer \\
\hline Non-ionic surfactant Triton ${ }^{\circledR}$ X-100 & \multirow{2}{*}{ Acros Organics } \\
\hline 1,3-propanosultone $97 \%$ & \\
\hline Sulfosuccinic acid (SSA) $70 \%$ & \multirow{17}{*}{ Sigma-Aldrich } \\
\hline Sodium hydride (NaH) 95\% dry & \\
\hline Sodium nitrite $\left(\mathrm{NaNO}_{3}\right) 99.5 \%$ & \\
\hline Formic acid $(\geq 99 \%)$ & \\
\hline Acetic acid $(\geq 99 \%)$ & \\
\hline Tetrahydrofuran (THF) ( $\geq 99.8 \%$ ) & \\
\hline Dulbecco’s Phosphate Buffer Saline (PBS) & \\
\hline Dulbecco’s Modified Eagle’s Medium & \\
\hline Claycomb medium & \\
\hline Sodium hydroxide $(\mathrm{NaOH})$ solution $1 \mathrm{M}$ & \\
\hline Dimethylformamide (DMF) & \\
\hline 4',6-diamidino-2-phenylindole (DAPI) & \\
\hline Thiazolyl blue tetrazolium bromide & \\
\hline Lactic acid solution $\geq 85 \%$ & \\
\hline Glycolic acid solution $70 \%$ & \\
\hline Chloroform $\left(\mathrm{CHCl}_{3}\right)$ & \\
\hline Hexafluoroisopropanol (HFIP) & \\
\hline Chlorhydric acid (HCl) 37\% & Panreac \\
\hline Ethanol absolute $\left(\mathrm{C}_{2} \mathrm{H}_{5} \mathrm{OH}\right)$ & \multirow{4}{*}{ Sharlau } \\
\hline Extra-pure potassium permanganate $\left(\mathrm{KMnO}_{4}\right)$ & \\
\hline Sulphuric acid $\left(\mathrm{H}_{2} \mathrm{SO}_{4}\right) 95-98 \%$ & \\
\hline Hydrogen peroxide $\left(\mathrm{H}_{2} \mathrm{O}_{2}\right) 30 \%$ & \\
\hline Paraformaldehyde (PFA) & VWR Chemicals \\
\hline Foetal bovine serum (FBS) & \multirow{3}{*}{ Gibco } \\
\hline Penicillin & \\
\hline Streptomycin & \\
\hline L-Glutamine & Millipore \\
\hline Ultra-pure water type 1 (ISO 3696) [1] & $\begin{array}{l}\text { Produced in the } \\
\text { laboratory }\end{array}$ \\
\hline
\end{tabular}

\subsubsection{Obtaining of silicon microparticles}

The silicon microparticles were obtained by the Chemical Technology Institute of the Polytechnic University of Valencia (CSIC-UPV). Briefly, polydisperse silicon microparticles were obtained from metallurgical grade silicon powder (Silgrain ${ }^{\circledR}$ with $99.5 \%$ of purity from Elkem), through a process of grinding. Screening of the particles was performed achieving that the $98 \%$ were smaller than $2 \mu \mathrm{m}$ [2]. The macroscopic appearance of the silicon milled microparticles is shown in Figure 2.2. 


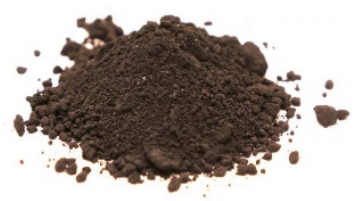

Figure 2.2. Macroscopic appearance of silicon milled microparticles.

\subsubsection{Sulfonation of poly(vinyl alcohol) (PVA)}

The sulfonation of the poly(vinyl alcohol) (PVA) was carried out in collaboration with Dr. S. Sánchez-Ballester in the DREMAP facilities. For this purpose, 1,3-propanesultone was used as a precursor for the introduction of sulfonic groups in its structure. The sulfonation reaction was performed in two stages: the preparation of the sulfonated sodium salt and the protonation process, according to the sequence shown in Figure 2.2.

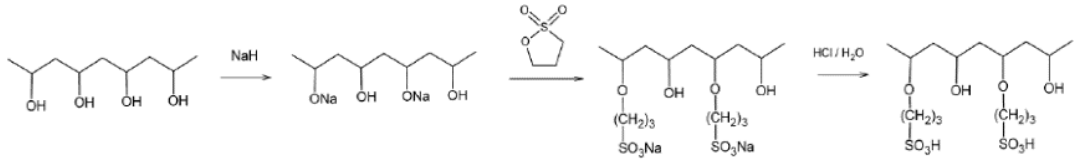

Figure 2.2. PVA sulfonation sequence.

In the first step, $250 \mathrm{~mL}$ of ethanol was added into a $500 \mathrm{~mL}$ round bottom flask and, then, $10 \mathrm{~g}$ of PVA were introduced into the flask. Subsequently, $4.8 \mathrm{~g}$ of sodium hydride $(\mathrm{NaH})$ was slowly added to the PVA/ethanol mixture in continuous magnetic stirring. Next, $5 \mathrm{~g}$ of 1,3-propanosultone was added after heating with a source of hot air to prevent solidification at room temperature, and added dropwise to the mixture. This mixture was allowed to react at $80{ }^{\circ} \mathrm{C}$ with magnetic stirring for $24 \mathrm{~h}$.

In the second stage, a $12 \mathrm{~h}$ washing was carried out with $100 \mathrm{~mL}$ of an aqueous solution of $\mathrm{HCl}(0.5 \mathrm{M})$ with the purpose of replacing the $\mathrm{Na}^{+}$of the added groups by $\mathrm{H}^{+}$. Next, the reacted PVA was filtered and washed with ethanol. Finally, the sulfonated PVA (SPVA) was dried for $4 \mathrm{~h}$ in a vacuum oven at $50^{\circ} \mathrm{C}$.

\subsubsection{Obtaining of graphene oxide (GO)}

The obtaining of graphene oxide (GO) was carried out in collaboration with Dr. S. Sánchez-Ballester in the DREMAP facilities. The graphene oxide (GO) was obtained by the modified Hummers method, according to the literature [3], as shown in Figure 2.4. 


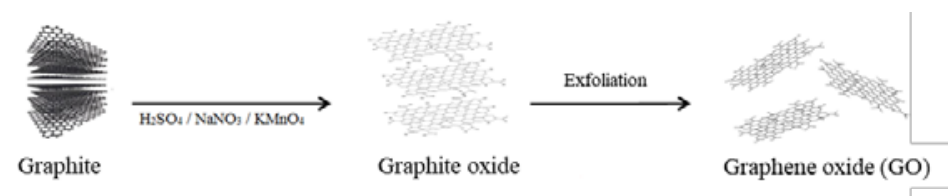

Figure 2.4. Graphene oxide (GO) obtaining sequence. Modified Hummers method

[3].

For this purpose, $2 \mathrm{~g}$ of powdered graphite and $1 \mathrm{~g}$ of sodium nitrate $\left(\mathrm{NaNO}_{3}\right)$ were mixed in $46 \mathrm{~mL}$ of concentrated sulphuric acid $\left(\mathrm{H}_{2} \mathrm{SO}_{4}\right)$. These compounds were mixed under continuous stirring in a vessel that was cooled to $0{ }^{\circ} \mathrm{C}$ into an ice bath as a safety measure. After $5 \mathrm{~min}, 6 \mathrm{~g}$ of potassium permanganate $\left(\mathrm{KMnO}_{4}\right)$ was added to the suspension. The addition rate was carefully controlled to prevent the temperature of the suspension from exceeding $20^{\circ} \mathrm{C}$. The ice bath was removed and the temperature of the suspension reached a value of $35 \pm 3^{\circ} \mathrm{C}$ for $30 \mathrm{~min}$. The solution obtained was diluted with $92 \mathrm{~mL}$ of distilled water in continuous stirring for $1 \mathrm{~h}$ and at a temperature of $35^{\circ} \mathrm{C}$. Next, $280 \mathrm{~mL}$ of distilled water was added slowly with stirring to the paste obtained, of a grey-brown colour, causing a violent effervescence and an increase in temperature up to $98^{\circ} \mathrm{C}$. After $30 \mathrm{~min}$, the solution was filtered and treated with a $30 \%$ aqueous solution of hydrogen peroxide $\left(\mathrm{H}_{2} \mathrm{O}_{2}\right)$ to reduce residual permanganate and manganese dioxide $\left(\mathrm{MnO}_{2}\right)$ to colourless and soluble manganese sulphate. After the treatment with the peroxide, the suspension turned bright yellow. This suspension was filtered resulting in a yellow/brown solid residue. Filtration was carried out while the suspension was still hot to prevent precipitation of the slightly soluble salt of methyl acid formed as a secondary reaction. Then, the resulting product was washed several times with $\mathrm{HCl}$ and then with ethanol until the $\mathrm{pH}$ reached the value 7. Finally, the graphene oxide (GO) powder was dispersed in distilled water for $3 \mathrm{~h}$ by sonication and subsequently, it was filtered and dried in a vacuum oven for $12 \mathrm{~h}$. The appearance of the GO obtained is shown in Figure 2.5.


Figure 2.5. Macroscopic and microscopic appearance of graphene oxide (GO). 


\subsubsection{Sulfonation of graphene oxide (GO)}

The sulfonated graphene oxide (SGO) was obtained from GO by addition of free radical using the aryl diazonium salt of the sulfanilic acid following the steps detailed below. $50 \mathrm{mg}$ of GO were added to $8 \mathrm{ml}$ of $0.06 \mathrm{M}$ sulfanilic acid solution at $70{ }^{\circ} \mathrm{C}$. Then, $2 \mathrm{ml}$ of $6 \cdot 10^{-3} \mathrm{M}$ sodium nitrite solution was added dropwise under continuous stirring, and the mixture was maintained at $70{ }^{\circ} \mathrm{C}$ for $12 \mathrm{~h}$. The diazonium salt of sulfanilic acid obtained in situ from the reaction of sulfanilic acid with sodium nitrite was converted to aryl radical by transfer of a delocalized GO electron. The aryl radical then reacted rapidly with the carbon atoms in the GO layers to form new covalent bonds, changing the hybridization of sp2 to sp3 [4]. The product was washed several times with distilled water and centrifuged until $\mathrm{pH}$ 7. Finally, the obtained SGO was filtered and dried in a vacuum oven for $12 \mathrm{~h}$. 


\subsection{PRocessing TECHNIQUES}

In this section, the standard conditions and features of the different equipment used for membrane processing and obtaining are described. Given the wide number of membrane processing operations, the specific details about the composition of the membranes and the precise processing conditions have been included in the corresponding contributions in Chapters 4, 5 and 6.

\subsubsection{Photo-stabilised polyolefins for outdoor applications}

\section{Polymer composite preparation and pelletization}

In the first step of the preparation of the composites, raw PP pellets, MAH$\mathrm{PP}$ pellets and $\mathrm{Si}$ microparticles were mixed, considering different compositions. The resulting specimens were labelled as described in Table 2.2.

Table 2.2. PP-(PP-MAH)-Si compositions.

\begin{tabular}{cccll}
\hline PP & PP-MAH & Si & \multirow{2}{*}{ ID } \\
\cline { 1 - 4 }$(\mathbf{\%}$ wt. $)$ & (\%wt.) & $\mathbf{( \% w t . )}$ & \\
\hline 100 & - & - & PP \\
\hline 97 & 3 & - & PP-MAH \\
\hline 94 & 3 & 3 & PP-MAH-3Si \\
\hline 92 & 3 & 5 & PP-MAH-5Si \\
\hline
\end{tabular}

Then, the composite preparation was carried out in a laboratory-scale corotating extruder at the ITM facilities in the UPV campus of Alcoy, shown in Figure 2.6. The extruder working conditions were $40 \mathrm{rpm}$ and a temperature program of $185-190-195^{\circ} \mathrm{C}$ from feeder to die. The extruded monofilament was then cooled into a water bath and finally pelletized into a Brabender Granulator.

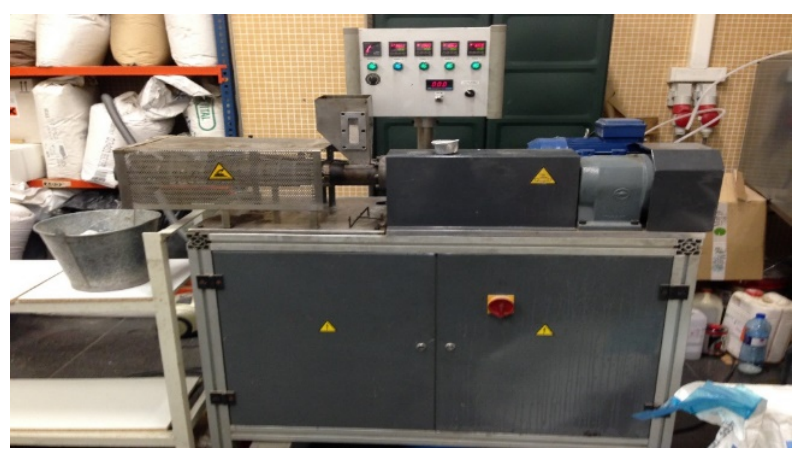

Figure 2.6. Laboratory-scale co-rotating extruder. 


\section{Compression moulding}

The compression moulding setup was used in this study to obtain PP/Si composite polymeric membranes with controlled thickness. For this purpose, a prototype four-axe hot plates press was used, equipped with heating and cooling systems in both upper and lower plates and accurate control of the temperature by means of two Selec PID528 controllers. The pressure was applied by means of a hydraulic pump under the lower plate, according to the setup shown in Figure 2.7.

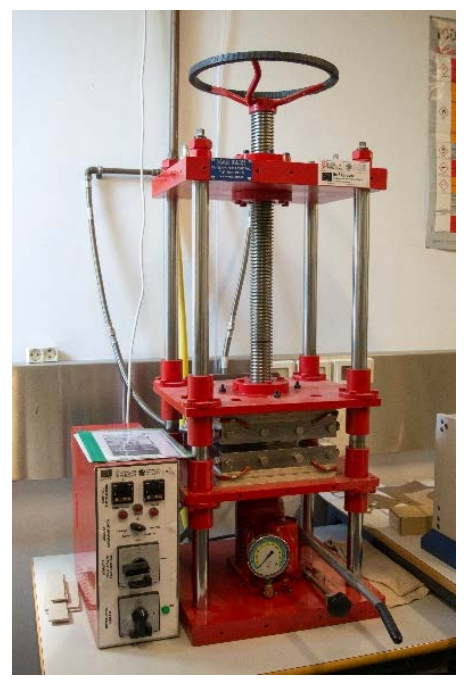

Figure 2.7. Four-axe hot plates press.

Composite membranes were prepared into $200 \mu \mathrm{m}$ thickness Teflon ${ }^{\circledR}$ moulds. The operation procedure usually consisted in a pre-heating of the press at the desired temperature, followed by the introduction of the mould assembly and the application of pressure for a given time. Once at $190{ }^{\circ} \mathrm{C}$, the following program was considered with a force $(\mathrm{kN})$ - time (min) relation of (i) $0-20$, (ii) $440-3$, (iii) $660-3$ and (iv) $880-4$. Afterwards, the plates were opened and the membranes were removed from the moulds and subjected to a quenching step to room temperature through water immersion. Then, the samples were dried under vacuum conditions at 40 ${ }^{\circ} \mathrm{C}$ for $24 \mathrm{~h}$ and stored for further analyses.

\subsubsection{Polyelectrolyte membranes for fuel cells}

\section{Electrospinning}

The electrospinning technique is an attractive approach for processing polymeric materials into fibres in the low micro and nanoscale range, being able to control the morphology, porosity and composition of the fibres by 
means of a relatively simple equipment. This process has gained much interest in over the past decade due to its versatility and simplicity. The electrospinning system permits to develop smaller pores and greater surface area than polymeric fibres obtained by means of other techniques, along with the ability to control the composition of the nanofibres to achieve tailored functionality and properties [5].

The electrospinning technique is based on the work developed on electrospraying in 1897 by Rayleigh, studied in detail by Zeleny in 1914 [6], patented by Formhals in 1934 [7], and boosted by the work of Taylor (1969) in aircraft electric propulsion [8]. The term electrospinning, derived from electrostatic yarn, is relatively recent, since it has been used from 1994 onwards. However, as introduced before, its origin goes back to more than 60 years ago. From 1934 to 1944, Formhals published a series of patents that describe an experimental set-up for the production of polymer strands using an electrostatic force. The first patent (USA, code: 2116942) in the electrospinning technique was issued for the manufacture of textile yarns and used a $57 \mathrm{kV}$ voltage to the electrospinning of cellulose acetate with acetone and ethylene glycol monomethyl ether as solvents. They also published other related patents (USA, codes: 2116942, 2160962, and 2187306) in 1938, 1939 and 1940. From that time until the present, there have been more than 50 patents for polymer electrospinning [9]. In addition, since 1952, various inventors like Vonnegut and Newbauber [10], Drozin [11], Simons [12] and Baumgarten [13] have developed many equipment with various applications, which have as a basis the electrospinning technique. Since 1980, especially in recent years, the electrospinning process has regained more attention due to an increase in the interest in the field of nanotechnology. The popularity of this technique is reflected in the immense number of publications and patents based on this technique published in the last decades.

The equipment of electrospinning is composed of three main components: a source of potential for high voltage, a spinner (metal needle) and a collector (conductor at the base). There are two typical setups -vertical and horizontal-. The vertical device allows placement of the syringe perpendicular to the collector, dropping the dissolution of polymer by gravity and placing the collector below. Sometimes, the jet can be tilted at a defined angle to control the flow rate. On the other hand, the horizontal device has a pump to start the flow of the dissolution. In general, in both cases, a pump is required to drive effectively the fluid. This process has a limited productivity since the dissolution of polymer has to be fed at rates relatively low to allow the evaporation of the solvent in the path of the needle to the collector and get nanofibres in a uniform manner. The overview of the process is shown in Figure 2.8. 




Figure 2.8. Electrospinning technique overview.

The process is based on the uniaxial elongation of a viscoelastic jet coming from a polymeric solution that has been previously introduced into a syringe. It involves the use of high voltage to induce the formation of liquid jet. Next, a solid continuous fibre is generated and stretches continuously due to the electrostatic repulsions between the surface charges and the evaporation of the solvent. Normally, the electrospinning technique is carried out at ambient temperature and humidity, although these parameters can also be controlled. Some solutions of polymer can emit corrosive or toxic vapours so that in such cases it is convenient to use a ventilation system.

In more detail, the performance of this technique consists in applying a high voltage between the tip of the needle and the collector, where the drop of polymer that hangs from the tip of the needle is highly electrified. The drop undergoes two main types of electrostatic forces: repulsion between surface and coulomb charges exercised by the external electric field. Due to the electric field-induced charge repulsion, a force directly opposite to the surface tension of polymer fluid is generated. As it increases the intensity of the electric field, the hemispherical surface of fluid or drop of liquid on the tip stretches and generates a conical shape, known as the Taylor cone. Once the strength of the electric field has exceeded its limit value, the electrostatic forces overcome the surface tension of the dissolution of the polymer and causes the liquid jet of fluid ejection from the tip. The jet is continuously submitted to a stretching and rotational trend that generates a long and thin fibre. As the jet is stretched and the solvent evaporates, its diameter can be reduced substantially. Finally, fibre is randomly deposited onto the collector.

The process of electrospinning is governed by different parameters, which include those of the polymer dissolution, process and environmental factors, as gathered in Table 2.4. The dissolution parameters mainly are the viscosity, the concentration, the conductivity, the molar mass of the 
polymer or the surface tension. As well, the process parameters are the applied electric field, the flow rate or the tip-to-collector distance. Finally, environmental parameters such as temperature or humidity may influence the electrospinning of a given solution [14], [15].

The goal of this technique is the obtaining of fibres with a uniform, consistent and controllable diameter, a surface free from defects and a fibre continuously collected. For this purpose, the electrospinning process must be optimised for a polymer-solvent pair to avoid, for instance, the formation of spherical particles as droplets or beads. The presence of spherical particles instead of fibres is due to the confluence of the several out-of-range parameters during electrospinning.

In the field of electrolytes for fuel cells, electrospun nanofibres are gaining attention in the last decade [16]. Nanofibres are not commonly used as a solely electrolyte due to their intrinsic high porosity which would allow the fuel crossover, but as part of composite polyelectrolyte membranes [17][20].

The development of nanofibres as polyelectrolyte membranes were performed in a compact lab-scale Bioinicia Fluidnatek ${ }^{\circledR}$ LE-10 assembled a high voltage source, a programmable syringe pump, a HSW Norm-Ject $20 \mathrm{~mL}$ Luer Lock syringe, Teflon ${ }^{\circledR}$ tubing, a gauge 21 metallic needle and a grounded flat collector, as shown in Figure 2.9.

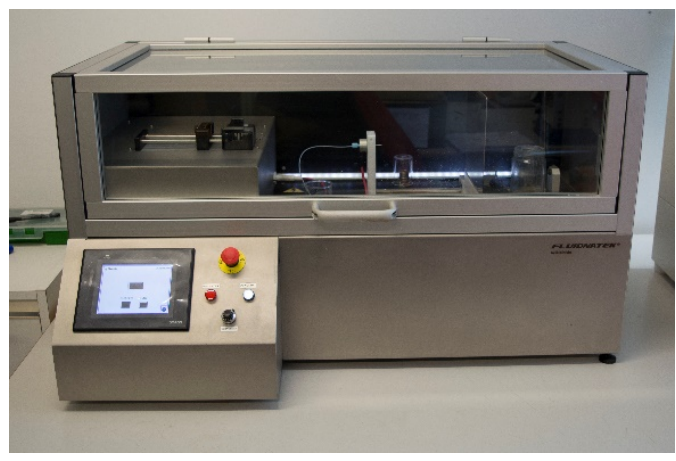

Figure 2.9. Bioinicia Fluidnatek ${ }^{\circledR}$ LE-10 electrospinning setup. 
Table 2.4. Effect of the parameters of electrospinning on the morphology of fibres.

\begin{tabular}{|c|c|c|}
\hline & Parameters & Effect on the morphology of fibres \\
\hline \multirow{7}{*}{ 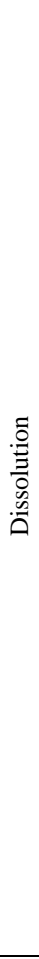 } & Viscosity & $\begin{array}{l}\text { The viscosity plays a decisive role in the morphology and size of polymer } \\
\text { fibres obtained by electrospinning. This parameter is subsequently influenced } \\
\text { by other parameters, as described below. Low viscosity would result in lower } \\
\text { entanglement capability and failure in the electrospinning process. However, } \\
\text { too high viscosity would difficult the drop formation and elongation. }\end{array}$ \\
\hline & Concentration & $\begin{array}{l}\text { A minimum concentration is required to prevent the emergence of spherical } \\
\text { particles in the nanofibres. Increasing viscous resistance increases the } \\
\text { diameter of the fibres. Concentration should be sufficiently high to have } \\
\text { enough polymer entanglements but not excessively high that prevent the flow } \\
\text { of polymer into the needle. }\end{array}$ \\
\hline & Molar mass & $\begin{array}{l}\text { The polymer molar mass significantly influences the electrical and } \\
\text { rheological properties of a polymeric solution. Normally, low molar mass } \\
\text { results in the formation of spherical particles. The molar mass of a polymer } \\
\text { reflects its entanglement capability and is highly correlated with the solution } \\
\text { viscosity for a given concentration. }\end{array}$ \\
\hline & $\begin{array}{l}\text { Electric } \\
\text { conductivity }\end{array}$ & $\begin{array}{l}\text { Enough electric conductivity allow the current path and thus favour the } \\
\text { formation of fibres. High solution conductivity is typically correlated with } \\
\text { fibres with small diameter. }\end{array}$ \\
\hline & $\begin{array}{l}\text { Surface } \\
\text { tension }\end{array}$ & $\begin{array}{l}\text { The decrease of the surface tension allows the formation of a clean jet. } \\
\text { Spherical particles may appear in the fibres electrospun from a high surface } \\
\text { tension solution. }\end{array}$ \\
\hline & Volatility & $\begin{array}{l}\text { Too high volatility would result in the fast evaporation of solvent and } \\
\text { clogging of the tip of the needle. As well, low volatility would produce the } \\
\text { coalescence of the nanofibres into a film. }\end{array}$ \\
\hline & $\begin{array}{l}\text { Dissolution } \\
\text { time }\end{array}$ & $\begin{array}{l}\text { Alternative solvents have been proposed for electrospinning with the aim of } \\
\text { reducing the exposure of technicians to toxic solvents. Some of them possess } \\
\text { an acidic nature that will promote changes in hydrolysable polymers such as } \\
\text { polyesters by means of hydrolytic degradation of ester bonds. Subsequently, } \\
\text { the physico-chemical properties and morphology of the electrospun fibres } \\
\text { will strongly depend on the dissolution time. }\end{array}$ \\
\hline \multirow{4}{*}{ 岕 } & Voltage & $\begin{array}{l}\text { The voltage should be high enough to ensure the jet stretching but not too } \\
\text { high, since it may produce the presence of spherical particles in the collector, } \\
\text { even turning into electrospray for extremely high voltages. }\end{array}$ \\
\hline & Flow rate & $\begin{array}{l}\text { The flow rate is closely related to the voltage for a suitable electrospinning. } \\
\text { The solution should be fed at a similar rate to that of solution consuming by } \\
\text { means of jet formation. Low flow rate would result in lower fibre diameter } \\
\text { and it may facilitate the evaporation of the solvent. High flow rate may } \\
\text { increase the fibre diameter and the appearance of macroscopic droplets in the } \\
\text { nanofibres. }\end{array}$ \\
\hline & $\begin{array}{l}\text { Tip-to- } \\
\text { collector } \\
\text { distance }\end{array}$ & $\begin{array}{l}\text { The effect of the tip-to-collector distance on the morphology of fibres is not } \\
\text { a determining factor. A minimum tip-to-collector distance is required for the } \\
\text { fibres to have evaporated the solvent before they reach the } \\
\text { collector. Increasing the distance decreases the probability of droplets } \\
\text { deposition in the collector, which would dissolve the obtained nanofibres. }\end{array}$ \\
\hline & Collector type & $\begin{array}{l}\text { A plate collector is commonly considered to obtain random ordered } \\
\text { nanofibres. However the orientation of the fibres can be controlled by means } \\
\text { of a rotating drum collector, among other setups. }\end{array}$ \\
\hline \multirow{2}{*}{ 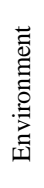 } & Temperature & $\begin{array}{l}\text { The temperature is closely related to the viscosity of a given solution. } \\
\text { Accordingly, the consequences of the variation of the solution viscosity } \\
\text { would be reflected in the obtained fibres. }\end{array}$ \\
\hline & Humidity & $\begin{array}{l}\text { High humidity lead to the formation of pores in the fibres. Too low humidity } \\
\text { would result in higher evaporation of volatile solvents that can produce the } \\
\text { blockage of the needle. }\end{array}$ \\
\hline
\end{tabular}




\section{Solvent casting}

The solvent casting technique was considered in this thesis to obtain filmshaped membranes following a simple and cost-effective procedure, for polyelectrolyte membrane development.

The polymeric solutions were firstly prepared, with an adequate concentration to get complete dissolution and suitable viscosity that allow avoiding the presence of bubbles during casting. Then, the solutions were casted into round-shaped Teflon ${ }^{\circledR}$ moulds with a $10 \mathrm{~cm}$ diameter. Afterwards, the solvent was allowed to evaporate at room temperature into a fume-hood. Finally, the membranes were removed from the moulds and stored for further analyses. Given the concentration and the casting volume, membranes with different thicknesses were prepared. The sequence followed for the solvent casting procedure is shown in Figure 2.10.

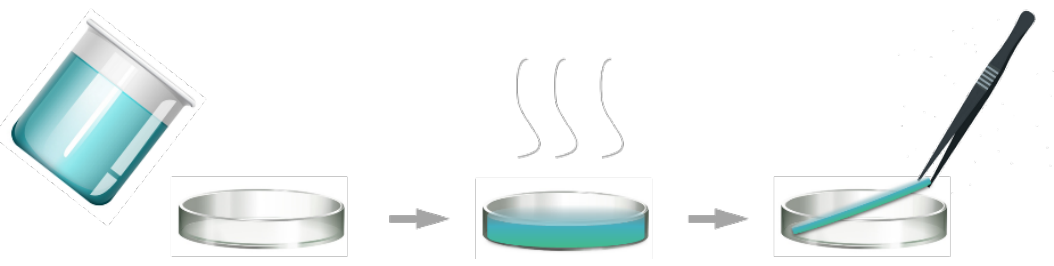

Figure 2.10. Solvent casting sequence overview.

\section{Thermal crosslinking}

The thermal crosslinking of the polyelectrolyte membranes for fuel cell applications was conducted in order to provide thermal and mechanical stability, as well as reducing the solubility of the membranes in contact with fuel during operation. The crosslinking procedure was carried out by means of two different methods, in order to investigate and choose the most effective method for obtaining crosslinked membranes.

On the one hand, the crosslinking was performed into a convection oven (Heraeus UT-6060). For this purpose, membranes were placed between two sheets of Teflon ${ }^{\circledR}$ reinforced with fibre-glass and, in turn, sandwiched between two metal discs to ensure a flat arrangement during crosslinking. Membranes were introduced into the oven at different temperatures between 110 and $130^{\circ} \mathrm{C}$ for $2 \mathrm{~h}$. 


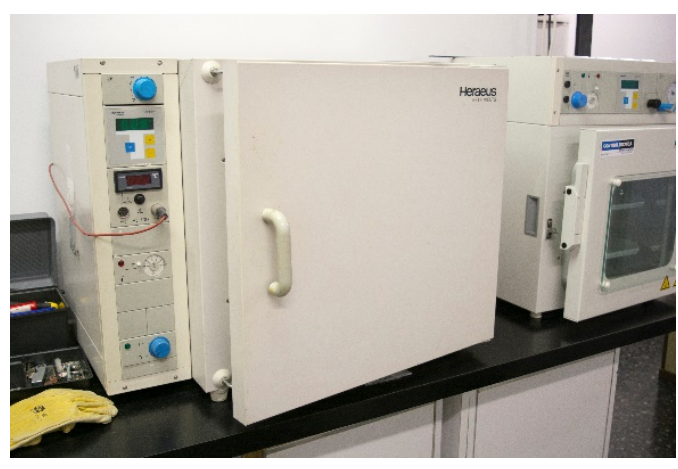

Figure 2.11. Heaeus UT-6060 oven.

On the other hand, the crosslinking was performed into a four-axe hydraulic hot plates press to obtain polymeric membranes with controlled thickness, according to the setup shown in Figure 2.11. The press was firstly pre-heated at $110{ }^{\circ} \mathrm{C}$. Afterwards, the membranes, placed into different thickness Teflon ${ }^{\circledR}$ moulds and covered by Teflon ${ }^{\circledR}$ reinforced with fibreglass film were introduced into the plates, guaranteeing contact but avoiding significant pressure. Once the crosslinking time had elapsed $(2 \mathrm{~h})$, the mould assembly was allowed to cool to room temperature. Finally, the samples were removed from the moulds, stored in zip plastic bags and saved into a desiccator at room temperature for further analyses.

\subsubsection{Scaffolds for tissue engineering}

\section{Electrospinning}

In the context of biomedical applications and tissue engineering field, more than 100 polymers have been satisfactorily electrospun and many interesting reviews may be found in the literature [5], [21]-[35]. The preparation of nanofibrous scaffolds for tissue engineering was carried out by means of three different electrospinning setups, as described below.

Firstly, a horizontal electrospinning prototype was used, in collaboration with the Department of Fiber and Polymer Technology of the KTH Royal Institute of Technology, shown in Figure 2.12. This prototype was composed of a Spellman SL80 high voltage supply, a Thermo Orion Sage ${ }^{\circledR}$ 361 programmable syringe pump, a Normax Ruthe $20 \mathrm{~mL}$ Luer Lock glass syringe, silicon tube, and a Luer-Lock gauge 21 metallic needle and a grounded flat collector. 


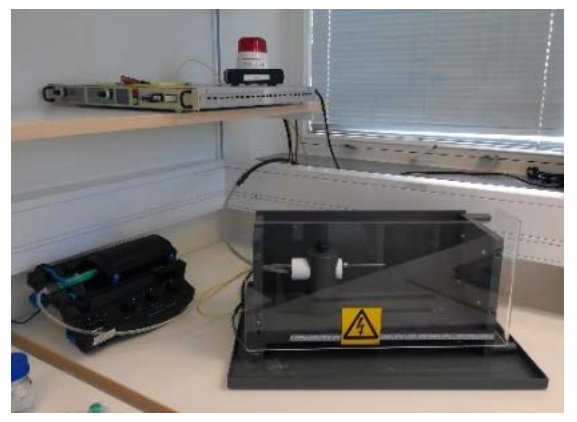

Figure 2.12. Lab-made horizontal electrospinning setup.

Then, the compact lab-scale Bioinicia Fluidnatek ${ }^{\circledR}$ LE-10 described in the previous section and shown in Figure 2.9 was used. Briefly, it assembled a high voltage source, a programmable syringe pump, a HSW Norm-Ject $20 \mathrm{~mL}$ Luer Lock syringe, Teflon ${ }^{\circledR}$ tubing, a gauge 21 metallic needle and a grounded flat collector.

Finally, the Yflow Electrospinner 2.2.D-350 was used, in collaboration with the AITEX Textile Research Institute. The equipment, shown in Figure 2.13 incorporated double polarisation, integrated drum collector, control panel and robotised stage to move the electrospinning source in an alternative fashion covering a $400 \times 400 \mathrm{~mm}^{2}$ area. The solution jet emerging from the stainless steel wire used as the positive electrode ( 0.9 mm inner diameter).

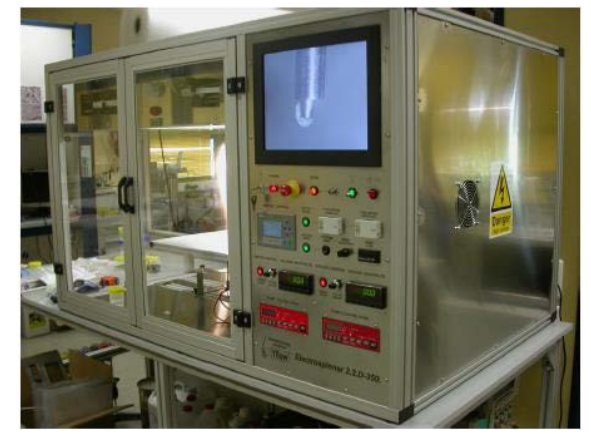

Figure 2.12. Yflow Electrospinner 2.2.D-350.

For all the electrospinning processes, the polymer solution was prepared, according both to literature and to previous results. After that, syringes were filled with the solution and placed into the pump. Then, the electrospinning parameters such as feeding rate, voltage and tip-tocollector distance were adjusted for each solvent-system. Electrospun fibres were mainly collected onto a flat surface covered with waxed paper. Then, the fibres were allowed to evaporate residual solvent at room temperature for $2 \mathrm{~h}$, prior to storing them into zip bags for further analyses. 


\subsection{ANALYTICAL TECHNIQUES AND CALCULATION METHODS}

The developed membranes were physico-chemically characterised by means of several analytical techniques and calculation methods, in order to evaluate their main features in terms of chemical structure, molar mass, surface morphology, thermal properties, thermo-oxidative stability, thermo-mechanical properties or dielectric properties. In this section, a brief technique description along with the general experimental conditions are reported. Specific experimental procedures are included in the corresponding contributions in Chapters 4, 5 and 6.

\subsubsection{Chemical structure. Fourier-transform infrared spectroscopy (FT-IR)}

The Fourier-transformed infrared spectroscopy (FT-IR) provides information about the chemical structure and allows identification and quantification of functional groups in polymeric materials. This technique is based on the analysis of the vibrations of the atoms of a molecule.

The molecular structure of a given substance is assessed by means of the interaction between the electromagnetic radiation and the sample. As the radiation is absorbed, net charge changes occur in the rotational and vibrational levels of the molecules. When a molecule shows infrared absorption, the vibration or rotation movements cause a net change in its electric dipole moment. Therefore, the interaction between the infrared radiation and the molecules is closely related to the changes in the molecular dipoles.

Vibrations can cause changes in the length of the link (stretching) or in the angle (bending) as well as can occur in-phase (symmetrically) or out-ofphase (asymmetrically). The equipment collects the resulting signal known as interferogram and provides information on the amount of energy absorbed by the sample. The interferogram must be converted to the domain of the frequencies by the Fourier transform method to provide information on the identification and quantification of substances and functional groups.

There are several technical accessories to allow the measurement of different geometries and shapes of the samples. One of the most used technical aids is the attenuated total reflection (ATR) mode, in which solid samples can be easily analysed. In the ATR setup, a crystal is used, to which the infrared beam is directed. The change in the refractive index at the crystal surface causes the beam to be back-reflected several times 
before if finally exits to the detector. When the sample is in contact with the crystal, the beam interacts with the surface of the sample, allowing a fast a simple analysis of solid specimens.

The FT-IR analysis was performed by means of a Thermo Nicolet 5700 spectrometer, shown in Figure 2.14. In this case, the equipment was coupled with the specific module for the measurement of solid samples in the ATR setup with diamond crystal. The IR spectrum was taken between the wavelengths of $4000 \mathrm{~cm}^{-1}$ and $400 \mathrm{~cm}^{-1}$ with a resolution of $4 \mathrm{~cm}^{-1}$ over 64 scans. A background was performed before the analysis of the samples. The effect of water and atmospheric $\mathrm{CO}_{2}$ was corrected and subtracted from the spectra. Further corrections such as baselines, refractive indexes and incident angles were also applied. Infrared analysis was performed with the aid of the Omnic Software. At least 5 spectrums were obtained from different points of the same sample and the average spectra were taken as representative.

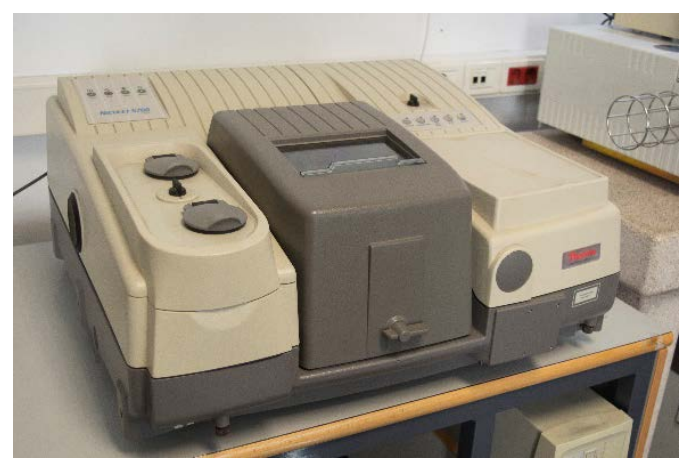

Figure 2.14. Thermo Nicolet 5700 FT-IR.

\subsubsection{Molar mass. Size exclusion chromatography (SEC)}

The size exclusion chromatography (SEC), also known as gel permeation chromatography (GPC), was considered to evaluate the molar mass of the polymeric materials. This technique is based on the separation of polymeric molecules according to their hydrodynamic radius $(R h)$ or volume $(V h)$. The separation process takes place into one or more columns which are packed with porous particles. Because of their size, the larger molecules are excluded from some of the pores in the packing material and therefore elute faster through the column than the smaller ones. Thus, the molecules are separated by size, with the largest eluting first and the smallest last.

The results obtained by SEC usually consists in the molar mass distribution $(M W D)$. However, depending on the type and number of detectors used in the experiment, various types of calibrations and calculations are employed to compute parameters such as average molar mass in weight or number 
$(M w, M n)$, intrinsic viscosity $(I V)$, hydrodynamic radius $(R h)$ and radius of gyration $(R g)$.

The size exclusion chromatography was carried out by means of a Malvern Instrument Omnisec Resolve chromatograph, as shown in Figure 2.15. It combined an integrated pump, a degasser, an autosampler and a column oven, along with a Malvern Instruments Omnisec Reveal multi-detector Ultraviolet (UV), Refractive Index (RI), Low and Right Angle Light Scattering (LALS and RALS) and Viscosity (VISC)-. A monodisperse polystyrene standard with dn/dc value of 0.185 was used for previous calibration. Two columns from Malvern Instruments (T2000 and T4000) were used $(300 \times 8 \mathrm{~mm})$. Tetrahydrofuran $(\mathrm{THF})$ was used as mobile phase at a flow rate of $1 \mathrm{~mL} \cdot \mathrm{min}^{-1}$ and a column temperature of $35{ }^{\circ} \mathrm{C}$. The samples were dissolved in THF with concentrations of around $2.0 \mathrm{mg} \cdot \mathrm{mL}^{-}$ ${ }^{1}$ and filtered through $0.45 \mu \mathrm{m}$ PTFE filters. Two injections per sample were performed and the obtained data was analysed with the aid of the Omnisec V10 ${ }^{\mathrm{TM}}$ software.

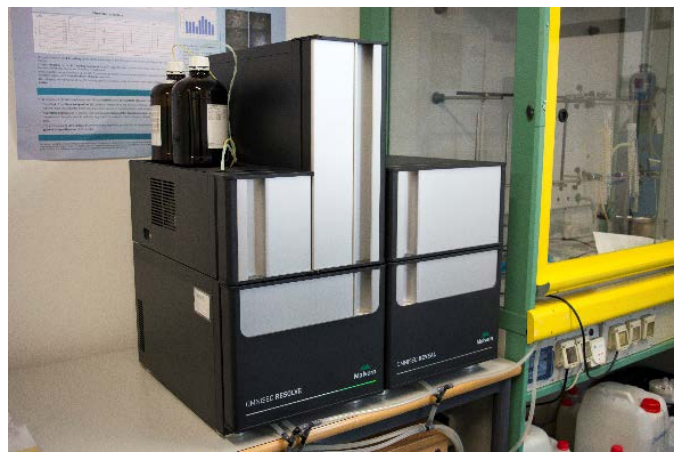

Figure 2.15. Malvern Instruments Omnisec.

\subsubsection{Surface morphology. Field emission scanning electron microscopy (FE-SEM)}

The field emission scanning electron microscopy (FE-SEM) provides topographical and elemental information of the surface of a given specimen. Electrons are liberated from a field emission source and accelerated in a high electrical field gradient. Within the high vacuum column, these so-called primary electrons are focused and deflected by electronic lenses to produce a narrow scan beam that bombards the sample. As a result, secondary electrons are emitted from each spot on the specimen. The angle and velocity of these secondary electrons relates to the surface structure of the object. A detector catches the secondary electrons and produces an electronic signal. This signal is amplified and transformed to a video scan-image that can be seen on a monitor or to a 
digital image that can be saved and processed. In this technique, there is no need to refocus the signal-carrying particles generated in the specimen. This makes it possible to examine rough, solid specimens with minimum of specimen preparation.

The surface topology of the specimens was analysed by means of a Zeiss Ultra 55 field emission scanning electron microscope (FE-SEM), as shown in Figure 2.16. The samples were cut into small pieces and dried at $50{ }^{\circ} \mathrm{C}$ in a vacuum oven for $24 \mathrm{~h}$ and then kept in a desiccator during $48 \mathrm{~h}$. Afterwards, the specimens were mounted on metal studs and sputter-coated with a platinum layer during 15 s using a Leica EM MED020 sputtering equipment represented in Figure 2.16. In general, testing was performed at room temperature at low voltages to preserve the sample structure (1-2 $\mathrm{kV}$ ). For the fibrous samples, the fibre diameters were measured from the FE-SEM micrographs at random locations $(n=100)$ with the aid of the Image J software.


Figure 2.16. Zeiss Ultra 55 FE-SEM and Leica EM MED020 sputter-coater.

\subsubsection{Thermal properties. Differential scanning calorimetry (DSC)}

The evaluation of the thermal properties by means of differential scanning calorimetry (DSC) consists in subjecting the sample to a controlled temperature program and measuring the energy differences absorbed or released by the sample with respect to a reference capsule.

Polymeric materials are susceptible to undergo changes that involve both first-order and second-order transitions. The former corresponds to transformations between a vitreous and an amorphous state (the glass transition), or to transitions involving crystalline order (processes of fusion, crystallisation, crystal-crystal transitions). When these transitions appear, energy is absorbed or released as heat.

Typical results from DSC experiments display the heat flow as a function of the temperature or time, which denote the thermal transitions as base- 
line changes or peaks. Particularly, the use of this technique in thermoplastic polymers allows the observation of the glass transition, the melting and the crystallisation. As well, the characteristic enthalpies and temperatures can be obtained from the resulting thermograms.

Calorimetric data were obtained by means of a Mettler-Toledo DSC 820 series, shown in Figure 2.17, equipped with a Haake EK 90/MT cooling system. Prior to the analysis, the DSC equipment was calibrated following the procedure of Indium and Zinc. The samples, with a mass of about $4 \mathrm{mg}$ were placed into aluminium crucibles perforated on top, with capacity of $40 \mu \mathrm{L}$. In general, the evaluation of the thermal properties was assessed over heating/cooling segments, held at $10^{\circ} \mathrm{C} \cdot \mathrm{min}^{-1}$, between 0 and $200{ }^{\circ} \mathrm{C}$. All experiments were performed using under $\mathrm{N}_{2}$ as protective gas (50 $\left.\mathrm{mL} \cdot \mathrm{min}^{-1}\right)$. The DSC analyses were performed with the aid of the software $\mathrm{STAR}^{\mathrm{e}} 9.10$ from Mettler-Toledo. The specimens were characterised in triplicates and the averages of temperatures and enthalpies were taken as representative values.

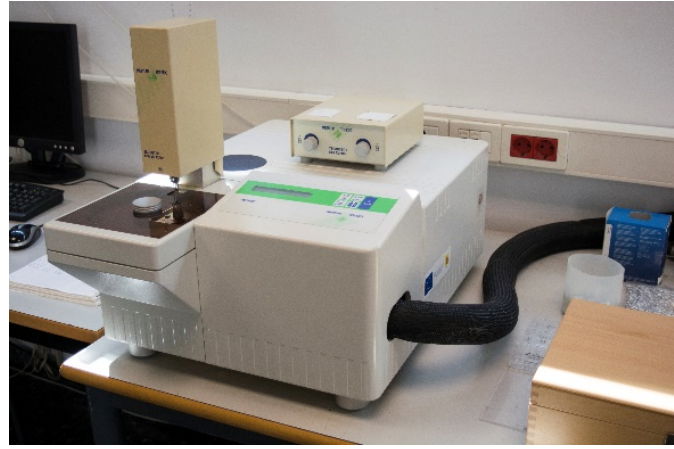

Figure 2.17. Mettler-Toledo DSC 820 series.

In semicrystalline samples, the crystallinity degree $\left(X_{c}\right)$ was evaluated from the polymer melting enthalpy results, by using Equation 2.1,

$$
X_{c}(\%)=\frac{1}{w_{p}} \cdot \frac{\Delta h_{m}}{\Delta h_{m}^{0}}
$$

Where $w_{p}$ is the weight percentage of the polymer in the sample, $\Delta h_{m}$ is the experimental melting enthalpy of the polymer and $\Delta h_{m 0}$ is the melting enthalpy of a perfect crystal of this material.

As well, with the purpose of deeply characterise the crystalline structure of the nanofibres, lamellar thickness distributions were calculated by applying the Thomson-Gibbs equation (Equation 2.2), based on the temperatures associated to the melting transitions [36]-[38],

$$
l_{C}\left(T_{m}\right)=\left[\left(1-\frac{T_{m}}{T_{m}^{0}}\right) \cdot \frac{\Delta h_{m V}}{2 \cdot \sigma_{e}}\right]^{-1}
$$


where $T_{m}$ is the melting temperature; $T_{m}{ }^{0}$ is the equilibrium melting temperature of an infinite crystal; $\sigma_{e}$ is the surface free energy of the basal plane where the chains fold; and $\Delta h_{m V}$ is the melting enthalpy per volume unit.

\subsubsection{Thermal and thermo-oxidative stability. Thermogravimetric analysis (TGA)}

The thermogravimetric analysis (TGA) is a thermal analysis technique based on the study of the thermal and thermo-oxidative stability and the evaluation of the fraction of volatile components in a sample by monitoring the change in mass when subjected to a temperature program. Accordingly, the control of the weight of the sample and the temperatures is essential in this technique. By means of the thermogravimetric curves, it is possible to study the thermal decomposition of polymers, the decomposition rate, the order of reaction, the activation energy and the determination of additives and fillers in complex formulations.

The TGA measurements can be performed in either inert (argon or nitrogen) or oxidant atmosphere (air or oxygen). The output data are collected as changes in the mass as a function of increasing temperature (dynamic experiments) or time (isothermal experiments). Typical thermogravimetric thermograms correspond to sigmoidal curves with one or more steps, depending on the chemical nature of the components and the composition of the sample. The remaining mass at the end of the experiment is assigned to the residue or non-degraded material. The thermogravimetric analysis can also be presented as differential curve (DTG), that corresponds to the first derivate of the thermogravimetric curve. The maximum slope drops of the thermogravimetric curve correspond to peaks in the DTG curve.

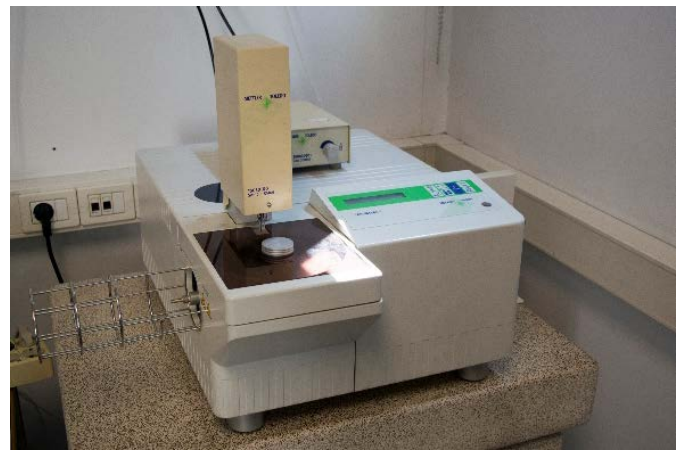

Figure 2.18. Mettler-Toledo TGA 851 series. 
The thermal and thermo-oxidative stability was assessed by means of a Mettler-Toledo TGA 851 series, shown in Figure 2.18. The samples, with a mass of about $4 \mathrm{mg}$ were introduced into TGA Mettler-Toledo perforated alumina crucibles, with capacity of $70 \mu \mathrm{L}$. In general, the specimens were analysed through a dynamic procedure, with a heating rate of $10^{\circ} \mathrm{C} \cdot \mathrm{min}^{-1}$ in the temperature range of 25 to $800^{\circ} \mathrm{C}$, either under oxidative atmosphere of $\mathrm{O}_{2}$ at $50 \mathrm{~mL} \cdot \mathrm{min}^{-1}$ or inert atmosphere of $\mathrm{Ar}$ at $50 \mathrm{~mL} \cdot \mathrm{min}^{-1}$. The TGA analyses were performed with the aid of the software $\mathrm{STAR}^{\mathrm{e}} 9.10$ from Mettler-Toledo. The specimens were characterised in triplicates and the averages of temperatures and enthalpies were taken as representative values.

\subsubsection{Thermo-mechanical properties. Dynamic-mechanic- thermal analysis (DMTA)}

The dynamic thermo-mechanical analysis (DMTA) is a technique used to study and characterise the viscoelastic behaviour of polymers. This technique is based in the imposition of a small continuous cyclic deformation on the sample. Due to the viscoelastic nature of certain materials, if the frequency of the strain that produces the deformation is very high or the temperature is low, the molecular chains do not have enough time to relax and therefore a phase difference is created between the load applied to the material $\sigma(t)$ and the deformation that occurs in it $\varepsilon(t)$. This technique allows measuring that phase difference. The measurements are made as a function of temperature at a fixed deformation frequency or as a function of the deformation frequency, keeping the temperature constant. Accordingly, the changes that occur at the molecular level can be detected. As a result, the storage $\left(E^{\prime}\right)$, the loss modulus $\left(E^{\prime \prime}\right)$ correlated to the elastic and viscous contributions are obtained. As well, the phase angle $(\delta)$, correlated to the proportion between the energy dissipated, in the form of heat, and the energy stored per cycle is acquired.

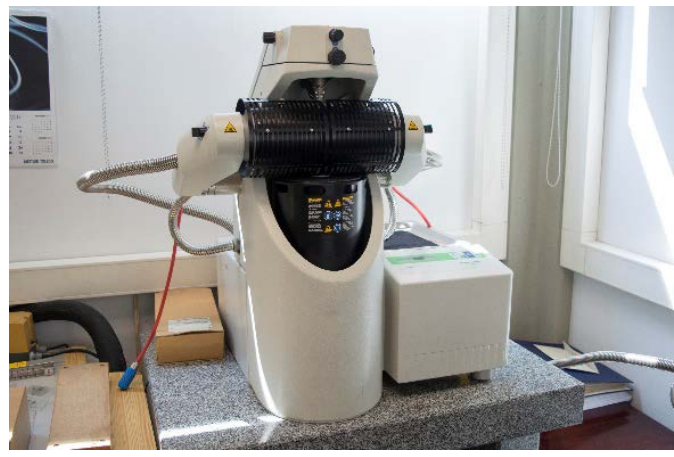

Figure 2.19. Mettler-Toledo DMA861e equipment. 
The dynamic mechanic thermal analyses were conducted in a small clamping assembly in the tension mode, with $5 \mathrm{~mm}$ of effective length between clamps, by means of the Mettler-Toledo DMA861e equipment, shown in Figure 2.19. The displacement was checked before all the experiments. In general, the deformation force was set at $0.1 \mathrm{~N}$. Experiments at $1 \mathrm{~Hz}$ were carried out during heating from 35 to $130{ }^{\circ} \mathrm{C}$ with isothermal steps of $1{ }^{\circ} \mathrm{C}$. The DMTA analyses were performed with the aid of the software STAR ${ }^{\text {e }} 9.10$ from Mettler-Toledo. Analyses were performed at least three times per sample to ensure reproducibility.

\subsubsection{Dielectric properties. Dielectric-thermal analysis (DETA)}

The dielectric properties were assessed by means of electrochemical impedance spectroscopy measurements (EIS). The evaluation of the dielectric properties by means of EIS is an efficient, non-intrusive technique based on the study of the response of a circuit to an alternating current as a function of frequency [39]. The voltage and current response is analysed by a frequency response analyser to determine the resistive capacitive and inductive behaviour and the impedance of the sample at a particular frequency. The proton conductivity and the electrical conductivity can be assessed by this technique.

According to Ohm's law, shown in Equation 2.3, the electrical resistance $(R)$ in direct current circuits (DC) can be defined as the ratio of voltage $(E)$ to current $(I)$ and gives information about the opposition to the flow of electric current through the conductor.

$$
R=\frac{E}{I}
$$

(Equation 2.3)

In the alternating current circuits (AC), the current often exhibits a more complex behaviour, in which besides the standard resistance, the are two complementary mechanisms that prevent the current flow through the circuit. On the one hand, the inductance $(L)$ represents the voltages induction in the conductor, that is self-induced by the magnetic fields of the current. On the other hand, the capacitance $(C)$ represents the electrostatic charge storage induced by voltage between conductors. The inductance and capacitance are together called the reactance $(X)$. Altogether, the concept of resistance has been defined as impedance $(Z)$ in the AC circuits. The impedance possess both magnitude and phase angle and is usually represented as a complex number, in which the real part of impedance is correlated with the resistance and the imaginary part is correlated with the reactance [39]. 
The magnitude of the impedance $|Z|$ can be expressed in terms of real and imaginary components, as shown in Equation 2.4,

$$
|Z|=\sqrt{Z_{r}^{2}+Z_{j}^{2}}
$$

and the phase angle $(\theta)$ can be obtained by means of Equation 2.5,

$$
\theta=\tan ^{-1} \frac{Z_{j}}{Z_{r}}
$$

Nyquist plot and Bode plots are commonly used to represent the impedance measurements. In the Nyquist plot, the real part of the impedance is represented in the $x$-axis and the imaginary part of the impedance is represented in the $y$-axis and each point in the Nyquist plot corresponds to impedance at one frequency. One major limitation in the Nyquist plot is that the frequency cannot be ascertained by simply looking at the plot. This limitation has been overcome in the Bode plot, where the impedance is plotted with the logarithmic frequency on the $x$-axis and both the absolute value of impedance and the phase angle are plotted on the $y$-axis.

The impedance measurements were conducted using a Novocontrol Broadband Dielectric Impedance Spectrometer, in the frequency range of $10^{-2}$ to $10^{7} \mathrm{~Hz}$, connected to a Novocontrol Alpha-A Frecuency Response Analyzer, shown in the Figure 2.20. The polymer films were cut into small disks of $20 \mathrm{~mm}$ diameter and were previously equilibrated with distilled water for $24 \mathrm{~h}$ to ensure fully hydrated state. Then, the membranes were sandwiched between two stainless steel electrodes BDS-1308 (Novocontrol).

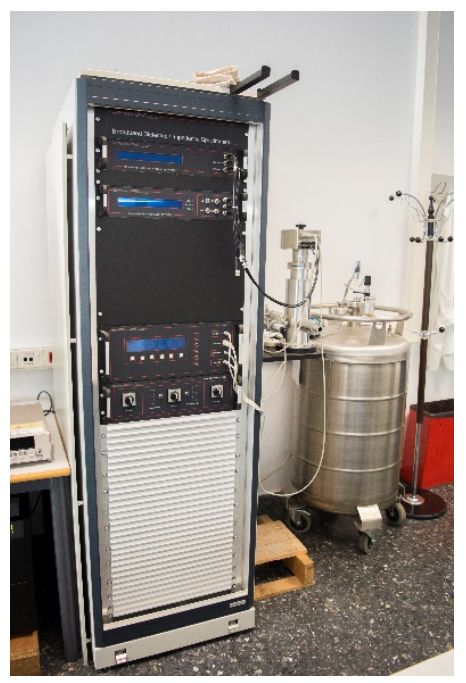

Figure 2.20. Novocontrol Broadband Dielectric Impedance Spectrometer. 
The proton conductivity ( $\left.\sigma_{\text {prot }}\right)$ of the membranes was calculated according to the Equation 2.6.

$$
\sigma_{\text {prot }}=\frac{L}{A \cdot R_{o}}
$$

where $L$ is the thickness of the conducting membranes in $\mathrm{cm}, A$ the area of the electrode in contact with the membrane in $\mathrm{cm}^{2}$, and $R_{0}$ the protonic resistance in ohms $(\Omega)$. The value of $R_{o}$ is taken from the Bode plot in the high frequencies range, in which the value of $\log |Z|$ becomes constant and the phase angle reaches its maximum value [40].

The electric conductivity $\left(\sigma_{\text {elec }}\right)$ was measured at room temperature using the same equipment. The electric conductivity $\left(\sigma_{\text {elec }}\right.$ ) was considered at low frequencies, where the measured real part of the conductivity $\left(\sigma^{\prime}\right)$ reaches a plateau that is correlated to the DC conductivity $\left(\sigma_{0}\right)$. 


\subsection{VALIDATION OF PHOTO-STABILISED POLYOLEFINS FOR OUTDOOR APPLICATIONS}

\subsubsection{Accelerated sunlight irradiation procedure}

The evaluation of the resistance of materials to weathering can be performed directly by exposing them to outdoor conditions and interaction with natural sunlight and other environmental factors. However, due to the high time-consuming and economic reasons, the material performance is usually assessed by exposure to artificial or simulated sources. In this sense, the accelerated exposure to simulated sunlight irradiation can be performed using xenon lamps as light sources.

In this study, the accelerated sunlight irradiation procedure was carried out by exposing the samples to controlled cycles of intense light into an Atlas Suntest XLS+ Xenon Exposure equipment, shown in Figure 2.21, with black panel temperature of $50{ }^{\circ} \mathrm{C}$ and irradiance of $600 \mathrm{~J} \cdot \mathrm{s}^{-1} \cdot \mathrm{m}^{-2}$ in the UVvisible range wavelength $(\lambda=280-800 \mathrm{~nm})$.

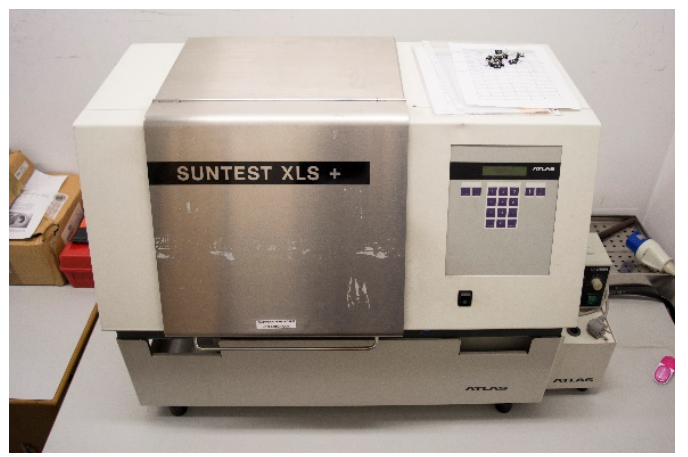

Figure 2.21. Atlas Suntest XLS+ Xenon Exposure equipment.

Several irradiation stages were considered at 250, 750, 1500, 2250 and 3000 h. Even though such testing cannot reproduce all the elements of weathering and exactly predict the performance of these samples in a real outdoor exposure, some meaningful relative comparisons can be done. As a reference, the data at Jacksonville, Florida (USA), with an annual total radiant energy of $5800 \mathrm{MJ} \cdot \mathrm{m}^{-2}(\lambda=280-3000 \mathrm{~nm})$ were considered. According to bibliography [41], this total radiation in the UV-visible range $(\lambda=280-800 \mathrm{~nm})$ would correspond to $3248 \mathrm{MJ} \cdot \mathrm{m}^{-2}$. Thus, the equivalence of $1 \mathrm{~h}$ of simulated irradiation would be equivalent to $5.83 \mathrm{~h}$ of real 
exposure in Jacksonville, Florida. Table 2.5 shows the equivalence for the different stages of irradiation.

Table 2.5. Approximated real exposure time for Jacksonville, Florida (USA) of the considered irradiation stages in the UV-visible wavelength range.

\begin{tabular}{cc}
\hline $\begin{array}{c}\text { Simulated exposure } \\
\text { time } \\
\text { (hours) }\end{array}$ & $\begin{array}{c}\text { Approximated real } \\
\text { exposure time } \\
\text { (months) }\end{array}$ \\
\hline 250 & 2.02 \\
\hline 750 & 6.07 \\
\hline 1500 & 12.14 \\
\hline 2250 & 18.21 \\
\hline 3000 & 24.27 \\
\hline
\end{tabular}




\subsection{VALIDATION OF POLYELECTROLYTE MEMBRANES FOR FUEL CELLS}

The validation of the polyelectrolytes for fuel cell applications can be implemented in terms of solution uptake ability and stability under simulated service conditions. These analyses along with the physicochemical characterisation described in section 2.4 in terms of the thermalstability or the proton conductivity, may define the suitability of these membranes as polymer electrolytes for fuel cell applications. In this section, the description of the experimental procedure considered for the polyelectrolyte validation is reported.

\subsubsection{Ethanol permeability}

The ethanol permeability of the membranes was evaluated by means of a glass diffusion cell with two reservoirs, each of 1 L capacity, as shown in Figure 2.22. Membranes were sandwiched between the two modules that contained deionised water and $2 \mathrm{M}$ ethanol solution, respectively. Permeability was indirectly measured from conductivity variation of both solutions. The signals were processed with the LabView software as a function of time. Measurements were carried out under magnetic stirring and thermostatically controlled at $40^{\circ} \mathrm{C}$.

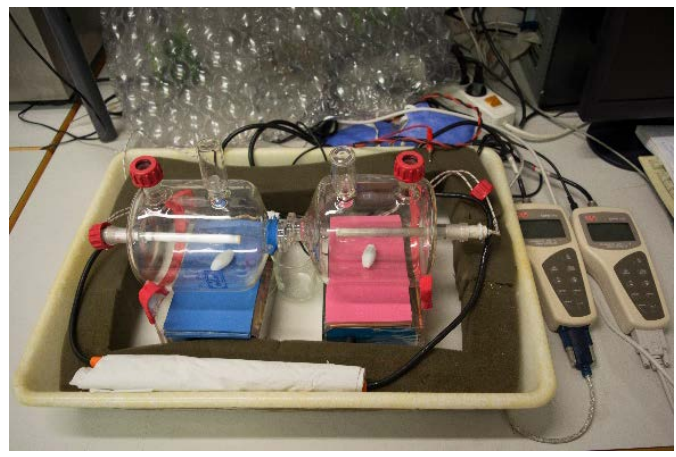

Figure 2.22. Ethanol permeability measure setup.

\subsubsection{Swelling and solution uptake}

The study of the membrane swelling and the solution uptake was performed in the polyelectrolyte membranes, as it may give valuable information about the membrane hydration ability in contact with the fuel. This solution uptake is closely related to the proton conductivity and 
subsequently influences the Grotthuss and vehicular conductive mechanisms [42], [43].

A typical swelling test consists in submerging the polymer sample into a given solution and studying the solvent absorption as a function of the time. The absorption of the solvent into the polymer is monitored gravimetrically by the mass difference between the exposed samples $\left(m_{t}\right)$ and the dry sample $\left(m_{0}\right)$, and normalized respect to the dry sample, as shown in Equation 2.7.

$$
m_{s}(\%)=\frac{m_{t}-m_{0}}{m_{0}} \times 100
$$

In this study, the samples were cut in a rectangular shape $\left(4 \times 1 \mathrm{~cm}^{2}\right)$ and dried at $40{ }^{\circ} \mathrm{C}$ under vacuum for $24 \mathrm{~h}$ prior to the analysis to remove remnant humidity into a Heraeus Vacutherm 6025, shown in Figure 2.23. Then, the samples were immersed in test tubes containing $20 \mathrm{~mL}$ of solution and kept into Selecta Unitronic isothermal baths at $60{ }^{\circ} \mathrm{C}$. The samples were periodically removed from the liquid, the surface dried with a tissue, and quickly weighed on a Mettler Toledo XS105 precision balance. Then the samples were re-immersed in the liquid and the process was repeated over different time intervals. The solution uptake was measured gravimetrically until saturation $\left(m_{s}\right)$, when no further gain weight was perceived. The setup for the swelling and solution uptake measurements is shown in Figure 2.23.
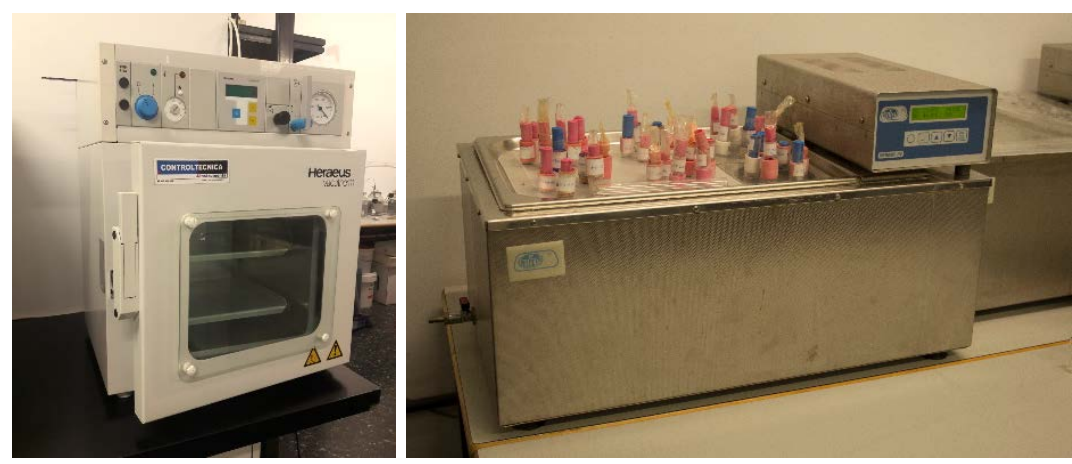

Figure 2.23. Heraeus Vacutherm 6025 (left) and isothermal Selecta Unitronic bath (right).

\subsubsection{Behaviour under simulated service conditions}

The evaluation of the stability of the membrane during service conditions is essential for a satisfactory application as polyelectrolyte. For this reason, the physico-chemical changes occurred in the polyelectrolytes when submitted to simulated service conditions were assessed as a function of the immersion time. For this assay, the setup utilised for the study of 
swelling and solution uptake was extended, and long-term extractions were considered.

As in the swelling conditions described above, the temperature was set at $60{ }^{\circ} \mathrm{C}$ and the aqueous solution was replaced after each interval to preserve it fresh. The samples were removed after 7, 14, 28, 56 and 100 days, and dried under vacuum at $30{ }^{\circ} \mathrm{C}$ for $48 \mathrm{~h}$. The changes after immersion were characterised in terms of the variation of the macro and microscopic appearance, the thermal properties and the thermo-oxidative stability. As well, the proton conductivity was measured after immersion.

\subsubsection{Direct ethanol fuel cell (DEFC) test}

The direct ethanol fuel cell (DEFC) performance tests of the membranes were conducted with a single cell F-107 from H-TEC with diffusing layers. The membranes were previously equilibrated with a $2 \mathrm{M}$ ethanol solution during $24 \mathrm{~h}$ to ensure their fully hydrated state, and were sandwiched between two electrode catalysts sheets of platinum (Pt). The active area of the single cell was approximately $4 \times 4 \mathrm{~cm}^{2}$. The gas flow rates of the $2 \mathrm{M}$ ethanol solution as fuel and oxidant humid air stream were kept constant at $0.250 \mathrm{~L} \cdot \mathrm{min}^{-1}$ and $1.6 \mathrm{~L} \cdot \mathrm{min}^{-1}$, respectively. 


\subsection{VALIDATION OF SCAFFOLDS FOR TISSUE ENGINEERING}

The validation of the scaffolds for biomedical applications can be evaluated from several perspectives. These include the analyses of diverse functional features such as the interaction of the scaffolds within aqueous solutions in terms of hydrophilicity, the biocompatibility evaluation when in contact with cells and living tissues, the electric conductivity that may stimulate the cell spreading, as well as the in vitro degradation behaviour when submitted to physiologic conditions. In this section, the description of the experimental procedure considered in this thesis for the scaffold validation is reported.

\subsubsection{Hydrophilicity. Contact angle}

The contact angle is one of the most common methods to evaluate the wettability of a given surface. The contact angle $(\theta)$ is defined as the angle formed by the intersection of the liquid-solid interface and the liquidvapour interface and is geometrically acquired by applying a tangent line from the contact point along the liquid-vapour interface in the droplet profile, as shown in Figure 2.24.
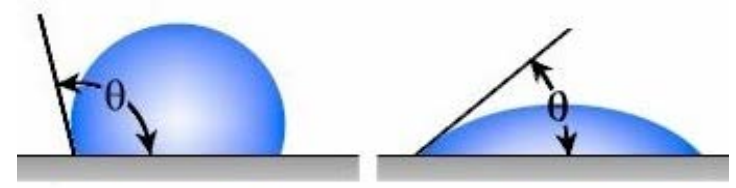

Figure 2.24. Contact angle measurement for hydrophobic (left) and hydrophilic (right) surfaces.

When water is used as the liquid to be deposited onto a solid surface, the hydrophilicity can be evaluated. On the one hand, high values of water contact angle $\left(>90^{\circ}\right)$ suggest weak water-solid interactions, so that the fluid will minimise its contact with the surface and form a compact liquid droplet, i. e. hydrophobic behaviour. On the other hand, low values of water contact angle $\left(<90^{\circ}\right)$ point out a strong water-solid interaction, i. e. hydrophilicity. In this case, the fluid tends to spread over a large area of the surface. A zero contact angle indicates complete or perfect wetting.

The water wettability measurements of the membranes were performed in collaboration of the Institute of Polymer Science and Technology (ICTPCSIC). The analysis were performed at room temperature using a KSV Theta Optical Tensiometer, equipped with a CCD camera connected to a 
computer, as shown in Figure 2.25. A drop of distilled water $(2 \mu \mathrm{L})$ was deposited onto the sample surface at five different sites and the average of measured values was taken as a representative value.

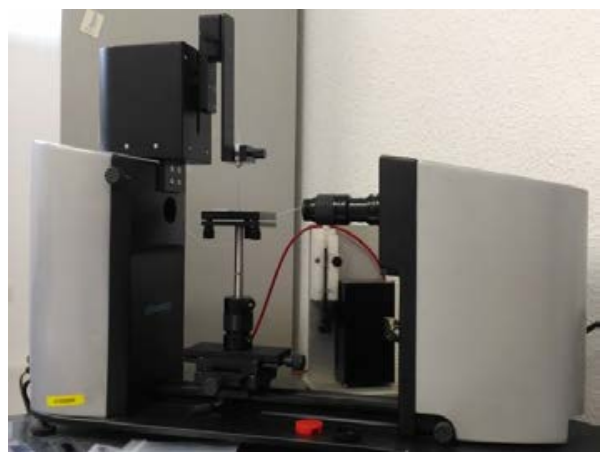

Figure 2.25. KSV Theta Optical Tensiometer, equipped with a CCD camera.

\subsubsection{Biocompatibility}

The biocompatibility studies were conducted in collaboration with the Cardiac Regeneration and Transplantation Group (RETRACAR) of the Sanitary Investigation Institute La Fe (IIS La Fe).

The scaffold biocompatibility was studied in terms of the cellular adhesion, the cells morphology and proliferation, the inflammatory profile, and the effect of the scaffold degradation compounds on the cell viability. These studies were assessed by means of immunofluorescence, critical point drying (CPD) and field-emission scanning electron microscopy (FE-SEM), methyl tetrazolium (MTT), and pyrogen assays by means of real-time polymerase chain reaction (RT-PCR), respectively.

\section{Cell culture}

Several cell culture lines were seeded, according to specific tissue engineering applications, as gathered in Table 2.6 and described below. All the cellular culture was performed at $37{ }^{\circ} \mathrm{C}$ in a saturated humidity atmosphere containing $95 \% \mathrm{O}_{2}$ and $5 \% \mathrm{CO}_{2}$.

Table 2.6. Cell culture lines seeded.

\begin{tabular}{ccc}
\hline Cell family & Application & Scaffold type \\
\hline Human fibroblasts & Skin tissue engineering & PLGA \\
\cline { 1 - 1 } Human keratinocites (HaCaT) & & PCL/Ge \\
\hline Mice cardiomyocytes (HL-1) & Cardiac tissue engineering & PCon \\
\hline
\end{tabular}

On the one hand, human fibroblasts were cultured in high-glucose Dulbecco's Modified Eagle's Medium supplemented with $10 \%$ of foetal bovine serum (FBS), penicillin (100 U. $\left.\mathrm{mL}^{-1}\right)$ and streptomycin (100 
$\mu \mathrm{g} \cdot \mathrm{mL}^{-1}$ ) Human keratinocytes were cultured in low-glucose Dulbecco's Modified Eagle's Medium supplemented with $10 \%$ of chelated FBS, penicillin $\left(100 \mathrm{U} \cdot \mathrm{mL}^{-1}\right)$ and streptomycin $\left(100 \mu \mathrm{g} \cdot \mathrm{mL}^{-1}\right)$.

On the other hand, HL- 1 cells were plated at $4 \cdot 10^{4}$ cells $\cdot \mathrm{cm}^{2}$ onto scaffolds in Claycomb medium containing $10 \%$ foetal bovine serum and $1 \% \mathrm{~L}-$ Glutamine. Proliferation was measured after $48 \mathrm{~h}$ and $96 \mathrm{~h}$ by MTT assay. Absorbance was measured at $550 \mathrm{~nm}$ using a Perkin-Elmer Victor3 1420 Multilabel Counter microplate reader.

\section{Cell-adhesion corroboration. Immunofluorescence}

In order to evaluate the cell attachment to the scaffolds, 40000 cells were plated onto $1 \mathrm{~cm}^{2}$ of the polymer sheet in triplicates. Cells were allowed to attach for $30 \mathrm{~min}$ and then cultured in the appropriate medium for 48 and 96 h. Thereafter, scaffolds were washed with cold phosphate buffer saline solution (PBS) and fixed for 20 min with 2\% PFA at room temperature, then washed again and finally stained with 4',6-diamidino-2-phenylindole (DAPI) for $10 \mathrm{~min}$ at room temperature. Images were acquired in a Leica DM2500 fluorescence microscope shown in Figure 2.26.

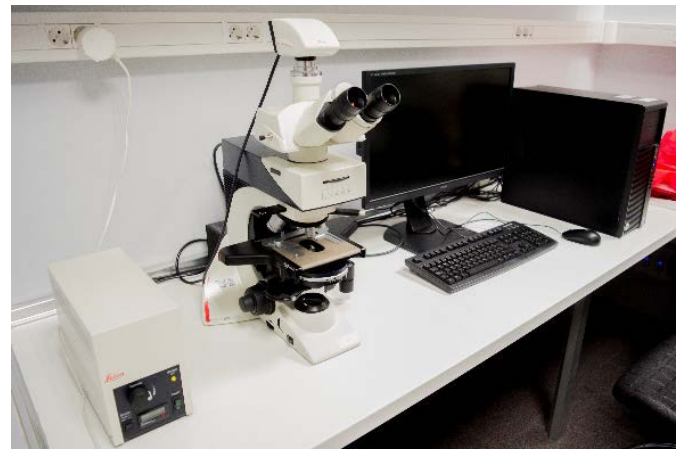

Figure 2.26. Leica DM2500 fluorescence microscope.

Cell adhesion morphology. Critical point drying (CPD) and fieldemission scanning electron microscopy (FE-SEM)

For a deeper characterisation of the cell attachment and morphology, fieldemission scanning electron microscope images were acquired. Briefly, seeded scaffolds were fixed with $3 \%$ glutaraldehyde solution during $60 \mathrm{~min}$ at $37{ }^{\circ} \mathrm{C}$ and subsequently critical point dried (CPD). This procedure removes liquids from the specimen and avoids surface tension effects, by never allowing a liquid/gas interface to develop [44]. The CPD protocol considered was dehydration through a graded series of ethanol (10\%, 20\%, $30 \%, 50 \%$ and $70 \%$, once for $10 \mathrm{~min}$ at each step), and then immersed in $100 \%$ ethanol twice for $30 \mathrm{~min}$ each. The tissues were then transferred to a Leica CPD300 critical point dryer shown in Figure 2.27, using liquefied 
carbon dioxide as transitional fluid. Finally, samples were sputter-coated and analysed according to the protocol described in section 2.4.2.

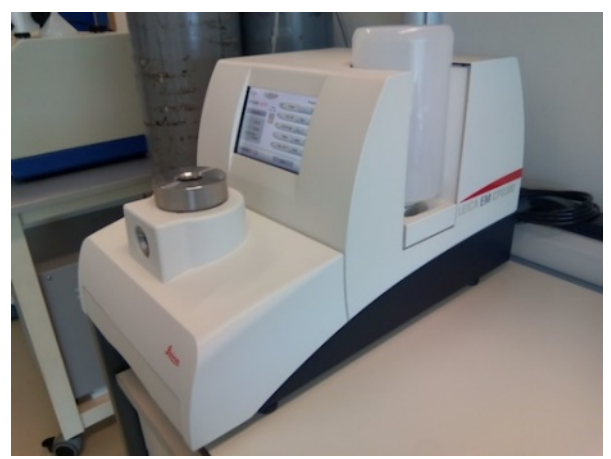

Figure 2.27. Leica CPD 300 critical point dryer.

\section{Toxicity of the scaffolds. Methyl tetrazolium (MTT) assay}

The toxicity of the scaffolds was assessed by means of the methyl tetrazolium (MTT) test. Human fibroblasts were plated at a density of $40000 \mathrm{cell} \cdot \mathrm{cm}^{-2}$ onto the scaffolds. Proliferation was measured in triplicates after 48 and $96 \mathrm{~h}$ using thiazolyl blue tetrazolium bromide (MTT assay), following the manufacturer's instructions. Absorbance was measured at $550 \mathrm{~nm}$ using a plate reader Dynamica Scientific Halo Led 96, shown in Figure 2.28. The obtained absorbance values indicated the cell viability.

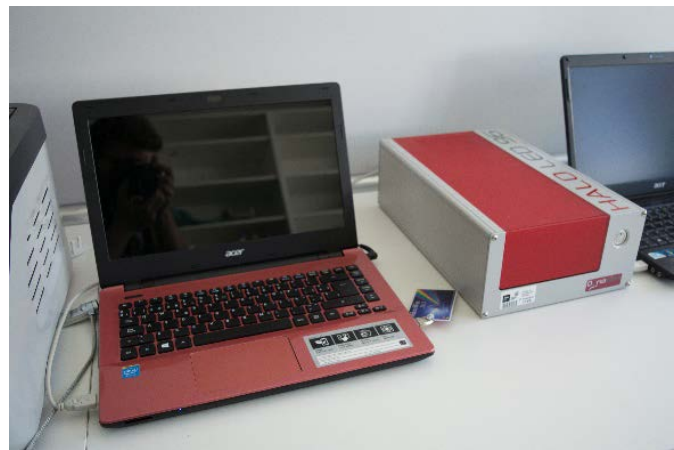

Figure 2.28. Dynamica Scientific Halo Led 96 plate reader.

Toxicity of the degradation compounds. Methyl tetrazolium (MTT) assay

The evaluation of the toxicity of the compounds released during the scaffold degradation was performed. For this purpose, different concentrations of monomers were tested (mM): 0, 10, 20, 30, 40, 50 and 60 . Fibroblast and keratinocytes were seeded (10000 cells per well of a 96 
well plate) and incubated during $24 \mathrm{~h}$ with the determined monomer solutions in the described concentrations. Then, the methyl tetrazolium (MTT) test was performed, as described in the previous section.

\section{Inflammatory response. Pyrogen test and real-time polymerase chain reaction (RT-PCR)}

The inflammatory response was assessed by means of the pyrogen test. For this purpose, blood was obtained from the Valencian Blood Tissue Bank after informed consent and was processed as described previously [45]. Briefly, peripheral blood mononuclear cells (PBMCs) were isolated by Ficoll density gradient centrifugation and incubated in triplicates with the scaffolds during $5 \mathrm{~h}$ at a density of $6 \cdot 10^{6}$ cells $\cdot \mathrm{mL}^{-1}$. Poly(3hydroxybutyrate) (PHB) scaffolds were used as positive control. Once incubated, the RNA of the cells was obtained using QIAzol Lysis Reagent and purification was carried out with a Qiagen RNeasy Plus Mini Kit. RNA was quantified by spectrometry using a NanoDrop ND-2000, shown in Figure 2.29.

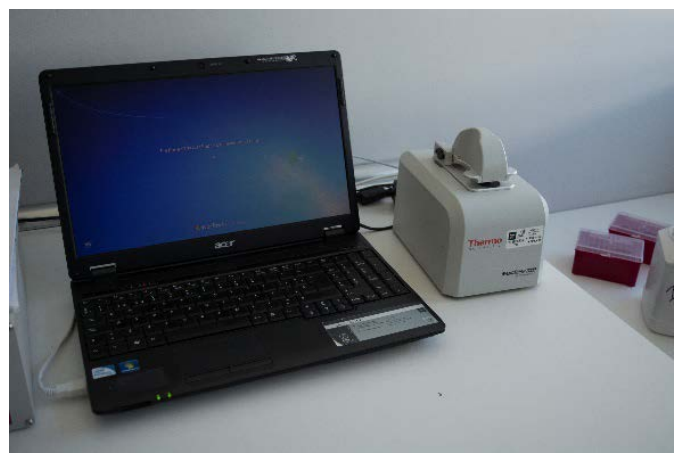

Figure 2.29. NanoDrop ND-2000 spectrometer.

In order to assess the inflammatory response, cells were studied by means of the reverse transcription and real-time polymerase chain reaction (RTPCR). For this purpose, cDNA was synthesized from $1 \mu \mathrm{g}$ of total purified RNA using the Applied Biosystems High-Capacity cDNA Reverse Transcription kit. Primers were designed [45] and RT-PCR was performed as previously described [46]. The following pro-inflammatory cytokines were analysed: IL-1 $\beta$, IL-6, IL-10 and TNF- $\alpha$, while the gene expression levels were normalised to the human housekeeping actin-beta (ACTB). Data was represented as the average from triplicate samples.

\section{Scaffold subcutaneous implantation}

Adult C57BL6J mice from Charles River Laboratories $(n=18)$ were maintained under pathogen-free laboratory conditions. Prior to implantation, mice were anesthetized with isofluorane. Subsequently, a 2 
$\mathrm{cm}^{2}$ subcutaneous pocket was made at the dorsal region. Then, scaffold material $\left(1 \mathrm{~cm}^{2}\right)$ was implanted subcutaneously placed on top of the muscular fascia and the skin was sutured with B/Braun Monosyn 3/0. All animals survived the surgical procedure. Grafts were examined after 15 days. 3 mice used for each scaffold composition. Following sacrifice, the grafts were excised and processed for histology. All animal procedures were approved by institutional ethical and animal care committees.

\section{Histology}

Skin sections were fixed with ethanol, embedded in paraffin and 5-10 transverse sections of $5 \mu \mathrm{m}$ at the area of implantation were stained with haematoxylin/eosin (H/E). Images were acquired with a digital microimaging device Leica DMD108 shown in Figure 2.30.

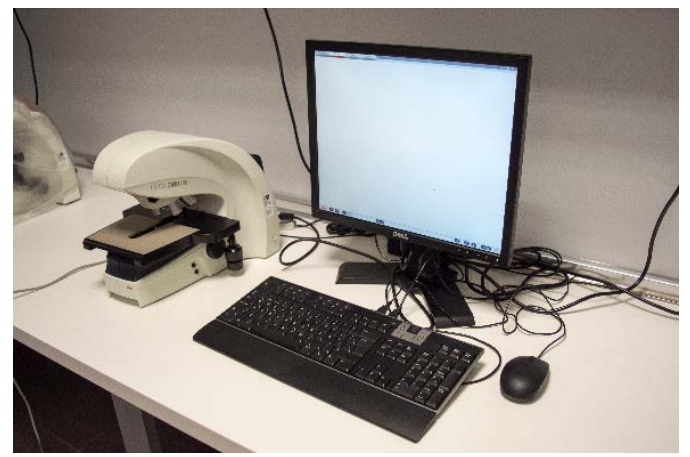

Figure 2.30. Microimaging microscope Leica DMD108.

\subsubsection{In vitro hydrolytic degradation in physiologic conditions}

The in vitro hydrolytic degradation was performed under simulated physiologic conditions in phosphate buffer saline solution (PBS), according to the international norm ISO 10993-13:2010, method 4.3 [47]. As well, ultra-pure water was considered as the elementary hydrolytic media for intrinsically evaluation of the changes in the scaffolds as well as comparison purposes.

The initial electrospun scaffolds were cut into rectangular specimens with a mass around $10 \mathrm{mg}$. The specimens were weighed $\left(m_{0}\right)$ and placed in a previous weighed vial $\left(m_{\text {vial }}\right)$. Then, $10 \mathrm{~mL}$ of degradation medium were introduced, the vials were sealed with polytetrafluoroethylene (PTFE) threaded plugs and placed in a Heraeus Function Line thermostatically controlled incubator at $37^{\circ} \mathrm{C}$, as shown in Figure 2.31. The $\mathrm{pH}$ of the PBS solution was adjusted to 7.4 with $\mathrm{NaOH} 1 \mathrm{M}$. In order to monitor the process, the samples were withdrawn from the solutions by triplicate after 
certain periods. A number of extractions were considered along the hydrolytic degradation as a function of the immersion time, which varied from several tens up to hundreds of days. Solid and liquid fractions were separated. The liquid fraction was analysed immediately after extraction, while the solid fraction followed a washing-drying-keeping procedure before further analysis. Actually, those specimens coming from the saline buffer were washed with deionised water and then, along with specimens coming from water environment, were dried under vacuum at $37{ }^{\circ} \mathrm{C}$ to constant mass into their degradation vials $\left(m_{d r y}\right)$ and saved for further analysis.

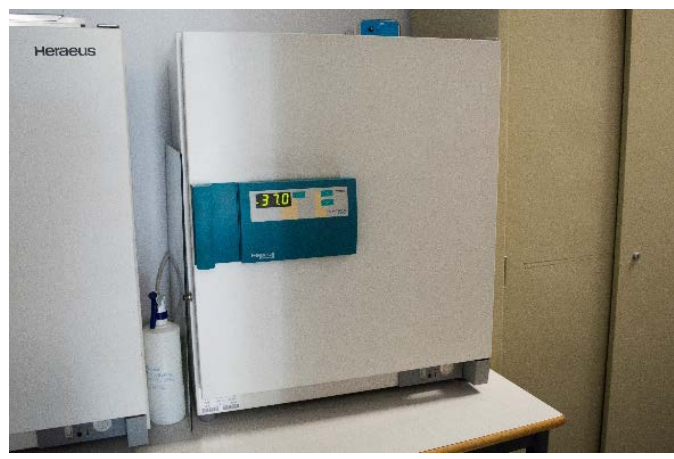

Figure 2.31. Heraeus Function Line thermostatically controlled incubator

The in vitro hydrolytic degradation was preliminarily monitored from the residual mass of the samples and the $\mathrm{pH}$ and the conductivity of the hydrolytic media. The remnant mass of the scaffolds was determined by the Equation 2.8,

$$
\% \text { mass }=\frac{m_{d r y}-m_{\text {vial }}}{m_{0}} \times 100 \quad \text { (Equation 2.8) }
$$

where $m_{0}$ and $m_{\text {vial }}$ are the initial mass of the specimen, and the empty vial, respectively; and $m_{d r y}$ is the mass of the vacuum dry assembly sample-vial after degradation.

The $\mathrm{pH}$ and conductivity of the degradation media were measured at room temperature by means of Crison pH25 and Crison CM35 devices, shown in Figure 2.32. Three buffer solutions from Crison were used to calibrate the pH-meter: $\mathrm{pH} 4.01$ (phthalate buffer solution), $\mathrm{pH} 7.00$ (phosphate buffer solution), $\mathrm{pH} 10.01$ (borate buffer solution). Different $\mathrm{KCl}$ solutions $\left(0.1 \mathrm{M}, 0.01 \mathrm{M}\right.$ and $0.001 \mathrm{M}$ ) with conductivities of $12.88 \mathrm{mS}^{\cdot} \mathrm{cm}^{-1}, 1413$ $\mu \mathrm{S} \cdot \mathrm{cm}^{-1}$ and $147 \mu \mathrm{S} \cdot \mathrm{cm}^{-1}$, respectively, were used to calibrate the conductometer. Measurements were carried out in three different specimens per sample and the averages were taken as representative values. 


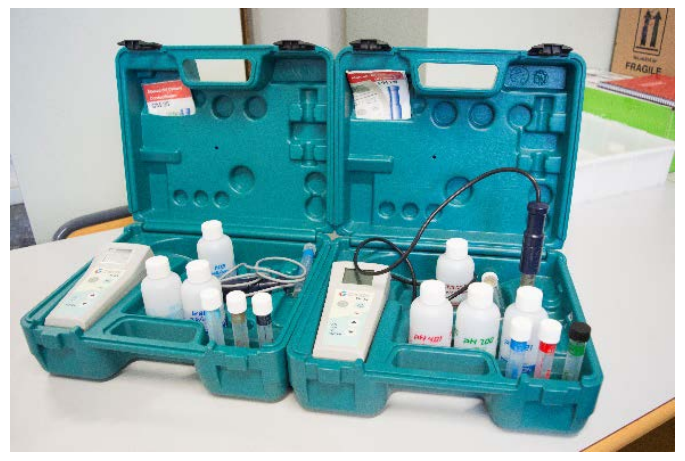

Figure 2.32. Crison pH25 (left) and Crison CM35 (right) devices.

Finally, the degradation of the scaffolds was physico-chemically characterised in terms of the molar mass, surface morphology, thermal properties and chemical structure, as described in section 2.4. 


\subsection{REFERENCES OF CHAPTER 2}

[1] "ISO 3696. Water for analytical laboratory use - Specification and test methods," 1987.

[2] M. I. Rodríguez, R. Fenollosa Esteve, F. J. Meseguer Rico, and A. G. PérezRoldán Tacumi, "Formulation comprising Silicon microparticles as a pigment that can absorb visible UV radiation and reflect IR radiation," WO/2012/101306-PCT/ES2012/070034, 03-Aug-2012.

[3] W. S. Hummers and R. E. Offeman, "Preparation of Graphitic Oxide,” J. Am. Chem. Soc., vol. 80, no. 6, pp. 1339-1339, 1958.

[4] C. F. Chien HC, Tsai LD, Huang CP, Kang Cy, Lin JN, “Sulfonated graphene oxide/Nafion composite membranes for highperformance direct methanol fuel cells.," Int J Hydrog. Energy, vol. 38, p. 13792-801., 2012.

[5] D. Kai, S. S. Liow, and X. J. Loh, "Biodegradable polymers for electrospinning: Towards biomedical applications,” Mater. Sci. Eng. C, vol. 45, pp. 659-670, 2015.

[6] Zeleny J., "The electrical discharge from liquid points, and a hydrostatic method of measuring the electric intensity at their surfaces.," Phys Rev, vol. 3, pp. 69-91, 1914.

[7] Formhals, A., "Process and apparatus for preparing artificial threads. U.S. Patent No. 1, 975, 504.,” 1934.

[8] Taylor GI, "Electrically Driven Jets.,” Proc R Soc Lond, A Math Phys Sci, vol. 313, pp. 453-75, 1969.

[9] X. Y. Li D, "Electrospinning of nanofibers: reinventing the wheel.," Adv Mater, vol. 16, pp. 1151-70, 2004.

[10] N. R. Vonnegut B, "Production of monodisperse liquid particles by electrical atomization.," J Colloid Sci, vol. 7, pp. 616-22, 1952.

[11] D. VG., “The electrical dispersion of liquids as aerosols.,” J Colloid Sci, vol. 10, pp. 158-64, 1955.

[12] Simons HL., "Process and Apparatus for Producing Patterned Nonwoven Fabrics. US patent 3, 280, 229, 1966.,” 1966.

[13] Baumgarten PK., "Electrostatic spinning of acrylic microfibers.," J Colloid Interface Sci, vol. 36, pp. 71-9, 1971.

[14] N. Bhardwaj and S. C. Kundu, "Electrospinning: A fascinating fiber fabrication technique,” Biotechnol. Adv., vol. 28, no. 3, pp. 325-347, 2010.

[15] a. Martins, R. L. Reis, and N. M. Neves, "Electrospinning: processing technique for tissue engineering scaffolding,” Int. Mater. Rev., vol. 53, no. 5, pp. 257-274, 2008.

[16] R. Sood, S. Cavaliere, D. J. Jones, and J. Rozière, "Electrospun nanofibre composite polymer electrolyte fuel cell and electrolysis membranes," Nano Energy, vol. 26, pp. 729-745, 2016.

[17] M. Tanaka, "Development of ion conductive nanofibers for polymer electrolyte fuel cells,” Polymer Journal, vol. 48, no. 1. Nature Publishing Group, pp. 51-58, 16-Jan-2016.

[18] J. L. Reyes-Rodriguez, O. Solorza-Feria, A. García-Bernabé, E. Giménez, O. 
Sahuquillo, and V. Compañ, "Conductivity of composite membrane-based poly(ether-ether-ketone) sulfonated (SPEEK) nanofiber mats of varying thickness,” RSC Adv., vol. 6, no. 62, pp. 56986-56999, 2016.

[19] G.-M. Liao, P.-C. Li, J.-S. Lin, W.-T. Ma, B.-C. Yu, H.-Y. Li, Y.-L. Liu, C.C. Yang, C.-M. Shih, and S. J. Lue, "Highly conductive quasi-coaxial electrospun quaternized polyvinyl alcohol nanofibers and composite as highperformance solid electrolytes,” J. Power Sources, vol. 304, pp. 136-145, 2016.

[20] G. Ito, M. Tanaka, and H. Kawakami, "Sulfonated polyimide nanofiber framework: Evaluation of intrinsic proton conductivity and application to composite membranes for fuel cells,” Solid State Ionics, vol. 317, pp. 244255, Apr. 2018.

[21] S. Agarwal, J. H. Wendorff, and A. Greiner, "Use of electrospinning technique for biomedical applications,” Polymer (Guildf)., vol. 49, no. 26, pp. 56035621, 2008.

[22] S. Agarwal, A. Greiner, and J. H. Wendorff, "Functional materials by electrospinning of polymers,” Prog. Polym. Sci., vol. 38, no. 6, pp. 963-991, Jun. 2012.

[23] S. Agarwal, J. H. Wendorff, and A. Greiner, "Progress in the field of electrospinning for tissue engineering applications,” Adv. Mater., vol. 21, no. 32-33, pp. 3343-3351, Sep. 2009.

[24] N. Bhardwaj and S. C. Kundu, "Electrospinning: A fascinating fiber fabrication technique,” Biotechnol. Adv., vol. 28, no. 3, pp. 325-347, 2010.

[25] A. Haider, S. Haider, and I. K. Kang, “A comprehensive review summarizing the effect of electrospinning parameters and potential applications of nanofibers in biomedical and biotechnology,” Arab. J. Chem., vol. In press, 2015.

[26] D. I. Braghirolli, D. Steffens, and P. Pranke, "Electrospinning for regenerative medicine: a review of the main topics," Drug Discov. Today, vol. 19, no. 6, pp. 743-753, 2014.

[27] A. Martins, R. L. Reis, and N. M. Neves, "Electrospinning: processing technique for tissue engineering scaffolding,” Int. Mater. Rev., vol. 53, no. 5, pp. 257-274, 2008.

[28] D. Li and Y. Xia, "Electrospinning of nanofibers: Reinventing the wheel?," Adv. Mater., vol. 16, no. 14, pp. 1151-1170, 2004.

[29] Q. P. Pham, U. Sharma, and A. G. Mikos, "Electrospinning of Polymeric Nanofibers for Tissue Engineering Applications: A Review,” Tissue Eng., vol. 12, no. 5, pp. 1197-1211, May 2006.

[30] W. E. Teo and S. Ramakrishna, "A review on electrospinning design and nanofibre assemblies.,” Nanotechnology, vol. 17, no. 14, pp. R89-R106, 2006.

[31] R. J. Wade and J. a. Burdick, "Advances in nanofibrous scaffolds for biomedical applications: From electrospinning to self-assembly,” Nano Today, vol. 9, no. 6, pp. 722-742, 2014.

[32] W.-E. Teo, R. Inai, and S. Ramakrishna, "Technological advances in electrospinning of nanofibers,” Sci. Technol. Adv. Mater., vol. 12, no. 1, p. 13002, 2011.

[33] Z. Ma, M. Kotaki, R. Inai, and S. Ramakrishna, "Potential of nanofiber matrix 
as tissue-engineering scaffolds,” Tissue Eng., vol. 11, no. 1, pp. 101-109, 2005.

[34] L. A. Smith and P. X. Ma, "Nano-fibrous scaffolds for tissue engineering," Colloids Surfaces B Biointerfaces, vol. 39, no. 3, pp. 125-131, 2004.

[35] J. . Deitzel, J. Kleinmeyer, D. Harris, and N. . Beck Tan, "The effect of processing variables on the morphology of electrospun nanofibers and textiles,” Polymer (Guildf)., vol. 42, no. 1, pp. 261-272, Jan. 2001.

[36] J. D. H. J. I. Jr. Lauritzen, "Theory of polymer crystals with folded chains in dilute solution,” J. Res. Natl. Bur. Stand., vol. 64A, p. 73, 1960.

[37] J. D. Hoffman and J. I. Lauritzen, "Crystallization of Bulk Polymers With Chain Folding: Theory of Growth of Lamellar Spherulites,” J. Res. Natl. Bur. Stand. - A. Phys. Chem., vol. 65, no. August, p. 1961, 1961.

[38] J. I. Lauritzen and J. D. Hoffman, "Formation of Polymer Crystals with Folded Chains from Dilute Solution,” J. Chem. Phys., vol. 31, no. 6, pp. 1680-1681, 1959.

[39] F. Mansfeld, "Electrochemical impedance spectroscopy (EIS) as a new tool for investigating methods of corrosion protection,” Electrochim. Acta, vol. 35, no. 10, pp. 1533-1544, 1990.

[40] X. Qian, N. Gu, Z. Cheng, X. Yang, E. Wang, and S. Dong, "Methods to study the ionic conductivity of polymeric electrolytes using a.c. impedance spectroscopy,” J. Solid State Electrochem., vol. 6, no. 1, pp. 8-15, 2001.

[41] J. Robinson, A. Linder, and A. Gemmel, "Comparison of standard UV test methods for the ageing of cables,” Proc. 60th Int. Wire Cable Symp., pp. 329337, 2011.

[42] A.Martínez-Felipe, C.Moliner-Estopiñán, C.T.Imrie, and A.Ribes-Greus, "Characterization of Crosslinked PVA-based membranes.," Polym. Polym. Compos., vol. 21, no. 7, pp. 449-456, 2012.

[43] S. Zhong, X. Cui, Y. Gao, W. Liu, and S. Dou, "Fabrication and properties of poly(vinyl alcohol)-based polymer electrolyte membranes for direct methanol fuel cell applications,” Int. J. Hydrogen Energy, vol. 39, no. 31, pp. 1785717864, 2014.

[44] A. K. Pathan, J. Bond, and R. E. Gaskin, "Sample preparation for SEM of plant surfaces,” Mater. Today, vol. 12, no. SUPPL., pp. 32-43, 2009.

[45] D. Castellano, M. Blanes, B. Marco, I. Cerrada, A. Ruiz-Saurí, B. Pelacho, M. Araña, J. A. Montero, V. Cambra, F. Prosper, and P. Sepúlveda, “A Comparison of Electrospun Polymers Reveals Poly(3-Hydroxybutyrate) Fiber as a Superior Scaffold for Cardiac Repair," Stem Cells Dev., vol. 23, no. 13, pp. 1479-1490, Jul. 2014.

[46] R. Carrero, I. Cerrada, E. Lledó, J. Dopazo, F. García-García, M.-P. Rubio, C. Trigueros, A. Dorronsoro, A. Ruiz-Sauri, J. A. Montero, and P. Sepúlveda, "IL1 $\beta$ induces mesenchymal stem cells migration and leucocyte chemotaxis through NF-кB.," Stem Cell Rev., vol. 8, no. 3, pp. 905-16, Sep. 2012.

[47] "ISO 10993-12. Biological evaluation of medical devices.” 2010. 


\section{CHAPTER 3.}

\section{Photo-stabilised polyolefins}

for outdoor applications 


\subsection{Polyolefin DEGRADATION: POLYPROPYLENE (PP) AS A MODEL CASE}

The degradation of polymers is defined as a set of chemical and physical transformations, which lead to the loss of their properties [1]. Therefore, their stabilisation against degradation agents is a field of great interest in the material science. The durability of polymers when exposed to outdoor conditions is a key factor to take into account during the design stage for a given application.

Among the polyolefin family, the polypropylene (PP) is one of the most used polymers for outdoor applications [2]. The PP is a thermoplastic polymer, partially crystalline, obtained from the polymerisation of propylene (or propene). The chemical name according to IUPAC is poly(1methylethylene) and its repeating unit can be seen in Figure 3.1.

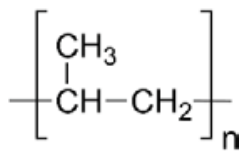

Figure 3.1. Constitutional repeating unit of the polypropylene (PP).

The PP molecules are composed of a main chain of carbon atoms bonded together, from which methyl groups $\left(-\mathrm{CH}_{3}\right)$ hang on either side of the chain. Due to the presence of the methyl group, the PP molecule can have several configurations, namely, isotactic, syndiotactic and atactic. When all the substituent groups of the main chain are above or below the plane of the main chain it is called isotactic. If the substituent groups are alternately above and below the plane, the configuration is called syndiotactic, while the random sequence corresponds to the atactic configuration. The type of configuration also conditions the behaviour of the material. Isotactic polypropylene is the most interesting from an industrial point of view due to its better mechanical properties, derived from its crystallinity.

The virgin polypropylene obtained from a commercial process is very susceptible to UV irradiation and oxidation. Although saturated polymers such as PP do not contain UV sensitive groups in their structure, the photosensitising action of impurities such as double bonds, traces of catalyst, hydroperoxides and structural irregularities plays a key role in the susceptibility to photo-degradation [3]. If non-stabilised, the durability, strength and physical properties of the PP products can undergo rapid deterioration over a period of weeks or months [4]. In this sense, the conditions to which it is subjected such as the temperature, the available 
oxygen and the intensity of the UV radiation are very important factors [5], [6].

The degradation of the PP polymer leads to a reduction in its molar mass, which in turns, leads to a change in many of its properties [7], [8]. One of the most damaging changes is the loss of ductility, and therefore a drastic decrease in the toughness of the polymer [9]. In addition, the chain scission and oxidation processes produce crystallisation and formation of extra chemical groups, as hydroperoxides and carbonyl species such as ketones, esters and acids that cause a change in the colour of the polymer and adversely affect the durability of the final products of PP [10].

In the solid form, PP is a semicrystalline polymer with a crystalline content between $30 \%$ and $60 \%$. The crystalline regions are essentially impermeable to oxygen, so oxidation occurs mainly in the amorphous regions. Moreover, due to the slow rate of the diffusion of oxygen in comparison to the reaction rate, the oxidation process can be considered as a superficial phenomenon [11].

The majority of polyolefin degradation reactions can be associated with a reverse process of vinyl polymerisation, with four stages: radical initiation, depropagation, chain branching under oxidising conditions, and radical termination [12]. Except for the initiation, the thermal, photolytic and radiolytic degradation processes are similar in many aspects and can be described by the same reaction scheme [13].

The cleavage of the covalent bond, with formation of free radicals, is the initiation process of the chemical degradation of PP. The mechanisms of initiation depend on the structure of the polymer, the presence of both internal and external impurities, and degradation conditions [12]. This primary event requires energy, which can be supplied by heat (thermal degradation), by UV photons (photo-degradation), by mechanical forces (mechano-chemical degradation) and chemical reagents (solvolysis,) among others, as schematised in Figure 3.2. 


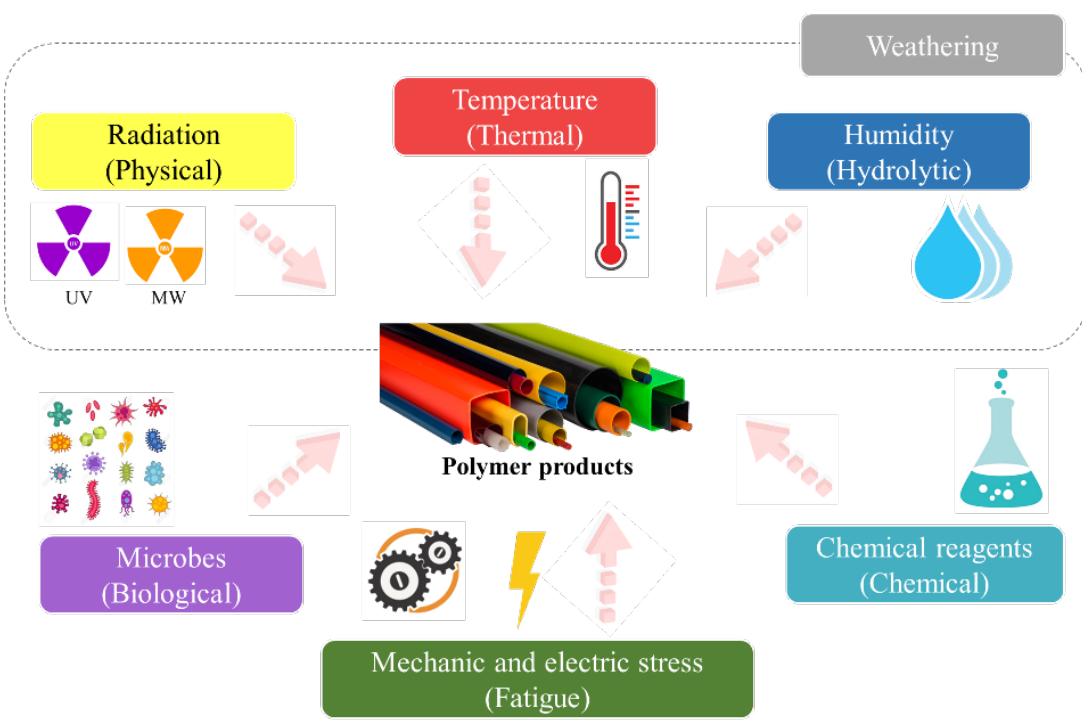

Figure 3.2. Several factors affecting the degradation of polymers.

The photo-degradation mechanism involves the presence of chromophore groups in the polymer able to interact with the photons and oxygen molecules and give as a result new radicals. The rate of this process is strictly correlated to the nature of the polymer, the thickness, the crystallinity, the oxygen solubility and the irradiance degree [14]. Although the mode of initiation may vary during the course of the reaction, in the presence of oxygen, the formation of hydroperoxides followed by their decomposition quickly becomes the predominant mode of initiation [7], [8].

$$
\begin{gathered}
\mathrm{RH}+\mathrm{O}_{2} \rightarrow \mathrm{R} \bullet+\mathrm{HOO} \bullet \\
\mathrm{R} \bullet+\mathrm{HOO} \bullet \rightarrow \mathrm{ROOH}
\end{gathered}
$$

where $\mathrm{RH}$ are polypropylene molecules, $\mathrm{R} \bullet$ is an alkyl radical, $\mathrm{HOO} \bullet$ is a peroxide radical and $\mathrm{ROOH}$ hydroperoxide.

The propagation of degradation is mainly produced by a serial autooxidative scheme as represented below. In the formation of peroxide radicals ( $\mathrm{ROO} \bullet$ ) and hydroperoxide $(\mathrm{ROOH})$, the $\mathrm{R} \cdot$ macroradicals, which appeared at initiation, can easily react with oxygen molecules to give ROO peroxide radicals, which can pick up hydrogen from other polymer molecules to form polymeric hydroperoxides [15].

$$
\begin{gathered}
\mathrm{R} \bullet+\mathrm{O}_{2} \rightarrow \mathrm{ROO} \bullet \\
\mathrm{ROO} \bullet+\mathrm{RH} \rightarrow \mathrm{R} \bullet+\mathrm{ROOH} \\
\mathrm{R} \bullet+\mathrm{R}^{\prime} \mathrm{H} \rightarrow \mathrm{RH}+\mathrm{R}^{\prime} \bullet
\end{gathered}
$$


The branching of the chain is produced by the decomposition of hydroperoxides of the polymer. From small fragments of free radicals, which are very active, they contribute to the propagation of the degradation through the following two reactions.

$$
\begin{aligned}
\mathrm{RH}+\mathrm{HOO} \bullet & \rightarrow \mathrm{R} \bullet+\mathrm{H}_{2} \mathrm{O}_{2} \\
\mathrm{RH}+\mathrm{HO} \bullet & \rightarrow \mathrm{R} \bullet+\mathrm{H}_{2} \mathrm{O}
\end{aligned}
$$

The last step of the degradation process is the termination, where the radicals are extinguished. The number of radicals can be reduced by combining two radicals to form a non-radical product. However, several reactions can result in termination, as described below [16].

$$
\begin{gathered}
\mathrm{R} \cdot+\cdot \mathrm{R}^{\prime} \rightarrow \mathrm{R}-\mathrm{R}^{\prime} \\
\mathrm{RO} \cdot+\cdot \mathrm{R} \rightarrow \mathrm{ROR} \\
2 \mathrm{ROO} \cdot \rightarrow \mathrm{ROOR}+\mathrm{O}_{2} \\
2 \mathrm{RO} \cdot \rightarrow \mathrm{ROOR}
\end{gathered}
$$

Several protective measures have been thus proposed to increase stability against sunlight irradiation and different kinds of additives have been considered along the last decades [17], [18]. Therefore, the addition of appropriate stabilisers is necessary to convert PP into a durable and useful material for outdoor applications [19], [20]. 


\subsection{ULTRAVIOLET STABILISATION OF POLYPROPYLENE (PP)}

Given the high susceptibility of the raw polymers to degradation, the success of these materials, depends to a large extent on the performance of the stabilisers, $70 \%$ of which are used for polyolefins [21]. In general, additives are auxiliary materials that are physically dispersed in a polymeric matrix, without affecting its molecular structure. The incorporation of additives to plastics can significantly improve the properties of the material [22].

The ideal protection agents against photo-oxidation should efficiently absorb UV light and present good dissipation properties of energy, be stable to UV light action and present low optical absorption on the visible domain [3], [23].

According to their protection activity, polymer stabilisers are conventionally classified as radical scavengers, hydroperoxide decomposers, deactivators. UV light absorbers and UV light screeners [19], [20], [24].

\subsubsection{Radical scavengers}

Since the degradation of the polymer is initiated by free radicals, one of the most effective way for UV stabilisation is to reduce the number of species of reactive radicals [25].

\section{Antioxidant radical scavengers}

The secondary aromatic amines and the substituted phenolic derivatives are among the most used radical scavenger stabilisers. The stabilising action of these compounds is based on the formation of aminoxy and phenoxy radicals, respectively, which can compact the propagation of the radicals formed during degradation. The amine additives are converted into conjugated by-products that absorb visible light [26]. For this reason, hindered phenols are preferred in applications where discoloration is undesirable [27]. Typical phenolic antioxidants are protected with bulky alkyl substituents at positions 2, 4 and 6 positions to reduce the reactivity of phenoxy radicals to the hydrogen atom abstraction reactions. The main mode of action of phenols with steric hindrance is the transfer of a hydrogen atom to the propagation of alkyl radicals $(\mathrm{R} \bullet)$ and alkylperoxid radicals (ROO•), as shown in Figure 3.3. Phenoxy radicals have a relatively long duration and can undergo self-dissolution, recombination with alkylperoxid radicals, or isomeric rearrangement followed by 
recombination. The resulting compounds may have some stabilising activity [28]. However, the most conventional phenolic antioxidants suffer from limitated photostability and cannot be used for long-term photostabilisation [29].

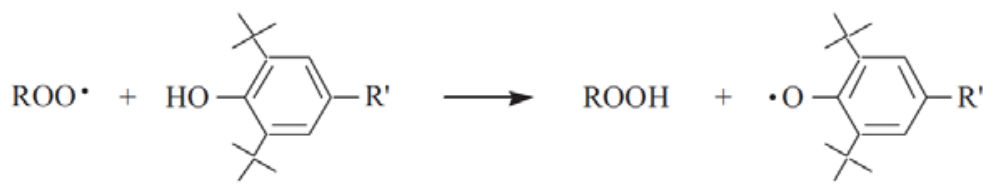

Figure 3.3. Phenolic radical elimination.

\section{Hindered amine light stabilisers (HALS)}

The hindered amine light stabilisers (HALS) were introduced more than 25 years ago and they led to a considerable improvement of polyolefin light stability based on radical scavenging [30].

There are several generation of HALS. The first stabilizer HALS-1 was based in bis (2,2,6,6-tetramethyl-4-piperidinyl) sebacate. Then, the HALS2 was developed as the polymeric form of the dimethyl ester of butyric acid with 4-hydroxy-2,2,6,6-tetramethyl pyridine and the HALS-3 was based in poly[[6-[1,1,3,3-tetramethylbutyl)amino]-1,6-hexandiyl[(2,2,6,6-

tetramethyl-4-piperidinyl)imino]]. Other hindered amines used with good results in the photo-stabilisation of polyolefin are derivatives of piperidine.

The HALS have been successfully used for the light stabilisation of many polymers, especially in polyolefin, polyamides and polyurethanes due to their competitive costs and high performances [31], [32]. HALS have been also recognised as long-term heat stabilisers [33], which mechanism of action is controversial [34].

The basic nature of HALS, however, intrinsically possess some drawbacks. The effect of temperature along with some acidic substances have a large negative effect on their effectiveness. The $\mathrm{HCl}, \mathrm{HBr}$ or $\mathrm{HNO}_{3}$ and, in general, the acid rain that takes place in the atmosphere of developed countries due to contamination can deactivate the protective capacity of HALS [35]. As well, the effectiveness of HALS decrease along their service life, given the consumption of the radical scavenger molecules. Moreover, antagonism between phenolic antioxidants has been found in the literature [36], [37].

\subsubsection{Hydroperoxide decomposers}

The peroxides are the responsible for the self-acceleration stage during the oxidative degradation of the polymers. Hydroperoxide decomposers, which cause the reduction of hydroperoxides to alcohols, comprise two 
main chemical classes: organic compounds of sulfur and trivalent phosphorus, which are generally used in combination with phenolic antioxidants [28]. The mechanism of decomposition is complex and involves radical and non-radical processes. During the course of the decomposition, a mixture of oxidation products is formed, generally endowed with additional properties [12].

\subsubsection{Deactivators/energy quenchers}

The deactivators are used to neutralise the excess energy of excited chromophores and dissipates it as vibrational energy, before that degradation reactions could be initiated [38]. These deactivators must have excited stages with energies of activation lower that the excited state of polymer molecule. Once energy is transferred, the additive returns to its natural state by means of the emission of heat, fluorescence or phosphorescence [39].

The most effective deactivators are based on nickel complexes (phenolate, dithiocarbamate, dithiophosphate) and are used almost exclusively in polyolefins at a concentration of 0.2 to $0.5 \%$. The nickel complexes confer a green coloration to the plastic products [40].

\subsubsection{UV light absorbers}

The UV light absorbers are additives considered to prevent photodegradation and can be used alone or in combination with other light stabilisers. The UV absorbers absorb harmful UV light more efficiently than the polymer and can transform the excess of energy as heat or less harmful radiation.

One of the most efficient stabilisers is the carbon black [41]. However, the blackish coloration and the generation of heat that may cause thermal degradation in the polymer have prevented its extended use as UV absorber [42].

Most commercial UV absorbers are derivatives of benzophenone, benzotriazole, triazine, oxanilide, or cyanoacrylate with aromatic substituents. All have a highly delocalised $\pi$-electron structure with a high molar attenuation coefficient in a wavelength close to the UV region (290$350 \mathrm{~nm}$ ). The molar attenuation coefficient, an intrinsic property of a given substance, is a measurement of how strongly a molecule attenuates light at a given wavelength.

The essential difference between the UV absorbers and the energy quenchers is based on the protection mechanism: while UV absorbers directly protect the polymer by absorbing UV light, the quenchers 
deactivate the excited states of the polymer molecules. However, in reality, it was shown that the UV absorbers can perform also as quenchers [3].

\subsubsection{UV light screeners}

The best and most effective mode to avoid photo-degradation is to prevent the photons from reaching the polymer either by applying a paint, coating the surface or by mixing the polymer with particles that screen light [23].

The UV light screeners operate by absorbing the incident radiation preventing it from reaching the bulk of the polymer and reflecting or scattering the received radiation. In particular, the addition of substances as UV light screeners involves the mirroring of the UV light and the incidental interaction of light with polymer molecules in a lower proportion. The addition of $\mathrm{TiO}_{2}$ particles or aluminium, along with pigmentation has been proposed in this field [3]. However, several adverse factors such as colouring, dispersion concerns or changes in electrical and mechanical properties have been reported. An important disadvantage of UV absorbers is the fact that they need a certain absorption depth to provide good protection to a polymer. In addition, an excess of the UV light reflectors such as the $\mathrm{TiO}_{2}$ nanoparticles can cause photocatalytic degradation of polyethylene, polypropylene or epoxy resins, among others [43]. 


\subsection{SILICON MICROPARTICLES AS NOVEL ULTRAVIOLET STABILISERS}

The outdoor use of the polymeric materials is subjected to the direct incidence of radiation, which is one of the most decisive factors of the polymer degradation [44]. In line with the proposed UV light absorbers and screeners, a novel micro-sized material has been recently developed which can improve significantly resistance to photo-degradation when added to a polymeric matrix in comparison with conventional screeners, preventing from harmful drawbacks.

Silicon nano and microparticles obtained either by chemical methods [45][47] or through milling process [48], may absorb efficiently sun radiation in the whole UV-visible range and reflect infrared radiation. This protective mechanism is due to the huge value of the refractive index much larger than that for any other material, as titanium dioxide, used for light protection [47].

On the one hand, the silicon colloids consists of almost perfect spheres in the micro-scale range $(0.5$ to $5 \mu \mathrm{m})$ with a very smooth surface, as shown in Figure 3.4. These colloids are obtained by chemical vapour deposition techniques. Under conditions of controlled chemical reaction, silicon colloids nucleate and grow in disilane gas similar to the process of obtaining silica colloids in a liquid solution containing appropriate precursors [49]. In gas, colloidal particles become highly spherical thanks to surface tension forces. The particles diffuse into the gas and produce "rain" of spheres of micrometric size that are deposited on the walls of the gas reactor or on any substrate previously introduced in the reactor [47].

On the other hand, the polydisperse silicon milled microparticles are usually obtained from highly pure metallurgical grade silicon powder through a process of grinding until achieving particles with low polydispersity in size and smaller than $2 \mu \mathrm{m}$, as shown in Figure 3.4. With a low cost of production, these particles may bring protection in a wide range of electromagnetic radiation. Indeed, they have been reported as UVvisible radiation absorbers and IR radiation reflectors [48]. 

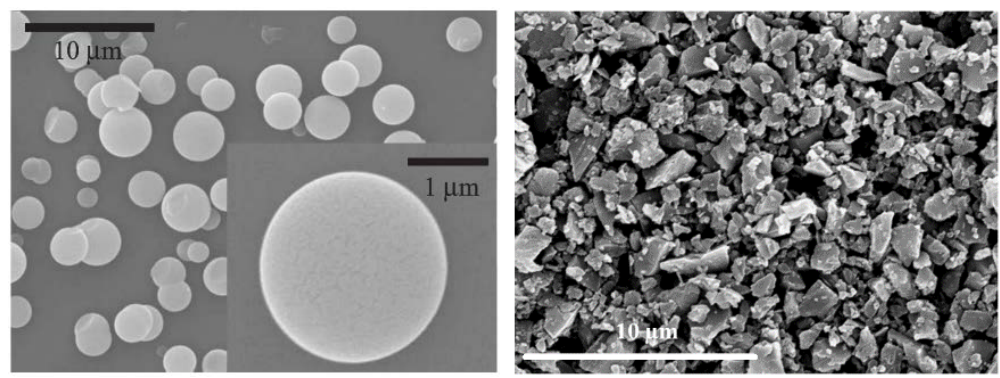

Figure 3.4. Silicon colloid microparticle (left) and silicon milled microparticle (right).

The main application of the silicon particles is in photonics due to its optical properties [47]. Moreover, they can be used as a UV stabilisers to prevent ageing of polymers due to their ability to trap light very efficiently in a wide wavelength range that covers from the visible to the far infrared regions [46]. Although both silicon colloids and milled microparticles confer a dark coloration, they can be effective when dispersed into a polymer matrix to prevent photo-degradation and improving the mechanical properties.

The combination of a polymer matrix and metallic microparticles gives as a result a polymer composite. In order to avoid problems derived of phase separation between matrix and particles, some additives acting as coupling agents can be added to the composite. For the case of study of PP, maleic anhydride (MAH) grafted PP, shown in Figure 3.5, has been proved to be an effective functional molecule for the reactive coupling between polypropylene (PP) and other polymers [50], [51] and charges [52]-[56].

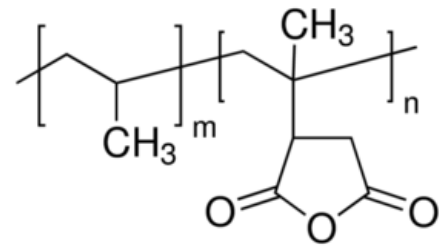

Figure 3.5. Maleic anhydride grafted PP.

Therefore, a composite of grafted MAH-PP blended with non-additivated raw PP and silicon microparticles may bring new solutions in the stabilisation of polymers against photo-degradation field. 


\subsection{REFERENCES OF CHAPTER 3}

[1] L. A. Wall and J. H. Flynn, "Degradation of Polymers," Rubber Chem. Technol., vol. 35, no. 5, pp. 1157-1221, Nov. 1962.

[2] C. Maier and T. Calafut, "Polypropylene: the definitive user's guide and databook,” PDL Handb. Ser., vol. c, p. xx, 432 p., 1998.

[3] E. M. Lungulescu and T. Zaharescu, "Stabilization of Polymers Against Photodegradation," in Photochemical Behavior of Multicomponent Polymericbased Materials, D. Rosu and P. M. Visakh, Eds. Springer, Cham, 2016, pp. 165-192.

[4] O. Agboola, R. Sadiku, T. Mokrani, I. Amer, and O. Imoru, "Polyolefins and the environment," in Polyolefin Fibres: Structure, Properties and Industrial Applications: Second Edition, Elsevier, 2017, pp. 89-133.

[5] T. C. Uzomah and S. C. O. Ugbolue, "Time and Temperature Effects on the Tensile Yield Properties of Polypropylene,” J Appl Polym Sci, vol. 66, no. June, pp. 625-633, Nov. 1996.

[6] M. R. Thompson, C. Tzoganakis, and G. L. Rempel, "Evaluation of vinylidene group content in degraded polypropylene,” J. Polym. Sci. Part A Polym. Chem., vol. 35, no. 14, pp. 3083-3086, Oct. 1997.

[7] D. J. Carlsson and D. M. Wiles, "The Photooxidative Degradation of Polypropylene. Part I. Photooxidation and Photoinitiation Processes,” J. Macromol. Sci. Part C, vol. 14, no. 1, pp. 65-106, Jan. 1976.

[8] D. J. Carlsson, A. Garton, and D. M. Wiles, "Initiation of Polypropylene Photooxidation. 2. Potential Processes and Their Relevance to Stability," Macromolecules, vol. 9, no. 5, pp. 695-701, Sep. 1976.

[9] S. I. Senatova, F. S. Senatov, D. V. Kuznetsov, A. A. Stepashkin, and J. P. Issi, "Effect of UV-radiation on structure and properties of PP nanocomposites," $J$. Alloys Compd., vol. 707, pp. 304-309, Jun. 2017.

[10] E. Abdel-Bary, Handbook Of Plastic Films. 2003.

[11] T. Hirotsu and P. Nugroho, "Surface Coating Protective Against Oxidative Plasma Etching of Polypropylene,” J. Appl. Polym. Sci., vol. 66, no. 6, pp. 1049-1057, Nov. 1997.

[12] T. Meyer and J. T. F. Keurentjes, Handbook of Polymer Reaction Engineering. Wiley-VCH, 2008.

[13] J. Rychlý and L. Rychlá, "Polyolefins: From Thermal and Oxidative Degradation to Ignition and Burning," Springer, Cham, 2016, pp. 285-314.

[14] J. W. Martin, R. A. Ryntz, J. Chin, and R. A. Dickie, Service Life Prediction of Polymeric Materials: Global Perspectives, vol. 2008. Boston, MA: Springer Science+Business, 2008.

[15] J. Lacoste, D. Vaillant, and D. J. Carlsson, "Gamma-, photo-, and thermallyinitiated oxidation of isotactic polypropylene," J. Polym. Sci. Part A Polym. Chem., vol. 31, no. 3, pp. 715-722, Mar. 1993.

[16] J. E. Guillet, "Fundamental processes in the u.v. degradation and stabilization of polymers,” Pure Appl. Chem., vol. 30, no. 1-2, pp. 135-144, Jan. 1972.

[17] O. Cicchetti, "Mechanisms of Oxidative Photodegradation and of UV 
Stabilization of Polyolefins,” Adv. Polym. Sci, vol. 7, pp. 70-112, 1970.

[18] P. Gijsman, "Photostabilisation of Polymer Materials," in Photochemistry and Photophysics of Polymer Materials, John Wiley and Sons, 2010, pp. 627-679.

[19] P. Gijsman, "Polymer Stabilization," in Applied Plastics Engineering Handbook: Processing, Materials, and Applications: Second Edition, Elsevier, 2016, pp. 395-421.

[20] M. Tolinski, Additives for Polyolefins: Getting the Most out of Polypropylene, Polyethylene and TPO. 2015.

[21] F. Gugumus, "Advances in the stabilization of polyolefins," Polym. Degrad. Stab., vol. 24, no. 4, pp. 289-301, Jan. 1989.

[22] N. S. Allen, A. Chirinis-Padron, and T. J. Henman, "The photo-stabilisation of polypropylene: A review,” Polym. Degrad. Stab., vol. 13, no. 1, pp. 31-76, Jan. 1985.

[23] S. Al-Malaika, “Photostabilizers,” Springer, Dordrecht, 1999, pp. 581-590.

[24] S. Al-Malaika, "Perspectives in stabilisation of polyolefins," Adv. Polym. Sci., vol. 169, pp. 121-150, 2004.

[25] E. Höft, Atmospheric Oxidation and Antioxidants, vol. 188, no. Part_1_2. Elsevier Science, 1995.

[26] G. Kasza, K. Mosnáčková, A. Nádor, Z. Osváth, T. Stumphauser, G. Szarka, K. Czaniková, J. Rychlý, Š. Chmela, B. Iván, and J. Mosnáček, "Synthesis of hyperbranched poly(ethyleneimine) based macromolecular antioxidants and investigation of their efficiency in stabilization of polyolefins,” Eur. Polym. J., vol. 68, pp. 609-617, Jul. 2015.

[27] P. P. Klemchuk and P. L. Horng, "Transformation products of hindered phenolic antioxidants and colour development in polyolefins," Polym. Degrad. Stab., vol. 34, no. 1-3, pp. 333-346, Jan. 1991.

[28] I. Vulic, G. Vitarelli, and J. M. Zenner, "Structure-property relationships: Phenolic antioxidants with high efficiency and low colour contribution," Polym. Degrad. Stab., vol. 78, no. 1, pp. 27-34, Jan. 2002.

[29] J. Pospisil, "Transformations of Phenolic Antioxidants and the Role of Their Products in the Long-Term Properties of Polyolefins," Advan. Chem. Ser., 36, vol. 36, pp. 70-133, 1980.

[30] P. Gijsman, J. Hennekens, and D. Tummers, "The mechanism of action of hindered amine light stabilizers,” Polym. Degrad. Stab., vol. 39, no. 2, pp. 225-233, Jan. 1993.

[31] F. Gugumus, "Possibilities and limits of synergism with light stabilizers in polyolefins 2. UV absorbers in polyolefins,” Polym. Degrad. Stab., vol. 75, no. 2, pp. 309-320, Jan. 2002.

[32] F. Gugumus, "Aspects of the impact of stabilizer mass on performance in polymers 1. Performance of low and high molecular mass HALS in PP," Polym. Degrad. Stab., vol. 66, no. 1, pp. 133-147, Oct. 1999.

[33] P. Gijsman and M. Gitton, "Hindered amine stabilisers as long-term heat stabilisers for polypropylene,” Polym. Degrad. Stab., vol. 66, no. 3, pp. 365371, Dec. 1999.

[34] P. Gijsman, "A review on the mechanism of action and applicability of Hindered Amine Stabilizers,” Polym. Degrad. Stab., vol. 145, pp. 2-10, Nov. 2017. 
[35] D. J. Carlsson, Z. Can, and D. M. Wiles, "Polypropylene photostabilization by hindered amines in the presence of acidic species,” J. Appl. Polym. Sci., vol. 33, no. 3, pp. 875-884, Feb. 1987.

[36] J. Lucki, J. F. Rabek, and B. Rånby, "Photostabilizing effect of hindered piperidine compounds: Interaction between hindered phenols and hindered piperidines,” Polym. Photochem., vol. 5, no. 1-6, pp. 351-384, Jan. 1984.

[37] R. Gensler, C. J. . Plummer, H.-H. Kausch, E. Kramer, J.-R. Pauquet, and H. Zweifel, "Thermo-oxidative degradation of isotactic polypropylene at high temperatures: phenolic antioxidants versus HAS," Polym. Degrad. Stab., vol. 67, no. 2, pp. 195-208, Feb. 2000.

[38] K. Feron, W. J. Belcher, C. J. Fell, and P. C. Dastoor, "Organic solar cells: Understanding the role of f̈orster resonance energy transfer,” Int. J. Mol. Sci., vol. 13, no. 12, pp. 17019-17047, Dec. 2012.

[39] J. Malík, G. Ligner, and L. Ávár, "Polymer bound HALS - Expectations and possibilities,” Polym. Degrad. Stab., vol. 60, no. 1, pp. 205-213, Apr. 1998.

[40] E. M. Abdel-Bary, A. A. Sarhan, and E. A. Abdel-Razik, "Studies of the photooxidation of polydienes: Part 1-Photo-stabilising effect of some derivatives of diacetyl-monooxime benzoylhydrazone nickel(II) chelates on cis-1,4polybutadiene,” Polym. Degrad. Stab., vol. 18, no. 2, pp. 145-155, Jan. 1987.

[41] M. Kurzböck, G. M. Wallner, and R. W. Lang, "Black pigmented polypropylene materials for solar absorbers," in Energy Procedia, 2012, vol. 30, pp. 438-445.

[42] M. Liu and A. R. Horrocks, "Effect of carbon black on UV stability of LLDPE films under artificial weathering conditions," Polym. Degrad. Stab., vol. 75, no. 3, pp. 485-499, Jan. 2002.

[43] M. M. Kamrannejad, A. Hasanzadeh, N. Nosoudi, L. Mai, and A. A. Babaluo, "Photocatalytic degradation of polypropylene/TiO2 nano-composites," Mater. Res., vol. 17, no. 4, pp. 1039-1046, Aug. 2014.

[44] N. D. Searle, M. McGreer, and A. Zielnik, "Weathering of Polymeric Materials," in Encyclopedia of Polymer Science and Technology, Hoboken, NJ, USA: John Wiley \& Sons, Inc., 2010.

[45] F. J. Meseguer Rico, R. Fenollosa Esteve, and M. Tymczenko, "Microesferas de silicio y esponjas fotónicas, procedimiento de producción y sus aplicaciones en la fabricación de dispositivos fotónicos.," WO/2008/155438PCT/ES2008/070102, 25-Dec-2008.

[46] F. Meseguer, R. Fenollosa, I. Rodriguez, E. Xifré-Pérez, F. Ramiro-Manzano, M. Garn, and M. Tymczenko, "Silicon colloids: A new enabling nanomaterial," in Journal of Applied Physics, 2011, vol. 109, no. 10, p. 102424.

[47] R. Fenollosa, F. Meseguer, and M. Tymczenko, "Silicon colloids: From microcavities to photonic sponges,” Adv. Mater., vol. 20, no. 1, pp. 95-98, Jan. 2008.

[48] M. I. Rodríguez, R. Fenollosa Esteve, F. J. Meseguer Rico, and A. G. PérezRoldán Tacumi, "Formulation comprising Silicon microparticles as a pigment that can absorb visible UV radiation and reflect IR radiation," WO/2012/101306-PCT/ES2012/070034, 03-Aug-2012.

[49] L. Shi, X. Lu, R. Fenollosa, I. Rodriguez, J. T. Harris, F. Ramiro-Manzano, B. 
A. Korgel, and F. Meseguer, "Processing and Characterization of Monodisperse Silicon Colloids,” Protoc. Exch., Aug. 2013.

[50] R. Holsti-Miettinen, J. Seppälä, and O. T. Ikkala, "Effects of compatibilizers on the properties of polyamide/polypropylene blends," Polym. Eng. Sci., vol. 32, no. 13, pp. 868-877, Jul. 1992.

[51] K. Cho, F. Li, and J. Choi, "Crystallization and melting behavior of polypropylene and maleated polypropylene blends,” Polymer (Guildf)., vol. 40, no. 7, pp. 1719-1729, Mar. 1999.

[52] B. Mailhot, S. Morlat, J. L. Gardette, S. Boucard, J. Duchet, and J. F. Gérard, "Photodegradation of polypropylene nanocomposites," in Polymer Degradation and Stability, 2003, vol. 82, no. 2, pp. 163-167.

[53] O. Picazo, J. C. Merino, and D. Garc, "Polypropylene - clay nanocomposites : effect of compatibilizing agents on clay dispersion," Eur. Polym. J., vol. 39, no. 5, pp. 945-950, May 2003.

[54] W. Xu, G. Liang, H. Zhai, S. Tang, G. Hang, and W. P. Pan, "Preparation and crystallization behaviour of PP/PP-g-MAH/Org-MMT nanocomposite,” Eur. Polym. J., vol. 39, no. 7, pp. 1467-1474, Jul. 2003.

[55] M. Z. Rong, M. Q. Zhang, and W. H. Ruan, "Surface modification of nanoscale fillers for improving properties of polymer nanocomposites: a review,” Mater. Sci. Technol., vol. 22, no. 7, pp. 787-796, Jul. 2006.

[56] X. M. Chen, J. W. Shen, and W. Y. Huang, "Novel electrically conductive polypropylene/graphite nanocomposites,” J. Mater. Sci. Lett., vol. 21, no. 3, pp. 213-214, 2002. 


\subsection{CONTRIBUTIONS OF CHAPTER 3}

The oxidation of polyolefins by sunlight irradiation is a significant limitation for their use in several applications, particularly those in outdoor environment. Given the wide application of polypropylene (PP) in applications exposed to sunlight irradiation, such as automotive parts or wires, it was chosen as polymer matrix. With the aim of inducing photostabilisation, in this functionalisation strategy, novel silicon microparticles (Si) were added to raw polypropylene (PP) in different compositions -3 and $5 \%$ wt.- with maleic anhydride (MAH) as coupling agent. Composites were prepared by hot melt extrusion and compression moulding and subjected to accelerated sunlight irradiation tests for validation. The stability of thermal properties, mechanical performance and thermal decomposition behaviour of composites showed the potential of silicon microparticles to protect PP from degradation when exposed to an accelerated sunlight irradiation procedure, in terms of preservation of appearance and performance. Particularly, the addition of silicon particles in a $5 \%$ wt. provided a suitable protection against sunlight irradiation.

Figure 3.6 shows the sequence approach for the functionalisation strategy, characterisation and validation of the photo-stabilised polypropylene for outdoor applications.

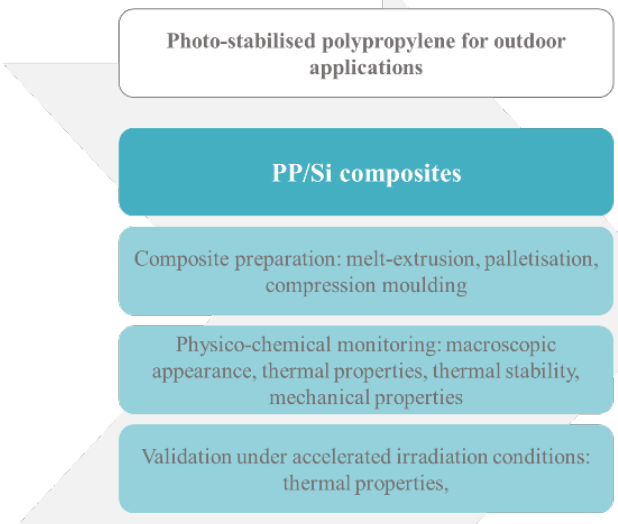

Figure 3.6. Sequence approach for the functionalisation strategy, characterisation and validation of the photo-stabilised polypropylene for outdoor applications.

The results of this research line were reported in:

Contribution 3.1. Novel silicon microparticles to improve sunlight stability of raw polypropylene. 


\section{Contribution 3.1.}

Novel silicon microparticles to improve sunlight stability of raw polypropylene

O. Gil-Castell, J. D. Badia, R. Teruel-Juanes, I. Rodriguez, F. Meseguer, A. Ribes-Greus. Novel silicon microparticles to improve sunlight stability of raw polypropylene. European Polymer Journal 2015; 70, 247-261

This is an open-access version, according to:

http://www.sherpa.ac.uk/romeo/issn/0014-3057

Full text available at:

http://www.sciencedirect.com/science/article/pii/S0014305715003353\#

DOI:

http://dx.doi.org/10.1016/j.eurpolymj.2015.06.031 


\title{
Novel silicon microparticles to improve sunlight stability of raw polypropylene
}

\author{
O. Gil-Castell ${ }^{1}$, J. D. Badia ${ }^{1,2}$, R. Teruel-Juanes ${ }^{1}$, I. Rodriguez ${ }^{3}$, F. \\ Meseguer $^{3, *}$, A. Ribes-Greus ${ }^{1, *}$ \\ ${ }^{1}$ Instituto de Tecnología de Materiales. Universitat Politècnica de València. Camí de Vera, s/n, \\ 46022 Valencia, Spain.
${ }^{2}$ Departament d'Enginyeria Química. Escola Tècnica Superior d'Enginyeria, Universitat de València, Av. de la Universitat, s/n, 46100 Burjassot, Spain \\ ${ }^{3}$ Instituto de Tecnología Química (CSIC-UPV). Av. de los Naranjos, s/n, 46022 Valencia, Spain \\ *Corresponding authors: \\ F. Meseguer fmese@fis.upv.es
}

A. Ribes-Greus aribes@ter.upv.es 


\title{
Novel silicon microparticles to improve sunlight stability of raw polypropylene
}

\author{
O. Gil-Castell, J. D. Badia, R. Teruel-Juanes, I. Rodriguez, F. Meseguer, \\ A. Ribes-Greus
}

\begin{abstract}
Oxidation of polyolefins by ultraviolet/visible irradiation is a significant limitation for their use in several technological applications. The use of high-tech additives such as silicon microparticles becomes a compositing strategy that can improve the performance of these materials at long-term service conditions. Silicon particles were added to non-additivated raw polypropylene (PP) prepared by hot melt extrusion and subjected to accelerated sunlight irradiation tests. The stability of thermal properties, mechanical performance and thermal decomposition behaviour of composites was evaluated by differential scanning calorimetry, dynamic mechanical-thermal analysis and thermogravimetry. This paper shows the potential of silicon microparticles to protect PP from degradation during both processing and accelerated sunlight irradiation. The addition of polydisperse silicon microparticles to the raw polypropylene preserved the appearance and improved the thermal behaviour, mechanical properties and thermal stability. It was found that silicon particles at $5 \%$ wt. provided a suitable protection of raw non-additivated PP against sunlight irradiation.
\end{abstract}

\section{Graphical abstract}

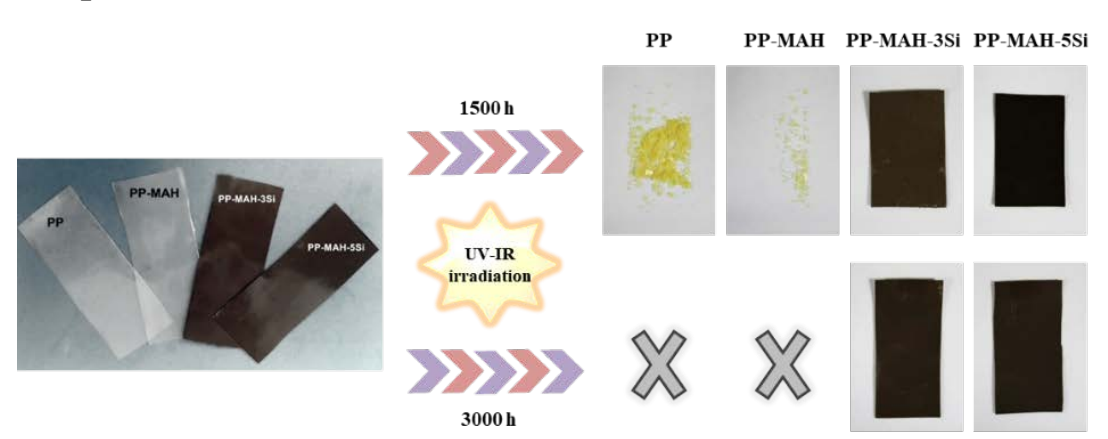

\section{Keywords}

Silicon microparticles, polypropylene, polyolefin, composite, sunlight irradiation, photo-degradation, thermal analysis, plastic additives, near-IR reflective pigment 


\section{Introduction}

Polypropylene (PP) is one of the most extensively used polymers in several industrial sectors due to its attractive properties such as suitable processability, feasible mechanical properties, low price and low weight, among others [1]. Wiring, construction, automotive and packaging are some of the main areas. Therefore, the stabilization against different factors which cause polymer degradation such as UV-radiation, temperature, stress loading, water absorption and weathering, among others, is considered crucial for long-term applications.

It is well known that the main effects of photo-oxidation of polypropylene consist in the reduction in molecular size, crystallisation and formation of extra chemical groups, as hydroperoxides and carbonyl species such as ketones, esters and acids [2]-[6]. Several protective measures have been thus proposed to increase stability against sunlight irradiation and different kinds of additives have been considered.

Hindered amine light stabilizers (HALS) were introduced more than 25 years ago and they led to considerable improvement of polyolefin light stability based on radical scavenging in which nitroxides play a key role reacting with alkyl radicals and forming amino ether, but some drawbacks have been also observed [7]-[9]. The basic nature of HALS causes that some acidic substances have a large negative effect on its effectivity. Thus, high temperatures along with $\mathrm{HCl}, \mathrm{HBr}$ or $\mathrm{HNO}_{3}$ and, in general, acid rain which are present in the atmosphere of developed countries due to pollution may deactivate the protective capability of HALS [10].

UV-absorbers used solely or in combination with other light stabilizers are considered other group of additives to prevent photo-degradation. Combinations with nickel derivatives were used, especially for the stabilization of polyethylene films applied in agriculture and horticulture [11]. These substances absorb the harmful UV light more effectively than the polymer and can transform the excess of energy as heat or less-harmful radiation. A main disadvantage of UV absorbers, however, is the necessity of certain sample thickness that permits a proper absorption depth [9], [12] [13]. Moreover, as well as described below for HALS, UV absorbers possess an intrinsic durability which can turn in a considerable drawback. Sun irradiation near-IR reflective pigments, based on light scattering like titanium dioxide, zinc oxide or light absorption as carbon black have been considered to prevent polymers from photo-degradation [14]-[18]. Nevertheless, the majority of these systems consist in the addition of nanoparticles, which can provoke toxicity and harmful effects when inhaled or ingested by living organisms [19]. In this line, a novel microsized material has been recently developed which can improve significantly resistance to photo-degradation when added to a polymeric 
matrix in comparison with conventional screeners, preventing from harmful drawbacks. Silicon nano and microparticles obtained either by chemical methods [20]-[22] or through milling process [23], block very efficiently sun radiation in the whole UV, visible and infrared regions when coated on a surface. A $20 \mu \mathrm{m}$ thick coating of silicon microparticles is able to block $99 \%$ of the whole sun radiation. This protective mechanism is due to huge value of the refractive index much larger than that for any other material, as titanium dioxide, used for light protection [20].

The aim of the present study concerns determining the capability of the polydisperse silicon microparticles for sunlight protection when added to a non-additivated raw polypropylene matrix. In order to avoid problems derived of phase separation between matrix and particles, some additives acting as coupling agents can be added to the composite. Maleic anhydride (MAH) grafted PP has been proved to be an effective functional molecule for the reactive coupling between polypropylene (PP) and other polymers [24], [25] and loadings [26]-[31]. Concretely, for silicon microparticles the use of MAH prevented the composites from the phase separation and conglomeration of silicon domains. Moreover, the inclusion of micronsized particles usually affects polymer properties and behaviour, as crystallisation process, melt processing, thermal stability or mechanical properties, which have to be studied [32]-[35]. Therefore, a composite of grafted MAH-PP blended with non-additivated raw PP and silicon microparticles was considered for the study. For this purpose, an initial characterisation of the materials prior to the exposition should be accurately considered. Then, in order to determine how these particles avoid the degradation process, a monitored accelerated sunlight irradiation procedure was carried out.

\section{Experimental procedure}

\subsection{Materials description and sample preparation}

Polydisperse silicon microparticles were obtained from metallurgical grade silicon powder (Silgrain ${ }^{\circledR}$ with $99.5 \%$ of purity from Elkem), through a process of grinding. Screening of the particles was performed achieving that the 98\% were smaller than $2 \mu \mathrm{m}$ (see Figure 1) [23].

Unstabilised isotactic PP ISPLEN PP040 G1E (MFI 3 g/10 min at $230{ }^{\circ} \mathrm{C}$ ) was supplied by Repsol YPF (Spain) as pellets. Maleic anhydride grafted polypropylene (MAH-PP) from Eastman (Tennessee, USA), coded as G3003 with a maleic anhydride content of 1\%, a molecular weight of 52000 $\mathrm{g} / \mathrm{mol}$ and a viscosity of $60000 \mathrm{cP}$ (measured at $190{ }^{\circ} \mathrm{C}$ ) was used to ensure coupling of the polypropylene matrix with Si microparticles.

$\mathrm{PP}, \mathrm{MAH}-\mathrm{PP}$ and Si were mixed considering different compositions and resulting specimens were labelled as follows: PP (raw polypropylene), PP- 
MAH (PP mixed with a 3 \%wt. of MAH-PP), and PP-MAH-3Si and PPMAH-5Si (PP-MAH mixed with 3 \%wt. and $5 \%$ wt. of Si, respectively). Mixtures were prepared in a laboratory-scale co-rotating extruder working at $40 \mathrm{rpm}$ and a temperature program of $185-190-195^{\circ} \mathrm{C}$ from feeder to die. Afterwards, $200 \mu \mathrm{m}$ thick probes were obtained by hot compression moulding at $190{ }^{\circ} \mathrm{C}$, following a force $(\mathrm{kN})$ - time (min) program of (i) 020, (ii) 440-3, (iii) $660-3$ and (iv) $880-4$, followed by a quenching step to room temperature through water immersion.

\subsection{Accelerated sunlight irradiation procedure}

Accelerated sunlight irradiation was carried out by exposing the samples to controlled cycles of intense light into an Atlas Suntest XLS+ Xenon Exposure equipment (Illinois, USA) with black panel temperature of $50^{\circ} \mathrm{C}$ and irradiance of $600 \mathrm{~J} \cdot \mathrm{s}^{-1} \cdot \mathrm{m}^{-2}$ in the $\mathrm{UV}$-visible range wavelength $(\lambda=$ $280-800 \mathrm{~nm}$ ). Several irradiation stages were considered at 250, 750, 1500, 2250 and $3000 \mathrm{~h}$. Even though such testing cannot reproduce all the elements of weathering and exactly predict the performance of these samples in a real outdoor exposure, some meaningful relative comparisons can be done. As a reference, the data at Jacksonville, Florida (USA), with an annual total radiant energy of $5800 \mathrm{MJ} \cdot \mathrm{m}^{-2}(\lambda=280-3000 \mathrm{~nm})$ are considered. According to bibliography [36], this total radiation in the UVvisible range $\left(\lambda=280-800 \mathrm{~nm}\right.$ ) would correspond to $3248 \mathrm{MJ} \cdot \mathrm{m}^{-2}$. Thus, the equivalence of 1 hour of simulated irradiation would be equivalent to 5.83 hours of real exposure in Jacksonville, Florida. Table 1 shows the equivalence for the different stages of irradiation.

Table 1. Approximated real exposure for Jacksonville, Florida (USA) of the considered irradiation stages in the UV-visible wavelength range.

\begin{tabular}{ccc}
\hline Stage & $\begin{array}{c}\text { Simulated exposure } \\
\text { (hours) }\end{array}$ & $\begin{array}{c}\text { Approximated real } \\
\text { exposure } \\
\text { (months) }\end{array}$ \\
\hline A & 250 & 2.02 \\
B & 750 & 6.07 \\
C & 1500 & 12.14 \\
D & 2250 & 18.21 \\
E & 3000 & 24.27 \\
\hline
\end{tabular}

\subsection{Analytical techniques}

Particles morphology and size distribution profile were assessed by Scanning Electron Microscopy (SEM) and Dynamic Light Scattering (DLS) respectively. Thermal properties and stability as well as mechanical properties were characterised by differential scanning calorimetry (DSC), dynamic mechanical-thermal analysis (DMTA) and thermogravimetric analysis (TGA) to study both the effect of the addition on the initial 
properties of PP and on its durability along exposure to UV-visible irradiation.

\subsubsection{Scanning Electron Microscopy (SEM)}

Scanning electronic Microscopy images were taken on a Jeol JSM-6300 scanning electronic microscope after a gold sputtering of the samples deposited on SEM mounts. Accelerating voltages of $20 \mathrm{kV}$ were employed.

Composite polymers were cut perpendicularly to the lamellar direction in order to examine particles distribution inside the samples and to obtain a cross section view of the specimens.

\subsubsection{Dynamic Light Scattering (DLS)}

Particle size distribution profile was obtained by a Mastersizer 2000 (Malvern) based on dynamic light scattering technique.

\subsubsection{Differential scanning calorimetry (DSC)}

Calorimetric experiments were carried out by means of a Mettler-Toledo DSC 820 series (Columbus, USA), previously calibrated by In and Zn standards. Samples of $\sim 4 \mathrm{mg}$ were analysed between 20 and $200{ }^{\circ} \mathrm{C}$ with a heating/cooling/heating rate of $10^{\circ} \mathrm{C} \cdot \mathrm{min}^{-1}$ under a nitrogen flow of 50 $\mathrm{ml} \cdot \mathrm{min}^{-1}$. The specimens were characterized at least by triplicate and the averages of temperatures and enthalpies were taken as representative values. The melting and crystallisation peak temperatures $\left(T_{m}, T_{c}\right)$ were determined from their peaks in thermograms and the enthalpies associated to those events $\left(\Delta h_{m}, \Delta h_{c}\right)$ were determined using constant integration limits. The degree of crystallinity $\left(X_{c}\right)$ was calculated by Equation 1.

$$
X_{c}=\frac{1}{\left(1-m_{p}\right)} \frac{\Delta h_{m}}{\Delta h_{m 0}} \times 100
$$

(Equation 1)

where $\Delta h_{m 0}$ is the melting enthalpy for a $100 \%$ crystalline PP (207 J.g-1 [37]), and $\left(1-m_{p}\right)$ is the weight fraction of PP. The lamellar thickness distribution was calculated [38]-[40] by applying the Thomson-Gibbs equation (Equation 2),

$$
l_{C}\left(T_{m}\right)=\left[\left(1-\frac{T_{m}}{T_{m}^{0}}\right) \cdot \frac{\Delta h_{m V}}{2 \cdot \sigma_{e}}\right]^{-1}
$$

(Equation 2)

where $T_{m}$ is the melting temperature; $T_{m}{ }^{0}$ is the equilibrium melting temperature of an infinite crystal $\left(187.7^{\circ} \mathrm{C}\right) ; \sigma_{e}$ is the surface free energy of the basal plane where the chains fold $\left(49.6 \cdot 10^{-3} \mathrm{~J} \cdot \mathrm{m}^{-2}\right)$; and $\Delta h_{m V}$ is the melting enthalpy per volume unit $\left(1.34 \cdot 10^{8} \mathrm{~J} \cdot \mathrm{m}^{-3}\right)$ [41].

\subsubsection{Dynamic-mechanic-thermal analysis (DMTA)}

Dynamic mechanic thermal analyses were conducted in a small clamping assembly in tension mode, with $5 \mathrm{~mm}$ of effective length between clamps, 
by means of Mettler-Toledo DMA861e (Columbus, USA). The displacement was checked before all the experiments. The deformation force was set at $0.1 \mathrm{~N}$. Experiments at $1 \mathrm{~Hz}$ were carried out during heating from 35 to $130{ }^{\circ} \mathrm{C}$ with isothermal steps of $1^{\circ} \mathrm{C}$. Analyses were performed at least three times per sample to ensure reproducibility.

\subsubsection{Thermo-gravimetric analysis (TGA)}

Thermal stability was studied by thermogravimetric analysis by means of a Mettler-Toledo TGA 851 series (Columbus, USA). Samples with a mass of $4 \mathrm{mg}$ were introduced in perforated alumina crucibles with capacity of $70 \mu \mathrm{L}$, and analysed by a linear heating rate of $10{ }^{\circ} \mathrm{C} \cdot \mathrm{min}^{-1}$ in the temperature range of $25-800^{\circ} \mathrm{C}$, under a flow rate of $50 \mathrm{~mL} \cdot \mathrm{min}^{-1}$ of argon. The onset degradation temperature $\left(T_{\text {onset }}\right)$ was considered as the point in which sample weight decreased 5\%. Main peak degradation temperature $\left(T_{\text {peak }}\right)$ was taken as the minimum of the first-derivative thermogravimetric curve. Experiments were repeated at least three times and the averages were considered as representative values.

\section{Results and discussion}

The discussion of results is structured in two main sections. Firstly, the effect of the addition of maleic anhydride and Si microparticles to raw PP matrix is reported. Afterwards, the potential of improvement of sunlight protection by $\mathrm{Si}$ microparticles for raw PP is considered in terms of mechanical performance and thermal stability.

3.1 Preparation of composites: effect of Si microparticles and MAH coupling agent

\subsubsection{Dispersion of Si microparticles}

SEM image and particle size distribution profile of the employed silicon microparticles can be seen in Figure 1a and Figure 1b respectively. The SEM image of the transversal view (Figure 1c) as well as a top view optical microscopy image (Figure 1d) of the composite PP-MAH-5Si reveal that silicon microparticles are quite well dispersed inside the polymer matrix. 

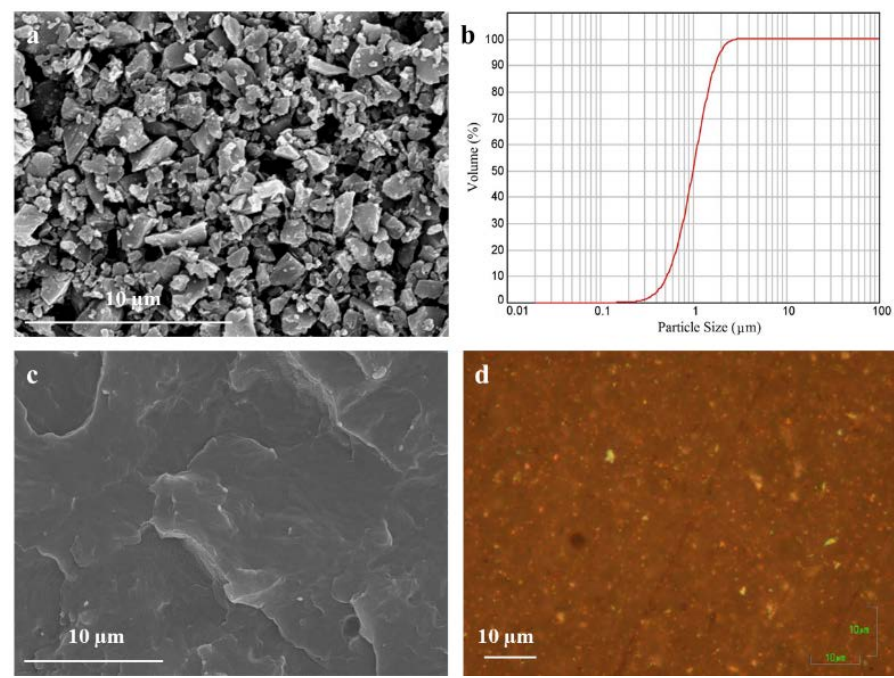

Figure 1. SEM image (a) and size distribution profile (b) of the employed silicon microparticles. SEM cross section view (c) and optical top view image (d) of the composite PP-MAH-5Si.

\subsubsection{Morphology and thermal processing windows}

Figure 2 shows the thermograms of first heating, cooling, and second heating scans for raw PP, PP-MAH and PP-MAH-Si composites. In general, the addition of a low amount of MAH and the inclusion of Si scarcely modified the crystallisation and melting behaviours of PP. It suggests that the same technological specifications to process PP could be extended to process PP-Si composites.
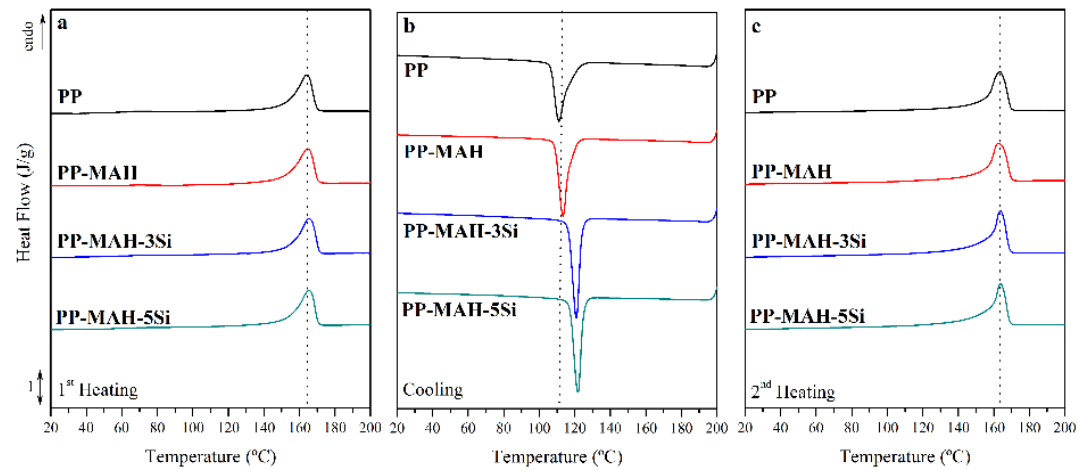

Figure 2. DSC thermograms of $1^{\text {st }}$ heating (a), cooling (b), and $2^{\text {nd }}$ heating scans (c) for raw PP, PP-MAH and PP-MAH-Si composites.

A particular study of the first heating scan (Figure 2a) showed that raw PP displayed a single melting peak, characteristic of quenched polypropylene 
[42], [43]. PP-MAH and PP-MAH-Si composites displayed the same behaviour: PP-MAH due to the low MAH content and the high molecular weight of the PP [25]; and composites due to the nucleating ability of Si microparticles [44], [45]. Both components tended to co-crystallize and melt in a single peak, at slightly higher temperatures values in the case of composites. Table 2 shows the peak temperatures, enthalpies and average lamellar thickness obtained from the first heating scan. After quenching procedure, the addition of MAH and Si barely modified the content of crystalline fraction, whereas it promoted the growth of crystals thickness $\left(l_{C}\right)$ (Figure 3a). The peak of the distribution increased from $\sim 14.6$ for raw PP to $15.1 \mathrm{~nm}$ for PP-MAH, and $15.6 \mathrm{~nm}$ for PP-MAH-3Si and 5Si. Unimodal curves indicated a single population of crystalline domains in each case.
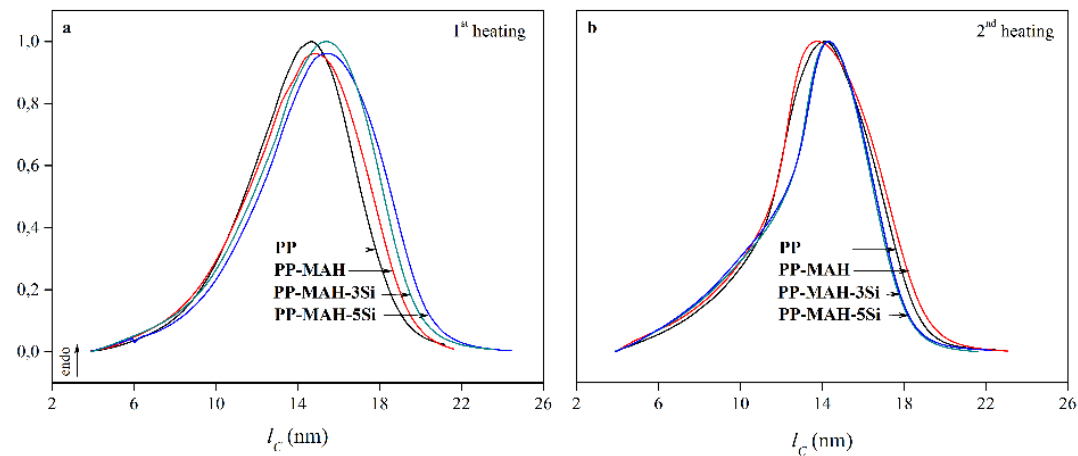

Figure 3. Lamellar thickness distribution for raw PP, PP-MAH and PP-MAH-Si composites in the $1^{\text {st }}$ heating (a) and $2^{\text {nd }}$ heating (b) scans.

Concerning the cooling scan (Figure $2 \mathbf{b}$ ), a single crystallisation peak $T_{C}$ for all materials is shown. Figure 8 contains the peak temperatures and enthalpies of this process. The presence of MAH induced an increment of $\sim 1.9 \%$ of $T_{c}$. A further addition of $3 \%$ wt. and $5 \%$ wt. of Si gave out an increase of $\sim 6.8 \%$ and $\sim 7.5 \%$ of $T_{c}$, respectively, taking PP-MAH as reference, as reported by other authors [46].

Regarding the second heating scan (Figure 2c), similar $T_{m}$ was found for all materials once the thermal history has been removed. Moreover, $\Delta h_{m}$ decreased for composites. Although this lower melting enthalpy is traduced in lower crystalline degree, Figure $\mathbf{3 b}$ shows that the average $l_{C}$ remained constant. In addition, it is important to remark that, for composites, the crystalline population was narrowed. Table 3 shows the peak temperatures, enthalpies and average lamellar thickness for all materials. 


\subsubsection{Mechanical properties of neat PP-Si composites}

Figure 4 shows the storage modulus ( $\left.E^{\prime}\right)$ values that were recorded through dynamic-mechanical thermal analysis at $1 \mathrm{~Hz}$ as a function of temperature for PP and composites. According to calorimetric results, the slight nucleating ability of MAH to induce the formation of crystalline fraction was traduced in an increase of $\sim 8 \%$ in $E$ '. When Si microparticles were added to the coupled PP matrix, $E$ ' increased $~ 85 \%$ for a $3 \%$ wt. of Si and arrived to a $\sim 115 \%$ for a $5 \%$ wt. of silicon microparticles. Those results were in agreement with other reports combining PP with particles such as zinc oxide [15], clay [26], calcium carbonate [26], [47] or silica [48]. It was remarkable that this increment in modulus was not linked to the crystalline nucleation or growth induced by the presence of Si. Indeed, as shown in the inset of Figure 4, similar slopes suggested that the silicon particles did not affect the profile of viscoelastic behaviour of PP, but just being displaced to higher $E$ ' values. There was therefore effective stress transfer from the PP matrix to Si particles due to entanglement of the polymer chains with the filler, increasing the stiffness of the segments in the surroundings of the particles [48], [49].

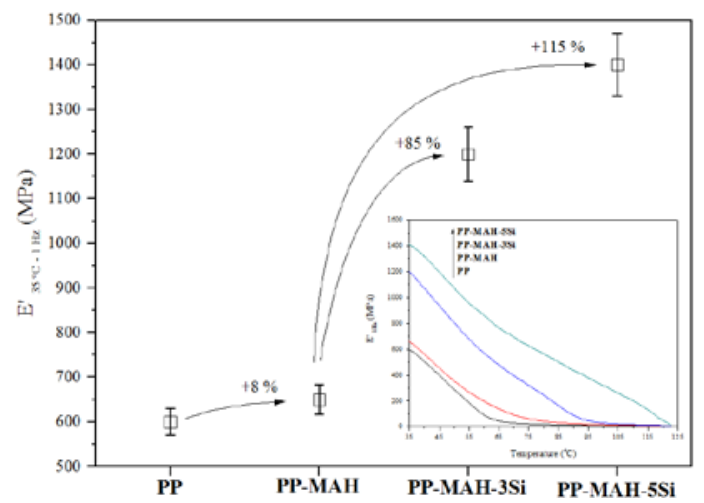

Figure 4. Storage modulus (E') values recorded at $1 \mathrm{~Hz}$ and $35^{\circ} \mathrm{C}$ for raw $\mathrm{PP}$, PPMAH and PP-MAH-Si composites. Inset: Storage modulus (E') profiles recorded at 1 $\mathrm{Hz}$ as a function of temperature.

\subsubsection{Thermal stability}

The thermal stability was assessed by means of thermogravimetric experiments under inert atmosphere. Results are gathered in Figure 5, in terms of thermogravimetric and first-derivative thermogravimetric curves (Figure 5a), as well as an evolution of peak and onset temperatures (Figures 5b and 5c, respectively). Neither the addition of MAH nor the addition of Si particles modified the mass-loss profile which took place through a single stage. However, the effect of MAH into the PP improved its thermal stability, as shown by slightly higher onset $T_{\text {onset }}$ and peak $T_{\text {peak }}$ 
temperature [48]. Due to the addition of $\mathrm{Si}$, a considerable increase in $T_{\text {onset }}$ and slight increase in $T_{\text {peak }}$ was found, being superior for PP with a $5 \%$ wt. of Si. This demonstrated the thermal stabilization by increasing the $\mathrm{Si}$ content, as reported using similar particles [33], [50].

As observed in decomposition curve for the composites, silicon microparticles became the remaining residue after combustion of the PPmatrix, remarking the possibility of recovering them at end of life after though a hypothetic energetic valorisation procedure. Thus, this additive can be reused after further purification if necessary, increasing its addedvalue.


Figure 5. (a) Thermal decomposition profiles and derivative curves, (b) peak decomposition temperature $\left(T_{\text {peak }}\right)$, and $(c)$ onset degradation temperature $\left(T_{\text {onset }}\right)$ for raw $\mathrm{PP}, \mathrm{PP}-\mathrm{MAH}$ and $\mathrm{PP}-\mathrm{MAH}-\mathrm{Si}$ composites.

\subsection{Durability of composites of PP filled with Si particles under sunlight radiation}

Figure 6 shows the appearance of raw PP, PP-MAH and PP-MAH-Si composites after 250, 750, 1500, 2250 and $3000 \mathrm{~h}$ of irradiation in the UVvisible wavelength range $(\lambda=280-800 \mathrm{~nm})$. For PP and PP-MAH, samples become semi-opaque after $250 \mathrm{~h}$ of irradiation due to the generation of new crystalline domains by chemi-crystallisation [51], [52] [53]. After $750 \mathrm{~h}$, transparent samples turned entirely opaque and whitish. Disintegration took place after $1500 \mathrm{~h}$ of irradiation due to the advance of chain scission [15], [54], [55] and the effect of chemi-crystallisation, which is responsible of the surface cracking by contraction of surface layers, causing grave weakening in different properties of the samples after shortterm exposures [54], [55].

In contrast, PP-MAH-3Si and PP-MAH-5Si after 250 and $750 \mathrm{~h}$ of irradiation showed an apparently similar state than that prior to the exposition. After $1500 \mathrm{~h}$, the sample surface slightly changed, being easily scratched during manipulation, detaching a fine powder. After $2250 \mathrm{~h}$ of exposition, the composite films turned slightly brittle and surface appeared 
to be rougher. Finally, after 3000 h, composites with $3 \%$ wt. of Si were delicate to handle and apparently more degraded than those with $5 \%$ wt. of Si particles. Thus, a deep study in order to understand the mechanisms and determine the durability of the quality of composites was carried out by thermal analysis [56].

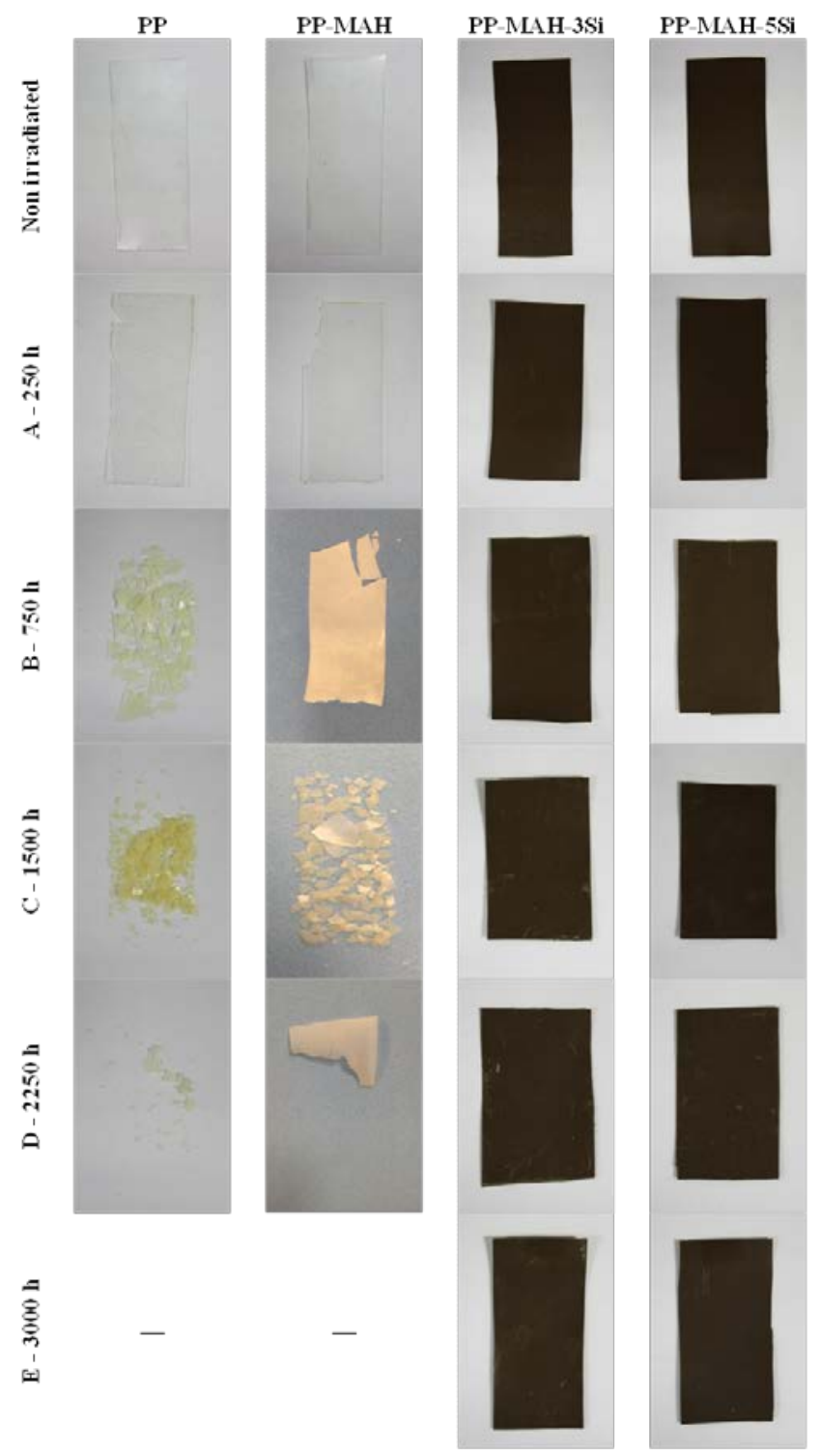

Figure 6. Appearance of raw PP, PP-MAH and PP-MAH-Si composites after 250, $750,1500,2250$ and $3000 \mathrm{~h}$ of irradiation in the UV-visible wavelength range ( $\lambda=$ $280-800 \mathrm{~nm})$. 
3.2.1 Impact of sunlight radiation on morphology and thermal performance

Figure 7 shows the thermograms of first heating, cooling, and second heating scans for raw PP, PP-MAH and PP-MAH-Si composites after 250, 750, 1500, 2250 and $3000 \mathrm{~h}$ of irradiation in the UV-visible wavelength range $(\lambda=280-800 \mathrm{~nm})$ obtained by differential scanning calorimetric analysis (DSC). Table 2 and Table 3 show the main temperatures, enthalpies of melting and crystallisation events as well as degree of crystallinity and lamellar thickness values corresponding to the heating scans of the Figure 7.
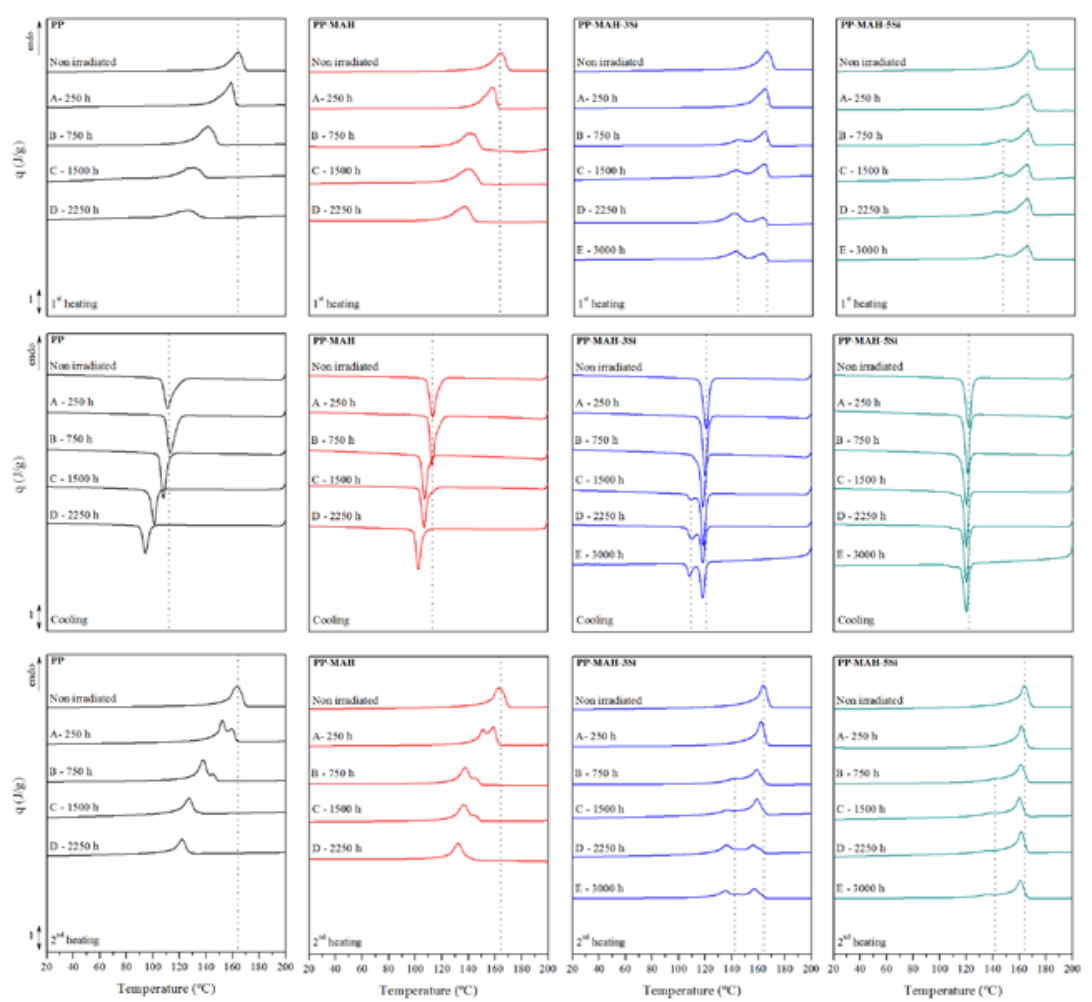

Figure 7. Thermograms of $1^{\text {st }}$ heating, cooling, and $2^{\text {nd }}$ heating scan for raw PP, PPMAH and PP-MAH-Si composites irradiated in the UV-visible wavelength range $(\lambda=$ $280-800 \mathrm{~nm})$.

In the first heating run, single melting peaks are generally found for PP and PP-MAH. The effect of degradation produced a significant decrease in the melting temperature of the unimodal peak. The addition of silicon particles promoted the apparition of a double-melting behaviour. The original unimodal melting peak remained in the same position, around $165{ }^{\circ} \mathrm{C}$ and a new melting peak appeared after $750 \mathrm{~h}$ of irradiation. 
Once the effect of thermal history has been removed during the first heating run, the study of the cooling scan indicated that PP and PP-MAH showed a crystallisation peak $\left(T_{c}\right)$ at lower temperatures the higher the exposure to sunlight irradiation was, as shown in Figure 8a. This reduction was barely more significant for PP than for PP-MAH. Conversely, the addition of Si drove the main crystallisation events, giving unaltered $T_{c}$. The presence of a 5 \%wt. of Si prevented the crystallisation of weaker crystalline domains, being the exotherm almost unimodal. Moreover, in Figure $8 \mathbf{b}$ the evolution of crystallisation enthalpy is represented. As occurred with peak temperature, enthalpy decreased along irradiation for PP and PP-MAH, whereas for PP-MAH-3Si it decreased in last stages of irradiation and for PP-MAH-5Si it remained almost constant. These facts reinforced that irradiation was attacking the amorphous fraction of PP and generated chemical irregularities that difficult the crystallisation process and delayed it [57]-[59].
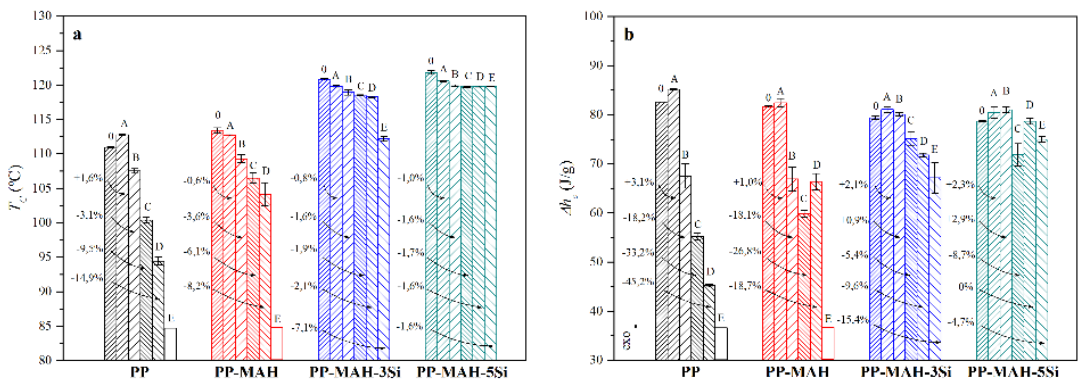

Figure 8. Crystallisation temperature $\left(\mathrm{T}_{\mathrm{c}}\right)(\mathrm{a})$ and crystallisation enthalpy $\left(\Delta \mathrm{h}_{\mathrm{c}}\right)(\mathrm{b})$ for the cooling run for raw PP, PP-MAH and PP-MAH-Si composites irradiated in the UV-visible wavelength range $(\lambda=280-800 \mathrm{~nm})$ (Stages: $\mathrm{A}=250 \mathrm{~h} ; \mathrm{B}=750 \mathrm{~h} ; \mathrm{C}=$ $1500 \mathrm{~h} ; \mathrm{D}=2250 \mathrm{~h} ; \mathrm{E}=3000 \mathrm{~h})$.

The study of the second DSC heating run shed light on understanding the bi-modal melting process of materials. Many explanations have been suggested for this phenomenon, such as the presence of different crystalline structures [60], [61]; crystal transformation during heating [62], [63]; reorganisation during heating [43], [64]; or segregation of molecules with low molecular weight which form crystals with lower $T_{m}$ [65]. A deep study by Rabello and White [57] concluded that degraded molecules form relatively unstable crystals during rapid cooling segment which melt, then re-crystallize into a more stable phase that afterwards melts at a higher temperature, leading to a double melting peak. Indeed, all materials showed a bi-modal melting as a result of a balance of low-T and high-T crystalline populations.

Figure 9 shows that raw PP effectively showed high extent of degradation with a continuous decrease of melting temperatures, moving the balance of initial high-T crystalline populations towards low-T domains [66]-[70]. 
This behaviour also appeared but slightly retarded by the addition of MAH. Concerning the stabilizing effect of Si microparticles, they retained the initial higher lamellar thicknesses around $15 \mathrm{~nm}$, regardless the advance of irradiation, being this influence more relevant for samples loaded with a 5 \%wt. of Si.
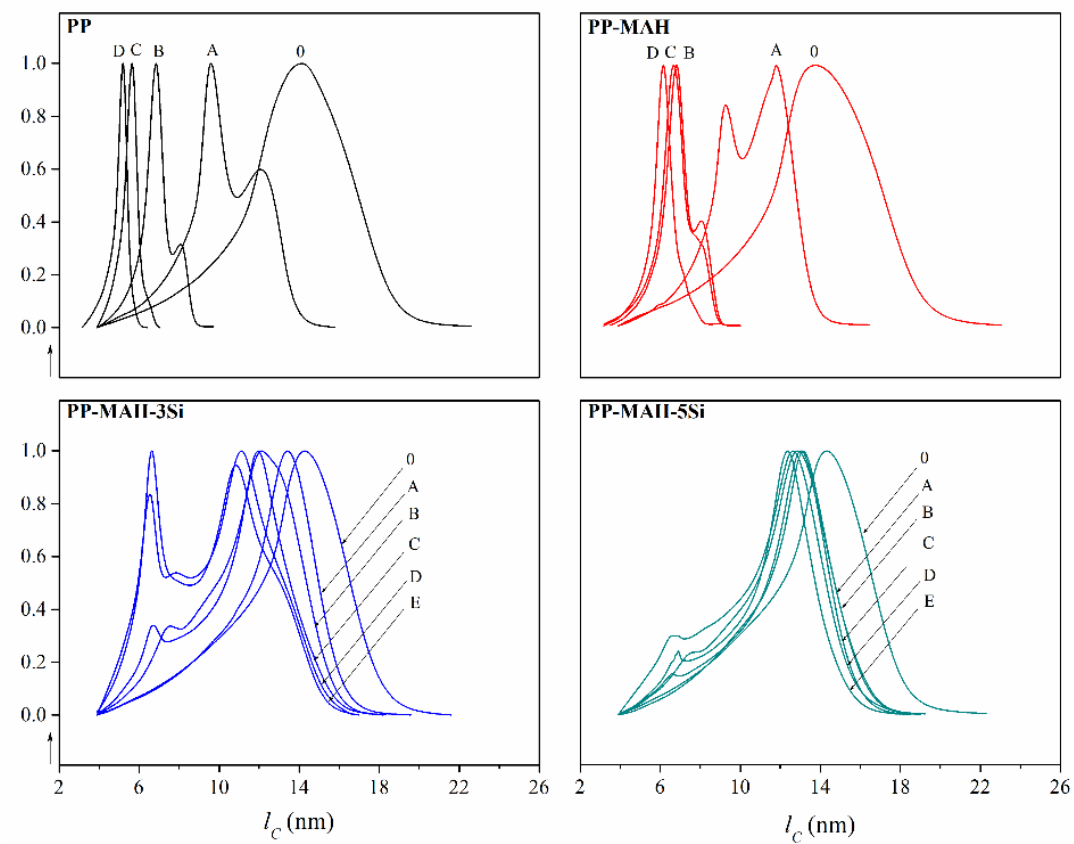

Figure 9. Lamellar thickness distributions for raw PP, PP-MAH and PP-MAH-Si composites in the $2^{\text {nd }}$ heating scan irradiated in the UV-visible wavelength range $(\lambda=$ $280-800$ nm) (Stages: A = 250 h; B $=750$ h; C = 1500 h; D = 2250 h; E = 3000 h).

Figure 10 plots the evolution of the crystalline degree $\left(X_{c}\right)$ for all materials along the sunlight irradiation tests. Raw PP showed a first increasing $X_{c}$ tendency with irradiation, ascribed to the chemi-crystallisation of freed segments from chain scission up to 750 h of irradiation [51]-[53], [71][76]. Further exposure provoked a decrease due to massive chain scission. In contrast, PP-MAH did not showed the $X_{c}$ decrease at longer times of irradiation, thus stabilizing PP due to the chemical bonding of PP and $\mathrm{MAH}$, which let less liable sites for degradation. The addition of $\mathrm{Si}$ microparticles hindered chain scission and thus subsequent chemicrystallisation of low-T crystalline domains, keeping the size of high-T populations, being this effect more relevant with PP loaded with $5 \%$ wt. of Si. Therefore, the crystalline degree is maintained and even increased regardless the irradiation time. 


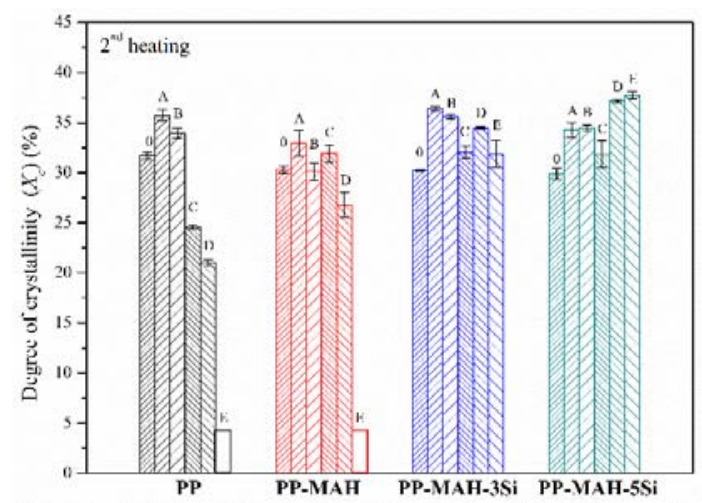

Figure 10. Degree of crystallinity $\left(\mathrm{X}_{\mathrm{c}}\right)$ for raw PP, PP-MAH and PP-MAH-Si composites irradiated in the UV-visible wavelength range $(\lambda=280-800 \mathrm{~nm})$, as calculated from for the $2^{\text {nd }}$ heating scan (Stages: A $=250 \mathrm{~h} ; \mathrm{B}=750 \mathrm{~h} ; \mathrm{C}=1500 \mathrm{~h}$; D $=2250 \mathrm{~h} ; \mathrm{E}=3000 \mathrm{~h})$.

Si microparticles affected the crystalline fraction, but more than a matter of the effect of irradiation on the degree of crystallinity [77], it was about the distribution of this crystalline phase in the polymer matrix. In fact, a competitive behaviour seems to take place. On the one hand, the natural sunlight degradation profile of PP, which drove the crystalline domains to lower sizes and the stabilizing effect of Si particles, which retains the initial higher lamellar thicknesses around $15 \mathrm{~nm}$, regardless the advance of irradiation. This effect was more relevant for samples loaded with a $5 \%$ wt. of Si.

As suggested by Zhao et al. [15], the non-significant variation in $X_{c}$ for the composites may be due to lower extent of photo-degradation, as a consequence of the effective protection and stabilisation function of the Si particles against irradiation, which hindered the chemi-crystallisation phenomenon.

High refractive index microparticles scatter light very efficiently, especially at wavelength values of the order of the particles size [78]. Theory predicts that silicon microparticles can block light up to ten times the size of the particles for wavelength values of the Mie resonances. Although the blocking effect is restricted to a narrow wavelength region, a polydisperse suspension of silicon particles ranging between 0.1 and $2 \mu \mathrm{m}$ would block very efficiently the whole sun radiation spectrum. 
Table 2. Main parameters of calorimetric analysis along the $1^{\text {st }}$ heating scan for raw PP, PP-MAH and PP-MAH-Si composites irradiated in the UVvisible wavelength range $(\lambda=280-800 \mathrm{~nm})$.

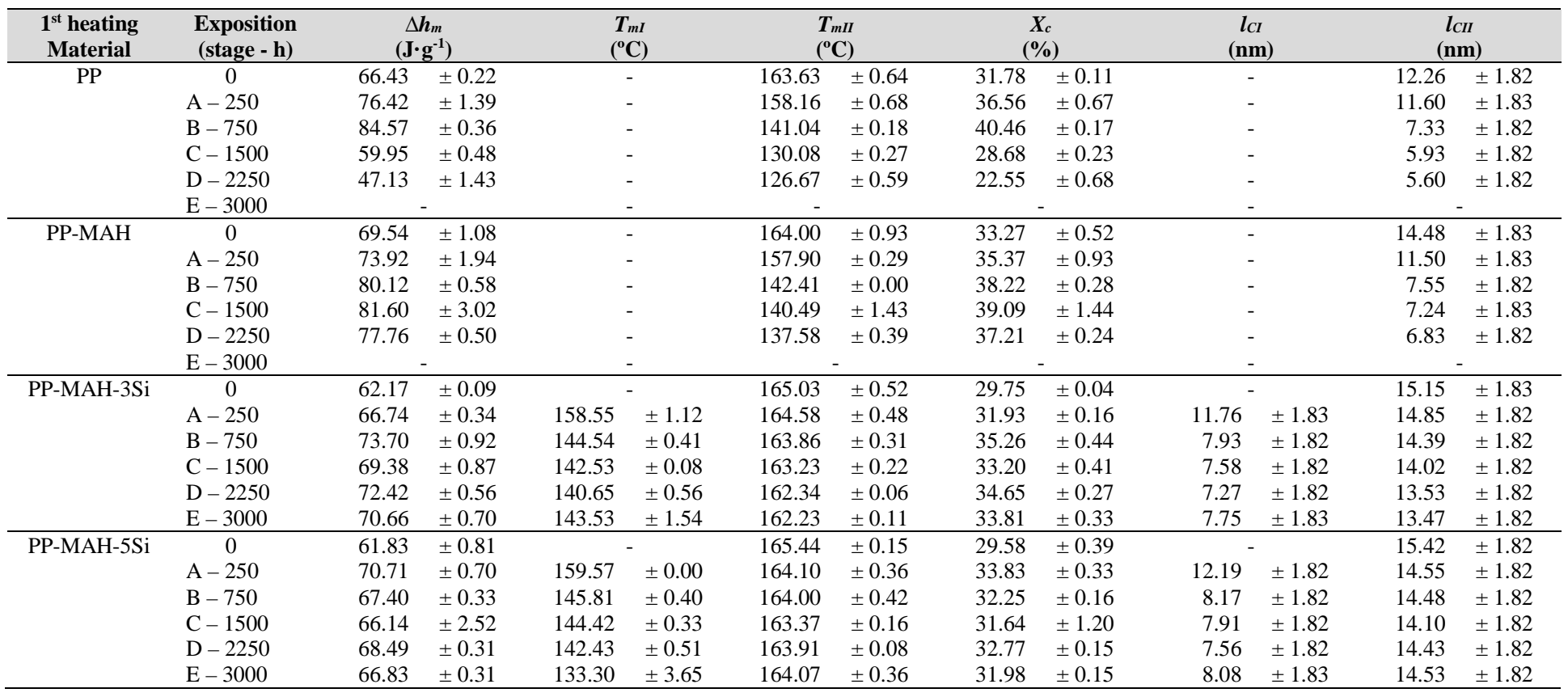


Table 3. Main parameters of calorimetric analysis along the $2^{\text {nd }}$ heating scan for raw PP, PP-MAH and PP-MAH-Si composites irradiated in the UVvisible wavelength range $(\lambda=280-800 \mathrm{~nm})$.

\begin{tabular}{|c|c|c|c|c|c|c|c|c|c|c|c|}
\hline \multirow{2}{*}{ 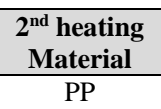 } & \multirow{3}{*}{$\begin{array}{c}\begin{array}{c}\text { Irradiation } \\
\text { (stage - h) }\end{array} \\
0 \\
A-250\end{array}$} & \multicolumn{2}{|c|}{$\begin{array}{c}\Delta \boldsymbol{h}_{m} \\
\left(\mathbf{J} \cdot \mathbf{g}^{-1}\right)\end{array}$} & \multicolumn{2}{|c|}{$\begin{array}{c}T_{m}{ }^{I} \\
\left({ }^{\circ} \mathrm{C}\right)\end{array}$} & \multicolumn{2}{|c|}{$\begin{array}{l}T_{m}{ }^{I I} \\
\left({ }^{\circ} \mathrm{C}\right)\end{array}$} & \multicolumn{2}{|c|}{$\begin{array}{c}I_{C}^{I} \\
(\mathrm{~nm})\end{array}$} & \multicolumn{2}{|c|}{$\begin{array}{c}I_{C}{ }^{I I} \\
(\mathrm{~nm})\end{array}$} \\
\hline & & 66.23 & \pm 0.70 & & & 162.88 & \pm 0.83 & 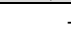 & & 13.83 & \pm 1.83 \\
\hline & & 74.70 & \pm 1.13 & 151.72 & \pm 0.40 & 159.01 & \pm 0.44 & 9.52 & \pm 1.82 & 11.95 & \pm 1.82 \\
\hline & B -750 & 70.91 & \pm 1.03 & 136.89 & \pm 1.18 & 144.19 & \pm 1.40 & 9.40 & \pm 1.83 & 7.87 & \pm 1.82 \\
\hline & $C-1500$ & 51.39 & \pm 0.44 & & & 127.11 & \pm 0.18 & . & & 5.64 & \pm 1.82 \\
\hline & $\mathrm{D}-2250$ & 43.83 & \pm 0.61 & & & 121.95 & \pm 0.25 & - & & 5.19 & \pm 1.82 \\
\hline & $E-3000$ & \multicolumn{2}{|c|}{-} & \multicolumn{2}{|c|}{-} & \multicolumn{2}{|c|}{-} & \multicolumn{2}{|c|}{-} & \multicolumn{2}{|c|}{-} \\
\hline \multirow[t]{6}{*}{ PP-MAH } & 0 & 63.35 & \pm 0.72 & \multicolumn{2}{|c|}{-} & 162.36 & \pm 0.74 & \multicolumn{2}{|c|}{-} & 13.54 & \pm 1.83 \\
\hline & $A-250$ & 68.83 & \pm 2.63 & 151.29 & \pm 0.91 & 158.73 & \pm 0.77 & 9.40 & \pm 1.83 & 11.84 & \pm 1.83 \\
\hline & B -750 & 62.94 & \pm 1.77 & 137.61 & \pm 0.80 & 145.50 & \pm 0.52 & 6.83 & \pm 1.83 & 8.11 & \pm 1.82 \\
\hline & $C-1500$ & 66.71 & \pm 1.77 & 136.54 & \pm 1.34 & 144.14 & \pm 1.49 & 6.68 & \pm 1.83 & 7.85 & \pm 1.83 \\
\hline & $D-2250$ & 55.99 & \pm 2.58 & & & 132.23 & \pm 1.22 & \multirow{2}{*}{\multicolumn{2}{|c|}{ - }} & 6.16 & \pm 1.83 \\
\hline & $E-3000$ & \multicolumn{2}{|c|}{-} & \multicolumn{2}{|c|}{-} & \multicolumn{2}{|c|}{-} & & & \multicolumn{2}{|c|}{ - } \\
\hline \multirow[t]{6}{*}{ PP-MAH-3Si } & 0 & 63.17 & \pm 0.25 & \multicolumn{2}{|c|}{-} & 163.37 & \pm 0.43 & \multicolumn{2}{|c|}{-} & 14.1 & \pm 1.82 \\
\hline & $A-250$ & 76.16 & \pm 0.39 & \multicolumn{2}{|c|}{ - } & 162.26 & \pm 0.32 & \multicolumn{2}{|c|}{ - } & 13.48 & \pm 1.82 \\
\hline & B - 750 & 74.39 & \pm 0.48 & 142.32 & \pm 0.28 & 160.17 & \pm 0.87 & 7.54 & \pm 1.82 & 12.46 & \pm 1.83 \\
\hline & $C-1500$ & 66.96 & \pm 1.26 & 136.54 & \pm 0.58 & 159.04 & \pm 0.10 & 6.69 & \pm 1.82 & 11.96 & \pm 1.82 \\
\hline & $D-2250$ & 71.96 & \pm 0.27 & 136.07 & \pm 0.14 & 156.07 & \pm 0.19 & 6.62 & \pm 1.82 & 10.83 & \pm 1.82 \\
\hline & $E-3000$ & 66.60 & \pm 2.81 & 132.66 & \pm 2.54 & 159.56 & \pm 2.48 & 6.21 & \pm 1.84 & 12.18 & \pm 1.84 \\
\hline \multirow[t]{6}{*}{ PP-MAH-5Si } & 0 & 62.45 & \pm 1.10 & \multicolumn{2}{|c|}{-} & 163.56 & \pm 0.29 & \multicolumn{2}{|c|}{-} & 14.22 & \pm 1.82 \\
\hline & $A-250$ & 71.63 & \pm 1.63 & \multicolumn{2}{|c|}{-} & 161.67 & \pm 0.23 & \multicolumn{2}{|c|}{-} & 13.18 & \pm 1.82 \\
\hline & B - 750 & 72.01 & \pm 0.66 & 142.34 & \pm 0.09 & 161.01 & \pm 0.49 & 7.54 & \pm 1.82 & 12.85 & \pm 1.82 \\
\hline & $C-1500$ & 66.58 & \pm 2.78 & 137.94 & \pm 0.16 & 160.00 & \pm 0.16 & 6.87 & \pm 1.82 & 12.38 & \pm 1.82 \\
\hline & $D-2250$ & 77.71 & \pm 0.30 & 135.93 & \pm 0.17 & 161.38 & \pm 0.07 & 6.60 & \pm 1.82 & 13.03 & \pm 1.82 \\
\hline & $E-3000$ & 78.87 & \pm 0.77 & 136.28 & \pm 0.61 & 162.41 & \pm 0.25 & 6.65 & \pm 1.82 & 13.57 & \pm 1.82 \\
\hline
\end{tabular}




\subsubsection{Improvement of storage modulus}

Figure 11 shows the storage modulus $\left(E^{\prime}\right)$ values recorded at $35{ }^{\circ} \mathrm{C}$ from DMTA analyses at $1 \mathrm{~Hz}$ for irradiated raw PP, PP-MAH and PP-MAH-Si composites. Due to effect of irradiation, the storage modulus could not be measured in PP and PP-MAH owing to the brittleness and the reduced thickness of the samples. In contrast, composites loaded with a $3 \% w t$. and $5 \%$ \%t. of Si particles showed similar profiles of reduction of $E^{\prime}$. Degradation is supposed to have affected the polymer matrix due to sunlight irradiation, but mechanical stresses were supported by the presence of $\mathrm{Si}$ in their compositions. In particular, the addition of $5 \%$ wt. of Si permitted to obtain significantly high $E^{\prime}$ values after $3000 \mathrm{~h}$ of irradiation, at higher levels than those shown by the composites with a 3 \%wt. of Si.

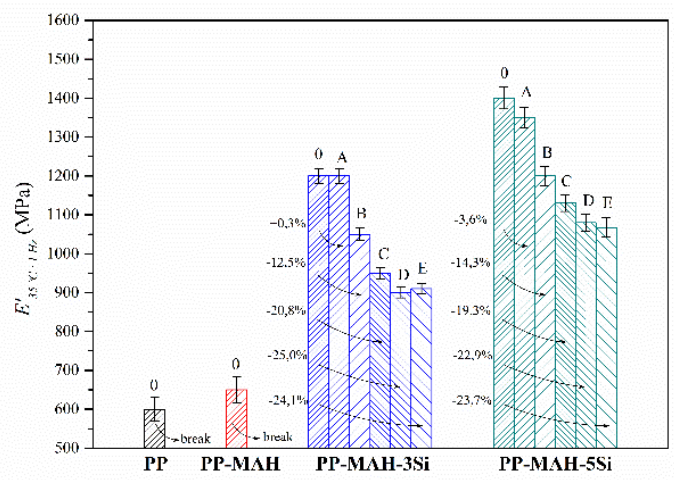

Figure 11. Storage modulus $\left(E^{\prime}\right)$ values recorded at $35^{\circ} \mathrm{C}$ and $1 \mathrm{~Hz}$ for raw PP, PPMAH and PP-MAH-Si composites irradiated in the UV-visible wavelength range $(\lambda=$ $280-800$ nm) (Stages: A = 250 h; B = 750 h; C = 1500 h; D = 2250 h; E = 3000 h).

\subsubsection{Thermal decomposition behaviour}

Thermograms of thermal decomposition along with their first-derivative curves are shown in Figure 12 for irradiated raw PP, PP-MAH and PPMAH-Si composites. Figure 13 displays the evolution of their thermal decomposition onset ( $T_{\text {onset }}$ ) (Figure 13a) and peak $\left(T_{\text {peak }}\right)$ temperatures (Figure 13b) along irradiation. Despite $T_{\text {peak }}$ is usually taken as indicator of degradation, the use of $T_{\text {onset }}$ is more sensible and it provides results at a technological context [79]-[81]. The initial decomposition process, which consumed around a $10-20 \%$ of mass, was enough to trigger the main decomposition process, which was widened in temperature the longer the irradiation was [15]. The most irradiated raw PP started decomposition at temperature immediately above the melting process $\left(\sim 165^{\circ} \mathrm{C}\right)$, due to the weakened structure. The addition of MAH had no stabilizing effect at this stage and similar profiles than those shown by raw PP were found, even showing fairly similar percentages of reduction in onset and peak 
temperatures. In contrast, the addition of Si retarded the starting of the first decomposition process, thus preventing the main decomposition up to 750 $\mathrm{h}$ of exposition for the case of a $3 \% \mathrm{wt}$. of Si and keeping the onset of decomposition within a range of control of $\sim 12.5 \%$ up to $3000 \mathrm{~h}$ of exposition for the case of a $5 \%$ wt. of Si. Thus, the effectiveness of $\mathrm{Si}$ particles to stabilize PP along irradiation was shown.
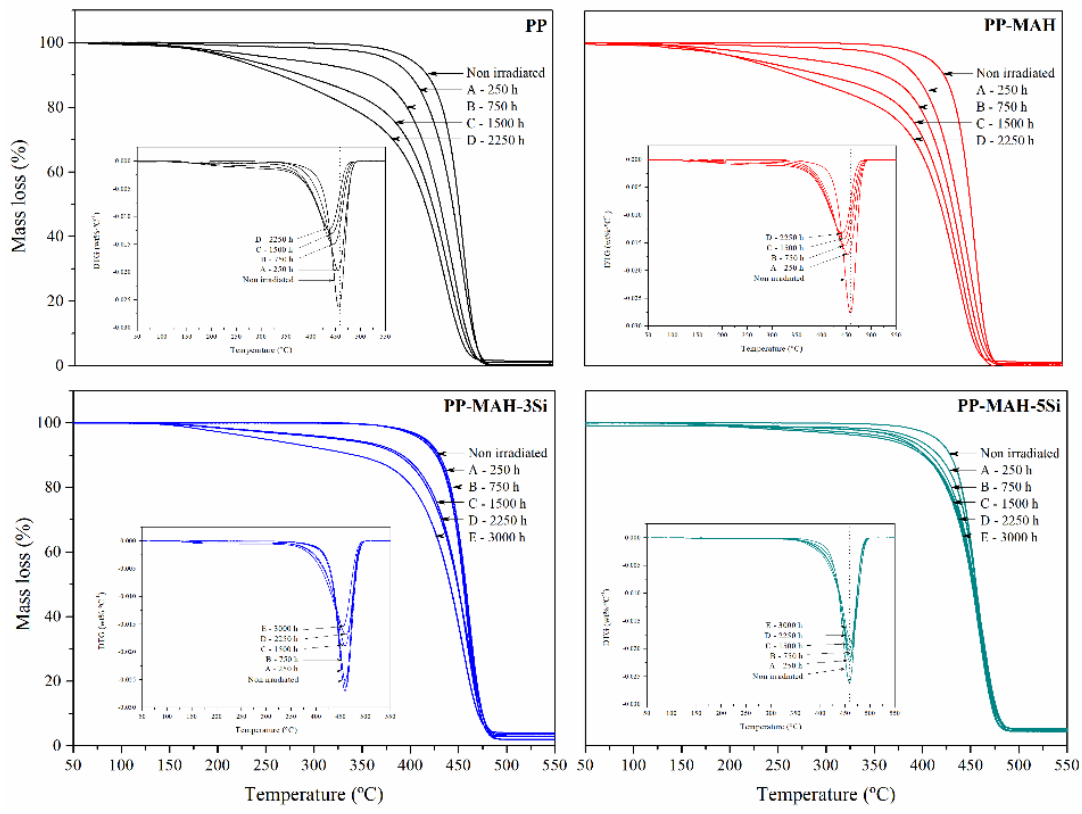

Figure 12. Thermal decomposition profiles and derivative curves (inserted) for raw $\mathrm{PP}, \mathrm{PP}-\mathrm{MAH}$ and PP-MAH-Si composites irradiated in the UV-visible wavelength range $(\lambda=280-800 \mathrm{~nm})$.
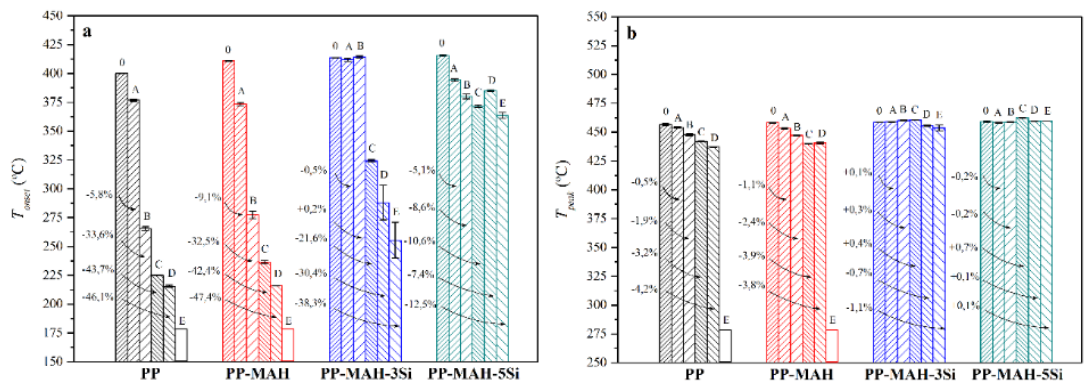

Figure 13. Thermal decomposition onset (a) and peak (b) temperatures ( $\mathrm{T}_{\text {onset }}$ and $\mathrm{T}_{\text {peak }}$ ) for raw PP, PP-MAH and PP-MAH-Si composites irradiated in the UV-visible wavelength range $(\lambda=280-800 \mathrm{~nm})$ (Stages: $A=250 \mathrm{~h} ; \mathrm{B}=750 \mathrm{~h} ; \mathrm{C}=1500 \mathrm{~h} ; \mathrm{D}=$ $2250 \mathrm{~h} ; \mathrm{E}=3000 \mathrm{~h})$. 


\section{Conclusions}

This paper shows the potential of novel patented high-tech silicon microparticles to protect polypropylene from degradation during both processing and accelerated sunlight irradiation. Silicon colloids provided UV-protection, which hindered the chemi-crystallisation phenomenon. Preservation of appearance, thermal, structural and mechanical properties as well as thermal decomposition behaviour were found. The stabilization of PP was more relevant for samples loaded with $5 \%$ wt. of Si.

The addition of silicon microparticles to coupled raw polypropylene matrix did not significantly alter the thermal processing conditions. It just slightly reduced the time of crystallization upon cooling and offered similar crystalline populations, with close lamellar thickness distributions, regardless the amount of Si microparticles. Similar thermal decomposition profiles were also found. Finally, mechanical properties were affected by increasing the dynamic storage modulus up to a $115 \%$, result which was independent form the nucleation effect of Si to grow crystal fractions in the PP matrix.

\section{Acknowledgements}

B.Sc. A. Montesinos is acknowledged for his dedication in the lab and his outstanding attitude towards learning. Ph.D. L. Santonja-Blasco is thanked for revision of the work and endless and enjoyable discussions. The authors would like to acknowledge the Spanish Ministry of Economy and Competitiveness, through the Research Project MAT2012-3504. The Spanish Ministry of Education, Culture and Sports is also thanked for the predoctoral FPU grant of O. Gil-Castell (FPU13/01916). Generalitat Valenciana is thanked for the PROMETEOII/2014/026, the APOSTD 2014/041 of J.D. Badia and the GRISOLIA/2012/003 for R. Teruel-Juanes. Universitat Politècnica de València is thanked for the support through the PAID-06-SP20120581 project and for the FPI grant of O. Gil-Castell. Repsol (Tarragona, Spain) is acknowledged for providing the raw polypropylene (PP) homopolymer.

\section{References}

[1] Maier C, Haber T. Polypropylene. The Definitive User's Guide and Databook. Norwich: William Andrew; 1998. ISBN: 978-1-884207-58-7.

[2] Carlsson DJ, Wiles DM. The photo-oxidation of polypropylene. Part I. Photooxidation and photoinitiation processes. Journal of Macromolecular Science - Reviews in Macromolecular Chemistry \& Physics 1976;14:65-106.

[3] Rabek JF. Photostabilization of polymers. London and New York: Elsevier Applied Science; 1990.

[4] Quin H, Zhang S, Liu H, Xie S, Yang M, Shen D. Photo-oxidative degradation of polypropylene/montmorillonite nanocomposites. Polymer 2005;46(9)3149-3156. 
[5] Morlat S, Mailhot B, Gonzalez D, Gardette JL. Photo-oxidation of PP/montmorillonite nanocomposites. Influence of nanoclay and compatibilizing agent. Chemistry of Materials 2004;16:377-383.

[6] Carlsson DJ , Garton A, Wiles DM. Initiation of Polypropylene Photooxidation. 2. Potential Processes and Their Relevance to Stability. Macromolecules 1976;9(5)695-701.

[7] Gugumus F. In: Scott G, editor. Developments in polymer stabilisation - 1. London: Applied Science Publishers Ltd.; 1979.

[8] Gugumus F. Possibilities and limits of synergism with light stabilizers in polyolefins: 1. HALS in polyolefins. Polymer Degradation and Stability, 2002; 75: 295-308.

[9] Gijsman P. Polymer Stabilization. Handbook of Environmental Degradation of Materials. Oxford: Elsevier; 2012.

[10] Carlsson DJ, Zhang K, Wiles DM. Polypropylene photostabilization by hindered amines in the presence of acidic species. Journal of Applied Polymer Science 1987;33:875-84.

[11] Saenz de Juano V. Contribución al estudio de la degradación ambiental de poliolefinas fotoestabilizadas. PhD Thesis. Universitat Politècnica de València: Spain.

[12] Gugumus F. In: Klemchuk P, Pospisil J, editors. Inhibition of oxidation processes in organic materials, vol. 2. Boca Raton, Florida (USA): CRC Press; 1989.

[13] Gugumus F, Zweifel H, editors. Plastics additives handbook, 5th edition, Munich: Hanser Publishers; 2001.

[14] Ammala A, Hill AJ, Meakin P, Pas SJ, Turney TW. Degradation studies of polyolefins incorporating nanoparticulate zinc oxide UV stabilizers. Journal of Nanoparticle Research 2002;4:167-174.

[15] Zhao H, Robert K. Y. Li. A study on the photo-degradation of zinc oxide (ZnO) filled polypropylene composites. Polymer 2006;47:3207-3217.

[16] Allen NS, Chirinis-Padron A, Henman TJ. The photo-stabilisation of polypropylene: A review. Polymer Degradation and Stability 1985;13:31-76.

[17] Li R, Yabe S, Yamashita M, Momose S, Yoshida S, Yin S, Sato T. UV-shielding properties of zinc oxide-doped ceria fine powders derived via soft solution chemical routes. Materials Chemistry and Physics 2002;75:39-44.

[18] Moustaghfir A, Rivaton A, Tomasella E, Mailhot B, Cellier J, Jacquet M, Gardette JL. Photostabilization of polycarbonate by ZnO coatings. Journal of Applied Polymer Science 2004;95(2):380-385.

[19] Reijnders L. The release of $\mathrm{TiO} 2$ and $\mathrm{SiO} 2$ nanoparticles from composites. Polymer Degradation and Stability 2009; 94(5):873-876.

[20] Fenollosa R, Meseguer F, Tymczenko M. Silicon Colloids: From Microcavities to Photonic Sponges. Advanced Materials 2008;20(1):95-98.

[21] Fenollosa R, Meseguer F, Tymczenko M. Spain patent no. PCT/ES2008/070102 (18 June 2007).

[22] Fenollosa R, Meseguer F, Tymczenko M. U. S. Patent no. 11/984870 (23 November 2007).

[23] I. Rodriguez, R. Fenollosa, F. Meseguer, A. Perez-Roldan. Patent Ref. WO 2012/101306. Formulation comprising silicon microparticles, as a pigment that can absorb visible, UV radiation and reflect IR radiation.

[24] Holsti-Miettinen R, Seppala J, Ikkala OT. Effects of compatibilizers on the properties of polyamide/polypropylene blends. Polymer Engineering \& Science 1992;32(13):868-877.

[25] Cho K, Li F, Choi J. Crystallization and melting behaviour of polypropylene and maleated polypropylene blends. Polymer 1999;40:1719-1729.

[26] Morreale M, Dintcheva N Tz, La Mantia FP. Accelerated weathering of PP based nanocomposites: Effect of the presence of maleic anhydride grafted polypropylene. eXPRESS Polymer Letters 2013;7(8):703-715.

[27] Mailhot B, Morlat S, Gardette JL, Boucard S, Duchet J, Gérard JF. Photodegradation of polypropylene nanocomposites. Polymer Degradation and Stability 2003;82:163-167. 
[28] García-López D, Picazo O, Merino JC, Pastor JM. Polypropylene-clay nanocomposites: effect of compatibilizing agents on clay dispersión. European Polymer Journal 2003;39(5):945-950.

[29] Xu W, Liang G, Zhai H, Tang S, Hang G, Pan WP. Preparation and crystallization behavior of PP/PP-g-MAH/Org-MMT nanocomposite. European Polymer Journal 2003;39(7):14671474.

[30] Rong MZ, Zhang MQ, Ruan WH. Surface modification of nanoscale fillers for improving properties of polymer nanocomposites: a review. Materials Science and Technology 2006;22(7):787-796.

[31] Chen XM, Shen JW, Huang WY. Novel electrically conductive polypropylene/graphite nanocomposites. Journal of Materials Science Letters 2002;21(3):213-214.

[32] Ray S, Okamoto M. Polymer/layered silicate nanocomposites: a review from preparation to processing. Progress in Polymer Science 2003;28:1539-641.

[33] Paul DR, Robeson LM. Polymer nanotechnology: nanocomposites. Polymer 2008;49:3187_ 3204.

[34] Usuki A, Kojima Y, Kawasumi M, Okada A, Fukusihima Y, Kurauchi TT. Synthesis of nylon 6-clay hybrid. Material Research 1993;8:1179-1184.

[35] Palza H, Reznik B, Kappes M, Hennrich F, Naue IFC, Wilhelm M. Characterization of melt flow instabilities in polyethylene/carbon nanotube composites. Polymer 2010;51:37533761.

[36] Robinson J, Poulsen KV, Högström PA, Linder A, Burkhard H, Kobilsek M, Gemmel A. Comparison of standard UV tests methods for the ageing of cables. Proceedings of the 60th IWCS Conference. International Wire \& Cable Symposium, 2011; pp. 329-337.

[37] Wunderlich B, Thermal Analysis, London: Academic Press; 1990.

[38] Lauritzen JL, Hoffman JD. Theory of formation of polymer crystals with folded chains in dilute solution. Journal of Research of the National Bureau of Standards 1960;64:73-102.

[39] Lauritzen JL, Hoffman JD. Crystallization of bulk polymers with chain folding: theory of growth of lamellar spherulites. Journal of Research of the National Bureau of Standards 1961;65:297-336.

[40] Hoffman JD, Davis GT, Lauritzen JL. In: Hannay NB, editor. Crystalline and noncrystalline solids, vol. 3. New York: Plenum Press; 1976.

[41] Mark James E. Polymer Data Handbook, New York: Oxford University Press; 1999.

[42] Samuels RJ. Quantitative structural characterization of the melting behavior of isotactic polypropylene. Journal of Polymer Scence 1975;13:1417.

[43] Guerra G, Petraccone V, Corradini P, De-Rosa C, Napolitano R, Pirozzi B, Giunchi G. Crystalline order and melting behavior of isotactic polypropylene ( $\alpha$ form). Journal of Polymer Science, Polymer Physics 1984;22:1029.

[44] Rabello MS, White JR. Photodegradation of polypropylene containing a nucleating agent. Journal of Applied Polymer Science 1997;64(13):2505-2517.

[45] Tang J, Wang Y, Liu H, Belfiore A. Effects of organic nucleating agents and zinc oxide nanoparticles on isotactic polypropylene crystallization. Polymer 2004;45:2081-2091.

[46] Chen X, Yu J, Guo S. Structure and properties of polypropylene composites filled with magnesium hydroxide. Journal of Applied Polymer Science 2006;102:4943-4951.

[47] Ming-Rui M, Qiang D. Effect of filler treatment on crystallization morphology and mechanical properties of polypropylene/calcium carbonate composites. Journal of Macromolecular Science, Part B: Physics 2009;48:213-225.

[48] Palza H, Vergara R, Zapata P. Composites of polypropylene melt blended with synthesized silica nanoparticles. Composites Science and Technology 2011;71:535-540.

[49] Sternstein SS, Zhu AJ. Reinforcement mechanism of nanofilled polymer melts as elucidated by nonlinear viscoelastic behaviour. Macromolecules 2002;35:7262-7273.

[50] Manias E. Nanocomposites - Stiffer by design. Nature Materials 2007;6:9-11. 
[51] Rabello MS, White JR. Crystallization and melting behaviour of photodegraded polypropylene - I. Chemi-crystallization. Polymer 1997; 38(26):6379-6387.

[52] Papet G, Jirackova-Audouin L, Verdu J. Diffusion controlled radiochemical oxidation of low density polyethylene-I. Depth dependence of morphological changes. Radiation Physics and Chemistry 1987;29:65-69.

[53] Wunderlich B. Macromolecular Physics. Vol. 2: Crystal Nucleation, Growth, Annealing, New York: Academic Press; 1976.

[54] Schoolenberg GE, Vink P. Ultra-violet degradation of polypropylene: 1. Degradation profile and thickness of the embrittled surface layer. Polymer 1991;32:432-437.

[55] Schoolenberg GE, Meijer HDF. Ultra-violet degradation of polypropylene: 2. Residual strength and failure mode in relation to the degraded surface layer. Polymer 1991;32:438444.

[56] Badía JD, Vilaplana F, Karlsson S, Ribes-Greus A. Thermal analysis as a quality tool for assessing the influence of thermo-mechanical degradation on recycled poly(ethylene terephthalate). Polymer Testing 2009; 28(2):169-75.

[57] Rabello MS, White JR. Crystallization and melting behaviour of photodegraded polypropylene - II. Re-crystallization of degraded molecules. Polymer 1997; 38(26):63896399.

[58] Martuscelli E, Pracella M, Crispino L. Crystallization behaviour of fractions of isotactic polypropylene with different degrees of stereoregularity. Polymer 1983;24(6):693-699.

[59] Janimak JJ, Cheng SZD, Giusti PA, Hsieh ET. Isotacticity effect on crystallization and melting in polypropylene fractions. II. Linear crystal growth rate and morphology study. Macromolecules 1991;24(9):2253-2260..

[60] Kamide K, Yamaguchi K. Change in fine structures of isotactic polpropylene during isothermal crystallization. Die Makromolekulare Chemie 1972;162(1)219-233.

[61] Shi G, Zhang X, Cao Y, Hong J. Melting behavior and crystalline order of ß-crystalline phase poly(propylene). Die Makromolekulare Chemie 1993; 149(1)269-277.

[62] Rybnikar FJ. Transition of $\beta$ to $\alpha$ phase in isotactic polypropylene. Journal of Macromolecular Science - Physics 1991;30(3)201-223.

[63] O'Kane WJ, Young RJ, Ryan AJ, Bras W, Derbyshire GE, Mant GR. Simultaneous SAXS/WAXS and DSC analysis of the melting and recrystallization behaviour of quenched polypropylene. Polymer 1994;35(7):1352-1358.

[64] Janimak JJ, Cheng SZD, Zhang A, Hsieh ET. Isotacticity effect on crystallization and melting in polypropylene fractions: 3. Overall crystallization and melting behaviour. Polymer 1992; 33(4);728-735.

[65] Duvall J, Selliti C, Myers C, Hiltner A, Baer E. Interfacial effects produced by crystallization of polypropylene with polypropylene-g-maleic anhydride compatibilitzers. Journal of Applied Polymer science 1994;52(2)207-216.

[66] Badia JD, Santonja-Blasco L, Martínez-Felipe A, Ribes-Greus A. Hygrothermal ageing of reprocessed polylactide. Polymer Degradatio and Stability 2012;97(10):1881-1890.

[67] Badia JD, Strömberg E, Karlsson S, Ribes-Greus A. Material valorisation of amorphous polylactide. influence of thermo-mechanical degradation on the morphology, segmental dynamics, thermal and mechanical performance. Polymer Degradation and Stability 2012, 97(4):670-678.

[68] Badia JD, Strömberg E, Karlsson S, Ribes-Greus A. The role of crystalline, mobile amorphous and rigid amorphous fractions in the performance of recycled poly (ethylene terephthalate) (PET). Polymer Degradation and Stability 2012;97(1):98-107.

[69] Santonja-Blasco L, Moriana R, Badía JD, Ribes-Greus A. Thermal analysis applied to the characterization of degradation in soil of polylactide: I. calorimetric and viscoelastic analyses. Polymer Degradation and Stability 2010;95(11):2192-2199. 
[70] Santonja-Blasco L, Ribes-Greus A, Alamo RG. Comparative thermal, biological and photodegradation kinetics of polylactide and effect on crystallization rates. Polymer Degradation and Stability 2013;98(3):771-784.

[71] Blais P, Carlsson DJ, Wiles DM. Surface changes during polypropylene photo-oxidation: A study by infrared spectroscopy and electron microscopy. Journal of Polymer Science Part A-1: Polymer Chemistry 1972;10:1077-1092.

[72] Vink P. Degradation and Stabilisation of Polyolefins, ed. N.S. Allen. London: Applied Science; 1983.

[73] Severini F, Gallo R, Ipsale S. Environmental degradation of polypropylene. Polymer Degradation and Stability 1988;22:185-194.

[74] Mani R, Singh RP, Sivaram S, Lacoste J. Effect of UV irradiation on the structure of heterophasic ethylene-propylene copolymers. Polymer Journal 1994;26(10):1132-1141.

[75] Ogier L, Rabello MS, White JR. Influence of morphology and surface preparation on the weatherability of polypropylene. Journal of Materials Science 1995; 30(9):2364-2376.

[76] Rabello MS, White JR. Photodegradation of talc-filled polypropylene. Polymer composites 1996;17:691-704.

[77] Rabello MS, White JR. The role of physical structure and morphology in the photodegradation behaviour of polypropylene. Polymer Degradation and Stability 1997;56:55-73.

[78] Bohren CF and Huffman DR, Absorption and Scattering of Light by Small Particles. John Wiley \& Sons, New York, 1998.

[79] Badia JD, Martinez-Felipe A, Santonja-Blasco L, Ribes-Greus A. Thermal and thermooxidative stability of reprocessed poly(ethylene terephthalate). Journal Analytical of Applied Pyrolysis 2013;99:191-202.

[80] Badia JD, Santonja-Blasco L, Martínez-Felipe A, Ribes-Greus A. Reprocessed polylactide: Studies of thermo-oxidative decomposition. Bioresource Technology 2012;114:622-8.

[81] Badia JD, Santonja-Blasco L, Martínez-Felipe A, Ribes-Greus A. A methodology to assess the energetic valorization of bio-based polymers from the packaging industry: Pyrolysis of reprocessed polylactide. Bioresource Technology 2012;111:468-475. 


\section{CHAPTER 4 .}

\section{Polyelectrolyte membranes}

for fuel cells 


\subsection{PRoton EXCHANGE FUEL CELLS FED WITH ALCOHOLS}

Fuel cells are among the most promising energy storage and conversion electrochemical systems. A typical fuel cell is composed of two electrodes (anode and cathode) that produce the oxidation of hydrogen and the reduction of oxygen, by means of an electrolyte membrane that favours the exchange of ions generated between both reactions. Fuel cells offer electric power with a high efficiency and without polluting emissions during its operation.

Nowadays, one of the most relevant fuel cell systems are the so-called proton exchange membrane fuel cells (PEMFCs) whose schematic diagram is shown in Figure 4.1. The PEMFCs consider the proton $\mathrm{H}^{+}$as the mobile ion and are composed of the electrolyte or membrane, the anode and the cathode electrodes, usually coated with a catalyst that promotes and enhances the separation of protons and electrons from the fuel, and the gas diffusion layers. The operation of PEMFCs results in the generation of water, electricity and heat. The electrochemical half-reactions and the overall reaction in these fuel cells are:

Anode: $H_{2} \rightarrow 2 H^{+}+2 e^{-}$

Cathode: $\frac{1}{2} \mathrm{O}_{2}+2 \mathrm{H}^{+}+2 e^{-} \rightarrow \mathrm{H}_{2} \mathrm{O}$

Overall reaction: $\mathrm{H}_{2}+\frac{1}{2} \mathrm{O}_{2} \rightarrow \mathrm{H}_{2} \mathrm{O}$

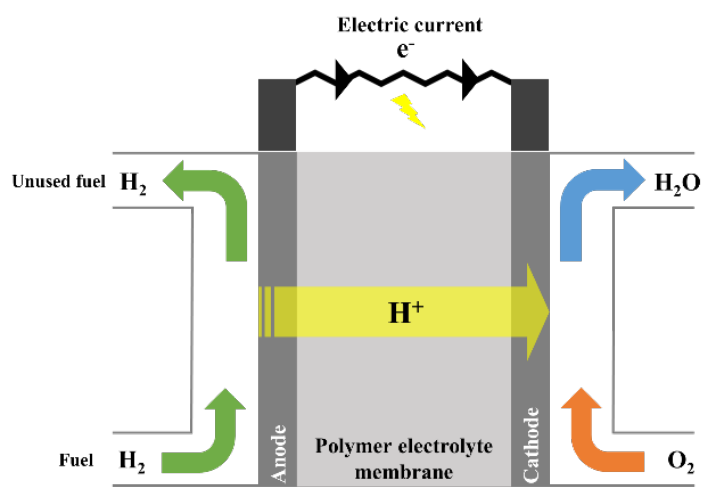

Figure 4.1. Proton exchange membrane fuel cell (PEMFC) scheme. 
In a PEMFC, the fuel is oxidised at the anode electrode-membrane interface in the presence of the catalyst. Then, the protons travel through the membrane to the cathode, while the electrons travel through the external circuit to the cathode where they combine with the protons and oxygen in the catalyst to form water and close the cycle.

The combination of the anode/membrane/cathode is called the membrane electrode assembly (MEA). To complete an electrochemical cell, the MEA is sandwiched between gas diffusion layers and the gas flow fields distributed by the reactants to the electrodes. PEMFCs are compact, lightweight, and especially suitable for portable applications. Although PEMFCs work with an efficiency of $60 \%$, a single cell usually generates a potential inferior to $1 \mathrm{~V}$. For this reason, several cells, in series or parallel, are commonly required to generate a suitable tension, forming a stack.

Among other requirements, the electrolyte must allow only the transport of protons, while being a complete insulator to the electrons, since it would reduce the decrease of the electronic flow through the external circuit and causing voltage losses. Moreover, the electrolyte must be perm-selective to the fuel. The fuel crossover from the anode to the cathode would result in the substantial reduction of the fuel cell performance. The use of a solid polymer as an electrolyte (PEM) has some advantages such as avoiding the corrosion and the increased versatility. PEMs offer the possibility of high functionalisation and operate at low temperature, avoiding the need for thermal insulation [1].

The proton conductivity in polyelectrolyte membranes is known to be closely related to the hydration degree, since water act as the medium to promote the proton mobility via the Grotthuss and the vehicular mechanisms [2]-[4].

In the Grotthuss mechanism, the proton mobility takes place through an interconnected network of hydrophilic ionic clusters, in which the protons hops from one ionic site to another by the formation and destruction of hydrogen bonds. This mechanism is strictly related to the water that remains in the structure of the polyelectrolyte, also known as bounded water.

In the vehicular or diffusion mechanism, the free volume and the mobile water molecules are the key factors to guarantee proton transport. The proton aggregates, carrying one or more molecules of water, diffuse to the cathode through the free volume pathways. These water molecules have the ability to move and displace into the polyelectrolyte and are considered as free water molecules.

Moreover, other mechanisms such as the direct transport via polymer chain segmental motions have been proposed [5]. However, this type of proton 
transport is restricted to polymers with amorphous morphology, in which especially the side chains are able and free to move, thus reducing the distance between chains for proton conduction. In this sense, proton conduction through this mechanism is only available above the glass transition temperature of these polyelectrolytes.

The commented proton transport mechanisms are schematised in Figure 4.2, as proposed by Gao and Lian [5].

(a)
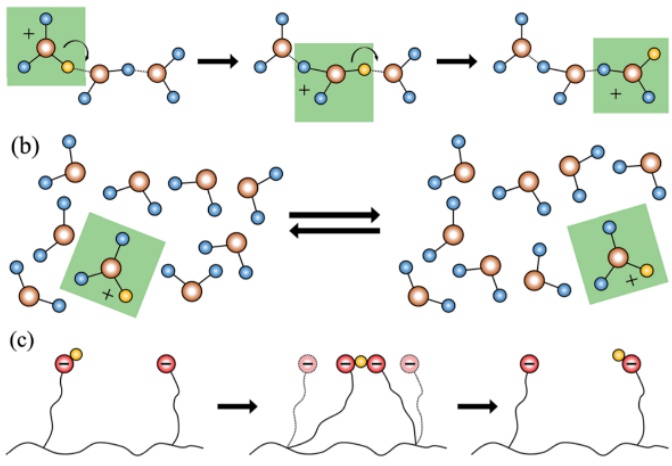

Figure 4.2. Schematic representation of the main proton conducting mechanisms: (a) Grotthuss mechanism, (b) vehicular mechanism, and (c) direct transport via polymer chain segmental motions.

Polymer electrolytes have been deeply studied and optimised for PEMFCs. At the moment, some polyelectrolytes are commercially available such as the Nafion, the Dow membranes and the perfluorinated ionomer membranes [6]. Although these membranes showed extraordinary properties, such as high proton conductivity and high chemical inertness, the temperature-related limitations, the safety concerns due to the formation of toxic and corrosive gases above $150^{\circ} \mathrm{C}$ and the high cost have prevented the general implantation of these fuel cells. Moreover, PEMFCs require a pure hydrogen input stream to avoid the poisoning of the catalysts that would decrease the overall performance. On the other hand, the transport and storage of hydrogen is still dangerous and sometimes a reason of controversy. In last decade, the development of alternative cells with easy to handle fuels has gained considerable attention. For this reason, different fuels such as methanol and ethanol have been proposed in the socalled direct alcohol fuel cells (DAFCs).

In DAFCs, the alcohol is oxidised to protons, electrons and carbon dioxide, as represented in Figure 4.3. Then, the electrons flow through the external circuit towards de cathode and the protons diffuse through the electrolyte membrane. Finally, at the cathode, the protons react with the oxygen and 
the electrons to form water, as represented in the following half-reactions and overall reaction, considering ethanol as fuel:

$$
\begin{aligned}
& \text { Anode: } \mathrm{C}_{2} \mathrm{H}_{5} \mathrm{OH}+3 \mathrm{H}_{2} \mathrm{O} \rightarrow 2 \mathrm{CO}_{2}+12 \mathrm{H}^{+}+12 e^{-} \\
& \quad \text { Cathode: } 3 \mathrm{O}_{2}+12 \mathrm{H}^{+}+12 e^{-} \rightarrow 6 \mathrm{H}_{2} \mathrm{O} \\
& \text { Overall reaction: } \mathrm{C}_{2} \mathrm{H}_{5} \mathrm{OH}+3 \mathrm{H}_{2} \mathrm{O}+3 \mathrm{O}_{2} \rightarrow 6 \mathrm{H}_{2} \mathrm{O}
\end{aligned}
$$



Figure 4.3. Proton exchange membrane fuel cell (PEMFC) scheme.

The transport and storage of ethanol and methanol makes them more suitable for portable technological applications, given that they are liquid in the temperature ranges from -114 to $78{ }^{\circ} \mathrm{C}$ and from -97 to $64{ }^{\circ} \mathrm{C}$ at atmospheric pressure, respectively. Moreover, the existing technology for traditional fuels can be used with these alcohols.

Unfortunately, currently developed electrolytes have high permeability to alcohols, resulting in low performance, sensitivity to impurities, as well as high cost. The polymer electrolytes used in traditional PEMFCs present the fuel crossover effect, in which the fuel passes through the polyelectrolyte membrane, highly decreasing the efficiency and increasing the fuel cell temperature, that prevent its use with alcohols. These limitations are currently under study to find new technologies and adequate materials for the manufacture of polyelectrolyte membranes for fuel cells fed with alcohols (DAFCs). Among the main strategies, the development of new polymer electrolytes with suitable proton conductivity and selective to the diffusion of alcohols is one of the main approaches.

The polyelectrolyte membrane, as the key component in the fuel cell, has been studied and optimised to improve the performance in terms of profitability, efficiency, durability and cost that may boost its commercialisation in the market. However, the accomplishment of the 
strict requirements to become the ideal membrane are still under investigation.

Mainly, polyelectrolytes for DAFCs must possess high proton conductivity, while being an electronic insulator, so that the circuit is externally closed generating electrical current. In addition, low fuel permeability is required to avoid potential drops or crossover, hydrolytic, thermal and dimensional stability, hydration capacity and low production cost [7]. Among these required features, the proton conductivity is essential to achieve the desired fuel cell performance. Indeed, the mass and energy transfer processes may be optimised to guarantee the optimum operation of the fuel cell. The progress in the performance of proton conducting fuel cells are thus closely related to the progresses in the polyelectrolyte development. Some reviews have been proposed in the literature along the last decades for the polyelectrolyte membranes for proton transport fuel cells [8]-[16].

Several polymeric families have been proposed as polyelectrolytes, such as the fluorinated polymers, the non-fluorinated hydrocarbon polymers or the acid-base complexes. More specifically, proposed polyelectrolytes could be classified according to the polymer type, as Nafion-like, modified Nafion-based, polystyrene-based, sulfonated polyimide-based, polyphosphazene-based, polybenzimidazole-based, poly(arylene ether)based, polysulfone-, polysulfone-ether- and polyphenylsulfone-based and natural polymer-based membranes.

Moreover, different fabrication approaches such as the preparation of random copolymers, graft copolymers, block copolymers, blends, impregnated membranes, coated membranes, layered membranes and composite membranes have been studied [9].

In recent years, the development of alternative polymeric membranes as electrolytes for fuel cell applications has gained great attention. Such is the case of the poly(vinyl alcohol) (PVA) based polyelectrolytes for DAFCs, due to its promising intrinsic features and low production cost [6]. 


\subsection{POLY(VINYL ALCOHOL) (PVA)- BASED POLYELECTROLYTE MEMBRANES}

Poly(vinyl alcohol) (PVA) is a water-soluble, atactic, semicrystalline synthetic polymer with the constitutional repeating unit shown in Figure 4.4. The PVA was first discovered by Fritz Klatte in 1912, obtained by the hydrolysis in basic medium of the polyvinyl acetate. In 1924, Herman and Haehnel obtained PVA through the hydrolysis of polyvinyl acetate in ethanol with potassium hydroxide. Currently, the commercial production of the PVA is based on the hydrolysis of acetate by ester exchange with methanol in the presence of sodium hydroxide [6]. In terms of microstructure, it is mainly composed of 1,3-diol linkages, but it may contain a few extent of 1,2-diols depending on the polymerisation conditions [17]. Accordingly, it may have different hydrolysis degree, because of the replacement of acetate groups by hydroxyl groups.<smiles>CC(C)(C)CC(O)C(C)(C)C</smiles>

Figure 4.4. Constitutional repeating unit of the fully hydrolysed PVA.

The PVA can be described as an odourless, non-toxic, translucent, white or cream granular powder. The main manufacturers of PVA are DuPont (Evanol®), Celanese (Sevol ${ }^{\mathrm{TM}}$ Premiol), Kuraray Co. (Exceval $^{\mathrm{TM}}$ and Poval $^{\mathrm{TM}}$ ), and Nipon Gohsei (Hi-Selon ${ }^{\circledR}$ ). It is a biodegradable polymer easily obtainable, with low cost and distinguished for its good chemical stability, good mechanical properties, high functionalisation capability and good hydrophilicity. Moreover, it is recognised as a high oxygen, aroma and alcohol barrier. Actually, it has been widely considered for the pervaporation of alcohol/water mixtures. This high alcohol selectivity makes this polymer interesting for the fabrication of polymer electrolyte membranes that reduce the fuel crossover in DAFCs [18].

Regarding its application in polyelectrolyte development, PVA requires functionalisation to induce proton conductivity as well as crosslinking to reduce its intrinsic water solubility. The modification of the PVA can be performed according to different strategies, such as the copolymerisation, the polymer grafting, the crosslinking or by means of the combination with inorganic particles to form composite materials, among others [6]. The selection of the PVA as the base material resides in its versatility and ability to be functionalised to accomplish the required features as proton conducting polyelectrolyte membranes. 
For the proton conductivity enhancement, the inclusion of sulfonic groups by attachment to the side chains is a good alternative. In this sense, concentrated sulfuric acid, sulfophthalic acid, sulfoacetic acid and chlorosulfonic acid have been considered in the literature [6]. In addition, PVA can be modified by copolymerisation with other monomer units. PVA has been copolymerised with polyaniline (PAni), sulfonated poly(etherether-ketone) (SPEEK), Nafion ${ }^{\circledR}$, polystyrene (sulfonic acid) (PSSA), polystyrene (sulfonic acid-co-maleic acid) (PSSA-MA) or poly(3,4ethylenedioxythiophene) (PEDOT), among others [6], [19], [20].

If these functionalisation agents contain two or more reactive functional groups they can also induce PVA chemical crosslinking [21]. The crosslinking of the PVA is essential not only to improve the hydrolytic stability, but also to improve the thermal stability and the mechanical strength. At the same time, the crosslinking may reduce the water uptake ability that can compromise the structural stability, may increase the selectivity to alcohols permeation and, depending on the type of crosslinking agent, enhance the proton conductivity capacity [16], [22]. PVA has been crosslinked with sulfusoccinic acid (SSA) [21]-[25], glutaraldehyde (GA) [26]-[29], poly(acrylic acid) (PAA) [30], [31], poly(methacrylic acid-2-acrylamido-2-methyl-1-propanesulfonic acidvinyltriethoxysilicone) (PMAV) [32], polystyrene(sulfonic acid co-maleic acid) (PSSA-MA) [33], [34], chitosan (CS) [35], [36] or glyoxal [37], among others [6]. Among the most interesting crosslinking agents for fuel cell application, the sulfusoccinic acid (SSA) presents reactive groups in its molecular structure such as carboxylic acids that can react with the hydroxyl groups of PVA and give a crosslinked structure, providing an improvement in their properties in terms of hydrothermal, mechanical and thermal resistance. Moreover, the presence of the sulfonic groups of the SSA molecules may provide adequate proton conductivity of the PVA based polyelectrolytes. The chemical structure of the SSA molecules is shown in Figure 4.5.<smiles>O=C(O)CC(C(=O)O)S(=O)(=O)O</smiles>

Figure 4.5. Sulfosuccinic acid (SSA) chemical structure.

However, the membranes based on functionalised and crosslinked PVA still show some drawbacks in their operation, which could be solved with the combination or synergy of the different methods of functionalisation commented above, as well as through the combination with inorganic 
materials dispersed in the matrix to improve the performance of the membrane [38], [39]. These multicomponent systems can present a cumulative behaviour and develop an adequate synergy that optimise their properties. In addition, the charges or reinforcements included in the polymer matrix can provide an improvement in the barrier effect to methanol, thus reducing the crossover through the membrane.

The functionalisation strategy of the PVA therefore consists in an improvement of the protonic conductivity induced through the modification of its structure, through the chemical cross-linking reaction, as well as through the combination with other polymers or inorganic materials in composite membranes [6].

\subsubsection{Nanocomposite PVA-based polyelectrolytes}

Several strategies have been proposed for improving the proton conductivity, the mechanical stability, and the operational consistency of the polyelectrolyte membranes. The preparation of ionically-functionalised crosslinked structures or the formation of composite polyelectrolytes by the combination of polymer matrices with inorganic nanoparticles or polymer nanofibres have been reported as feasible alternatives that favour the formation of ion-conductive domains in the PEM matrix, that increase the proton conductivity of the membranes. For the case of the PVA-based polyelectrolytes, the crosslinking and the incorporation of nanofillers, whether nanoparticles or nanofibres, is essential not only for improving the proton conductivity, but also for reducing the fuel crossover and enhancing the service stability.

\section{Composite membranes with nanoparticles}

The incorporation of functionalised nanoparticles aims to combine the advantages of inorganic materials, such as the thermal and dimensional stability, and those of polymers, such as conductivity and flexibility [40]. The objective of the development of nanocomposite membranes is the production of polyelectrolytes that overcome the existing limitations with lower cost and high functional performance.

In general, the combination of polymers and inorganic particles results in poor surface adhesion, since their surfaces are of different chemical nature. Accordingly, the interfacial morphology determines the resulting general electrochemical and mechanical properties. The dispersion of the particles governs the optimisation of the characteristics of the membrane, i.e. the proton conductivity, the water absorption behaviour and the fuel permeability [39], [41]. The main factors that affect the dispersion of particles are the dimensions of the particle -size, shape, and porosity-, surface chemistry - polarity and reactivity- and manufacturing parameters 
-temperature or solvent-. Some strategies used to avoid the consequences of a feeble polymer-charge interaction consist in carefully selecting the starting materials and studying their intrinsic properties, choosing the adequate solvent or adding a coupling agent that facilitates the chemical interactions between them. In addition, there are external manufacturing processes to improve the dispersion of particles such as sonication to increase interfacial adhesion. There is also the possibility of functionalisation of both polymers and nanoparticles to incorporate functional groups that facilitate a strong covalent bond between them.

The inorganic phase strongly influences the general characteristics of the membrane. On the one hand, at high temperatures, the inorganic particles that are proton conductors embedded into the polymer matrix increase their conductivity and, when the matrix is properly hydrated, these conductive particles act as a bridge to connect adjacent ionic groups [41], [42]. That is the reason why the inorganic particles must not agglomerate forming blockages in the hydrophilic channels. On the other hand, the incorporation of nanoparticles to the membrane may reduce the fuel crossover. The fuel permeation is produced by diffusion through pores or holes as well as through hydrophilic channels. The addition of inorganic particles that block the holes or transport routes intends to reduce the fuel permeability and subsequent crossover. In this way, a suitable balance between good proton conductivity and low fuel permeability can be achieved [40].

The chemical structure of the polymer brings most of the electrochemical properties of the membrane. As well, the molar mass of the polymer is responsible for its behaviour, morphology, mechanical and thermal stability. However, the polymer molar mass, which will determine to a greater extent its intrinsic viscosity, can influence the agglomeration of the inorganic phase and, therefore, result in poor dispersion of the particles into the polymer matrix.

The selection of inorganic materials as nanoparticles for proton conducting polyelectrolytes must consider the hygroscopic capacity, the specific surface and the compatibility with the matrix. The materials most commonly used as nanofillers in nanocomposite protonic conductive polyelectrolytes are metal oxides $\left(\mathrm{SiO}_{2}\right.$ [43]-[45], $\mathrm{TiO}_{2}$ [46]-[48], $\mathrm{Al}_{2} \mathrm{O}_{3}$, $\mathrm{ZrO}_{2}$ and $\mathrm{SnO}_{2}$ [6]), clays [49], [50], silicates [51], heteropolyacids (HPA) [52], metal phosphates [53], [54] and advanced materials such as carbon nanotubes (CNT) [55] or graphene oxide (GO) [7], [56].

Graphene oxide (GO) has recently received considerable interest because of having a unique two-dimensional structure with excellent dimensional, chemical, thermal and mechanical stability, low permeability, low cost, surface functionality and minimum thickness [7]. One of the keys of the $\mathrm{GO}$ is that it can be produced from graphite using several oxidation routes 
in a relatively easy way [57]. The GO structure consists of carbons connected to each other by covalent bonds and interconnected to hydrogen and oxygen, to form a structure stratified with epoxy, hydroxyl and carboxyl groups in the basal plane and at the edge for providing a high specific surface area, as shown in Figure 4.6. The presence of such groups provides the structure with high functionality and excellent capacity to interact with various materials. The GO oxygen polar groups make it strongly hydrophilic, which provides good dispersion in water and improves interfacial adhesion between the GO and the hydrophilic matrix. In addition, the GO is characterised by being an electronic insulator, justified by the presence of oxygen in its structure. That is why it is considered the best candidate to reinforce a hydrophilic polymers such as the PVA [46], [58], [59].

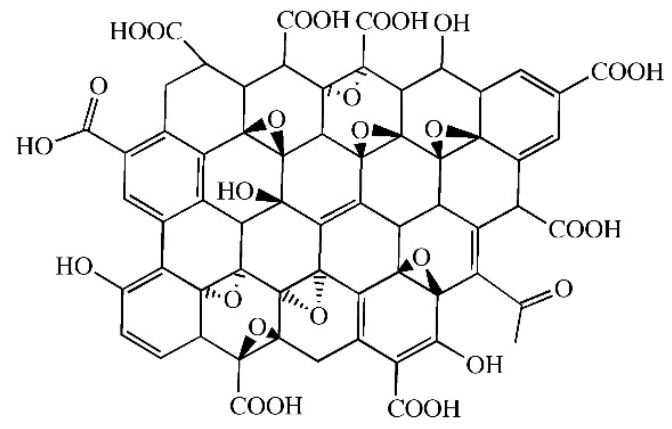

Figure 4.6. Graphene oxide (GO) chemical structure.

The GO has gained interest over the past decade for applications in fuel cells. It has been shown that the incorporation of GO into a polymeric matrix can have an excellent potential application in PEMFCs [7], [56]. By introducing these nanoparticles into an ion-conducting polymer, it increases the tortuosity in the advance of the fuel and improves the barrier effect.

There are also some strategies and techniques for composite membrane production that allow controlling the interfacial morphology to prevent the agglomeration of particles. These techniques include dissolution-discharge [60], deposition layer by layer [61], coating by immersion [40], phase inversion, infiltration, solvent-casting and electrospinning [62], among others [63].

One of the most common methods for the incorporation of $\mathrm{GO}$ is the combination with a polymeric matrix in solution, followed by a process of dispersion and sonication and subsequent pouring into a mould and evaporation of the solvent for film formation. There are several investigations in this regard where the incorporation of GO in the polymer 
matrices was carried out, obtaining high performance polyelectrolytes with a high fuel barrier capacity and good results in terms of proton conductivity [56], [64], [65].

\section{Composite nanofibrous membranes}

The development of nanofibrous structures based on polymeric materials for their application as components of polyelectrolyte membranes in fuel cells is currently under study [66]. Electrospinning is one of the main approaches to obtain functionalised nanofibrous mats, including homopolymers, blends or composites [67].

Given the wide versatility of the electrospinning technique, allowing the preparation of nanofibres of controlled size and morphology, the possibility of development of functionalised polyelectrolytes for fuel cell applications has been explored [68].

As mentioned above, the poly(vinyl alcohol) (PVA) is one of the most widely used materials in this field. Apart from the crosslinking reaction to give stability to the electrospun nanofibrous structure, the nanofibres can be functionalised by the addition of other agents or fillers, giving rise to a nanocomposite nanofibre. Indeed, PVA-based composite nanofibres have been proposed as a good alternative for the development of new nanofibrous polyelectrolytes with improved functionality [69]. The incorporation of inorganic particles such as graphene oxide (GO) in the PVA solution prior to electrospinning, would result in PVA/GO nanocomposite nanofibres. There are some studies in the literature in which PVA/GO nanocomposite nanofibres have been obtained using the electrospinning technique [20], [35], [46], [59], [62], [70].

As occur with other polymers, the morphology, the microstructure and the physico-chemical properties of the electrospun PVA nanofibres is highly dependent on the experimental conditions. Given the good water solubility, aqueous solutions are frequently considered for PVA electrospinning. However, due to the high viscosity of the PVA solution at low concentrations, especially those of high molar mass, it is sometimes required the presence of a surfactant to reduce the surface tension to guarantee effective electrospinning. In this sense, several type of surfactants such as cationic quaternary ammonium, non-ionic polyoxyethylene-polyoxypropylene-ether or amphoteric lauryl betaine [71]. Moreover, other types of surfactants have been used in the PVA electrospinning such as the Triton X-100 [58] or the sodium dodecyl sulfate (SDS) [46].

\section{Nanofibre reinforced composite membranes}

As introduced above, the production of polymer nanocomposites by means of the combination of polymer matrices with inorganic particles, showed 
interesting improvement in the mechanical and thermal properties, as well as in the proton conductivity for fuel cell applications. Although this approach is quite novel, there are some studies in the literature that combined nanofibrous mats with polymeric matrices. To accomplish this strategy, the use of consolidated methods for the union and compatibility of the nanofibrous structures with polymeric matrices is required. Such is the case of thermocompression, impregnation or dip coating, among other processing approaches.

Processing methods such as the thermo-compression provide some advantages in terms of thickness control, processing speed and good physical interaction between components, given by the effect of pressure and temperature [72]. Other methods, such as dip coating or impregnation, have advantages in terms of good chemical interaction between the phases with no delamination [73]. However, it requires a matrix with high resistance to be manipulated. It is considered that the combination of several of these processing techniques is necessary to obtain a membrane with the optimal properties to be used in fuel cells. That is the reason why the definition of a clear and simple process is essential for the development of self-reinforced nanocomposite membranes with nanofibres for application in proton exchange fuel cells (PEMFCs).

For example, the combination of both impregnation and subsequent drying and crosslinking by thermo-compression, was effective for obtaining, generating nanofibre reinforced nanocomposite membrane [72]. The results showed a good interaction between fibres and matrix. The use of this new technique would generate positive effects in the composite membranes by incorporating nanofibres that act as mechanical reinforcement and may increase the proton conductivity, allowing establishing a more favourable route of proton conduction.

Several studies in the literature proposed the fabrication of nanofibre-based composite polyelectrolytes for fuel cell applications. Some of them considered the combination of the nanofibres with Nafion ${ }^{\circledR}$ with promising results [73], [74]. Other composite nanofibres were studied, based in sulfonated polyimide nanofibre framework [75], [76], sulfonated poly(arylene ether sulfone) [77], sulfonated polysulfone [78] or polybenzimidazole [79], among others.

Some poly(vinyl alcohol) based nanofibrous composites have been proposed in the literature, such as the nanocomposite membranes with SPEEK-PVB nanofibres and a SPEEK-PVA polymer matrix [72] or the highly conductive quasi-coaxial quaternised polyvinyl alcohol nanofibres and composite electrolytes [80]. In these studies, the nanofibres and the matrix were based in the same polymeric material, and self-reinforced composite polyelectrolyte membranes would be produced [81], [82]. 


\subsubsection{Blended PVA-CS polyelectrolytes}

The preparation of blended membranes can combine and show interesting synergistic properties of both individual polymers [83]. Cost-effective and eco-friendly polymer electrolytes from renewable sources can become a promising substitute for synthetic polymers for use in electrochemical devices involving energy generation and storage. Among natural polymers, polysaccharides are among the best candidates due to their abundance in environment [84].

In the literature, various PVA-based polymer blend membranes with natural polysaccharides have been prepared [85]-[87]. Particularly, good results have been obtained by mixing chitosan (CS) with poly(vinyl alcohol) (PVA) [88]-[90]. CS and PVA are miscible in one another, and compatible for blending [91]. The effect of strong hydrogen bonding between the hydroxyl groups in CS and the hydroxyl groups in PVA as a result of blending may provide good mechanical properties [92].

Chitosan (CS), as a polysaccharide bio resource, is one of the promising membrane materials and has been studied widely. CS is the N-deacetylated derivative of chitin $(\mathrm{CH})$ which is naturally abundant polysaccharide and the supporting material of crustaceans, insects, etc. Chitin is easily obtained from crabs or shrimp shells and fungal mycelia. Chitosan is inert, hydrophilic and is insoluble in water, alkali and organic solvents. Its solubility in dilute organic acids allows for gel formation in various configurations. CS is presented as an odorless, translucent, white granular powder, with the chemical structured shown in Figure 4.7.

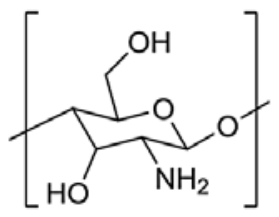

Figure 4.7. Chitosan (CS) chemical structure.

Free amine and hydroxyl functional groups on the chitosan backbone enable various chemical modification of chitosan to tailor it for specific applications such as polymer electrolyte membrane in different applications [93]. Membranes based on natural low-cost CS are easily formed and have high hydrophilicity, good chemical and thermal resistance.

CS is a potentially useful membrane material for DAFCs due to its nonpermeability to alcohols. However, in its native state, CS films exhibit very low conductivities and high degrees of swelling [94]. Although high swelling levels in the membrane are a prerequisite for reaching high proton 
conductivities, they are also usually related to a decrease of the membrane performance, in terms of methanol permeability, dimensional and thermal stability. To solve the low conductivity and high swelling problems, CS is usually either ionically crosslinked [95], blended with other polymers [84], or reinforced [96]. Different chitosan-based PEMs have been studied and have showed promising properties for application in the field of PEMFCs [89], [97], [98]. 


\subsection{REFERENCES OF CHAPTER 4}

[1] K. Pourzare, Y. Mansourpanah, and S. Farhadi, "Advanced nanocomposite membranes for fuel cell applications: a comprehensive review,” Biofuel Res. J., vol. 3, no. 4, pp. 496-513, 2016.

[2] E. Bakangura, L. Wu, L. Ge, Z. Yang, and T. Xu, "Mixed matrix proton exchange membranes for fuel cells: state of the art and perspectives Mixed matrix proton exchange membranes for fuel cells: state of the art and perspectives,” Prog. Polym. Sci., vol. 57, pp. 103-152, Jun. 2015.

[3] J. Zhang, J. Wu, and H. Zhang, PEM Fuel Cell Testing and Diagnosis. Elsevier Science, 2013.

[4] B. Emonts, L. Blum, T. Grube, W. Lehnert, J. Mergel, M. Müller, and R. Peters, “Technical Advancement of Fuel-Cell Research and Development,” in Fuel Cell Science and Engineering, Weinheim, Germany: Wiley-VCH Verlag GmbH \& Co. KGaA, 2012, pp. 1-42.

[5] H. Gao and K. Lian, "Proton-conducting polymer electrolytes and their applications in solid supercapacitors: a review," RSC Adv., vol. 4, no. 62, pp. 33091-33113, 2014.

[6] J. Maiti, N. Kakati, S. H. Lee, S. H. Jee, B. Viswanathan, and Y. S. Yoon, "Where do poly(vinyl alcohol) based membranes stand in relation to Nafion ${ }^{\circledR}$ for direct methanol fuel cell applications?,” J. Power Sources, vol. 216, pp. 48-66, 2012.

[7] U. R. Farooqui, A. L. Ahmad, and N. A. Hamid, "Graphene oxide: A promising membrane material for fuel cells," Renewable and Sustainable Energy Reviews, vol. 82. Pergamon, pp. 714-733, 01-Feb-2018.

[8] V. Neburchilov, J. Martin, H. Wang, and J. Zhang, "A review of polymer electrolyte membranes for direct methanol fuel cells,” J. Power Sources, vol. 169, no. 2, pp. 221-238, Jun. 2007.

[9] N. W. DeLuca and Y. A. Elabd, "Polymer electrolyte membranes for the direct methanol fuel cell: A review,” J. Polym. Sci. Part B Polym. Phys., vol. 44, no. 16, pp. 2201-2225, Aug. 2006.

[10] C. Lamy, A. Lima, V. LeRhun, F. Delime, C. Coutanceau, and J. M. Léger, "Recent advances in the development of direct alcohol fuel cells (DAFC)," $J$. Power Sources, vol. 105, no. 2, pp. 283-296, 2002.

[11] X. Li, B. Yu, and X. Jiang, "The development of study on direct alcohol fuel cell (DAFC)," in 2011 International Conference on Electrical and Control Engineering, 2011, pp. 1814-1815.

[12] K. D. Kreuer, "On the development of proton conducting polymer membranes for hydrogen and methanol fuel cells,” J. Memb. Sci., vol. 185, pp. 29-39, 2001.

[13] S. P. S. Badwal, S. Giddey, A. Kulkarni, J. Goel, and S. Basu, "Direct ethanol fuel cells for transport and stationary applications - A comprehensive review," Appl. Energy, vol. 145, pp. 80-103, May 2015.

[14] S. J. Peighambardoust, S. Rowshanzamir, and M. Amjadi, Review of the proton exchange membranes for fuel cell applications, vol. 35, no. 17. 2010.

[15] B. N. Li Q, He R, Jensen JO, “Approaches and recent development of polymer 
electrolyte membranes for fuel cells operating above $100 \circ$ C," Chem Mater, vol. 15, pp. 4896-915, 2003.

[16] A. Kraytsberg and Y. Ein-eli, "A Review of Advanced Materials for Proton Exchange Membrane Fuel Cells,” 2014.

[17] J. Pajak, M. Ziemski, and N. Bozena, "Poly(vinyl alcohol ) - biodegradable vinyl material science,” Chemik, vol. 64, no. 7-8, pp. 523-530, 2010.

[18] N. M. Sammes, A. Smirnova, O. Vasylyev, and North Atlantic Treaty Organization., Fuel Cell Technologies: State and Perspectives, vol. 202. Springer, 2005.

[19] A. M. Albu, I. Maior, C. A. Nicolae, and F. L. Bocăneală, "Novel Pva Proton Conducting Membranes Doped With Polyaniline Generated By in-Situ Polymerization,” Electrochim. Acta, vol. 211, pp. 911-917, 2016.

[20] N. A. Zubair, N. A. Rahman, H. N. Lim, R. M. Zawawi, and Y. Sulaiman, "Electrochemical properties of PVA-GO/PEDOT nanofibers prepared using electrospinning and electropolymerization techniques," RSC Adv., vol. 6, no. 21, pp. 17720-17727, 2016.

[21] A.Martínez-Felipe, C.Moliner-Estopiñán, C.T.Imrie, and A.Ribes-Greus, "Characterization of Crosslinked PVA-based membranes.," Polym. Polym. Compos., vol. 21, no. 7, pp. 449-456, 2013.

[22] J. Zhang, G. Jiang, and J. Shi, "Poly (vinyl alcohol)/sulfosuccinic acid (PVA/SSA) as proton-conducting membranes for fuel cells : Effect of crosslinking and plasticizer addition,” p. 2013.

[23] J. W. Rhim, H. B. Park, C. S. Lee, J. H. Jun, D. S. Kim, and Y. M. Lee, "Crosslinked poly(vinyl alcohol) membranes containing sulfonic acid group: Proton and methanol transport through membranes,” J. Memb. Sci., vol. 238, no. 1-2, pp. 143-151, 2004.

[24] D. Ebenezer, A. P. Deshpande, and P. Haridoss, "Cross-linked poly (vinyl alcohol)/sulfosuccinic acid polymer as an electrolyte/electrode material for H2-O2 proton exchange membrane fuel cells,” J. Power Sources, vol. 304, pp. 282-292, Feb. 2016.

[25] J. M. Morancho, J. M. Salla, A. Cadenato, X. Fernández-Francos, P. Colomer, Y. Calventus, X. Ramis, and R. Ruíz, "Thermal analysis of enhanced poly(vinyl alcohol)-based proton-conducting membranes crosslinked with sulfonation agents for direct methanol fuel cells,” J. Appl. Polym. Sci., vol. 124, 2012.

[26] K.-J. Kim, S.-B. Lee, and N.-W. Han, "Kinetics of crosslinking reaction of PVA membrane with glutaraldehyde,” Korean J. Chem. Eng., vol. 11, no. 1, pp. 41-47, Jan. 1994.

[27] F. S. Matty, M. T. Sultan, and A. K. Amine, "Swelling Behavior of Cross-link PVA with Glutaraldehyde,” Pure Appl. Sci. Ibn Al-Haitham Jour. Pure Appl. Sci, vol. 28, no. 282, 2015.

[28] K. C. S. Figueiredo, T. L. M. Alves, and C. P. Borges, "Poly(vinyl alcohol) films crosslinked by glutaraldehyde under mild conditions," J. Appl. Polym. Sci., vol. 111, no. 6, pp. 3074-3080, Jan. 2009.

[29] H. S. Mansur, C. M. Sadahira, A. N. Souza, and A. A. P. P. Mansur, "FTIR spectroscopy characterization of poly (vinyl alcohol) hydrogel with different hydrolysis degree and chemically crosslinked with glutaraldehyde,” vol. 28, 
no. 4, pp. 539-548, May 2008.

[30] Y. H. F. Al-qudah, G. A. Mahmoud, and M. A. Abdel Khalek, "Radiation crosslinked poly (vinyl alcohol)/acrylic acid copolymer for removal of heavy metal ions from aqueous solutions," J. Radiat. Res. Appl. Sci., vol. 7, no. 2, pp. 135-145, Apr. 2014.

[31] K. Kumeta, I. Nagashima, S. Matsui, and K. Mizoguchi, "Crosslinking reaction of poly(vinyl alcohol) with poly(acrylic acid) (PAA) by heat treatment: Effect of neutralization of PAA,” J. Appl. Polym. Sci., vol. 90, no. 9, pp. 2420-2427, Nov. 2003.

[32] S. Zhong, X. Cui, Y. Gao, W. Liu, and S. Dou, "Fabrication and properties of poly(vinyl alcohol)-based polymer electrolyte membranes for direct methanol fuel cell applications,” Int. J. Hydrogen Energy, vol. 39, no. 31, pp. 1785717864, 2014.

[33] D. S. Kim, M. D. Guiver, S. Y. Nam, T. Il Yun, M. Y. Seo, S. J. Kim, H. S. Hwang, and J. W. Rhim, "Preparation of ion exchange membranes for fuel cell based on crosslinked poly(vinyl alcohol) with poly(styrene sulfonic acid-comaleic acid),” J. Memb. Sci., vol. 281, no. 1-2, pp. 156-162, Sep. 2006.

[34] D. S. Kim, H. Il Cho, D. H. Kim, B. S. Lee, B. S. Lee, S. W. Yoon, Y. S. Kim, G. Y. Moon, H. Byun, and J. W. Rhim, "Surface fluorinated poly(vinyl alcohol)/poly(styrene sulfonic acid-co-maleic acid) membrane for polymer electrolyte membrane fuel cells,” J. Memb. Sci., vol. 342, no. 1-2, pp. 138144, Oct. 2009.

[35] Y. Liu, M. Park, H. K. Shin, B. Pant, J. Choi, Y. W. Park, J. Y. Lee, S. J. Park, H. Y. Kim, Yanan Liu and others, Y. Liu, M. Park, H. K. Shin, B. Pant, J. Choi, Y. W. Park, J. Y. Lee, S. J. Park, and H. Y. Kim, "Facile preparation and characterization of poly(vinyl alcohol)/chitosan/graphene oxide biocomposite nanofibers,” J. Ind. Eng. Chem., vol. 20, no. 6, pp. 4415-4420, 2014.

[36] S. G. Cao, Z. F. Liu, B. H. Hu, and H. Q. Liu, "Stabilization of electrospun poly(Vinyl Alcohol) nanofibrous mats in aqueous solutions," Chinese $J$. Polym. Sci. (English Ed., vol. 28, no. 5, pp. 781-788, 2010.

[37] B. Ding, H. Y. Kim, S. C. Lee, C. L. Shao, D. R. Lee, S. J. Park, G. B. Kwag, and K. J. Choi, "Preparation and characterization of a nanoscale poly(vinyl alcohol) fiber aggregate produced by an electrospinning method," J. Polym. Sci. Part B Polym. Phys., vol. 40, no. 13, pp. 1261-1268, 2002.

[38] M. J. Hickner MA, Ghassemi H, Kim YS, Einsla BR, "Alternative polymer systems for proton exchange membranes (PEMs).," Chem Rev, vol. 104, pp. 617-4587, 2004.

[39] K. W. Moore TT, Mahajan R, Vu DQ, "Hybrid membrane materials comprising organic polymers with rigid dispersed phases. 2004;50:311-21.," AIChE J, vol. 50, pp. 311-21, 2004.

[40] R. K. Nunes S, Ruffmann B, Rikowski E, Vetter S, "Inorganic modification of proton conductive polymer membranes for direct methanol fuel cells.," $J$ Membr Sci, vol. 203, pp. 215-25, 2002.

[41] K. S. Chung TS, Jiang LY, Li Y, "Mixed matrix membranes (MMMs) comprising organic polymers with dispersed inorganic fillers for gas separation.," Prog Polym Sci, vol. 32, pp. 483-507, 2007.

[42] S. R. Miyake N, Wainright J, "Evaluation of a sol-gel derived nafion/silica hybrid membrane for proton electrolyte membrane fuel cell applications: I. 
Proton conductivity and water content.,” J Electrochem Soc, vol. 148, pp. 898904, 2001.

[43] D. S. Kim, H. B. Park, J. W. Rhim, and Y. M. Lee, "Preparation and characterization of crosslinked $\mathrm{PVA} / \mathrm{SiO} 2$ hybrid membranes containing sulfonic acid groups for direct methanol fuel cell applications," J. Memb. Sci., vol. 240, no. 1-2, pp. 37-48, 2004.

[44] Z. Ma, J. Gao, Y. Huai, J. Guo, Z. Deng, and J. Suo, "Preparation and characterization of inorganic-organic hybrid proton exchange membranes based on phosphorylated PVA and PEG-grafted silica particles,” J. Sol-Gel Sci. Technol., vol. 48, no. 3, pp. 267-271, Dec. 2008.

[45] W. Xu, C. Liu, X. Xue, Y. Su, Y. Lv, W. Xing, and T. Lu, "New proton exchange membranes based on poly (vinyl alcohol) for DMFCs," Solid State Ionics, vol. 171, no. 1-2, pp. 121-127, Jun. 2004.

[46] B. Wang, Z. Chen, J. Zhang, J. Cao, S. Wang, Q. Tian, M. Gao, and Q. Xu, "Fabrication of PVA/graphene oxide/TiO2 composite nanofibers through electrospinning and interface sol-gel reaction: Effect of graphene oxide on PVA nanofibers and growth of TiO2," Colloids Surfaces A Physicochem. Eng. Asp., vol. 457, no. 1, pp. 318-325, 2014.

[47] C.-C. Yang, S.-J. Chiu, K.-T. Lee, W.-C. Chien, C.-T. Lin, and C.-A. Huang, "Study of poly(vinyl alcohol)/titanium oxide composite polymer membranes and their application on alkaline direct alcohol fuel cell," J. Power Sources, vol. 184, no. 1, pp. 44-51, Sep. 2008.

[48] C.-C. Yang, "Synthesis and characterization of the cross-linked PVA/TiO2 composite polymer membrane for alkaline DMFC,” J. Memb. Sci., vol. 288, no. 1-2, pp. 51-60, Feb. 2007.

[49] C.-C. Yang, Y.-J. Lee, and J. M. Yang, "Direct methanol fuel cell (DMFC) based on PVA/MMT composite polymer membranes," J. Power Sources, vol. 188, no. 1, pp. 30-37, 2009.

[50] C. C. Yang and Y. J. Lee, "Preparation of the acidic PVA/MMT nanocomposite polymer membrane for the direct methanol fuel cell (DMFC)," Thin Solid Films, vol. 517, no. 17, pp. 4735-4740, 2009.

[51] Y. Jin, J. C. Diniz da Costa, and G. Q. Lu, "Proton conductive composite membrane of phosphosilicate and polyvinyl alcohol,” Solid State Ionics, vol. 178, no. 13-14, pp. 937-942, May 2007.

[52] D. R. Vernon, F. Meng, S. F. Dec, D. L. Williamson, J. A. Turner, and A. M. Herring, "Synthesis, characterization, and conductivity measurements of hybrid membranes containing a mono-lacunary heteropolyacid for PEM fuel cell applications,” J. Power Sources, vol. 139, no. 1-2, pp. 141-151, Jan. 2005.

[53] Y. Yang, C. Liu, P. R. Chang, Y. Chen, D. P. Anderson, and M. Stumborg, "Properties and structural characterization of oxidized starch/PVA/ $\alpha$ zirconium phosphate composites,” J. Appl. Polym. Sci., vol. 115, no. 2, pp. 1089-1097, Jan. 2010.

[54] M. Helen, B. Viswanathan, and S. Srinivasa Murthy, "Fabrication and properties of hybrid membranes based on salts of heteropolyacid, zirconium phosphate and polyvinyl alcohol,” J. Power Sources, vol. 163, no. 1, pp. 433439, Dec. 2006.

[55] J. Maiti, N. Kakati, S. H. Lee, S. H. Jee, and Y. S. Yoon, "PVA nano composite membrane for DMFC application,” Solid State Ionics, vol. 201, no. 1, pp. 21- 
26, Oct. 2011.

[56] R. P. Pandey, G. Shukla, M. Manohar, and V. K. Shahi, "Graphene oxide based nanohybrid proton exchange membranes for fuel cell applications: An overview," Adv. Colloid Interface Sci., vol. 240, pp. 15-30, 2016.

[57] W. S. Hummers and R. E. Offeman, "Preparation of Graphitic Oxide,” J. Am. Chem. Soc., vol. 80, no. 6, pp. 1339-1339, 1958.

[58] Y. Y. Qi, Z. X. Tai, D. F. Sun, J. T. Chen, H. B. Ma, X. B. Yan, B. Liu, and Q. J. Xue, "Fabrication and characterization of poly(vinyl alcohol)/graphene oxide nanofibrous biocomposite scaffolds,” J. Appl. Polym. Sci., vol. 127, no. 3, pp. 1885-1894, 2013.

[59] C. Guo, L. Zhou, and J. Lv, "Layer- Structured Poly(vinyl alcohol) / Graphene Oxide Nanocomposites with Improved Thermal and Mechanical Properties," Polym. Polym. Compos., vol. 21, no. 7, pp. 449-456, 2013.

[60] C. M. Branco, S. Sharma, M. M. De Camargo Forte, and R. SteinbergerWilckens, "New approaches towards novel composite and multilayer membranes for intermediate temperature-polymer electrolyte fuel cells and direct methanol fuel cells,” J. Power Sources, vol. 316, no. x, pp. 139-159, 2016.

[61] N. Joseph, P. Ahmadiannamini, R. Hoogenboom, and I. F. J. Vankelecom, "Layer-by-layer preparation of polyelectrolyte multilayer membranes for separation,” Polym. Chem., vol. 5, no. 6, pp. 1817-1831, 2014.

[62] C. Wang, Y. Li, G. Ding, X. Xie, and M. Jiang, "Preparation and characterization of graphene oxide/poly(vinyl alcohol) composite nanofibers via electrospinning,” J. Appl. Polym. Sci., vol. 127, no. 4, pp. 3026-3032, 2013.

[63] B. Ding and J. Yu, Electrospun Nanofibers for Energy and Environmental Applications. 2014.

[64] H. Beydaghi, M. Javanbakht, and E. Kowsari, "Synthesis and Characterization of Poly(vinyl alcohol)/Sulfonated Graphene Oxide Nanocomposite Membranes for Use in Proton Exchange Membrane Fuel Cells (PEMFCs),” Ind. Eng. Chem. Res., vol. 53, no. 43, pp. 16621-16632, 2014.

[65] S. Mo, L. Peng, C. Yuan, C. Zhao, W. Tang, C. Ma, J. Shen, W. Yang, Y. Yu, Y. Min, and A. J. Epstein, "Enhanced properties of poly(vinyl alcohol) composite films with functionalized graphene,” RSC Adv., vol. 5, no. 118, pp. 97738-97745, 2015.

[66] R. Sood, S. Cavaliere, D. J. Jones, and J. Rozière, "Electrospun nanofibre composite polymer electrolyte fuel cell and electrolysis membranes," Nano Energy, vol. 26, pp. 729-745, 2016.

[67] H. Junoh, J. Jaafar, M. N. A. Mohd Norddin, A. F. Ismail, M. H. D. Othman, M. A. Rahman, N. Yusof, W. N. Wan Salleh, and H. Ilbeygi, “A Review on the Fabrication of Electrospun Polymer Electrolyte Membrane for Direct Methanol Fuel Cell,” J. Nanomater., vol. 2015, pp. 1-16, Mar. 2015.

[68] M. Tanaka, "Development of ion conductive nanofibers for polymer electrolyte fuel cells,” Polymer Journal, vol. 48, no. 1. Nature Publishing Group, pp. 51-58, 16-Jan-2016.

[69] A. Laforgue, L. Robitaille, A. Mokrini, and A. Ajji, "Fabrication and characterization of ionic conducting nanofibers," Macromol. Mater. Eng., vol. 
292, no. 12, pp. 1229-1236, 2007.

[70] F. Barzegar, A. Bello, M. Fabiane, S. Khamlich, D. Momodu, F. Taghizadeh, J. Dangbegnon, and N. Manyala, "Preparation and characterization of poly(vinyl alcohol)/graphene nanofibers synthesized by electrospinning," $J$. Phys. Chem. Solids, vol. 77, pp. 139-145, 2015.

[71] L. Jia and X. Qin, "The effect of different surfactants on the electrospinning poly(vinyl alcohol) (PVA) nanofibers,” J. Therm. Anal. Calorim., vol. 112, no. 2, pp. 595-605, May 2013.

[72] J. L. Reyes-Rodriguez, O. Solorza-Feria, A. García-Bernabé, E. Giménez, O. Sahuquillo, and V. Compañ, "Conductivity of composite membrane-based poly(ether-ether-ketone) sulfonated (SPEEK) nanofiber mats of varying thickness,” RSC Adv., vol. 6, no. 62, pp. 56986-56999, 2016.

[73] I. Shabani, M. M. Hasani-Sadrabadi, V. Haddadi-Asl, and M. Soleimani, "Nanofiber-based polyelectrolytes as novel membranes for fuel cell applications,” J. Memb. Sci., vol. 368, no. 1-2, pp. 233-240, Feb. 2011.

[74] H.-Y. Li and Y.-L. Liu, "Nafion-functionalized electrospun poly(vinylidene fluoride) (PVDF) nanofibers for high performance proton exchange membranes in fuel cells,” J. Mater. Chem. A, vol. 2, no. 11, pp. 3783-3793, Feb. 2014

[75] G. Ito, M. Tanaka, and H. Kawakami, "Sulfonated polyimide nanofiber framework: Evaluation of intrinsic proton conductivity and application to composite membranes for fuel cells,” Solid State Ionics, vol. 317, pp. 244255, Apr. 2018.

[76] T. Tamura and H. Kawakami, "Aligned Electrospun Nanofiber Composite Membranes for Fuel Cell Electrolytes,” Nano Lett., vol. 10, no. 4, pp. 1324 1328, Apr. 2010.

[77] J. Choi, K. M. Lee, R. Wycisk, P. N. Pintauro, and P. T. Mather, "Nanofiber network ion-exchange membranes,” Macromolecules, vol. 41, no. 13, pp. 4569-4572, 2008.

[78] J. Choi, K. M. Lee, R. Wycisk, P. N. Pintauro, and P. T. Mather, "Sulfonated Polysulfone/POSS Nanofiber Composite Membranes for PEM Fuel Cells,” $J$. Electrochem. Soc., vol. 157, no. 6, p. B914, Jun. 2010.

[79] H.-Y. Li and Y.-L. Liu, "Polyelectrolyte composite membranes of polybenzimidazole and crosslinked polybenzimidazole-polybenzoxazine electrospun nanofibers for proton exchange membrane fuel cells,” J. Mater. Chem. A, vol. 1, no. 4, pp. 1171-1178, Dec. 2013.

[80] G.-M. Liao, P.-C. Li, J.-S. Lin, W.-T. Ma, B.-C. Yu, H.-Y. Li, Y.-L. Liu, C.C. Yang, C.-M. Shih, and S. J. Lue, "Highly conductive quasi-coaxial electrospun quaternized polyvinyl alcohol nanofibers and composite as highperformance solid electrolytes,” J. Power Sources, vol. 304, pp. 136-145, 2016.

[81] C. Gao, L. Yu, H. Liu, and L. Chen, "Development of self-reinforced polymer composites,” Prog. Polym. Sci., vol. 37, no. 6, pp. 767-780, 2012.

[82] Á. Kmetty, T. Bárány, and J. Karger-Kocsis, "Self-reinforced polymeric materials: A review,” Prog. Polym. Sci., vol. 35, no. 10, pp. 1288-1310, Oct. 2010.

[83] A. C. Dupuis, "Proton exchange membranes for fuel cells operated at medium 
temperatures: Materials and experimental techniques,” Prog. Mater. Sci., vol. 56, no. 3, pp. 289-327, 2011.

[84] J. Ma and Y. Sahai, "Chitosan biopolymer for fuel cell applications," Carbohydr. Polym., vol. 92, no. 2, pp. 955-975, 2013.

[85] F. E. F. Silva, M. C. B. Di-Medeiros, K. A. Batista, K. F. Fernandes, F. E. F. Silva, M. C. B. Di-Medeiros, K. A. Batista, K. F. Fernandes, M. C. B. DiMedeiros, K. A. Batista, K. Fernandes, and T. F., "PVA/Polysaccharides Blended Films: Mechanical Properties,” J. Mater., vol. 2013, pp. 1-6, Apr. 2013.

[86] C. Santos, C. J. Silva, Z. Büttel, R. Guimarães, S. B. Pereira, P. Tamagnini, and A. Zille, "Preparation and characterization of polysaccharides/PVA blend nanofibrous membranes by electrospinning method," Carbohydr. Polym., vol. 99, pp. 584-592, Jan. 2014.

[87] Y.-S. Ye, J. Rick, and B.-J. Hwang, "Water Soluble Polymers as Proton Exchange Membranes for Fuel Cells," Polymers (Basel)., vol. 4, no. 4, pp. 913-963, Mar. 2012.

[88] N. C. Mat and A. Liong, "Chitosan-poly (vinyl alcohol) and calcium oxide composite membrane for direct methanol fuel cell applications," Eng. Lett., vol. 17, no. 4, 2009.

[89] B. Smitha, S. Sridhar, and A. A. Khan, "Synthesis and characterization of poly(vinyl alcohol)-based membranes for direct methanol fuel cell," J. Appl. Polym. Sci., vol. 95, no. 5, pp. 1154-1163, Mar. 2005.

[90] A. Abraham, P. A. Soloman, and V. O. Rejini, "Preparation of ChitosanPolyvinyl Alcohol Blends and Studies on Thermal and Mechanical Properties,” Procedia Technol., vol. 24, pp. 741-748, Jan. 2016.

[91] K. Lewandowska, "Miscibility and thermal stability of poly(vinyl alcohol)/chitosan mixtures," Thermochim. Acta, vol. 493, no. 1, pp. 42-48, 2009.

[92] M. H. Buraidah and A. K. Arof, "Characterization of chitosan/PVA blended electrolyte doped with NH4I,” J. Non. Cryst. Solids, vol. 357, no. 16-17, pp. 3261-3266, 2011.

[93] T. Chakrabarty, M. Kumar, and V. Shahi, "Chitosan Based Membranes for Separation, Pervaporation and Fuel Cell Applications: Recent Developments,” Biopolymers, pp. 5-8, Sep. 2010.

[94] P. Mukoma, B. R. Jooste, and H. C. M. Vosloo, “A comparison of methanol permeability in Chitosan and Nafion 117 membranes at high to medium methanol concentrations," J. Memb. Sci., vol. 243, no. 1-2, pp. 293-299, Nov. 2004.

[95] P. Mukoma, B. R. Jooste, and H. C. M. Vosloo, "Synthesis and characterization of cross-linked chitosan membranes for application as alternative proton exchange membrane materials in fuel cells," J. Power Sources, vol. 136, no. 1, pp. 16-23, Sep. 2004.

[96] Q. A. L. X. Z. X. H. C. Ma B., "Structure and properties of chitin whisker reinforced chitosan membranes,” Int. J. Biol. Macromol., vol. 64, pp. 341-346, 2014.

[97] E. Dashtimoghadam, M. M. Hasani-Sadrabadi, and H. Moaddel, "Structural modification of chitosan biopolymer as a novel polyelectrolyte membrane for 
green power generation,” Polym. Adv. Technol., vol. 21, no. 10, pp. 726-734, Jun. 2010.

[98] B. Smitha, S. Sridhar, and A. A. Khan, "Polyelectrolyte complexes of chitosan and poly(acrylic acid) as proton exchange membranes for fuel cells," Macromolecules, vol. 37, no. 6, pp. 2233-2239, 2004. 


\subsection{CONTRIBUTIONS OF CHAPTER 4}

The polyelectrolyte membranes, as the key component in the fuel cell, have been largely studied to improve the performance in terms of efficiency, durability and cost. However, the accomplishment of the strict requirements to become the ideal membrane are still under investigation. The preparation of specific matrices and nanofibres based on similar polymers stand out as suitable ingredients for the future development of self-reinforced nanocomposite membranes. For this functionalisation strategy, the development of new polyelectrolyte membranes was assessed considering the crosslinking reaction between poly(vinyl alcohol) (PVA) and sulfosuccinic acid (SSA) as the base scenario for functionalisation and modification with polysaccharides such as chitosan or nanoparticles such as grapheme oxide (GO). The global structure of this research line is summarised in Figure 4.8.



Figure 4.8. Sequence approach for the functionalisation strategy, characterisation and validation of the polyelectrolyte membranes for fuel cells.

Firstly, the combination of PVA with graphene oxide (GO) and sulfonated graphene oxide (SGO) in several percentages ranging from $0.25 \%$ to 1.00 $\%$ by weight were considered. The PVA/SSA/GO and PVA/SSA/SGO based membranes were obtained by means of a solvent-casting procedure with an homogeneous and regular morphology and controlled thickness. The crossover of the ethanol solution was reduced by the addition of GO and SGO. This reduction was more significant for the SGO functionalized membranes. Membranes subjected to service conditions were stable after a 
long-term evaluation. Although the proton conductivity decreased due to the probable deprotonation during immersion, the addition of GO and SGO particles allowed to keep similar values to that found prior to immersion. In this sense, the addition of SGO was more effective.

In parallel, nanofibrous structures based on polymeric materials were proposed as components of polyelectrolyte membranes. Electrospinning allowed obtaining functionalised nanofibrous mats with controlled size and morphology. Nanofibrous crosslinked PVA/SSA/GO and SPVA/SSA/GO based nanocomposite membranes were developed. The GO contributed to strongly retain humidity, which significantly influenced the proton conductivity of the nanofibres. As well, the developed nanofibres were found to be electric insulators, essential for some polyelectrolyte applications. As well, the crosslinked nanofibrous membranes were found to be stable after an accelerated hydrothermal assay. In general, the developed composite nanofibres can be considered as good candidates for being exploited as valuable components for the preparation of ionic polyelectrolyte membranes.

Subsequently, the functionalisation of PVA-based membranes with polysaccharides, such as chitosan, was performed, due to the large number of chemical sites for functionalisation and/or crosslinking. Functionalised chitosan/poly(vinyl alcohol) CS/PVA-based membranes were successfully obtained by means of the combination with sulfosuccinic acid (SSA) as crosslinking and sulfonating agent, and glycerol (GL) to promote flexibility to favour the manageability of the membranes. The combination of solvent-casting and thermal-crosslinking permitted to obtain homogeneous membranes with controlled morphology. In general terms, all CS/PVA membranes showed a synergetic increase of thermal stabilities, absorption and diffusion of ethanol and proton conductivity, in contrast to those of neat CS or crosslinked PVA. The ranges of thermal stability, the electrical insulating behaviour, and the ethanol absorption capabilities, were appropriate to be used in typical service conditions of fuel cells.

The results of this research line were reported in:

Contribution 4.1. Functionalised poly(vinyl alcohol)/graphene oxide membranes for energy applications.

Contribution 4.2. Crosslinked sulfonated poly(vinyl alcohol)/ graphene oxide electrospun nanofibres as polyelectrolytes.

Contribution 4.3. Crosslinked chitosan/poly(vinyl alcohol)-based membranes for proton exchange polyelectrolytes. 


\section{Contribution 4.1.}

\section{Functionalised poly(vinyl alcohol)/graphene oxide membranes for energy applications}

O. Gil-Castell, R. Teruel-Juanes, R. Cerveró, J. D. Badia, A. Ribes-Greus. Functionalised poly(vinyl alcohol)/graphene oxide membranes for energy applications. Short manuscript presented at the International Conference on Materials and Energy (ICOME), San Sebastián, Spain ( $3^{\text {rd }}$ April $-4^{\text {th }}$ May 2018). 


\title{
Functionalised poly(vinyl alcohol)/graphene oxide membranes for energy applications
}

\author{
O. Gil-Castell ${ }^{1}$, R. Teruel-Juanes ${ }^{1}$, R. Cerveró1 ${ }^{1}$ J. D. Badia ${ }^{1,2}$, A. Ribes- \\ Greus $^{1^{*}}$ \\ ${ }^{1}$ Institute of Technology of Materials (ITM), Universitat Politècnica de València, Camino de \\ Vera s/n, 46022, Valencia, Spain \\ ${ }^{2}$ Department of Chemical Engineering. School of Engineering. Universitat de València. Av. de la \\ Universitat, s/n, 46100, Burjassot, Spain \\ *Corresponding author:
}

A. Ribes-Greus aribes@ter.upv.es 


\title{
Functionalised poly(vinyl alcohol)/graphene oxide membranes for energy applications
}

\author{
O. Gil-Castell, R. Teruel-Juanes, R. Cerveró, J. D. Badia, A. Ribes-Greus
}

\begin{abstract}
In this study, PVA composite membranes were developed as an alternative to polymer electrolyte membranes for low temperature fuel cell applications in direct ethanol fuel cells (DEFC) to avoid the crossover phenomenon. The influence of the addition of graphene oxide (GO) and sulfonated graphene oxide (SGO) as well as the crosslinking with sulfosuccinic acid (SSA) to the PVA matrix was assessed in simulated service conditions. GO and SGO contributed to reduce the ethanol crossover and improved the stability after long-term immersion.
\end{abstract}

\section{Keywords}

Proton exchange membranes; Poly(vinyl alcohol); Direct methanol fuel cells; Sulfonated graphene oxide; Graphene oxide; Stability; Proton conductivity 


\section{Introduction}

Composite materials have received great attention as feasible alternative with great potential for application as polymer electrolyte membranes in direct ethanol fuel cells (DEFCs). The cross-linked poly(vinyl alcohol) (PVA) with sulfosuccinic acid (SSA) is one of the best candidates for polymer electrolyte fabrication due to its environmentally friendly preparation, low price and non-toxicity and its barrier effect to ethanol crossover. As well, PVA is frequently filled with organic or inorganic particles to reduce the ethanol crossover. The addition of graphene oxide (GO) and sulfonated graphene oxide (SGO) was assessed in terms of the fuel uptake ability and ethanol crossover of these polyelectrolytes. The macroscopic appearance, the thermo-oxidative stability, the thermal properties and the proton conductivity were evaluated as a function of the immersion time in simulated working conditions.

\section{Materials and methods}

\subsection{Materials}

Poly(vinyl alcohol) (PVA) (99\% hydrolysed, $M_{w}=130000 \mathrm{~g} \cdot \mathrm{mol}^{-1}$ ) and $70 \%$ sulfosuccinic acid (SSA), was purchased from Sigma Aldrich; absolute ethanol $\left(\mathrm{C}_{2} \mathrm{H}_{5} \mathrm{OH}\right)$ from Scharlau. Ultra-pure water was obtained from an ultra-filtration/ion-exchange procedure. Graphene oxide (GO) and sulfonated GO (SGO) were obtained by the modified Hummers method [1], and functionalised [2].

\subsection{Membrane preparation}

The membranes were obtained by means of a solvent-casting procedure and further crosslinked by compression moulding at $120{ }^{\circ} \mathrm{C}$ to achieve dimensional control. For this purpose, a PVA solution was prepared (15\%wt) at $90{ }^{\circ} \mathrm{C}$ for $6 \mathrm{~h}$. Then, 30\%wtpva of SSA was added and, afterwards, sonicated GO and SGO solutions were incorporated to the membranes to achieve concentrations, ranging from 0.25 to $1.00 \%$ wtPVA.

\subsection{Fourier Transformed Infrared Spectroscopy (FTIR)}

The chemical structure of membranes was evaluated by means of a Thermo Nicolet 5700 in a attenuated total reflectance (ATR) setup. The IR spectra was assessed between 4000 and $400 \mathrm{~cm}^{-1}$ with a resolution of $4 \mathrm{~cm}^{-1}$ along 64 accumulations.

\subsection{Differential Scanning Calorimetry (DSC)}

DSC was performed into a Mettler Toledo DSC $822^{\mathrm{e}}$ equipped with a cooling system. Samples between 3 and $5 \mathrm{mg}$ were placed into $40 \mu \mathrm{l}$ aluminium crucibles. Three consecutive heating-cooling-heating segments 
from $50{ }^{\circ} \mathrm{C}$ to $250{ }^{\circ} \mathrm{C}$ with a heating/cooling rate of $10^{\circ} \mathrm{C} \cdot \mathrm{min}^{-1}$ were performed under inert $\mathrm{N}_{2}$ atmosphere at a flow rate of $50 \mathrm{ml} \cdot \mathrm{min}^{-1}$.

\subsection{Thermogravimetry (TGA)}

The samples, with a mass between 3 and $5 \mathrm{mg}$, were introduced into $70 \mu \mathrm{l}$ alumina capsules. The samples were then placed in the Mettler Toledo TGA 851 analyser and subjected to a dynamic test, from $25{ }^{\circ} \mathrm{C}$ to $800{ }^{\circ} \mathrm{C}$ with a heating rate of $10^{\circ} \mathrm{C} \cdot \mathrm{min}^{-1}$. The tests were carried out under an $\mathrm{O}_{2}$ atmosphere with at a flow rate of $50 \mathrm{ml} \cdot \mathrm{min}^{-1}$.

\subsection{Field Emission Scanning Electron Microscopy (FE-SEM)}

The surface topology of the specimens was analysed by means of a Zeiss Ultra 55 field emission scanning electron microscope (FE-SEM). The samples were cut into small pieces and dried at $50^{\circ} \mathrm{C}$ in a vacuum oven for $24 \mathrm{~h}$ and then kept in a desiccator during $48 \mathrm{~h}$. Afterwards, the specimens were mounted on metal studs and sputter-coated with a platinum layer during $15 \mathrm{~s}$ using a Leica EM MED020 sputter coater. FE-SEM images were taken at $22{ }^{\circ} \mathrm{C}$ with a $2 \mathrm{kV}$ voltage.

\subsection{Ethanol permeability}

The ethanol permeability of the membranes was evaluated by means of a glass diffusion cell with two reservoirs, each of $1 \mathrm{~L}$ capacity. Membranes were sandwiched between the two modules that contained deionised water and $2 \mathrm{M}$ ethanol solution, respectively. Permeability was indirectly measured from conductivity variation of both solutions. The signals were processed with the LabView software as a function of time. Measurements were carried out under magnetic stirring and thermostatically controlled at $40{ }^{\circ} \mathrm{C}$.

\subsection{Ethanol solution uptake}

Membrane samples about $1 \times 1 \mathrm{~cm}^{2}$ were immersed into $20 \mathrm{~mL}$ of $2 \mathrm{M}$ ethanol solution and placed in a Selecta Unitronic Bath at $40^{\circ} \mathrm{C}$. Water absorption was monitored gravimetrically up to $120 \mathrm{~h}$ of immersion.

\subsection{Hydrolytic stability}

The hydrolytic stability of the membranes was studied after immersion for several long-term stages. Accordingly, samples were removed after 7, 14, 28,56 and 100 days, and dried under vacuum at $30^{\circ} \mathrm{C}$ for $48 \mathrm{~h}$. The ethanol solution was replaced once a week in order to preserve it fresh. The changes after immersion were characterised in terms of the variation of the macro and microscopic appearance, the thermal properties (DSC) and the thermooxidative stability (TGA). As well, the proton conductivity was measured after 100 days of immersion. 


\subsection{Proton conductivity}

Proton conductivity $\left(\sigma_{p r o t}\right)$ was measured in an alpha mainframe frequency analyser in conjunction with an active cell (Concept 40, Novocontrol Technologies BmgH \& Co.). The response was measured from $10^{-2}$ to $10^{7}$ $\mathrm{Hz}$, at room temperature $\left(25^{\circ} \mathrm{C}\right)$. The sample electrode assembly (SEA) consisted in two stainless steel electrodes filled with the polymer. The diameters of the electrodes were $20 \mathrm{~mm}$ and the thickness was kept around $30 \mu \mathrm{m}$. The membranes were fully hydrated with ultra-pure water for $24 \mathrm{~h}$. The $\sigma_{\text {prot }}\left(\mathrm{S} \cdot \mathrm{cm}^{-1}\right)$ of the membranes was calculated according to

$$
\sigma_{\text {prot }}=\frac{l}{A \cdot R_{0}}
$$

where $l$ is the thickness of the conducting membranes in $\mathrm{cm}, A$ the area of the electrode in contact with the membrane in $\mathrm{cm}^{2}$, and $R_{0}$ the protonic resistance taken from the Bode plot at high frequencies in ohms $(\Omega)$ [3].

\section{Results and discussion}

\subsection{Physico-chemical characterisation}

The obtained membranes were initially characterised in terms of the chemical structure, thermo-oxidative stability, thermal properties and proton conductivity. Regarding the chemical composition, GO, PVA, PVA/SSA and PVA/SSA/GO(SGO) composites were assessed. FTIR spectra are plotted in Figure 1.

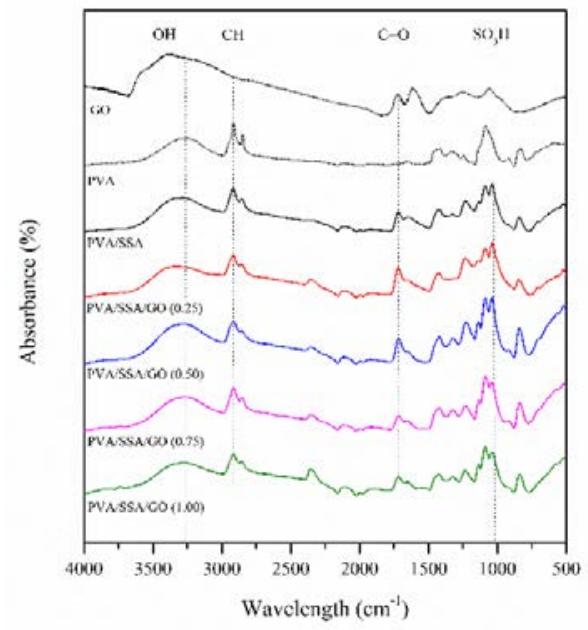

Figure 1. FTIR spectra.

PVA membranes showed a broad band between 3400 and $3000 \mathrm{~cm}^{-1}$, associated to the hydroxyl group stretching $(-\mathrm{OH})$ of intra and 
intermolecular interactions and retained water molecules. Moreover, the peaks between $3000-2800 \mathrm{~cm}^{-1}$ and $1500-1300 \mathrm{~cm}^{-1}$ corresponded to the stretching and bending of the $-\mathrm{CH}_{2}-$ of the PVA backbone [4]. The addition of SSA was perceived in the 1780 and $1710 \mathrm{~cm}^{-1}$ bands associated to the carboxyl $(-\mathrm{COOH})$ and acetate groups and corroborated in the peak at $1040 \mathrm{~cm}^{-1}$, correlated with sulfonic groups $\left(-\mathrm{SO}_{3} \mathrm{H}\right)$ [5]. GO showed the characteristic peaks at 3450,1720,1600, 1400 and $1100 \mathrm{~cm}^{-1}$, which can be correlated to hydroxyl stretching $(-\mathrm{OH})$, carboxyl stretching $(\mathrm{C}=\mathrm{O})$, backbone of non-oxidised graphite and $\mathrm{C}=\mathrm{C}$ bond, and bending of $(\mathrm{O}-\mathrm{H})$ and $(\mathrm{C}-\mathrm{O})$ of hydroxyl groups, respectively [6]. However, due to the low concentration of GO in the composites, the bands of these particles were overlapped in the PVA/SSA/GO membranes. The absence of the GO peaks can be associated to a satisfactory particle dispersion.

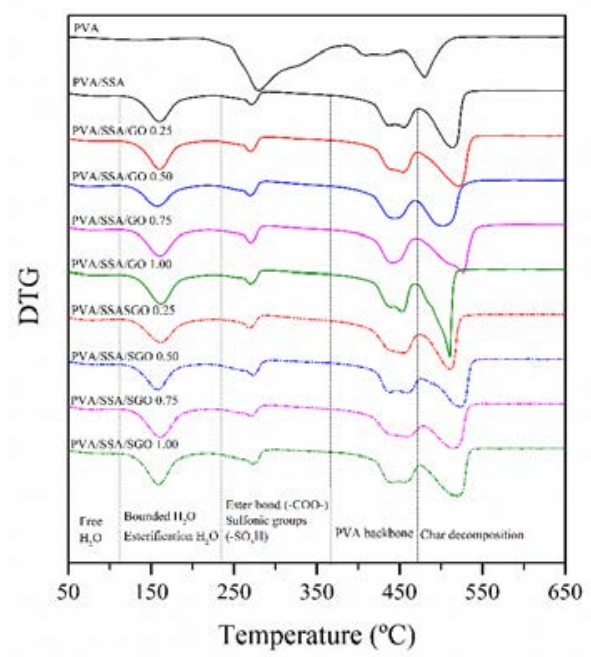

Figure 2. Derivative thermo-gravimetric curve.

The study of the thermo-oxidative stability of the pure PVA membrane revealed the typical two-step mass loss behaviour, as shown in Figure 2. The first step, until $200{ }^{\circ} \mathrm{C}$, involved the free water evaporation ( $\left.\sim 5 \%\right)$. Then, the degradation of side groups from the main chain and the loss of bound water was observed between 230 and $400{ }^{\circ} \mathrm{C}$. This stage involved the elimination of bound water and hydroxyl groups $(-\mathrm{OH})$ that promote a polyene structure, chain scission and cyclization reactions. Finally, above $400{ }^{\circ} \mathrm{C}$, the degradation of the polymer backbone took place [5]. In the PVA/SSA based crosslinked membranes, a multi-stage decomposition behaviour was perceived. Free water was released between 50 and $100^{\circ} \mathrm{C}$, followed by the release of bound water, and also water produced by further esterification reactions between 100 and $230^{\circ} \mathrm{C}$. Then, the sulfonic group $\left(-\mathrm{SO}_{3} \mathrm{H}\right)$ decomposition and ester bond scission was found between 230 
and $350^{\circ} \mathrm{C}$. Finally, above $400{ }^{\circ} \mathrm{C}$, the decomposition of the PVA backbone was observed [7]. If compared to pure PVA, this stage was more pronounced for the PVA/SSA based membranes and moved towards higher temperatures. Moreover, residual mass values increased from $~ 2$ to $~ 15 \%$. These changes can be explained by the highly crosslinked structure of these materials [5]. For PVA/SSA/GO and PVA/SSA/SGO composites, similar TGA curves were perceived. The effect of the small amount of GO or SGO particles $(<1 \%)$ was irrelevant regarding the thermo-oxidative stability of these materials.

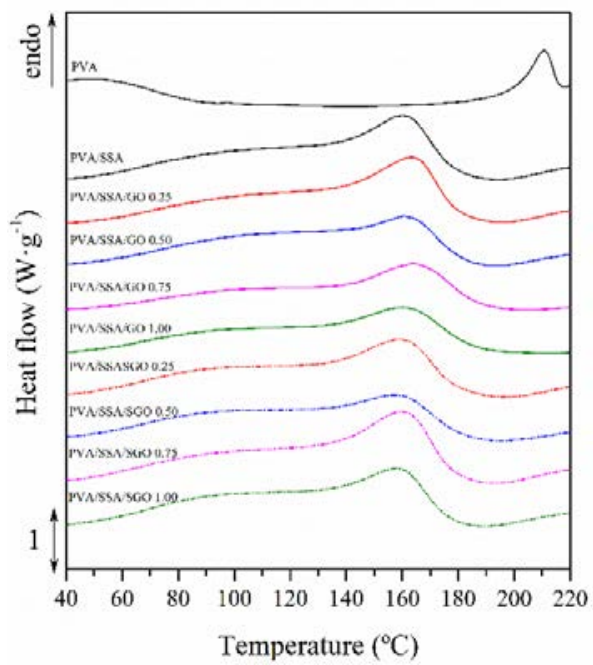

Figure 3. Calorimetric thermograms of the first heating scan.

The thermal properties were evaluated from calorimetric traces of the first heating scan, as plotted in Figure 3. Pure PVA showed a wide endotherm from 40 to $80^{\circ} \mathrm{C}$ that involved the release of free water. Then, around 210 ${ }^{\circ} \mathrm{C}$, a melting peak of the crystalline structure of PVA molecules was found. However, for crosslinked PVA/SSA based membranes, a wide bimodal endotherm from 40 to $180{ }^{\circ} \mathrm{C}$ was observed. These peaks can be correlated to those observed in the prior TGA analysis. The first peak, around $90{ }^{\circ} \mathrm{C}$, is ascribed to the free water release. Accordingly, the peak around $160{ }^{\circ} \mathrm{C}$ involved the release of bound water and water produced by esterification reactions. The addition of GO and SGO particles, slightly moved these events towards higher temperatures $\left(1-2{ }^{\circ} \mathrm{C}\right)$. Given this behaviour, it seems that thermal properties were unaltered by the addition of GO and SGO particles. From the second heating scan, immediately after a controlled cooling in the DSC equipment, it was found a glass transition for pure PVA around $123^{\circ} \mathrm{C}$, that increased with crosslinking in PVA/SSA to $134{ }^{\circ} \mathrm{C}$ and disappeared with the addition of GO and SGO. This phenomenon may suggest an even more compacted and crosslinked structure of PVA, SSA 
and GO or SGO that prevented the PVA molecules from having the glass transition [8].

Table 1. Proton conductivity.

\begin{tabular}{ccc}
\hline \multirow{2}{*}{$\begin{array}{c}\boldsymbol{\sigma}_{\text {prot }} \\
\left(\mathbf{m S} \cdot \mathbf{c m}^{-1}\right)\end{array}$} & \multicolumn{2}{c}{ PVA/SSA } \\
\cline { 2 - 3 } & \multicolumn{2}{c}{0.5861} \\
\hline $\mathbf{0 . 2 5}$ & 0.4691 & PVA/SSA/SGO \\
\hline $\mathbf{0 . 5 0}$ & 0.1459 & 0.0715 \\
\hline $\mathbf{0 . 7 5}$ & 0.0520 & 0.4406 \\
\hline $\mathbf{1 . 0 0}$ & 0.0915 & 0.1146 \\
\hline
\end{tabular}

The proton conductivity of the membranes was assessed at $25^{\circ} \mathrm{C}$, which results are gathered in Table 1 . The increase of the GO content reduced the proton conductivity. GO particles seemed to have hindered the proton transport pathways. However, when SGO was added, the proton conductivity moderately decreased. The contribution of the sulfonic groups grafted to the GO particles may have regulated the decrease of the proton conductivity. Overall, the proton conductivity values were lower to that reported in the literature. Although the proton conductivity measurements were carried out after $24 \mathrm{~h}$ of immersion into water to guarantee proper hydration, the low thickness of the studied membranes, around $30 \mu \mathrm{m}$, may have resulted in lower hydration degree and high desorption rate of swelled humidity, which is crucial for proton transport through the membrane [9], [10].



Figure 4. Relative variation of the conductivity of the water reservoir for the $2 \mathrm{M}$ and $4 \mathrm{M}$ ethanol solution. 


\subsection{Ethanol permeability}

The ethanol permeability was evaluated from the relative conductivity variation of the water reservoir as a function of time, as plotted in Figure 4 for a $2 \mathrm{M}$ ethanol solution. As observed, the relative conductivity remained constant. It slightly increased due to the ambient $\mathrm{CO}_{2}$ diluted in the reservoir along the experiment. Given these results, membranes seemed to be impermeable to ethanol under the selected conditions, in comparison to Nafion 117 membrane (dash line). Composite membranes behaved similar to PVA/SSA.

\subsection{Ethanol solution absorption}

Membranes submitted to $2 \mathrm{M}$ ethanol solutions at $40{ }^{\circ} \mathrm{C}$ swelled as a function of the immersion time. The ethanol solution penetrated into the membranes and the mass increased. The mass variation until saturation is plotted in Figure 5. PVA/SSA membrane swelled up to $40 \%$ of ethanol solution. As GO content increased, solution uptake decreased. GO may have hindered the advance of penetrant along the membrane, which will contribute to reduce ethanol crossover. Moreover, the functional groups of GO may have interacted with PVA and SSA molecules, giving raise to a more solid structure with less free volume available for the penetrant. When SGO was incorporated to the membranes, this behaviour was emphasised, and solution uptake decreased even more.

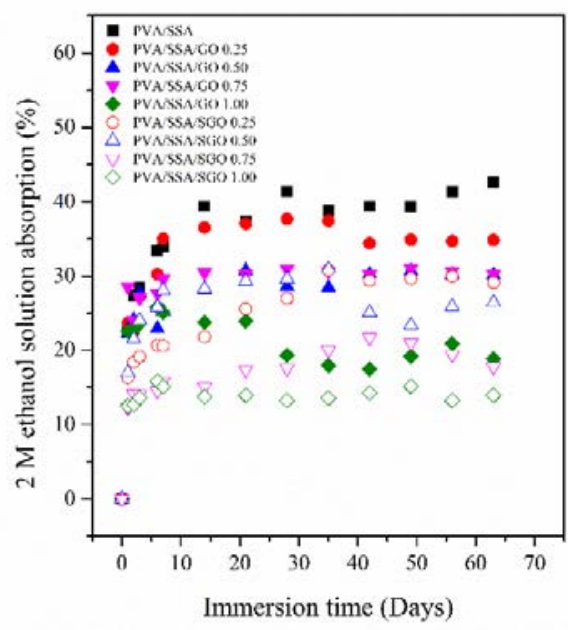

Figure 5. Ethanol solution absorption profiles.

\subsection{Hydrolytic stability}

The characterisation of the stability of the membranes against the immersion into $2 \mathrm{M}$ ethanol solution, is closely related to the performance of these materials for application as electrolytes in fuel cell applications. 
For this reason, membranes were evaluated after long-term stages of immersion. The blackish original membranes turned into a clearer appearance after 100 days of immersion. This change was more perceivable for PVA/SSA membrane and those that contained SGO, as shown in Table 2.

Table 2. Macroscopic appearance after 100 days of immersion.

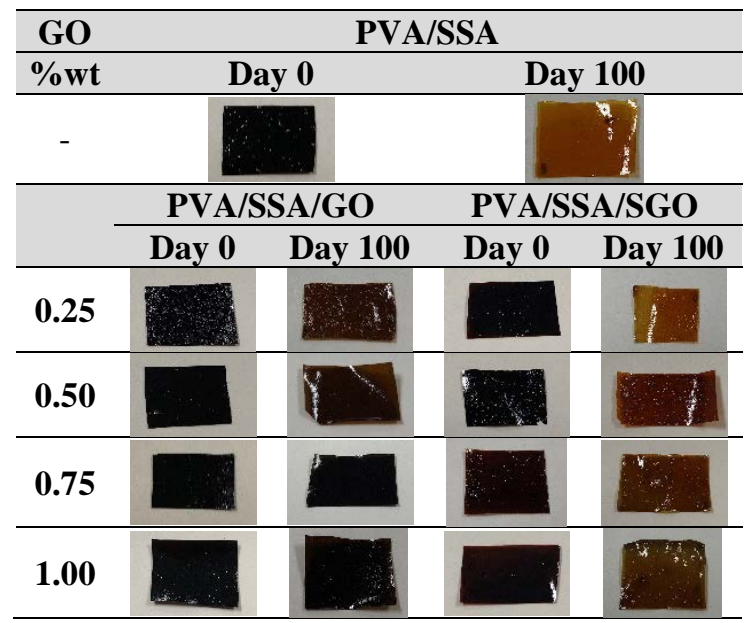

However, the microscopic surface of the membranes seemed to remain unaffected, as exposed in Figure 6.

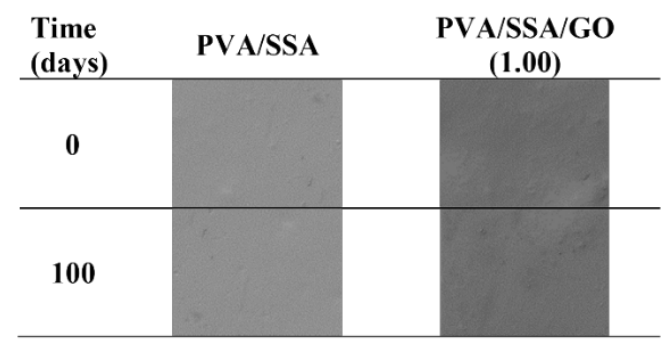

Figure 6. Microscopic appearance after 100 days of immersion (500×).

The thermo-oxidative stability analyses revealed that the peak associated to the release of bound water and water molecules generated by the esterification reaction lost importance and moved towards higher temperatures along immersion in all cases. On the one hand, residual esterification reactions may have been completed during immersion, which contribution during the TGA analysis disappeared. On the other hand, higher immersion time may have promoted better water-polymer interaction that needed more temperature to be released. This observation was also visible in the calorimetric results. Moreover, the thermo-oxidative stability evaluation showed the considerable reduction of the desulfonation 
peak in the DTG curve. Unreacted SSA molecules may have leached from the membrane to the surrounding media. This observation was perceivable from the first stage of immersion. Finally, the peak that involved the backbone decomposition of the PVA decreased as a function of the immersion time. Highly swelled membranes after 100 days of immersion may have left more free volume through which oxygen molecules diffused and promoted lower thermo-oxidative stability. As an example of these observations the thermo-gravimetric and its derivative curves, along with calorimetric thermograms are shown in Figure 7 as a function of the immersion time for the PVA/SSA/GO 0.75 membrane. The behaviour was similar, regardless the presence of GO or SGO in the membranes.
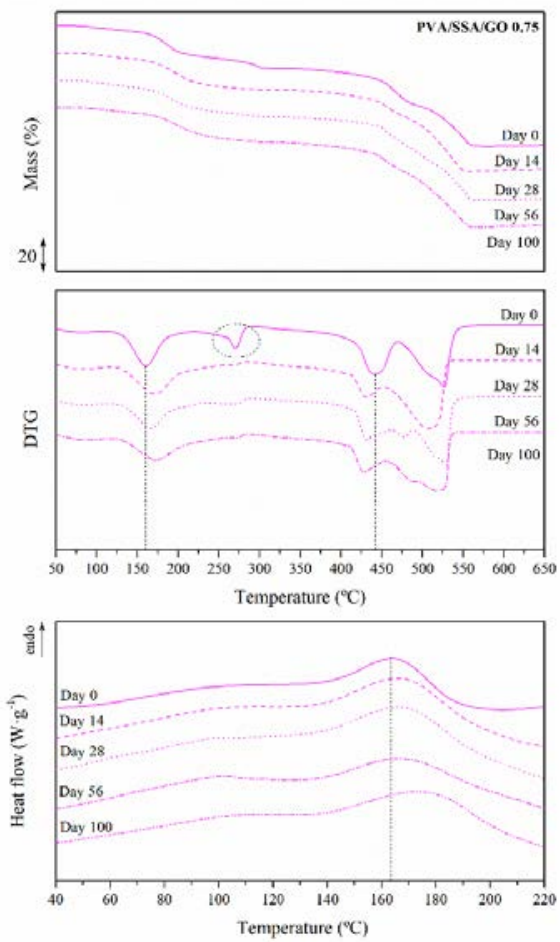

Figure 7. Calorimetric, TGA and DTG traces as a function of the immersion time.

Table 4. Proton conductivity after 100 days of immersion.

\begin{tabular}{ccc}
\hline \multirow{2}{*}{$\begin{array}{c}\boldsymbol{\sigma}_{\text {prot }} \\
\left(\mathbf{m S} \cdot \mathbf{c m}^{-1}\right)\end{array}$} & \multicolumn{2}{c}{ PVA/SSA } \\
\cline { 2 - 3 } & PVA/SSA/GO & PVA/SSA/SGO \\
\hline $\mathbf{0 . 2 5}$ & 0.0032 & 0.0044 \\
\hline $\mathbf{0 . 5 0}$ & 0.0410 & 0.0684 \\
\hline $\mathbf{0 . 7 5}$ & 0.0388 & 0.0741 \\
\hline $\mathbf{1 . 0 0}$ & 0.0131 & 0.0193 \\
\hline
\end{tabular}


The proton conductivity was assessed in the membranes after being submitted to 100 days of immersion in $2 \mathrm{M}$ ethanol solution and results are gathered in Table 4. Conductivity decreased after immersion in all cases. While this decrease was dramatic for PVA/SSA, membranes containing 0.50 and $0.75 \%$ of GO and SGO, showed similar conductivity than before immersion. The crosslinking between PVA, SSA and GO particles may have contributed to preserve the proton conductivity after immersion.

\section{Conclusions}

The combination of a solvent-casting and thermal crosslinking procedure resulted in an effective mode to produce functionalised PVA/SSA/GO and PVA/SSA/SGO composite membranes. Although the addition of GO and SGO reduced proton conductivity, a reduction of the ethanol solution swelling and crossover was found. This behaviour was more significant for SGO functionalized membranes, which showed high barrier effect against ethanol crossover. The membranes submitted to service conditions were found to be stable after long-term evaluation. Although the proton conductivity decreased due to the probable deprotonation during immersion, the addition of GO and SGO particles permitted to retain similar values to that found prior to immersion. In this sense, the addition of SGO was more effective.

\section{Acknowledgments}

The authors would like to thank the support of the European Union is through the European Regional Development Funds (ERDF). The Spanish Ministry of Economy, Industry and Competitiveness, is thanked for the research projects POLYCELL (ENE2014-53734-C2-1-R), POLYDECARBOCELL (ENE2017-86711-C3-1-R) and UPOV13-3E1947. The Spanish Ministry of Education, Culture and Sports is thanked for the FPU grant for O. Gil-Castell (FPU13/01916). The Generalitat Valenciana is acknowledged for the project APOSTD14/041 for J. D. Badia and for the GRISOLIAP/2012/056 grant for R. Teruel.

\section{References}

[1] W. S. Hummers and R. E. Offeman, "Preparation of Graphitic Oxide,” J. Am. Chem. Soc., vol. 80, no. 6, pp. 1339-1339, 1958.

[2] S. C. Sánchez Ballester, "Synthesis and characterization of new polymer electrolytes to use in fuel cells fed with bio-alcohols,” Universitat Politècnica de València, 2017.

[3] X. Qian, N. Gu, Z. Cheng, X. Yang, E. Wang, and S. Dong, "Methods to study the ionic conductivity of polymeric electrolytes using a.c. impedance spectroscopy,” J. Solid State Electrochem., vol. 6, no. 1, pp. 8-15, Dec. 2001.

[4] S. Yun, H. Im, Y. Heo, and J. Kim, "Crosslinked sulfonated poly(vinyl alcohol)/sulfonated multi-walled carbon nanotubes nanocomposite membranes for direct methanol fuel cells,” J. Memb. Sci., vol. 380, no. 1-2, pp. 208-215, 2011.

[5] A.Martínez-Felipe, C.Moliner-Estopiñán, C.T.Imrie, and A.Ribes-Greus, "Characterization of Crosslinked PVA-based membranes.," Polym. Polym. Compos., vol. 21, no. 7, pp. 449-456, 2013. 
[6] S. Mo, L. Peng, C. Yuan, C. Zhao, W. Tang, C. Ma, J. Shen, W. Yang, Y. Yu, Y. Min, and A. J. Epstein, "Enhanced properties of poly(vinyl alcohol) composite films with functionalized graphene,” RSC Adv., vol. 5, no. 118, pp. 97738-97745, 2015.

[7] J. W. Rhim, H. B. Park, C. S. Lee, J. H. Jun, D. S. Kim, and Y. M. Lee, “Crosslinked poly(vinyl alcohol) membranes containing sulfonic acid group: Proton and methanol transport through membranes,” J. Memb. Sci., vol. 238, no. 1-2, pp. 143-151, 2004.

[8] S. Yun, H. Im, Y. Heo, and J. Kim, "Crosslinked sulfonated poly(vinyl alcohol)/sulfonated multi-walled carbon nanotubes nanocomposite membranes for direct methanol fuel cells,” J. Memb. Sci., vol. 380, no. 1-2, pp. 208-215, Sep. 2011.

[9] T. Okada, G. Xie, O. Gorseth, S. Kjelstrup, N. Nakamura, and T. Arimura, "Ion and water transport characteristics of Nafion membranes as electrolytes,” Electrochim. Acta, vol. 43, no. 24, pp. 3741-3747, Aug. 1998.

[10] M. A. Witt, G. M. O. Barra, J. R. Bertolino, and A. T. N. Pires, "Crosslinked chitosan/poly (vinyl alcohol) blends with proton conductivity characteristic,” J. Braz. Chem. Soc., vol. 21, no. 9, pp. 1692-1698, 2010. 
Contribution 4.2.

Crosslinked sulfonated poly(vinyl alcohol)/ graphene oxide electrospun nanofibres as polyelectrolytes

O. Gil-Castell, D. Galindo-Alfaro, R. Teruel-Juanes, J. D. Badia, A. RibesGreus. Crosslinked sulfonated poly(vinyl alcohol)/graphene oxide electrospun nanofibres as polyelectrolytes. Manuscript in preparation. 


\title{
Crosslinked sulfonated poly(vinyl alcohol)/graphene oxide electrospun nanofibres as polyelectrolytes
}

\author{
O. Gil-Castell ${ }^{1}$, D. Galindo-Alfaro ${ }^{1}$, R. Teruel-Juanes ${ }^{1}$, J.D. Badia ${ }^{1,2}$, A. \\ Ribes-Greus,**
}

${ }^{1}$ Instituto de Tecnología de Materiales (ITM), Universitat Politècnica de València (UPV). Camino de Vera s/n, 46022 Valencia, Spain.

\section{${ }^{2}$ Departament d’Enginyeria Química. Escola Tècnica Superior d’Enginyeria. Universitat de} València. Av. de la Universitat s/n, 46100 Burjassot, Spain.

*Corresponding author:

A. Ribes-Greus aribes@ter.upv.es 


\title{
Crosslinked sulfonated poly(vinyl alcohol)/graphene oxide electrospun nanofibres as polyelectrolytes
}

\author{
O. Gil-Castell, D. Galindo-Alfaro, R. Teruel-Juanes, J.D. Badia, A. \\ Ribes-Greus
}

\begin{abstract}
Nanofibrous structures based on polymeric materials have been recently proposed as components of polyelectrolyte membranes. Electrospinning allows obtaining functionalised nanofibrous mats with controlled size and morphology. Among other materials, the poly(vinyl alcohol) (PVA) has raised as a feasible alternative with low cost and high capability of functionalisation for polyelectrolyte development. In this sense, the crosslinking of the PVA macromolecules with agents with specific ionic groups such as the sulfosuccinic acid (SSA), the addition of functional groups by means of grafting strategies such as the PVA sulfonation (SPVA) and the combination with inorganic particles such as graphene oxide (GO) may bring new possibilities in this field. In this study, nanofibrous crosslinked PVA/SSA/GO and SPVA/SSA/GO based nanocomposite membranes were developed, which were found to be highly stable. The chemical composition was ascertained and the presence of the sulfonic groups in the crosslinked structure was corroborated. The GO contributed to strongly retain humidity, which significantly influenced the proton conductivity of the nanofibres. As well, the developed nanofibres were found to be electric insulators, essential for some polyelectrolyte applications. As well, the crosslinked nanofibrous membranes were found to be stable after an accelerated hydrothermal assay. In general, the developed nanofibrous composite membranes can be considered as good candidates for being exploited as valuable components for the preparation of ionic polyelectrolyte membranes.
\end{abstract}

\section{Keywords}

Poly(vinyl alcohol) (PVA), graphene oxide (GO), crosslinked, nanofibres, proton conductivity 


\section{Introduction}

The development of nanofibrous structures based on polymeric materials for their application as components of polyelectrolyte membranes is a topic of interest in different fields of application [1].

Electrospinning is one of the main approaches to obtain functionalised nanofibrous mats, including homopolymers, blends or composites [2]-[4]. Given the wide versatility of the electrospinning technique, allowing the preparation of nanofibres of controlled size and morphology, the possibility of development of functionalised polyelectrolytes has been explored [5].

Many materials have been considered for the production of nanofibrous polyelectrolytes such as the poly(vinyl alcohol) (PVA) [6]-[8], polyvinylidenefluoride (PVDF) [9], polystyrene (PS) [10], polysulfone (PSU) [11], sulfonated poly(ether sulfone) (SPES) [12], sulfonated poly(ether ether ketone) (sPEEK) [13], poly(vinyl butyral) (PVB) [14] or sulfonated polyimide (PI) [15]. Among them, the use of poly(vinyl alcohol) (PVA) has been considered as an economically feasible alternative with promising results in terms of cost, versatility, processability and capability of functionalisation [16].

Regarding its application in the development of polyelectrolytes, PVA requires functionalisation to induce specific ionic properties as proton conductivity, for instance. As well, some other properties such as mechanical, hydrolytic and chemical stability may be enhanced. In this sense, the crosslinking strategy of the PVA macromolecules with agents containing two or more reactive functional groups has been proposed [17], [18]. The PVA chemical crosslinking may not only improve the stability, but also regulate the water uptake ability, the selectivity or the ionic transport capacity [19], [20]. PVA has been crosslinked with sulfusoccinic acid (SSA) [17], [20]-[23], glutaraldehyde (GA) [24]-[27], poly(acrylic acid) (PAA) [28], [29], polystyrene(sulfonic acid co-maleic acid) (PSSAMA) [30], [31], chitosan (CS) [32], [33] or glyoxal [34], among others [35], [36]. Among the most interesting crosslinking agents, the sulfusoccinic acid (SSA) presents carboxylic acid reactive groups in its molecular structure that react with the hydroxyl groups of PVA. Moreover, the presence of the sulfonic groups of the SSA molecules may provide adequate ion conductivity of the PVA-based polyelectrolytes. Complementarily, the sulfonation of the PVA may be also reached by means of the grafting of sulfonic groups at the hydroxyl side group of the polymer macromolecules [37], [38].

The modification of PVA can be also performed according to different strategies, such as the copolymerization, the polymer grafting, or by means of the combination with inorganic particles to form composite materials 
[35]. These multicomponent systems can present synergic properties that optimise their performance [39], [40]. The charges or reinforcements included in the polymer matrix can provide an improvement in the barrier and selectivity effect to the diffusion of determined substances through the membrane [41]. The incorporation of functionalised nanoparticles aims to combine the advantages of inorganic materials, such as the thermal and dimensional stability, and those of polymers, such as functionalisation versatility to overcome the existing limitations with lower cost and high functional performance [41].

The selection of inorganic materials as nanoparticles for proton conducting polyelectrolytes must consider the specific surface and the compatibility with the matrix. The most commonly used nanofillers in PVA-based nanocomposite polyelectrolytes in bulk are metal oxides $\left(\mathrm{SiO}_{2}\right.$ [42]-[44], $\mathrm{TiO}_{2}$ [45]-[47], $\mathrm{Al}_{2} \mathrm{O}_{3}, \mathrm{ZrO}_{2}$ and $\mathrm{SnO}_{2}$ [35]), clays [48], [49], silicates [50], metal phosphates [51], [52] and advanced materials such as carbon nanotubes (CNT) [53] or graphene oxide (GO) [54], [55]. Graphene oxide (GO) has recently received considerable interest because of its unique twodimensional structure with excellent dimensional, chemical, thermal and mechanical stability, low permeability, low cost, surface functionality and minimum thickness [54]. One of the keys of the GO is that it can be produced from graphite using several oxidation routes in a relatively easy way [56]. The GO structure consists of carbons connected to each other by covalent bonds and interconnected to hydrogen and oxygen, to form a structure stratified with epoxy, hydroxyl and carboxyl groups in the basal plane and at the edge for providing a high specific surface area. The GO oxygen polar groups make it strongly hydrophilic, which provides good dispersion in water and improves interfacial adhesion between the GO and hydrophilic polymer matrix such as PVA [45], [57], [58].

PVA-based composite nanofibres have been proposed as a good alternative for the development of new nanofibrous polyelectrolytes with improved functionality [59]. Specifically, some studies in the literature assessed PVA/GO nanocomposite nanofibres obtained using the electrospinning technique [8], [32], [45], [58], [60], [61]. In this study, the design of nanofibres of poly(vinyl alcohol) (PVA) and sulfonated PVA (SPVA) combined with graphene oxide (GO) nanoparticles and crosslinked with sulfosuccinic acid (SSA) was performed. The obtained crosslinked nanocomposite nanofibres were evaluated as potential candidates for the development of polyelectrolyte membranes.

\section{Materials and methods}

\subsection{Materials}

Non-ionic surfactant Triton ${ }^{\circledR}$ X-100 and 1,3-propanesultone 97\% were purchased from Acros Organics; 70\% sulfosuccinic acid (SSA) in water, 
95\% dry sodium hydride (NaH), poly(vinyl alcohol) (PVA) (99\% hydrolysed, $\left.M_{w} 130000 \mathrm{~g} \cdot \mathrm{mol}^{-1}\right)$ and $99.5 \%$ sodium nitrate $\left(\mathrm{NaNO}_{3}\right)$ from Sigma Aldrich; 37\% hydrochloric acid ( $\mathrm{HCl}$ ) from Panreac; absolute ethanol $\left(\mathrm{C}_{2} \mathrm{H}_{5} \mathrm{OH}\right)$, extra pure potassium permanganate $\left(\mathrm{KMnO}_{4}\right)$, $95-98 \%$ sulphuric acid $\left(\mathrm{H}_{2} \mathrm{SO}_{4}\right)$, and $30 \%$ hydrogen peroxide $\left(\mathrm{H}_{2} \mathrm{O}_{2}\right)$ from Scharlau. Ultra-pure water was obtained from an ultra-filtration/ion-exchange procedure.

\subsection{Sulfonation of poly(vinyl alcohol)}

The sulfonation of poly(vinyl alcohol) (PVA) was performed by the use of 1,3-propanesultone as a precursor for the introduction of sulfonic groups into its structure. The sulfonation reaction was carried out in two stages, the preparation of the sulfonated sodium salt and the protonation process [62]. In the first step, $10 \mathrm{~g}$ of PVA were added to $250 \mathrm{~mL}$ of ethanol. Then, $4.8 \mathrm{~g}$ of sodium hydride $(\mathrm{NaH})$ was added slowly to the PVA/ethanol mixture under magnetic stirring. Next, $5 \mathrm{~g}$ of propane-sultone was added after heating at $40^{\circ} \mathrm{C}$, adding dropwise to the mixture. This mixture was allowed to react at $80{ }^{\circ} \mathrm{C}$ with magnetic stirring for $24 \mathrm{~h}$. In the second stage, a washing procedure during $12 \mathrm{~h}$ was performed with $100 \mathrm{~mL}$ of 0.5 $\mathrm{M} \mathrm{HCl}$ in order to replace the $\mathrm{Na}^{+}$by $\mathrm{H}^{+}$. Thereafter, the reacted PVA was filtered and washed with ethanol. Finally, the sulfonated PVA (SPVA) was dried for $4 \mathrm{~h}$ in a vacuum oven at $50{ }^{\circ} \mathrm{C}$.

\subsection{Obtaining of graphene oxide}

Graphene oxide (GO) was obtained by the modified Hummers method [56]. $2 \mathrm{~g}$ of graphite powder and $1 \mathrm{~g}$ of $\mathrm{NaNO}_{3}$ were mixed in $46 \mathrm{~mL}$ of concentrated $\mathrm{H}_{2} \mathrm{SO}_{4}$ under continuous stirring at $0{ }^{\circ} \mathrm{C}$, for safety purposes. After $5 \mathrm{~min}, 6 \mathrm{~g}$ of $\mathrm{KMnO}_{4}$ were carefully added to the suspension at 20 ${ }^{\circ} \mathrm{C}$. The temperature of the slurry was kept at $35{ }^{\circ} \mathrm{C}$ for $30 \mathrm{~min}$. The obtained solution was diluted in $92 \mathrm{~mL}$ of distilled water under continuous stirring for $1 \mathrm{~h}$ at $35^{\circ} \mathrm{C}$. Then, $280 \mathrm{~mL}$ of distilled water were slowly added under stirring to the obtained paste, causing violent effervescence and temperature raised to $98{ }^{\circ} \mathrm{C}$. After $30 \mathrm{~min}$, the solution was filtered and treated with a $30 \%$ aqueous solution of $\mathrm{H}_{2} \mathrm{O}_{2}$ to reduce the residual permanganate and the $\mathrm{MnO}_{2}$ to soluble manganese sulphate. This suspension was filtered while the slurry was still hot to avoid precipitation of the slightly soluble salt of methyl acid formed as a secondary reaction. The resulting product was then washed with $\mathrm{HCl}$ and then with ethanol until the $\mathrm{pH}$ reached the value 7 . Finally, the GO powder was dispersed in distilled water for $3 \mathrm{~h}$ by sonication, filtered and dried in a vacuum oven for $12 \mathrm{~h}$. 


\subsection{Obtaining of nanofibres}

\subsubsection{Dissolution preparation}

A main aqueous solution of $8 \% \mathrm{wt}$ of PVA in $50 \mathrm{~mL}$ of deionized water was prepared and left at $90{ }^{\circ} \mathrm{C}$ for $6 \mathrm{~h}$, together with a reflux system and temperature control. After that, a $0.25 \%$ wt $t_{P V A}$ of Triton ${ }^{\circledR} \mathrm{X}-100$ non-ionic surfactant was added to reduce the surface tension of the solution [6], [63]. To achieve crosslinking and increase the proton conductivity of the developed nanofibres, sulfosuccinic acid (SSA) as a crosslinking agent was added in 30\%wtpVA [20], [35]. This solution was stirred for $24 \mathrm{~h}$ to achieve good homogenization before adding the GO to the mixture.

Simultaneously, the GO solutions were prepared with a concentration of $0.25,0.50,0.75$ and $1.00 \%$ wtPVA $_{\text {in }} 10 \mathrm{~mL}$ of deionized water to achieve a good dispersion. These GO solutions were sonicated for $30 \mathrm{~min}$ in an ATU ATM40-2LCD ultrasonic bath. Subsequently, the GO solutions were added to the PVA dissolution and stirred for $30 \mathrm{~min}$. Taking into account the addition of the $10 \mathrm{~mL}$ of the GO solution to the mixture of PVA/Triton ${ }^{\circledR} / S S A$, the concentration of the latter was adjusted to achieve the desired final concentrations. The same process was repeated for the case of sulfonated PVA (SPVA), with the same concentrations of Triton ${ }^{\circledR}$, SSA and GO defined for PVA.

\subsubsection{Electrospinning}

The electrospinning process was carried out by means of a Bioinicia Fluidnatek LE-10 equipment. The solutions cited in the previous section were taken and filled into a Becton Dickinson Plastic syringe $(5 \mathrm{~mL})$ with a diameter of $11.99 \mathrm{~mm}$. The distance from the tip of the needle to the flat collector was set as $17 \mathrm{~cm}$. Electrospinning was carried out with a variable feeding rate between 300 and $800 \mu \mathrm{L} \cdot \mathrm{h}^{-1}$ and a voltage ranging from 16 to $18 \mathrm{kV}$. The time of electrospinning varied as a function of the flow rate, in order to obtain the same quantity of electrospun material in all the samples, and varied between 2 and $3 \mathrm{~h}$. A nanofibrous mat of $4 \times 4 \mathrm{~cm}^{2}$ surface with a thickness of approximately $20 \mu \mathrm{m}$ was obtained. The equipment was cleaned before and after each experiment, using hot deionized water as solvent. Figure 1 summarises the designation of the nanofibres obtained in the present study. Once obtained, they were protected in plastic bags and stored into a desiccator at room temperature for subsequent steps.

\subsubsection{Nanofibre crosslinking}

PVA-based nanofibres obtained by electrospinning were subjected to a crosslinking reaction with the molecules of the SSA, to prevent the nanofibres from being diluted in contact to aqueous environments and improve their thermal stability, as well as providing sulfonic functional groups that improve the proton conductivity. The obtained nanofibres were 
placed between two sheets of Teflon ${ }^{\circledR}$ reinforced with glass fibre and, in turn, placed between two metallic disks to ensure the crosslinking reaction in a planar arrangement. The entire assembly was then introduced into a Heraeus UT-6060 convection oven at $110{ }^{\circ} \mathrm{C}$ for $2 \mathrm{~h}$. Finally, the crosslinked nanofibres were stored in zip bags and placed into a desiccator at room temperature.

\subsection{Analytical assessment}

\subsubsection{Field-emission scanning electron microscopy (FE-SEM)}

Field-emission scanning electron microscopy was performed by means of a Zeiss Ultra 55 microscope. Nanofibres were mounted into sample holders and sputter coated into a Mitec K950 Sputter Coater device under inert atmosphere and vacuum conditions. Samples were platinum coated during $15 \mathrm{~s}$. The micrographs were taken with a working distance of $7 \mathrm{~mm}$ and a voltage of $2 \mathrm{kV}$ at different degrees of magnification. The diameter of the nanofibres was measured from the average of 100 measurements by means of the Image $\mathrm{J}$ software.

\subsubsection{Fourier-transformed infrared spectroscopy (FT-IR)}

The infrared spectroscopy was performed into a Thermo Nicolet ${ }^{\mathrm{TM}} 5700$ FT-IR spectrometer, equipped with a total attenuated reflectance (ATR) module, specific for the measurement of solid samples. The IR spectrum was taken between 4000 and $400 \mathrm{~cm}^{-1}$ and a resolution of $4 \mathrm{~cm}^{-1}$ along 64 scans. Five assays were performed from different points in the same sample and the mean spectra were taken as representative.

\subsubsection{Thermogravimetry (TGA)}

Thermogravimetric assays were performed by means of a Mettler Toledo TGA 851 analyser. The samples (5-8 mg) were introduced into $70 \mu \mathrm{L}$ alumina capsules. Then, they were subjected to a dynamic test, based on a heating segment of $25^{\circ} \mathrm{C}$ to $800{ }^{\circ} \mathrm{C}$ with a heating rate of $10{ }^{\circ} \mathrm{C} \cdot \mathrm{min}^{-1}$. The tests were carried out under an oxygen oxidative atmosphere with an $\mathrm{O}_{2}$ feeding rate of $50 \mathrm{~mL} \cdot \mathrm{min}^{-1}$. Samples were studied in triplicate and the averages were taken as representative values.

\subsubsection{Differential scanning calorimetry (DSC)}

Differential scanning calorimetry was performed into a Mettler Toledo DSC $822^{\mathrm{e}}$ equipped with a cooling system and previously calibrated following the In and $\mathrm{Zn}$ method. The samples (3-5 mg) were placed into $40 \mu \mathrm{L}$ aluminium crucibles. The method of analysis consisted in different consecutive heating/cooling/heating segments between $50{ }^{\circ} \mathrm{C}$ and $250{ }^{\circ} \mathrm{C}$ with a heating/cooling rate of $10{ }^{\circ} \mathrm{C} \cdot \mathrm{min}^{-1}$. The assays were carried out under inert atmosphere at a flow rate of $50 \mathrm{~mL} \cdot \mathrm{min}^{-1} \mathrm{~N}_{2}$. Samples were 
studied in triplicate and the averages and deviation were taken as representative values.

\subsubsection{Dielectric Thermal Analysis (DETA)}

Proton conductivity $\left(\sigma_{\text {prot }}\right)$ was measured in dielectric thermal analyser (DETA) composed of an alpha mainframe frequency analyser in conjunction with an active cell Concept 40, Novocontrol Technologies. The response was measured from $10^{-2}$ to $10^{7} \mathrm{~Hz}$, at room temperature (25 ${ }^{\circ} \mathrm{C}$ ). The sample electrode assembly (SEA) consisted in two stainless steel electrodes filled with the polymer. The diameters of the electrodes were 20 $\mathrm{mm}$ and the thickness was kept around $30 \mu \mathrm{m}$. The membranes were fully hydrated with ultra-pure water for $24 \mathrm{~h}$. The $\sigma_{\text {prot }}\left(\mathrm{S} \cdot \mathrm{cm}^{-1}\right)$ was calculated according to Equation 1.

$$
\sigma_{\text {prot }}=\frac{l}{A \cdot R_{0}}
$$

(Equation 1)

Where $l$ is the thickness of the conducting nanofibrous membranes in $\mathrm{cm}$, $A$ is the area of the electrode in contact with the sample in $\mathrm{cm}^{2}$, and $R_{0}$ is the protonic impedance taken from the Bode plot at high frequencies in ohms $(\Omega)$ [64].

The electrical conductivity $\left(\sigma_{\text {elec }}\right)$ was measured at room temperature using the same equipment. The electric conductivity $\left(\sigma_{\text {elec }}\right)$ was considered at low frequencies, where the measured real part of the conductivity $\left(\sigma^{\prime}\right)$ reaches a plateau that is strictly correlated to the DC conductivity $\left(\sigma_{0}\right)$.

\subsubsection{Immersion in simulated service conditions}

The characterization of the stability of the nanofibres under simulated service conditions was assessed by means of the immersion of the nanofibres into ultra-pure water, which can be correlated to the performance of these materials for application as polyelectrolytes in fuel cells [65]. For this purpose, samples with a surface of $4 \times 4 \mathrm{~cm}^{2}$ were introduced in test tubes filled with deionized water and placed in a Selecta Unitronic Bath at $60{ }^{\circ} \mathrm{C}$ during $120 \mathrm{~h}$. After reaching the proposed time limit, they were removed from the test tubes, the surface water was removed with the aid of a dry cloth, and dried under vacuum at a temperature of $30{ }^{\circ} \mathrm{C}$ for $48 \mathrm{~h}$. The changes after immersion were characterised in terms of the variation of the nanofibre morphology by means of field emission electron microscopy (FE-SEM).

\section{Results and discussion}

In this section, the effect of the presence of SSA, the crosslinking reaction, the sulfonation of the PVA matrix and the addition of GO nanoparticles was assessed, as summarised in Figure 1. The discussion is given in terms of the surface morphology, the chemical composition, the thermal 
properties, the thermo-oxidative stability, the stability when submitted to simulated service conditions and the proton conductivity of the electrospun nanofibres.

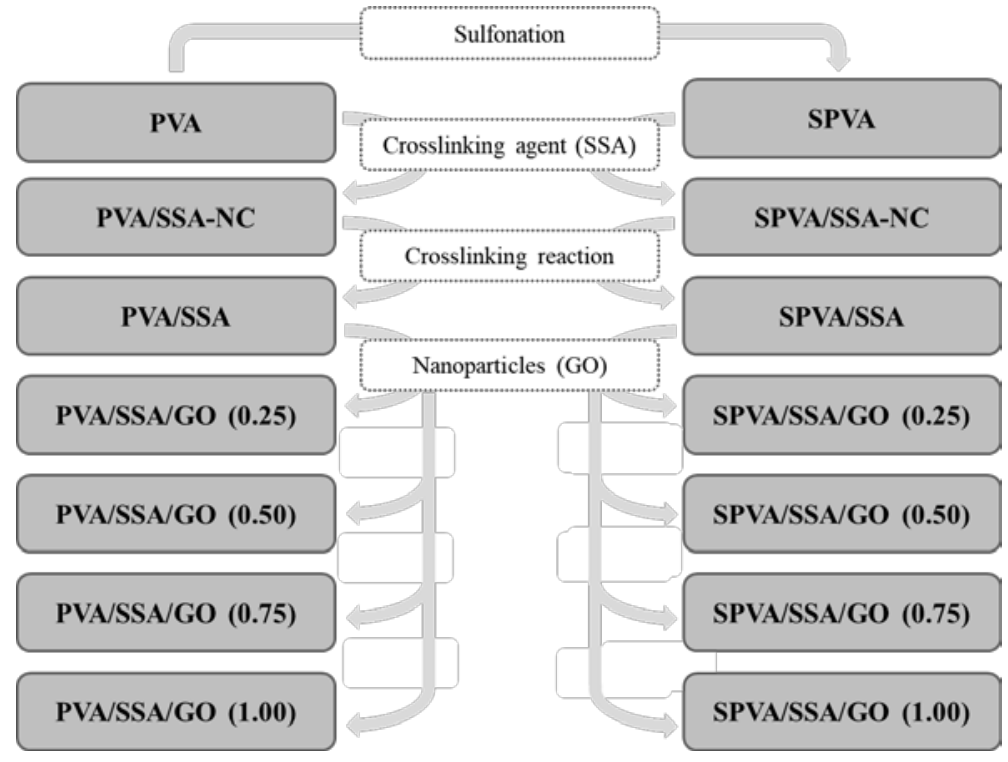

Figure 1. Fibre composition and studied effects on the physico-chemical properties: matrix sulfonation, addition of SSA, crosslinking reaction and addition of nanoparticles. (NC stands for non-crosslinked)

\subsection{Surface morphology}

The surface morphology of the obtained PVA/SSA/GO and SPVA/SSA/GO composite electrospun nanofibres was characterised by means of field emission scanning electron microscopy (FE-SEM). The obtained electronic micrographs along with fibre diameter histograms are gathered in Figure 2. Smooth electrospun nanofibres without significant defects were obtained in all cases.

The plain PVA nanofibres showed an average diameter around $350 \mathrm{~nm}$. However, for plain sulfonated PVA (SPVA), the average diameter was found to be around $200 \mathrm{~nm}$. The SPVA-based nanofibres showed, in general, histograms displaced towards lower values in comparison to those of PVA, which can be correlated to the higher conductivity of the SPVA solution during electrospinning [62]. As occurred with SPVA, the addition of the sulfonic groups of the SSA molecules also reduced the fibre diameter. This effect was especially perceivable for the PVA/SSA noncrosslinked nanofibres.

The crosslinking effect was assessed for the PVA/SSA and SPVA/SSA nanofibres. A $10 \%$ reduction of the nanofibre diameter was perceived in 
both cases. After the crosslinking treatment, the average fibre diameter decreased, which may suggest a more compact structure due to the intra and inter-molecular chemical interactions between the PVA polymer chains and the SSA crosslinking agent that reduced the free volume into the fibres. As well, the feasible release of water molecules during the crosslinking reaction at $110{ }^{\circ} \mathrm{C}$ may have contributed to the reduction of the fibre diameter.

The addition of the GO nanoparticles slightly modified the nanofibre diameter. The low content of GO below $1 \%$ was found to be too low to significantly influence the diameter of the electrospun nanofibres, which is relevant for the design of dimensionally stable polyelectrolytes. 


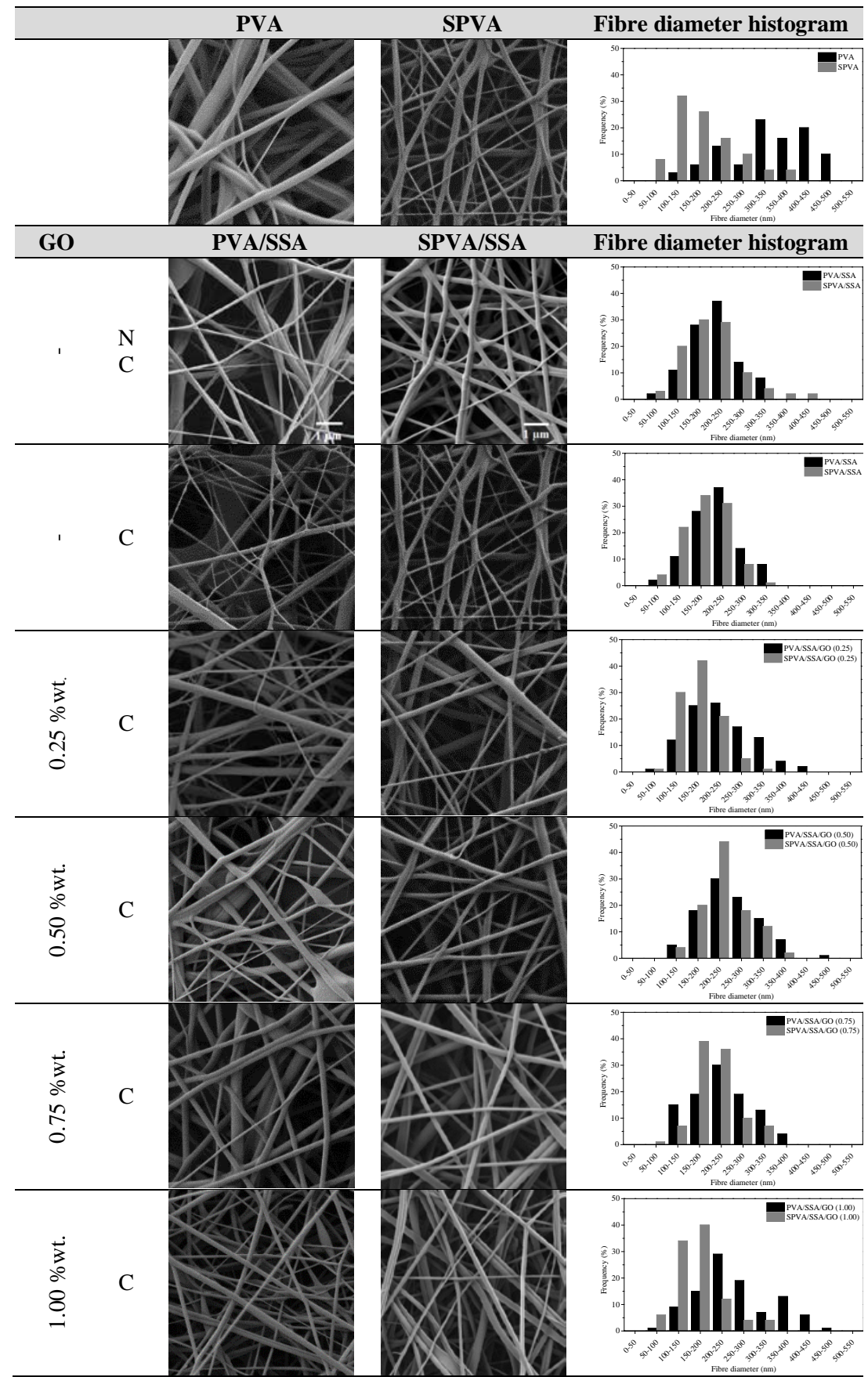

Figure 2. Surface morphology $(10000 \times)$ and fibre diameter histograms of the nanofibres of PVA and sulfonated PVA and their corresponding GO-based composites. (C stands for crosslinked and NC for non-crosslinked) 


\subsection{Chemical composition}

The analysis of the chemical composition was assessed by Fourier transformed infrared spectroscopy (FT-IR), which is considered as a useful method for the study of the crosslinking in a polymeric structure, as well as to evaluate the effect of the sulfonation of PVA and the addition of GO to the electrospun nanofibres. The FT-IR spectra studied for all the obtained compositions are plotted in Figure 3. As well, the spectra for the GO, the PVA and the SPVA were included, so that the effect of each component could be properly compared and evaluated.

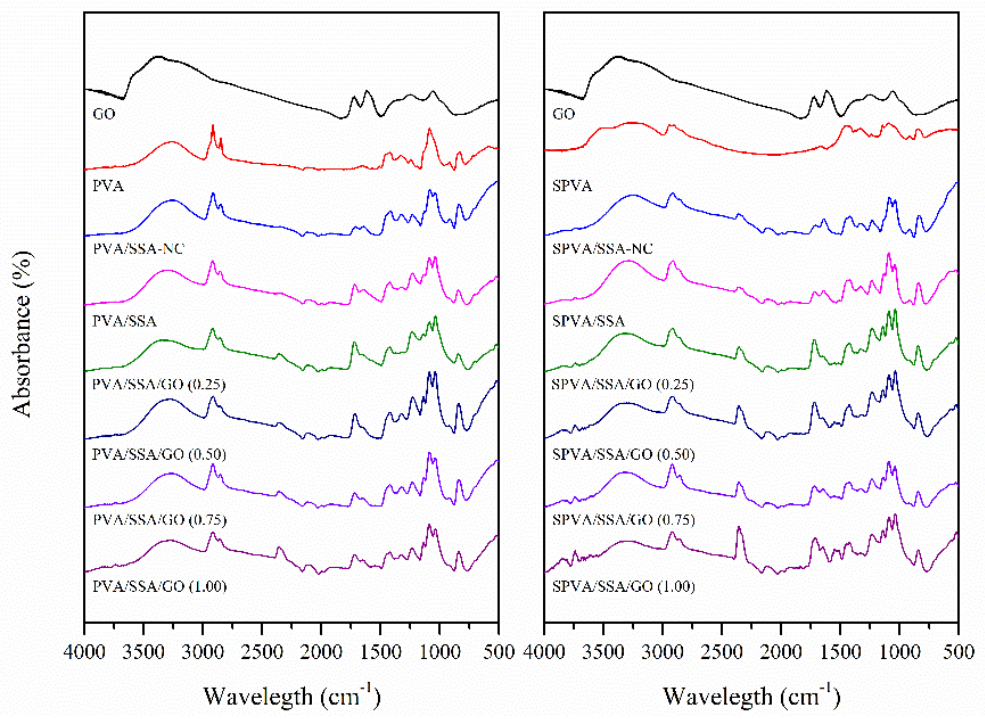

Figure 3. Infrared absorbance spectra of the GO, nanofibres of PVA and sulfonated PVA and their corresponding GO-based composites. (NC stands for non-crosslinked)

Both in PVA and SPVA based nanofibres, a wide absorption band between 3000 and $3400 \mathrm{~cm}^{-1}$ associated to the stretching of $-\mathrm{OH}$ groups was shown, belonging to different intra or intermolecular contributions inherent of the structure of PVA. The peaks between 1660 and $1640 \mathrm{~cm}^{-1}$ are correlated to the $-\mathrm{OH}$ bending of the $\mathrm{H}_{2} \mathrm{O}$ molecules retained into the material, due to its high hydrophilicity. The peaks between 2800 and $3000 \mathrm{~cm}^{-1}$ and between 1300 and $1500 \mathrm{~cm}^{-1}$ corresponded to the stretching and deformation vibrations of the $-\mathrm{CH}_{2}-$ groups of the PVA molecule, respectively [62]. The peak around $1080 \mathrm{~cm}^{-1}$ can be associated to the vibration stretching of the $\mathrm{C}-\mathrm{O}$ bonds of the PVA [66]. For the SPVA, an intense peak around $1040 \mathrm{~cm}^{-1}$ associated with the presence of sulfonic groups $\left(\mathrm{SO}_{3} \mathrm{H}\right)$ was observed, confirming the effective sulfonation strategy for this material [17]. 
When SSA was added to the nanofibres, an increase of the bands associated with the carboxyl $(-\mathrm{COOH})$ and acetate $(-\mathrm{COO}-)$ groups was observed between 1780 and $1710 \mathrm{~cm}^{-1}$. Then, a widening of the band between 2500 and $3000 \mathrm{~cm}^{-1}$ of the vibration of stretching the $\mathrm{O}-\mathrm{H}$ bond of the carboxyl groups was observed. As well, an increase in the peak intensity of 1040 $\mathrm{cm}^{-1}$ associated with the stretching of the sulfonic groups $\left(\mathrm{SO}_{3} \mathrm{H}\right)$ was perceived [17], [67]. The crosslinking strategy resulted in the reduction in the intensity of the stretch vibration signal of the $-\mathrm{OH}$ group, given its reaction with the SSA molecules [62].

The GO spectrum is characterised by peaks at 3450, 1720, 1600, 1400 and $1100 \mathrm{~cm}^{-1}$, assigned to the $-\mathrm{OH}$ group stretching vibrations, stretching vibrations of $\mathrm{C}=\mathrm{O}$ groups, skeletal vibrations of non-oxidized graphite domains and $\mathrm{C}=\mathrm{C}$ bonds, and to deformation vibrations of the $\mathrm{O}-\mathrm{H}$ and $\mathrm{C}-$ $\mathrm{O}$ bonds, respectively [57], [68]. In the nanocomposite nanofibres of PVA/SSA/GO and SPVA/SSA/GO, given the low percentage of GO, the representative peaks of the nanoparticles were overlapped. This absence may be correlated to a good dispersion of the GO into the PVA matrix.

\subsection{Thermal properties}

The thermal properties of the developed nanofibres were studied by means of differential scanning calorimetry (DSC), which can bring valuable information about the microstructure and morphology of polymer based materials [69]. For this purpose, a first heating segment was carried out to evaluate the thermal history of the material, then a cooling segment was performed and finally another heating segment was carried out to intrinsically evaluate the material. The thermograms obtained for all the studied nanofibres are shown in Figure 4. The effect of the addition of SSA, the crosslinking, the sulfonation of the PVA and the addition of GO were studied.

In the first heating scan, pure PVA nanofibres showed an endothermic peak between 50 and $100{ }^{\circ} \mathrm{C}$ associated to the evaporation of free water followed by an endothermic peak at $229^{\circ} \mathrm{C}$ due to the melting of crystalline domains. In the cooling scan, a crystallization peak was shown with its maximum located at $191{ }^{\circ} \mathrm{C}$. Finally, in the second heating, once removed the water content during the first scan, only a melting peak was observed with its maximum at $220^{\circ} \mathrm{C}$. These results corroborated the typical semicrystalline morphology of the pure PVA [23].

In contrast, sulfonated PVA (SPVA) nanofibres showed an endothermic peak between $150{ }^{\circ} \mathrm{C}$ and $200^{\circ} \mathrm{C}$, which was associated with the release of bound water. Given the absence of melting and crystallization peaks in the subsequent heating and cooling segments, the sulfonated SPVA was revealed as an amorphous material. The formation of hydrogen bonding 
between the PVA molecules and the sulfonic groups may have prevented the crystallisation of this material [62].
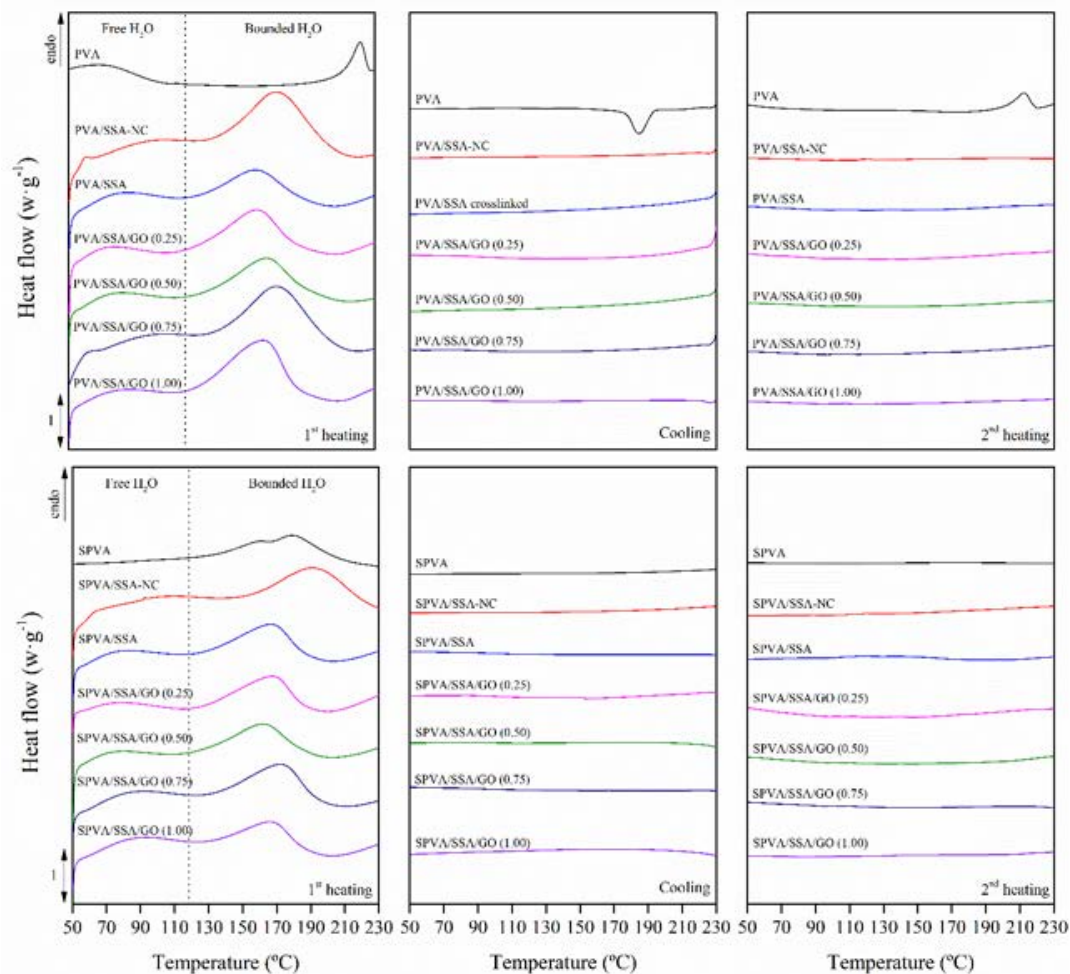

Figure 4. Calorimetric thermograms of the first heating (left), cooling (centre) and second heating (right) scans of the nanofibres of PVA and sulfonated PVA and their corresponding GO-based composites. (NC stands for non-crosslinked)

For all the studied nanofibres containing the crosslinking agent (SSA), regardless the crosslinking reaction, the sulfonation of the PVA and the addition of $\mathrm{GO}$, two broad endothermic peaks were observed in the first heating scan, the first between $60{ }^{\circ} \mathrm{C}$ and $110^{\circ} \mathrm{C}$ and the second between $130{ }^{\circ} \mathrm{C}$ and $210^{\circ} \mathrm{C}$. The characteristic values of the peak temperatures are shown in Table 1. According to literature, these endothermic peaks would correspond to free water and bound water release processes, respectively, both from the PVA matrix and from the SSA molecules. The free water is simply retained physically inside the nanofibres, while the bound water is chemically linked to the hydroxyl groups of the PVA and to the SSA molecules by hydrogen bonding [21], [42]. Moreover, the water release peaks may have overlapped a change in the baseline of the thermograms in the range of 80 to $90^{\circ} \mathrm{C}$ that could be associated with a glass transition of the PVA/SSA based material, given the amorphous morphology reported 
for PVA with a concentration greater than 15\% of SSA [21], [23], [42]. This phenomenon is correlated to the absence of melting and crystallisation peaks in the subsequent cooling and heating scans.

The effect of the crosslinking was perceived as a decrease in the temperature of water release, especially those related to the bound water. The crosslinked material may have a more compact structure, with less space available for the free water presence. In addition, once the PVA and SSA molecules reacted and crosslinking reaction is completed, the hydroxyl groups in the matrix as well as the carboxyl groups of the crosslinking agent, available to interact with water molecules considerably decreased, reducing the capacity of the material to interact with water through hydrogen bonding [21], [42].

The presence of the GO nanoparticles in the nanofibres resulted in a slight increase in the temperatures of the water release peaks. This observation can be attributed to the huge amount of hydroxyl groups in the surface of the GO nanoparticles able to strongly interact with the water molecules, slightly increasing the release temperature of bound water. In this sense, GO holds the water into the nanofibres.

Table 1. Calorimetric temperatures of the release of free $\left(T_{\text {free }} D S C\right)$ and bound $\left(T_{\text {bound }}\right.$ DSC) water. Standard deviation between 1 and $2 \%$ omitted for the sake of clarity.

\begin{tabular}{lcc}
\hline & \multicolumn{2}{c}{ Water release } \\
\cline { 2 - 3 } & $\begin{array}{c}\boldsymbol{T}_{\text {free }} \text { DSC } \\
\left({ }^{\circ} \mathbf{C}\right)\end{array}$ & $\begin{array}{c}\boldsymbol{T}_{\text {bound } \text { DSC }} \\
\left.{ }^{\circ} \mathbf{C}\right)\end{array}$ \\
\hline PVA & 70.72 & - \\
\hline PVA/SSA-NC & 87.04 & 176.07 \\
\hline PV/SSA & 70.80 & 162.77 \\
\hline PVA/SSA/GO 0.25 & 70.45 & 169.40 \\
\hline PVA/SSA/GO 0.50 & 69.93 & 171.05 \\
\hline PVA/SSA/GO 0.75 & 63.31 & 170.97 \\
\hline PVA/SSA/GO 1.00 & 62.84 & 170.36 \\
\hline SPVA & 70.59 & 179.23 \\
\hline SPVA/SSA-NC & 89.42 & 169.53 \\
\hline SPV/SSA & 62.90 & 166.05 \\
\hline SPVA/SSA/GO 0.25 & 65.17 & 167.18 \\
\hline SPVA/SSA/GO 0.50 & 71.21 & 167.73 \\
\hline SPVA/SSA/GO 0.75 & 71.46 & 169.65 \\
\hline SPVA/SSA/GO 1.00 & 72.22 & 170.02 \\
\hline
\end{tabular}

\subsection{Thermo-oxidative stability}

The thermo-oxidative stability was assessed by means of thermogravimetric analysis (TGA), which may bring valuable information about the effect of the composition and the crosslinking procedure in the nanofibres. The thermogravimetric curves (TG) along with the first 
derivative thermogravimetric curve (DTG) obtained under oxidative atmosphere for all the developed nanofibres are plotted in Figure 5. The thermo-oxidative stability was characterised in terms of the mass loss from the TG curves and the characteristic temperatures from the peaks of the DTG curves for each stage. These results are gathered in Table 2.

Neat PVA nanofibres underwent two stages of mass loss in the assessed temperature range. The first stage between 100 and $200^{\circ} \mathrm{C}$ with a mass loss around 33\% comprised mainly the gradually loss of free and bounded water, respectively. The second degradation process between $250{ }^{\circ} \mathrm{C}$ and $300^{\circ} \mathrm{C}$, was dominated by the cleavage reactions of the $-\mathrm{OH}$ groups of the PVA molecules and represented around $61 \%$ of mass loss [18].

The decomposition of the neat SPVA nanofibres resulted in a curve with different stages. The first step, with a peak in the DTG curve at $178{ }^{\circ} \mathrm{C}$ is associated with the loss of bounded water. Then, around $300{ }^{\circ} \mathrm{C}$, the decomposition of the $-\mathrm{SO}_{3} \mathrm{H}$ groups was found [21], [38]. Both stages showed a mass loss around $25 \%$.

In general, the TG curves for the nanofibres containing SSA showed a thermo-oxidation behaviour in multiple stages. When non crosslinked, a first stage with a mass loss of around $10 \%$ was observed from 50 to 100 ${ }^{\circ} \mathrm{C}$, attributed to the loss of free water. In the second stage, between 100 and $230^{\circ} \mathrm{C}$, a mass loss of $20 \%$ took place, attributed to the bounded water molecules. In this case, water molecules are assumed to be bonded to the polymer chains in the hydroxyl groups $(-\mathrm{OH})$ or to the sulfonic $\left(-\mathrm{SO}_{3} \mathrm{H}\right)$ and carboxylic $(-\mathrm{COOH})$ groups of the SSA molecules by hydrogen bonding [42]. Overall, a mass loss of about $30 \%$ correlated to water was found. Once crosslinked, the overall water release decreased to around $25 \%$. The third region of mass loss from 230 to $350^{\circ} \mathrm{C}$ was associated with the desulfonation process, the degradation of hydroxyl groups and breakage of crosslinking ester bonds [21]. Finally, from $350{ }^{\circ} \mathrm{C}$ onwards, the degradation of the polymeric backbone of the PVA took place. 

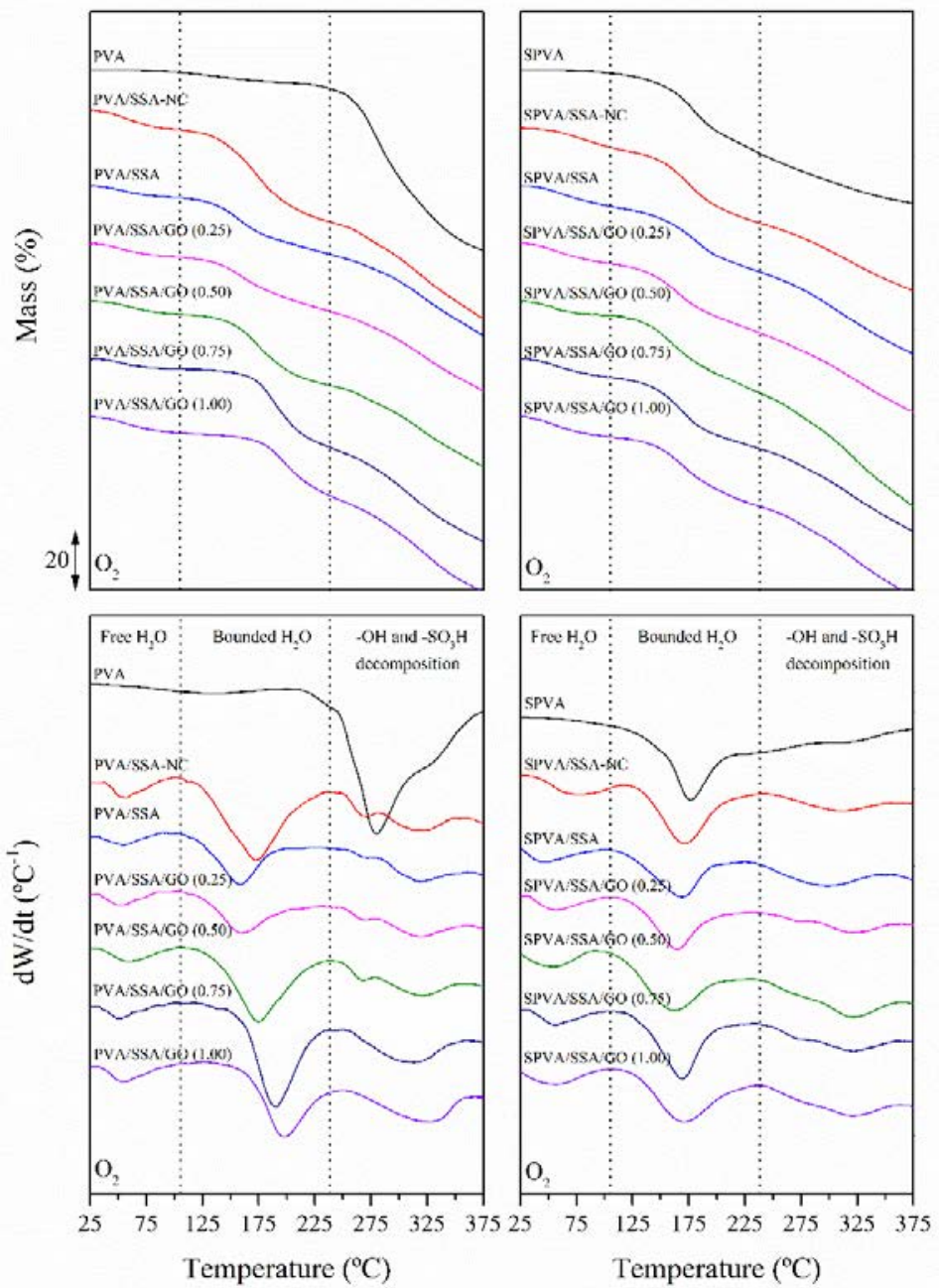

Figure 5. Thermogravimetric (TG) (up) and first derivative (DTG) (down) thermograms of the nanofibres of PVA and sulfonated PVA and their corresponding GO-based composites. (NC stands for non-crosslinked) 
Table 2. Temperatures of the release of free ( $T_{\text {free }}$ TGA $)$ and bound ( $T_{\text {bound }}$ TGA $)$ water and thermo-oxidative decomposition peak of the $-\mathrm{OH}\left(T_{d-\mathrm{OH}}\right)$ and $-\mathrm{SO}_{3} \mathrm{H}\left(T_{d-\mathrm{SO} H}\right)$ groups along with the mass-loss associated with each stage. Standard deviation between 1 and $2 \%$ omitted for the sake of clarity.

\begin{tabular}{lcccccc}
\hline & \multicolumn{3}{c}{ Water release } & \multicolumn{3}{c}{ Decomposition } \\
\cline { 2 - 8 } & $\begin{array}{c}\boldsymbol{T}_{\text {free TGA }} \\
\left({ }^{\circ} \mathbf{C}\right)\end{array}$ & $\begin{array}{c}\boldsymbol{T}_{\text {bound }} \\
\text { TGA } \\
\left({ }^{\circ} \mathbf{C}\right)\end{array}$ & $\begin{array}{c}\text { Mass- } \\
\text { loss } \\
(\%)\end{array}$ & $\begin{array}{c}\boldsymbol{T}_{\boldsymbol{d}-\text { OH }} \\
\left({ }^{\circ} \mathbf{C}\right)\end{array}$ & $\begin{array}{c}\boldsymbol{T}_{d-\text { SO3H }} \\
\left({ }^{\circ} \mathbf{C}\right)\end{array}$ & $\begin{array}{c}\text { Mass- } \\
\text { loss } \\
(\%)\end{array}$ \\
\hline PVA & - & 123.28 & 5.06 & 280.10 & - & 60.89 \\
\hline PVA/SSA-NC & 56.49 & 172.01 & 32.89 & 271.13 & 313.12 & 60.85 \\
\hline PVA/SSA & 54.52 & 158.58 & 22.89 & 271.41 & 320.16 & 51.29 \\
\hline PVA/SSA/GO 0.25 & 54.54 & 159.25 & 23.88 & 271.13 & 320.69 & 50.23 \\
\hline PVA/SSA/GO 0.50 & 56.36 & 174.92 & 26.30 & 268.21 & 320.89 & 51.80 \\
\hline PVA/SSA/GO 0.75 & 53.30 & 190.31 & 26.19 & - & 320.40 & 57.59 \\
\hline PVA/SSA/GO 1.00 & 55.28 & 197.78 & 24.16 & - & 322.84 & 55.81 \\
\hline SPVA & - & 177.75 & 24.70 & - & 300.44 & 25.34 \\
\hline SPVA/SSA-NC & 65.62 & 172.37 & 34.61 & - & 312.91 & 60.66 \\
\hline SPVA/SSA & 51.31 & 167.59 & 30.21 & - & 315.24 & 60.19 \\
\hline SPVA/SSA/GO 0.25 & 56.28 & 162.87 & 27.66 & - & 320.37 & 60.12 \\
\hline SPVA/SSA/GO 0.50 & 54.69 & 161.51 & 26.86 & - & 320.46 & 61.11 \\
\hline SPVA/SSA/GO 0.75 & 55.28 & 169.72 & 27.84 & - & 321.45 & 59.20 \\
\hline SPVA/SSA/GO 1.00 & 53.11 & 171.15 & 26.50 & - & 320.19 & 60.44 \\
\hline
\end{tabular}

Regarding the composite nanofibres containing GO, although the mass of the water release stage remained almost constant, the bound water release temperature increased as a function of the GO content. The functional groups of the GO nanoparticles available to interact with water molecules may have formed stronger hydrogen bonds. Moreover, the presence of the GO nanoparticles may have increased tortuosity and have hindered the release of water during the assay.

In general, if compared PVA and SPVA based nanofibres, those based on SPVA revealed slightly higher mass loss during the desulfonation process from $320{ }^{\circ} \mathrm{C}$ onwards (5-10\% more), given the presumably greater amount of sulfonic groups in these materials [70].

\subsection{Dielectric properties}

The protonic $\left(\sigma_{\text {prot }}\right)$ and electric $\left(\sigma_{\text {elec }}\right)$ conductivity of the nanofibres were assessed by means of a dielectric thermal analyser (DETA) composed of an alpha mainframe frequency analyser in conjunction with an active cell at $25^{\circ} \mathrm{C}$ through a single sweep procedure in a wide frequency range from $10^{-2}$ to $10^{7} \mathrm{~Hz}$.

The electric conductivity $\left(\sigma_{\text {elec }}\right)$ was considered at low frequencies, where the measured real part of the conductivity $\left(\sigma^{\prime}\right)$ reaches a plateau that is strictly correlated to the DC conductivity $\left(\sigma_{0}\right)$. The Figure 6 plots the electric conductivity as a function of the frequency. The $\sigma_{\text {elec }}$ was found in the range between $10^{-7}$ and $10^{-8} \mathrm{~S} \cdot \mathrm{cm}^{-1}$ for all the developed nanofibres. 
Therefore, they can be considered as good insulators that prevent the flow of electrons through them, which is especially relevant for some polyelectrolyte applications, such as membranes in fuel cells [12].

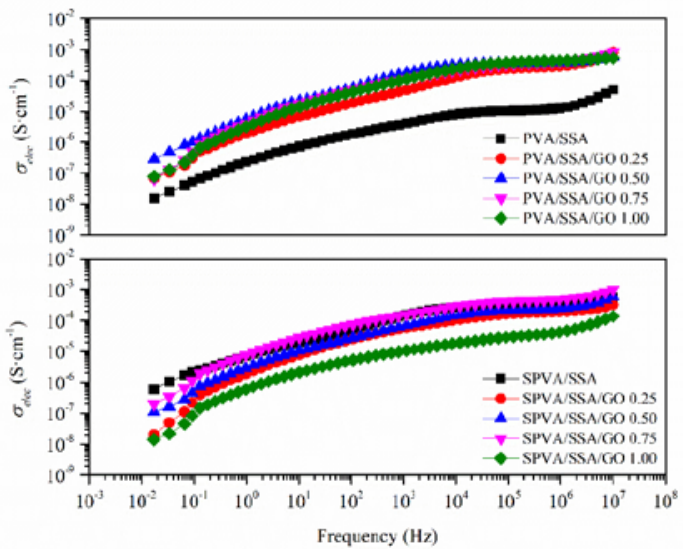

Figure 6. Electric conductivity $\left(\sigma_{\text {elec }}\right)$ as a function of frequency of the nanofibres of PVA and sulfonated PVA and their corresponding GO-based composites.

Regarding the protonic conductivity, there are two main proton conduction pathways in the PVA/SSA and SPVA/SSA based membranes [17], [36]. On the one hand, the groups of protons may interact with others through the jump mechanism (Grotthus) due to the sulfonic groups both from the SSA crosslinking agent and from the sulfonation procedure of PVA. On the other hand, they can use the vehicle mechanism through the hydroxyl and carboxyl groups of the structure of PVA, SSA and GO, which may interact with water molecules, boosting the proton conductivity. Thus, the proton conductivity strongly depends on the degree of hydration of the material. For this reason, the nanofibres were measured after being subjected to a hydration process through immersion for $24 \mathrm{~h}$ into distilled water. Afterwards, the effect of the incorporation of sulfonic groups on the sulfonation of the PVA, the addition of SSA, as well as the incorporation of GO with respect to the protonic conductivity was studied. Figure 7 represents the Bode diagram, showing the real part of the impedance and the phase angle as a function of the frequency at the selected temperature of $25{ }^{\circ} \mathrm{C}$. It was observed that the real impedance reached a constant value and the phase angle reached a maximum close to zero for high frequencies. The protonic conductivity $\left(\sigma_{\text {prot }}\right)$ values, as calculated by means of Equation 1, are shown in Table 3.

The proton conductivity of the PVA/SSA/GO nanofibres increased as a function of the GO content, from values of $0.250 \mathrm{mS} \cdot \mathrm{cm}^{-1}$ to $0.436 \mathrm{mS} \cdot \mathrm{cm}^{-}$ 1 for the nanofibres containing $1.00 \%$ of GO. In contrast, for SPVA/SSA/GO nanofibres, slightly dissimilar results were observed. In 
this case, the proton conductivity was reduced by the presence of $0.25 \%$ of GO from 0.333 to $0.187 \mathrm{mS} \cdot \mathrm{cm}^{-1}$. Then, it increased from 0.187 to 0.428 $\mathrm{mS} \cdot \mathrm{cm}^{-1}$ for $0.75 \%$ of GO. Finally, for $1.00 \%$ of GO it decreased again.
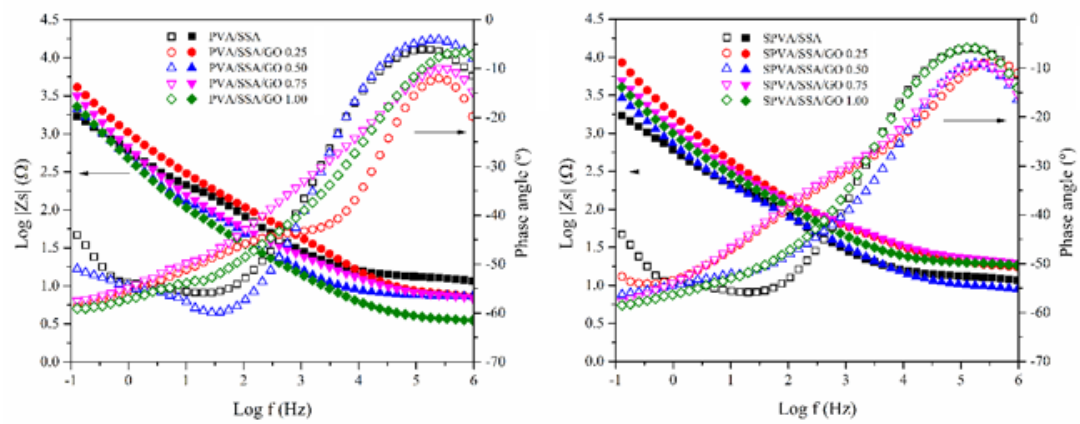

Figure 7. Bode diagrams for the PVA/SSA (left) and SPVA/SSA (right) based composite nanofibres.

Table 3. Proton conductivity ( $\sigma_{\text {prot }}$ ) of the nanofibres of PVA and sulfonated PVA and their corresponding GO-based composites.

\begin{tabular}{lc}
\hline & $\begin{array}{c}\boldsymbol{\sigma}_{\text {prot }} \\
\left(\mathbf{m S} \cdot \mathbf{c m}^{-1}\right)\end{array}$ \\
\hline PV/SSA & $0.250 \pm 0.013$ \\
\hline PVA/SSA/GO 0.25 & $0.268 \pm 0.021$ \\
\hline PVA/SSA/GO 0.50 & $0.375 \pm 0.026$ \\
\hline PVA/SSA/GO 0.75 & $0.385 \pm 0.019$ \\
\hline PVA/SSA/GO 1.00 & $0.436 \pm 0.017$ \\
\hline SPV/SSA & $0.333 \pm 0.027$ \\
\hline SPVA/SSA/GO 0.25 & $0.187 \pm 0.019$ \\
\hline SPVA/SSA/GO 0.50 & $0.226 \pm 0.014$ \\
\hline SPVA/SSA/GO 0.75 & $0.428 \pm 0.021$ \\
\hline SPVA/SSA/GO 1.00 & $0.111 \pm 0.058$ \\
\hline
\end{tabular}

Regarding the designing strategy, the PVA/SSA based crosslinked nanofibres combined with GO allowed to better control the proton conductivity, in comparison to the use of SPVA/SSA based composite nanofibres. In general, it can be considered that, given the small thickness of the nanofibrous membranes, they showed relatively high proton conductivity values [10], [35], [71].

\subsection{Hydrothermal stability}

The evaluation of the long-term behaviour when exposed to service conditions is essential for the corroboration of the suitability a polymeric material for a given application [72]-[75]. Polyelectrolytes require being stable when subjected to service conditions. Most of them are used under aqueous or humid environments and should retain its nanofibrous morphology during application [65]. For this reason, the hydrothermal 
stability of the nanofibres was evaluated through the immersion in distilled water at $60{ }^{\circ} \mathrm{C}$ for $120 \mathrm{~h}$, as a comparative accelerated procedure. The stability was assessed in terms of the change of the nanoscaled surface morphology and the average diameter of the nanofibres. The surface micrographs, along with the histograms of diameter of nanofibres are shown in Figure 8. Likewise, the average diameter of the nanofibres prior to and after immersion are gathered in Table 4.

Both PVA and SPVA based non crosslinked nanofibres completely lost the nanofibrous morphology after immersion. Fibres swelled until coalescence, which is completely undesirable for application as polyelectrolyte membranes.

The crosslinked nanofibres retained their fibrous morphology after the hydrothermal treatment in all cases. A general increase in the average fibre diameter was observed, caused by swelling due to the water absorption. The largest increase in diameter was perceived for the PVA/SSA and SPVA/SSA nanofibres. The presence of GO in the nanofibres resulted into a more compact structure, with less swelling capacity. In addition, the added GO, could have established hydrogen bonds with the PVA molecules, as well as with the remnant water molecules prior to immersion. This would result in a lower amount of hydrophilic groups available for the incorporation of water into the structure [65]. It can be stated, therefore, that the crosslinked nanofibres have a good hydrothermal stability when submitted to simulated service life conditions 


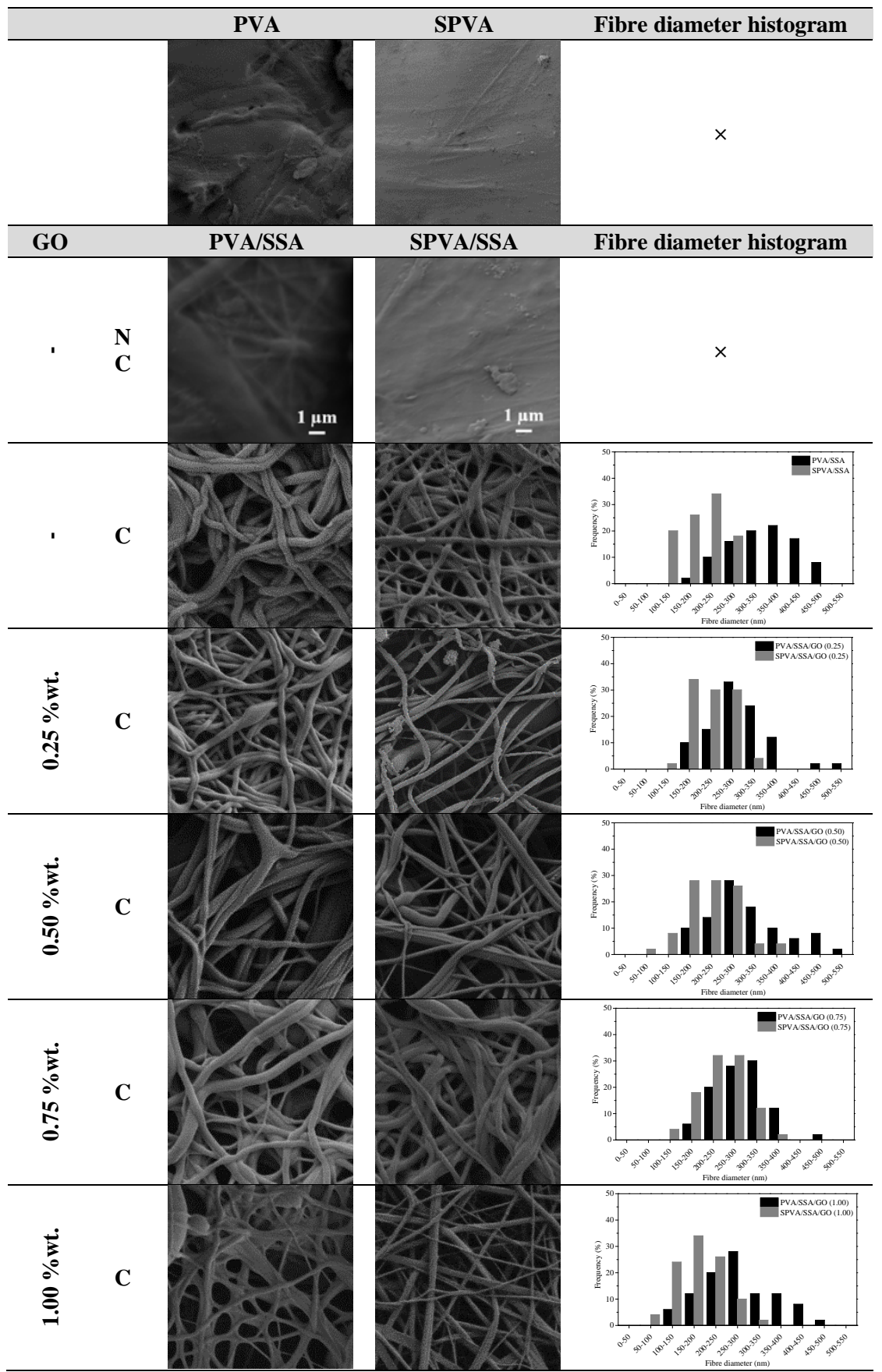

Figure 8. Surface morphology and fibre diameter histograms of the nanofibres of PVA and sulfonated PVA and the GO-based composites prior to and after immersion at $60{ }^{\circ} \mathrm{C}$ for $120 \mathrm{~h}$. (C stands for crosslinked and NC for non-crosslinked) 
Table 4. Average diameter of the nanofibres of PVA and sulfonated PVA and their corresponding GO-based composites prior to and after immersion at $60^{\circ} \mathrm{C}$ for $120 \mathrm{~h}$.

(NC stands for non-crosslinked)

\begin{tabular}{lccc} 
& \multicolumn{2}{c}{ Average fibre diameter $(\mathbf{n m})$} & \multirow{2}{*}{$\begin{array}{c}\text { Variation } \\
(\mathbf{\%})\end{array}$} \\
\cline { 2 - 4 } & Initial & Final & $\times$ \\
\hline PVA & $354 \pm 120$ & $\times$ & $\times$ \\
\hline PVA/SSA-NC & $207 \pm 60$ & $\times$ & +75.25 \\
\hline PV/SSA & $198 \pm 59$ & $347 \pm 69$ & +19.65 \\
\hline PVA/SSA/GO 0.25 & $229 \pm 78$ & $274 \pm 53$ & +14.10 \\
\hline PVA/SSA/GO 0.50 & $241 \pm 74$ & $275 \pm 60$ & +15.66 \\
\hline PVA/SSA/GO 0.75 & $249 \pm 66$ & $288 \pm 58$ & +7.14 \\
\hline PVA/SSA/GO 1.00 & $238 \pm 85$ & $255 \pm 86$ & $\times$ \\
\hline SPVA & $200 \pm 66$ & $\times$ & $\times$ \\
\hline SPVA/SSA-NC & $189 \pm 48$ & $\times$ & +28.02 \\
\hline SPV/SSA & $182 \pm 33$ & $233 \pm 88$ & +18.27 \\
\hline SPVA/SSA/GO 0.25 & $186 \pm 64$ & $220 \pm 49$ & +7.30 \\
\hline SPVA/SSA/GO 0.50 & $212 \pm 42$ & $219 \pm 55$ & +8.74 \\
\hline SPVA/SSA/GO 0.75 & $201 \pm 50$ & $217 \pm 61$ &
\end{tabular}

\section{Conclusions}

Nanofibrous crosslinked PVA/SSA/GO and SPVA/SSA/GO nanocomposite membranes were developed by means electrospinning and processing conditions were accordingly optimised.

The combination of PVA and SPVA with SSA as crosslinking agent and subsequent crosslinking reaction resulted in highly stable composite nanofibrous membranes. The chemical composition was ascertained and the presence of the sulfonic groups in the crosslinked structure was corroborated.

The evaluation of the thermal and thermo-oxidative behaviour revealed the effect of the GO nanoparticles, which shown a good interaction within the PVA/SSA and SPVA/SSA matrices. As well, the GO contributed to strongly retain humidity, essential for some polyelectrolyte membrane applications.

With regards to the dielectric properties, the developed nanofibres were found to be electric insulators and proton conductors, which is specially relevant for some polyelectrolyte applications. The PVA/SSA based crosslinked nanofibres combined with GO allowed to better control the proton conductivity, in comparison to that of SPVA/SSA based composite nanofibres.

Finally, the crosslinked nanofibrous membranes were found to be stable after an accelerated hydrothermal assay. Although fibre diameter increased after immersion, the presence of GO contributed to higher diameter stability. 
In general, the developed nanofibrous composite membranes are good candidates for being exploited as polyelectrolyte membranes. They could be considered as valuable components for the preparation of ionic polyelectrolyte membranes used in proton exchange fuel cells.

\section{Acknowledgements}

The authors would like to thank the support of the European Regional Development Fund and the Spanish Ministry of Economy, Industry and Competitiveness, through the Research Projects ENE2017-86711-C3-1-R, ENE2014-53734-C2-1-R and UPOV13-3E-1947. The Spanish Ministry of Education, Culture and Sports is also thanked for the FPU grant for O. GilCastell (FPU13/01916). The Generalitat Valenciana is recognised for the APOSTD14/041 program for J.D. Badia. S. Sanchez-Ballester is acknowledged for her kind collaboration during the graphene oxide obtaining.

\section{References}

[1] R. Sood, S. Cavaliere, D. J. Jones, and J. Rozière, "Electrospun nanofibre composite polymer electrolyte fuel cell and electrolysis membranes,” Nano Energy, vol. 26, pp. 729-745, 2016.

[2] H. Junoh, J. Jaafar, M. N. A. Mohd Norddin, A. F. Ismail, M. H. D. Othman, M. A. Rahman, N. Yusof, W. N. Wan Salleh, and H. Ilbeygi, “A Review on the Fabrication of Electrospun Polymer Electrolyte Membrane for Direct Methanol Fuel Cell,” J. Nanomater., vol. 2015, pp. 1-16, Mar. 2015.

[3] O. Gil-Castell, J. D. D. Badia, E. Strömberg, S. Karlsson, and A. Ribes-Greus, "Effect of the dissolution time into an acid hydrolytic solvent to tailor electrospun nanofibrous polycaprolactone scaffolds,” Eur. Polym. J., vol. 87, pp. 174-187, 2017.

[4] O. Gil-Castell, J. D. D. Badia, and A. Ribes-Greus, “Tailored electrospun nanofibrous polycaprolactone/gelatin scaffolds into an acid hydrolytic solvent system,” Eur. Polym. J., vol. 101, pp. 273-281, Apr. 2018.

[5] M. Tanaka, "Development of ion conductive nanofibers for polymer electrolyte fuel cells,” Polymer Journal, vol. 48, no. 1. Nature Publishing Group, pp. 51-58, 16-Jan2016.

[6] P. Supaphol and S. Chuangchote, "On the electrospinning of PVA nanofiber mats. Supaphol,” Polym. Polym. Compos., vol. 21, no. 7, pp. 449-456, 2013.

[7] G.-M. Liao, P.-C. Li, J.-S. Lin, W.-T. Ma, B.-C. Yu, H.-Y. Li, Y.-L. Liu, C.-C. Yang, C.-M. Shih, and S. J. Lue, "Highly conductive quasi-coaxial electrospun quaternized polyvinyl alcohol nanofibers and composite as high-performance solid electrolytes,” $J$. Power Sources, vol. 304, pp. 136-145, 2016.

[8] F. Barzegar, A. Bello, M. Fabiane, S. Khamlich, D. Momodu, F. Taghizadeh, J. Dangbegnon, and N. Manyala, "Preparation and characterization of poly(vinyl alcohol)/graphene nanofibers synthesized by electrospinning," J. Phys. Chem. Solids, vol. 77, pp. 139-145, 2015.

[9] H.-Y. Li and Y.-L. Liu, "Nafion-functionalized electrospun poly(vinylidene fluoride) (PVDF) nanofibers for high performance proton exchange membranes in fuel cells,” $J$. Mater. Chem. A, vol. 2, no. 11, pp. 3783-3793, Feb. 2014.

[10] O. J. O. Pedroza, J. C. Dutra Filho, P. H. S. Picciani, and M. L. Dias, "Morphology and proton conductivity of composite membranes based on poly(styrene sulfonic acidmaleic anhydride) nanofibers prepared by electrospinning,” Ionics (Kiel)., vol. 21, no. 3, pp. 755-764, 2015.

[11] J. Choi, K. M. Lee, R. Wycisk, P. N. Pintauro, and P. T. Mather, "Sulfonated Polysulfone/POSS Nanofiber Composite Membranes for PEM Fuel Cells,” J. Electrochem. Soc., vol. 157, no. 6, p. B914, Jun. 2010. 
[12] I. Shabani, M. M. Hasani-Sadrabadi, V. Haddadi-Asl, and M. Soleimani, "Nanofiberbased polyelectrolytes as novel membranes for fuel cell applications,” J. Memb. Sci., vol. 368, no. 1-2, pp. 233-240, Feb. 2011.

[13] J. L. Reyes-Rodriguez, O. Solorza-Feria, A. García-Bernabé, E. Giménez, O. Sahuquillo, and V. Compañ, "Conductivity of composite membrane-based poly(etherether-ketone) sulfonated (SPEEK) nanofiber mats of varying thickness,” RSC Adv., vol. 6, no. 62, pp. 56986-56999, 2016.

[14] E. Baştürk, E. Çakmakçi, S. Madakbaş, and M. V. Kahraman, "Surface and proton conductivity properties of electrospun poly(vinyl butyral)/polyaniline nanofibers," Adv. Polym. Technol., May 2017.

[15] G. Ito, M. Tanaka, and H. Kawakami, "Sulfonated polyimide nanofiber framework: Evaluation of intrinsic proton conductivity and application to composite membranes for fuel cells,” Solid State Ionics, vol. 317, pp. 244-255, Apr. 2018.

[16] B. Ding and J. Yu, Electrospun Nanofibers for Energy and Environmental Applications. 2014.

[17] A.Martínez-Felipe, C.Moliner-Estopiñán, C.T.Imrie, and A.Ribes-Greus, "Characterization of Crosslinked PVA-based membranes.," Polym. Polym. Compos., vol. 21, no. 7, pp. 449-456, 2013.

[18] A. Martínez-Felipe, C. Moliner-Estopiñán, C. T. Imrie, and A. Ribes-Greus, "Characterization of crosslinked poly(vinyl alcohol)-based membranes with different hydrolysis degrees for their use as electrolytes in direct methanol fuel cells," J. Appl. Polym. Sci., vol. 124, no. 2, pp. 1000-1011, 2012.

[19] A. Kraytsberg and Y. Ein-eli, "A Review of Advanced Materials for Proton Exchange Membrane Fuel Cells,” 2014.

[20] J. Zhang, G. Jiang, and J. Shi, "Poly (vinyl alcohol)/sulfosuccinic acid (PVA/SSA) as proton-conducting membranes for fuel cells : Effect of cross-linking and plasticizer addition,” p. 2013.

[21] J. W. Rhim, H. B. Park, C. S. Lee, J. H. Jun, D. S. Kim, and Y. M. Lee, “Crosslinked poly(vinyl alcohol) membranes containing sulfonic acid group: Proton and methanol transport through membranes,” J. Memb. Sci., vol. 238, no. 1-2, pp. 143-151, 2004.

[22] D. Ebenezer, A. P. Deshpande, and P. Haridoss, "Cross-linked poly (vinyl alcohol)/sulfosuccinic acid polymer as an electrolyte/electrode material for $\mathrm{H} 2-\mathrm{O} 2$ proton exchange membrane fuel cells,” J. Power Sources, vol. 304, pp. 282-292, Feb. 2016.

[23] J. M. Morancho, J. M. Salla, A. Cadenato, X. Fernández-Francos, P. Colomer, Y. Calventus, X. Ramis, and R. Ruíz, "Thermal analysis of enhanced poly(vinyl alcohol)based proton-conducting membranes crosslinked with sulfonation agents for direct methanol fuel cells,” J. Appl. Polym. Sci., vol. 124, 2012.

[24] K.-J. Kim, S.-B. Lee, and N.-W. Han, "Kinetics of crosslinking reaction of PVA membrane with glutaraldehyde,” Korean J. Chem. Eng., vol. 11, no. 1, pp. 41-47, Jan. 1994.

[25] F. S. Matty, M. T. Sultan, and A. K. Amine, "Swelling Behavior of Cross-link PVA with Glutaraldehyde,” Pure Appl. Sci. Ibn Al-Haitham Jour. Pure Appl. Sci, vol. 28, no. 282, 2015.

[26] K. C. S. Figueiredo, T. L. M. Alves, and C. P. Borges, "Poly(vinyl alcohol) films crosslinked by glutaraldehyde under mild conditions,” J. Appl. Polym. Sci., vol. 111, no. 6, pp. 3074-3080, Jan. 2009.

[27] H. S. Mansur, C. M. Sadahira, A. N. Souza, and A. A. P. P. Mansur, "FTIR spectroscopy characterization of poly (vinyl alcohol) hydrogel with different hydrolysis degree and chemically crosslinked with glutaraldehyde,” vol. 28, no. 4, pp. 539-548, May 2008.

[28] Y. H. F. Al-qudah, G. A. Mahmoud, and M. A. Abdel Khalek, "Radiation crosslinked poly (vinyl alcohol)/acrylic acid copolymer for removal of heavy metal ions from aqueous solutions,” J. Radiat. Res. Appl. Sci., vol. 7, no. 2, pp. 135-145, Apr. 2014.

[29] K. Kumeta, I. Nagashima, S. Matsui, and K. Mizoguchi, "Crosslinking reaction of poly(vinyl alcohol) with poly(acrylic acid) (PAA) by heat treatment: Effect of neutralization of PAA,” J. Appl. Polym. Sci., vol. 90, no. 9, pp. 2420-2427, Nov. 2003.

[30] D. S. Kim, M. D. Guiver, S. Y. Nam, T. Il Yun, M. Y. Seo, S. J. Kim, H. S. Hwang, and J. W. Rhim, "Preparation of ion exchange membranes for fuel cell based on crosslinked 
poly(vinyl alcohol) with poly(styrene sulfonic acid-co-maleic acid),” J. Memb. Sci., vol. 281, no. 1-2, pp. 156-162, Sep. 2006.

[31] D. S. Kim, H. Il Cho, D. H. Kim, B. S. Lee, B. S. Lee, S. W. Yoon, Y. S. Kim, G. Y. Moon, H. Byun, and J. W. Rhim, "Surface fluorinated poly(vinyl alcohol)/poly(styrene sulfonic acid-co-maleic acid) membrane for polymer electrolyte membrane fuel cells," J. Memb. Sci., vol. 342, no. 1-2, pp. 138-144, Oct. 2009.

[32] Y. Liu, M. Park, H. K. Shin, B. Pant, J. Choi, Y. W. Park, J. Y. Lee, S. J. Park, H. Y. Kim, Yanan Liu and others, Y. Liu, M. Park, H. K. Shin, B. Pant, J. Choi, Y. W. Park, J. Y. Lee, S. J. Park, and H. Y. Kim, "Facile preparation and characterization of poly(vinyl alcohol)/chitosan/graphene oxide biocomposite nanofibers,” J. Ind. Eng. Chem., vol. 20, no. 6, pp. 4415-4420, 2014.

[33] S. G. Cao, Z. F. Liu, B. H. Hu, and H. Q. Liu, "Stabilization of electrospun poly(Vinyl Alcohol) nanofibrous mats in aqueous solutions," Chinese J. Polym. Sci. (English Ed., vol. 28, no. 5, pp. 781-788, 2010.

[34] B. Ding, H. Y. Kim, S. C. Lee, C. L. Shao, D. R. Lee, S. J. Park, G. B. Kwag, and K. J. Choi, "Preparation and characterization of a nanoscale poly(vinyl alcohol) fiber aggregate produced by an electrospinning method,” J. Polym. Sci. Part B Polym. Phys., vol. 40, no. 13, pp. 1261-1268, 2002.

[35] J. Maiti, N. Kakati, S. H. Lee, S. H. Jee, B. Viswanathan, and Y. S. Yoon, "Where do poly(vinyl alcohol) based membranes stand in relation to Nafion ${ }^{\circledR}$ for direct methanol fuel cell applications?,” J. Power Sources, vol. 216, pp. 48-66, 2012.

[36] S. Zhong, X. Cui, Y. Gao, W. Liu, and S. Dou, "Fabrication and properties of poly(vinyl alcohol)-based polymer electrolyte membranes for direct methanol fuel cell applications,” Int. J. Hydrogen Energy, vol. 39, no. 31, pp. 17857-17864, 2014.

[37] C. Y. Tseng, Y. S. Ye, K. Y. Kao, J. Joseph, W. C. Shen, J. Rick, and B. J. Hwang, "Interpenetrating network-forming sulfonated poly(vinyl alcohol) proton exchange membranes for direct methanol fuel cell applications,” Int. J. Hydrogen Energy, vol. 36, no. 18, pp. 11936-11945, 2011.

[38] S. Yun, H. Im, Y. Heo, and J. Kim, "Crosslinked sulfonated poly(vinyl alcohol)/sulfonated multi-walled carbon nanotubes nanocomposite membranes for direct methanol fuel cells,” J. Memb. Sci., vol. 380, no. 1-2, pp. 208-215, Sep. 2011.

[39] M. J. Hickner MA, Ghassemi H, Kim YS, Einsla BR, "Alternative polymer systems for proton exchange membranes (PEMs).,” Chem Rev, vol. 104, pp. 617-4587, 2004.

[40] K. W. Moore TT, Mahajan R, Vu DQ, "Hybrid membrane materials comprising organic polymers with rigid dispersed phases. 2004;50:311-21.,” AIChE J, vol. 50, pp. 311-21, 2004.

[41] R. K. Nunes S, Ruffmann B, Rikowski E, Vetter S, "Inorganic modification of proton conductive polymer membranes for direct methanol fuel cells.,” J Membr Sci, vol. 203, pp. 215-25, 2002.

[42] D. S. Kim, H. B. Park, J. W. Rhim, and Y. M. Lee, "Preparation and characterization of crosslinked PVA/SiO2 hybrid membranes containing sulfonic acid groups for direct methanol fuel cell applications,” J. Memb. Sci., vol. 240, no. 1-2, pp. 37-48, 2004.

[43] Z. Ma, J. Gao, Y. Huai, J. Guo, Z. Deng, and J. Suo, "Preparation and characterization of inorganic-organic hybrid proton exchange membranes based on phosphorylated PVA and PEG-grafted silica particles,” J. Sol-Gel Sci. Technol., vol. 48, no. 3, pp. 267-271, Dec. 2008.

[44] W. Xu, C. Liu, X. Xue, Y. Su, Y. Lv, W. Xing, and T. Lu, "New proton exchange membranes based on poly (vinyl alcohol) for DMFCs,” Solid State Ionics, vol. 171, no. 1-2, pp. 121-127, Jun. 2004.

[45] B. Wang, Z. Chen, J. Zhang, J. Cao, S. Wang, Q. Tian, M. Gao, and Q. Xu, "Fabrication of PVA/graphene oxide/TiO2 composite nanofibers through electrospinning and interface sol-gel reaction: Effect of graphene oxide on PVA nanofibers and growth of TiO2,” Colloids Surfaces A Physicochem. Eng. Asp., vol. 457, no. 1, pp. 318-325, 2014.

[46] C.-C. Yang, S.-J. Chiu, K.-T. Lee, W.-C. Chien, C.-T. Lin, and C.-A. Huang, "Study of poly(vinyl alcohol)/titanium oxide composite polymer membranes and their application on alkaline direct alcohol fuel cell,” J. Power Sources, vol. 184, no. 1, pp. 44-51, Sep. 2008.

[47] C.-C. Yang, "Synthesis and characterization of the cross-linked PVA/TiO2 composite 
polymer membrane for alkaline DMFC,” J. Memb. Sci., vol. 288, no. 1-2, pp. 51-60, Feb. 2007.

[48] C.-C. Yang, Y.-J. Lee, and J. M. Yang, "Direct methanol fuel cell (DMFC) based on PVA/MMT composite polymer membranes,” J. Power Sources, vol. 188, no. 1, pp. 3037, 2009.

[49] C. C. Yang and Y. J. Lee, "Preparation of the acidic PVA/MMT nanocomposite polymer membrane for the direct methanol fuel cell (DMFC),” Thin Solid Films, vol. 517, no. 17, pp. 4735-4740, 2009.

[50] Y. Jin, J. C. Diniz da Costa, and G. Q. Lu, "Proton conductive composite membrane of phosphosilicate and polyvinyl alcohol,” Solid State Ionics, vol. 178, no. 13-14, pp. 937942, May 2007.

[51] Y. Yang, C. Liu, P. R. Chang, Y. Chen, D. P. Anderson, and M. Stumborg, "Properties and structural characterization of oxidized starch/PVA $/ \alpha$ - zirconium phosphate composites,” J. Appl. Polym. Sci., vol. 115, no. 2, pp. 1089-1097, Jan. 2010.

[52] M. Helen, B. Viswanathan, and S. Srinivasa Murthy, "Fabrication and properties of hybrid membranes based on salts of heteropolyacid, zirconium phosphate and polyvinyl alcohol,” J. Power Sources, vol. 163, no. 1, pp. 433-439, Dec. 2006.

[53] J. Maiti, N. Kakati, S. H. Lee, S. H. Jee, and Y. S. Yoon, "PVA nano composite membrane for DMFC application,” Solid State Ionics, vol. 201, no. 1, pp. 21-26, Oct. 2011.

[54] U. R. Farooqui, A. L. Ahmad, and N. A. Hamid, "Graphene oxide: A promising membrane material for fuel cells,” Renewable and Sustainable Energy Reviews, vol. 82. Pergamon, pp. 714-733, 01-Feb-2018.

[55] R. P. Pandey, G. Shukla, M. Manohar, and V. K. Shahi, "Graphene oxide based nanohybrid proton exchange membranes for fuel cell applications: An overview,” Adv. Colloid Interface Sci., vol. 240, pp. 15-30, 2016.

[56] W. S. Hummers and R. E. Offeman, "Preparation of Graphitic Oxide,” J. Am. Chem. Soc., vol. 80, no. 6, pp. 1339-1339, 1958.

[57] Y. Y. Qi, Z. X. Tai, D. F. Sun, J. T. Chen, H. B. Ma, X. B. Yan, B. Liu, and Q. J. Xue, "Fabrication and characterization of poly(vinyl alcohol)/graphene oxide nanofibrous biocomposite scaffolds,” J. Appl. Polym. Sci., vol. 127, no. 3, pp. 1885-1894, 2013.

[58] C. Guo, L. Zhou, and J. Lv, "Layer- Structured Poly(vinyl alcohol) / Graphene Oxide Nanocomposites with Improved Thermal and Mechanical Properties,” Polym. Polym. Compos., vol. 21, no. 7, pp. 449-456, 2013.

[59] A. Laforgue, L. Robitaille, A. Mokrini, and A. Ajji, "Fabrication and characterization of ionic conducting nanofibers,” Macromol. Mater. Eng., vol. 292, no. 12, pp. 1229-1236, 2007.

[60] N. A. Zubair, N. A. Rahman, H. N. Lim, R. M. Zawawi, and Y. Sulaiman, "Electrochemical properties of PVA-GO/PEDOT nanofibers prepared using electrospinning and electropolymerization techniques,” RSC Adv., vol. 6, no. 21, pp. 17720-17727, 2016.

[61] C. Wang, Y. Li, G. Ding, X. Xie, and M. Jiang, "Preparation and characterization of graphene oxide/poly(vinyl alcohol) composite nanofibers via electrospinning,” J. Appl. Polym. Sci., vol. 127, no. 4, pp. 3026-3032, 2013.

[62] S. Yun, H. Im, Y. Heo, and J. Kim, "Crosslinked sulfonated poly(vinyl alcohol)/sulfonated multi-walled carbon nanotubes nanocomposite membranes for direct methanol fuel cells,” J. Memb. Sci., vol. 380, no. 1-2, pp. 208-215, 2011.

[63] L. Jia and X. Qin, "The effect of different surfactants on the electrospinning poly(vinyl alcohol) (PVA) nanofibers,” J. Therm. Anal. Calorim., vol. 112, no. 2, pp. 595-605, May 2013.

[64] X. Qian, N. Gu, Z. Cheng, X. Yang, E. Wang, and S. Dong, "Methods to study the ionic conductivity of polymeric electrolytes using a.c. impedance spectroscopy,” J. Solid State Electrochem., vol. 6, no. 1, pp. 8-15, Dec. 2001.

[65] H. Beydaghi, M. Javanbakht, and E. Kowsari, "Synthesis and Characterization of Poly(vinyl alcohol)/Sulfonated Graphene Oxide Nanocomposite Membranes for Use in Proton Exchange Membrane Fuel Cells (PEMFCs),” Ind. Eng. Chem. Res., vol. 53, no. 43, pp. 16621-16632, 2014.

[66] C. Bao, Y. Guo, L. Song, Y. Hu, F. J. Lamelas, C. A. Wilkie, A. Ivaska, Y. Sung, M. D. 
Ger, C. C. M. Ma, M. H. Hsiao, I. A. Aksay, R. K. Prud'homme, and L. C. Brinson, "Poly(vinyl alcohol) nanocomposites based on graphene and graphite oxide: a comparative investigation of property and mechanism,” J. Mater. Chem., vol. 21, no. 36, p. 13942, 2011.

[67] N. Kakati, J. Maiti, G. Das, S. H. Lee, and Y. S. Yoon, “An approach of balancing the ionic conductivity and mechanical properties of PVA based nanocomposite membrane for DMFC by various crosslinking agents with ionic liquid,” Int. J. Hydrogen Energy, vol. 40, no. 22, pp. 7114-7123, 2015.

[68] S. Mo, L. Peng, C. Yuan, C. Zhao, W. Tang, C. Ma, J. Shen, W. Yang, Y. Yu, Y. Min, and A. J. Epstein, "Enhanced properties of poly(vinyl alcohol) composite films with functionalized graphene,” RSC Adv., vol. 5, no. 118, pp. 97738-97745, 2015.

[69] O. Gil-Castell, J. D. Badia, R. Teruel-Juanes, I. Rodriguez, F. Meseguer, and A. RibesGreus, "Novel silicon microparticles to improve sunlight stability of raw polypropylene,” Eur. Polym. J., vol. 70, pp. 247-261, 2015.

[70] B. Wang, Z. Chen, J. Zhang, J. Cao, S. Wang, Q. Tian, M. Gao, and Q. Xu, "Fabrication of PVA/graphene oxide/TiO2composite nanofibers through electrospinning and interface sol-gel reaction: Effect of graphene oxide on PVA nanofibers and growth of TiO2,” Colloids Surfaces A Physicochem. Eng. Asp., vol. 457, no. 1, pp. 318-325, 2014.

[71] A. M. Albu, I. Maior, C. A. Nicolae, and F. L. Bocăneală, "Novel Pva Proton Conducting Membranes Doped With Polyaniline Generated By in-Situ Polymerization," Electrochim. Acta, vol. 211, pp. 911-917, 2016.

[72] J. D. Badia, O. Gil-Castell, and A. Ribes-Greus, "Long-term properties and end-of-life of polymers from renewable resources,” Polym. Degrad. Stab., vol. 137, pp. 35-57, 2017.

[73] O. Gil-Castell, J. D. D. Badia, T. Kittikorn, E. Strömberg, M. Ek, S. Karlsson, A. RibesGreus, E. Strömberg, M. Ek, S. Karlsson, and A. Ribes-Greus, "Impact of hydrothermal ageing on the thermal stability, morphology and viscoelastic performance of PLA/sisal biocomposites,” Polym. Degrad. Stab., vol. 132, pp. 87-96, Mar. 2016.

[74] O. Gil-Castell, J. D. D. Badia, T. Kittikorn, E. Strömberg, A. Martínez-Felipe, M. Ek, S. Karlsson, and A. Ribes-Greus, "Hydrothermal ageing of polylactide/sisal biocomposites. Studies of water absorption behaviour and Physico-Chemical performance,” Polym. Degrad. Stab., vol. 108, pp. 212-222, Oct. 2014.

[75] O. Gil-Castell, J. D. Badia, I. Ontoria-Oviedo, D. Castellano, B. Marco, A. Rabal, J. J. Bou, A. Serra, L. Monreal, M. Blanes, P. Sepúlveda, and A. Ribes-Greus, "In vitro validation of biomedical polyester-based scaffolds: Poly(lactide-co-glycolide) as modelcase,” Polym. Test., vol. 66, pp. 256-267, Apr. 2018. 
Contribution 4.3.

Crosslinked chitosan/poly(vinyl alcohol)-based membranes for proton exchange polyelectrolytes

O. Gil-Castell, R. Teruel-Juanes, F. Arenga, A. M-Salaberria, M. G. Baschetti, J. Labidi, J. D. Badia, A. Ribes-Greus. Crosslinked chitosan/poly(vinyl alcohol)-based membranes for proton exchange polyelectrolytes. Manuscript in preparation. 


\title{
Crosslinked chitosan/poly(vinyl alcohol)-based membranes for proton exchange polyelectrolytes
}

\author{
O. Gil-Castell ${ }^{1}$, R. Teruel-Juanes ${ }^{1}$, F. Arenga ${ }^{2}$, A. M-Salaberria ${ }^{3}$, M. G. \\ Baschetti $^{2}$, J. Labidi ${ }^{3}$, J. D. Badia ${ }^{1,4}$, A. Ribes-Greus ${ }^{1, *}$ \\ ${ }^{1}$ Instituto de Tecnología de Materiales (ITM). Universitat Politècnica de València. Camino de \\ Vera s/n, 46022 Valencia, Spain.
}

${ }^{2}$ Dipartimento di Ingegneria Civile, Chimica, Ambientale e dei Materiali (DICAM), Alma Mater Studiorum - Università di Bologna. Via Terracini, 28, 40131, Bologna, Italy.
${ }^{3}$ Departamento de Ingeniería Química y del Medio Ambiente. Universidad del País Vasco. Plaza Europa 1, 20018, San Sebastián, Spain. ${ }^{3}$ Departament d’Enginyeria Química. Escola Tècnica Superior d’Enginyeria. Universitat de
València. Av. de la Universitat, s/n, 46100, Burjassot, Spain.

${ }^{*}$ Corresponding author:

A. Ribes-Greus aribes@ter.upv.es 


\title{
Crosslinked chitosan/poly(vinyl alcohol)-based membranes for proton exchange polyelectrolytes
}

\author{
O. Gil-Castell, R. Teruel-Juanes, F. Arenga, A. M-Salaberria, M. G. \\ Baschetti, J. Labidi, J. D. Badia, A. Ribes-Greus
}

\begin{abstract}
The preparation of cost-effective and eco-friendly membranes based in crosslinked poly(vinyl alcohol) (PVA) and chitosan (CS) was considered as a feasible alternative to develop highly functionalised polyelectrolyte membranes that would improve the massive application of the proton exchange fuel cell technologies. CS/PVA-based membranes were combined with sulfosuccinic acid (SSA) as crosslinking and sulfonating agent, and glycerol (GL) to promote flexibility to favour the manageability of the membranes. The chemical stability, thermo-oxidative behaviour, ethanol solution absorption profiles, electric and proton conductivity and performance on direct ethanol fuel cells (DEFC) were assessed. In general terms, all CS/PVA membranes showed a synergetic increase of thermal stabilities, absorption and diffusion of ethanol and proton conductivity, with appropriate performance to be used in typical service conditions of fuel cells. The incorporation of GL in the CS/PVA membranes reacted with SSA, reducing the ethanol absorption, diffusion coefficient and proton conductivity, but in turn acted as a plasticiser that increased the ductile manageability of membranes to be mounted on the membrane-electrode assemblies (MEAs). The crosslinked membrane 40CS/PVA/20GL, which contained a 40 \%wt.. of CS referred to PVA, and a $20 \%$ wt.. of GL referred to CS, showed the best behaviour in the DEFC test, with a value of $P_{\max }$ of $746.79 \mathrm{~mW}$. The higher the presence of chitosan and the higher the proportion of glycerol was in the membrane, the closer to the behaviour of Nafion ${ }^{\circledR} 117$ was that of the CS/PVA membranes in the DEFC, showing similar profiles at low intensities.
\end{abstract}

\section{Keywords}

Polyelectrolyte, DEFC, proton exchange membrane, poly(vinyl alcohol) (PVA), chitosan, sulfosuccinic acid (SSA) 


\section{Introduction}

A proton exchange fuel cell (PEFC) is a device that converts the chemical energy of hydrogen into electricity through an electrochemical reaction, producing water and heat as by-products, and can be considered as promising power generation system [1]. Although fuel cell technology has substantially matured over the past decades, technological barriers, such as the hydrogen storage and transport infrastructure, lifetime and fuel cell component costs, still delay their commercialisation in many applications. Among the most investigated polyelectrolytes, solid polymer-based membranes offer advantages such as high efficiency and high energy density. Furthermore, the applicability of bio-fuels as methanol or ethanol has been considered in direct alcohol fuel cells (DAFCs). In this sense, the most important component of a DAFC is the polymer electrolyte membrane (PEM) [2]. Nafion $\AA$, as the most common and commercially available PEM for DAFCs, possess ideal properties for being used with hydrogen, such as high proton conductivity and good chemical, mechanical, and thermal stability. Despite their favourable features, these membranes have several intrinsic disadvantages, e.g. high cost, and shortcomings when used with alternative fuels such as fuel permeability, or instability and dehydration at temperatures above $80^{\circ} \mathrm{C}$ [3]. Therefore, there is a need to develop less expensive new materials in order to improve fuel-cell performance.

In recent years, there has been extensive research on the development of high performance, cost-effective and eco-friendly polymer electrolytes. Among the novel proposed materials for polyelectrolyte development, the biomass-derived resources have received increasing attention due to due to their renewable origin, suitable properties, high availability and low cost [4]. In this context, polysaccharides can be considered as candidates, due to their abundance in the environment. Particularly, chitosan (CS), as a polysaccharide bioresource, is one of the promising polyelectrolyte membrane materials [5]. It is the N-deacetylated derivative of chitin $(\mathrm{CH})$, which is a naturally abundant polysaccharide, easily obtained from crabs or shrimp shells and fungal mycelia.

Chitosan (CS) is inert, hydrophilic and insoluble in water, alkali and organic solvents. Its solubility in diluted organic acids allows for the gel formation in various configurations [6]. Free amine and hydroxyl functional groups on the chitosan backbone enable various chemical modifications to tailor it for specific applications [7]. CS is a potentially useful membrane material for PEMs due to its non-permeability to alcohol [8]. However, in its native state, CS films exhibit very low proton conductivities and high degrees of swelling [9]. Although high swelling levels in the membranes are a prerequisite for reaching high proton conductivities, they are also usually related to a decrease of the membrane 
performance in terms of alcohol permeability, dimensional and thermal stability. To solve the low conductivity and high swelling problems, CS was usually either ionically crosslinked [10], blended with other polymers [5], or reinforced [11]. Different chitosan-based PEMs, blended with poly(acrylic acid), poly(ether sulfone) and poly(vinyl alcohol), for instance, have been studied and have showed promising properties for their application in the field of PEMFCs [12]-[15].

CS-based blended membranes are a feasible alternative to improve the shortcomings of this renewable material [16]. In the literature, various chitosan-based polymer blend membranes were prepared. Good results were obtained by blending chitosan with poly(vinyl alcohol) (PVA), which are miscible and compatible for blending [17]. Actually, they strongly interact through hydrogen bonding between their hydroxyl groups, which results in high compatibility [18].

Poly(vinyl alcohol) (PVA) is a synthetic water soluble non-toxic polymer with a carbon backbone attached to hydroxyl groups with good mechanical strength and high chemical and thermal stability [18]. The physical characteristics and its specific properties are closely related to the molar mass and the degree of hydrolysis [19]. PVA membranes have been extensively used as alcohol dehydrating agents due to its high water/alcohol selectivity. Taking advantage of this high affinity, PVA is an attractive material for PEM preparation [20], [21]. However, due to the absence of negatively charged ions, it is a poor proton conductor when compared to the commercially available Nafion ${ }^{\circledR}$ membrane [22]. Hence, PVA requires functionalisation in order to promote the required features for being used as PEM. The crosslinking with functionalised molecules has been reported as a feasible mode to obtain three-dimensional networks with improved properties in terms of dimensional stability, thermal and mechanical properties, proton conductivity and ethanol permeability [23]. Interesting results have been obtained using sulfosuccinic acid (SSA) as a crosslinking agent through which a negative charged ion group is introduced in the PVA structure [15].

In order to explore the synergetic improvement of performance of chitosan and poly(vinyl alcohol), the preparation of cost-effective and eco-friendly membranes based in crosslinked CS/PVA membranes was considered in this study as a feasible alternative to develop highly functionalised polyelectrolytes for direct ethanol fuel cells (DEFC). In this sense, CS/PVA-based membranes were combined with sulfosuccinic acid (SSA) as crosslinking and sulfonating agent, and glycerol (GL) to promote plasticity to handle the membranes. The combination of the assessment of their chemical stability, thermo-oxidative behaviour, ethanol absorption profiles, electric and proton conductivity and performance on direct ethanol fuel cells (DEFC) was proposed as validation methodology. 


\section{Materials and methods}

\subsection{Materials}

Chitosan (CS) with an average molar mass in number $\left(M_{n}\right)$ in the range from 50000 to $190000 \mathrm{~g} \cdot \mathrm{mol}^{-1}$, poly(vinyl alcohol) (PVA) with $M_{n} 130000$ $\mathrm{g} \cdot \mathrm{mol}^{-1}$ and degree of hydrolysis min. $99 \%$, and glacial acetic acid (AcOH) 99.8\% anhydrous were all purchased from Sigma-Aldrich. To crosslink CS/PVA membranes, sulfosuccinic acid (SSA) (70 \%wt. solution in water) was also purchased from Sigma-Aldrich.

\subsection{Membrane preparation}

Blended chitosan/poly(vinyl alcohol) (CS/PVA)-based membranes were prepared by means of a joint solvent-casting/crosslinking procedure. For this purpose, a $8 \%$ wt. PVA solution was prepared in deionised water and left into a reflux system at $90{ }^{\circ} \mathrm{C}$ for $6 \mathrm{~h}$ under magnetic stirring. The concentration of the CS solution was fixed at $2 \% w t$. in diluted acetic acid and was left to dissolve under magnetic stirring at room temperature for 6 h.

The PVA/CS blends were obtained by mixing and homogenising the CS and PVA solutions at $65{ }^{\circ} \mathrm{C}$ under magnetic stirring for $16 \mathrm{~h}$ in the above cited reflux system. The weight ratio of both components was varied in the range 100:0, 60:40, 50:50, 40:60, 20:80 and 0:100 of CS:PVA.

In order to improve the plasticity of the membranes glycerol (GL) was added to the CS/PVA blends in 10 and $20 \% w t$. in relation to CS. To achieve crosslinking and, at the same time, functionalisation of the developed membranes by addition of sulfonic groups, sulfosuccinic acid (SSA) was added to the mixture in a $30 \%$ wt. in relation to PVA and homogenized under magnetic stirring for $30 \mathrm{~min}$ [24].

The membranes were identified as $x \mathrm{CS} / \mathrm{PVA} / y \mathrm{GL}$, where $x$ is referred to the total CS weight percentage (CS to PVA) and $y$ to the weight percentage of glycerol in relation to CS. The experimental composition and the nomenclature used for each membrane are shown in Table 1.

The membranes were prepared by solution casting and solvent evaporation [18], [25]-[27]. The homogeneous solutions were poured into Teflon ${ }^{\circledR}$ moulds and the cast membranes were allowed to dry at room temperature for $48 \mathrm{~h}$. Then, the dried membranes were peeled off the Teflon ${ }^{\circledR}$ plates and crosslinked by thermo-compression into a made-to-order hydraulic hot plates press at $110{ }^{\circ} \mathrm{C}$ for $2 \mathrm{~h}$. For this, the membranes were introduced into a Teflon ${ }^{\circledR}$ mould of $50 \mu \mathrm{m}$ thickness and, in turn, between sheets of Teflon ${ }^{\circledR}$ reinforced with fiberglass. Once the crosslinking time had elapsed, the mould assembly was allowed to cool to room temperature. 
Finally, the membranes were kept into zip plastic bags and stored into a desiccator at room temperature for the subsequent characterisation steps.

Table 1. Nomenclature and experimental composition of CS/PVA-based films.

\begin{tabular}{lccccc}
\hline \multicolumn{1}{c}{ Membrane } & $\begin{array}{c}\text { CS:PVA } \\
\text { weight ratio }\end{array}$ & $\begin{array}{c}\text { CS } \\
\text { (\% wt.) }\end{array}$ & $\begin{array}{c}\text { PVA } \\
\text { (\% wt.) }\end{array}$ & $\begin{array}{c}\text { SSA } \\
\text { (\% wt.pVA) }\end{array}$ & $\begin{array}{c}\text { GL } \\
\text { (\%wt.cs) }\end{array}$ \\
\hline CS & $100: 0$ & 100 & - & - & - \\
\hline 60CS/PVA & $60: 40$ & 53.57 & 35.71 & 10.71 & - \\
\hline 50CS/PVA & $50: 50$ & 43.48 & 43.48 & 13.04 & - \\
\hline 40CS/PVA & $40: 60$ & 33.90 & 50.85 & 15.25 & - \\
\hline 20CS/PVA & $20: 80$ & 16.13 & 64.52 & 19.35 & - \\
\hline PVA & $0: 100$ & - & 76.92 & 23.08 & - \\
\hline 60CS/PVA/10GL & $60: 40$ & 50.85 & 33.90 & 10.17 & 5.08 \\
\hline 50CS/PVA/10GL & $50: 50$ & 41.67 & 41.67 & 12.50 & 4.16 \\
\hline 40CS/PVA/10GL & $40: 60$ & 32.80 & 49.18 & 14.75 & 3.27 \\
\hline 20CS/PVA/10GL & $20: 80$ & 15.88 & 63.49 & 19.05 & 1.58 \\
\hline PVA/10GL & $0: 100$ & - & 71.43 & 21.43 & 7.14 \\
\hline 60CS/PVA/20GL & $60: 40$ & 50.00 & 33.33 & 10.00 & 6.67 \\
\hline 50CS/PVA/20GL & $50: 50$ & 40.00 & 40.00 & 12.00 & 8.00 \\
\hline 40CS/PVA/20GL & $40: 60$ & 30.77 & 46.15 & 13.84 & 9.23 \\
\hline 20CS/PVA/20GL & $20: 80$ & 14.29 & 57.14 & 17.14 & 11.43 \\
\hline PVA/20GL & $0: 100$ & - & 66.67 & 20.00 & 13.33 \\
\hline
\end{tabular}

\subsection{Membrane characterisation}

\subsubsection{Fourier transform infrared spectroscopy (FT-IR)}

The Fourier transform infrared spectroscopy (FTIR) analysis was performed using a Thermo Nicolet 5700 FT-IR spectrometer. The FTIR spectra were collected in the range of $4000-400 \mathrm{~cm}^{-1}$ using the Attenuated Total Reflectance (ATR) mode at a resolution of $4 \mathrm{~cm}^{-1}$. In order to obtain accurate results, 64 scans were performed at three different locations of the sample and the average was calculated. Backgrounds spectra were collected before each series of experiments in order to eliminate any interference from the environment.

\subsubsection{Thermogravimetric analysis (TGA)}

The thermogravimetric analysis (TGA) was performed using a Mettler Toledo TGA/STDA 851 analyser. The samples, with a mass between 3 and $5 \mathrm{mg}$, were filled into $70 \mu \mathrm{L}$ alumina capsules. Then, they were placed on the equipment, previously calibrated. Samples were analysed under a dynamic segment with a heating rate of $10^{\circ} \mathrm{C} \cdot \mathrm{min}^{-1}$ from 30 to $700{ }^{\circ} \mathrm{C}$ and oxidative atmosphere of oxygen at $50 \mathrm{~mL} \cdot \mathrm{min}^{-1}$. The samples were assessed in triplicate and the averages of results were taken as representative values. 


\subsubsection{Ethanol solution uptake}

The absorption of ethanol solution was evaluated by performing swelling tests on the membranes. Samples were cut into rectangular specimens and dried at $30{ }^{\circ} \mathrm{C}$ in a vacuum oven Heraeus Vacutherm for $12 \mathrm{~h}$ before analysis, in order to ensure the elimination of humidity. Then, the samples were immersed into tests tubes containing a $2 \mathrm{M}$ ethanol solution and subjected to $40{ }^{\circ} \mathrm{C}$. The sorption measurements consisted in removing the sample from the solution, blotting the surface free of surface liquid, quickly weighing the sample on a Mettler Toledo model XS105 balance with a precision of $0.01 \mathrm{mg}$, and then re-immersing the film into the liquid. This process was repeated many times over a short time interval between $30 \mathrm{~min}$ and $2 \mathrm{~h}$, then the time interval was extended to 4, 8, 12, $24 \mathrm{~h}$ until no further gain weight was observed and equilibrium wet mass $\left(M_{e q}\right)$ was reached. The variation of the sample mass due to the solution absorbed along the absorption process $\left(M_{t}\right)$ was calculated according to Equation 1.

$$
M_{t}=\frac{m_{t}-m_{0}}{m_{0}} \times 100
$$

(Equation 1)

where $m_{t}$ is the mass measured during ethanol solution absorption and $m_{0}$ is the mass at the beginning.

The solution to Fick's law for diffusion is different depending on the geometric structure of the material under study [28]. For a plane sheet geometry, as that of the obtained membranes, if the mass uptake at time $t$ is used as $M_{t}$ and the water uptake at the equilibrium as $M_{e q}$, the Fick's law can be simplified using Stefan's approximation (Equation 2). This estimation is used for describing the earlier stages of water uptake, usually for $M_{t} / M_{S} \leq 0.5$.

$$
\frac{M_{t}}{M_{e q}}=\frac{8}{\pi^{1 / 2}}\left(\frac{D t}{l^{2}}\right)^{1 / 2}
$$

(Equation 2)

where $D$ is the diffusion coefficient, $l$ is the thickness of the sample and $t$ the time of absorption. If the semi-saturation time $\left(t_{1 / 2}\right)$ is considered when $\frac{M_{t}}{M_{e q}}=0.5$, the Equation 2 could be expressed as Equation 3.

$$
t_{1 / 2} \approx \frac{\pi}{256} \cdot\left(\frac{L^{2}}{D}\right)
$$

(Equation 3)

Which in turn, finally results in Equation 4 for the calculation of $D$.

$$
D \approx 0.01224 \frac{L^{2}}{t_{1 / 2}}
$$

\subsubsection{Dielectric-thermal impedance spectrometry (DETA)}

The impedance measurements were performed using the equipment Novocontrol Broadband Dielectric Impedance Spectrometer (BDIS) 
connected with a Novocontrol Alpha-A Frequency Response Analyser. A BDS-1200 Novocontrol parallel-plated capacitor with two plated electrodes system was used as dielectric cell test. The membrane thicknesses were evaluated using a micrometre Mitutoyo Comparator Stand 215-611 BS-10M taking the average of 6 measurements in different positions of the sample. Next, the analyses consisted in a single sweep at room temperature $\left(25 \pm 1^{\circ} \mathrm{C}\right)$ in a frequency range from $10^{-2}$ to $10^{7} \mathrm{~Hz}$.

The proton conductivity of the membranes was calculated according to the Equation 5.

$$
\sigma_{\text {prot }}=\frac{l}{A \cdot R_{o}}
$$

(Equation 5)

where $l$ is the thickness of the membranes in $\mathrm{cm}, A$ the area of the electrode in contact with the membrane in $\mathrm{cm}^{2}$, and $R_{0}$ the protonic resistance in ohms $(\Omega)$. The value of $R_{0}$ is taken from the Bode plot in the high frequencies range, in which the value of $\log |Z|$ tends to a non-frequency dependent asymptotic value and the phase angle reaches its maximum value [29].

The electric conductivity $\left(\sigma_{\text {elec }}\right)$ was measured at low frequencies, where the measured real part of the conductivity $\left(\sigma^{\prime}\right)$ reaches a plateau, that is correlated to the DC conductivity $\left(\sigma_{0}\right)$.

\subsubsection{Direct ethanol fuel cell (DEFC) test}

The direct ethanol fuel cell (DEFC) performance tests of the membranes were conducted with a single cell F-107 from H-TEHC with diffusing layers. The membranes were previously equilibrated with a $2 \mathrm{M}$ ethanol solution during $24 \mathrm{~h}$ to ensure their fully hydrated state, and were sandwiched between two electrode catalysts sheets of platinum (Pt). The active area of the single cell was approximately $4 \times 4 \mathrm{~cm}^{2}$. The gas flow rates of the $2 \mathrm{M}$ ethanol solution as fuel and oxidant humid air stream were kept constant at $0.250 \mathrm{~L} \cdot \mathrm{min}^{-1}$ and $1.6 \mathrm{~L} \cdot \mathrm{min}^{-1}$, respectively.

\section{Results and discussion}

\subsection{Macroscopic appearance}

The macroscopic appearance of the developed CS/PVA crosslinked membranes is shown in Table 2. In general, a flat morphology and a uniform surface with a thickness between 35 and $55 \mu \mathrm{m}$ was achieved. All membranes, initially transparent, experienced a change of colour after crosslinking. This change was more pronounced for membranes with high content of PVA, which confirms that the change of the colour is due to the crosslinking reaction with the SSA molecules. During manipulation, the neat CS/PVA crosslinked membranes were rigid, whilst those containing glycerol seemed much more flexible and handily. 
Table 2. Macroscopic appearance of the CS/PVA-based crosslinked membranes.

\begin{tabular}{|c|c|c|c|c|c|c|}
\hline \multirow{2}{*}{$\begin{array}{l}\text { Glycerol } \\
\text { (\% wt.cs) }\end{array}$} & \multirow[b]{2}{*}{ 100:0 } & \multicolumn{5}{|c|}{ CS:PVA weight ratio } \\
\hline & & $60: 40$ & $50: 50$ & $40: 60$ & $20: 80$ & 0:100 \\
\hline- & & & & & & \\
\hline 10 & $x$ & & & & & \\
\hline 20 & $x$ & & & & & \\
\hline
\end{tabular}

\subsection{Structural characterisation}

The structural characterisation of the membranes was assessed by Fourier transform infrared spectroscopy (FTIR), in order to assess the blending, the crosslinking reaction of CS/PVA with the SSA molecules and the effect of the addition of glycerol. The obtained FTIR spectra of all prepared CS/PVA-based membranes are plotted in Figure 1 in comparison to those of neat CS and neat PVA.
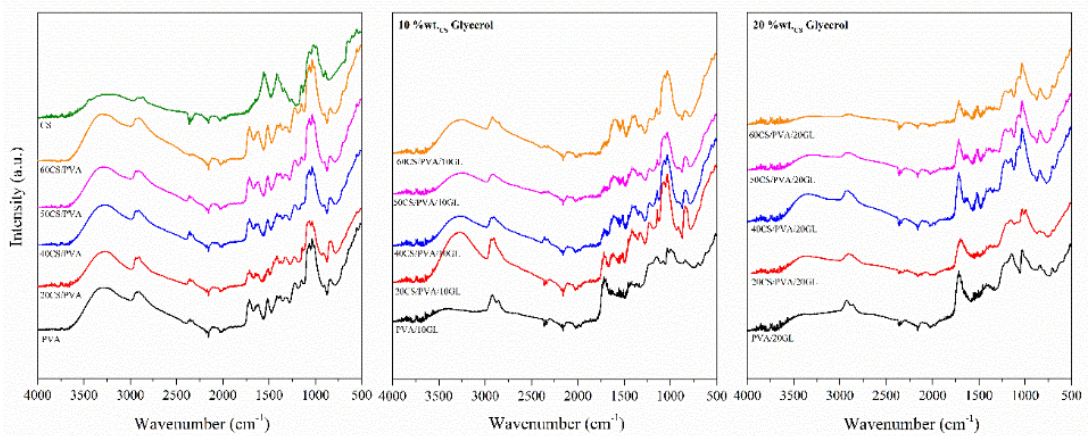

Figure 1. FTIR spectra of the crosslinked CS/PVA-based films.

In general, the FTIR spectra of the membranes showed a broad absorption band around $3200-3300 \mathrm{~cm}^{-1}$ due to the $-\mathrm{OH}$ stretching vibration in the PVA polymer and the $-\mathrm{NH}$ stretching vibration in the CS polymer [26]. The characteristic absorption bands for the methylene groups $\left(-\mathrm{CH}_{2}-\right)$ of PVA and CS matrix appeared at $2950 \mathrm{~cm}^{-1}$ and $2900 \mathrm{~cm}^{-1}$ and were assigned to the asymmetric and symmetric $\mathrm{C}-\mathrm{H}$ stretching vibration, respectively [30]. Confirming the crosslinking reaction, all membranes showed an absorption band between $1710 \mathrm{~cm}^{-1}$ and $1730 \mathrm{~cm}^{-1}$ corresponding to the $\mathrm{C}=\mathrm{O}$ stretching vibration of the ester groups of SSA. The vibrations at 1550 and $1470 \mathrm{~cm}^{-1}$ were assigned to the stretching of 
primary and secondary amides, respectively of the CS polymer [31]. Additionally, two bands appeared at $1120 \mathrm{~cm}^{-1}$ and $1240 \mathrm{~cm}^{-1}$ attributed to the stretching vibration of $\mathrm{C}-\mathrm{O}-\mathrm{C}$ bonds formed during the crosslinking reaction between PVA and SSA. Finally, the peaks at $1100-1030 \mathrm{~cm}^{-1}$ were associated with the symmetric stretching vibration of the $-\mathrm{SO}_{3} \mathrm{H}$ group introduced by the SSA [32].

When glycerol was added to the membranes, there was a widening and lowering of the band between 3000 and $3500 \mathrm{~cm}^{-1}$ associated with the vibrations of the hydroxyl group $(-\mathrm{OH})$, which pointed out the interaction of the $-\mathrm{OH}$ groups with the active sites of CS/PVA. Moreover, for the films containing $20 \%$ wt.cs of glycerol an increase in the peak of the vibrations of the ester group of the SSA and of the peak between 1100 and 1240 linked to the $\mathrm{C}-\mathrm{O}-\mathrm{C}$ bond formed by crosslinking was perceived.

\subsection{Thermo-oxidative stability}

The thermo-oxidative degradation processes of the CS/PVA membranes were investigated using thermogravimetric analysis (TGA) under oxidative atmosphere. Figure 2 shows the obtained thermogravimetric (TG) and the first-order derivative (DTG) curves.

According to the results, the neat CS film exhibited two main stages of decomposition, identified in the derivative curve with two peaks at $104{ }^{\circ} \mathrm{C}$ and $280{ }^{\circ} \mathrm{C}$, attributed to the loss of humidity and to the degradation of the chitosan polymer backbone, respectively [33], [34].

The PVA, which is crosslinked with SSA, showed a multiple stage thermooxidation behaviour. In the first stage, between 50 and $250{ }^{\circ} \mathrm{C}$, a mass loss of $10 \%$ took place, which was attributed to the loss of free and bounded water. The second region of mass-loss corresponded to a thermo-oxidative decomposition process in the region of 250 to $380{ }^{\circ} \mathrm{C}$, associated with the desulfonation process, the degradation of hydroxyl groups and cleavage of crosslinking bonds [35]. Finally, a degradation of the polymeric skeleton of PVA took place at $380-600{ }^{\circ} \mathrm{C}$.

When the glycerol was added to the crosslinked PVA, i.e. PVA/10GL and PVA/20GL, the stage associated to the humidity release considerably diminished, due to the strong interaction of the hydrophilic sites of PVA and SSA with those of glycerol by hydrogen bonding. Finally, a characteristic peak decomposition of the glycerol backbone between 200 and $300{ }^{\circ} \mathrm{C}$ was found [36].

For the polymer blend films, the combination of the CS and PVA decomposition stages were observed. Accordingly, four main decomposition steps. The first stage was found between 100 and $250{ }^{\circ} \mathrm{C}$ and it was attributed to the loss of moisture and to the decomposition of the hydroxyl groups $(-\mathrm{OH})$. The second stage took place from 250 to $400{ }^{\circ} \mathrm{C}$ 
and was attributed to the decomposition of chitosan macromolecules. The mass-loss in this stage increased with the increase of the CS percentage in the film. A third decomposition stage was observed between 400 and 500 ${ }^{\circ} \mathrm{C}$, due to the thermal desulfonation processes. For the membranes that contained the highest PVA percentages, and consequently the highest SSA percentage, two different peak temperatures could be distinguished, associated with the loss of the sulfonic acid groups $\left(-\mathrm{SO}_{3} \mathrm{H}\right)$ and the breakdown of the crosslinking bond. Finally, the last decomposition stage was observed in the range from 500 to $600{ }^{\circ} \mathrm{C}$ and was associated to the breakage and decomposition of the main chain by means of chain-scission mechanism of the PVA [15].
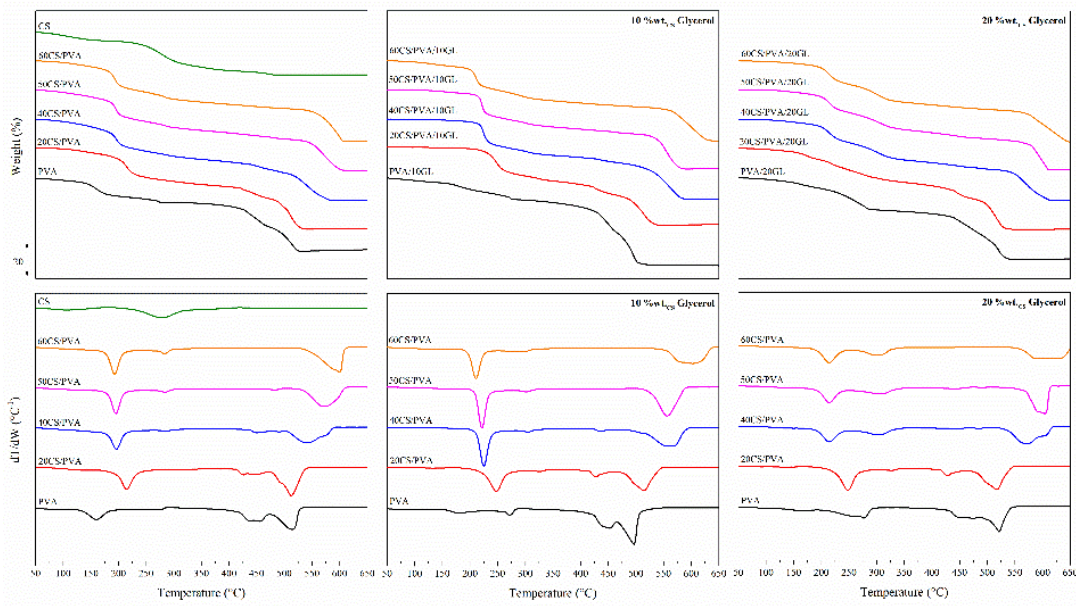

Figure 2. Thermogravimetric (TG) and derivative curves (DTG) of the CS/PVAbased membranes.

Regarding the variations in the temperatures and mass-loss associated to the above-described thermo-decomposition stages, the Table $\mathbf{3}$ summarises the mass-loss percentage along with the peak temperature of the DTG curves obtained for each membrane.

In general, it was observed that the first stage, associated to the release of bound water, moved towards higher temperatures with the increase of the PVA percentage in the membrane, due to the associated higher presence of SSA. Even though, the peak temperature of this stage for the CS/PVA membranes was higher to that found for the PVA, which suggested a kind of synergistic affect, traduced as a strong interaction between CS, PVA, SSA and water molecules. 
Table 3. Temperature peak $(T)$ of the DTG curve along with the mass-loss $(\Delta W)$ of each stage during thermo-oxidative decomposition of the CS/PVA-based membranes.

\begin{tabular}{|c|c|c|c|c|c|c|c|c|c|c|}
\hline \multirow{2}{*}{$\begin{array}{l}\text { Glycerol } \\
\text { (\%wt.cs) }\end{array}$} & \multirow{2}{*}{$\begin{array}{c}\text { CS:PVA } \\
\text { weight ratio }\end{array}$} & \multicolumn{2}{|c|}{ Stage 1} & \multicolumn{2}{|c|}{ Stage 2} & \multicolumn{3}{|c|}{ Stage 3} & \multicolumn{2}{|c|}{ Stage 4} \\
\hline & & $\begin{array}{c}T_{1} \\
\left({ }^{\circ} \mathrm{C}\right)\end{array}$ & $\begin{array}{l}\Delta W_{1} \\
(\%)\end{array}$ & $\begin{array}{c}T_{2} \\
\left({ }^{\circ} \mathrm{C}\right)\end{array}$ & $\begin{array}{l}\Delta W_{2} \\
(\%)\end{array}$ & $\begin{array}{l}T_{3.1} \\
\left({ }^{\circ} \mathrm{C}\right)\end{array}$ & $\begin{array}{l}T_{3.2} \\
\left({ }^{\circ} \mathrm{C}\right)\end{array}$ & $\begin{array}{l}\Delta W_{3} \\
(\%)\end{array}$ & $\begin{array}{c}T_{4} \\
\left({ }^{\circ} \mathrm{C}\right)\end{array}$ & $\begin{array}{l}\Delta W_{4} \\
(\%)\end{array}$ \\
\hline \multirow{6}{*}{ - } & 100:0 & 104.22 & 9.53 & 277.72 & 58.43 & - & - & - & - & - \\
\hline & $60: 40$ & 193.07 & 37.41 & 283.23 & 13.77 & - & - & - & 599.63 & 38.57 \\
\hline & $50: 50$ & 195.21 & 37.40 & 283.88 & 12.89 & - & 499.95 & 7.80 & 572.51 & 36.27 \\
\hline & $40: 60$ & 196.18 & 37.34 & 285.73 & 12.23 & 450.36 & 508.08 & 16.59 & 540.96 & 27.48 \\
\hline & 20:80 & 214.70 & 34.56 & - & - & 426.22 & 443.94 & 30.56 & 512.68 & 26.86 \\
\hline & 0:100 & 160.25 & 10.22 & - & - & 441.35 & 452.08 & 15.53 & 510.09 & 61.97 \\
\hline \multirow{5}{*}{10} & $60: 40$ & 210.99 & 35.69 & 295.64 & 13.97 & - & - & 4.10 & 602.25 & 40.45 \\
\hline & $50: 50$ & 221.69 & 33.22 & 302.14 & 12.83 & 460.74 & - & 5.83 & 556.22 & 41.47 \\
\hline & $40: 60$ & 225.15 & 32.56 & 304.21 & 12.51 & 436.64 & - & 9.35 & 564.00 & 39.74 \\
\hline & 20:80 & 247.68 & 27.48 & 325.75 & 17.97 & 428.00 & - & 23.36 & 514.34 & 20.99 \\
\hline & 0:100 & 180.61 & 19.74 & 271.77 & 15.10 & 443.69 & 451.45 & 20.87 & 496.17 & 49.11 \\
\hline \multirow{5}{*}{20} & $60: 40$ & 214.30 & 26.28 & 298.38 & 24.04 & - & - & 5.21 & 587.62 & 39.21 \\
\hline & $50: 50$ & 214.45 & 27.55 & 306.73 & 23.58 & 475.70 & - & 7.03 & 617.86 & 37.14 \\
\hline & $40: 60$ & 214.52 & 28.21 & 299.56 & 23.55 & 484.91 & - & 7.30 & 572.31 & 37.15 \\
\hline & 20:80 & 245.68 & 26.48 & 324.65 & 17.82 & 432.45 & - & 20.78 & 514.34 & 19.76 \\
\hline & $0: 100$ & 138.40 & 23.22 & 276.52 & 16.59 & 448.78 & 473.31 & 31.35 & 521.44 & 23.91 \\
\hline
\end{tabular}

The incorporation of glycerol into the CS/PVA membranes resulted in a remarkable increase in the peak temperature of the first mass-loss stage in the DTG curve. As commented before, this stage can be associated to the release of the bound water. This observation can be correlated to the plasticising effect and chemical reaction with glycerol. The low molar mass molecules of glycerol may have modified the three-dimensional organization of the polymer matrix, occupying the free available volume and strongly interacting with the CS and PVA macromolecules through hydrogen bonding [37]. As a result, a more compact and stronger structure may have resulted in higher bound water release temperature. As well, the mass-loss contribution to this stage decreased as PVA and glycerol content increased in the membranes, which corroborates that strong interaction and lower humidity released content.

Another remarkable perception was the last decomposition stage, between 500 and $600{ }^{\circ} \mathrm{C}$. The peak temperature of the DTG curve considerably decreased with the increase of crosslinked PVA. It could be expected that the membranes with higher concentration of SSA would show better thermal stability than those with lower concentration due to the crosslinking effect. However, the results showed the opposite trend, which was ascribed to the fact that the elimination reactions of the hydroxyl groups under acidic conditions are catalysed [38]. Moreover, the lower amount of hydroxyl groups in the membranes with higher crosslinking degree may have reduced the hydrogen bonding interactions between the 
polymer chains responsible for the structure stabilisation. Therefore, the thermo-oxidative stability was not only controlled by the catalytic effect of the acidic groups contained in the membranes, but also by the hydrogen bonding interactions between the polymer chains.

\subsection{Ethanol solution uptake behaviour}

The ethanol uptake behaviour was studied by means of sorption measurements at $40{ }^{\circ} \mathrm{C}$ into a $2 \mathrm{M}$ ethanol aqueous solution. Figure 3 shows the uptake profiles obtained as a function of the immersion time.
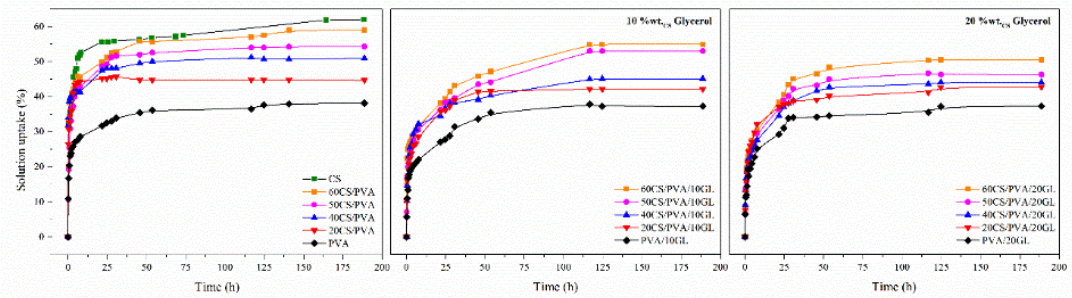

Figure 3. $2 \mathrm{M}$ ethanol aqueous solution uptake profiles of the CS/PVA-based membranes as a function of time. Standard deviation between 1 and $5 \%$ omitted for the sake of clarity.

The equilibrium ethanol uptake was found in a range between $35 \%$ and $60 \%$ for crosslinked CS/PVA membranes, essential for their application as fuel cell membranes due to the promotion of the vehicular proton transport mechanism [39]-[41]. Furthermore, no deformations in the membrane samples were observed, corroborating the stabilising effect of the crosslinking reaction. The Table 4 gathers the values of the solvent absorbed at the equilibrium point $\left(M_{e q}\right)$, estimated from the experimental swelling curves.

The uptake ability strongly depended on the CS:PVA ratio. In general, the solvent absorption increased with the increase of the percentage of CS. This is attributed to the high water affinity of chitosan molecules and the lower degree of crosslinking, which made the membranes less rigid and increased its swelling ability.

The membranes containing glycerol showed a decrease of the water uptake, due to its plasticising effect that can close the micro-voids in the film and gives rise to a more compact structure, and due to the chemical interaction of glycerol with CS and SSA, which reduces the available sites for hydrogen bonding [42]. These results are in agreement with the observations perceived during the analysis of the FT-IR spectra and the thermo-oxidative decomposition profiles, in which the addition of glycerol was found to have reduced the humidity content of the membranes. 
Moreover, a normalisation of the solution absorption between 0 and 1 was carried out for a better comparison of the saturation rates between the materials, which results are plotted in Figure 4. As well, the diffusion coefficient $(D)$ was calculated, which results are gathered in Table 4. As perceived in the normalised profiles and corroborated by $D$, the composition of the membrane significantly influenced the solution uptake rate. Regardless the CS:PVA ration and the presence of glycerol in the membranes, the blends showed in all cases a higher $D$ than neat CS or crosslinked PVA, which points out the synergistic effect of blending in terms of diffusion. The highest absorption rates were obtained for the 40:60 CS:PVA composition, independently of the amount of glycerol. This behaviour could be correlated to the high affinity of both materials to water, although the compact crosslinked structure resulted in intermediate $M_{e q}$.
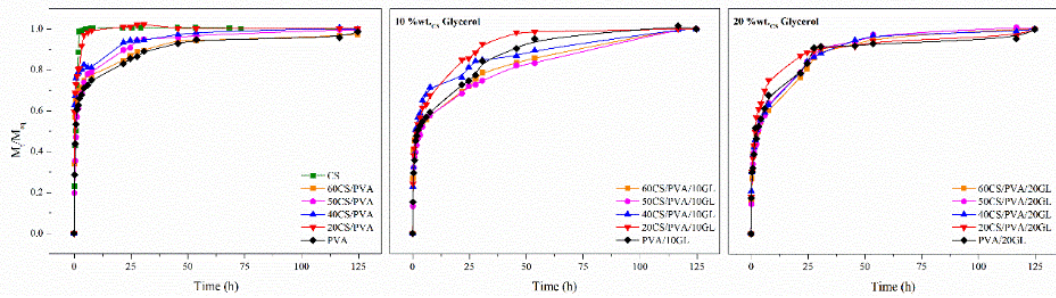

Figure 4. Normalised profiles of the $2 \mathrm{M}$ ethanol aqueous solution uptake of the CS/PVA-based membranes as a function of time.

Table 4. Equilibrium solution uptake $\left(M_{e q}\right)$ and diffusion coefficient $(D)$ for the CS/PVA-based membranes.

\begin{tabular}{|c|c|c|c|}
\hline $\begin{array}{l}\text { Glycerol } \\
\text { (\%wt. cs) }\end{array}$ & $\begin{array}{c}\text { CS:PVA } \\
\text { weight ratio }\end{array}$ & $\begin{array}{l}M_{e q} \\
(\%)\end{array}$ & $\begin{array}{c}D \cdot 10^{10} \\
\left(\mathrm{~cm}^{2} \cdot \mathrm{s}^{-1}\right)\end{array}$ \\
\hline \multirow{6}{*}{ - } & 100:0 & 62.08 & 0.30 \\
\hline & $60: 40$ & 59.31 & 1.13 \\
\hline & $50: 50$ & 54.29 & 1.35 \\
\hline & $40: 60$ & 50.96 & 3.62 \\
\hline & $20: 80$ & 44.70 & 3.59 \\
\hline & $0: 100$ & 38.29 & 1.24 \\
\hline \multirow{5}{*}{10} & 60:40 & 54.92 & 0.42 \\
\hline & $50: 50$ & 53.05 & 0.24 \\
\hline & $40: 60$ & 45.14 & 0.69 \\
\hline & $20: 80$ & 42.17 & 0.23 \\
\hline & $0: 100$ & 37.25 & 0.22 \\
\hline \multirow{5}{*}{20} & $60: 40$ & 50.49 & 0.13 \\
\hline & $50: 50$ & 46.32 & 0.18 \\
\hline & $40: 60$ & 44.10 & 0.62 \\
\hline & $20: 80$ & 42.74 & 0.56 \\
\hline & $0: 100$ & 37.29 & 0.28 \\
\hline
\end{tabular}

The increase in the percentage of glycerol content in the membranes resulted in a remarkable reduction of the diffusion coefficient. As 
suggested before, a part from reducing the water absorption capability of the membranes, it was verified that the above-mentioned strong interaction within CS and PVA, resulted in a slow solution absorption rate, which is beneficial for a progressive swelling behaviour that prevents the membrane from excessive dimensional changes in a short time.

\subsection{Electric and proton conductivity}

The electric conductivity $\left(\sigma_{\text {elec }}\right)$ and proton conductivity $\left(\sigma_{\text {prot }}\right)$ of the polyelectrolyte membranes are some of the most important parameters to validate their suitability for fuel cell applications. These properties were assessed by means of a dielectric thermal analyser (DETA) at $25{ }^{\circ} \mathrm{C}$ through a single sweep procedure in a wide frequency range from $10^{-2}$ to $10^{7} \mathrm{~Hz}$.

Given the intrinsic design of the proton exchange fuel cells, the electrical conductivity through the membranes should be avoided and, subsequently, high electrical resistance is required to promote the electronic flux in the external circuit. The electric conductivity $\left(\sigma_{\text {elec }}\right)$ was considered at low frequencies, where the measured real part of the conductivity $\left(\sigma^{\prime}\right)$ reaches a plateau that is correlated to the DC conductivity $\left(\sigma_{0}\right)$, as shown in Figure 5. The obtained values are gathered in Table 5. In general, the $\sigma_{\text {elec }}$ was found around $10^{-8} \mathrm{~S} \cdot \mathrm{cm}^{-1}$ for all the developed membranes, regardless the CS:PVA ratio or the amount of glycerol, which corroborated their insulator feature, required for fuel cell applications [43]. 


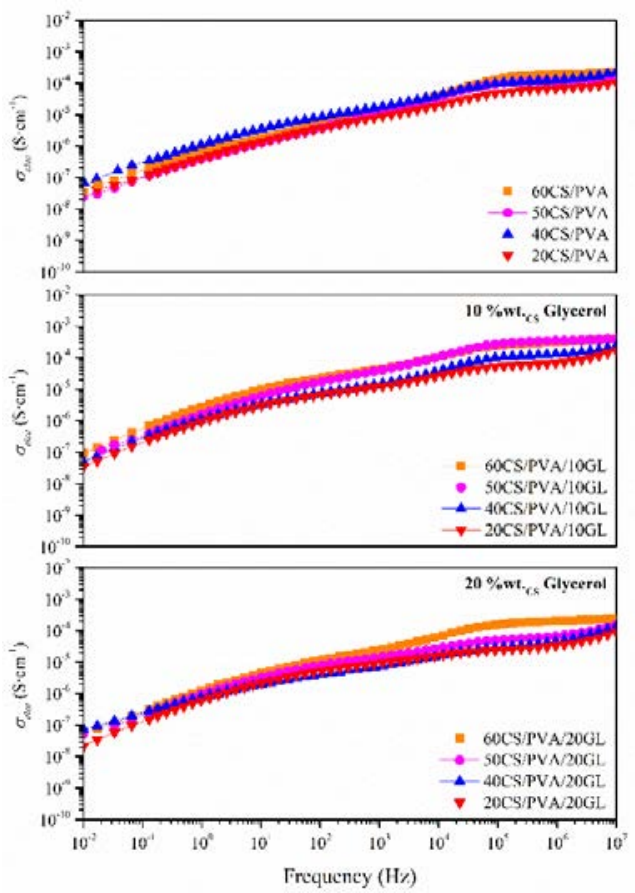

Figure 5. Electric conductivity $\left(\sigma_{\text {elec }}\right)$ as a function of frequency of CS/PVA-based membranes.

The proton conductivity $\left(\sigma_{p r o t}\right)$ was assessed from the Bode diagrams, which were obtained from the impedance measurements at room temperature for the pre-hydrated CS/PVA membranes. The resulting diagrams are plotted in Figure $\mathbf{6}$ and the calculated $\sigma_{\text {prot }}$ values are gathered in Table 5. Despite improved behaviour of the blended CS/PVA membranes, the obtained values were lower to that of the Nafion ${ }^{\circledR}$ membrane (6 mS $\mathrm{cm}^{-1}$ at $25{ }^{\circ} \mathrm{C}$ [15]). However, the results of the performance in the DEFC test shown in next section are relevant enough to continue investigating in the development of membranes based on crosslinked CS/PVA.

The CS/PVA blending strategy, along with the crosslinking reaction with SSA, improved the proton conductivity of the membranes. The sulfonic acid groups $\left(-\mathrm{SO}_{3} \mathrm{H}\right)$ of the crosslinked membranes can be dissociated under hydrated conditions and act as proton carriers. The values of proton conductivity obtained for all CS/PVA were higher in relation to those of the pure CS and PVA films of $3.05 \cdot 10^{-3}$ and $0.250 \mathrm{mS} \cdot \mathrm{cm}^{-1}$, respectively. This synergetic improvement gave rise to an equilibrated water absorption and retention ability, enabling easy proton transfer [27]. The highest value of proton conductivity was achieved for the 40CS/PVA film $\left(0.735 \mathrm{mS} \cdot \mathrm{cm}^{-}\right.$ 
${ }^{1}$ ), showing a significant improvement if compared to the neat CS and crosslinked PVA membranes.

As expected, when glycerol was added to the CS/PVA, a decrease in the proton conductivity was perceived. This trend was in close relation to the ethanol solution uptake measurements, which confirmed the essential relationship between the proton conductivity and the ability of the membranes to retain liquids.

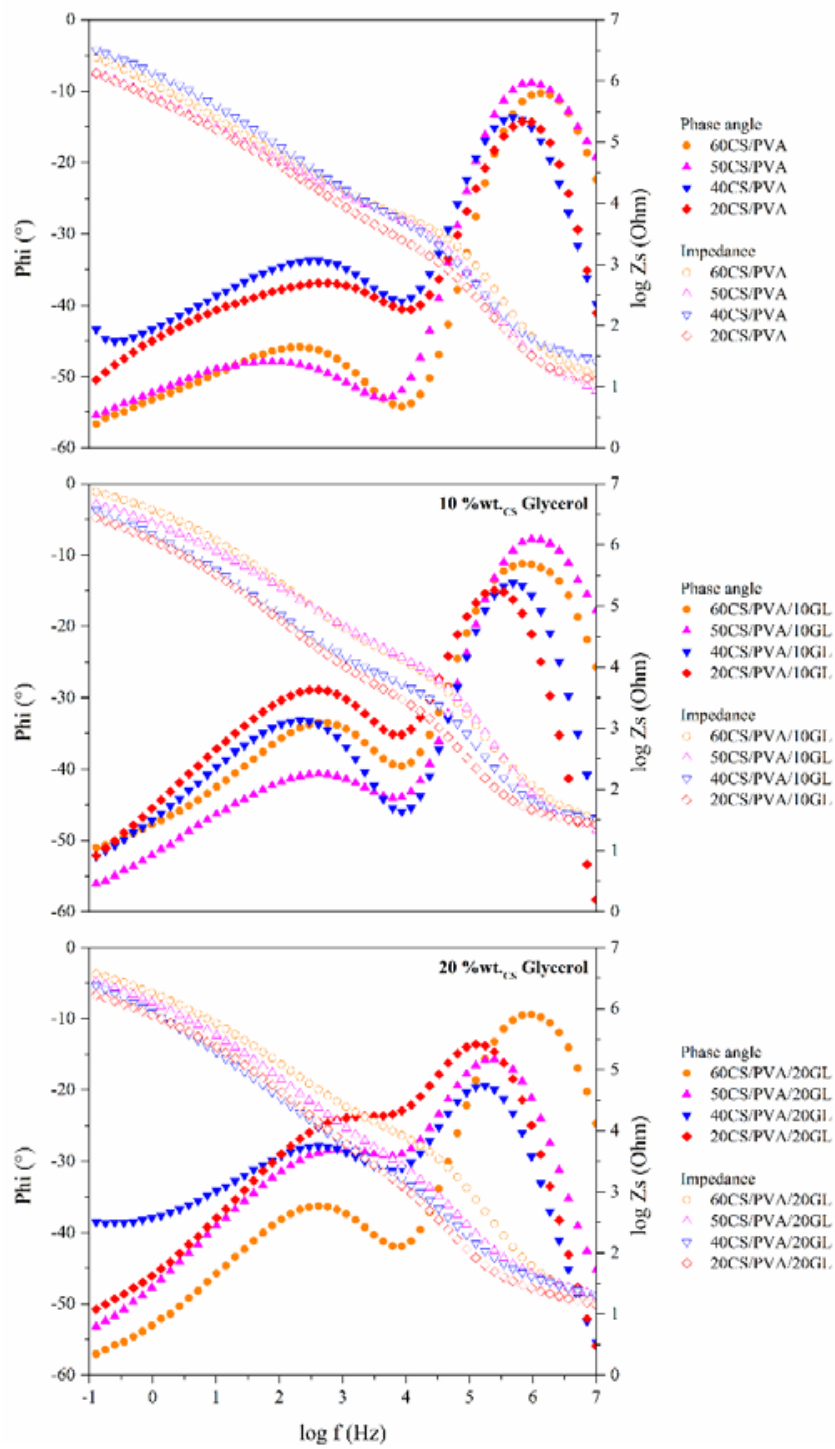

Figure 6. Bode diagram of the pre-hydrated CS/PVA membranes. 
Table 5. Proton conductivity ( $\left.\sigma_{p r o t}\right)$ and electric conductivity $\left(\sigma_{e l e c}\right)$ for the prehydrated CS/PVA membranes.

\begin{tabular}{|c|c|c|c|}
\hline $\begin{array}{l}\text { Glycerol } \\
\text { (\%wt.cs) }\end{array}$ & $\begin{array}{c}\text { CS:PVA } \\
\text { weight ratio }\end{array}$ & $\begin{array}{l}\sigma_{\text {elec }} \cdot 10^{8} \\
\left(\mathrm{~S} \cdot \mathrm{cm}^{-1}\right)\end{array}$ & $\begin{array}{c}\sigma_{\text {prot }} \\
\left(\mathrm{mS}^{\prime} \cdot \mathbf{c m}^{-1}\right)\end{array}$ \\
\hline \multirow{4}{*}{ - } & $60: 40$ & 5.36 & 0.246 \\
\hline & $50: 50$ & 2.50 & 0.225 \\
\hline & 40:60 & 6.85 & 0.735 \\
\hline & $20: 80$ & 3.65 & 0.285 \\
\hline \multirow{4}{*}{10} & $60: 40$ & 9.07 & 0.112 \\
\hline & 50:50 & 5.84 & 0.118 \\
\hline & $40: 60$ & 5.01 & 0.151 \\
\hline & $20: 80$ & 3.45 & 0.106 \\
\hline \multirow{4}{*}{20} & 60:40 & 3.98 & 0.186 \\
\hline & $50: 50$ & 5.24 & 0.120 \\
\hline & $40: 60$ & 7.25 & 0.189 \\
\hline & 20:80 & 2.17 & 0.190 \\
\hline
\end{tabular}

\subsection{Direct ethanol fuel cell (DEFC) test}

The performance of the crosslinked and plasticised CS/PVA membranes was evaluated in a direct ethanol fuel cell (DEFC) at $20^{\circ} \mathrm{C}$ and $2 \mathrm{M}$ ethanol as fuel. Among all the prepared membranes, the 40CS/PVA and 20CS/PVA plasticised films were specially selected for the DEFC test as a proof of concept. These membranes offered the most appropriate balance of flexibility and manageability to mount them onto the electrode assembly (MEA) without generating fragile cracks, uniform surface to ensure homogenous conductive behaviour, and reasonable values of absorption, high diffusion coefficient and proton conductivity.

The polarisation curves of the CS/PVA/GL membranes in a DEFC were compared to those of the Nafion ${ }^{\circledR} 117$, measured at the same operating conditions, as shown in Figure 7. The values of maximum power density $\left(P_{\max }\right)$ obtained are summarized in Table 6. According to the results, the power density is strongly influenced by both the CS/PVA ratio and the percentage of glycerol. The higher the presence of chitosan and the higher the proportion of glycerol was in the membrane, the closer to the behaviour of Nafion ${ }^{\circledR} 117$ was that of the CS/PVA membranes in the DEFC, being quite similar at low intensities. In particular, promising results were found for the 40CS/PVA/20GL, with a value of $P_{\max }$ of $746.79 \mathrm{~mW}$. 

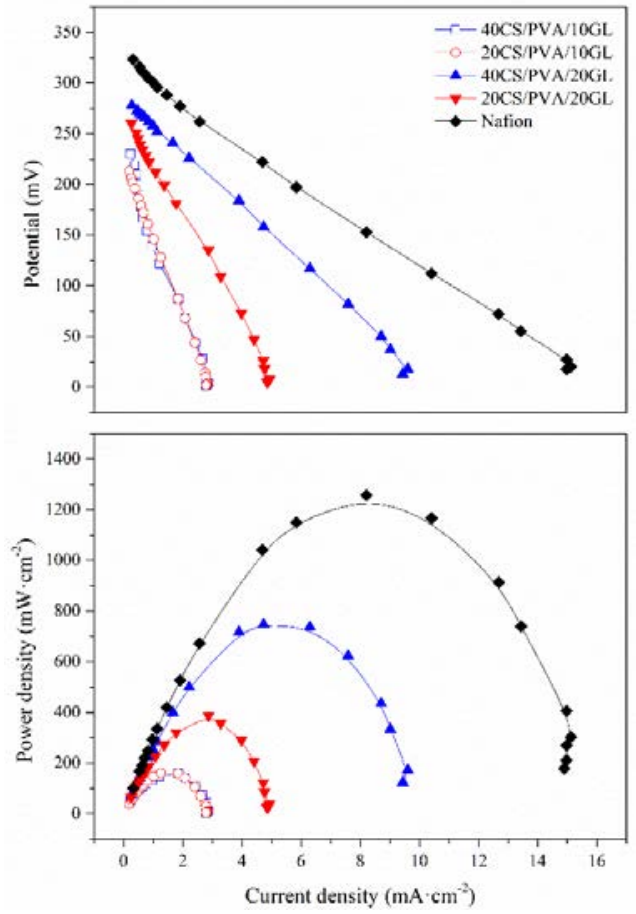

Figure 7. DEFC polarisation curves of the CS/PVA membranes, in comparison to that of Nafion ${ }^{\circledR} 117$, measured at $20^{\circ} \mathrm{C}$ and $2 \mathrm{M}$ ethanol as fuel.

Table 6. Maximum power density $\left(P_{\max }\right)$ of the 40:60 and 20:80 CS/PVA membranes, measured at $20^{\circ} \mathrm{C}$ and $2 \mathrm{M}$ ethanol as fuel.

\begin{tabular}{ccc}
\hline $\begin{array}{c}\text { Glycerol } \\
\text { (\%wt.cs) }\end{array}$ & $\begin{array}{c}\text { CS:PVA } \\
\text { weight ratio }\end{array}$ & $\begin{array}{c}\boldsymbol{P}_{\max } \\
\text { (mW) }\end{array}$ \\
\hline \multirow{2}{*}{$\mathbf{1 0}$} & $\mathbf{2 0 : 8 0}$ & 140.76 \\
\hline \multirow{2}{*}{$\mathbf{2 0}$} & $\mathbf{4 0 : 6 0}$ & 160.82 \\
\hline & $\mathbf{2 0 : 8 0}$ & 386.98 \\
\hline
\end{tabular}

\section{Conclusions}

Functionalised chitosan/poly(vinyl alcohol) CS/PVA-based membranes were successfully obtained by means of the combination with sulfosuccinic acid (SSA) as crosslinking and sulfonating agent, and glycerol (GL) to promote flexibility to favour the manageability of the membranes. The combination of solvent-casting and thermal-crosslinking permitted to obtain homogeneous membranes with controlled morphology.

In general terms, all CS/PVA membranes showed a synergetic increase of thermal stabilities, absorption and diffusion of ethanol and proton conductivity, in contrast to those of neat CS or crosslinked PVA. The 
ranges of thermal stability -far above $60^{\circ} \mathrm{C}$-, the electrical insulating behaviour -around $10^{-8} \mathrm{~S} \cdot \mathrm{cm}^{-1}$, and the ethanol absorption capabilities between $35 \%$ and $60 \%$-, were appropriate to be used in typical service conditions of fuel cells.

The increase of CS in the CS/PVA membranes resulted in higher ethanol absorption capability, and showed maxima of diffusion coefficient and proton conductivity for membranes with a 20 and $40 \%$ wt. of CS.

The incorporation of GL in the CS/PVA membranes reacted with SSA, reducing the ethanol absorption, diffusion coefficient and proton conductivity, but in turn acted as a plasticiser that increase the ductile manageability of membranes to be mounted on MEAs, reducing the probabilities of fragile breakage.

The membrane 40CS/PVA/20GL, which contained a $40 \%$ wt. of CS referred to PVA, and a $20 \%$ wt. of GL referred to CS, showed the best behaviour in the DEFC test, with a value of $P_{\max }$ of $746.79 \mathrm{~mW}$. The higher the presence of chitosan and the higher the proportion of glycerol was in the membrane, the closer to the behaviour of Nafion ${ }^{\circledR} 117$ was in the DEFC, showing similar profiles at low intensities. In this sense, the research to increase the proton conductivity and power of biopolymerbased membranes such as that of CS/PVA, which are, inexpensive, nonhazardous, and environmentally benign, can represent a challenging but feasible alternative to current polyelectrolytes for fuel cells.

\section{Acknowledgements}

The Spanish Ministry of Economy, Industry and Competitiveness is acknowledged for the projects ENE2017-86711-C3-1-R, ENE201453734-C2-1-R and UPOV13-3E-1947. The Spanish Ministry of Education, Culture and Sports is thanked for the pre-doctoral FPU grant for O. GilCastell (FPU13/01916).

\section{References}

[1] N. Shaari and S. K. Kamarudin, "Chitosan and alginate types of bio-membrane in fuel cell application: An overview,” J. Power Sources, vol. 289, pp. 71-80, 2015.

[2] H. Vaghari, H. Jafarizadeh-Malmiri, A. Berenjian, and N. Anarjan, "Recent advances in application of chitosan in fuel cells,” Sustain. Chem. Process., vol. 1, no. 1, p. 16, 2013.

[3] K. Pourzare, Y. Mansourpanah, and S. Farhadi, "Advanced nanocomposite membranes for fuel cell applications: a comprehensive review,” Biofuel Res. J., vol. 3, no. 4, pp. 496-513, 2016.

[4] J. D. Badia, O. Gil-Castell, and A. Ribes-Greus, "Long-term properties and end-of-life of polymers from renewable resources,” Polym. Degrad. Stab., vol. 137, pp. 35-57, 2017.

[5] J. Ma and Y. Sahai, "Chitosan biopolymer for fuel cell applications," Carbohydr. Polym., vol. 92, no. 2, pp. 955-975, 2013.

[6] C. Author, H. Jafarizadeh Malmiri, M. Ali Ghaz Jahanian, and A. Berenjian, "Potential Applications of Chitosan Nanoparticles as Novel Support in Enzyme Immobilization,” 
Am. J. Biochem. Biotechnol., vol. 8203219, no. 84, pp. 203-219, 2012.

[7] T. Chakrabarty, M. Kumar, and V. Shahi, "Chitosan Based Membranes for Separation, Pervaporation and Fuel Cell Applications: Recent Developments,” Biopolymers, pp. 58, Sep. 2010.

[8] V. Zargar, M. Asghari, and A. Dashti, "A Review on Chitin and Chitosan Polymers: Structure, Chemistry, Solubility, Derivatives, and Applications.”

[9] P. Mukoma, B. R. Jooste, and H. C. M. Vosloo, “A comparison of methanol permeability in Chitosan and Nafion 117 membranes at high to medium methanol concentrations," $J$. Memb. Sci., vol. 243, no. 1-2, pp. 293-299, Nov. 2004.

[10] P. Mukoma, B. R. Jooste, and H. C. M. Vosloo, "Synthesis and characterization of crosslinked chitosan membranes for application as alternative proton exchange membrane materials in fuel cells,” J. Power Sources, vol. 136, no. 1, pp. 16-23, Sep. 2004.

[11] Q. A. L. X. Z. X. H. C. Ma B., "Structure and properties of chitin whisker reinforced chitosan membranes,” Int. J. Biol. Macromol., vol. 64, pp. 341-346, 2014.

[12] E. Dashtimoghadam, M. M. Hasani-Sadrabadi, and H. Moaddel, "Structural modification of chitosan biopolymer as a novel polyelectrolyte membrane for green power generation,” Polym. Adv. Technol., vol. 21, no. 10, pp. 726-734, Jun. 2010.

[13] B. Smitha, S. Sridhar, and A. A. Khan, "Polyelectrolyte complexes of chitosan and poly(acrylic acid) as proton exchange membranes for fuel cells,” Macromolecules, vol. 37, no. 6, pp. 2233-2239, 2004.

[14] B. Smitha, S. Sridhar, and A. A. Khan, "Synthesis and characterization of poly(vinyl alcohol)-based membranes for direct methanol fuel cell,” J. Appl. Polym. Sci., vol. 95, no. 5, pp. 1154-1163, Mar. 2005.

[15] S. Meenakshi, S. D. Bhat, A. K. Sahu, P. Sridhar, S. Pitchumani, and A. K. Shukla, "Chitosan-polyvinyl alcohol-sulfonated polyethersulfone mixed-matrix membranes as methanol-barrier electrolytes for DMFCs,” J. Appl. Polym. Sci., vol. 124, no. SUPPL. 1, pp. E73-E82, Jun. 2012.

[16] A. C. Dupuis, "Proton exchange membranes for fuel cells operated at medium temperatures: Materials and experimental techniques,” Prog. Mater. Sci., vol. 56, no. 3, pp. 289-327, 2011.

[17] K. Lewandowska, "Miscibility and thermal stability of poly(vinyl alcohol)/chitosan mixtures,” Thermochim. Acta, vol. 493, no. 1, pp. 42-48, 2009.

[18] M. H. Buraidah and A. K. Arof, "Characterization of chitosan/PVA blended electrolyte doped with NH4I,” J. Non. Cryst. Solids, vol. 357, no. 16-17, pp. 3261-3266, 2011.

[19] S. K. Saxena, "POLYVINYL ALCOHOL (PVA) Chemical and Technical Assessment (CTA) First draft prepared,” Chem. Tech. Assess., vol. 61, no. 13.

[20] R. O. C. W.-Y. Chiang, Department of Chemical Engineering, Tatung Institute of Technology, 40 Chungshan N. Rd., 3rd Sec., Taipei 10451, Taiwan, Separation of water-alcohol mixture by using polymer membranes. Elsevier Science Pub. Co.

[21] B. S. Pivovar, Y. X. Wang, and E. L. Cussler, "Pervaporation membranes in direct methanol fuel cells,” J. Memb. Sci., vol. 154, no. 2, pp. 155-162, 1999.

[22] Y.-S. Ye, J. Rick, and B.-J. Hwang, "Water Soluble Polymers as Proton Exchange Membranes for Fuel Cells,” Polymers (Basel)., vol. 4, no. 4, pp. 913-963, Mar. 2012.

[23] S. J. Peighambardoust, S. Rowshanzamir, and M. Amjadi, Review of the proton exchange membranes for fuel cell applications, vol. 35, no. 17. Elsevier Ltd, 2010.

[24] A. R. D. Galindo Alfaro, J. Badia Valiente, "UPV TFM, Sulfonación e incorporación de óxido de grafeno a membranas electrohiladas basadas en poli ( vinil alcohol ),” 2017.

[25] N. C. Mat and A. Liong, "Chitosan-poly (vinyl alcohol) and calcium oxide composite membrane for direct methanol fuel cell applications,” Eng. Lett., vol. 17, no. 4, 2009.

[26] J. Ming Yang and H. Chih Chiu, "Preparation and characterization of polyvinyl alcohol/chitosan blended membrane for alkaline direct methanol fuel cells," J. Memb. Sci., vol. 419-420, pp. 65-71, 2012.

[27] V. V. Binsu, R. K. Nagarale, V. K. Shahi, and P. K. Ghosh, "Studies on N-methylene phosphonic chitosan/poly(vinyl alcohol) composite proton-exchange membrane," React. Funct. Polym., vol. 66, no. 12, pp. 1619-1629, Dec. 2006.

[28] P. Neogi, Diffusion in Polymers. Marcel Dekker, 1996.

[29] X. Qian, N. Gu, Z. Cheng, X. Yang, E. Wang, and S. Dong, "Methods to study the ionic conductivity of polymeric electrolytes using a.c. impedance spectroscopy,” J. Solid State 
Electrochem., vol. 6, no. 1, pp. 8-15, 2001.

[30] C. Pradal, P. Kithva, D. Martin, M. Trau, and L. Grøndahl, "Improvement of the wet tensile properties of nanostructured hydroxyapatite and chitosan biocomposite films through hydrophobic modification.”

[31] B. Ma, X. Li, A. Qin, and C. He, “A comparative study on the chitosan membranes prepared from glycine hydrochloride and acetic acid,” Carbohydr. Polym., vol. 91, pp. 477-482, 2013.

[32] A. A. M. S. Boroglu, S. Cavus, I. Boz, "Synthesis and characterization of poly(vinyl alcohol) proton exchange membranes modified with 4,4-diaminodiphenylether-2,2disulfonic acid.”

[33] S. C. M. Fernandes, C. S. R. Freire, A. J. D. Silvestre, C. Pascoal Neto, A. Gandini, L. A. Berglund, and L. Salmén, "Transparent chitosan films reinforced with a high content of nanofibrillated cellulose,” Carbohydr. Polym., vol. 81, no. 2, pp. 394-401, Jun. 2010.

[34] S. C. M. Fernandes, L. Oliveira, C. S. R. Freire, A. J. D. Silvestre, C. P. Neto, A. Gandini, and J. Desbriéres, "Novel transparent nanocomposite films based on chitosan and bacterial cellulose,” Green Chem., vol. 11, no. 12, p. 2023, Dec. 2009.

[35] A. R.-G. A. Martınez-Felipe, C. Moliner-Estopinan, C. T. Imrie, "Characterization of Crosslinked Poly(vinyl alcohol)-Based Membranes with Different Hydrolysis Degrees for Their Use as Electrolytes in Direct Methanol Fuel Cells,” Polym. Polym. Compos., vol. 21, no. 7, pp. 449-456, 2013.

[36] A. Gómez-Siurana, A. Marcilla, M. Beltrán, D. Berenguer, I. Martínez-Castellanos, and S. Menargues, "TGA/FTIR study of tobacco and glycerol-tobacco mixtures," Thermochim. Acta, vol. 573, pp. 146-157, Dec. 2013.

[37] M. Mohsin, A. Hossin, and Y. Haik, "Thermal and Mechanical Properties of Poly(vinyl alcohol) Plasticized with Glycerol,” J Appl Polym Sci, vol. 122, pp. 3102-3109, 2011.

[38] J. M. Morancho, J. M. Salla, A. Cadenato, X. Fernández-Francos, X. Ramis, P. Colomer, Y. Calventus, and R. Ruíz, "Kinetic studies of the degradation of poly(vinyl alcohol)based proton-conducting membranes at low temperatures,” Thermochim. Acta, vol. 521, no. 1-2, pp. 139-147, 2011.

[39] E. Bakangura, L. Wu, L. Ge, Z. Yang, and T. Xu, "Mixed matrix proton exchange membranes for fuel cells: state of the art and perspectives Mixed matrix proton exchange membranes for fuel cells: state of the art and perspectives,” Prog. Polym. Sci., vol. 57, pp. 103-152, Jun. 2015.

[40] J. Zhang, J. Wu, and H. Zhang, PEM Fuel Cell Testing and Diagnosis. Elsevier Science, 2013.

[41] B. Emonts, L. Blum, T. Grube, W. Lehnert, J. Mergel, M. Müller, and R. Peters, “Technical Advancement of Fuel-Cell Research and Development," in Fuel Cell Science and Engineering, Weinheim, Germany: Wiley-VCH Verlag GmbH \& Co. KGaA, 2012, pp. $1-42$.

[42] L. O. dos S. Melissa Gurgel Adeodato Vieira, Mariana Altenhofen da Silva and Marisa Masumi Beppu, "Natural-based plasticizers and biopolymer films: A review."

[43] I. Shabani, M. M. Hasani-Sadrabadi, V. Haddadi-Asl, and M. Soleimani, "Nanofiberbased polyelectrolytes as novel membranes for fuel cell applications,” J. Memb. Sci., vol. 368, no. 1-2, pp. 233-240, Feb. 2011. 


\section{CHAPTER 5.}

Scaffolds for tissue

\section{engineering}




\subsection{TISSUE ENGINEERING}

The tissue engineering field involves the combination of cells, engineering and materials to improve or replace damaged tissues. Indeed, it can be considered as a multidisciplinary field, in which materials engineering, biology and medicine share some of their knowledge areas, as schematised in Figure 5.1. As an interdisciplinary technique, tissue engineering considers the use of three basic components such as cells, substrates and biomolecules to develop bio-functional substitutes for restoring and maintenance of tissue functions. Certainly, tissue engineering requires considerable biological contribution to understand the cells behaviour during culture in vitro and after implantation in vivo. Moreover, it requires broad engineering expertise to produce and process materials for appropriate tissue regeneration [1].

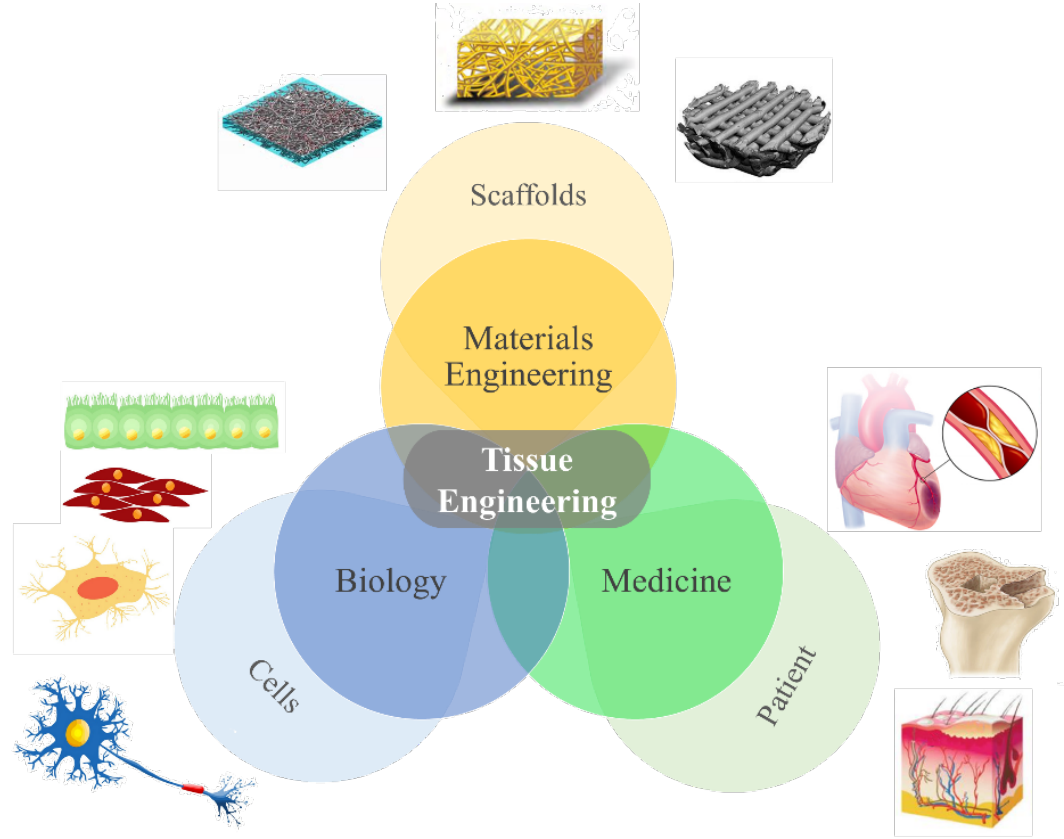

Figure 5.1. Tissue engineering as a multidisciplinary field.

As stated by Langer and Vacanti, tissue engineering is "an interdisciplinary field that applies the principles of engineering and life sciences toward the development of biological substitutes that restore, maintain, or improve the biological tissue function or a whole organ" [2]. Tissue engineering has also been defined by MacArthur and Oreffo as "understanding the 
principles of tissue growth, and applying this to produce functional replacement tissue for clinical use” [3].

In general, the target of the tissue engineering field is closely related to applications in the bone, cartilage, muscle, skin or nerve tissues. In this sense, great advances have been yielded in the development of new implementation strategies. Novel biomaterials, processing techniques, cells, differentiation factors and validation procedures have been proposed along the last decade.

One of the most promising research advances are the engineered extracellular matrices also known as scaffolds, which have been proposed as an effective alternative for cell culture, proliferation, subsequent differentiation and ultimately tissue morphogenesis [4]. In this sense, artificial scaffolds simulate the natural extra-cellular matrix (ECM) that is usually described as a nanofibrous mat, composed of randomly oriented fibrils with subcellular diameters, ranging from several tends to hundreds of nanometers [5]. The human ECM is a dynamic and hierarchically organised structure synthesised by the adjacent cells composed of polysaccharides and proteins, that mechanically and chemically interacts and regulate the architecture of the tissues [6]. In this complex structure, proteins such as collagen fibres act as structural agents and provide signals for cell attaching. The diffusion of nutrients, metabolites and signalling molecules takes place through the extracellular space filled with a hydrated gel, composed of proteoglycans and other proteins [7].

Tissue engineering scaffolds need to provide a reproducible threedimensional cellular microenvironment with a highly porous architecture and suitable surface chemistry to support cell attachment, proliferation and natural ECM production. An ideal scaffold should closely mimic the structural and functional properties of the materials found in the native ECM of a given tissue, until host cells can repopulate and resynthesize a new natural matrix. As well, the scaffolds should possess appropriate mechanical properties similar to those of the damaged tissue and be biocompatible and biodegradable with controllable degradation kinetics. They must retain structural integrity and stability when the specialist handles and implants it into the defect site of the host. After surgery, the structure at the implant site must provide sufficient biomechanical support during the process of tissue regeneration and structure degradation [1].

The accomplishment of the simulated structural features and architecture by the scaffolds will determine their success during cell culture. Moreover, the scaffold should act as a template for the neovascularisation of the regenerated tissue and actively participate in the regeneration process through the release of growth or differentiation factors [8]. These physical and chemical signals intrinsic of the natural occurring ECM, may be 
implemented into artificial tissue engineering scaffolds for a successful simulation of the cell environment that mimic specific biological functions in cellular processes. In this sense, biomaterials play a crucial role in the development of new functionalised scaffolds for the regenerative medicine and may be considered for tailoring the cellular behaviour and promote the desired function for the regeneration of a given tissue. In summary, the essential requirements for an optimum scaffold design are proper biocompatibility, porosity, mechanical stability and biodegradability [9].

In order to optimise scaffolds for tissue engineering, all the required features need to be balanced to guide proper tissue regeneration. While the composition and surface chemistry of the scaffolds will determine the initial cell attach, the morphology of the scaffold plays a key role in controlling their ability to migrate. Besides allowing cell penetration, a proper architecture of the scaffold will allow nutrients and oxygen to flow into the inner part as well as to remove waste produced by the cells to increase cell survival and hence to regenerate tissue [10]. Moreover, enough porosity will not only permit to allocate cells, but also allow cell migration to the inner part through the different pores. All these properties need to be well-adjusted with the degradation of the scaffold. Indeed, the scaffold should ideally degrade at the same time as new natural tissue is being formed, which growth may be stimulated by the biomaterial. These basic features can be accomplished by the use of natural or synthetic materials, usually degradable biopolymers, which may fulfil the abovementioned requirements.

The processing of scaffolds for tissue engineering is an essential aspect that would subsequently determine the features and effectiveness of these devices when in contact with cells. Conventional techniques such as fibre extrusion, fibre bonding, gas foaming, template synthesis, membrane lamination, melt spinning, solvent-casting with particulate leaching or phase separation have been used for scaffold fabrication [11]. However, there is a growing interest in the development of highly porous scaffolds, based on the electrospinning process.

Among the several types of scaffolds proposed for tissue engineering, electrospun nanofibres seem to have specific advantageous properties. Indeed, electrospun scaffolds consists of nanofibrous structures with high surface area-to-volume ratio and diameters between 50 and $1000 \mathrm{~nm}$ that can provide the suitable environment for cell attachment, proliferation and differentiation, being a promising alternative for the tissue engineering field [12]. Electrospinning is a versatile technique that allows the preparation of nanofibres based in homopolymers, copolymers, blends of polymers or composites, along with other substances and additives to obtain functionalised scaffolds [13]. 
The development of more complex functionality, as well as both functional and biomechanical stability during the in vitro cell culture and subsequent in vivo transplantation are among the main challenges to overcome by tissue engineering. In this sense, the appropriate selection of the material for the scaffold fabrication is crucial for a suitable application. Biomaterials are defined as any natural or synthetic substances engineered to interact with biological systems with an appropriate host response. For scaffold development, natural occurring biomaterials such as collagen, hyaluronic acid, alginate or chitosan, among others, have been considered as suitable candidates to simulate the native cellular environment. However, the large variation between batches upon isolation from biological tissues and the restricted versatility in the design of cell culture devices with specific biomechanical properties have prevented them from an extended use as solely materials for scaffold development [14]. In this sense, synthetic polymers have been appointed as a promising alternative biomaterials that offer greater control over the design and tailoring of suitable physico-chemical properties of the scaffolds for biomedical applications [9]. The advantages of natural and synthetic polymers may provide interesting solutions in the tissue engineering field. 


\subsection{POLYMER-BASED FUNCTIONALISED SCAFFOLDS}

Polymeric materials outstand as promising candidates for scaffold development, due to their intrinsic capacity to be tailored that promote unique material properties [12]. Indeed, the host response to tissue engineering scaffolds strongly depends on the chemical, physical and biological properties of these materials [15].

Regarding the design of polymeric biodegradable biomaterials, some considerations must be bore in mind [16]. They must have appropriate mechanical properties and adequate permeability and processability for biomedical applications. Moreover, once implanted, they must not evoke a sustained inflammatory response, possess a proportional degradation time to their function and produce non-toxic degradation by-products that can be resorbed or excreted by the organism. In general, these desired properties strongly depend on the material chemistry, molar mass, hydrophilicity, and degradation and erosion mechanism, among others.

In the first stages of the development of tissue engineering, adaptations of commodity plastics such as polyethylene, polyurethane and silicone rubbers were considered. However, due to their intrinsic nonbiodegradability, scaffolds composed of these materials remained into the organism after implantation and tissue regeneration as a permanent implant [1]. These artificial scaffolds showed poor biocompatibility as well as may trigger the foreign body reaction that turned into chronic inflammation after long periods, which resulted in failure and rejection. For this reason, biodegradable polymeric biomaterials that could be resorbed after implantation have risen as the adequate alternative for scaffold development [17]. These materials are considered as hydrolytically degradable polymers that possess labile chemical bonds in their backbone that can be hydrolysed and broken down in smaller polymeric chains or low molar mass molecules. As a consequence of hydrolytic degradation, the broken bond results in two new products gaining each one a hydrogen atom and an hydroxyl group, respectively [16]. The use of biodegradable polymeric materials may be subjected by the host response due to the changes induced by the chain breakage, that vary the properties of the scaffolds as a function of time. This, along with the changes promoted in the micro-environment of the scaffold due to the release of the degradation by-products that may cause long-term host responses, need to be taken into account [18]. In this sense, an advanced in vitro validation procedure is required to evaluate and predict the possible adverse effects on the cells and/or host once the scaffold has been implanted [19]. 
Synthetic biodegradable polyesters such as polylactide (PLA), polyglycolide (PGA), polycaprolactone (PCL), polyhydroxybutyrate (PHB) or poly(glyceril sebacate) (PGS) or poly(ester-ethers) such as polydioxanone (PDO) have been widely considered for the development of scaffolds [20]. Moreover, other degradable polymeric families with hydrolytically degradable bonds, including anhydrides, acetals, carbonates, amides, urethanes, and phosphates have been considered for the production of scaffolds [4]. However, they usually do not accomplish with the required properties as a solely material. They frequently have low bioactivity and poor biocompatibility due to the lack of hydrophilic functional groups that allow satisfactory cell attachment. Although there is a large number of polymeric biomaterials, it does not exist an ideal candidate that meets all the requirements for tissue engineering applications. Alternatively, there exist a large number of strategies available for combining and leveraging the best qualities of each individual material to meet the needs required in the field of tissue engineering [9].

The combination of different synthetic polymers with dissimilar features allowed developing functionalised scaffolds with specifically tailored properties for a given application, specially improving the hydrophilicity and modulating the degradation behaviour. The production of copolymers, the preparation of polymer blends or the surface modification through coating or grafting procedures have been appointed as promising alternatives for the development of tailored functionalised scaffolds [9]. The use of copolymers is a suitable strategy to generate new materials with better properties in comparison to the available homopolymers. This is the case of poly(lactide-co-glyocolide) (PLGA) which offers a good compromise between hydrophilicity and durability in comparison to polylactide and polyglycolide for some applications [21]. Moreover, the preparation of blended scaffolds may be a simple and a cost-effective method to combine the properties of the blend components.

Nevertheless, the combination of synthetic polymers is not usually sufficient to achieve the desired properties in certain specific applications, in which a high level of biocompatibility is required. The traditional synthetic biodegradable polymers that have been used for scaffold production usually do not possess any specific groups for an optimal interaction with cells. Therefore, the combination of synthetic polymers and natural biomaterials has allowed the development of biofunctionalised and biocompatible scaffolds able to enhance the cell adhesion and proliferation [22]. Some biomaterials have been proposed along the last years for this purpose. Among them, the combination of synthetic biodegradable polymers with proteins and poly(amino acid)s as well as polysaccharides, has brought new possibilities in the tissue engineering field [4]. Materials from different families such as collagen, gelatin, fibrin, 
elastin, hyaluronic acid or chitosan have been proposed for the biocompatibilisation of synthetic polymeric scaffolds [11].

Natural and synthetic polymers are therefore, widely employed as the basic material in tissue engineering scaffolds. Table 2.1 summarises some of the most promising synthetic and natural polymers as the basis for the development of biodegradable and biocompatible scaffolds for tissue engineering applications.

Highly functionalised scaffolds, essential for specific tissue engineering applications, would require deeper functionalisation alternatives. Apart from being highly porous, mechanically stable during application, highly biocompatible and biodegradable, the scaffolds must include specific signals provided by bioactive substances such as medicines or growth factors. Moreover, the combination with inorganic particles or conductive polymers would bring new possibilities of interaction between scaffolds and cells for specific tissues [23]-[25]. This scaffold designing strategy is represented in Figure 5.2.

The functionalisation of scaffolds by means of the combination of polymer matrices with electric conductive polymers may improve the differentiation and proliferation of cardiac, neural, bone and mesenchymal stem cells due to the propagation of electric signals between them [26] [29]. Among the most used conductive polymers, polypyrrole (PPy) [30], [31] or polyaniline (PAni) [32], [33] have shown interesting results both in vitro and in vivo, allowing to tune cellular activities through electrical stimulation. However, conductive polymers possess some drawbacks that should be consequently addressed [34]. Their intrinsic poor processability, along with high stability and low biodegradability, has resulted in their combination with biodegradable matrices - synthetic polyesters and natural biomaterials- as polymer blends or composites with as low content as possible [26]. 
Table 5.1. Most promising candidates for the development of biodegradable scaffolds.

\begin{tabular}{|c|c|c|}
\hline Origin* & Family & Polymer \\
\hline \multirow{10}{*}{ Synthetic } & \multirow{6}{*}{ Polyesters } & Polylactide (PLA) \\
\hline & & Polyglycolide (PGA) \\
\hline & & Poly(lactide-co-glycolyde) (PLGA) \\
\hline & & Polycaprolactone (PCL) \\
\hline & & Poly(propylene fumarate) (PPF) \\
\hline & & Poly(glyceryl sebacate) (PGS) \\
\hline & Poly(ester-ethers) & Polydioxanone (PDO) \\
\hline & \multirow{2}{*}{ Polyethers } & Poly(ethylene glycol) (PEG) \\
\hline & & Poly(propylene glycol) (PPG) \\
\hline & Other families & $\begin{array}{l}\text { Polyanhydrides, polyphospazenes, } \\
\text { polyurethanes, polyphosphoesters, } \\
\text { polycarbonates, polyacetals }\end{array}$ \\
\hline \multirow{12}{*}{ Natural } & \multirow{2}{*}{ Polyhydroxyalkanoates } & Polyhydroxybutyrate (PHB) \\
\hline & & Poly(hydroxybutyrate-co-valerate) (PHBV) \\
\hline & \multirow{4}{*}{ Polysachharides } & Hyaluronic acid (HA) \\
\hline & & Chitosan (CS) \\
\hline & & Agarose \\
\hline & & Alginate \\
\hline & \multirow{6}{*}{ Polypeptides } & Collagen \\
\hline & & Gelatin (Ge) \\
\hline & & Fibrin \\
\hline & & Silk \\
\hline & & Elastin \\
\hline & & Albumin \\
\hline
\end{tabular}

*Although separated in synthetic and natural polymers according to their most established production routes, some of them could be obtained from synthetic and natural resources.

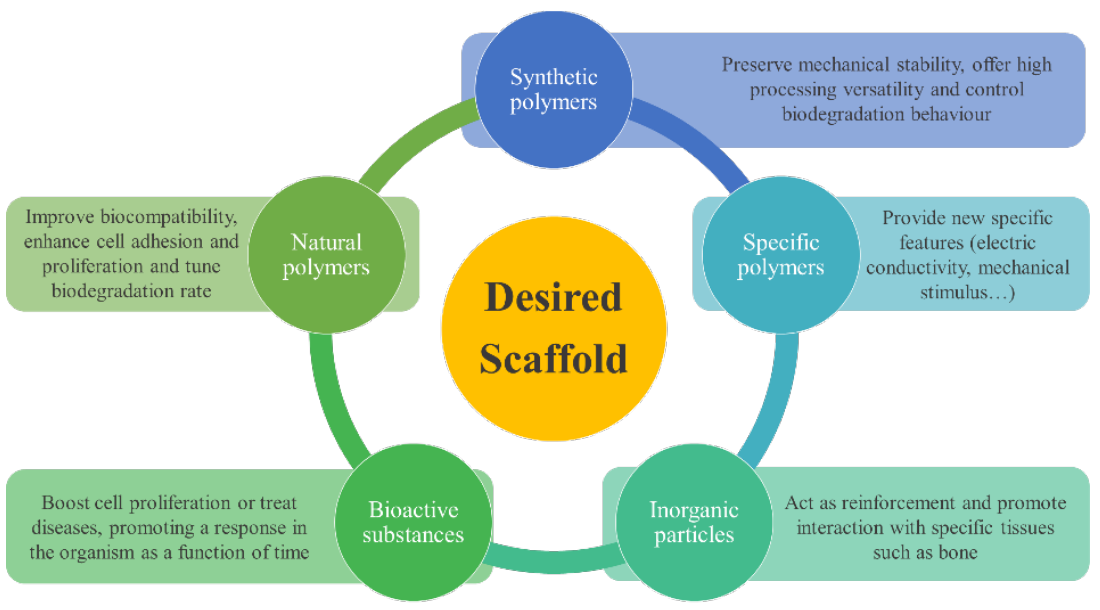

Figure 5.2. Scaffold designing strategy. 


\subsubsection{Poly(lactide-co-glycolide) (PLGA)}

Poly(lactide-co-glycolide) (PLGA) is the random copolymer of lactic and glycolic acid units, which constitutional repeating unit of the 50:50 copolymer is shown in Figure 5.3.<smiles>CC(OC(=O)COC1CCCCC1)C(=O)Cl</smiles>

Figure 5.3. Constitutional repeating unit of 50:50 poly(lactic-co-glycolic acid)

$$
\text { (PLGA). }
$$

The PLGA is a biodegradable polyester with good biocompatibility that has been deeply studied and proposed for the production of scaffolds for tissue engineering, among other biomedical applications [35]. It can be easily processed into scaffolds by different techniques such as electrospinning, melt spinning or gas foaming [36] that have been proposed for skin, cartilage, tendon, bone and nerve tissue engineering [37]-[39].

The composition of the PLGA, in terms of the lactic and glycolic units, considerably influences the crystalline morphology of this material and, subsequently, the degradation period, ranging from 1-2 months for 50:50 PLGA and 5-6 months for 85:15 PLGA [16]. The 50:50 PLGA has an amorphous morphology with a glass transition in the 44 to $55^{\circ} \mathrm{C}$ range. The degradation mechanism of PLGA's devices follows a bulk erosion pattern, in which aqueous solution rapidly diffuse to the inner part and then, hydrolysis of the ester bonds and global disintegration takes place [19]. Afterwards, glycolic and lactic acid units along with oligomer acidic species are released to the surrounding media [40].

\subsubsection{Polycaprolactone (PCL)}

Polycaprolactone (PCL) is a biodegradable semicrystalline aliphatic polyester, which constitutional repeating unit is shown in Figure 5.4. It is a hydrophobic synthetic polymer with a glass transition temperature around $-55^{\circ} \mathrm{C}$ and melting temperature between 55 and $60^{\circ} \mathrm{C}$ [16]. This polymer possess high plasticity, ductility and a slow degradation rate. As a polyester, the PCL can be degraded by means of the hydrolysis of its ester linkages under physiological conditions and has therefore received great attention for use in tissue engineering applications [41]. As a consequence of the hydrolytic degradation, caproic acid is released, which can be metabolised via the tricarboxylic acid cycle or eliminated by direct renal secretion [42], [43]. 


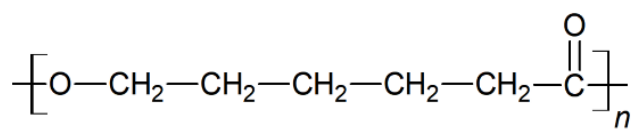

Figure 5.4. Constitutional repeating unit of polycaprolactone (PCL).

The PCL can be especially considered for the preparation of long term implantable devices in bone, ligament, cartilage, skin and nerve tissues [44]. However, its intrinsic slow degradation rate -more than 24 monthsand low cell adhesion have prevented its implantation in tissue engineering as a solely material [45], [46]. Due to this long-term behaviour, the PCL is usually copolymerised or blended with other biomaterials to improve biocompatibility and modulate the degradation behaviour [47]-[52].

\subsubsection{Polyhydroxybutyrate (PHB)}

The polyhydroxybutyrate (PHB), which constitutional repeating unit is shown in Figure 5.5, is a semicrystalline biodegradable polyester from the family of polyhydroxyalkanoates that can be obtained from bacterial and synthetic routes [53]. The PHB shows a glass transition temperature around $5{ }^{\circ} \mathrm{C}$ and a melting temperature in the range from 160 to $180^{\circ} \mathrm{C}$ [54]. The PHB is highly biocompatible and easy to process, with a remarked hydrophobic behaviour, that can be slowly hydrolytically degraded in physiological conditions following the surface erosion pattern [55], [56]. Due to its slow degradation rate, it is usually considered for long-term applications, in which PHB remains stable for a long period [57]. The degradation of the PHB polymer chains ultimately results in 3hydroxybutyric acid, which can be assimilated by the human organism [58]. As well as occurred with PCL, a noteworthy research has been conducted in copolymerisation and blending strategies with other biomaterials to tailor its biodegradability [54], [59]-[63]. The PHB has been proposed for bone, cardiac or skin tissue engineering applications [64]-[66].

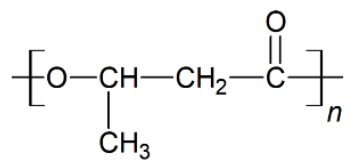

Figure 5.5. Constitutional repeating unit of polyhydroxybutyrate (PHB).

\subsubsection{Polydioxanone (PDO)}

Polydioxanone (PDO or PDX) is a colourless, semicrystalline poly(ester ether) synthesised by ring-opening polymerisation of the $p$-dioxanone [67]. The constitutional repeating unit with ester and ether linkages is shown in 
Figure 5.6. The PDO shows a glass transition temperature in the range from -10 to $0{ }^{\circ} \mathrm{C}$ and a melting temperature around $115^{\circ} \mathrm{C}$. Regarding its mechanical behaviour, it shows a low modulus but good flexibility and strength maintenance until disintegration [16]. The PDO has been widely used in medicine as suture monofilaments, bone fixation devices, or fasteners, and is currently under investigation for tissue engineering applications [68]-[70]. The degradation behaviour under physiological conditions of the PDO can be considered as between that of long aliphatic polyesters and that of fast degrading polymers such as PLGA [71]. As a result of the hydrolytic degradation, low molar mass hydroxy-acid species are released, that can be absorbed by the human body [72].<smiles>O=C([Te])COCCCO[Te]</smiles>

Figure 5.6. Constitutional repeating unit of polydioxanone (PDO).

\subsubsection{Gelatin (Ge)}

Gelatin (Ge) is a water soluble natural protein-based biopolymer derived from collagen through the denaturalisation of the triple-helix into singlestranded molecules by breaking intermolecular bonds, resulting in the macromolecule shown in Figure 5.7 [73]. Depending on the source of collagen and the type of conversion of collagen to gelatin, it may offer dissimilar properties. On the one hand, the gelatin obtaining by means of the acidic pre-treatment (type A) slightly affects the amide groups. On the other hand, the alkaline pre-treatment (type B) modifies the amide groups of asparagine and glutamine and hydrolyses them into carboxyl groups.<smiles>CC1CC(O)CN1C(=O)C1CCCN1C(=O)C1CCCN1C(C)(C)C</smiles>

Figure 5.7. Constitutional repeating unit of Gelatin (Ge).

Gelatin possess excellent biocompatibility, biodegradability and low cost, in comparison to collagen [74]. It contains arginyl-glycyl-aspartic amino acid sequence, which is a three amino-acid recognition structure that offers biochemical signals to promote cell integrin mediated adhesion and subsequent migration, proliferation and differentiation [75], [76]. When diluted in water gelatin forms an hydrogel, and it can either entangle to form coils or form an helical structure similar to collagen at high and low temperatures, respectively [11]. However, due to the high water swelling, 
gelatin shows poor mechanical stability and usually losses its conformation as a solely material for scaffold development, which is an important challenge to overcome. Gelatin can be either chemically crosslinked to stabilise structure [77], [78] or physically blended with other polymers [47], [79]-[82]. Due to its intrinsic structure, gelatin undergoes enzymatically degradation by collagenases. 


\subsection{REFERENCES OF CHAPTER 5}

[1] K. Harrisson, "Introduction to polymeric scaffolds for tissue engineering," in Biomedical Polymers, J. M, Ed. Cambridge, England: Woodhead Publishing Limited, 2007.

[2] R. Langer and J. P. Vacanti, “Tissue engineering,” Science (80-. )., vol. 260, no. 5110, p. 920 LP-926, May 1993.

[3] B. D. MacArthur and R. O. C. Oreffo, “Bridging the gap,” Nat. 2005 4337021, Jan. 2005.

[4] F. J. O’Brien, “Biomaterials \& scaffolds for tissue engineering,” Mater. Today, vol. 14, no. 3, pp. 88-95, Mar. 2011.

[5] R. J. Wade and J. a. Burdick, "Advances in nanofibrous scaffolds for biomedical applications: From electrospinning to self-assembly,” Nano Today, vol. 9, no. 6, pp. 722-742, 2014.

[6] A. Martins, J. V Araújo, R. L. Reis, and N. M. Neves, "Electrospun nanostructured scaffolds for tissue engineering applications.," Nanomedicine (Lond)., vol. 2, no. 6, pp. 929-942, 2007.

[7] C. Frantz, K. M. Stewart, and V. M. Weaver, "The extracellular matrix at a glance.,” J. Cell Sci., vol. 123, no. Pt 24, pp. 4195-200, Dec. 2010.

[8] A. Martins, R. L. Reis, and N. M. Neves, "Electrospinning: processing technique for tissue engineering scaffolding,” Int. Mater. Rev., vol. 53, no. 5, pp. 257-274, 2008.

[9] F. Khan, M. Tanaka, and S. R. Ahmad, "Fabrication of polymeric biomaterials: a strategy for tissue engineering and medical devices," J. Mater. Chem. B, vol. 3, no. 42, pp. 8224-8249, Oct. 2015.

[10] A. Atala, "Tissue Engineering and Regenerative Medicine: Concepts for Clinical Application,” Rejuvenation Res., vol. 7, no. 1, pp. 15-31, May 2004.

[11] R. Narayan, “Biomedical materials,” Biomed. Mater., pp. 1-566, 2009.

[12] N. Bhardwaj and S. C. Kundu, "Electrospinning: A fascinating fiber fabrication technique,” Biotechnol. Adv., vol. 28, no. 3, pp. 325-347, 2010.

[13] S. Agarwal, A. Greiner, and J. H. Wendorff, "Functional materials by electrospinning of polymers,” Prog. Polym. Sci., vol. 38, no. 6, pp. 963-991, Jun. 2013.

[14] J. Marler, J. Upton, R. Langer, and J. Vacanti, “Transplantation of cells in matrices for tissue regeneration.," Adv. Drug Deliv. Rev., vol. 33, no. 1-2, pp. 165-182, 1998.

[15] B. Dhandayuthapani, Y. Yoshida, T. Maekawa, and D. S. Kumar, "Polymeric scaffolds in tissue engineering application: A review,” Int. J. Polym. Sci., vol. 2011, no. ii, 2011.

[16] B. D. Ulery, L. S. Nair, and C. T. Laurencin, "Biomedical applications of biodegradable polymers,” J. Polym. Sci. Part B Polym. Phys., vol. 49, no. 12, pp. 832-864, 2011.

[17] A. Asti and L. Gioglio, "Natural and synthetic biodegradable polymers: Different scaffolds for cell expansion and tissue formation," International Journal of Artificial Organs, vol. 37, no. 3. pp. 187-205, Mar-2014. 
[18] A. Göpferich, "Mechanisms of polymer degradation and erosion," Biomaterials, vol. 17, no. 2, pp. 103-114, Jan. 1996.

[19] O. Gil-Castell, J. D. Badia, I. Ontoria-Oviedo, D. Castellano, B. Marco, A. Rabal, J. J. Bou, A. Serra, L. Monreal, M. Blanes, P. Sepúlveda, and A. RibesGreus, "In vitro validation of biomedical polyester-based scaffolds: Poly(lactide-co-glycolide) as model-case,” Polym. Test., vol. 66, pp. 256-267, Apr. 2018.

[20] D. I. Braghirolli, D. Steffens, and P. Pranke, "Electrospinning for regenerative medicine: a review of the main topics," Drug Discov. Today, vol. 19, no. 6, pp. 743-753, 2014.

[21] F. von Burkersroda, L. Schedl, A. Göpferich, and A. G. F. von Burkersroda, L. Schedl, "Why degradable polymers undergo surface erosion or bulk erosion,” Biomaterials, vol. 23, no. 21, pp. 4221-4231, Nov. 2002.

[22] D. M. Yoon and J. P. Fisher, "Natural and Synthetic Polymeric Scaffolds," in Biomedical Materials, R. Narayan, Ed. Springer, 2009, pp. 415-442.

[23] B. Guo, B. Lei, P. Li, and P. X. Ma, "Functionalized scaffolds to enhance tissue regeneration,” Regen. Biomater., vol. 2, no. 1, pp. 47-57, 2015.

[24] S. Stratton, N. B. Shelke, K. Hoshino, S. Rudraiah, and S. G. Kumbar, "Bioactive polymeric scaffolds for tissue engineering," Bioact. Mater., vol. 1, no. 2, pp. 93-108, Dec. 2016.

[25] K. Rezwan, Q. Z. Chen, J. J. Blaker, and A. R. Boccaccini, "Biodegradable and bioactive porous polymer/inorganic composite scaffolds for bone tissue engineering,” Biomaterials, vol. 27, no. 18, pp. 3413-3431, Jun. 2006.

[26] B. Guo, L. Glavas, and A.-C. Albertsson, "Biodegradable and electrically conducting polymers for biomedical applications,” Prog. Polym. Sci., vol. 38, no. 9, pp. 1263-1286, Sep. 2013.

[27] N. K. Guimard, N. Gomez, and C. E. Schmidt, "Conducting polymers in biomedical engineering,” Prog. Polym. Sci., vol. 32, no. 8-9, pp. 876-921, Aug. 2007.

[28] R. Ravichandran, S. Sundarrajan, J. R. Venugopal, S. Mukherjee, and S. Ramakrishna, "Applications of conducting polymers and their issues in biomedical engineering,” J. R. Soc. Interface, vol. 7, no. Suppl_5, pp. S559S579, 2010.

[29] A.-D. Bendrea, L. Cianga, and I. Cianga, "Review paper: Progress in the Field of Conducting Polymers for Tissue Engineering Applications,” J. Biomater. Appl., vol. 26, no. 1, pp. 3-84, Jul. 2011.

[30] X. Wang, X. Gu, C. Yuan, S. Chen, P. Zhang, T. Zhang, J. Yao, F. Chen, and G. Chen, "Evaluation of biocompatibility of polypyrrole in vitro and in vivo," J. Biomed. Mater. Res., vol. 68A, no. 3, pp. 411-422, Mar. 2004.

[31] A. Ramanaviciene, A. Kausaite, S. Tautkus, and A. Ramanavicius, "Biocompatibility of polypyrrole particles: an in-vivo study in mice," $J$. Pharm. Pharmacol., vol. 59, no. 2, pp. 311-315, Feb. 2007.

[32] P. Humpolicek, V. Kasparkova, P. Saha, and J. Stejskal, "Biocompatibility of polyaniline,” Synth. Met., vol. 162, no. 7-8, pp. 722-727, May 2012.

[33] C. H. Wang, Y. Q. Dong, K. Sengothi, K. L. Tan, and E. T. Kang, "In-vivo tissue response to polyaniline,” Synth. Met., vol. 102, no. 1-3, pp. 1313-1314, Jun. 1999. 
[34] G. Kaur, R. Adhikari, P. Cass, M. Bown, and P. Gunatillake, "Electrically conductive polymers and composites for biomedical applications."

[35] Z. Pan and J. Ding, "Poly(lactide-co-glycolide) porous scaffolds for tissue engineering and regenerative medicine.," Interface Focus, vol. 2, no. 3, pp. 366-77, Jun. 2012.

[36] J.-M. Lü, X. Wang, C. Marin-Muller, H. Wang, P. H. Lin, Q. Yao, and C. Chen, "Current advances in research and clinical applications of PLGA-based nanotechnology,” Expert Rev. Mol. Diagn., vol. 9, no. 4, pp. 325-341, 2009.

[37] P. Gentile, V. Chiono, I. Carmagnola, and P. V. Hatton, "An overview of poly(lactic-co-glycolic) Acid (PLGA)-based biomaterials for bone tissue engineering,” Int. J. Mol. Sci., vol. 15, no. 3, pp. 3640-3659, 2014.

[38] J. Xie, X. Li, J. Lipner, C. N. Manning, A. G. Schwartz, S. Thomopoulos, and Y. Xia, “'Aligned-to-random' nanofiber scaffolds for mimicking the structure of the tendon-to-bone insertion site," Nanoscale, vol. 2, no. 6, p. 923, Jun. 2010.

[39] S. H. Bhang, J. S. Lim, C. Y. Choi, Y. K. Kwon, and B.-S. Kim, “The behavior of neural stem cells on biodegradable synthetic polymers.," J. Biomater. Sci. Polym. Ed., vol. 18, no. 2, pp. 223-39, 2007.

[40] E. Vey, C. Roger, L. Meehan, J. Booth, M. Claybourn, A. F. Miller, and A. Saiani, "Degradation mechanism of poly(lactic-co-glycolic) acid block copolymer cast films in phosphate buffer solution," Polym. Degrad. Stab., vol. 93, no. 10, pp. 1869-1876, Oct. 2008.

[41] L. A. Bosworth and S. Downes, "Physicochemical characterisation of degrading polycaprolactone scaffolds,” Polym. Degrad. Stab., vol. 95, no. 12, pp. 2269-2276, Dec. 2010.

[42] A. Höglund, M. Hakkarainen, and A. Albertsson, "Degradation Profile of Poly( $\epsilon$-caprolactone)-the Influence of Macroscopic and Macromolecular Biomaterial Design,” J. Macromol. Sci. Part A, vol. 44, no. 9, pp. 1041-1046, Jun. 2007.

[43] E. Díaz, I. Sandonis, and M. B. Valle, "In Vitro Degradation of Poly(caprolactone)/nHA Composites,” J. Nanomater., vol. 2014, pp. 1-8, Oct. 2014.

[44] A. Cipitria, A. Skelton, T. R. Dargaville, P. D. Dalton, and D. W. Hutmacher, "Design, fabrication and characterization of PCL electrospun scaffolds-a review,” J. Mater. Chem., vol. 93, no. ii, pp. 1539-1550, 2011.

[45] Y. Li, X. Li, R. Zhao, C. Wang, F. Qiu, B. Sun, H. Ji, J. Qiu, and C. Wang, "Enhanced adhesion and proliferation of human umbilical vein endothelial cells on conductive PANI-PCL fiber scaffold by electrical stimulation,” Mater. Sci. Eng. C, vol. 72, pp. 106-112, 2017.

[46] S. R. Gomes, G. Rodrigues, G. G. Martins, M. A. Roberto, M. Mafra, C. M. R. Henriques, and J. C. Silva, "In vitro and in vivo evaluation of electrospun nanofibers of PCL, chitosan and gelatin: A comparative study,” Mater. Sci. Eng. C, vol. 46, pp. 348-358, 2015.

[47] S. Gautam, A. K. Dinda, and N. C. Mishra, "Fabrication and characterization of PCL/gelatin composite nanofibrous scaffold for tissue engineering applications by electrospinning method," Mater. Sci. Eng. C, vol. 33, no. 3, pp. 1228-1235, 2013. 
[48] H. M. Powell and S. T. Boyce, "Engineered Human Skin Fabricated Using Electrospun Collagen-PCL Blends: Morphogenesis and Mechanical Properties,” Tissue Eng. Part A, vol. 15, no. 8, pp. 2177-2187, Aug. 2009.

[49] Y. Zhu, C. Gao, and J. Shen, "Surface modification of polycaprolactone with poly(methacrylic acid) and gelatin covalent immobilization for promoting its cytocompatibility,” Biomaterials, vol. 23, no. 24, pp. 4889-4895, 2002.

[50] I. H. L. Pereira, E. Ayres, L. Averous, G. Schlatter, A. Hebraud, S. T. O. L. Mendes, and R. L. Oréfice, "Elaboration and characterization of coaxial electrospun poly(??-caprolactone)/gelatin nanofibers for biomedical applications,” Adv. Polym. Technol., vol. 33, no. S1, pp. 1-10, 2014.

[51] L. Ghasemi-Mobarakeh, M. P. Prabhakaran, M. Morshed, M.-H. NasrEsfahani, and S. Ramakrishna, "Electrospun poly( $\varepsilon$-caprolactone)/gelatin nanofibrous scaffolds for nerve tissue engineering,” Biomaterials, vol. 29, no. 34, pp. 4532-4539, Dec. 2008.

[52] W. Fu, Z. Liu, B. Feng, R. Hu, X. He, H. Wang, M. Yin, H. Huang, H. Zhang, and W. Wang, "Electrospun gelatin/PCL and collagen/PLCL scaffolds for vascular tissue engineering," Int. J. Nanomedicine, vol. 9, no. 1, pp. 23352344, 2014.

[53] H. Ueda and Y. Tabata, "Polyhydroxyalkanonate derivatives in current clinical applications and trials,” Adv. Drug Deliv. Rev., vol. 55, no. 4, pp. 501-518, Apr. 2003.

[54] M. Avella, E. Martuscelli, and M. Raimo, "Review Properties of blends and composites based on poly(3-hydroxy)butyrate (PHB) and poly(3hydroxybutyrate-hydroxyvalerate) (PHBV) copolymers,” J. Mater. Sci., vol. 35, no. 3, pp. 523-545, 2000.

[55] C. Zhijiang, "Biocompatibility and Biodegradation of novel PHB porous substrates with controlled multi-pore size by emulsion templates method,” $J$. Mater. Sci. Mater. Med., vol. 17, no. 12, pp. 1297-1303, Dec. 2006.

[56] O. Suwantong, S. Waleetorncheepsawat, N. Sanchavanakit, P. Pavasant, P. Cheepsunthorn, T. Bunaprasert, and P. Supaphol, "In vitro biocompatibility of electrospun poly(3-hydroxybutyrate) and poly(3-hydroxybutyrate-co-3hydroxyvalerate) fiber mats.," Int. J. Biol. Macromol., vol. 40, no. 3, pp. 21723, Feb. 2007.

[57] G.-Q. Chen and Q. Wu, "The application of polyhydroxyalkanoates as tissue engineering materials.," Biomaterials, vol. 26, no. 33, pp. 6565-78, Nov. 2005.

[58] T. Laeger, C. C. Metges, and B. Kuhla, "Role of $\beta$-hydroxybutyric acid in the central regulation of energy balance," Appetite, vol. 54, no. 3, pp. 450-455, Jun. 2010.

[59] M. Zhang and N. L. Thomas, "Blending polylactic acid with polyhydroxybutyrate: The effect on thermal, mechanical, and biodegradation properties,” Adv. Polym. Technol., vol. 30, no. 2, pp. 67-79, Jun. 2011.

[60] M.-L. Cheng, P.-Y. Chen, C.-H. Lan, and Y.-M. Sun, "Structure, mechanical properties and degradation behaviors of the electrospun fibrous blends of PHBHHx/PDLLA,” Polymer (Guildf)., vol. 52, no. 6, pp. 1391-1401, Mar. 2011.

[61] A. Wagner, V. Poursorkhabi, A. K. Mohanty, and M. Misra, "Analysis of Porous Electrospun Fibers from Poly(l-lactic acid)/Poly(3-hydroxybutyrate- 
co-3-hydroxyvalerate) Blends,” ACS Sustain. Chem. Eng., vol. 2, no. 8, pp. 1976-1982, Aug. 2014.

[62] A. Bianco, M. Calderone, and I. Cacciotti, "Electrospun PHBV/PEO cosolution blends: microstructure, thermal and mechanical properties.," Mater. Sci. Eng. C. Mater. Biol. Appl., vol. 33, no. 3, pp. 1067-77, Apr. 2013.

[63] I. Cacciotti, M. Calderone, and A. Bianco, "Tailoring the properties of electrospun PHBV mats: Co-solution blending and selective removal of PEO,” Eur. Polym. J., vol. 49, no. 10, pp. 3210-3222, Oct. 2013.

[64] D. Castellano, M. Blanes, B. Marco, I. Cerrada, A. Ruiz-Saurí, B. Pelacho, M. Araña, J. A. Montero, V. Cambra, F. Prosper, and P. Sepúlveda, “A Comparison of Electrospun Polymers Reveals Poly(3-Hydroxybutyrate) Fiber as a Superior Scaffold for Cardiac Repair,” Stem Cells Dev., vol. 23, no. 13, pp. 1479-1490, Jul. 2014.

[65] F. Senatov, N. Anisimova, M. Kiselevskiy, A. Kopylov, V. Tcherdyntsev, and A. Maksimkin, "Polyhydroxybutyrate/Hydroxyapatite Highly Porous Scaffold for Small Bone Defects Replacement in the Nonload-bearing Parts,” J. Bionic Eng., vol. 14, no. 4, pp. 648-658, Oct. 2017.

[66] D. Castellano, A. Sanchis, M. Blanes, M. D. M. D. Pérez del Caz, A. RuizSaurí, M. Piquer-Gil, B. Pelacho, B. Marco, N. Garcia, I. Ontoria-Oviedo, V. Cambra, F. Prosper, and P. Sepúlveda, "Electrospun poly(hydroxybutyrate) scaffolds promote engraftment of human skin equivalents via macrophage M2 polarization and angiogenesis,” J. Tissue Eng. Regen. Med., vol. 12, no. 2, pp. e983-e994, Jan. 2017.

[67] K. K. Yang, X. L. Wang, and Y. Z. Wang, "Poly(p-dioxanone) and its copolymers,” J. Macromol. Sci. - Polym. Rev., vol. 42, no. 3, pp. 373-398, 2002.

[68] B. S. Ahmad, M. Blanchy, G. Mbele, L. Pidial, V. Vanneaux, P. Menasché, G. R. Williams, and D. Kalfa, "The influence of electrospinning parameters on polydioxanone scaffold properties,” Biomed. Phys. Eng. Express, vol. 4, no. 2, p. 025023, Jan. 2018.

[69] O. Hakimi, P.-A. Mouthuy, C. Yapp, A. Wali, N. Z. Baboldashti, and A. Carr, "Evaluation of polydioxanone scaffolds of varying architecture for tendon repair,” Orthop. Proc., vol. 96-B, no. SUPP_11, p. 248, Jul. 2014.

[70] M. J. Mcclure, S. A. Sell, D. G. Simpson, and G. L. Bowlin, "Vascular Scaffolds : Uniaxial Cyclic Distension,” J. Eng. Fiber. Fabr., vol. 4, no. 2, pp. 18-25, 2009.

[71] N. Goonoo, A. Bhaw-Luximon, I. A. Rodriguez, D. Wesner, H. Schönherr, G. L. Bowlin, and D. Jhurry, "Poly(ester-ether)s: II. Properties of electrospun nanofibres from polydioxanone and poly(methyl dioxanone) blends and human fibroblast cellular proliferation,” Biomater. Sci., vol. 2, no. 3, pp. 339351, Feb. 2014.

[72] M. A. Sabino, J. Albuerne, A. Müller, J. Brisson, and R. E. Prud'homme, "Influence of in vitro hydrolytic degradation on the morphology and crystallization behavior of poly(p-dioxanone)," Biomacromolecules, vol. 5, no. 2, pp. 358-370, 2004.

[73] A. S. Hoffman, "Hydrogels for biomedical applications," Adv. Drug Deliv. Rev., vol. 54, no. 1, pp. 3-12, Jan. 2002.

[74] A. A. Aldana and G. A. Abraham, "Current advances in electrospun gelatin- 
based scaffolds for tissue engineering applications,” Int. J. Pharm., vol. 523, no. 2, pp. 441-453, May 2017.

[75] Q. Jiang, H. Xu, S. Cai, and Y. Yang, "Ultrafine fibrous gelatin scaffolds with deep cell infiltration mimicking 3D ECMs for soft tissue repair,” J. Mater. Sci. Mater. Med., vol. 25, no. 7, pp. 1789-1800, Jul. 2014.

[76] P. Sajkiewicz and D. Kołbuk, "Electrospinning of gelatin for tissue engineering - molecular conformation as one of the overlooked problems," $J$. Biomater. Sci. Polym. Ed., vol. 25, no. 18, pp. 2009-2022, Dec. 2014.

[77] K. Sisson, C. Zhang, M. C. Farach-Carson, D. B. Chase, and J. F. Rabolt, "Evaluation of Cross-Linking Methods for Electrospun Gelatin on Cell Growth and Viability,” Biomacromolecules, vol. 10, no. 7, pp. 1675-1680, Jul. 2009.

[78] Y. Z. Zhang, J. Venugopal, Z.-M. Huang, C. T. Lim, and S. Ramakrishna, "Crosslinking of the electrospun gelatin nanofibers," Polymer (Guildf)., vol. 47, no. 8, pp. 2911-2917, Apr. 2006.

[79] L. H. Chong, M. M. Lim, and N. Sultana, "Fabrication and Evaluation of Polycaprolactone / Gelatin-Based Electrospun Nanofibers with Antibacterial Properties,” vol. 2015, 2015.

[80] I. Rajzer, E. Menaszek, R. Kwiatkowski, J. A. Planell, and O. Castano, "Electrospun gelatin/poly(E-caprolactone) fibrous scaffold modified with calcium phosphate for bone tissue engineering," Mater. Sci. Eng. C, vol. 44, pp. 183-190, 2014.

[81] N. S. Binulal, A. Natarajan, D. Menon, V. K. Bhaskaran, U. Mony, and S. V. Nair, "PCL-gelatin composite nanofibers electrospun using diluted acetic acidethyl acetate solvent system for stem cell-based bone tissue engineering," $J$. Biomater. Sci. Polym. Ed., vol. 25, no. 4, pp. 325-340, Mar. 2014.

[82] O. Gil-Castell, J. D. D. Badia, and A. Ribes-Greus, "Tailored electrospun nanofibrous polycaprolactone/gelatin scaffolds into an acid hydrolytic solvent system,” Eur. Polym. J., vol. 101, pp. 273-281, Apr. 2018. 


\subsection{CONTRIBUTIONS OF CHAPTER 5}

The development of functionalised scaffolds for tissue engineering is one of the most promising research advances in biomedicine, which have been proposed as an effective alternative for cell culture, proliferation, subsequent differentiation and ultimately tissue morphogenesis. The approach followed for the design of this research line is schematised in Figure 5.8.

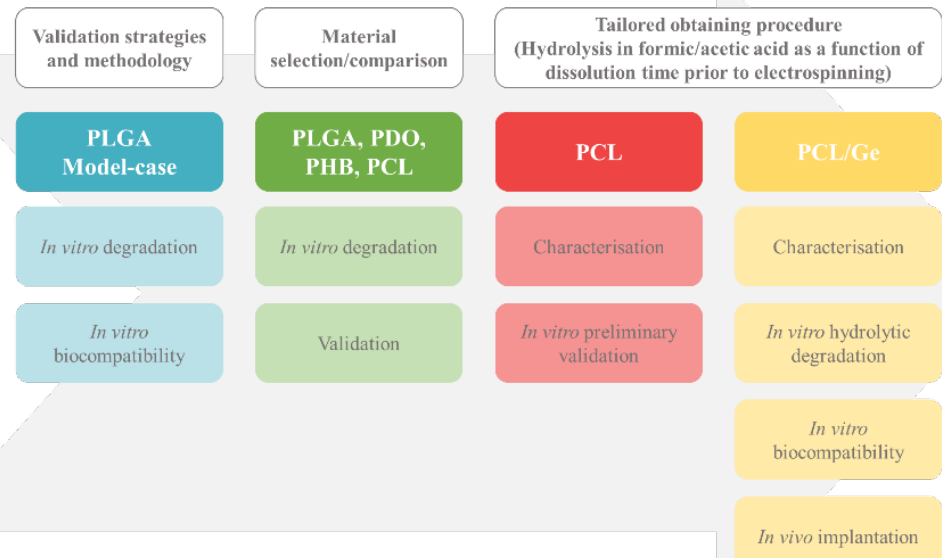

Figure 5.8. Sequence approach for the functionalisation strategy, characterisation and validation of the scaffolds for tissue engineering.

Firstly, monitoring and understanding the in vitro behaviour of polyester based scaffolds, both comprising the study of the hydrolytic degradation and the cell seeding viability, was essential to ensure the desired functionality, according to a given biomedical purpose. For this reason, a methodology for the validation of polyester-based scaffolds was proposed, taking the poly(lactide-co-glycolide) (PLGA) as model case. Results showed specific experimental indicators to set up an appropriate plan of analysis of the degradation of polyester-based scaffolds, depending on the balance between the interest in ascertaining the trigger of degradation or deep into the knowledge of the causes and effects along validation.

Subsequently, several polyester-based scaffolds were studied and compared during in vitro hydrolytic degradation. The degradation patterns of poly(lactide-co-glycolide) (PLGA), polycaprolactone (PCL), polydioxanone (PDO) and polyhydroxybutyrate (PHB) were assessed. The considered methodology permitted to ascertain the degradation process regardless the time lifespan of the scaffolds when subjected to physiological conditions. The most relevant indicators were the relative 
molar mass-loss and the degree of crystallinity of the fibres. On the one hand, the scaffolds for short-time applications were PLGA and PDO, which showed a faster disintegration and, subsequently, a pronounced acidification of the medium. On the other hand, the scaffolds for long-term applications were PCL and PHB, which resistant pattern was mainly ascribed to the stability of the crystalline domains of the fibres. Under a perspective of an adequate balance between the durability and degradation, the results of this comparison served as a reference point in the stage of design and material selection for the development of new polyester-based electrospun scaffolds for biomedical applications.

From this point onwards, the polycaprolactone (PCL) polymer was selected as a promising candidate for scaffold development, regardless its long-term degradation behaviour. Accordingly, scaffolds of PCL were produced by means of electrospinning. In order to tailor its physicochemical properties and subsequent behaviour when submitted to physiologic conditions, the hydrolysis of the polycaprolactone (PCL) as a function of the dissolution time in a formic/acetic acid mixture prior to electrospinning was considered. Hence, the correlation between the dissolution time of the polymer in the acid solvent with the physicochemical properties of the electrospun nanofibrous scaffolds and their further service life behaviour was performed.

With the aim of improving the biocompatibility, blended nanofibrous scaffolds based on polycaprolactone (PCL) and gelatin (Ge) were successfully electrospun in several compositions ranging from 100/0 to 20/80 \%wt in steps of $10 \% w t$. As well, the hydrolysis of the PCL diluted in the formic/acetic acid mixture was considered as a method for tailoring the surface morphology and physico-chemical features of the nanofibrous PCL/Ge scaffolds as a function of the dissolution time. The reduction of the intrinsic viscosity, molar mass and hydrodynamic radius found for the PCL molecules as a function of the dissolution time, consequently diminished the entanglement capability of the polymeric chains, and significantly influenced the nanofibre size and morphology. As well, the crystalline structure of the scaffolds varied with the dissolution time and PCL/Ge composition, offering a wide range of tailored specific properties for tissue engineering applications.

Finally, the PCL/Ge developed scaffolds were validated in terms of the in vitro degradation in physiologic conditions, in vitro biocompatibility and in vivo implantation. The most promising results were found for the balanced compositions of PCL/Ge -60/40, 50/50 and 40/60-. As a whole, the effect of the dissolution time was found to play a key role in the degradability, biocompatibility and bioassimilation of these scaffolds. As well, the perceived progressive behaviour as a function of the dissolution time, and the partial or complete assimilation during in vivo implantation 
confirmed and corroborated the tailoring strategy to obtain highly biocompatible scaffolds with a controlled degradation rate.

The results of this research line were reported in:

Contribution 5.1. In vitro validation of biomedical polyester-based scaffolds: poly(lactide-co-glycolide) as model-case.

Contribution 5.2. Comparison of in vitro hydrolytic degradation patterns of short-term and long-term polyester-based electrospun scaffolds.

Contribution 5.3. Effect of the dissolution time into an acid hydrolytic solvent to tailor electrospun nanofibrous polycaprolactone scaffolds.

Contribution 5.4. Tailored electrospun nanofibrous polycaprolactone/ gelatin scaffolds into an acid hydrolytic solvent system.

Contribution 5.5. Validation of tailored electrospun nanofibrous polycaprolactone/gelatin based scaffolds. 


\section{Contribution 5.1.}

In vitro validation of biomedical polyester-based scaffolds: poly(lactide-co-glycolide) as model-case

O. Gil-Castell, J. D. Badia, I. Ontoria-Oviedo, D. Castellano, B. Marco, A. Rabal, J. J. Bou, A. Serra, L. Monreal, M. Blanes, P. Sepúlveda, A. RibesGreus. In vitro validation of biomedical polyester-based scaffolds: Poly(lactide-co-glycolide) as model-case. Polymer Testing 2018;66:256267

This is an open-access version, according to:

http://www.sherpa.ac.uk/romeo/issn/0142-9418/

Full text available at:

https://www.sciencedirect.com/science/article/pii/S0142941817315647

DOI:

https://doi.org/10.1016/j.polymertesting.2018.01.027 


\section{In vitro validation of biomedical polyester-based scaffolds: poly(lactide-co-glycolide) as model-case}

O. Gil-Castell ${ }^{1}$, J. D. Badia ${ }^{1,2,3}$, I. Ontoria-Oviedo ${ }^{4}$, D. Castellano ${ }^{4}$, B. $\mathrm{Marco}^{5}$, A. Rabal ${ }^{5}$, J. J. Bou ${ }^{6}$, A. Serra ${ }^{2}$, L. Monreal ${ }^{1}$, M. Blanes ${ }^{5}$, P. Sepúlveda $^{4}$, A. Ribes-Greus ${ }^{1, *}$

${ }^{1}$ Instituto de Tecnología de Materiales (ITM), Universitat Politècnica de València, Camino de Vera s/n, 46022 Valencia, Spain

${ }^{2}$ Departament de Química Orgànica i Analítica, Universitat Rovira i Virgili, C/ Marcel·lí Domingo s/n, 43007 Tarragona, Spain

${ }^{3}$ Departament d’Enginyeria Química. Escola Tècnica Superior d’Enginyeria, Universitat de València, Av. de la Universitat, s/n, 46100 Burjassot, Spain

${ }^{4}$ Unidad de Regeneración y Trasplante Cardíaco, Instituto de Investigación Sanitaria La Fe, Av. Fernando Abril Martorell Torre A, 46026 Valencia, Spain

${ }^{5}$ Grupo de Investigación de Acabados Técnicos, Salud y Medioambiente, Instituto Tecnológico Textil (AITEX), Plaza Emilio Sala 1, 03801 Alcoy, Spain

${ }^{6}$ Departament d’Enginyeria Química, Universitat Politècnica de Catalunya, Av. Diagonal 647 (ETSEIB), 08028 Barcelona, Spain

${ }^{*}$ Corresponding author:

A. Ribes-Greus

aribes@ter.upv.es 


\title{
In vitro validation of biomedical polyester-based scaffolds: poly(lactide-co-glycolide) as model-case
}

\author{
O. Gil-Castell, J. D. Badia, I. Ontoria-Oviedo, D. Castellano, B. Marco, \\ A. Rabal, J. J. Bou, A. Serra, L. Monreal, M. Blanes, P. Sepúlveda, A. \\ Ribes-Greus
}

\begin{abstract}
Monitoring and understanding the in vitro behaviour of polyester based scaffolds both comprising the study of the hydrolytic degradation and the cell seeding viability is essential to ensure the desired functionality, according to a given biomedical purpose. As a model case to compare the performance of techniques to monitor the in vitro behaviour, poly(lactideco-glycolide) (PLGA) scaffolds were chosen.

The in vitro hydrolytic degradation of PLGA scaffolds was carried out in water and phosphate buffered saline (PBS). The evolution of the mass loss, the molar mass, the thermal properties and the surface morphology were monitored. The hydrolytic degradation media was correspondingly evaluated by means of the study of the $\mathrm{pH}$, the amount of acid released and the conductivity.

In addition, the in vitro biocompatibility regarding the cell culture viability was studied under physiological conditions. The cellular adhesion, cellular ability to proliferate on the scaffold, the scaffold inflammatory profile and the effect of the scaffold degradation compounds on the cells were assessed.

A comparative analysis of the exploited techniques in terms of promptness of identification, depth of knowledge, simplicity of obtaining results and cost of the technique was implemented. The results showed that, depending on the balance between the interest in ascertaining the trigger of degradation or deep into the knowledge of the causes and effects of cell culture viability, an appropriate plan of analysis of the validation of polyester-based scaffolds could be designed.
\end{abstract}

\section{Keywords}

Scaffold; polyester; poly(lactide-co-glycolide) (PLGA); in vitro validation; biocompatibility; polymer testing 


\section{Introduction}

Polyesters are one of the most used polymeric materials for biomedical applications such as sutures, implants, artificial skin and controlled drug release devices [1]-[4]. Such is the case of the poly(lactide) (PLA), poly(glycolide) (PGA), poly( $\varepsilon$-caprolactone) (PCL) or poly(lactide-coglycolide) (PLGA) [5]-[9]. The irruption of electrospinning in tissue engineering has boosted the technology of production of biomaterials comprising fibrous architectures which diameters can vary from several tens to hundreds of nanometres, mimicking the native extracellular matrix and allowing enough porosity to facilitate cellular growth [10]-[12]. Precisely, the tuning of these scaffolds is required to ensure a balance between enough time of structural endurance to permit angiogenesis, and appropriate degradation profiles to be decomposed without delivery of toxic low molar mass compounds [13]. In this sense, the development of protocols to establish the structure-to-performance relationship of biomedical scaffolds still represents a matter of interest.

The use of poly(lactide-co-glycolide) (PLGA) as biopolymeric scaffold is well-extended due to its equilibrium of performance of durability and bioassimilation trends [14], [15], and therefore was taken as model polyester in this work. An equilibrated water-affinity with reasonable degradation times has been found for 50:50 PLGA where the methyl sidegroups of the PLA macrosegments confer hydrophobicity to the copolymer [16]. The mechanism of degradation of PLGA under abiotic aqueous environments takes place through hydrolysis of the ester bonds, autocatalysed by carboxylic groups, exponentially increasing along the exposure time [17]. These microstructural changes induce the formation of macroscopic pores or cracks, and the loss of monomeric and oligomeric species, thus reducing the mass of the polymers and finally decomposing their architecture until bioassimilation or excretion [18]. PLGA permits different preparations and designs. For instance, Farahani et al. studied 50:50 PLGA as compressed discs for implants [19], Vey et al. assessed the degradation of cast films [20] and Wu et al. the biodegradation of PLGA rods with different compositions [21]. As electrospun scaffolds, some characterisation studies of the in vitro degradation have been reported [7], [22]-[28], generally considering the monitoring of mass-loss and molar mass along hydrolytic exposure.

Depending on the area of application and the purpose of the analysis, the focus on the research can vary from the deepest knowledge of the degradation mechanisms from the material science point of view [29]-[32], to a fast reference trial of materials to identify the relative times of decomposition and thus further infer the response under biological conditions in medical studies [7], [24], [33], [34]. Therefore, the aim of this work was to compare the suitability of the set of analytical techniques 
schematised in Figure 1 to validate the in vitro behaviour of a model electrospun polyester (PLGA) through the study of its hydrolytic degradation and biocompatibility. For this purpose, the hydrolytic degradation profiles were monitored in ultra-pure water and phosphate buffer solution (PBS) at $37{ }^{\circ} \mathrm{C}$. The scaffold was characterised by gravimetric analysis, size exclusion chromatography (SEC), differential scanning calorimetry (DSC) and field emission scanning electron microscopy (FE-SEM) while the degradation media was monitored by $\mathrm{pH}$ measurement, titration of released acids and conductometry. Biocompatibility was studied in terms of cellular adhesion, morphology and proliferation of cells, the inflammatory profile, and the effect of the scaffold degradation compounds on the cell viability were assessed by means of immunofluorescence, FE-SEM, methyl tetrazolium (MTT) and pyrogenic assays, respectively. Aspects such as promptness of identification, depth of knowledge, simplicity of obtaining results and cost of the techniques were taken into account as a basis for specialists to set up an appropriate plan of analysis of the degradation and durability of polyester-based scaffolds.

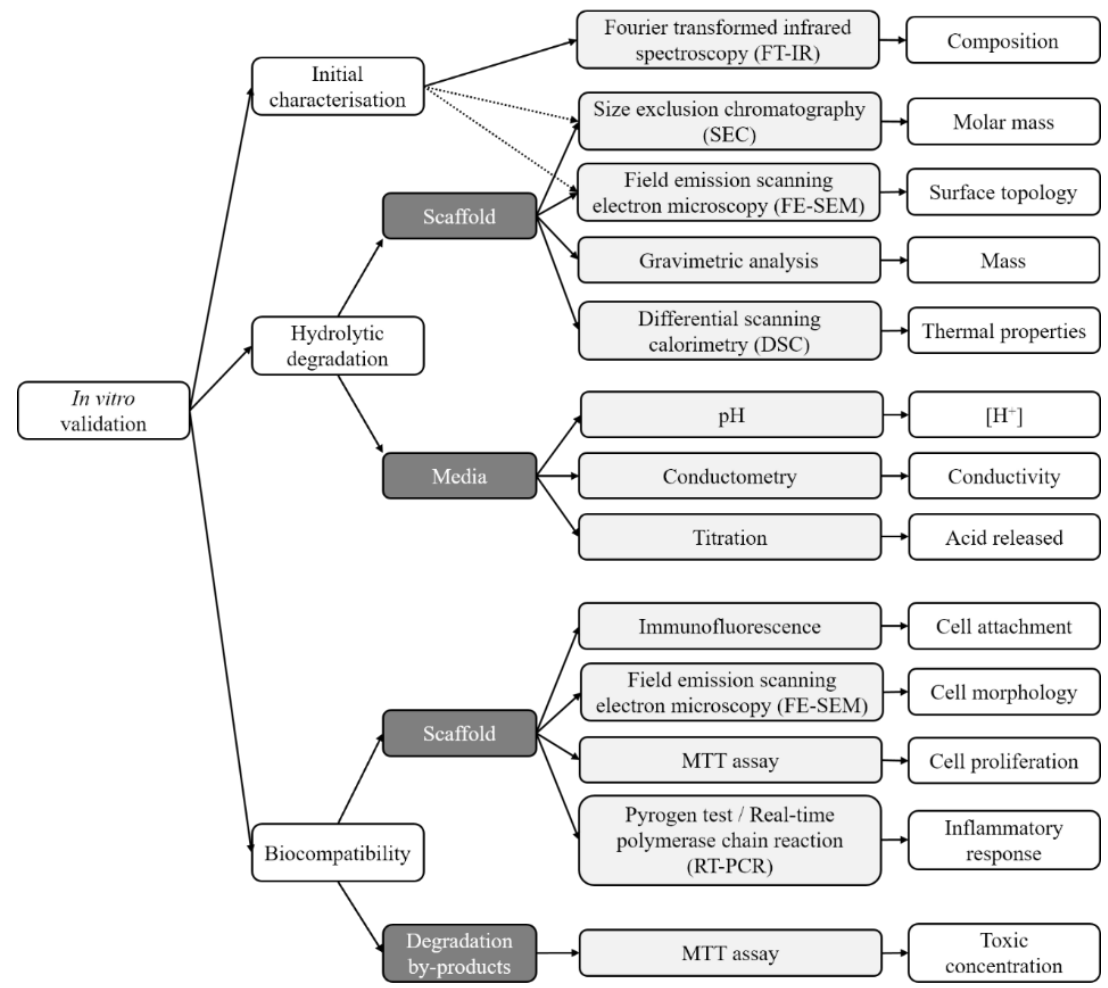

Figure 1. Scheme of the in vitro validation techniques used in this study along with the most representative indicators for each technique. 


\section{Materials and methods}

\subsection{Materials}

The 50:50 DL-PLGA used in this study was provided by Lactel Absorbable Polymers. Dimethylformamide (DMF) was used as solvent for electrospinning. For the hydrolytic degradation procedure, ultra-pure water of type 1 (ISO 3696) [35], Dulbecco’s Phosphate Buffered Saline solution (PBS, D1408) and $\mathrm{NaOH} 1 \mathrm{M}$ for adjusting $\mathrm{pH}$ in PBS, were used. All these reactants, except water, were supplied by Sigma-Aldrich and were used without further purification. For the in vitro biocompatibility tests paraformaldehyde (PFA) from VWR Chemicals and 4',6-diamidino-2phenylindole (DAPI) from Sigma-Aldrich were used.

\subsection{Scaffold preparation}

The PLGA scaffolds were obtained by means of an Yflow Electrospinner 2.2.D-350. It consisted in double polarization, integrated drum collector control panel and robotized stage to move the electrospinning source in an alternative fashion covering a $400 \times 400 \mathrm{~mm}^{2}$ area. PLGA solution was prepared at a $30 \%$ by weight in pure DMF under gentle stirring overnight at room temperature. The polymer solution was electrospun at a $14 \mathrm{kV}$ voltage, with a tip-to-collector distance of $20 \mathrm{~cm}$ and a solution flow rate of $1 \mathrm{ml} \cdot \mathrm{h}^{-1}$. The solution jet emerging from the stainless steel wire $(0.9 \mathrm{~mm}$ inner diameter) used as the positive electrode, was collected on a waxed paper. Scaffolds, with an average thickness of $1.35 \times 10^{-2} \mathrm{~mm}$, were obtained and dried over $12 \mathrm{~h}$ under vacuum to facilitate the removal of residual solvent and moisture.

\subsection{In vitro degradation}

The PLGA scaffolds were subjected to hydrolytic degradation under ultrapure water and phosphate buffer saline solution (PBS), according to the international norm ISO 10993-13:2010, method 4.3 [36]. Shortly, the initial electrospun scaffolds were cut into rectangular specimens with a mass around $10 \mathrm{mg}$. The specimens were weighed $\left(m_{0}\right)$ and placed in a previous weighed vial $\left(m_{\text {vial }}\right) .10 \mathrm{ml}$ of degradation medium were introduced, then the vials were sealed with polytetrafluoroethylene (PTFE) threaded plugs and placed in a thermostatically controlled oven at $37^{\circ} \mathrm{C}$. The $\mathrm{pH}$ of the PBS solution was adjusted to 7.4 with $\mathrm{NaOH} 1 \mathrm{M}$. Twelve extractions were considered along the hydrolytic degradation over 150 days. In order to monitor the process, after certain periods of time, samples were withdrawn from the environment by triplicate. Solid and liquid fractions were separated. The liquid fraction was analysed immediately after extraction, while the solid fraction followed a washing-dryingkeeping procedure before further analysis. Actually, those specimens coming from the saline buffer were washed with deionized water and then, 
along with specimens coming from water environment, were dried under vacuum to constant mass into their degradation vials $\left(m_{d r y}\right)$ and saved for further analysis.

\subsection{Scaffold characterisation}

\subsubsection{Mass loss monitoring}

The residual mass of the samples (\% mass) was determined by the Equation 1,

$$
\% \text { mass }=\frac{m_{d r y}-m_{\text {vial }}}{m_{0}} \times 100 \quad(\text { Equation 1) }
$$

where $m_{0}, m_{\text {vial }}$ are the initial mass of the specimen, and the vial, respectively; and $m_{d r y}$, the mass of the vacuum dry assembly sample-vial after degradation.

\subsubsection{Size exclusion chromatography (SEC)}

Size exclusion chromatography (SEC) analyses were carried out by means of an Agilent Infinity 1260 chromatograph. Separation was performed with a Jordi Associates mixed bed fluorinated column (permeation range: 100 $10 \times 10^{6}$ Dalton). All the samples were dissolved in mobile phase of hexafluoroisopropanol (HFIP) containing $2.72 \mathrm{~g} \cdot \mathrm{L}^{-1}$ of sodium trifluoroacetate (NaTFA). This solvent was previously degassed by vacuum filtration over PTFE $0.45 \mu \mathrm{m}$ pore membranes. Flow rate was set at $1 \mathrm{~mL} \cdot \mathrm{min}^{-1}$ and $100 \mu \mathrm{L}$ samples of about $0.1 \%$ concentration were injected. Detection was conducted by UV-vis-detector. Monodisperse PMMA samples from Sigma-Aldrich and Agilent were used for previous calibration. The specimens were characterised in triplicates and the averages were taken as representative values.

\subsubsection{Fourier transformed infrared spectroscopy (FT-IR)}

The assurance of the composition of the scaffolds was determined via attenuated total reflectance (ATR) in a Thermo Nicolet 5700 Fourier transform infrared spectrometer (FT-IR). The average spectra were collected from 64 accumulations with a resolution of $4 \mathrm{~cm}^{-1}$ in the 4000 $400 \mathrm{~cm}^{-1}$ range, from eight different locations of the same specimen.

\subsubsection{Differential scanning calorimetry (DSC)}

Calorimetric data were obtained by differential scanning calorimetry (DSC) with a Mettler-Toledo DSC 820 series. The DSC equipment was calibrated following the procedure of In and $\mathrm{Zn}$ standards. The samples, with a mass of about $4 \mathrm{mg}$ were analysed between -20 and $220{ }^{\circ} \mathrm{C}$ with a heating rate of $10{ }^{\circ} \mathrm{C} \cdot \mathrm{min}^{-1}$. All experiments were run under nitrogen atmosphere $\left(50 \mathrm{~mL} \cdot \mathrm{min}^{-1}\right)$. The specimens were characterised at least in 
triplicates and the averages of temperatures were taken as representative values.

\subsubsection{Field emission scanning electron microscopy (FE-SEM)}

The surface morphology of specimens was analysed by means of a Zeiss Ultra 55 field emission scanning electron microscope (FE-SEM). The samples were cut into small pieces and dried at $50{ }^{\circ} \mathrm{C}$ in a vacuum oven for $24 \mathrm{~h}$ and then kept in a desiccator during $48 \mathrm{~h}$. Afterwards, the specimens were mounted on metal studs and sputter-coated with a platinum layer during 10 s using a Leica EM MED020. Testing was performed at room temperature with a $3 \mathrm{kV}$ voltage. The fibre diameters were measured from the FE-SEM micrographs at random locations $(n=100)$ with the aid of Image J software.

\subsection{Characterisation of the degradation media}

\subsection{1. $\mathrm{pH}$ and conductivity measurements}

The $\mathrm{pH}$ and conductivity of the degradation media were measured at room temperature by means of Crison pH25 and Crison CM35 devices. Three buffer solutions from Crison were used to calibrate the $\mathrm{pH}$-meter: $\mathrm{pH} 4.01$ (phthalate buffer solution), $\mathrm{pH} 7.00$ (phosphate buffer solution), pH 10.01 (borate buffer solution). Different $\mathrm{KCl}$ solutions $(0.1 \mathrm{M}, 0.01 \mathrm{M}$ and 0.001 M) with conductivities of $12.88 \mathrm{mS} \cdot \mathrm{cm}^{-1}, 1413 \mu \mathrm{S} \cdot \mathrm{cm}^{-1}$ and $147 \mu \mathrm{S} \cdot \mathrm{cm}^{-1}$, respectively, were used to calibrate the conductometer. Measurements were carried out in three different specimens per sample and the averages were taken as representative values.

\subsubsection{Titration}

The amount of released acid was estimated by means of a titration of the degradation medium. In this method, only monomeric units of lactic and glycolic acids are supposed to be released according to the methodology proposed by Vey et al. [20]. Aqueous solutions of lactic and glycolic acids were prepared at $0.01 \mathrm{M}$ in order to establish an additive pattern curve which related the concentration of each compound with the $\mathrm{pH}$.

\subsection{In vitro biocompatibility}

\subsubsection{Cell culture}

Human fibroblasts were cultured in high-glucose Dulbecco's Modified Eagle's Medium (Sigma-Aldrich) supplemented with $10 \%$ of foetal bovine serum (FBS), penicillin (100 U. $\left.\mathrm{mL}^{-1}\right)$ and streptomycin $\left(100 \mu \mathrm{g} \cdot \mathrm{mL}^{-1}\right)$ (Gibco). Human keratinocytes were cultured in low-glucose Dulbecco's Modified Eagle's Medium (Sigma-Aldrich) supplemented with $10 \%$ of chelated FBS, penicillin $\left(100 \mathrm{U} \cdot \mathrm{mL}^{-1}\right)$ and streptomycin $\left(100 \mu \mathrm{g} \cdot \mathrm{mL}^{-1}\right)$. 
Cells were harvested for passaging with trypsin-EDTA (0.25\% trypsin and $0.02 \%$ EDTA) solution.

\subsubsection{Cell-adhesion assay}

In order to evaluate the cell attachment to the scaffolds, 40000 cells were plated onto $1 \mathrm{~cm}^{2}$ of the polymer sheet in triplicates. Cells were allowed to attach for $30 \mathrm{~min}$ and then cultured in the appropriate medium for 48 and 96 h. Thereafter, scaffolds were washed with cold PBS and fixed for 20 min with $2 \%$ PFA at room temperature, then washed again and finally stained with 4',6-diamidino-2-phenylindole (DAPI) for 10 min at RT. Images were acquired in a fluorescence microscope.

As well, to better characterize the cell attachment and morphology, scanning electron microscope images were acquired. Briefly, 40000 cells $\mathrm{cm}^{-2}$ were seeded onto the scaffold and cultured for $48 \mathrm{~h}$. Then, the cells were fixed with $3 \%$ glutaraldehyde solution during $60 \mathrm{~min}$ at $37^{\circ} \mathrm{C}$ and subsequently critical point dried (CPD). This procedure removes liquids from the specimen and avoids surface tension effects, by never allowing a liquid/gas interface to develop [37]. The CPD protocol considered was dehydration through a graded series of ethanol (10\%, 20\%, $30 \%, 50 \%$ and $70 \%$, once for $10 \mathrm{~min}$ at each step), and then immersed in $100 \%$ ethanol twice for $30 \mathrm{~min}$ each. The tissues were then transferred to a Quorum Technologies Polaron E3000 critical point dryer, using liquefied carbon dioxide as transitional fluid. Finally, samples were sputter-coated and analysed according to the protocol described in section 2.4.5.

\subsubsection{MTT assay}

Human fibroblasts were plated at a density of $40000 \mathrm{cell} \cdot \mathrm{cm}^{-2}$ onto scaffolds. Proliferation was measured in triplicates after 48 and 96 h using thiazolyl blue tetrazolium bromide (MTT assay; Sigma-Aldrich), following the manufacturer's instructions. Absorbance was measured at 550 nm using a plate reader Halo Led 96 (Dynamica Scientific Ltd.).

To evaluate the toxicity of the compounds obtained from the scaffold degradation (PLGA), different concentrations of lactic and glycolic acid were tested (mM): 0, 10, 20, 30, 40, 50 and 60. Fibroblast and keratinocytes were seeded (10000 cells per well of a 96 well plate) and incubated during $24 \mathrm{~h}$ with the determined concentrations.

\subsubsection{Pyrogen test}

Blood was obtained from the Valencian Blood Tissue Bank after informed consent and was processed as described previously [33]. Briefly, peripheral blood mononuclear cells (PBMCs) were isolated by Ficoll density gradient centrifugation and incubated in triplicates with the PLGA scaffolds during $5 \mathrm{~h}$ at a density of $6 \times 10^{6}$ cells $\mathrm{ml}^{-1}$. RNA was obtained using QIAzol Lysis 
Reagent and purification was carried out with RNeasy Plus Mini Kit (Qiagen). RNA was quantified by spectrometry using a NanoDrop ND2000 (NanoDrop Technologies). The same procedure was used with PBMCs incubated with poly(3-hydroxybutyrate) (PHB) scaffolds.

2.6.5. Reverse transcription and real-time polymerase chain reaction ( $R T$ PCR)

cDNA was synthesised from $1 \mu \mathrm{g}$ of total purified RNA using the HighCapacity cDNA Reverse Transcription kit (Applied Biosystems). Primers were designed [33] and RT-PCR was performed as previously described [38]. The following pro-inflammatory cytokines were analysed: IL-1 $\beta$, IL6 , IL-10 and TNF- $\alpha$, the gene expression levels were normalised to the human housekeeping ACTB. Data are represented as the average from triplicate samples.

\subsubsection{Statistical Analysis}

The results in this study are expressed as mean \pm standard deviation (SD). In the biocompatibility assays, comparison between experimental conditions were performed with Mann-Whitney test. Differences were considered statistically significant at $\mathrm{P}<0.05$ with a $95 \%$ confidence interval. Analyses were conducted with GraphPad Prism 5 software.

\section{Results and discussion}

\subsection{Initial characterisation of the scaffold}

The validation of a given scaffold for tissue engineering starts from an initial or preliminary characterisation of this device. Accordingly, it is essential to evaluate some fundamental features such as the surface morphology, the fibre diameter, the porosity, the chemical composition and the molar mass. These are key factors that will determine the behaviour of the scaffold during application.

Figure 2 shows a FE-SEM image of the surface morphology, along with the histogram of diameters of the electrospun PLGA scaffolds. For satisfactory cell attachment and proliferation, the fibre diameter $(d)$ must remain in the nanoscale range which is crucial and necessary to mimic the extracellular matrix (ECM) size [39]. For the case of PLGA scaffolds, a uniform non-woven nanofibrous structure was observed.

The estimated porosity (Ø) of the scaffold was calculated by means of the Equation 2,

$$
\varnothing(\%)=\left(1-\frac{\rho}{\rho_{0}}\right) \times 100
$$

(Equation 2)

where $\rho$ is the density of electrospun sheet considering a thickness of $1.35 \cdot 10^{-3} \mathrm{~cm}$ and a density $\left(\rho_{0}\right)$ of $1.25 \mathrm{~g} \cdot \mathrm{cm}^{-3}$ for the bulk PLGA [25]. As 
well, the surface density $\left(\rho_{s}\right)$, referred to the mass per unit area, was calculated by weighing a piece of the scaffold and normalised to the selected area.
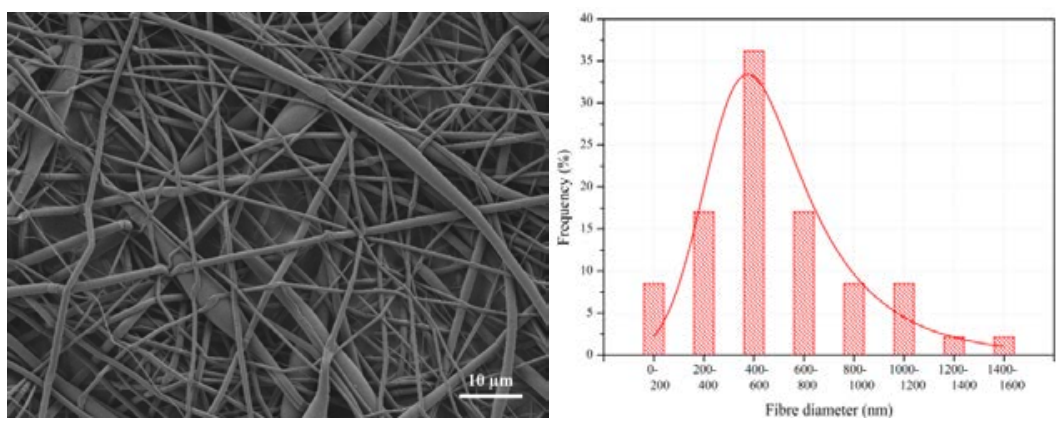

Figure 2. FE-SEM image (3kV, 1000x, $10 \mu \mathrm{m})$ and fibre diameter histogram of PLGA nanofibrous scaffold.

The chemical composition of the scaffold was assessed by means of infrared spectroscopy (FTIR). The typical infrared spectra of a given polyester shows the characteristic bands corresponding to specific functional groups in the polymer structure. The spectra of the PLGA shows two different characteristic bands corresponding to each one of the monomers. The first band located at $1452 \mathrm{~cm}^{-1}$ corresponds to the asymmetric bending of $-\mathrm{CH}_{3}$ from the lactic units and the second one is located at $1422 \mathrm{~cm}^{-1}$ and corresponds to the bending of $-\mathrm{CH}_{2}$ - from the glycolic units of the copolymer. Thus, the relative quantity of lactic and glycolic units could be estimated by the relative intensities of these two bands by means of Equation 3 and Equation 4, respectively [20],

$$
\begin{aligned}
& C_{L}=\frac{I_{1452}}{I_{1422}+I_{1452}} \\
& C_{G}=\frac{I_{1422}}{I_{1422}+I_{1452}}
\end{aligned}
$$

(Equation 3)

(Equation 4)

where $I_{1452}$ and $I_{1422}$ are the intensities of the bands at $1452 \mathrm{~cm}^{-1}$ and 1422 $\mathrm{cm}^{-1}$, respectively. The scaffold composition was revealed to be close to 1:1 ratio of glycolic-lactic units (56:44).

The molar mass analysis was performed by means of size exclusion chromatography (SEC) in terms of number average molar mass $\left(M_{n}\right)$ and weight average molar mass $\left(M_{w}\right)$. Result showed values around 45000 $\mathrm{g} \cdot \mathrm{mol}^{-1}$ for $M_{n}$ and $87000 \mathrm{~g} \cdot \mathrm{mol}^{-1}$ for $M_{\mathrm{w}}$. 
Table 1. Porosity, fibre diameter, composition and average molar masses of initial PLGA scaffold.

\begin{tabular}{cccccccc}
\hline & $\begin{array}{c}\boldsymbol{\rho}_{s} \\
\left(\mathbf{g} \cdot \mathbf{m}^{-2}\right)\end{array}$ & $\begin{array}{c}\boldsymbol{\sigma} \\
(\mathbf{\%})\end{array}$ & $\begin{array}{c}\mathbf{d} \\
(\mathbf{n m})\end{array}$ & $\begin{array}{c}\boldsymbol{C}_{\mathbf{G}} \\
(\mathbf{\%})\end{array}$ & $\begin{array}{c}\boldsymbol{C}_{\mathbf{L}} \\
(\mathbf{\%})\end{array}$ & $\begin{array}{c}\boldsymbol{M}_{\boldsymbol{n}} \\
\left(\mathbf{g} \cdot \mathbf{m o l}^{-\mathbf{1}}\right)\end{array}$ & $\begin{array}{c}\boldsymbol{M}_{\boldsymbol{w}} \\
\left(\mathbf{g} \cdot \mathbf{m o l}^{-\mathbf{1}}\right)\end{array}$ \\
\hline PLGA & 2.6 & 85 & 617 & 56 & 44 & 45000 & 87000 \\
\hline
\end{tabular}

Table 1 gathers the surface density, porosity, average fibre diameter, copolymer composition and average molar mass of the initial scaffold. As a result of the preliminary characterisation, the polyester based (PLGA) scaffold was revealed to accomplish the specifications to be used as a model case.

\subsection{In vitro hydrolytic degradation}

The hydrolytic degradation of polyester-based scaffolds under abiotic aqueous environments is known to take place through breakage of the ester bonds, exponentially auto-catalysed by the presence of carboxylic groups [17]. The microstructural changes occurred in the scaffold induce the formation of macroscopic pores or cracks and the loss of monomeric and oligomeric species, thus reducing the mass of the polymers and finally decomposing their architecture until bioassimilation or excretion [18].

The results of the monitoring of the scaffold along the in vitro hydrolytic degradation in ultra-pure water and PBS are plotted in Figure 3, under the same temporal $\mathrm{X}$-axis in order to compare the response given by different techniques. Parameters such as (a) mass, (b) average molar mass in number $\left(M_{n}\right)$, (c) temperature of the peak of the endotherm superimposed to the glass transition $\left(T_{g t-P}\right)$, (d) $\mathrm{pH}$, (e) conductivity and (f) amount of acid released were chosen for the degradation characterisation. A deep explanation is hereinafter given in each subsection in order to get a glance of the performance of each key indicator chosen for the analysis.

\subsubsection{Mass-loss}

Mass-loss evolution was measured on the sample-vial assembly by gravimetric analysis, which is the most commonly used parameter as indicator of degradation. For the case of PLGA scaffolds, the mass-loss profile was similar under both water and PBS media during the first 30 days, as shown in Fig. 3a. However, after 30 days, the remaining mass of degraded PLGA scaffolds followed different patterns depending on the medium of degradation. Under water, PLGA started to disintegrate until completion after $\sim 60$ days, with an important slope at its degradation profile. In contrast, under PBS, the mass of the scaffold remained almost constant until $\sim 90$ days. After that, a drop of mass took place after $\sim 125$ days with a similar slope than that shown under water. The samples were then completely disintegrated after $\sim 150$ days. These results were in 
accordance with those reported for other scaffolds of PLGA where similar degradation extents were found [27], [28].

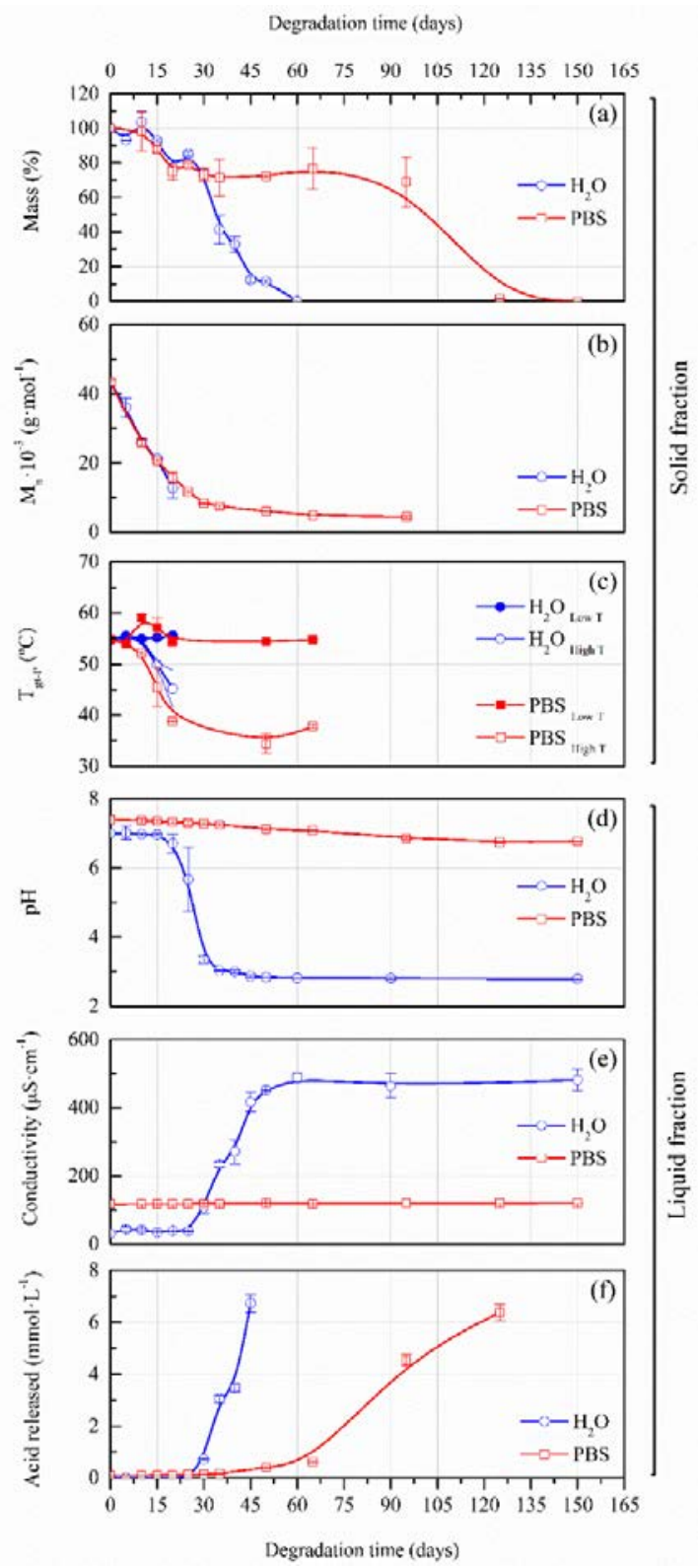

Figure 3. Evolution of hydrolytic degradation indicators for PLGA scaffolds in ultrapure water and phosphate buffer solution (PBS): (a) mass, (b) average molar mass in number $\left(M_{n}\right)$, (c) temperature of the peak of the endotherm superimposed to the glass transition $\left(T_{g t-P}\right),(\mathbf{d}) \mathrm{pH},(\mathbf{e})$ conductivity and (f) amount of acid released. 


\subsubsection{Molar mass}

The in vitro hydrolytic degradation was monitored in terms of molar mass by means of size exclusion chromatography (SEC). The average molar mass in number $\left(M_{n}\right)$ was considered as the most representative parameter of this analysis, which results are plotted in Fig. $\mathbf{3 b}$.

As a result of the hydrolytic degradation of the ester bond and the subsequent chain scission, a shift of the molar mass towards lower values was expected. Actually, when the PLGA scaffolds were submerged into water, a continuous linear fall from initial $M_{n}$ values $\sim 45 \cdot 10^{3} \mathrm{~g} \cdot \mathrm{mol}^{-1}$ to values $\sim 15 \cdot 10^{3} \mathrm{~g} \cdot \mathrm{mol}^{-1}$ up to $\sim 20$ days was found. Afterwards, the samples were impossible to handle. Under PBS, the decay was monitored up to 95 days, adapting the profile to an apparent exponential decrease function, until $M_{n}$ values $\sim 5 \cdot 10^{3} \mathrm{~g} \cdot \mathrm{mol}^{-1}$. After that, the specimens were entirely collapsed and no more analyses could be carried out. These results were in agreement with literature [20], [21], [28].
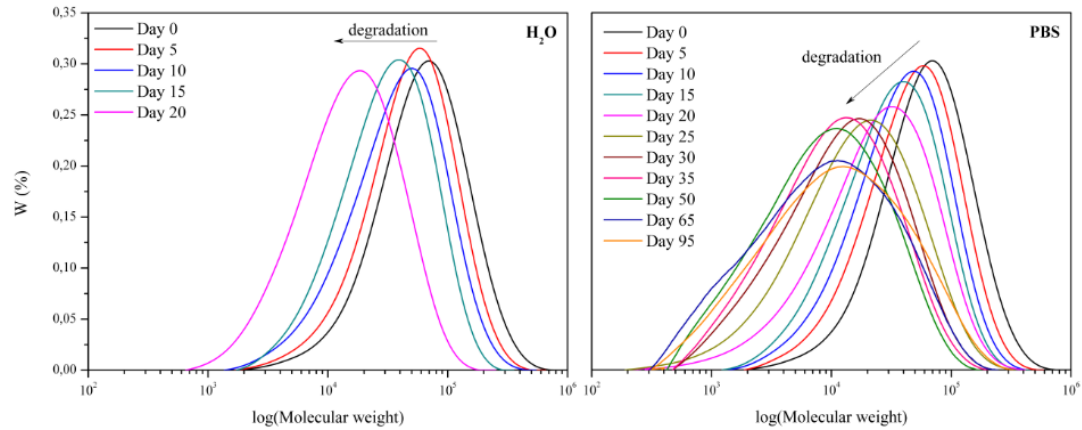

Figure 4. Molar mass distributions of PLGA scaffolds exposed to hydrolytic degradation in ultra-pure water (left) and PBS (right).

Deeper insight could be obtained from SEC analyses. Figure 4 shows the molar mass distributions of the PLGA scaffolds subjected to ultra-pure water and PBS media. A unimodal distribution was observed for nonexposed PLGA, which exhibited a sharp peak at $100 \mathrm{kDa}$. When exposed to ultra-pure water, the molar mass distribution were displaced to lower molar masses, slightly increasing their width. A breakage of the ester bonds seemed to take place for long polymer chains, producing a broader distribution of chain sizes. After $~ 20$ days of degradation, the peak was located around $10 \mathrm{kDa}$. In contrast, scaffolds immersed in PBS showed a different degradation pattern. Until 30 days, a diminution of the height and a broadening of the peaks were observed. The height and shape of the peak was practically maintained from day 30 to day 50 but displaced towards lower molar masses, suggesting that all polymeric chains were equally degraded. The lowest values of molar mass were reached after $\sim 20$ and 95 days in water and PBS, respectively. The formation of different 
segmental-size populations was suggested, due to the appearance of multimodal curves caused by the particular hydrolysis mechanism [18].

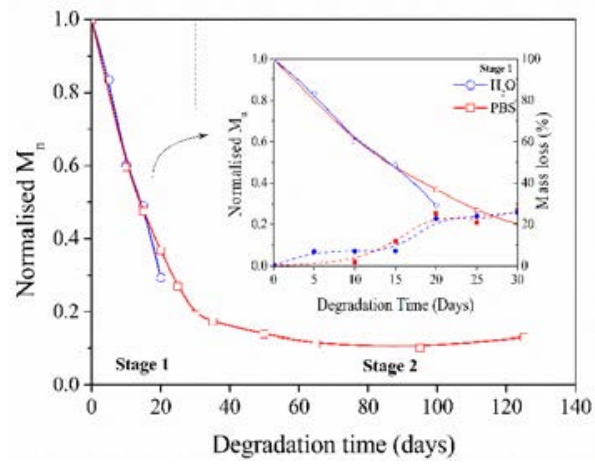

Figure 5. Normalised average molar mass in number $\left(M_{n}\right)$ as a function of the exposure time of PLGA scaffolds to ultra-pure water and PBS. Inset: Detail of the stage 1 from immersion to day $30^{\text {th }}$. Mass loss is included as dotted lines.

The degradation kinetics were studied in Figure 5, where the normalized value of $M_{n}$ is plotted as a function of the degradation time. As commented above, samples subjected to degradation in ultra-pure water after 20 days were impossible to handle so that the degradation mechanism was mainly studied for the PBS medium. According to the mass-loss evolution (Fig. 3a), two well differentiated stages could be observed. In the inset of Fig. 5 the normalized number-average molar mass and the mass-loss are plotted as a function of time. A stage 1 was defined between day 0 and day 30 . The non-linear behaviour of the mass loss perceived in this stage in both media suggested an autocatalytic predominant random scission [40]. However, the presumable acidification of the medium when immersed in water, may had promoted more autocatalytic hydrolysis reactions [17], [18]. Several studies found that a combination of random and end scission is the most common mechanism as well as that an autocatalytic process is more often expected than non-catalytic hydrolysis [41], [42]. From day 30 onwards, the stage 2 was observed. While the samples in water were completely disintegrated, a deceleration of the $M_{n}$ variation could be perceived in the PBS medium, which was indicative of a non-catalytic hydrolysis contribution. This lower catalytic behaviour in PBS was due to the capability of PBS to buffer the acidification of the media which would be supposed to have occurred due to the released low molecular weight acidic species.

\subsubsection{Thermal properties}

The use of differential scanning calorimetry is essential to understand the thermal properties of polymers subjected to different degrading conditions [43]-[50]. Indicators of degradation such as the cold-crystallization 
temperature [44], the partial melting areas [45], the crystallinity degree [51], the relative partial crystallinity or the balance among amorphous and rigid amorphous fractions [52] have been previously proposed for monitoring degradation.

For PLGA scaffolds, no relevant cold-crystallisation and melting behaviours were observed, which ensured that no formation of significant crystalline fractions that could difficult the bioassimilation of scaffolds by macrophagues was produced. Figure 6 shows the DSC traces of the first heating scan of non-exposed PLGA and those subjected to in vitro hydrothermal degradation in both media. The analysis was thus focused on the temperature region from 0 to $100^{\circ} \mathrm{C}$, where the glass transition and the endothermic enthalpy associated to the release of energy accumulated during physical annealing at temperatures below the glass transition are shown. This sharp endotherm was revealed at short degradation times, and became broader the longer the hydrolytic exposure was. This phenomenon variated from unimodal to bimodal after 15-20 days, which was ascribed to the different glass transitions of the components of the copolymer, i.e. poly(glycolide) (PGA), between 35 and $40^{\circ} \mathrm{C}$, and poly(lactide) (PLA), between 55 and $60{ }^{\circ} \mathrm{C}$ [53].

The temperatures of the peaks of the endotherm superimposed to the glasstransition ( $\left.T_{g t-P}\right)$ were chosen as indicators of degradation, as plotted in Fig. 3c. The initial $T_{g t-P}$ values were located around $54.5^{\circ} \mathrm{C}$, which decoupled towards high temperature (high-T) and low temperature peaks (low-T). The low-T peak, decreased to $\sim 45^{\circ} \mathrm{C}$ under water and to $\sim 35^{\circ} \mathrm{C}$ under PBS, corresponding to a $17 \%$ and a $35 \%$ of reduction, respectively, with similar fashion as that shown by mass-loss. These results are in concordance with other reports that suggested a more preferential hydrolytic degradation of the glycolic-glycolic and glycolic-lactic ester linkages, in contrast to that of the lactic-lactic bond in random poly(lactide-co-glycolide) polymer chains [54]. Thus, the generation of the independent homopolymeric new segments of poly(lactic acid) and poly(glycolic acid) would contribute to the appearance of separated glass transition events. 

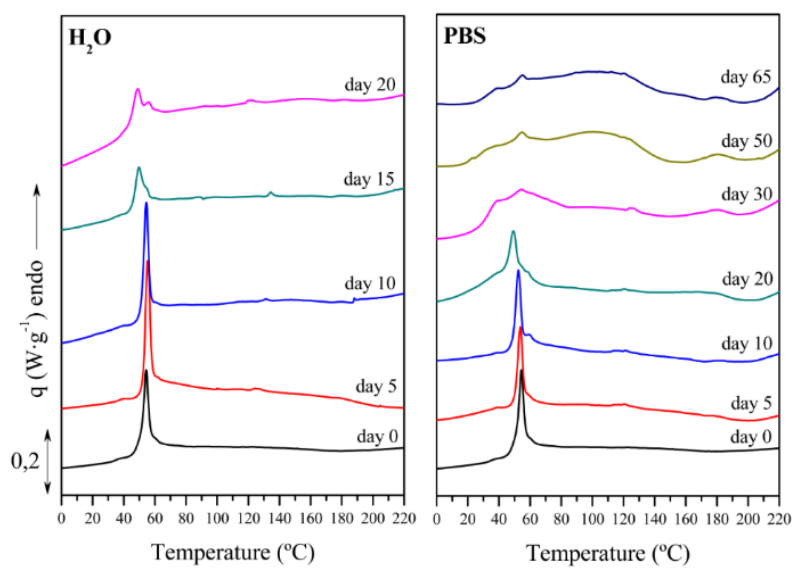

Figure 6. First heating DSC traces for PLGA scaffold after immersion in ultra-pure water and PBS as a function of the exposure time.

\subsubsection{Surface morphology}

The surface morphology of the scaffolds subjected to the in vitro hydrolytic degradation procedure was assessed by means of field-emission scanning electron microscopy (FE-SEM) as a function of the exposure time. Figure 7 shows the surface micrographs of PLGA scaffolds submitted to both media after 5, 10 and 15 days of immersion. Afterwards, handling samples was not possible.

In particular, for PLGA scaffolds immersed in water, a general coalescence, and loss of the initial nanofibrous arrangement as well as growth of pores was perceived. Fibres swelled and seemed to coalesce after 5 days of exposition. After 10 days of immersion, coalescence increased and pores seemed to appear in the surface of scaffolds. Finally, after 15 days, the structure completely coalesced and the pores continuously grew. This behaviour can be ascribed to the hydrolytic degradation behaviour of PLGA, in which water penetrated and diffused into fibres which substantially swelled until coalescence. Afterwards, hydrolytic degradation in bulk occurred and pores appeared due to the release of low molar mass compounds to the hydrolytic media [18], [55]. These observations were in agreement with the results drawn from experiments of mass-loss and DSC shown in Fig. 3, in which the main degradation stage seemed to be triggered around 15 days. Indeed, the molar mass of PLGA at this stage decreased by $50 \%$, thus supporting the statement of threshold of performance in this medium.

However, when subjected to PBS, the degradation process appeared to be considerably different and slower than that observed in water. Although a swelling effect seemed to take place after 5 days of immersion, 
conglutination was not reached. After 10 days, swelling hardly occurred and some fibres looked to be broken or separated, showing more terminal ends. In addition, tiny holes appeared in fibres, indicating individual fibre degradation. After 15 days, similar morphology was observed but small pores became higher and deeper, due to the advance of degradation. In contrast with the experiments in water, although PLGA also showed a 50\% reduction of molar mass at this stage and the trigger of degradation was pointed out by DSC, the mass-loss profile followed a plateau stage during longer times, due to the inhibition of acidic species by PBS, thus decelerating the chain scission of the scaffolds and consequently maintaining the structure.
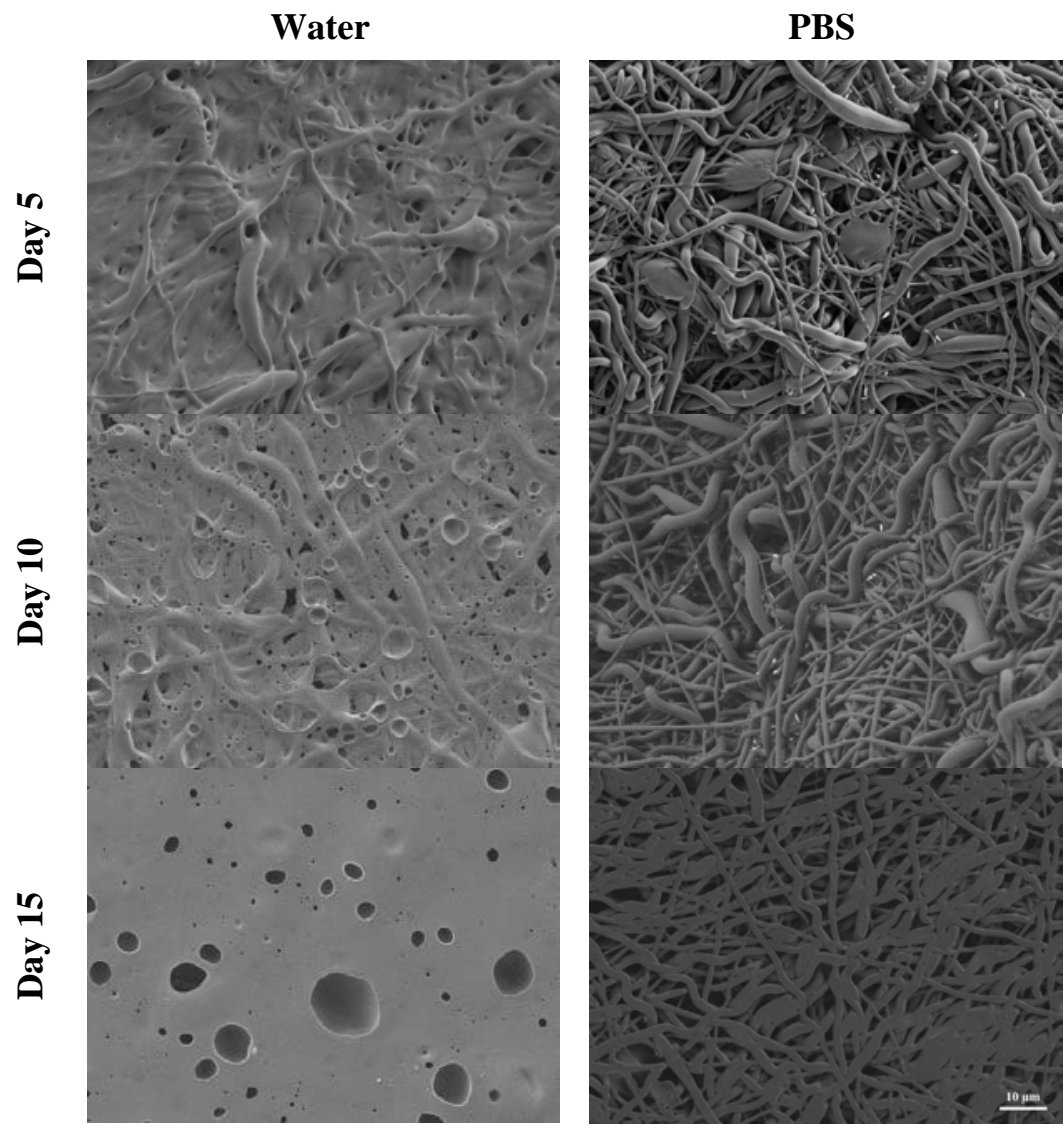

Figure 7. FE-SEM images ( $3 \mathrm{kV}, 1000 \times, 10 \mu \mathrm{m})$ of the scaffold surface subjected to degradation in water (left) and PBS (right). 


\subsubsection{Analysis of the hydrolytic degradation media}

Though the significance of the characterisation of the scaffolds is essential to understand the effects of the degradation on their molecular architecture and thus on their physico-chemical properties and performance, the parallel observation of the hydrolytic degrading media can offer quick information of the state of degradation and even more, fast data to infer the impact of the degradation of biopolymer polyester-based scaffolds. The evolution of the $\mathrm{pH}$, conductivity and acid released are shown in Figs. 3d, e and $\mathbf{f}$, respectively.

When immersed in water, the $\mathrm{pH}$ remained constant until day 15, when it dramatically decreased from neutral $\mathrm{pH} \sim 7$ to acidic $\mathrm{pH} \sim 3$ around day 30, as displayed in Fig. 3d. This drop was assigned to a large release of acidic species, not only glycolic and lactic acid units but also acidic oligomers that may cause acidification of the media, according to other studies [18], [21]. In contrast, when samples were exposed to PBS, the general tendency of the $\mathrm{pH}$ was to remain almost constant along the degradation process, due to the ability of this solution to neutralise acidic species released during degradation, as previously suggested. Nonetheless a slight diminution can be considered from $\mathrm{pH} 7.4$ to $\mathrm{pH} 6.6$ in concordance with results found by other authors [56]-[60], coinciding with the main mass-loss stage in Fig. 3a.

Concerning conductivity, it showed an inversed pattern than that exhibited by $\mathrm{pH}$ at similar stages (see Fig. 3e). When measured in ultra-pure water, the conductivity remained constant showing values around $35 \mu \mathrm{S} \cdot \mathrm{cm}^{-1} \mathrm{up}$ to 20 days. After that, an abrupt growth was observed, reaching conductivities near to $500 \mu \mathrm{S} \cdot \mathrm{cm}^{-1}$ almost symmetrically to the $\mathrm{pH}$ evolution. However, the intrinsic conductivity of the PBS media showed such a high value that the effect of acidic species released to the media was overlapped. Conductivity remained constant around $110 \mathrm{mS} \cdot \mathrm{cm}^{-1}$, characteristic of the phosphate buffer solution.

The $\mathrm{pH}$ and the release of acid species could be correlated by means of titration patterns, which were prepared for lactic and glycolic acids, as shown in Figure 8. Similar titration profiles were obtained for both species. A Boltzmann-like trend was observed in water and PBS. By measuring the $\mathrm{pH}$ of the degradation media and the aid of these curves, the amount of acid released in the degradation media as a function of time could be estimated. Thus, in Fig. 3f, a similar but delayed acid releasing profile was shown for ultra-pure water and PBS. First, a slow release period was found, followed by a fast release stage. In ultra-pure water, the inflection point was located after 30 days. However, in PBS, the slow release period was prolonged until $\sim 70$ days, when a fast release was found. Still, when the release was faster, it was quicker in water than in PBS, due to the autocatalytic 
hydrolytic reaction taking place in water, as proposed by the degradation kinetics studied by SEC.

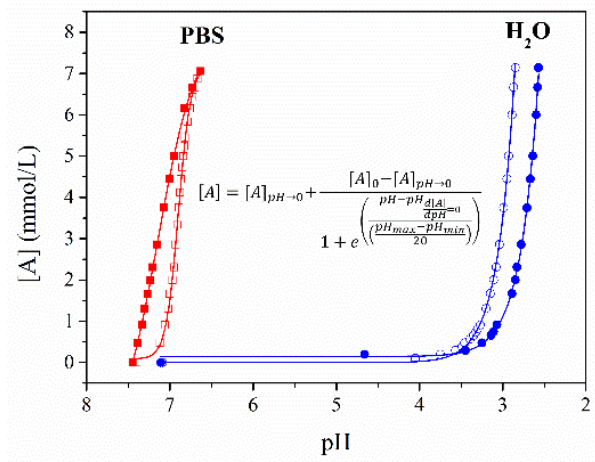

Figure 8. Titration pattern curves for water (circles) and PBS (squares) with lactic (solid) and glycolic (open) acids.

\subsection{In vitro biocompatibility}

\subsubsection{Cell attachment and viability}

The evaluation of the cell capacity to be attached and proliferate onto the scaffolds over time is one of the fundamental approaches to take into account when assessing biocompatibility. It is known that cells attachment decrease when the scaffolds pore size is increased [61] and similar effect could be observed depending on the nanofibrous arrangement. For this purpose, fibroblasts were seeded onto the PLGA scaffold and cultured along 48 and $96 \mathrm{~h}$. Then, the cells were nuclear stained with DAPI. A great number of cell was observed in both conditions, as shown in Figure 9a, indicating that PLGA supported cell adhesion. Indeed, scanning electron microscope images from scaffolds cultured during $48 \mathrm{~h}$ revealed that the cells were completely attached to the scaffold and formed a continuous layer, covering the whole surface (Figure 9b). The cell proliferation was also measured by MTT assay. As expected, cells were able to grown on the scaffold after 48 and $96 \mathrm{~h}$. It was observed a slight increase of proliferation over the time, which results are plotted in Figure 9c.

\subsubsection{Inflammatory response of cells}

When assessing biocompatibility, the study of whether the scaffold induces an inflammatory response on the cells is crucial [33], [62]. Among other methods to evaluate the inflammatory response, pyrogenic test is one of the fastest methods, giving as a result quite relevant information. In vitro pyrogen test method recommended by the FDA requires the measurement of IL-6 and IL-1 beta as pro-inflammatory cytokines. In this particular case, we decided to include TNF-a as well to make the assay more robust and IL-10 as an indicator of a potential anti-inflammatory effect. Peripheral 
blood mononuclear cells (PBMCs) were cultured onto PLGA scaffolds during $5 \mathrm{~h}$ and subsequently RNA was extracted for gene expression analysis. Cells were also incubated with PHB as positive control, as it is a widely used polymer in regenerative medicine [38], [63]. Cells cultured without any scaffold were considered as negative control. IL-1 $\beta$ (interleukin $1 \beta$ ) expression was induced after culture with PLGA scaffolds but values were lower than those observed with PHB scaffolds. Same results were observed with IL-6 (interleukin 6), IL-10 (interleukin 10) and TNF (tumour necrosis factor), as observed in Figure 9d.

a)
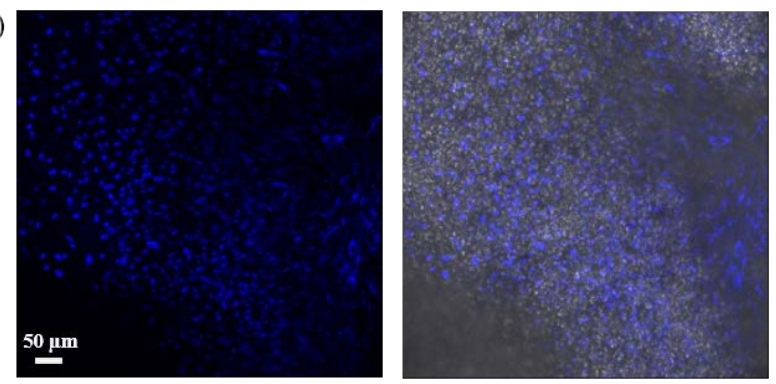

b)
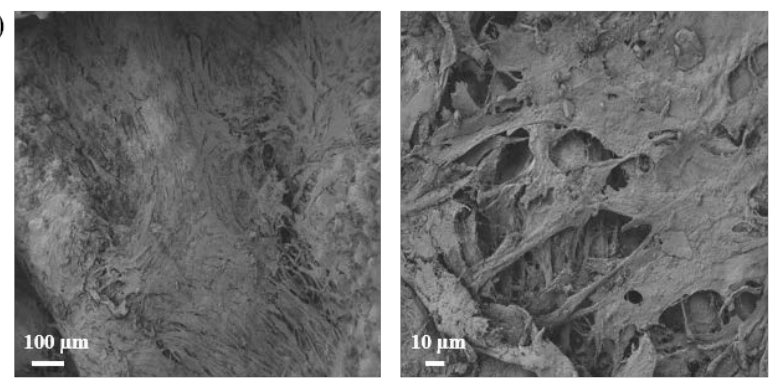

c)

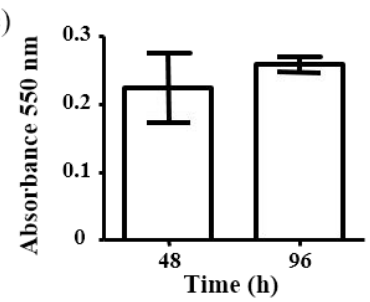

d)

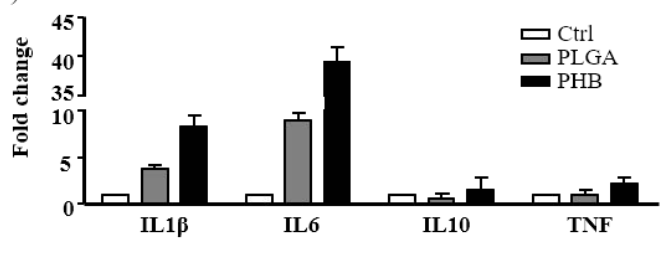

Figure 9. (a) Nuclear staining with DAPI of human fibroblasts cultured on PLGA scaffolds for $48 \mathrm{~h}$ (left) and overlapping images of DAPI and transmitted light (right). Scale bar $50 \mu \mathrm{m}$; (b) Scanning electron microscope images of fibroblasts cultured during $48 \mathrm{~h}$ in PLGA scaffolds. Scale bars $100 \mu \mathrm{m}$ (left) and $10 \mu \mathrm{m}$ (right); and (c) Fibroblasts viability on PLGA scaffolds measured at $48 \mathrm{~h}$ and $96 \mathrm{~h}$ by MTT assay. Absorbance was measured at $550 \mathrm{~nm}$, data are expressed as arbitrary units; (d) IL-1 $\beta$, IL-6, IL-10 and TNF gene expression of PBMCs incubated with PLGA scaffold, PHB scaffold and without any scaffold (control). 


\subsubsection{Toxicity of the monomeric constituents of the scaffold}

The hydrolytic degradation of the polyester based scaffolds generates the release of low molar mass compounds to the surrounding media of the implant. These compounds, ultimately comprise the monomeric constituents of the polymer material [18], [55]. The chemical composition of the scaffolds focused on this study is based on the copolymer poly(lactide-Co-glycolide) composed of lactic and glycolic acid units. Accordingly, the study of the effect of these monomeric compounds on the cell viability in terms of the toxic concentration is substantially relevant. The MTT results are shown in Figure 10a and 10b. Human fibroblasts and Keratinocytes were incubated on different concentrations of lactic and glycolic acids. In both acids, toxicity was found at concentrations above 30 $\mathrm{mM}$ which was correlated with a decrease of the absorbance measured at $550 \mathrm{~nm}$. Conversely, no toxicity was found at lower concentrations and no differences were observed in comparison to the control sample (0 mM).

a)

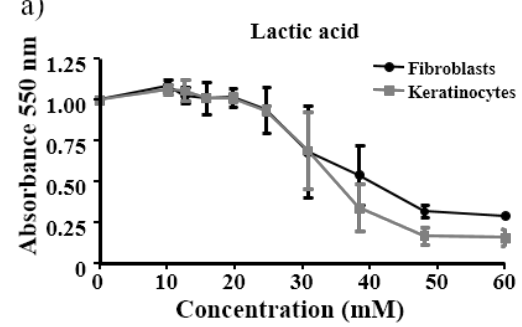

b)



Figure 10. Toxicity evaluation for different concentrations of lactic (a) and glycolic (b) acids by MTT assay.

3.4. Semi-quantitative comparison of monitoring techniques in terms of promptness of identification, simplicity, knowledge and cost

Two radar-like charts, plotted in Figures 11a and $\mathbf{1 1 b}$ were considered in this study to compare the several techniques used for the in vitro validation (hydrolytic degradation and biocompatibility, respectively) for a polyester based scaffold. Aspects such as the promptness of identification, the simplicity of obtaining results, the depth of offered knowledge, and the cost of the techniques need to be taken into account in order to offer a general overview of techniques. Accordingly, techniques were inter-compared in terms of the cited aspects and rated based on a Likert-scale with a range of 1 to 5 , where 1 denoted the lowest desired value and 5 the highest desired value for the appropriate evaluation of the technique for every factor of comparison. For the sake of clearness, it is important to remark that the square bound by corners represent the most convenient value for each variable. Thus, the highest frame square should represent the cheapest, 
simplest and promptest technique, which also provides more knowledge about what is happening during the degradation.

All the techniques and results shown above offer a particular and specific vision of the in vitro validation of polyester based scaffolds for biomedical applications, since each method possesses some characteristics that differentiate it from others. The appropriate analysis of these characteristics would result in a useful picture to set up a suitable plan of analysis for the in vitro validation of polyester-based scaffolds depending on the balance between the interest in ascertaining the trigger of the process or going deeper into the knowledge of the causes and effects along validation.
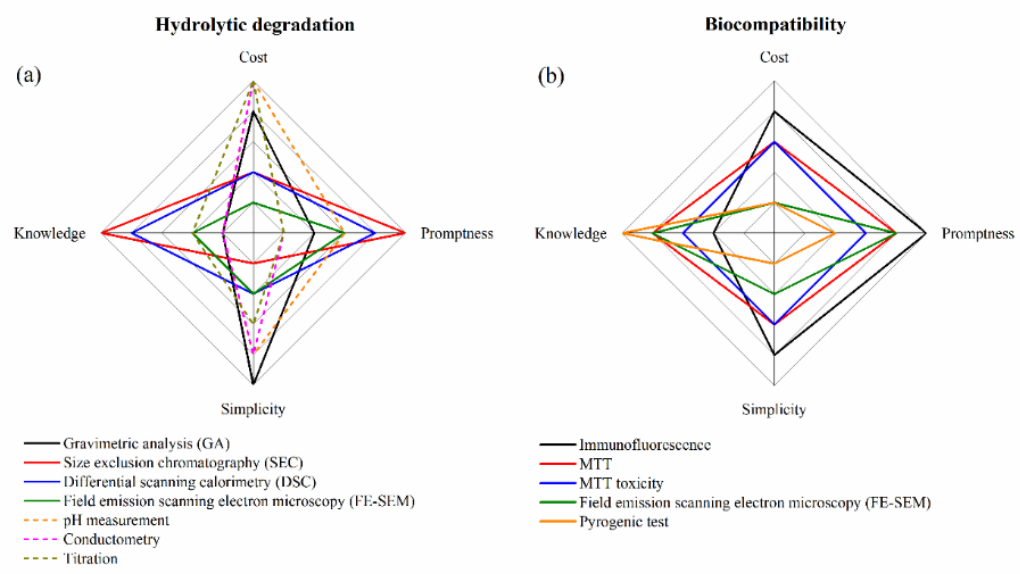

Figure 11. Radar-like chart comparing techniques for the in vitro validation of a polyester based scaffold in terms of (a) hydrolytic degradation and (b) biocompatibility according to promptness of identification, simplicity, depth of knowledge and favourable cost of the technique.

A comparison of the response of a set of different materials and/or formulations to an in vitro validation procedure can be expensive and highly time-consuming if all the techniques are applied. However, a fast trial to choose the right material according to the performance needs may be practical considering promptness of identification. The rapidness of identification of degradation is essential in preliminary tests. Hydrolytic degradation can be identified after a month of exposure for the majority of techniques. However, techniques such as SEC and DSC can offer information at shorter times, being the former extremely accurate in measuring degradation from the very beginning. Biocompatibility assays give, in general, a fast response in comparison to the study of the hydrolytic degradation. The immunofluorescence, MTT, FE-SEM, pyrogenic test and MTT toxicity assays bring results in a relative short time-span. 
The estimation of the simplicity of the techniques is relevant when aspects such as the proficiency needed to become expert in the technique to prepare samples and experiments, run tests and post-operate the results appropriately are considered. There are some techniques which are easy and simple to use, as the $\mathrm{pH}$ or conductivity measurements, the gravimetric analysis and the titration for ascertaining the hydrolytic degradation and immunofluorescence to assess biocompatibility, where one almost immediately gets the results without exhaustive preparation and post-data treatment. However, some other techniques such as FE-SEM, SEC, DSC or MTT assays require accurate sample preparation and a thorough procedure to perform the experiment and analyse the results. Pyrogenic test is also a highly complex technique in terms of preparation and performance of the experiments as well as during the interpretation of results.

The cost and maintenance of the techniques also plays an important role that needs to be taken into account. Some expensive and specific measurements were carried out by FE-SEM, DSC and SEC to understand degradation mechanisms. In contrast, ready available techniques used to identify and monitor the degradation profile were gravimetric analysis, $\mathrm{pH}$ measurement, conductometry and titration, which are considered as cheap, simple and easy-to-access techniques. In terms of cost, biocompatibility assays showed high variation. The pyrogenic test was the most expensive validation technique for the biocompatibility assessment, followed by the FE-SEM analysis, if compared to MTT and immunofluorescence assays. Actually, immunofluorescence is an economic technique that should be complemented with other assays. MTT and toxicity assays are techniques that offer interesting results at a reasonable cost.

The depth of knowledge permits distinguishing techniques according to the level, wideness and variety of results that can be obtained. In-depth techniques such as SEC and DSC offer results from which a great number of suggestions and explanations of the degradation mechanism can be obtained, as well as permits infer consequences on the physico-chemical properties. Conversely, there are other single-result techniques that offer a macroscopic observation of mass, $\mathrm{pH}$ or conductivity, which might render information about the occurrence of degradation, but not about its state. FE-SEM and titration would be in the middle of the proposed score, since they endow useful information suggesting some mechanism of degradation. Pyrogenic test and MTT assay give an overview on how inflammatory and toxic is a polymeric scaffold. Both techniques are required when validating the biocompatibility of a given biomedical device. The evaluation of the toxicity of the monomeric constituents of the polymer material is also essential to determine the maximum tolerable concentration of such compounds when released during the hydrolytic degradation. However, although the results obtained from 
immunofluorescence assay showed that cells are actually attached and spread onto the scaffold, this technique do not offer such knowledge as the pyrogenic test, the FE-SEM and the MTT assays.

\section{Conclusions}

Monitoring and understanding the in vitro behaviour of polyester-based scaffolds, both comprising the study of the hydrolytic degradation and the biocompatibility is essential to ensure the desired performance, according to a given biomedical purpose. Poly(lactide-co-glycolide) (PLGA) scaffolds were considered as a model-case for polyester-based devices to compare the performance of different analytical techniques to monitor the in vitro hydrolytic degradation and biocompatibility.

The suitability of techniques for the in vitro validation procedure was evaluated in terms of the promptness of identification, simplicity of obtaining results, depth of offered knowledge, and cost and maintenance. Results showed a useful picture to set up an appropriate plan of analysis of the degradation of polyester-based scaffolds depending on the balance between the interest in ascertaining the trigger of degradation or deep into the knowledge of the causes and effects along validation.

When assessing the hydrolytic degradation, the size exclusion chromatography and the differential scanning calorimetry were found to be the techniques that offered deeper knowledge and promptness of identification. However, these techniques are costly and complex to evaluate. Conversely, economic and simple techniques as the gravimetric analysis of the scaffold and the $\mathrm{pH}$ and conductivity measurements in the degradation media were considered, which offered little knowledge and late identification of the degradation.

Regarding the biocompatibility evaluation, the pyrogenic test is the most specific that brings more knowledge about the cell's response when seeded into the scaffold. Then, the MTT assay both for the scaffold and the monomeric constituents of the polymer was found to be an equilibrated technique in terms of the studied parameters. The immunofluorescence test was the simplest and the promptest technique at a favourable cost, that brings information about the cell viability and distribution onto the scaffold. In order to deeply evaluate the cell morphology and distribution, costly techniques such as FE-SEM are needed. This technique gives an accurate overview of the cell morphology and appearance over the scaffold surface.

These results can be of interest to researchers, technologists and physicians who plan to study the balance between performance and degradation of polyester-based scaffolds in a cost-effective way, depending on the focus of the test, i.e. from quick discarding trials according to simple promptness 
of identification, to a detailed tailoring of compositions according to the indepth knowledge of the physico-chemical reasons behind the behaviour under physiological conditions.

\section{Acknowledgements}

The authors would like to acknowledge the Spanish Ministry of Education, Culture and Sports for the predoctoral FPU grant of O. Gil-Castell (FPU13/01916). Generalitat Valenciana is thanked for the APOSTD/2014/041 for J.D. Badia. D. Castellano and I. Ontoria-Oviedo thanked RESOLTEX (Ministry of Economy, Industry and Competitiveness RETOS, RTC-2015-4185-1) and P. Sepúlveda acknowlewdges ISCIII for I3SNS Program.

\section{References}

[1] S. Shalaby, Ed., Biomedical Polymers: Designed-to-Degrade Systems. Munich: Hanser Publishers, 1994.

[2] B. D. (Buddy D. . Ratner, Biomaterials science: an introduction to materials in medicine. Academic Press, 2013.

[3] S. Stratton, N. B. Shelke, K. Hoshino, S. Rudraiah, and S. G. Kumbar, "Bioactive polymeric scaffolds for tissue engineering,” Bioact. Mater., vol. 1, no. 2, pp. 93-108, Dec. 2016.

[4] F. Pati, J. Jang, D.-H. Ha, S. Won Kim, J.-W. Rhie, J.-H. Shim, D.-H. Kim, and D.-W. Cho, "Printing three-dimensional tissue analogues with decellularized extracellular matrix bioink,” Nat. Commun., vol. 5, p. 3935, Jun. 2014.

[5] D. Puppi, F. Chiellini, M. Dash, and E. Chiellini, "Biodegradable polymers for biomedical applications,” Nova Science Publishers, Inc., 2011, pp. 545-604.

[6] P. A. Gunatillake and R. Adhikari, "Biodegradable synthetic polymers for tissue engineering.,” Eur. Cell. Mater., vol. 5, p. 1-16; discussion 16, May 2003.

[7] W.-J. Li, J. A. Cooper, R. L. Mauck, and R. S. Tuan, "Fabrication and characterization of six electrospun poly( $\alpha$-hydroxy ester)-based fibrous scaffolds for tissue engineering applications,” Acta Biomater., vol. 2, no. 4, pp. 377-385, Jul. 2006.

[8] S. Chung, N. P. Ingle, G. A. Montero, S. H. Kim, and M. W. King, "Bioresorbable elastomeric vascular tissue engineering scaffolds via melt spinning and electrospinning,” Acta Biomater., vol. 6, no. 6, pp. 1958-1967, Jun. 2010.

[9] O. Gil-Castell, J. D. D. Badia, E. Strömberg, S. Karlsson, and A. Ribes-Greus, "Effect of the dissolution time into an acid hydrolytic solvent to tailor electrospun nanofibrous polycaprolactone scaffolds,” Eur. Polym. J., vol. 87, pp. 174-187, 2017.

[10] W.-E. Teo, R. Inai, and S. Ramakrishna, "Technological advances in electrospinning of nanofibers,” Sci. Technol. Adv. Mater., vol. 12, no. 1, p. 13002, 2011.

[11] D. I. Braghirolli, D. Steffens, and P. Pranke, "Electrospinning for regenerative medicine: a review of the main topics,” Drug Discov. Today, vol. 19, no. 6, pp. 743-753, 2014.

[12] A. Haider, S. Haider, and I. K. Kang, "A comprehensive review summarizing the effect of electrospinning parameters and potential applications of nanofibers in biomedical and biotechnology,” Arab. J. Chem., vol. In press, 2015.

[13] J. D. Badia, O. Gil-Castell, and A. Ribes-Greus, "Long-term properties and end-of-life of polymers from renewable resources,” Polym. Degrad. Stab., vol. 137, pp. 35-57, 2017.

[14] D. Liang, B. S. Hsiao, and B. Chu, "Functional electrospun nanofibrous scaffolds for biomedical applications,” Adv. Drug Deliv. Rev., vol. 59, no. 14, pp. 1392-1412, Dec. 2007.

[15] S. Agarwal, A. Greiner, and J. H. Wendorff, "Functional materials by electrospinning of polymers,” Prog. Polym. Sci., vol. 38, no. 6, pp. 963-991, Jun. 2013.

[16] Edith Mathiowitz, Ed., Encyclopedia of controlled drug delivery. John Wiley \& Sons, 1999. 
[17] M. Hakkarainen, A.-C. Albertsson, and S. Karlsson, "Weight losses and molecular weight changes correlated with the evolution of hydroxyacids in simulated in vivo degradation of homo- and copolymers of PLA and PGA,” Polym. Degrad. Stab., vol. 52, no. 3, pp. 283-291, Jun. 1996.

[18] A. Göpferich, "Mechanisms of polymer degradation and erosion,” Biomaterials, vol. 17, no. 2, pp. 103-114, Jan. 1996.

[19] T. D. Farahani, A. A. Entezami, H. Mobedi, and M. Abtahi, "Degradation of Poly(D,Llactide-co-glycolide) 50:50 Implant in Aqueous Medium,” Iran. Polym. J., vol. 14, no. 8, pp. 753-763, 2005.

[20] E. Vey, C. Roger, L. Meehan, J. Booth, M. Claybourn, A. F. Miller, and A. Saiani, "Degradation mechanism of poly(lactic-co-glycolic) acid block copolymer cast films in phosphate buffer solution,” Polym. Degrad. Stab., vol. 93, no. 10, pp. 1869-1876, Oct. 2008.

[21] X. S. Wu and N. Wang, "Synthesis, characterization, biodegradation, and drug delivery application of biodegradable lactic/glycolic acid polymers. Part II: biodegradation.,” J. Biomater. Sci. Polym. Ed., vol. 12, no. 1, pp. 21-34, 2001.

[22] R. F. Pereira and P. J. Bártolo, "Degradation Behavior of Biopolymer-based Membranes for Skin Tissue Regeneration,” Procedia Eng., vol. 59, pp. 285-291, Jan. 2013.

[23] J. Venugopal and S. Ramakrishna, "Biocompatible Nanofiber Matrices for the Engineering of a Dermal Substitute for Skin Regeneration,” Tissue Eng., vol. 11, no. 56, pp. 847-854, May 2005.

[24] J. Yu, A.-R. Lee, W.-H. Lin, C.-W. Lin, Y.-K. Wu, and W.-B. Tsai, "Electrospun PLGA Fibers Incorporated with Functionalized Biomolecules for Cardiac Tissue Engineering," Tissue Eng. Part A, vol. 20, no. 13-14, pp. 1896-1907, Jul. 2014.

[25] H. Fouad, T. Elsarnagawy, F. N. Almajhdi, and K. A. Khalil, "Preparation and In Vitro Thermo-Mechanical Characterization of Electrospun PLGA Nanofibers for Soft and Hard Tissue Replacement,” Int. J. Electrochem. Sci, vol. 8, pp. 2293-2304, 2013.

[26] M. V. Jose, V. Thomas, K. T. Johnson, D. R. Dean, and E. Nyairo, “Aligned PLGA/HA nanofibrous nanocomposite scaffolds for bone tissue engineering,” Acta Biomater., vol. 5, no. 1, pp. 305-315, Jan. 2009.

[27] Y. You, B.-M. Min, S. J. Lee, T. S. Lee, and W. H. Park, "In vitro degradation behavior of electrospun polyglycolide, polylactide, and poly(lactide-co-glycolide),” J. Appl. Polym. Sci., vol. 95, no. 2, pp. 193-200, Jan. 2005.

[28] X. Zhou, Q. Cai, N. Yan, X. Deng, and X. Yang, "In vitro hydrolytic and enzymatic degradation of nestlike-patterned electrospun poly(D,L-lactide-co-glycolide) scaffolds," J. Biomed. Mater. Res. Part A, vol. 95A, no. 3, pp. 755-765, Dec. 2010.

[29] S. R. Andersson, M. Hakkarainen, S. Inkinen, A. Södergård, and A.-C. Albertsson, "Polylactide Stereocomplexation Leads to Higher Hydrolytic Stability but More Acidic Hydrolysis Product Pattern,” Biomacromolecules, vol. 11, no. 4, pp. 1067-1073, Apr. 2010.

[30] A. Höglund, S. Målberg, and A. C. Albertsson, "Assessing the Degradation Profile of Functional Aliphatic Polyesters with Precise Control of the Degradation Products," Macromol. Biosci., vol. 12, no. 2, pp. 260-268, Feb. 2012.

[31] V. Arias, P. Olsén, K. Odelius, A. Höglund, and A.-C. Albertsson, "Selective degradation in aliphatic block copolyesters by controlling the heterogeneity of the amorphous phase,” Polym. Chem., vol. 6, no. 17, pp. 3271-3282, Apr. 2015.

[32] A. Höglund, K. Odelius, and A.-C. Albertsson, "Crucial Differences in the Hydrolytic Degradation between Industrial Polylactide and Laboratory-Scale Poly( L -lactide)," ACS Appl. Mater. Interfaces, vol. 4, no. 5, pp. 2788-2793, May 2012.

[33] D. Castellano, M. Blanes, B. Marco, I. Cerrada, A. Ruiz-Saurí, B. Pelacho, M. Araña, J. A. Montero, V. Cambra, F. Prosper, and P. Sepúlveda, “A Comparison of Electrospun Polymers Reveals Poly(3-Hydroxybutyrate) Fiber as a Superior Scaffold for Cardiac Repair,” Stem Cells Dev., vol. 23, no. 13, pp. 1479-1490, Jul. 2014.

[34] P. Sangsanoh, S. Waleetorncheepsawat, O. Suwantong, P. Wutticharoenmongkol, O. Weeranantanapan, B. Chuenjitbuntaworn, P. Cheepsunthorn, P. Pavasant, and P. Supaphol, "In Vitro Biocompatibility of Schwann Cells on Surfaces of Biocompatible Polymeric Electrospun Fibrous and Solution-Cast Film Scaffolds,” Biomacromolecules, vol. 8, no. 5, pp. 1587-1594, May 2007. 
[35] “ISO 3696. Water for analytical laboratory use - Specification and test methods,” 1987.

[36] "ISO 10993-13. Biological evaluation of medical devices.” 2010.

[37] A. K. Pathan, J. Bond, and R. E. Gaskin, "Sample preparation for SEM of plant surfaces,” Mater. Today, vol. 12, no. SUPPL., pp. 32-43, 2009.

[38] R. Carrero, I. Cerrada, E. Lledó, J. Dopazo, F. García-García, M.-P. Rubio, C. Trigueros, A. Dorronsoro, A. Ruiz-Sauri, J. A. Montero, and P. Sepúlveda, "IL1 $\beta$ induces

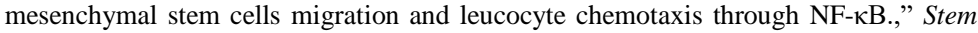
Cell Rev., vol. 8, no. 3, pp. 905-16, Sep. 2012.

[39] L. A. Smith and P. X. Ma, "Nano-fibrous scaffolds for tissue engineering," Colloids Surfaces B Biointerfaces, vol. 39, no. 3, pp. 125-131, 2004.

[40] H. Tsuji, Degradation of poly (lactide)-based biodegradable materials. Nova Science Publishers, 2008.

[41] A. Gleadall, J. Pan, M.-A. Kruft, and M. Kellomäki, "Degradation mechanisms of bioresorbable polyesters. Part 1. Effects of random scission, end scission and autocatalysis,” Acta Biomater., vol. 10, no. 5, pp. 2223-2232, May 2014.

[42] R. P. Batycky, J. Hanes, R. Langer, and D. A. Edwards, “A Theoretical Model of Erosion and Macromolecular Drug Release from Biodegrading Microspheres,” J. Pharm. Sci., vol. 86, no. 12, pp. 1464-1477, Dec. 1997.

[43] J. D. Badia, F. Vilaplana, S. Karlsson, and A. Ribes-Greus, "Thermal analysis as a quality tool for assessing the influence of thermo-mechanical degradation on recycled poly(ethylene terephthalate),” Polym. Test., vol. 28, no. 2, pp. 169-175, 2009.

[44] L. Santonja-Blasco, R. Moriana, J. D. Badía, and A. Ribes-Greus, “Thermal analysis applied to the characterization of degradation in soil of polylactide: I. Calorimetric and viscoelastic analyses,” Polym. Degrad. Stab., vol. 95, no. 11, pp. 2185-2191, Nov. 2010.

[45] J. D. Badia, E. Strömberg, S. Karlsson, and A. Ribes-Greus, "Material valorisation of amorphous polylactide. Influence of thermo-mechanical degradation on the morphology, segmental dynamics, thermal and mechanical performance," Polym. Degrad. Stab., vol. 97, no. 4, pp. 670-678, Apr. 2012.

[46] O. Gil-Castell, J. D. D. Badia, T. Kittikorn, E. Strömberg, M. Ek, S. Karlsson, A. RibesGreus, E. Strömberg, M. Ek, S. Karlsson, and A. Ribes-Greus, "Impact of hydrothermal ageing on the thermal stability, morphology and viscoelastic performance of PLA/sisal biocomposites,” Polym. Degrad. Stab., vol. 132, pp. 87-96, Mar. 2016.

[47] J. D. Badia, T. Kittikorn, E. Strömberg, L. Santonja-Blasco, A. Martínez-Felipe, A. Ribes-Greus, M. Ek, and S. Karlsson, "Water absorption and hydrothermal performance of PHBV/sisal biocomposites,” Polym. Degrad. Stab., vol. 108, pp. 166-174, Oct. 2014.

[48] O. Gil-Castell, J. D. D. Badia, T. Kittikorn, E. Strömberg, A. Martínez-Felipe, M. Ek, S. Karlsson, and A. Ribes-Greus, "Hydrothermal ageing of polylactide/sisal biocomposites. Studies of water absorption behaviour and Physico-Chemical performance,” Polym. Degrad. Stab., vol. 108, pp. 212-222, Oct. 2014.

[49] J. D. Badia and A. Ribes-Greus, "Mechanical recycling of polylactide, upgrading trends and combination of valorization techniques," Eur. Polym. J., vol. 84, pp. 22-39, 2016.

[50] O. Gil-Castell, J. D. Badia, and A. Ribes-Greus, "Suitability of blends from virgin and reprocessed polylactide: performance and energy valorisation kinetics,” Accept. Publ. J. Renew. Mater., 2017.

[51] J. D. Badia, L. Santonja-Blasco, A. Martínez-Felipe, and A. Ribes-Greus, "Hygrothermal ageing of reprocessed polylactide,” Polym. Degrad. Stab., vol. 97, no. 10, pp. 1881-1890, Oct. 2012.

[52] J. D. Badia, E. Strömberg, S. Karlsson, and A. Ribes-Greus, “The role of crystalline, mobile amorphous and rigid amorphous fractions in the performance of recycled poly (ethylene terephthalate) (PET),” Polym. Degrad. Stab., vol. 97, no. 1, pp. 98-107, Jan. 2012.

[53] I. Engelberg and J. Kohn, "Physico-mechanical properties of degradable polymers used in medical applications: a comparative study.,” Biomaterials, vol. 12, no. 3, pp. 292304, Apr. 1991.

[54] J. Li, R. M. Stayshich, and T. Y. Meyer, "Exploiting Sequence To Control the Hydrolysis Behavior of Biodegradable PLGA Copolymers,” J. Am. Chem. Soc., vol. 133, no. 18, pp. 6910-6913, May 2011.

[55] F. von Burkersroda, L. Schedl, A. Göpferich, and A. G. F. von Burkersroda, L. Schedl, 
"Why degradable polymers undergo surface erosion or bulk erosion,” Biomaterials, vol. 23, no. 21, pp. 4221-4231, Nov. 2002.

[56] C. M. Agrawal and K. A. Athanasiou, "Technique to control pH in vicinity of biodegrading PLA-PGA implants.,” J. Biomed. Mater. Res., vol. 38, no. 2, pp. 105-14, 1997.

[57] J. M. Kim, K. S. Seo, Y. K. Jeong, B. L. Hai, Y. S. Kim, and G. Khang, "Co-effect of aqueous solubility of drugs and glycolide monomer on in vitro release rates from poly(D,L-lactide-co-glycolide) discs and polymer degradation.,” J. Biomater. Sci. Polym. Ed., vol. 16, no. 8, pp. 991-1007, 2005.

[58] H. Li and J. Chang, "pH-compensation effect of bioactive inorganic fillers on the degradation of PLGA,” Compos. Sci. Technol., vol. 65, no. 14, pp. 2226-2232, Nov. 2005.

[59] M. Ramchandani, M. Pankaskie, and D. Robinson, "The influence of manufacturing procedure on the degradation of poly(lactide-co-glycolide) 85:15 and 50:50 implants,” J. Control. Release, vol. 43, no. 2-3, pp. 161-173, Jan. 1997.

[60] J. Y. Yoo, J. M. Kim, G. Khang, M. S. Kim, S. H. Cho, H. B. Lee, and Y. S. Kim, "Effect of lactide/glycolide monomers on release behaviors of gentamicin sulfate-loaded PLGA discs,” Int. J. Pharm., vol. 276, no. 1-2, pp. 1-9, May 2004.

[61] C. M. Murphy, M. G. Haugh, and F. J. O’Brien, “The effect of mean pore size on cell attachment, proliferation and migration in collagen-glycosaminoglycan scaffolds for bone tissue engineering,” Biomaterials, vol. 31, no. 3, pp. 461-466, Jan. 2010.

[62] B. Semete, L. I. J. Booysen, L. Kalombo, J. D. Venter, L. Katata, B. Ramalapa, J. A. Verschoor, and H. Swai, "In vivo uptake and acute immune response to orally administered chitosan and PEG coated PLGA nanoparticles," Toxicol. Appl. Pharmacol., vol. 249, no. 2, pp. 158-165, Dec. 2010.

[63] D. Castellano, A. Sanchis, M. Blanes, M. D. M. D. Pérez del Caz, A. Ruiz-Saurí, M. Piquer-Gil, B. Pelacho, B. Marco, N. Garcia, I. Ontoria-Oviedo, V. Cambra, F. Prosper, and P. Sepúlveda, "Electrospun poly(hydroxybutyrate) scaffolds promote engraftment of human skin equivalents via macrophage M2 polarization and angiogenesis,” J. Tissue Eng. Regen. Med., vol. 12, no. 2, pp. e983-e994, Jan. 2017. 


\section{Contribution 5.2.}

Comparison of in vitro hydrolytic degradation patterns of short-term and long-term polyester-based electrospun scaffolds

O. Gil-Castell, J. D. Badia, J. J. Bou, A. Ribes-Greus. Comparison of in vitro hydrolytic degradation patterns of short-term and long-term polyester-based electrospun scaffolds. Manuscript in preparation. 


\title{
Comparison of in vitro hydrolytic degradation patterns of short-term and long-term polyester-based electrospun scaffolds
}

\author{
O. Gil-Castell ${ }^{1}$, J. D. Badia ${ }^{1,2}$, J. J. Bou ${ }^{3}$, A. Ribes-Greus ${ }^{1, *}$ \\ ${ }^{1}$ Instituto de Tecnología de Materiales (ITM). Universitat Politècnica de València. Camino de \\ Vera s/n, 46022 Valencia, Spain. \\ 2Departament d'Enginyeria Química. Escola Tècnica Superior d’Enginyeria. Universitat de \\ València. Av. de la Universitat s/n, 46100 Burjassot, Spain \\ ${ }^{3}$ Departament d'Enginyeria Química. Universitat Politècnica de Catalunya. Av. Diagonal 647 \\ (ETSEIB), 08028 Barcelona, Spain \\ *Corresponding author:
}

A. Ribes-Greus aribes@ter.upv.es 


\title{
Comparison of in vitro hydrolytic degradation patterns of short-term and long-term polyester-based electrospun scaffolds
}

\author{
O. Gil-Castell, J. D. Badia, J. J. Bou, A. Ribes-Greus
}

\begin{abstract}
The evaluation of the performance of polyesters during in vitro hydrolytic degradation is essential to design and produce appropriate scaffolds with a concrete lifespan required for a given application. For this purpose, the degradation patterns of poly(lactide-co-glycolide) (PLGA), polycaprolactone (PCL), polydioxanone (PDO) and polyhydroxybutyrate (PHB) were monitored in ultra-pure water and phosphate buffer solution (PBS) and $37{ }^{\circ} \mathrm{C}$ as a simulation of service conditions for biopolymer scaffolds. The solid fraction was assessed in terms of the evolution of the mass, the surface morphology, the thermal properties and the molar mass, by means of gravimetric analysis, field emission scanning electron microscopy (FE-SEM), differential scanning calorimetry (DSC), and size exclusion chromatography (SEC), respectively. The liquid fraction showed the influence of low molar mass compounds released to the hydrolytic medium, as measured by $\mathrm{pH}$. The considered methodology permitted to ascertain the degradation process regardless the time lifespan of the scaffolds when subjected to physiological conditions. The most relevant indicators were the relative molar mass-loss and the degree of crystallinity of the fibres. On the one hand, scaffolds for short-time applications were PLGA and PDO, and showed a faster disintegration and, subsequently, a pronounced acidification of the medium. On the other hand, scaffolds for long-term applications were PCL and PHB, which resistant pattern was mainly ascribed to the stability of the crystalline domains of the fibres. Under a perspective of an adequate balance between the durability and degradation, the results of this comparison may serve as a reference point in the stage of design and material selection for the development of new polyester-based electrospun scaffolds for biomedical applications.
\end{abstract}

\section{Keywords}

Biopolymer, polyester, scaffolds, tissue engineering, in vitro hydrolytic degradation, poly(lactide-co-glycolide) (PLGA), polydioxanone (PDO), polycaprolactone (PCL), polyhydroxybutyrate (PHB) 


\section{Introduction}

Polyesters are one of the most used polymeric materials for biomedical applications such as sutures, implants, artificial skin and controlled drug release [1]-[5]. Such is the case of the use of polylactide (PLA), polyglycolide (PGA), polycaprolactone (PCL), poly(lactide-coglycolide) (PLGA), polydioxanone (PDO) or polyhydroxybutyrate (PHB). These polymeric materials degrade by hydrolytic processes, and result in low molar mass species, that can be bioabsorbed and metabolised by the human body.

The irruption of electrospinning in tissue engineering has boosted the technology of production of biomaterials based on architectures of fibres, which diameters can vary from the micro-metric scale to hundreds of nanometres [6]-[8], mimicking native extracellular matrix and allowing enough porosity to facilitate cellular growth [9]. Precisely, these scaffolds require ensuring an appropriate balance between enough time of structural endurance to permit angiogenesis, and suitable degradation profiles to be decomposed avoiding an inflammatory response and eluding the delivery of toxic low molar mass compounds. These degradation by-products may affect healthy cells as well as interact within sensitive substances such as proteins and peptides or drugs.

Monitoring and understanding the physico-chemical processes underwent by biopolymeric scaffolds along their exposure to physiological conditions is essential to ensure their performance during application. In this sense, the study of the degradation profiles of the scaffolds is essential to guarantee the desired performance, according to the biomedical purpose, such as skin reparation [10], [11] or cardiac surgeries [12], [13], among others, which will need different times of endurance [14]. In vitro experiments are relevant to test and compare the performance of biopolymeric materials. Concretely, in vitro degradation studies in aqueous media are interesting to assess their durability [15]. When the aqueous solution penetrates into the polymer, it swells incrementing the dimensions of the interface of contact, which promotes further degradation. The mechanism of degradation of polyesters under abiotic aqueous environments takes place through hydrolysis of the ester bonds, auto-catalysed by carboxylic groups, exponentially increasing along the exposure time [16]. These microstructural changes induce the formation of macroscopic pores or 
cracks, and the loss of monomeric and oligomeric species, thus reducing the mass of the polymers and finally decomposing their architecture until bioassimilation or excretion [17]. Accordingly, after a successful growing and spreading of the cells into the scaffold, polyester-based scaffolds are expected to be degraded, disintegrated and assimilated by the patient.

In order to assess the balance of the performance-to-degradation ratio of the scaffolds, the polymer composition plays an important role. Polymers from different origin and physico-chemical features have been proposed for tissue engineering [18]. Among them, natural polymers produced by microbes such as the polyhydroxybutyrate (PHB), as well as synthetic polymers such as the poly(lactide-co-glycolide) (PLGA), the polycaprolactone (PCL) or the polydioxanone (PDO) have been widely used for scaffold development. All of them are known to be resorbable, absorbable or bioabsorbable when implanted in the living body. However, their differences in the crystalline morphology may determine its hydrolytic degradation behaviour.

Characterisation studies of the in vitro degradation of the most used polyesters for biomedical applications in bulk have been reported, with respect to its water-uptake rate, degradation kinetics and mechanisms, morphology and physico-chemical properties [19]. As electrospun scaffolds, some characterisation studies of in vitro degradation have been reported, generally considering the monitoring of mass-loss and molarmass along hydrolytic exposure. The in vitro behaviour under physiologic conditions for PLGA [13], [20], [21], PDO [22], PCL [23] and PHB [24] scaffolds has been studied separately. Moreover, the in vitro degradation studies reported in the literature are usually carried out in the first stages of immersion and complete degradation or disintegration is not commonly addressed. Therefore, a comparison of different polymers under similar conditions may offer a broader vision of their applicability, having in mind the expected lifetime for the future specific application [25].

The aim of this study was therefore to compare the in vitro degradation behaviour of PLGA, PCL, PDO and PHB scaffolds from an experimental and comprehensive perspective, under simulated physiologic in vitro conditions. For this purpose, electrospun scaffolds were subjected to ultra-pure water and phosphate buffer solution (PBS) at $37{ }^{\circ} \mathrm{C}$ until complete disintegration. Accordingly, a set of analytical techniques such as gravimetry, $\mathrm{pH}$ measurement, field-emission scanning electron microscopy (FE-SEM), differential scanning calorimetry (DSC) and size-exclusion chromatography (SEC) was 
proposed to point out the appropriate indicators to monitor and compare the in vitro hydrolytic degradation profiles of these polyester-based scaffolds for biomedical purposes.

\section{Materials and methods}

\subsection{Materials}

PLGA and PDO were provided by Sigma-Aldrich under the grades Resomer RG 505 and Resomer X, respectively; PCL was provided by Perstorp under the grade CAPA 6800; and PHB grade P209 was provided by Biomer. Dimethylformamide (DMF), chloroform and hexafluoroisopropanol (HFIP) were used as solvents for electrospinning. For hydrolytic degradation, ultra-pure water of type 1 (ISO 3696) [26] and Dulbecco's Phosphate Buffered Saline solution (PBS, D1408) and $\mathrm{NaOH}$ $1 \mathrm{M}$ for adjusting $\mathrm{pH}$ in PBS, were used. All these reagents, except water, were supplied by Sigma-Aldrich and were used without further purification.

\subsection{Scaffold preparation}

The fibrous scaffolds were obtained by electrospinning by means of a Yflow Electrospinner 2.2.D-350. It consisted in double polarization, integrated drum collector, control panel and robotized stage to move the electrospinning source in an alternative fashion covering a $400 \times 400 \mathrm{~mm}^{2}$ area. The solutions were prepared at different conditions, as described in Table 1. The solution jet emerging from the stainless steel wire used as the positive electrode ( $0.9 \mathrm{~mm}$ inner diameter) was collected on a waxed paper. Scaffolds were dried over $12 \mathrm{~h}$ under vacuum to facilitate the removal of residual organic solvents and moisture, and stored for further analyses.

Table 1. Electrospinning conditions for the different scaffolds.

\begin{tabular}{lccccc}
\hline $\begin{array}{c}\text { Polymer } \\
\text { (type) }\end{array}$ & $\begin{array}{c}\text { Concentration } \\
\text { (\% wt) }\end{array}$ & $\begin{array}{c}\text { Solvent } \\
\text { (type) }\end{array}$ & $\begin{array}{c}\text { Feed rate } \\
\left(\mathbf{m L} \cdot \mathbf{h}^{-\mathbf{1}}\right)\end{array}$ & $\begin{array}{c}\text { Voltage } \\
\mathbf{( k V )}\end{array}$ & $\begin{array}{c}\text { Distance } \\
(\mathbf{c m})\end{array}$ \\
\hline PCL & 18 & $\mathrm{DMF} / \mathrm{CHCl}_{3} 1: 8$ & 4 & $7.32 /-5.54$ & 25 \\
\hline PDO & 8 & $\mathrm{HFIP}$ & 1 & $3.85 /-3.35$ & 21 \\
\hline PHB & 23 & $\mathrm{CHCl}_{3}$ & 1 & $7.80 /-1.93$ & 20 \\
\hline PLGA & 30 & $\mathrm{DMF}$ & 1 & $9.15 /-8.80$ & 20 \\
\hline
\end{tabular}

\subsection{In vitro degradation}

All the electrospun scaffolds were subjected to hydrolytic degradation, by exposition to ultra-pure water and phosphate buffer saline solution (PBS), according to international norm ISO 10993-13:2010, method 4.3 [27]. Shortly, the initial electrospun scaffolds were cut into rectangular specimens with a mass around $10 \mathrm{mg}$. The specimens were weighed $\left(\mathrm{m}_{0}\right)$ and placed in a previous weighed vial $\left(m_{\text {vial }}\right) .10 \mathrm{~mL}$ of degradation medium were introduced and then the vials were sealed with 
polytetrafluoroethylene (PTFE) threaded plugs and placed in a thermostatically controlled oven at $37^{\circ} \mathrm{C}$. The $\mathrm{pH}$ of the PBS solution was adjusted to 7.4 with $\mathrm{NaOH} 1 \mathrm{M}$. Between twelve and fifteen extractions were considered along the hydrolytic degradation for each scaffold up to disintegration. In order to monitor the process, after certain periods, the scaffolds were withdrawn from the environment by triplicates. The solid and liquid fractions were separated. The degradation media were analysed immediately after extraction, while the remaining scaffold followed a washing-drying-keeping procedure before further analysis. Actually, those specimens coming from the saline buffer were washed with deionized water and then, along with specimens coming from water environment, were dried under vacuum to constant mass into the vials $\left(m_{d r y}\right)$ and kept for further analysis. The residual mass of the samples (\% mass) was determined by the Equation 1,

$$
\% \text { mass }=\frac{m_{d r y}-m_{\text {vial }}}{m_{0}} \times 100 \quad(\text { Equation 1) }
$$

where $m_{0}, m_{\text {vial }}$ are the initial mass of the specimen and the vial, respectively, and $m_{d r y}$ is the mass of the vacuum dry assembly sample-vial after degradation.

The $\mathrm{pH}$ of the degradation media was measured at room temperature by means of a Crison pH25 device. Three buffer solutions from Crison were used to calibrate pH-meter: $\mathrm{pH} 4.01$ (phthalate buffer solution), $\mathrm{pH} 7.00$ (phosphate buffer solution), pH 10.01 (borate buffer solution).

\subsection{Scaffold characterisation}

\subsubsection{Field emission scanning electron microscopy (FE-SEM)}

The surface topology of specimens was analysed by means of a Zeiss Ultra 55 field emission scanning electron microscope (FE-SEM). The samples were cut into small pieces and dried at $50{ }^{\circ} \mathrm{C}$ in a vacuum oven for $24 \mathrm{~h}$ and then kept in a desiccator during $48 \mathrm{~h}$. Afterwards, the specimens were mounted on metal studs and sputter-coated with a platinum layer during 10 s using a Leica EM MED020. The testing was performed at room temperature with a $3 \mathrm{kV}$ voltage. The fibre diameters were measured from the FE-SEM micrographs at random locations $(n=100)$ with the aid of Image J software.

\subsubsection{Differential scanning calorimetry (DSC)}

The calorimetric data were obtained by means of a Mettler-Toledo DSC 820e differential scanning calorimeter, previously calibrated following the procedure of In and Zn standards. The samples, with a mass of about $4 \mathrm{mg}$ were analysed between 0 and $200{ }^{\circ} \mathrm{C}$ with a heating/cooling/heating rate of $10^{\circ} \mathrm{C} \cdot \mathrm{min}^{-1}$. All the experiments were run under nitrogen atmosphere with a flow of $50 \mathrm{~mL} \cdot \mathrm{min}^{-1}$. The specimens were characterised at least by 
triplicate and the averages of temperatures and enthalpies were taken as representative values. The crystallinity degree $\left(X_{c}\right)$ was evaluated from the melting enthalpy results, by means of the Equation 2,

$$
X_{c}(\%)=\frac{\Delta h_{m}}{\Delta h_{m}^{0}} \cdot 100
$$

(Equation 2)

where $\Delta h_{m}$ is the melting enthalpy of the sample and $\Delta h_{m 0}$ is the melting enthalpy of a perfect crystal of the given polymer (PDO $141 \mathrm{~J}^{-1} \mathrm{~g}^{-1}$ [28], PCL $148 \mathrm{~J}^{-1} \mathrm{~g}^{-1}$ [29] and PHB $\left.146 \mathrm{~J} \cdot \mathrm{g}^{-1}[30]\right)$.

\subsubsection{Size exclusion chromatography (SEC)}

Size exclusion chromatography (SEC) analyses were carried out by means of an Agilent Infinity 1260 chromatograph. Separation was performed with a Jordi Associates mixed bed fluorinated column (permeation range: 100 $10 \cdot 10^{6}$ Dalton). All samples were dissolved in mobile phase containing $2.72 \mathrm{~g} \cdot \mathrm{L}^{-1}$ of sodium trifluoroacetate (NaTFA). This solvent was previously degassed by vacuum filtration over PTFE $0.45 \mu \mathrm{m}$ pore membranes. Flow rate was set at $1 \mathrm{~mL} \cdot \mathrm{min}^{-1} .100 \mu \mathrm{L}$ samples of about $0.1 \%$ concentration were injected. Detection was conducted by UV-visdetector. Monodisperse PMMA samples from Sigma Aldrich and Agilent were used for previous calibration.

\section{Results and discussion}

In this section, a short initial characterisation of the starting scaffolds is given, as it will determine their subsequent behaviour during application. After that, the degradation profiles in ultra-pure water and PBS were studied in the remaining scaffold. On the one hand, ultra-pure water permitted to ascertain the pure hydrolytic degradation due to the effect of the water, the temperature and the changes in the hydrolytic media. On the other hand, the PBS solution allowed to simulate physiologic conditions and the buffering of the likely released acidic low molar mass compounds. After several stages of immersion, the mass-loss evolution, the surface morphology, the thermal properties and the molar mass of the scaffolds were evaluated. For this purpose, techniques such as gravimetric analysis, field emission scanning electron microscopy (FE-SEM) and differential scanning calorimetry (DSC) and size exclusion chromatography (SEC) were used. Additionally, the study of the $\mathrm{pH}$ of the hydrolytic degradation media was reported as indicator of the advance of the degradation. 


\subsection{Initial properties and morphology of the scaffolds}

The in vitro degradation behaviour is mainly controlled by the polymer chemistry and physical features of the scaffold. Accordingly, some of the most influent parameters of a scaffold that will determine its subsequent biomedical application were assessed [31]-[33]. The initial surface morphology, fibre diameter, bulk density $(\rho)$ and surface density $\left(\rho_{s}\right)$, along with the constitutional repeating unit (CRU) are gathered in Table 2. The surface densities were predicted by weighing a piece of a given region and normalised as a function of their surface.

As the surface morphology revealed, all the scaffolds showed a uniform non-woven fibrous structure. Fibre diameters moved from the nanometric scale for the PLGA to the low micrometric scale of PCL, PDO and PHB. In addition, the diameter distributions of the PLGA and the PDO showed a narrow pattern, while those of the PCL and PHB tended to be wider. Similar bulk and surface densities were observed for all the scaffolds. 
Table 2. Initial properties of the scaffolds.

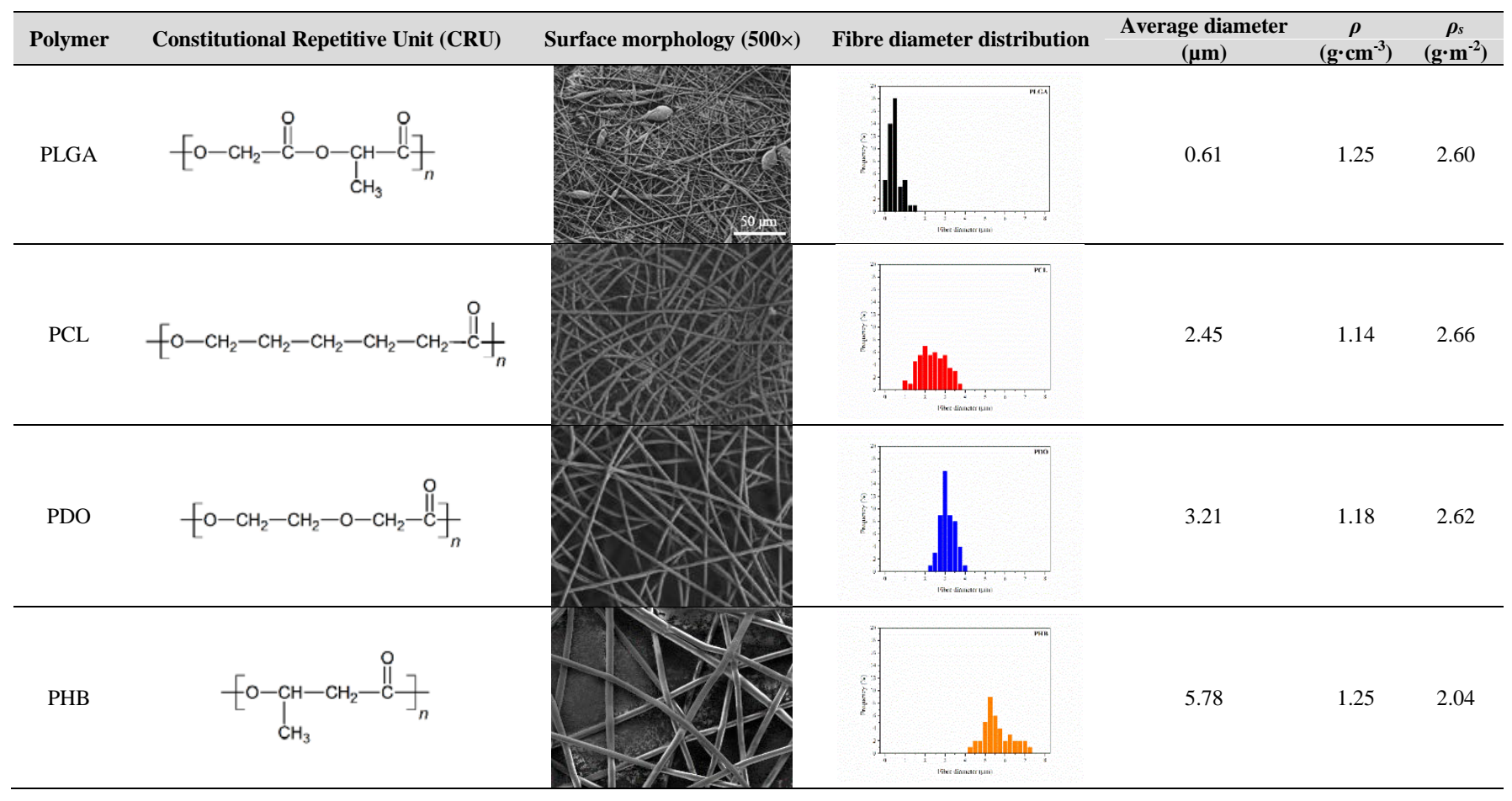




\subsection{In vitro hydrolytic degradation}

Due to the dissimilar degradation timespan of the studied scaffolds, results in this section were represented in two different time scales. On the one hand, the PLGA and PDO scaffolds were completely degraded and disintegrated in a relatively short period of time from day 0 until day 150 . In contrast, the degradation of the PCL and PHB was much slower and took place over a longer period. Even though the scaffolds were not completely dissolved in the degradation media after this time, the monitoring of the degradation was studied until disintegration, which took place around day 650 of immersion both for PCL and PHB scaffolds.

\subsubsection{Evolution of mass-loss}

The study of the mass evolution measured by gravimetric analysis is one of the most common used parameters as an indicator of the degradation, since it gives a rapid response about the macroscopic state of the scaffold. The remaining mass as a function of the immersion time in water and PBS for the different materials is plotted in Figure 1.

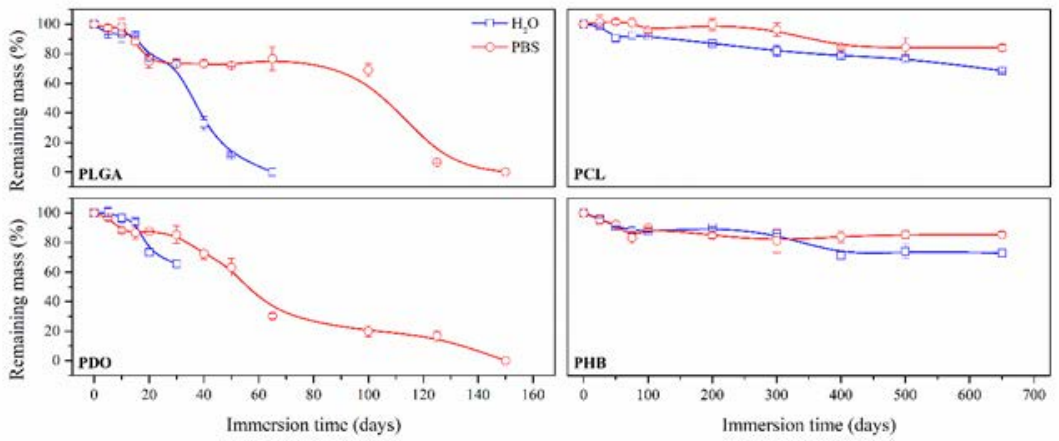

Figure 1. Remaining mass as a function of the degradation time in ultra-pure water and PBS for PLGA, PDO, PCL and PHB scaffolds.

The PLGA and PDO scaffolds showed a similar short-term degradation behaviour. The mass-loss of the PLGA scaffolds was similar under both media within the first 30 days. However, the remaining mass of the PLGA scaffolds afterwards followed different patterns, depending on the medium of degradation. In water, PLGA started to disintegrate until completion after 60 days, with an important slope at its degradation profile. In contrast, the mass of the scaffold remained almost constant until 90 days when immersed in PBS. After that, a drop of the mass took place after 125 days with a similar slope than that shown for PLGA scaffolds subjected to water. The scaffolds were completely disintegrated after 150 days. These results were in accordance with those reported for other scaffolds of PLGA, where similar degradation extents were found [21], [34]. 
PDO scaffolds showed a similar behaviour than those of PLGA. The main difference between them was the complete disintegration of the PDO scaffold after 30 days of immersion in water. However, when immersed in PBS, the mass decreased progressively as a function of the immersion time following an almost linear trend along 150 days.

Long-term disintegration behaviour was found for PCL and PHB scaffolds. Both showed a mass loss between $10 \%$ and $20 \%$ after 650 days of immersion. In addition, the scaffolds seemed to undergo the same performance in water and PBS. Although perceivable deterioration and disintegration of the scaffold structure took place at the end of the assay, the complete dissolution was not reached. Due to the difficulty of measuring the mass of the remnant disintegrated scaffolds, the assay was considered as concluded after 650 days of immersion. The advance of hydrolytic degradation was not consistently perceived in the mass. Deeper insight in the degradation of these scaffolds is given in the next sections.

\subsubsection{Monitoring of $p H$}

The characterisation of the solid fraction is essential to understand the effects of the degradation on the molecular architecture of the scaffolds and, consequently, on their physic-chemical properties and performance. However, the parallel observation of the liquid fraction can offer quick information of the state of degradation and even more, fast data to infer the impact of degradation of biopolymer scaffolds [25]. The evolution of $\mathrm{pH}$ was accordingly monitored and results are plotted in Figure 2.
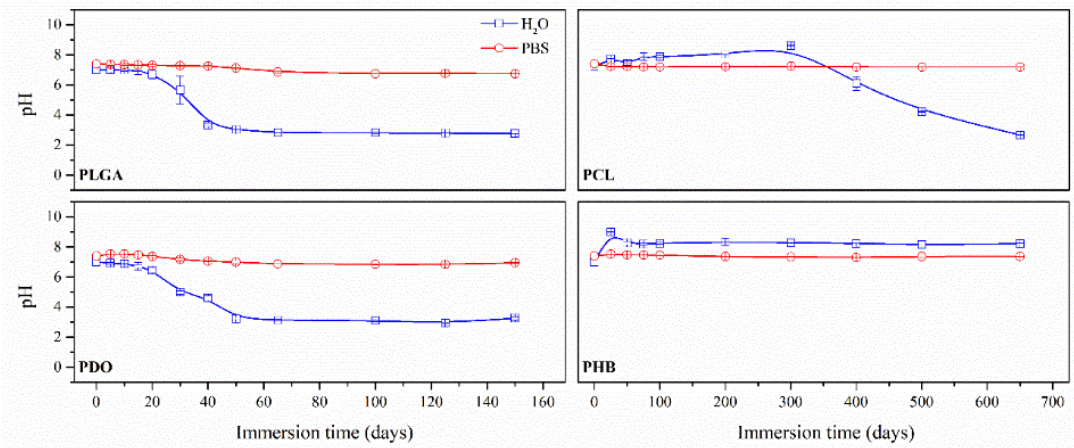

Figure 2. Average $\mathrm{pH}$ as a function of the degradation time in ultra-pure water and PBS for PLGA, PCL, PDO and PHB scaffolds.

For PLGA and PDO scaffolds, the monitoring of $\mathrm{pH}$ showed that, when the scaffolds were immersed in water, it remained constant in the first stage of immersion and then dramatically decreased from neutral to acid $\mathrm{pH}$. This drop was related to a large release of low molar mass acidic monomeric and oligomeric species such as glycolic acid, lactic acid for PLGA and low 
molar mass hydroxy-acid species for PDO [25], [35], that caused acidification of the media. In contrast, when samples were immersed into PBS, the $\mathrm{pH}$ slightly varied along the immersion due to the ability of this solution to buffer acidic species released during degradation. Nonetheless, a slight diminution was observed from neutral $\mathrm{pH} 7.4$ to $\mathrm{pH}$ 6.6. This observation suggested that the buffer capacity of the medium was exceeded, as it was not regenerated during the hydrolysis assay. From then onwards, the hydrolytic degradation may be catalysed [17]. It is important to remark that, in this case, the interpretation of the monitoring of $\mathrm{pH}$ was closely related to the mass loss discussion.

For PCL scaffolds, the $\mathrm{pH}$ remained constant along immersion until day 400 , when it started to decrease due to the released acidic species based on hexanoic acid. Indeed, a progressive reduction was observed until the end of the assay, when $\mathrm{pH}$ value of 2.7 was found. Conversely, when immersed into $\mathrm{PBS}$, the $\mathrm{pH}$ was maintained along the whole assay around 7.4. Again, the buffer ability of this solution permitted to preserve the $\mathrm{pH}$ [36], [37]. The hydrolytic degradation of the PHB scaffolds could not be perceived from the evaluation of the $\mathrm{pH}$ of the solution media. The $\mathrm{pH}$ remained constant both in water and PBS, along the whole assay. Although the degradation of the PHB polymer chains ultimately results in 3hydroxybutyric acids, which can be assimilated by the human organism [38], the slow degradation rate of this material seem to have prevented the production of acidic low molar mass compounds that would have modified the $\mathrm{pH}$ of the degradation media [39].

\subsubsection{Impact on the fibrous structure of the scaffolds}

The fibrous structure of the scaffold is required to remain for a certain period of time in order to help cells attach and proliferate [12]. Therefore, the change of the surface morphology of the scaffolds as a function of immersion time was monitored by means of field-emission scanning electron microscopy (FE-SEM). The surface micrographs of PLGA and PDO submitted to both media and taken after different periods of immersion is shown in Figure 3 while those of PCL and PHB scaffolds are shown in Figure 4. As well, the evolution of the average fibre diameter is plotted in Figure 5 as a function of the immersion time. Note that shown micrographs correspond to those which were handily. Different behaviour was perceived regarding the change in the fibrous morphology of the shortterm degraded scaffolds.

For the PLGA scaffolds, their fibres swelled and coalesced along immersion, as perceived in the fibre diameter increase [3]. As well, some microscopic pores appeared and grew in the flat surface of the fibres when immersed in water and, subsequently, disintegration occurred around day 20. When immersed into PBS, the fibres also swelled, but the degradation 
process seemed to be considerably slower than in water. Although a swelling effect took place, conglutination was not completely reached in the scaffolds after 65 days of immersion.

For PDO scaffolds, a slight reduction of the fibre diameter was found along immersion in both media. The degradation of the scaffolds occurred through fibre breakage in a longer time span than for PLGA. The fibrous structure remained apparently unaffected until disintegration, which happened around day 60 of immersion.

On the other hand, the fibrous structure of the PCL and PHB scaffolds remained almost unaffected during immersion, as revealed by the average fibre diameter [23]. Fibre breakage was perceived from day 500 onwards in the PCL scaffolds. After 650 days, the scaffolds were almost disintegrated as shown by the high degree of fibre rupture. Remarkable fibre breakage in PHB scaffolds was also found at 650 days of immersion. These observations confirm the high stability under hydrolytic service conditions of these polymers that permitted to preserve the fibres unaltered until the last stages of immersion, where macroscopic collapse and disintegration occurred. 


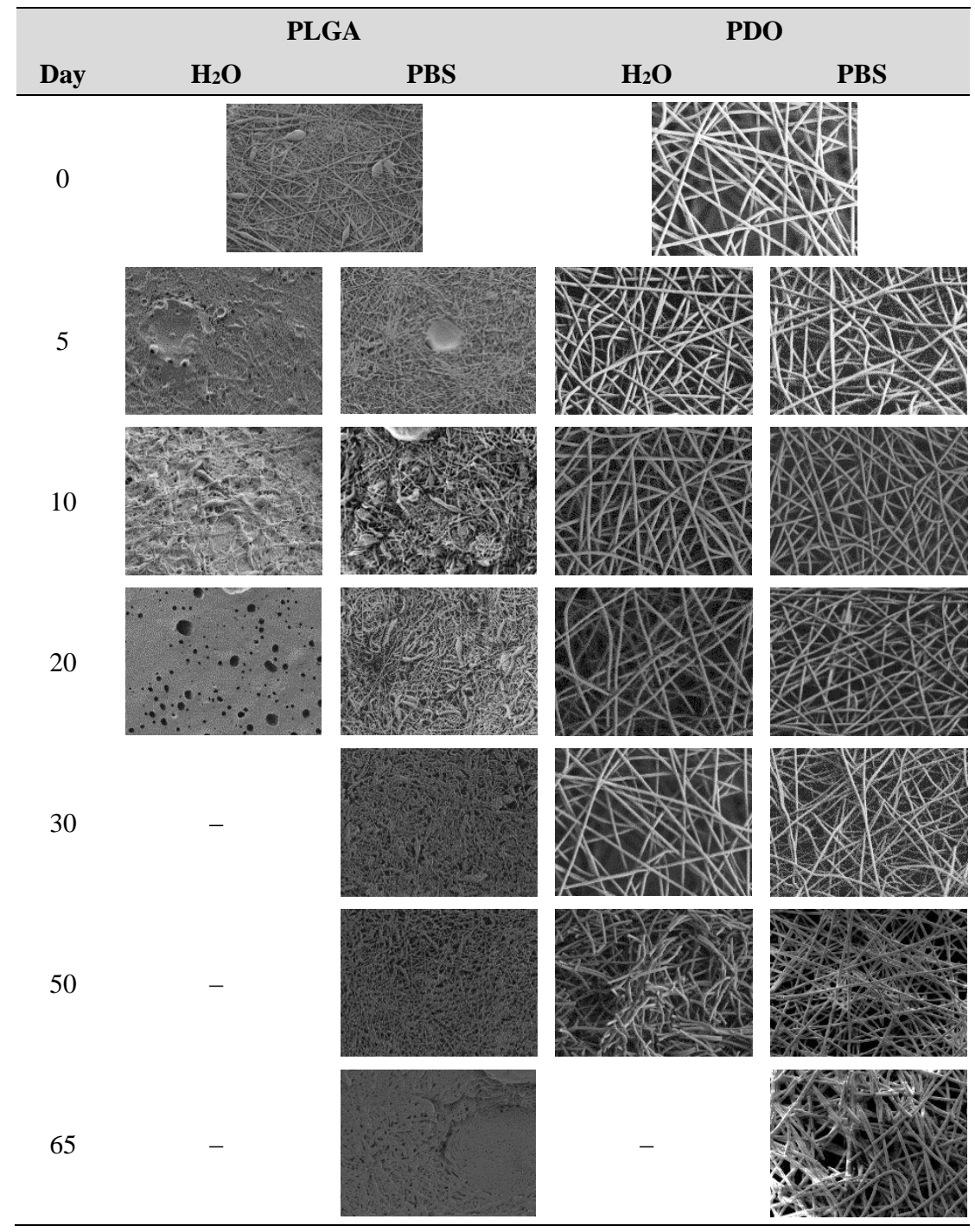

Figure 3. Surface morphology as a function of immersion time in ultra-pure water and PBS for PLGA and PDO scaffolds. 


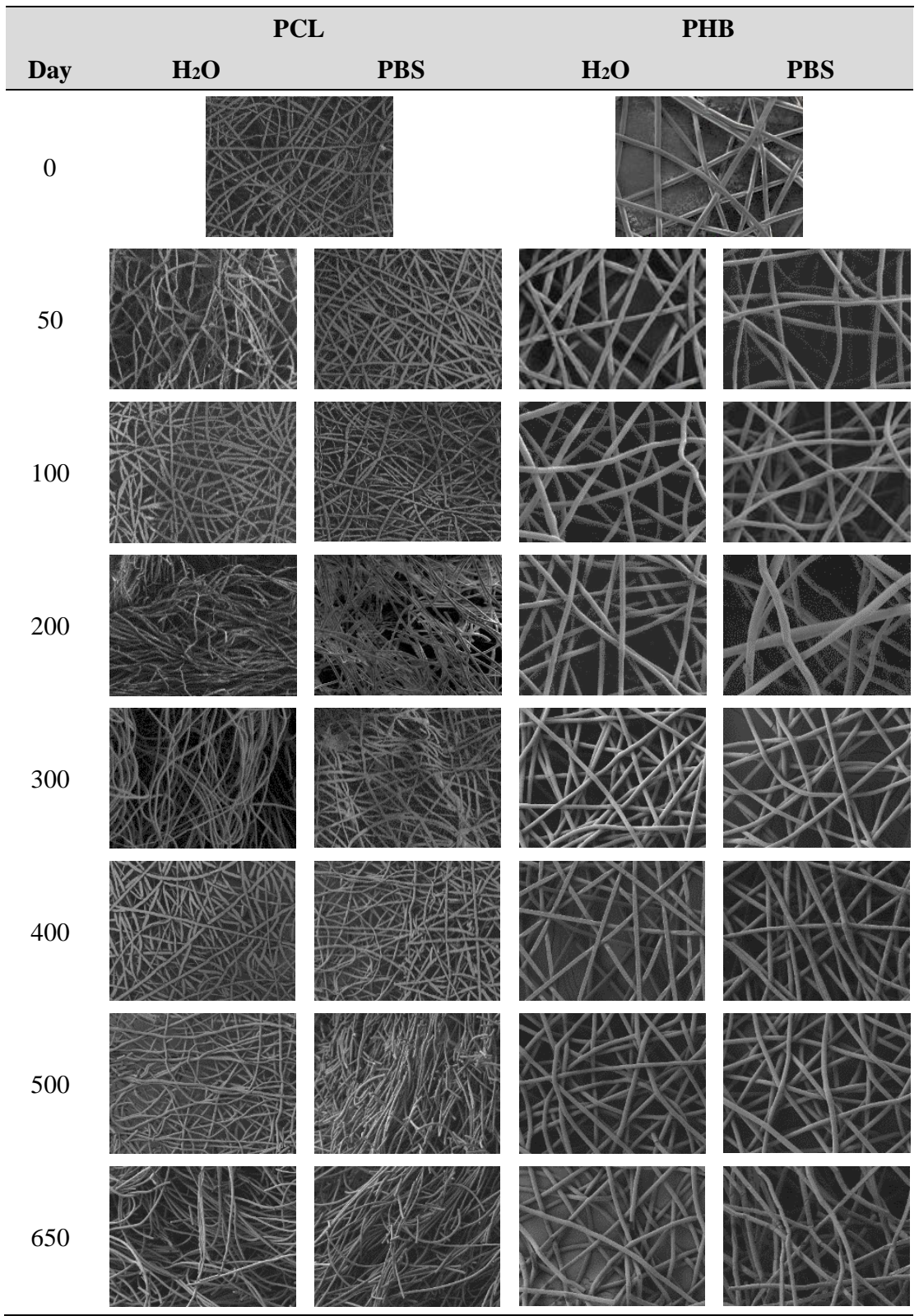

Figure 4. Surface morphology as a function of immersion time in ultra-pure water and PBS for PCL and PHB scaffolds. 

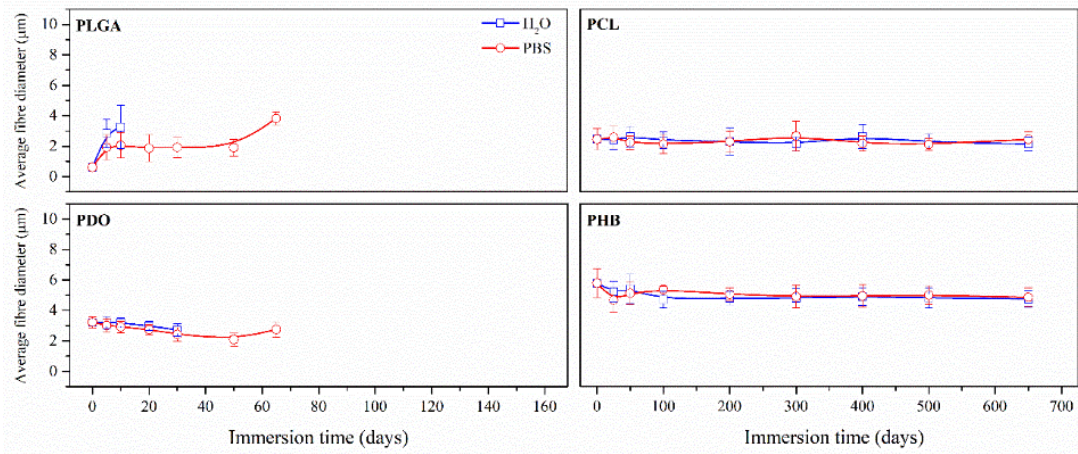

Figure 5. Average fibre diameter as a function of the degradation time in ultra-pure water and PBS for PLGA, PCL, PDO and PHB scaffolds.

3.2.4. Monitoring of thermal properties and stability of the crystalline domains

The thermal properties of the scaffolds as a function of the immersion time were assessed by differential scanning calorimetry (DSC). Figure 6 shows the calorimetric traces of the first heating scan of non-exposed scaffolds and those subjected to in vitro hydrothermal degradation in both media, ultra-pure water and PBS. In order to assure comparison between the different materials, the thermal properties were evaluated from 0 to $200^{\circ} \mathrm{C}$.
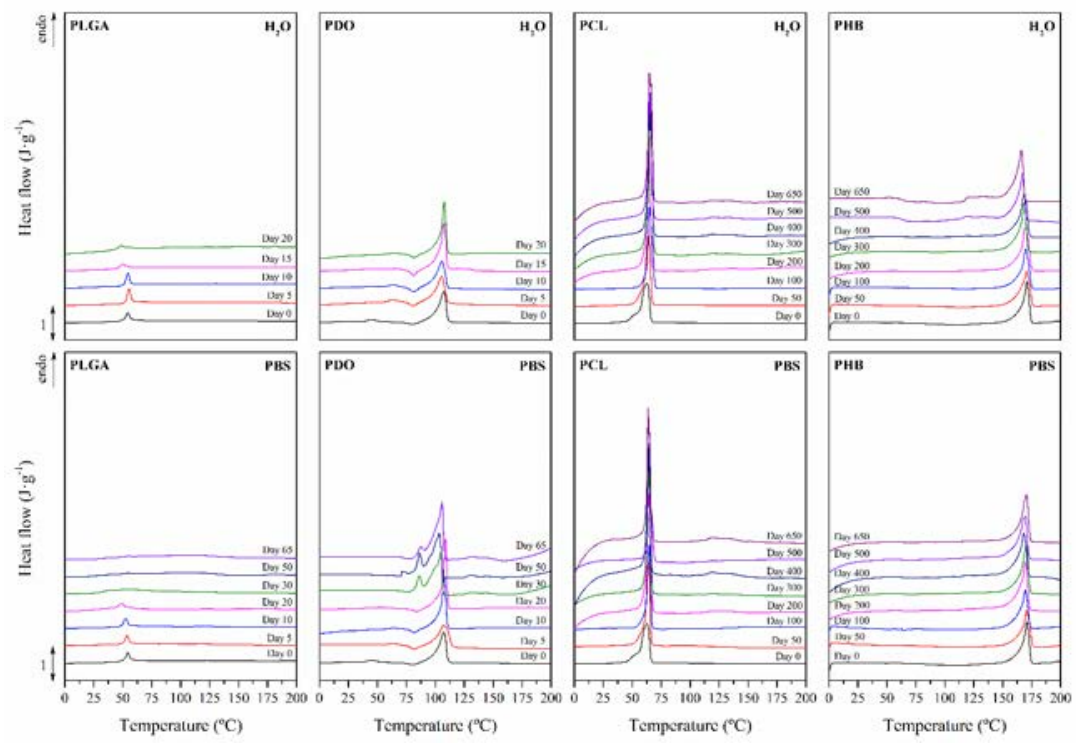

Figure 6. DSC traces as a function of immersion time in ultra-pure water and PBS for PLGA, PDO, PCL and PHB scaffolds. 
The study of the thermal properties is essential to understand the behaviour of polymers subjected to different degrading conditions. Indicators of degradation such as the partial melting areas, the crystallinity degree, the lamellar thickness or the balance among amorphous and rigid amorphous fractions have been previously proposed for monitoring degradation [40][48]. Due to the different morphology of the selected materials, the release of energy during the glass transition $\left(\Delta h_{r-g t}\right)$ was chosen for PLGA and the crystallinity degree $\left(X_{c}\right)$ for PDO, PCL and PHB scaffolds, which results are plotted in Figure 7. Moreover, Table 3 gathers the peak temperature of the heat release during the glass transition $\left(T_{r-g t}\right)$ for the PLGA and the peak melting temperature $\left(T_{m}\right)$ for the PDO, PCL and PHB scaffolds which is closely related to the lamellar thickness $\left(l_{c}\right)$ according to the ThomsonGibbs equation [49], [50].
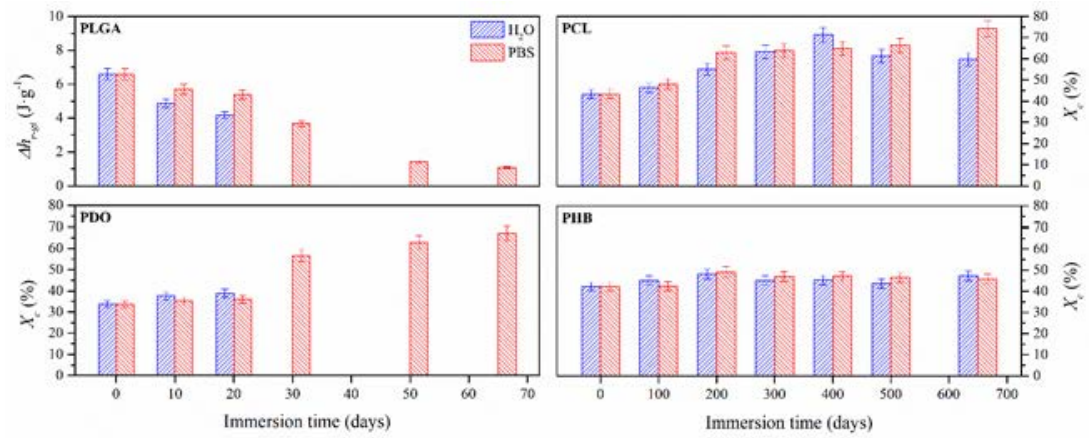

Figure 7. Evolution of the structural relaxation enthalpy $\left(\Delta h_{r-g t}\right)$ for PLGA and crystallinity degree $\left(X_{c}\right)$ for PDO, PCL and PHB scaffolds as a function of immersion time in ultra-pure water and PBS.

Table 3. Peak temperature of the heat release during the glass transition $\left(T_{r-g t}\right)$ for the PLGA and the peak melting temperature $\left(T_{m}\right)$ for the PDO, PCL and PHB scaffolds as a function of immersion time in ultra-pure water and PBS.

\begin{tabular}{|c|c|c|c|c|c|c|c|c|c|}
\hline $\begin{array}{c}\text { Immersion } \\
\text { time }\end{array}$ & \multicolumn{2}{|c|}{ PLGA } & \multicolumn{2}{|c|}{ PDO } & $\begin{array}{c}\text { Immersion } \\
\text { time }\end{array}$ & \multicolumn{2}{|c|}{ PCL } & \multicolumn{2}{|c|}{ PHB } \\
\hline (Days) & \multicolumn{2}{|c|}{$T_{r-g t}\left({ }^{\circ} \mathrm{C}\right)$} & \multicolumn{2}{|c|}{$T_{m}\left({ }^{\circ} \mathrm{C}\right)$} & (Days) & \multicolumn{2}{|c|}{$T_{m}\left({ }^{\circ} \mathrm{C}\right)$} & \multicolumn{2}{|c|}{$T_{m}\left({ }^{\circ} \mathrm{C}\right)$} \\
\hline & $\mathrm{H}_{2} \mathrm{O}$ & PBS & $\mathrm{H}_{2} \mathrm{O}$ & PBS & & $\mathrm{H}_{2} \mathrm{O}$ & PBS & $\mathrm{H}_{2} \mathrm{O}$ & PBS \\
\hline 0 & \multicolumn{2}{|c|}{54.46} & \multicolumn{2}{|c|}{107.85} & 0 & \multicolumn{2}{|c|}{63.04} & \multicolumn{2}{|c|}{170.9} \\
\hline 5 & 55.30 & 53.63 & 105.42 & 107.73 & 50 & 63.79 & 64.35 & 170.56 & 170.82 \\
\hline 10 & 54.47 & 52.46 & 105.86 & 107.76 & 100 & 64.78 & 64.52 & 169.80 & 169.51 \\
\hline 20 & 48.63 & 49.29 & 105.17 & 108.39 & 200 & 64.77 & 64.46 & 169.37 & 169.38 \\
\hline 30 & - & 41.14 & - & 104.07 & 300 & 65.98 & 64.14 & 168.53 & 170.57 \\
\hline 50 & - & - & - & 103.50 & 400 & 65.38 & 64.15 & 168.33 & 168.25 \\
\hline 65 & - & - & - & 105.90 & 500 & 64.18 & 64.23 & 167.63 & 169.51 \\
\hline 100 & - & - & - & - & 650 & 63.81 & 64.40 & 166.31 & 169.21 \\
\hline
\end{tabular}

In general, the PLGA scaffolds showed a typical amorphous behaviour. The endothermic peak associated to the glass transition was perceived. A similar but delayed behaviour was found after immersion in water and PBS. This transition sharpened at short degradation times, but reduced its associated enthalpy $\left(\Delta h_{r-g t}\right)$. Then, around day 15 in water and day 20 in 
PBS, it became broader the longer the hydrolytic exposure was until it almost disappeared. Particularly when immersed in PBS, the unimodal performance turned into bimodal transition pattern after day 20, which was ascribed to the glass transitions of the different segments of the copolymer, i.e. polyglycolide (PGA), between 35 and $40{ }^{\circ} \mathrm{C}$, and polylactide (PLA), between 55 and $60{ }^{\circ} \mathrm{C}$ [51]. These results are in line with other reports that suggested a preferential hydrolytic breakage of the glycolic-glycolic and glycolic-lactic ester linkages, in contrast to that of the lactic-lactic bond in random poly(lactide-co-glycolide) [54]. The generation of the independent homopolymeric new segments of PGA and PLA would contribute to the appearance of separated glass transition events. As a function of the immersion time, a lower peak temperature $\left(T_{r-g t}\right)$ was perceived, which suggested higher mobility of the shorter polymer segments as hydrolytic degradation progressed.

In the same time-scale, PDO scaffolds showed a complex semicrystalline behaviour. A cold-crystallisation exothermic peak was perceived immediately before the melting transition. According to Sabino et al., the cold-crystallisation around $80^{\circ} \mathrm{C}$ can be ascribed to a partially melting and recrystallization of non-stable crystalline structure [52]. Then, a unimodal melting transition around $108{ }^{\circ} \mathrm{C}$ was observed. When immersed in water, the cold-crystallisation remained constant and the melting enthalpy slightly increased, suggesting that crystallinity was developed during immersion [53]. The melting temperature $\left(T_{m}\right)$ slightly decreased, ascribed to more imperfect crystalline structure with lower lamellar thickness. However, when immersed in PBS, the cold-crystallisation peak disappeared as a function of time and the melting peak turned into a bimodal pattern, suggesting the existence of dissimilar crystalline populations. Highly degraded PDO segments with lower entanglement capability, seemed to have rearranged into an imperfect crystalline structure that melted at lower temperatures, around $86{ }^{\circ} \mathrm{C}$ [19]. The global crystallinity degree increased along immersion from $35 \%$ up to $60 \%$. As perceived in water, the $T_{m}$ of the main peak decreased as immersion time increased, which can be interpreted as crystalline structure with lower lamellar thickness due to the advance of degradation.

The PCL scaffolds showed a typical semi-crystalline behaviour with a melting transition around $63{ }^{\circ} \mathrm{C}$. No significant differences were perceived when immersed in water and PBS. In both media, the melting peak sharpened and increased the associated melting enthalpy. This behaviour was corroborated by the evaluation of the crystallinity degree, which increased from $40 \%$ up to $70 \%$ after 650 days of immersion. Shorter hydrolysed molecular PCL segments rearranged and crystallised as a function of time [31]. Given the small increase in the melting temperature, 
slightly more perfect crystals with higher lamellar thickness were developed during immersion [54].

The evaluation of the thermal properties of the PHB scaffolds revealed a semi-crystalline behaviour with a melting peak located around $171{ }^{\circ} \mathrm{C}$. Although no significant differences were perceived along immersion, the melting peak was perceived to have slightly displaced towards lower temperatures. This $T_{m}$ decrease would suggest more imperfect crystals as a function of the immersion time, due to the progress of the hydrolytic degradation. The melting enthalpy and the subsequent crystallinity slightly increased from $42 \%$ to $47 \%$ after 650 days of immersion both in water and PBS [55]. These results suggested that the microstructure of the PHB scaffolds remained almost stable during the immersion period considered in this study.

\subsubsection{Influence on the molar mass degradation patterns}

The degradation behaviour was deeply studied by means of the variation of the molar mass, which was monitored along immersion by means of size exclusion chromatography (SEC). The molar mass distributions for the PLGA, PDO, PCL and PHB scaffolds are plotted in Figure 8 as a function of the immersion time. Unimodal distributions were found for PLGA, PDO and PCL scaffolds, while PHB showed a complex multi-modal broad molar mass distribution. It is important to note that samples coming from the hydrolytic degradation with a mass lower than $20 \%$ of the initial value were so deteriorated that could not be handled and, subsequently, molar mass analysis were not performed.

In general, the molar mass distributions were displaced towards lower values as a function of the immersion time due to the hydrolytic degradation of the ester bonds. For PLGA and PCL scaffolds, the distributions increased in width along the degradation, turning into a more polydisperse polymer. Random ester bond breakage seemed to take place in all polymeric chains, producing a broader distribution of chain sizes. For the case of the PDO scaffolds, the molar mass distributions reduced their width, turning into a more concise and sharp curve, which can be correlated with a less polydisperse polymer. Some authors found experimental evidences that suggested a preferential degradation of higher molar mass PDO chains, such as tie molecules, that resulted in a more uniform distribution of shorter polymer segments [17], [52], [56], [57]. The broad multi-modal distribution pattern found for PHB showed two main peaks, correlated to low molar mass and high molar mas populations. This behaviour can be associated to the synthetic route of the PHB, in which microorganisms may have produced dissimilar size polymer chains [58], [59]. The PHB scaffolds reduced the high molar mass peak and increased that of low molar mass polymer chains as a function of the immersion time. 

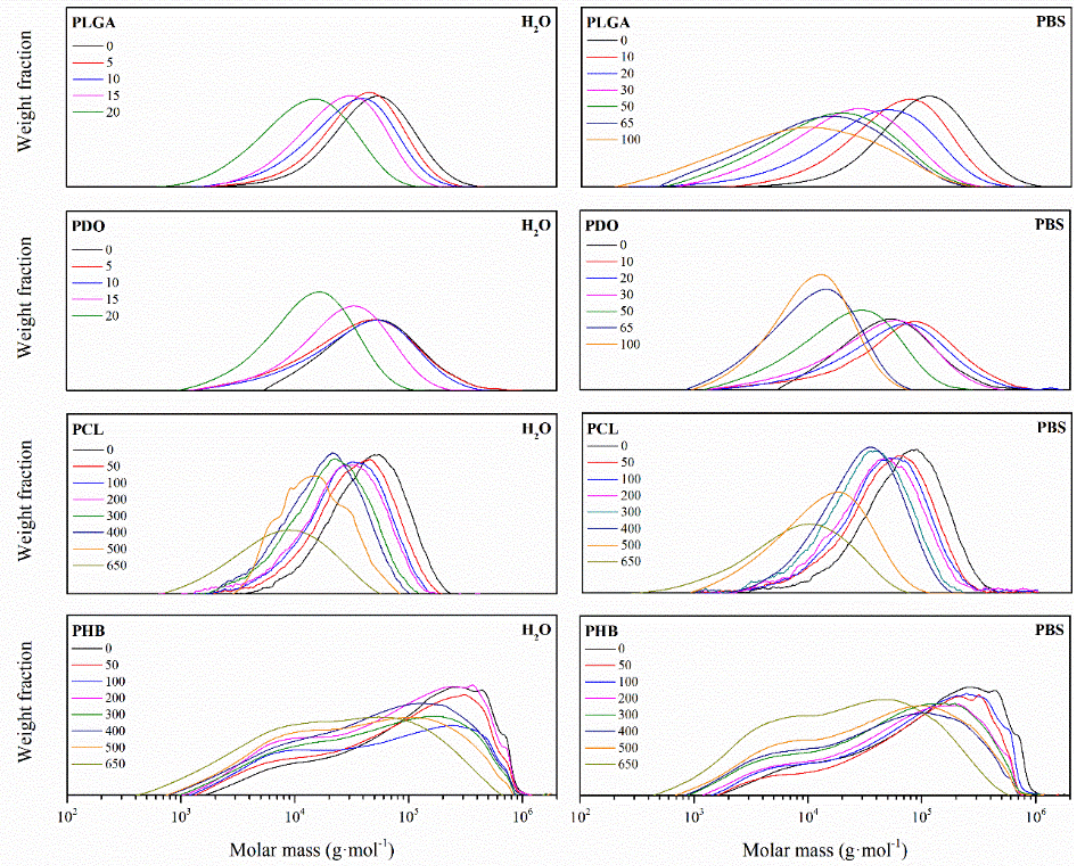

Figure 8. Molar mass distributions as a function of the degradation time in ultra-pure water and PBS for PLGA, PDO, PCL and PHB scaffolds.

In order to deeply characterise the evolution of the molar mass as a function of the immersion time in water and PBS, the average molar mass in number $\left(M_{n}\right)$ was considered as an appropriate indicator for comparison of the hydrolytic breakage of the polymer chains along immersion. The $M_{n}$ values are gathered in Table 4. However, given the heterogeneity in the molar mass distributions for the different materials, the $M_{n}$ was normalised to their initial molar masses in number, i.e. relative molar mass-loss, and its evolution as a function of the immersion time was represented in Figure 9 for a proper comparison.

Table 4. Average molar mass in number as a function of the degradation time in ultrapure water and PBS for PLGA, PDO, PCL and PHB scaffolds.

\begin{tabular}{|c|c|c|c|c|c|c|c|c|c|}
\hline $\begin{array}{c}\text { Immersion } \\
\text { time }\end{array}$ & \multicolumn{2}{|c|}{ PLGA } & \multicolumn{2}{|c|}{ PDO } & $\begin{array}{c}\text { Immersion } \\
\text { time }\end{array}$ & \multicolumn{2}{|c|}{ PCL } & \multicolumn{2}{|c|}{ PHB } \\
\hline (Days) & \multicolumn{4}{|c|}{$M_{n}\left(\mathrm{~g} \cdot \mathrm{mol}^{-1}\right)$} & (Days) & & $M_{n}(g$ & $\left.10 \mathbf{l}^{-1}\right)$ & \\
\hline & $\mathrm{H}_{2} \mathrm{O}$ & PBS & $\mathrm{H}_{2} \mathrm{O}$ & PBS & & $\mathrm{H}_{2} \mathrm{O}$ & PBS & $\mathrm{H}_{2} \mathrm{O}$ & PBS \\
\hline 0 & \multicolumn{2}{|c|}{43290} & \multicolumn{2}{|c|}{52000} & 0 & \multicolumn{2}{|c|}{42030} & \multicolumn{2}{|c|}{20450} \\
\hline 5 & 36080 & 38210 & 30800 & 50450 & 50 & 36080 & 34500 & 18490 & 19510 \\
\hline 10 & 26020 & 25780 & 28080 & 48880 & 100 & 30010 & 28820 & 15700 & 17040 \\
\hline 20 & 12690 & 15850 & 16620 & 30260 & 200 & 27810 & 25390 & 14900 & 14850 \\
\hline 30 & - & 8340 & 13030 & 21990 & 300 & 18470 & 19670 & 14250 & 13610 \\
\hline 50 & - & 5960 & - & 14460 & 400 & 8350 & 8380 & 13650 & 12350 \\
\hline 65 & - & 4800 & - & 12710 & 500 & 7520 & 5370 & 12960 & 12520 \\
\hline 100 & - & 4360 & - & 9450 & 650 & 3340 & 3060 & 10760 & 9440 \\
\hline
\end{tabular}


The decrease of the $M_{n}$ for the PLGA and PDO scaffolds followed a similar exponential decreasing pattern regardless the degradation medium, as observed by other authors [34], [35], [60]. Moreover, the molar mass reduction took place in an analogous time lapse. Although the degradation of the PLGA scaffolds in water and PBS followed an identical pattern, for the case of PDO scaffolds a slightly delayed behaviour was found when immersed in PBS. If results are compared to mass loss measurements, one can see that after $M_{n}$ percentage reached values near to the $20 \%$ of the initial values, a plateau in the mass-loss was found prior to the complete disintegration of both PLGA and PDO scaffolds.

Conversely, PCL and PHB scaffolds showed a similar progressive decrease of the $M_{n}$ percentage as a function of time. Although the measurements of mass-loss for PCL showed a reduction between 10 and 20\% after 650 days of immersion, the molar mass results revealed a massive reduction of $M_{n}$ of around an $80 \%$. However, in PHB scaffolds $M_{n}$ decreased a 50\% during the 650 days of immersion in both water and PBS. The particularly high resistance of the crystalline domains of the PCL and PHB scaffolds to the solution diffusion and subsequent hydrolytic degradation, as observed in previous section, may have prevented these scaffolds from a short-term substantial degradation along immersion.
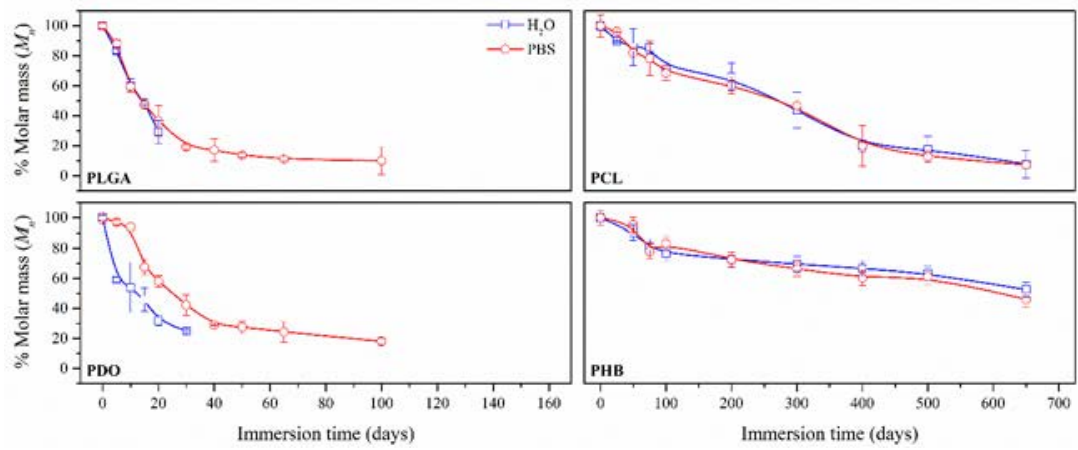

Figure 9. Average molar mass in number $\left(M_{n}\right)$ percentage as a function of the degradation time in ultra-pure water and PBS for PLGA, PDO, PCL and PHB scaffolds.

\subsection{Overview of the degradation patterns of scaffolds under physiologic} conditions

The comparison of performance of scaffolds under simulated nonenzymatic physiologic conditions is essential to discriminate the best design-to-performance ratio according to their expected life time-span [61]. Scaffolds of PLGA, PDO, PCL and PHB possess hydrolytically ester labile chemical bonds in their structure that can be broken due to the effect of water and/or temperature. Therefore, they are expected to lose their mass 
over time in the living body until disappearance and assimilation of the remnant chemical species. However, the nature and origin of the polymer strongly determines its degradation pattern when submitted to physiologic conditions [62]-[65]. The hydrolytic process of semicrystalline polyesters as those considered in this study usually occurs in two stages: (i) the attack of the less compacted amorphous regions where diffusion of the hydrolytic medium is easier and faster and (ii) the attack on the crystalline regions, usually hydrophobic and impermeable to the diffusion and penetration of the aqueous media [31], [32]. As shown above, significant differences were perceived in the degradation behaviour of these materials. In order to provide an overview and ease comparison, the main features of the in vitro degradation behaviour of these scaffolds when subjected to physiologic conditions (PBS, $37^{\circ} \mathrm{C}$ ) are gathered in the Table 5. On the one hand, PLGA and PDO showed short-term degradation, while PCL and PHB revealed a long-term and progressive degradation profile. The specific overview for each scaffold is given below.

The PLGA fibres swelled as a function of the immersion time, reducing the inter-fibre distance and tending to close the pores required for satisfactory cell adhesion and proliferation. The mainly amorphous morphology of this polymer may have contributed to a rapid diffusion of the aqueous solvent into the fibres. Meanwhile, the hydrolytic degradation of the polymer molecules occurred from the very beginning of immersion, following a random scission pattern, as suggested by the increase in the polydispersity index. Consequently, the molar mass dramatically decreased and low molar mass compounds were released from the scaffold, promoting an acidification of the surrounding media. Finally, the scaffold collapsed and released glycolic and lactic acid monomers and oligomers that were completely dissolved in the hydrolytic media [25].

The PDO scaffolds kept the fibrous morphology along the degradation until disintegration. The fibre diameter slightly diminished as a function of the immersion time and small cracks perpendicular to the axe of the fibres were perceived. The molar mass reduction, along with the development of crystallinity and the ether bond in the backbone may have promoted the more progressive degradation behaviour of this material [19]. The typical cold-crystallisation of this polymer disappeared along immersion and an imperfect crystalline population was developed. Then, the fibre erosion and breakage may have promoted the progressive perceived mass-loss and the reduction of the $\mathrm{pH}$ due to the release of low molar mass species, as produced from the preferential bond scission of the ester linkages [66].

The morphology of the PCL fibres remained mainly unaffected along immersion. The average fibre diameter slightly varied and the fibrous morphology persisted until disintegration. Crystallinity was developed in this scaffold due to the increase of mobility of short hydrolysed segments, 
aided by the plasticizing effect of water along with the temperature above the glass transition [54]. According to the calorimetric results, more perfect crystalline structure was developed, as suggested by the increase of the melting temperature. As a consequence of having more crystalline domains with higher lamellar thickness, PCL was more capable of preventing the structure of its fibres from degradation. The molar mass followed an almost-linear diminishing trend until complete disintegration. The polydispersity increased, suggesting a random chain scission phenomenon that resulted in dissimilar segment sizes during degradation [23].

The hydrolytic behaviour of the PHB fibres revealed that the mass, the $\mathrm{pH}$, the fibre diameter and the fibrous morphology remained constant until disintegration. Moreover, the crystallinity degree did not significantly varied during immersion. The highly stable crystalline structure of the PHB stimulated a slight and progressive chain scission along the immersion, as suggested by the evolution of the molar mass distributions. The broad multi-modal behaviour of PHB remained almost unchanged as a function of the immersion time. However, the peak correlated to high molar mass segments decreased, while that of low molar mass polymer chains increased. This behaviour suggested preferential degradation of high molar mass domains. Overall, the PHB scaffolds were found to be the most stable of the evaluated materials, which revealed the slowest degradation behaviour when submitted to physiologic conditions. 
Table 5. Overview of the hydrolytic degradation behaviour when submitted to physiologic conditions (PBS, $37^{\circ} \mathrm{C}$ ).

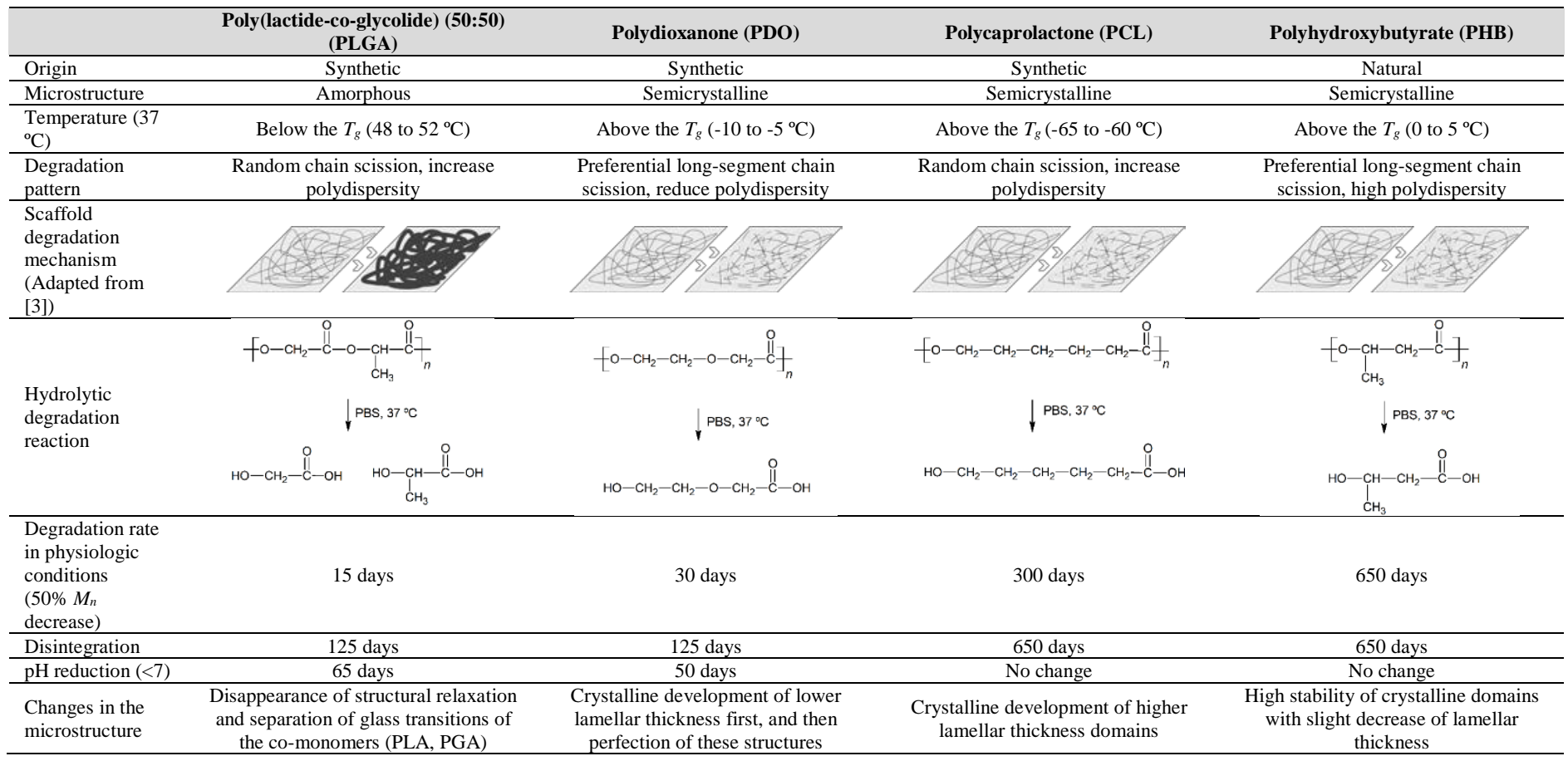




\section{Conclusions}

The hydrolytic degradation patterns of scaffolds based on polyesters such as poly(lactide-co-glycolide) (PLGA), polycaprolactone (PCL), polydioxanone (PDO) and polyhydroxybutyrate (PHB) were monitored under in vitro simulated physiologic conditions at $37^{\circ} \mathrm{C}$ in ultra-pure water and PBS buffer (pH 7.4).

The considered methodology permitted to monitor and compare the degradation patterns of the scaffolds regardless the time lifespan of the polymers when subjected to simulated physiological conditions. The most representative indicators were the mass-loss, the variation of the surface morphology, the evolution of the relative molar mass-loss, the change in the crystalline structure of the scaffolds and the variation of the degradation media, in terms of the $\mathrm{pH}$ evolution.

On the one hand, scaffolds for short-time applications were PLGA and PDO, and showed a faster disintegration and, subsequently, a pronounced acidification of the medium. The molar mass-loss of short-term scaffolds diminished down to a 20\%, in a 20-30 days lifespan. On the other hand, scaffolds for long-term applications were PCL and PHB, which resistant pattern was mainly ascribed to the stability of the crystalline domains of the fibres. The molar mass-loss of long-term scaffolds followed a progressive decrease, reaching values of the $10 \%$ for PCL and almost 50\% for PHB after 650 days of immersion.

The results of this study may serve as a reference point in the stage of designing and selection of materials for the development of new polyesterbased electrospun scaffolds for biomedical applications, from the perspective of an adequate balance between the durability and degradation pattern under physiologic conditions.

\section{Acknowledgements}

The authors would like to acknowledge the Spanish Ministry of Economy and Competitiveness for the projects ENE2017-86711-C3-1-R and UPOV13-3E-1947. The Spanish Ministry of Education, Culture and Sports is thanked for the predoctoral FPU grant of O. Gil-Castell (FPU13/01916). The Generalitat Valenciana is thanked for the APOSTD/2014/041 for J.D. Badia. Finally, AITEX Textile Research Institute is thanked for the scaffold supplying in the context of the MASCONFORT and IMINTEX projects, financed by Generalitat Valenciana. 


\section{References}

[1] B. D. Ulery, L. S. Nair, and C. T. Laurencin, "Biomedical applications of biodegradable polymers,” J. Polym. Sci. Part B Polym. Phys., vol. 49, no. 12, pp. 832-864, 2011.

[2] B. D. (Buddy D. . Ratner, Biomaterials science: an introduction to materials in medicine. Academic Press, 2013.

[3] W.-J. Li, J. A. Cooper, R. L. Mauck, and R. S. Tuan, "Fabrication and characterization of six electrospun poly( $\alpha$-hydroxy ester)-based fibrous scaffolds for tissue engineering applications,” Acta Biomater., vol. 2, no. 4, pp. 377-385, Jul. 2006.

[4] D. Puppi, F. Chiellini, M. Dash, and E. Chiellini, "Biodegradable polymers for biomedical applications,” Nova Science Publishers, Inc., 2011, pp. 545-604.

[5] P. A. Gunatillake and R. Adhikari, "Biodegradable synthetic polymers for tissue engineering.,” Eur. Cell. Mater., vol. 5, p. 1-16; discussion 16, May 2003.

[6] Q. P. Pham, U. Sharma, and A. G. Mikos, "Electrospinning of Polymeric Nanofibers for Tissue Engineering Applications: A Review,” Tissue Eng., vol. 12, no. 5, pp. 11971211, May 2006.

[7] D. I. Braghirolli, D. Steffens, and P. Pranke, "Electrospinning for regenerative medicine: a review of the main topics,” Drug Discov. Today, vol. 19, no. 6, pp. 743-753, 2014.

[8] O. Gil-Castell, J. D. Badia, and A. Ribes-Greus, "Tailored electrospun nanofibrous polycaprolactone/gelatin scaffolds into an acid hydrolytic solvent system,” Eur. Polym. J., vol. 101, pp. 273-281, 2018.

[9] W. Ji, Y. Sun, F. Yang, J. J. J. P. van den Beucken, M. Fan, Z. Chen, and J. A. Jansen, "Bioactive electrospun scaffolds delivering growth factors and genes for tissue engineering applications.,” Pharm. Res., vol. 28, no. 6, pp. 1259-72, Jun. 2011.

[10] R. F. Pereira and P. J. Bártolo, "Degradation Behavior of Biopolymer-based Membranes for Skin Tissue Regeneration,” Procedia Eng., vol. 59, pp. 285-291, Jan. 2013.

[11] J. Venugopal and S. Ramakrishna, "Biocompatible Nanofiber Matrices for the Engineering of a Dermal Substitute for Skin Regeneration,” Tissue Eng., vol. 11, no. 56, pp. 847-854, May 2005.

[12] D. Castellano, M. Blanes, B. Marco, I. Cerrada, A. Ruiz-Saurí, B. Pelacho, M. Araña, J. A. Montero, V. Cambra, F. Prosper, and P. Sepúlveda, “A Comparison of Electrospun Polymers Reveals Poly(3-Hydroxybutyrate) Fiber as a Superior Scaffold for Cardiac Repair,” Stem Cells Dev., vol. 23, no. 13, pp. 1479-1490, Jul. 2014.

[13] J. Yu, A.-R. Lee, W.-H. Lin, C.-W. Lin, Y.-K. Wu, and W.-B. Tsai, "Electrospun PLGA Fibers Incorporated with Functionalized Biomolecules for Cardiac Tissue Engineering,” Tissue Eng. Part A, vol. 20, no. 13-14, pp. 1896-1907, Jul. 2014.

[14] L. Yildirimer and A. M. Seifalian, "Three-dimensional biomaterial degradation Material choice, design and extrinsic factor considerations,” Biotechnol. Adv., vol. 32, no. 5, pp. 984-999, Sep. 2014.

[15] J. D. Badia, O. Gil-Castell, and A. Ribes-Greus, "Long-term properties and end-of-life of polymers from renewable resources,” Polym. Degrad. Stab., vol. 137, pp. 35-57, 2017.

[16] M. Hakkarainen, A.-C. Albertsson, and S. Karlsson, "Weight losses and molecular weight changes correlated with the evolution of hydroxyacids in simulated in vivo degradation of homo- and copolymers of PLA and PGA,” Polym. Degrad. Stab., vol. 52, no. 3, pp. 283-291, Jun. 1996.

[17] A. Göpferich, "Mechanisms of polymer degradation and erosion,” Biomaterials, vol. 17, no. 2, pp. 103-114, Jan. 1996.

[18] F. J. O’Brien, “Biomaterials $\{\&\}$ scaffolds for tissue engineering,” Mater. Today, vol. 14, no. 3, pp. 88-95, Mar. 2011.

[19] M. A. Sabino, S. González, L. Márquez, and J. L. Feijoo, "Study of the hydrolytic degradation of polydioxanone PPDX,” Polym. Degrad. Stab., vol. 69, no. 2, pp. 209216, Jul. 2000.

[20] H. Fouad, T. Elsarnagawy, F. N. Almajhdi, and K. A. Khalil, "Preparation and In Vitro Thermo-Mechanical Characterization of Electrospun PLGA Nanofibers for Soft and Hard Tissue Replacement,” Int. J. Electrochem. Sci, vol. 8, pp. 2293-2304, 2013.

[21] Y. You, B.-M. Min, S. J. Lee, T. S. Lee, and W. H. Park, "In vitro degradation behavior of electrospun polyglycolide, polylactide, and poly(lactide-co-glycolide),” J. Appl. 
Polym. Sci., vol. 95, no. 2, pp. 193-200, Jan. 2005.

[22] R. E. Abhari, P.-A. Mouthuy, N. Zargar, C. Brown, and A. Carr, "Effect of annealing on the mechanical properties and the degradation of electrospun polydioxanone filaments," 2017.

[23] L. A. Bosworth and S. Downes, "Physicochemical characterisation of degrading polycaprolactone scaffolds,” Polym. Degrad. Stab., vol. 95, no. 12, pp. 2269-2276, Dec. 2010.

[24] A. P. Bonartsev, A. P. Boskhomodgiev, A. L. Iordanskii, G. A. Bonartseva, A. V. Rebrov, T. K. Makhina, V. L. Myshkina, S. A. Yakovlev, E. A. Filatova, E. A. Ivanov, D. V. Bagrov, and G. E. Zaikov, "Hydrolytic Degradation of Poly(3-hydroxybutyrate), Polylactide and their Derivatives: Kinetics, Crystallinity, and Surface Morphology,” Mol. Cryst. Liq. Cryst., vol. 556, no. 1, pp. 288-300, May 2012.

[25] O. Gil-Castell, J. D. Badia, I. Ontoria-Oviedo, D. Castellano, B. Marco, A. Rabal, J. J. Bou, A. Serra, L. Monreal, M. Blanes, P. Sepúlveda, and A. Ribes-Greus, "In vitro validation of biomedical polyester-based scaffolds: Poly(lactide-co-glycolide) as modelcase,” Polym. Test., vol. 66, pp. 256-267, Apr. 2018.

[26] “ISO 3696. Water for analytical laboratory use - Specification and test methods,” 1987.

[27] “ISO 10993-13. Biological evaluation of medical devices.” 2010.

[28] K. Ishikiriyama, M. Pyda, G. Zhang, T. Forschner, J. Grebowicz, and B. Wunderlich, “Heat capacity of poly-p-dioxanone,” J. Macromol. Sci. Part B, vol. 37, no. 1, pp. 2744, Jan. 1998.

[29] J. E. Mark, Properties of Polymers Handbook. Springer, 2007.

[30] P. J. Barham, A. Keller, E. L. Otun, and P. A. Holmes, "Crystallization and morphology of a bacterial thermoplastic: poly-3-hydroxybutyrate,” J. Mater. Sci., vol. 19, no. 9, pp. 2781-2794, Sep. 1984.

[31] M. J. Jenkins and K. L. Harrison, "The effect of crystalline morphology on the degradation of polycaprolactone in a solution of phosphate buffer and lipase," Polym. Adv. Technol., vol. 19, no. 12, pp. 1901-1906, Dec. 2008.

[32] H. Cai, V. Dave, R. A. Gross, and S. P. McCarthy, "Effects of physical aging, crystallinity, and orientation on the enzymatic degradation of poly(lactic acid)," $J$. Polym. Sci. Part B Polym. Phys., vol. 34, no. 16, pp. 2701-2708, Nov. 1996.

[33] D. M. Yoon and J. P. Fisher, "Natural and Synthetic Polymeric Scaffolds," in Biomedical Materials, R. Narayan, Ed. Springer, 2009, pp. 415-442.

[34] X. Zhou, Q. Cai, N. Yan, X. Deng, and X. Yang, "In vitro hydrolytic and enzymatic degradation of nestlike-patterned electrospun poly(D,L-lactide-co-glycolide) scaffolds," J. Biomed. Mater. Res. Part A, vol. 95A, no. 3, pp. 755-765, Dec. 2010.

[35] E. Vey, C. Roger, L. Meehan, J. Booth, M. Claybourn, A. F. Miller, and A. Saiani, "Degradation mechanism of poly(lactic-co-glycolic) acid block copolymer cast films in phosphate buffer solution,” Polym. Degrad. Stab., vol. 93, no. 10, pp. 1869-1876, Oct. 2008.

[36] E. Díaz, I. Sandonis, and M. B. Valle, "In Vitro Degradation of Poly(caprolactone)/nHA Composites,” J. Nanomater., vol. 2014, pp. 1-8, Oct. 2014.

[37] A. Höglund, M. Hakkarainen, and A. Albertsson, "Degradation Profile of Poly(€caprolactone)-the Influence of Macroscopic and Macromolecular Biomaterial Design,” J. Macromol. Sci. Part A, vol. 44, no. 9, pp. 1041-1046, Jun. 2007.

[38] T. Laeger, C. C. Metges, and B. Kuhla, "Role of $\beta$-hydroxybutyric acid in the central regulation of energy balance,” Appetite, vol. 54, no. 3, pp. 450-455, Jun. 2010.

[39] E. I. Paşcu, J. Stokes, and G. B. McGuinness, "Electrospun composites of PHBV, silk fibroin and nano-hydroxyapatite for bone tissue engineering.," Mater. Sci. Eng. C. Mater. Biol. Appl., vol. 33, no. 8, pp. 4905-16, Dec. 2013.

[40] J. D. Badia, F. Vilaplana, S. Karlsson, and A. Ribes-Greus, "Thermal analysis as a quality tool for assessing the influence of thermo-mechanical degradation on recycled poly(ethylene terephthalate),” Polym. Test., vol. 28, no. 2, pp. 169-175, 2009.

[41] L. Santonja-Blasco, R. Moriana, J. D. Badía, and A. Ribes-Greus, “Thermal analysis applied to the characterization of degradation in soil of polylactide: I. Calorimetric and viscoelastic analyses,” Polym. Degrad. Stab., vol. 95, no. 11, pp. 2185-2191, Nov. 2010.

[42] J. D. Badia, E. Strömberg, S. Karlsson, and A. Ribes-Greus, "Material valorisation of amorphous polylactide. Influence of thermo-mechanical degradation on the 
morphology, segmental dynamics, thermal and mechanical performance," Polym. Degrad. Stab., vol. 97, no. 4, pp. 670-678, Apr. 2012.

[43] O. Gil-Castell, J. D. D. Badia, T. Kittikorn, E. Strömberg, M. Ek, S. Karlsson, A. RibesGreus, E. Strömberg, M. Ek, S. Karlsson, and A. Ribes-Greus, "Impact of hydrothermal ageing on the thermal stability, morphology and viscoelastic performance of PLA/sisal biocomposites,” Polym. Degrad. Stab., vol. 132, pp. 87-96, Mar. 2016.

[44] J. D. Badia, T. Kittikorn, E. Strömberg, L. Santonja-Blasco, A. Martínez-Felipe, A. Ribes-Greus, M. Ek, and S. Karlsson, "Water absorption and hydrothermal performance of PHBV/sisal biocomposites,” Polym. Degrad. Stab., vol. 108, pp. 166-174, Oct. 2014.

[45] O. Gil-Castell, J. D. D. Badia, T. Kittikorn, E. Strömberg, A. Martínez-Felipe, M. Ek, S. Karlsson, A. Ribes-Greus, E. Stromberg, A. Martinez-Felipe, M. Ek, S. Karlsson, A. Ribes-Greus, E. Strömberg, A. Martínez-Felipe, M. Ek, S. Karlsson, and A. RibesGreus, "Hydrothermal ageing of polylactide/sisal biocomposites. Studies of water absorption behaviour and Physico-Chemical performance,” Polym. Degrad. Stab., vol. 108, pp. 212-222, Oct. 2014.

[46] J. D. Badia and A. Ribes-Greus, "Mechanical recycling of polylactide, upgrading trends and combination of valorization techniques,” Eur. Polym. J., vol. 84, pp. 22-39, 2016.

[47] O. Gil-Castell, J. D. Badia, and A. Ribes-Greus, "Suitability of blends from virgin and reprocessed polylactide: performance and energy valorisation kinetics,” Accept. Publ. J. Renew. Mater., 2017.

[48] J. D. Badia, E. Strömberg, S. Karlsson, and A. Ribes-Greus, "The role of crystalline, mobile amorphous and rigid amorphous fractions in the performance of recycled poly (ethylene terephthalate) (PET),” Polym. Degrad. Stab., vol. 97, no. 1, pp. 98-107, Jan. 2012.

[49] J. D. Hoffman and J. I. Lauritzen, "Crystallization of Bulk Polymers With Chain Folding : Theory of Growth of Lamellar Spherulites,” J. Res. Natl. Bur. Stand. - A. Phys. Chem., vol. 65, no. August, p. 1961, 1961.

[50] J. I. Lauritzen and J. D. Hoffman, "Formation of Polymer Crystals with Folded Chains from Dilute Solution,” J. Chem. Phys., vol. 31, no. 6, pp. 1680-1681, 1959.

[51] I. Engelberg and J. Kohn, "Physico-mechanical properties of degradable polymers used in medical applications: a comparative study.,” Biomaterials, vol. 12, no. 3, pp. 292304, Apr. 1991.

[52] M. A. Sabino, J. Albuerne, A. Müller, J. Brisson, and R. E. Prud’homme, “Influence of in vitro hydrolytic degradation on the morphology and crystallization behavior of poly(p-dioxanone),” Biomacromolecules, vol. 5, no. 2, pp. 358-370, 2004.

[53] C. Ping Ooi and R. E. Cameron, "The hydrolytic degradation of polydioxanone (PDSII) sutures. Part I: Morphological aspects,” J. Biomed. Mater. Res., vol. 63, no. 3, pp. 280290, 2002.

[54] O. Gil-Castell, J. D. D. Badia, E. Strömberg, S. Karlsson, and A. Ribes-Greus, "Effect of the dissolution time into an acid hydrolytic solvent to tailor electrospun nanofibrous polycaprolactone scaffolds,” Eur. Polym. J., vol. 87, pp. 174-187, 2017.

[55] N. Sultana and T. H. Khan, "In Vitro Degradation of PHBV Scaffolds and nHA/PHBV Composite Scaffolds Containing Hydroxyapatite Nanoparticles for Bone Tissue Engineering,” J. Nanomater., vol. 2012, pp. 1-12, 2012.

[56] K. Kim, M. Yu, X. Zong, J. Chiu, D. Fang, Y.-S. Seo, B. S. Hsiao, B. Chu, and M. Hadjiargyrou, "Control of degradation rate and hydrophilicity in electrospun non-woven poly(d,l-lactide) nanofiber scaffolds for biomedical applications,” Biomaterials, vol. 24, no. 27, pp. 4977-4985, Dec. 2003.

[57] X. Zong, S. Ran, K. S. Kim, D. Fang, B. S. Hsiao, and B. Chu, "Structure and morphology changes during in vitro degradation of electrospun poly(glycolide-colactide) nanofiber membrane,” Biomacromolecules, vol. 4, no. 2, pp. 416-423, 2003.

[58] G.-Q. Chen and Q. Wu, "The application of polyhydroxyalkanoates as tissue engineering materials.,” Biomaterials, vol. 26, no. 33, pp. 6565-78, Nov. 2005.

[59] S. Chanprateep, "Current trends in biodegradable polyhydroxyalkanoates.," J. Biosci. Bioeng., vol. 110, no. 6, pp. 621-32, Dec. 2010.

[60] X. S. Wu and N. Wang, "Synthesis, characterization, biodegradation, and drug delivery application of biodegradable lactic/glycolic acid polymers. Part II: biodegradation.,” J. Biomater. Sci. Polym. Ed., vol. 12, no. 1, pp. 21-34, 2001. 
[61] Y. Ikada and H. Tsuji, "Biodegradable polyesters for medical and ecological applications," Macromol. Rapid Commun., vol. 21, no. 3, pp. 117-132, 2000.

[62] A. Arinstein, M. Burman, O. Gendelman, and E. Zussman, "Effect of supramolecular structure on polymer nanofibre elasticity,” Nat. Nanotechnol., vol. 2, no. 1, pp. 59-62, Jan. 2007.

[63] J. Gaumer, A. Prasad, D. Lee, and J. Lannutti, "Structure-function relationships and source-to-ground distance in electrospun polycaprolactone," Acta Biomater., vol. 5, no. 5, pp. 1552-1561, Jun. 2009.

[64] V. Guarino, V. Cirillo, P. Taddei, M. A. Alvarez-Perez, and L. Ambrosio, “Tuning Size Scale and Crystallinity of PCL Electrospun Fibres via Solvent Permittivity to Address hMSC Response,” Macromol. Biosci., vol. 11, no. 12, pp. 1694-1705, Dec. 2011.

[65] J. L. Lowery, N. Datta, and G. C. Rutledge, "Effect of fiber diameter, pore size and seeding method on growth of human dermal fibroblasts in electrospun poly( $\varepsilon$ caprolactone) fibrous mats,” Biomaterials, vol. 31, no. 3, pp. 491-504, Jan. 2010.

[66] B. OM, "Current concepts review: Absorbable implants for the fixation of fractures," $J$ Bone Joint Surg Am, vol. 73-A, no. 1. The Journal of Bone \& Joint Surgery, pp. 148153, 1991. 


\section{Contribution 5.3.}

Effect of the dissolution time into an acid hydrolytic

solvent to tailor electrospun nanofibrous

polycaprolactone scaffolds

O. Gil-Castell, J. D. Badia, E. Strömberg, S. Karlsson, A. Ribes-Greus. Effect of the dissolution time into an acid hydrolytic solvent to taylor electrospun nanofibrous polycaprolactone scaffolds. European Polymer Journal 2017;87:174-187

This is an open-access version, according to:

http://www.sherpa.ac.uk/romeo/issn/0014-3057/

Full text available at:

http://www.sciencedirect.com/science/article/pii/S001430571630831X

DOI:

http://dx.doi.org/10.1016/j.eurpolymj.2016.12.005 


\title{
Effect of the dissolution time into an acid hydrolytic solvent to tailor electrospun nanofibrous polycaprolactone scaffolds
}

\author{
O. Gil-Castell ${ }^{1}$, J. D. Badia ${ }^{1,2,3}$, E. Strömberg ${ }^{4}$, S. Karlsson ${ }^{4,5}$, A. Ribes- \\ Greus ${ }^{1, *}$
}

${ }^{1}$ Instituto de Tecnología de Materiales (ITM). Universitat Politècnica de València. Camino de Vera s/n, 46022 Valencia, Spain.
${ }^{2}$ Departament de Química Orgànica i Analítica, Universitat Rovira i Virgili, C/Marcel·lí Domingo s/n, 43007 Tarragona, Spain.
${ }^{3}$ Departament d’Enginyeria Química, Escola Tècnica Superior d’Enginyeria, Universitat de València, Avinguda de la Universitat s/n, 46100 Burjassot, Spain.

${ }^{4} \mathrm{KTH}$ Royal Institute of Technology, School of Chemical Science and Engineering, Fibre and Polymer Technology, Teknikrigen56-58, SE-10044 Stockholm, Sweden.

${ }^{5}$ Skövde University, SE-541 28 Skövde, Sweden

${ }^{*}$ Corresponding author:

A. Ribes-Greus aribes@ter.upv.es 


\title{
Effect of the dissolution time into an acid hydrolytic solvent to tailor electrospun nanofibrous polycaprolactone scaffolds
}

\author{
O. Gil-Castell, J. D. Badia, E. Strömberg, S. Karlsson, A. Ribes-Greus
}

\begin{abstract}
The hydrolysis of the polycaprolactone (PCL) as a function of the dissolution time in a formic/acetic acid mixture was considered as a method for tailoring the morphology of nanofibrous PCL scaffolds. Hence, the aim of this research was to establish a correlation between the dissolution time of the polymer in the acid solvent with the physico-chemical properties of the electrospun nanofibrous scaffolds and their further service life behaviour.
\end{abstract}

The physico-chemical properties of the scaffolds were assessed in terms of fibre morphology, molar mass and thermal behaviour. A reduction of the molar mass and the lamellar thickness as well as an increase of the crystallinity degree were observed as a function of dissolution time. Beadfree fibres were found after 24 and 48 h of dissolution time, with similar diameter distributions. The decrease of the fibre diameter distributions along with the apparition of beads was especially significant for scaffolds prepared after $72 \mathrm{~h}$ and $120 \mathrm{~h}$ of dissolution time in the acid mixture.

The service life of the obtained devices was evaluated by means of in vitro validation under abiotic physiological conditions. All the scaffolds maintained the nanofibrous structure after 100 days of immersion in water and PBS. The molar mass was barely affected and the crystallinity degree and the lamellar thickness increased along immersion, preventing scaffolds from degradation. Scaffolds prepared after $24 \mathrm{~h}$ and $48 \mathrm{~h}$ kept their fibre diameters, whereas those prepared after $72 \mathrm{~h}$ and $120 \mathrm{~h}$ showed a significant reduction.

This PCL tailoring procedure to obtain scaffolds that maintain the nanoscaled structure after such long in vitro evaluation will bring new opportunities in the design of long-term biomedical patches.

\section{Keywords}

Electrospinning, scaffold, hydrolysis, polycaprolactone (PCL), in vitro validation 


\section{Introduction}

The development of scaffolds for biomedical applications is focused on the fabrication of biological substitutes that restore, maintain or improve either a particular tissue or even an entire organ, through an adequate cell adhesion and proliferation procedure. These nanoscaled scaffolds mimic extracellular matrix (ECM) which is known to play a key role in tissue regeneration field [1], [2].

Electrospinning is one of the most applied methods for polymer-based fibrous devices production in the nanoscale range. This technique permits the fabrication of non-woven nanomats with large surface area-to-volume ratio and high porosity, which have found interesting applications in the biomedical sector [3]-[7]. The electrospinning process is based on the application of a high voltage electric field between the tip of a syringe and a collector to transform a polymer solution into mats of non-woven nanofibres [8]-[12]. The suitability of this process is known to depend on the synergistic effect of the solution and processing conditions [13], [14]. Indeed, some difficulties during the preparation of the scaffolds propitiated a field of interest.

A variety of natural and synthetic polymers have been widely used for scaffold fabrication such as poly(lactic acid) (PLA), poly(lactic-coglycolic acid) (PLGA) or poly(caprolactone) (PCL), with diverse applications according to their durability when subjected to service life conditions [9], [11]. Among these, PCL is a semicrystalline linear aliphatic polyester that is widely applied in biomedicine due to its biocompatibility and slow biodegradability. PCL has been validated both in vitro and in vivo in the biomedical sector for long-term applications [15]-[28]. However, producing electrospun bead-free fibres of PCL in the nanoscale range has become a delicate issue which has been tried to overcome [29]-[36]. This is the reason why highly toxic solvents such as chloroform, dimethylformamide, methylene chloride or dichloroethane have been required for the electrospinning of PCL [37]-[39].

Several alternative solvents have been recently proposed for the electrospinning of PCL, with the aim of reducing the exposure of technicians to toxic solvents [40]. Acetone was appointed by Bosworth et al. with promising results [41]. Bisnulal et al. produced nanofiber scaffolds via electrospinning of PCL using diluted acetic acid-ethyl acetate for bone tissue engineering [42]. Van der Schueren et al. found an innovative solvent mixture of formic/acetic acid with an effective nanofiber fabrication under steady-state conditions [43]. Although hydrolytic degradation of PCL through cleavage of the ester bond occurs in the aqueous acidic media, it was shown that the viscosity of a PCL solution in formic/acetic acid was high enough for suitable electrospinning in steady- 
state conditions [43]-[45]. Lavielle et al. studied the formation of PCL electrospun fibres in this acidic medium and modelled the loss of molar mass as a function of the time of dissolution of the polymer in the solution [44]. Taking these references as a baseline for this research, it seems therefore interesting to extent these studies to tailor the structure and physico-chemical performance of electrospun nanofibrous scaffolds as a function of the dissolution time of PCL in the acid solvent, which will determine its subsequent behaviour during its application [14], [29], [33], [46]-[48]. Literature propose that properties such as the fibre morphology, the molar mass, the crystallinity degree or the lamellar thickness play an important influence during the application of a biodegradable biomedical device, as studied for some polyesters such as PLA or PCL [19], [47]-[49]. Indeed, by adopting a particular fibre morphology (i.e. size scale) and mode of assembly of polymer chains (i.e. crystallinity), it is possible to influence the cell adhesion and proliferation kinetics, and further determine the course of their differentiation process [14]. During application, the rate of biodegradation is also a crucial aspect, determined by the accessibility of water to the ester bonds, which is affected by a number of factors such as the hydrophobicity of the monomer, the crystallinity of the sample, the molar mass or the bulk sample dimensions, among others [46]-[48]. Due to the reported higher degradation rate of amorphous regions versus that of the crystalline ones, the crystallinity degree is one of the most dominant factors. Actually, the effect of the molar mass on the crystallisation kinetics of PCL has been previously reported by Jenkins and Harrison [49]. As a consequence, a deep characterisation based on the morphology, the molar mass and the microstructure as well as the in vitro validation as a function of the time of dissolution of the polymer into the hydrolytic acid solvent is essentially required.

The aim of this research was therefore to establish a correlation between the dissolution time of the PCL in the hydrolytic solvent system based on formic/acetic acid (1:1) and its resultant structure, physico-chemical properties and further in vitro performance.

\section{Materials and methods}

\subsection{Materials}

Polycaprolactone (PCL) was provided by Perstorp as $3 \mathrm{~mm}$ diameter pellets under the CAPA ${ }^{\text {TM }} 6800$ grade $\left(M_{n}=85000 \mathrm{~g} \cdot \mathrm{mol}^{-1}\right.$ and $T_{m} 58-60$ $\left.{ }^{\circ} \mathrm{C}\right)$. Formic acid and acetic acid $(\geq 99 \%)$ were used as solvents for electrospinning. Tetrahydrofuran (THF) $(\geq 99.8 \%)$ was used as solvent for the GPC analyses. Dulbecco’s Phosphate Buffer Saline (PBS) and $\mathrm{NaOH}$ solution $1 \mathrm{M}$ were used for the in vitro validation procedure. All of them were supplied by Sigma-Aldrich and were used without further 
purification. Ultra-pure water, as obtained from an ultra-filtration/ionexchange procedure was used for the in vitro validation.

\subsection{Polymer solution and electrospinning}

Electrospinning was performed by means of an horizontal setup composed of a Spellman SL80 high voltage supply, a Thermo Orion Sage ${ }^{\circledR} 361$ programmable syringe pump, a Normax Ruthe $20 \mathrm{~mL}$ Luer Lock glass syringe, silicon tube, and a Luer-Lock gauge 21 metallic needle. The tipto-collector distance was maintained constant at $12.5 \mathrm{~cm}$. Solutions for electrospinning were prepared in 1:1 formic/acetic acid, with a polymer concentration of 15\% wt and were electrospun after 24, 48, 72 and $120 \mathrm{~h}$ of dissolution time. Complete dissolution of the polymer was guaranteed after $24 \mathrm{~h}$, whereas after $120 \mathrm{~h}$ the viscosity of the solution was excessively low to ensure stable electrospinning. The feeding rate varied between 0.5 , 1 and $1.5 \mathrm{~mL} \cdot \mathrm{h}^{-1}$ and the voltage varied between 15, 20 and $25 \mathrm{kV}$. Electrospinning was performed during $30 \mathrm{~min}$ at room temperature $\left(22^{\circ} \mathrm{C}\right)$ and $35 \%$ of relative humidity. Fibrous scaffolds were collected on aluminium foil, then dried and stored for further analyses.

\subsection{Scaffold characterisation}

\subsubsection{Field-emission scanning electron microscopy (FE-SEM)}

The surface topology of the specimens was analysed by means of a Zeiss Ultra 55 field emission scanning electron microscope (FE-SEM). The samples were cut into small pieces and dried at $50{ }^{\circ} \mathrm{C}$ in a vacuum oven for $24 \mathrm{~h}$ and then kept in a desiccator during $48 \mathrm{~h}$. Afterwards, the specimens were mounted on metal studs and sputter-coated with a platinum layer during 10 s using a Leica EM MED020 sputtering equipment. Testing was performed at room temperature with a $2 \mathrm{kV}$ voltage. The fibre diameters were measured from the FE-SEM micrographs (10000×) at random locations $(n=100)$ with the aid of the Image J software.

\subsubsection{Size exclusion chromatography (SEC)}

Size exclusion chromatography (SEC) analyses were carried out by means of a Malvern Instruments Omnisec Resolve chromatograph. It combined integrated pump, degasser, autosampler and column oven, along with a Malvern Instruments Omnisec Reveal multi-detector -UV, Refractive Index (RI), Low and Right Angle Light Scattering (LALS and RALS) and Viscosity (VISC)-. Two columns from Malvern Instruments (T2000 and T4000) were employed $(300 \times 8 \mathrm{~mm})$. The samples were dissolved in THF with concentrations of around $2.0 \mathrm{mg} \cdot \mathrm{ml}^{-1}$ and filtered through $0.45 \mu \mathrm{m}$ PTFE filters. As well, THF was used as mobile phase at a flow rate of 1 $\mathrm{mL} \cdot \mathrm{min}^{-1}$ and the column temperature was set at $35^{\circ} \mathrm{C}$. A monodisperse polystyrene standard with $\mathrm{dn} / \mathrm{dc}$ value of 0.185 was used for previous 
calibration. Two injections per sample were performed and the obtained data were analysed by means of the Omnisec V10 ${ }^{\mathrm{TM}}$ software.

\subsubsection{Fourier transformed infrared spectroscopy (FT-IR)}

The determination of the initial composition of the scaffolds as well as the preliminary study of the crystalline morphology was performed via attenuated total reflectance (ATR) in a Thermo Nicolet 5700 Fourier transform infrared spectrometer (FT-IR). The average spectra were collected from 64 scans with a resolution of $4 \mathrm{~cm}^{-1}$ in the $4000-600 \mathrm{~cm}^{-1}$ range, from eight different locations of the same specimen.

\subsubsection{Differential scanning calorimetry (DSC)}

Calorimetric data were obtained by differential scanning calorimetry by means of a Mettler-Toledo DSC $820^{\mathrm{e}}$ equipment, previously calibrated following the procedure of In and Zn standards. The samples, with a mass of about $4 \mathrm{mg}$, were analysed between 0 and $80{ }^{\circ} \mathrm{C}$ with a heating/cooling/heating rate of $10^{\circ} \mathrm{C} \cdot \mathrm{min}^{-1}$. All experiments were run under nitrogen atmosphere $\left(50 \mathrm{~mL} \cdot \mathrm{min}^{-1}\right)$. The specimens were characterised at least by triplicate and the averages of temperatures and enthalpies were taken as representative values.

The crystallinity degree $\left(X_{c}\right)$ was evaluated from the melting enthalpy results, by using Equation 1,

$$
X_{c}(\%)=\frac{\Delta h_{m}}{\Delta h_{m}^{0}} \cdot 100
$$

where $\Delta h_{m}$ is the melting enthalpy of the sample and $\Delta h_{m}{ }^{0}$ is the melting

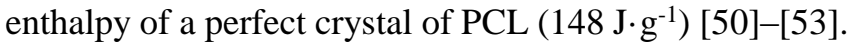

\subsection{In vitro hydrolytic degradation}

The electrospun PCL scaffolds were subjected to hydrolytic degradation in ultra-pure water and phosphate buffer solution (PBS), according to the international standard ISO 10993-13:2010, method 4.3 [54]. The pH of the PBS solution was previously adjusted to 7.4 with $\mathrm{NaOH} 1 \mathrm{M}$. The electrospun scaffolds were cut into rectangular specimens with a mass around $10 \mathrm{mg}$. The specimens were weighed $\left(m_{0}\right)$ and placed in a previous weighed vial $\left(m_{\text {vial }}\right) .10 \mathrm{~mL}$ of degradation medium were introduced and then the vials were sealed with polytetrafluoroethylene (PTFE) threaded plugs and placed in a thermostatically controlled oven at $37^{\circ} \mathrm{C}$. The effects of the hydrolytic degradation were evaluated after 100 days of immersion both in the solid and in the liquid. The liquid fraction was analysed immediately after extraction. The $\mathrm{pH}$ of the degradation media was measured at room temperature by using a Crison $\mathrm{pH} 25$ device. Three buffer solutions from Crison were used to calibrate the pH-meter: $\mathrm{pH} 4.01$ (phthalate buffer solution), pH 7.00 (phosphate buffer solution), pH 10.01 
(borate buffer solution). The remaining solid fraction coming from the saline buffer was washed with deionized water and then, along with specimens coming from water environment, dried under vacuum to constant mass into their degradation vials $\left(m_{d r y}\right)$ and saved for further analyses. The mass loss of the specimens was calculated according to Equation 2.

$$
\operatorname{Mass} \operatorname{loss}(\%)=100-\frac{\left(m_{\text {dry }}-m_{\text {vial }}\right)}{m_{0}} \cdot 100
$$

\section{Results and discussion}

\subsection{Preliminary study of the electrospinning viability}

The electrospinning viability was addressed under different experimental conditions: dissolution time of the PCL in the hydrolytic acid solvent (24$120 \mathrm{~h}$ ), feeding rate $\left(0.5-1 \mathrm{~mL} \cdot \mathrm{h}^{-1}\right)$ and voltage $(15-25 \mathrm{kV})$, in order to establish the effect of each parameter on the final electrospun scaffolds. Other factors such as the polymer type, solvent type, concentration, needle diameter, tip-to-collector distance, collector type, working time, temperature and humidity remained fixed, as specified in the experimental section. In general terms, the system turned unstable and dripped for low voltages and high feeding rates, while consumption of the material in the tip and unstable Taylor cone was found for high voltages and low feeding rates. Table 1 gathers the experimental conditions in which electrospinning was viable, which micrographs can be found in Figure 1.

Figure 2 shows that the influence of the voltage and the feeding rate on the fibre diameter regardless the dissolution time was not as relevant. Therefore, this study is focused from now onwards on the effect of the dissolution time in the hydrolytic acid solvent from the electrospun scaffolds labelled as 4, 8, 12 and 15 , obtained with a feeding rate of $1 \mathrm{~mL} \cdot \mathrm{h}^{-}$ ${ }^{1}$ and a voltage of $25 \mathrm{kV}$. 


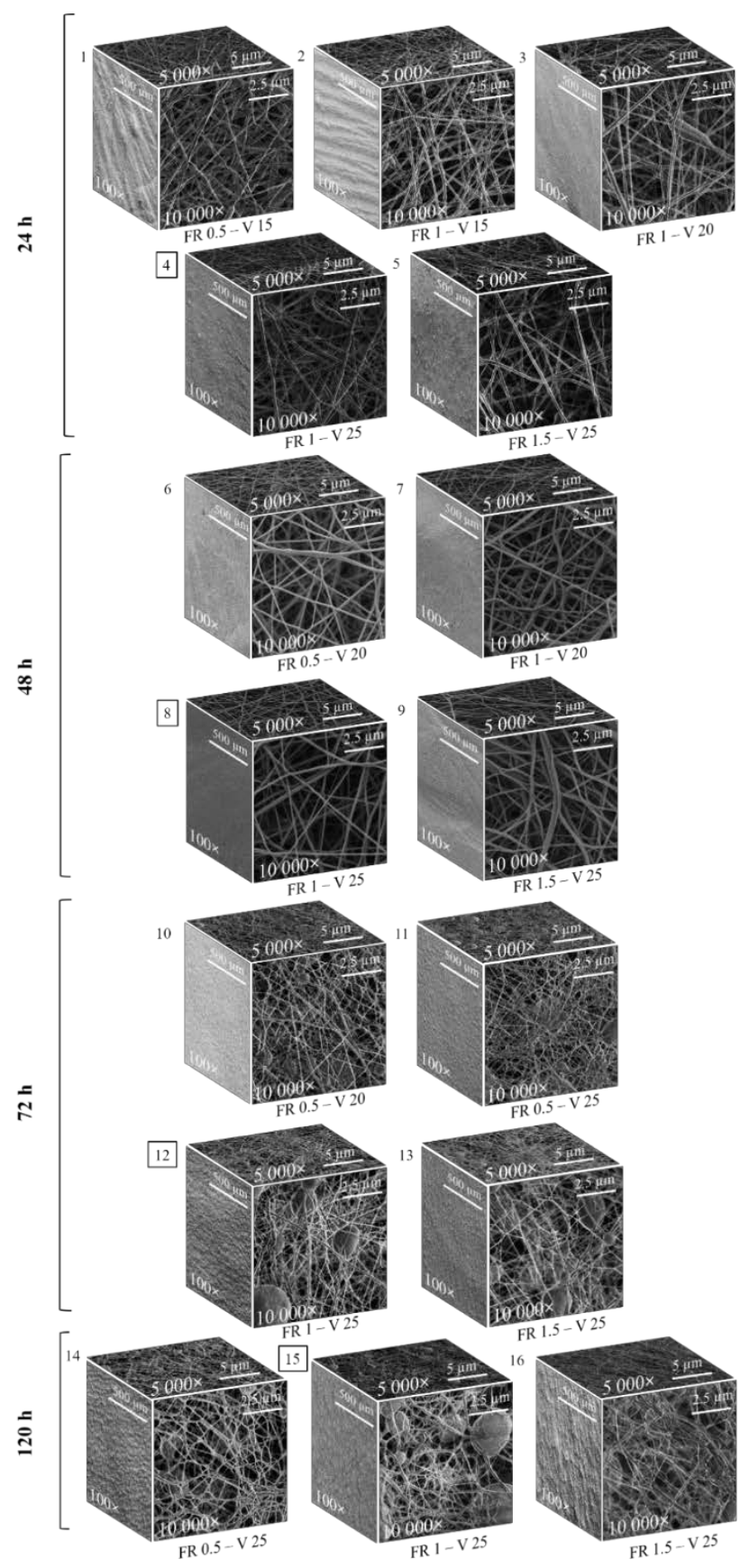

Figure 1. FE-SEM micrographs for the viable electrospinning process as function of dissolution time, feeding rate (FR) and voltage (V) (100, 5000 and $10000 \times, 3 \mathrm{kV})$.

( $\square$ Indicate those scaffolds chosen for further characterisation). 
Table 1. Electrospinning viability for dissolution time (24, 48, 72 and $120 \mathrm{~h}$ ), feeding rate $\left(0.5,1\right.$ and $\left.1.5 \mathrm{~mL} \cdot \mathrm{h}^{-1}\right)$ and voltage $(15,20$ and $25 \mathrm{kV}) .(\checkmark)$ Stands for viable, while (-) for unviable conditions. Superindexes are identifiers for the Figure 1. Indicate those specimens chosen for the study)

\begin{tabular}{|c|c|c|c|c|c|c|c|}
\hline \multirow{2}{*}{$\begin{array}{l}\text { Dissolution time } \\
\text { (h) }\end{array}$} & \multirow{2}{*}{$\begin{array}{c}\text { Feeding Rate } \\
\qquad\left(\mathbf{m L} \cdot \mathbf{h}^{-1}\right)\end{array}$} & \multicolumn{6}{|c|}{ Voltage (kV) } \\
\hline & & & 15 & & 20 & & 25 \\
\hline \multirow{3}{*}{24} & 0.5 & $\square$ & $1 \square$ & & - & & - \\
\hline & 1 & $\square$ & 2 & $\square$ & 3 & $\square$ & 44 \\
\hline & 1.5 & & - & & - & $\square$ & $5 \square$ \\
\hline \multirow{3}{*}{48} & 0.5 & & - & $\square$ & 6 & & - \\
\hline & 1 & & - & $\square$ & 7 & $\square$ & 84 \\
\hline & 1.5 & & - & & - & $\square$ & 9 \\
\hline \multirow{3}{*}{72} & 0.5 & & - & $\square$ & $10 \square$ & $\square$ & $11 \square$ \\
\hline & 1 & & - & & - & $\square$ & 124 \\
\hline & 1.5 & & - & & - & $\square$ & $13 \square \square$ \\
\hline \multirow{3}{*}{120} & 0.5 & & - & & - & $\square$ & $14 \square \square$ \\
\hline & 1 & & - & & - & $\square$ & 154 \\
\hline & 1.5 & & - & & - & $\square$ & $16 \square \square$ \\
\hline
\end{tabular}

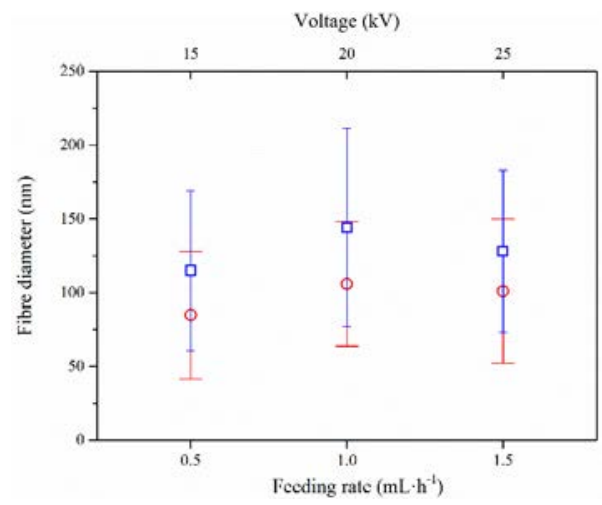

Figure 2. Influence of voltage (V) (square $\square$; DT $=24$ h) and influence of feeding rate (FR) (circle $\mathbf{O}$; DT $=72 \mathrm{~h}$ ) on scaffold fibre diameter. Mean fibre diameter and standard deviation, as calculated from the FE-SEM micrographs $(10000 \times)$ at random locations $(n=100)$. DT stands for dissolution time. 


\subsection{Influence of dissolution time on scaffold physico-chemical properties}

\subsubsection{Influence of dissolution time on the scaffold morphology}

Figure 3a shows the histogram and Figure $\mathbf{3 b}$ the box-whisker plot of the fibre diameter distribution of the scaffolds obtained after 24, 48, 72 and $120 \mathrm{~h}$ of dissolution time in the hydrolytic acid solvent, as calculated from micrographs in Figure 1. The fibre diameter showed a decreasing tendency to lower values as dissolution time increased, from mean values of $125 \mathrm{~nm}$ after $24 \mathrm{~h}$ to values around $95 \mathrm{~nm}$ after $120 \mathrm{~h}$. Bead-free fibres were found after 24 and 48 h of dissolution time, while some beads in the microscale range were found for longer dissolution times (72 and $120 \mathrm{~h}$ ). The diameter of these beads oscillated between $1.25 \mu \mathrm{m}$ and $1.60 \mu \mathrm{m}$ with concentrations of $9.75 \times 10^{-2}$ and $9.16 \times 10^{-2}$ beads $\cdot \mu \mathrm{m}^{-2}$, for scaffolds prepared after 72 and $120 \mathrm{~h}$ respectively. These beads seem to be the responsible of the intense roughness observed at micrographs with lower magnification. According to bibliography, for a given concentration, the reduction of fibre diameter and the appearance of beads are usually related to a reduction of the solution viscosity due to the hydrolytic action of the solvent, and the subsequent lower incidence of chain entanglements [14], [44], [55].
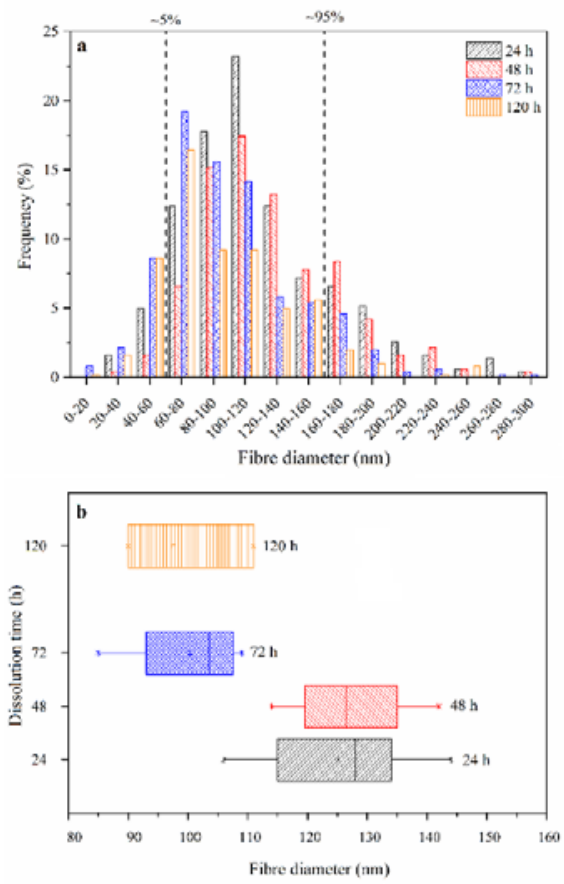

Figure 3. (a) Fibre diameter histogram for the scaffolds prepared after 24, 48, 72 and $120 \mathrm{~h}$ of dissolution. Dash lines indicate the approximated whisker limits (5 and 95\%). (b) Box-whisker plots of the fibre diameter as a function of dissolution time.

Box quartiles represent 25-75\% and whiskers are between 5-95\%. 


\subsubsection{Influence of dissolution time on the scaffold molar mass}

The molar mass of the scaffolds was assessed by means of size exclusion chromatography (SEC) in terms of average molar mass in number $\left(M_{n}\right)$, average molar mass in weight $\left(M_{w}\right)$ and polydispersity index (PDI), as shown in Figure $\mathbf{4}$ for the pellet of PCL and electrospun scaffolds as a function of dissolution time in the hydrolytic acid solvent.

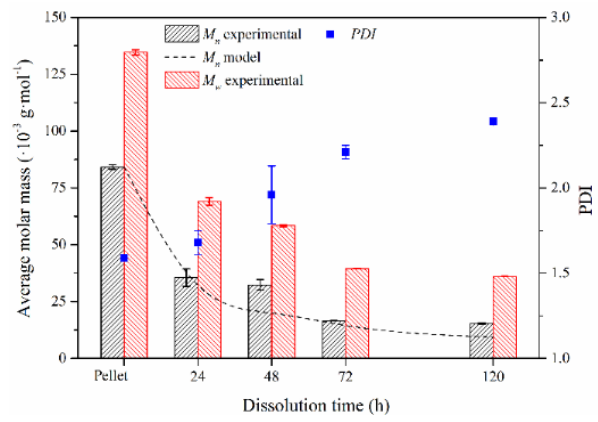

Figure 4. Average molar mass in number $\left(M_{n}\right)$, average molar mass in weight $\left(M_{w}\right)$ and polydispersity index $(P D I)$ for PCL pellet, and electrospun scaffolds processed after 24, 48, 72 and $120 \mathrm{~h}$ of dissolution. Dotted line corresponds to the theoretical average molar mass in number values, as calculated from the method proposed by

Lavielle et al. [44].

Overall, $M_{n}$ decreased from 85000 to $15000 \mathrm{~g} \cdot \mathrm{mol}^{-1}$, while $M_{w}$ moved from 135000 to $36000 \mathrm{~g} \cdot \mathrm{mol}^{-1}$ from the raw PCL (pellet) to the scaffold prepared after $120 \mathrm{~h}$ of solution preparation. As expected, the acidic nature of the solvent promoted a general decrease in the molar mass ascribed to the hydrolytic scission of the ester bond of PCL. The SEC analysis revealed that the chain scission of PCL was not linearly dependent on dissolution time: it was degraded faster at the early stage of solution preparation and tended to decrease slowly thereafter. Accordingly, an increase in the polydispersity index (PDI) was found from 1.59 to 2.39, which indicated the increase of cleavages of high molar mass segments, characteristic of a random chain scission according to the Flory's statistical theory [56]. All these results were in concordance with those obtained in other studies [43], [44]. In particular, a proper correlation (96\% coincidence) between the expected theoretical -as calculated according to Lavielle et al. (Supplementary Material)- and the experimental values was obtained.

\subsubsection{Influence of dissolution time on the scaffold microstructure}

Fourier transformed infrared spectroscopy (FT-IR) was considered to perform a preliminary analysis of the change in the microstructure after electrospinning. Figure 5a shows the absorbance spectra in the 1100-1300 $\mathrm{cm}^{-1}$ region for PCL pellet and electrospun scaffolds after 24, 48, 72 and $120 \mathrm{~h}$ of dissolution time in the hydrolytic acid solvent. It is well-known 
that, for polyesters, this spectral region appears to be the most sensitive to morphology differences, due to the appearance of $\mathrm{C}-\mathrm{C}-\mathrm{H}$ and $\mathrm{O}-\mathrm{C}-\mathrm{H}$ bending vibrations and $\mathrm{C}-\mathrm{C}$ and $\mathrm{C}-\mathrm{O}$ stretching vibrations [14], [57], [58]. Moreover, the bands located around 1162 and $1178 \mathrm{~cm}^{-1}$ are related with amorphous and crystalline morphology, respectively. The $I_{1178} / I_{1162}$ intensity ratio is commonly used as an indicator of the change in the internal morphology of the fibres [14], [58]. Figure 5b shows a noticeable increase of crystallinity as a function of the dissolution time in the hydrolytic acid solvent up to $72 \mathrm{~h}$, which remained from then onwards.
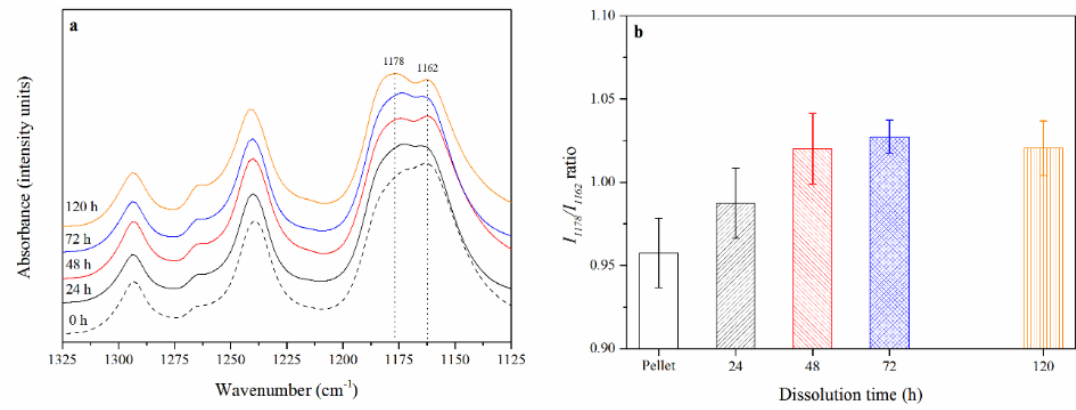

Figure 5. (a) FT-IR spectra in the $1325-1125 \mathrm{~cm}^{-1}$ region and (b) $I_{1162} / I_{1178}$ ratio for PCL pellet, and electrospun scaffolds processed after 24, 48, 72 and $120 \mathrm{~h}$ of dissolution.

In order to corroborate these changes along the dissolution time, the differential scanning calorimetry (DSC) technique was used, which is considered to be adequate to understand the change in the microstructure of polymers subjected to a given degradation process [59]-[65]. The discussion in this section is given in terms of melting/crystallisation peak temperatures $\left(T_{m 1}, T_{c} T_{m 2}\right)$, lamellar thickness $\left(l_{c 1}, l_{c 2}\right)$, specific enthalpies $\left(\Delta h_{m 1}, \Delta h_{c}, \Delta h_{m 2}\right)$ and crystallinity degree $\left(X_{c 1}, X_{c 2}\right)$, where subindexes 1 and 2 correspond to the $1^{\text {st }}$ and $2^{\text {nd }}$ heating scans, respectively. Figure 6 plots the DSC thermograms of the $1^{\text {st }}$ heating, cooling and $2^{\text {nd }}$ heating scans for PCL pellet and scaffolds electrospun after 24, 48, 72 and $120 \mathrm{~h}$ of dissolution time in the hydrolytic acid solvent. Values of the main peak temperatures and enthalpies of the melting and crystallisation events are gathered in Table 2. The differences between melting enthalpies and peak temperatures obtained from the $1^{\text {st }}$ and $2^{\text {nd }}$ heating scans are explained by the different crystallisation behaviour of the PCL after electrospinning and differential scanning calorimetry. While electrospinning produces straininduced crystallisation and was carried out at temperatures close to the $T_{c}$ of the PCL [19], [66], the dynamic cooling of the DSC did not permit to achieve the same crystalline development [67]. 




Figure 6. DSC traces of the $1^{\text {st }}$ heating, cooling and $2^{\text {nd }}$ heating scans for PCL pellet and scaffolds prepared after 24, 48, 72 and 120 h of dissolution.

Table 2. Melting enthalpy and temperature of the $1^{\text {st }}$ heating scan $\left(\Delta h_{m 1}, T_{m 1}\right)$, crystallisation enthalpy and temperature of the cooling scan $\left(\Delta h_{c}, T_{c}\right)$ and melting enthalpy and temperature of the $2^{\text {nd }}$ heating scan $\left(\Delta h_{m 2}, T_{m 2}\right)$ as a function of the dissolution time for PCL pellet and scaffolds prepared after 24, 48, 72 and $120 \mathrm{~h}$ of dissolution time.

\begin{tabular}{ccccccc}
\hline \multirow{2}{*}{ Dissolution time (h) } & $\begin{array}{c}\boldsymbol{T}_{\boldsymbol{m} \mathbf{1}} \\
\left({ }^{\mathbf{}} \mathbf{C}\right)\end{array}$ & $\begin{array}{c}\Delta \boldsymbol{h}_{\boldsymbol{m} \mathbf{1}} \\
\left(\mathbf{J} \cdot \mathbf{g}^{-\mathbf{1}}\right)\end{array}$ & $\begin{array}{c}\boldsymbol{T}_{\boldsymbol{c}} \\
\left({ }^{\mathbf{}} \mathbf{C}\right)\end{array}$ & $\begin{array}{c}\Delta \boldsymbol{h}_{\boldsymbol{c}} \\
\left(\mathbf{J} \cdot \mathbf{g}^{-\mathbf{1}}\right)\end{array}$ & $\begin{array}{c}\boldsymbol{T}_{\boldsymbol{m} \mathbf{2}} \\
\left({ }^{\circ} \mathbf{C}\right)\end{array}$ & $\begin{array}{c}\Delta \boldsymbol{h}_{\boldsymbol{m} 2} \\
\left(\mathbf{J} \cdot \mathbf{g}^{-\mathbf{1}}\right)\end{array}$ \\
\hline \multirow{2}{*}{ PCL pellet } & 63.51 & 45.60 & 21.29 & -35.60 & 59.70 & 30.22 \\
& \pm 1.27 & \pm 2.28 & \pm 0.43 & \pm 1.78 & \pm 1.19 & \pm 1.51 \\
\hline \multirow{2}{*}{24} & 61.78 & 54.05 & 27.40 & -40.45 & 58.27 & 39.67 \\
& \pm 1.24 & \pm 3.22 & \pm 1.11 & \pm 2.06 & \pm 1.09 & \pm 2.31 \\
\hline \multirow{2}{*}{48} & 60.50 & 52.34 & 28.47 & -39.39 & 57.53 & 36.83 \\
& \pm 1.21 & \pm 2.62 & \pm 0.57 & \pm 1.97 & \pm 1.15 & \pm 1.84 \\
\hline \multirow{2}{*}{72} & 60.63 & 60.18 & 29.96 & -44.89 & 56.38 & 44.22 \\
& \pm 0.10 & \pm 1.80 & \pm 0.35 & \pm 1.40 & \pm 0.30 & \pm 1.22 \\
\hline \multirow{2}{*}{120} & 60.31 & 58.39 & 30.59 & -43.63 & 56.87 & 43.03 \\
& \pm 0.12 & \pm 4.04 & \pm 0.49 & \pm 2.68 & \pm 0.64 & \pm 2.93 \\
\hline
\end{tabular}

In the $1^{\text {st }}$ heating scan the melting peak is the result of at least two different melting transitions. A melting shoulder, placed at around $45^{\circ} \mathrm{C}$, seemed to remain constant, and can be ascribed to a crystalline population with a smaller lamellar thickness. The main melting peak, around $60{ }^{\circ} \mathrm{C}$, is ascribed to the typical PCL melting behaviour, which sharpened and moved towards lower temperatures for a higher dissolution time in the hydrolytic acid solvent. During the cooling scan, a crystallisation transition occurred, which peak temperature $\left(T_{c}\right)$ moved towards higher values from $\sim 21{ }^{\circ} \mathrm{C}$ for PCL pellet to $\sim 30{ }^{\circ} \mathrm{C}$ after $120 \mathrm{~h}$ of dissolution time. Since the changes in the $T_{C}$ are closely related to the change in the molar mass of a polymer, the increase in the $T_{c}$ corroborate the lower molar mass of the PCL scaffolds as the dissolution time increased. Shorter polymer chains with enhanced mobility crystallised at higher temperatures. Finally, in the 
$2^{\text {nd }}$ heating scan, it was observed a melting peak located around $57^{\circ} \mathrm{C}$, which became sharper the longer the dissolution time was. With the purpose of deeply characterise the crystalline structure of the nanofibres, lamellar thickness distributions were calculated by applying the ThomsonGibbs equation (Equation 4), based on the temperatures associated to the melting transitions [68]-[71],

$$
l_{C}\left(T_{m}\right)=\left[\left(1-\frac{T_{m}}{T_{m}^{0}}\right) \cdot \frac{\Delta h_{m V}}{2 \cdot \sigma_{e}}\right]^{-1}
$$

(Equation 4)

where $T_{m}$ is the melting temperature; $T_{m}{ }^{0}$ is the equilibrium melting temperature of an infinite crystal (348 K); $\sigma_{e}$ is the surface free energy of the basal plane where the chains fold $\left(106 \cdot 10^{-3} \mathrm{~J} \cdot \mathrm{m}^{-2}\right)$; and $\Delta h_{m V}$ is the melting enthalpy per volume unit $\left(1.63 \cdot 10^{8} \mathrm{~J} \cdot \mathrm{m}^{-3}\right)$ [53]. Figure 7a shows the evolution of the lamellar thickness distributions for the $1^{\text {st }}$ heating scan. PCL pellet showed a wide distribution, with a most probable lamellar thickness $\left(l_{c}\right)$ around $45 \mathrm{~nm}$. After electrospinning, narrower crystalline populations were obtained, showing a $l_{c}$ around $32 \mathrm{~nm}$. The promotion of smaller crystals ascribed to both the fast rate of solvent evaporation during electrospinning [72]-[74] and the stretching of shorter macromolecular chains [19], produced a more homogeneus crystalline structure. This observation was corroborated by the parameter defined as the full width at medium height of the lamellar thickness distributions $(F W M H)$, which decreased with the dissolution time (Figure 7b).

With regards to the enthalpies for the aforementioned thermal transitions, in the $1^{\text {st }}$ heating scan $\Delta h_{m 1}$ increased after electrospinning and even more as a function of dissolution time. Indeed, this tendency was perceived in the crystallinity degree $\left(X_{c 1}\right)$, which ranged from $30.81 \%$ for PCL pellet to $36.52 \%$ and $40.66 \%$ for scaffolds prepared after $24 \mathrm{~h}$ and $120 \mathrm{~h}$, respectively. Then, in the cooling scan, the $\Delta h_{c}$ also increased with dissolution time, ranging from $-35.60 \mathrm{~J} \cdot \mathrm{g}^{-1}$ for PCL pellet to -40.45 and $44.88 \mathrm{~J} \cdot \mathrm{g}^{-1}$ for electrospun samples after $24 \mathrm{~h}$ and $120 \mathrm{~h}$, respectively. Consequently, as melting during the $2^{\text {nd }}$ heating scan is directly related to the previous crystallisation during cooling, the tendency was also preserved. Figure $\mathbf{7 b}$ shows how the crystallinity degree $\left(X_{c}\right)$ increased along with the aforementioned most probable lamellar thickness $\left(l_{c}\right)$ and FWMH reduction, which is ascribed to the homogenisation of the crystalline fraction. 

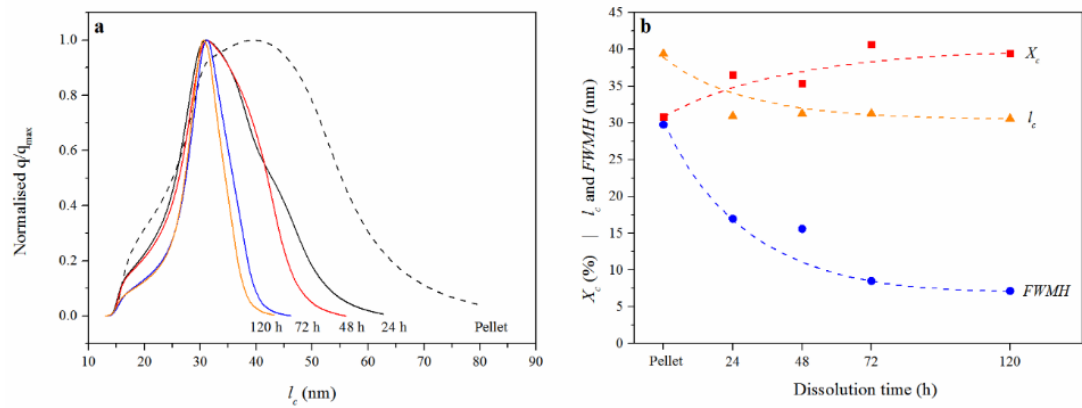

Figure 7. (a) Lamellar thickness distribution for PCL pellet and scaffolds prepared after 24, 48, 72 and $120 \mathrm{~h}$ of dissolution time as obtained in the $1^{\text {st }}$ heating scan; (b) Crystallinity degree $\left(X_{c}\right)$, most probable value of lamellar thickness $\left(l_{c}\right)$ and value of full width at medium height $(F W M H)$ as a function of dissolution time for PCL pellet and scaffolds prepared after 24, 48, 72 and $120 \mathrm{~h}$ of dissolution as obtained from the

$1^{\text {st }}$ heating scan. Error bars were omitted for the sake of clarity (Error $<5 \%$ ).

The most relevant results in this section can be inferred from the $1^{\text {st }}$ scan, which showed the effects of the dissolution time and the electrospinning procedure. Although electrospinning is known to promote limited crystallisation by fast rate of solvent evaporation, the hydrolytic degradation of the PCL during dissolution promoted a reduction of the length of the polymeric chains, as observed in the previous section. Shorter molecular chains with enhanced mobility were more capable of forming crystalline domains than longer polymer chains due to the higher stretching, which enhanced crystallisation and orientation along the fibre axis [19]. In addition, more concise crystalline populations with smaller lamellar thickness were found as dissolution time increased.

\subsection{In vitro validation of electrospun scaffolds}

The in vitro behaviour of the electrospun PCL scaffolds was assessed by means of immersion in ultra-pure water and phosphate buffer solution (PBS), according to the international norm ISO 10993-13:2010-method 4.3 [54]. The validation procedure extent was established to 100 days, which was considered as a reasonable time-span to evaluate physico-chemical changes along their hypothetical service life.

A qualitative and visual analysis of the changes in the surface morphology after the validation procedure is shown in Figure 8, whereas the quantification of those changes by means of the fibre diameter evaluation is shown in Figure 9. Then the variations of the mass, the $\mathrm{pH}$ of the degradation media, the molar mass, the crystallinity degree and the lamellar thickness are plotted in Figure 10. 


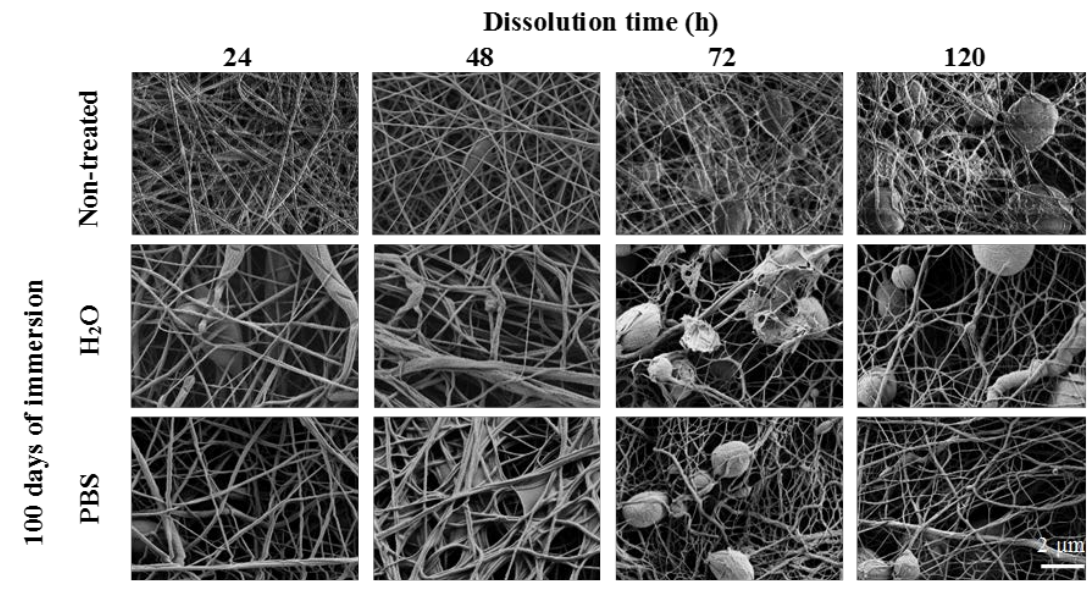

Figure 8. Fibre surface morphology $(10000 \times, 3 \mathrm{kV})$ as a function of dissolution time for PCL scaffolds prior to and after 100 days of immersion in ultra-pure water and PBS.

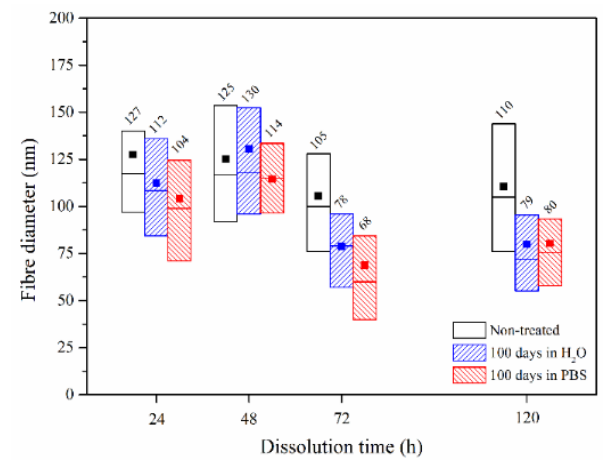

Figure 9. Box plot of the fibre diameter as a function of the dissolution time for PCL scaffolds prior to and after 100 days of immersion in ultra-pure water and PBS. Solid squares stand for the averages while the upper, middle and lower limits correspond to the first, second and third quartiles (75\%, 50\% and 25\%, respectively).

Apparently, the original nanofibrous structure seemed to remain unaffected after 100 days of immersion in both water and PBS media. Erosion at this stage was not significant enough to be appreciated from the fibre appearance, but a deep assessment of the fibre diameter showed two differentiated behaviours. As shown in Figure 10, the scaffolds prepared after $24 \mathrm{~h}$ and $48 \mathrm{~h}$ practically kept their fibre diameter distributions after immersion. However, the diameter reduction was found to be noticeable as dissolution time increased. The scaffolds prepared after $72 \mathrm{~h}$ and $120 \mathrm{~h}$ showed a significant reduction (30-40\%) of the fibre diameter after 100 days of in vitro validation. A similar behaviour was found in water and PBS, but a scarcely greater diameter decrease was observed in the buffered 
solution. Although the samples were vacuum dried before analysis, this performance could be ascribed to the higher fibre swelling due to the water absorption, compared to the lower PBS penetration.
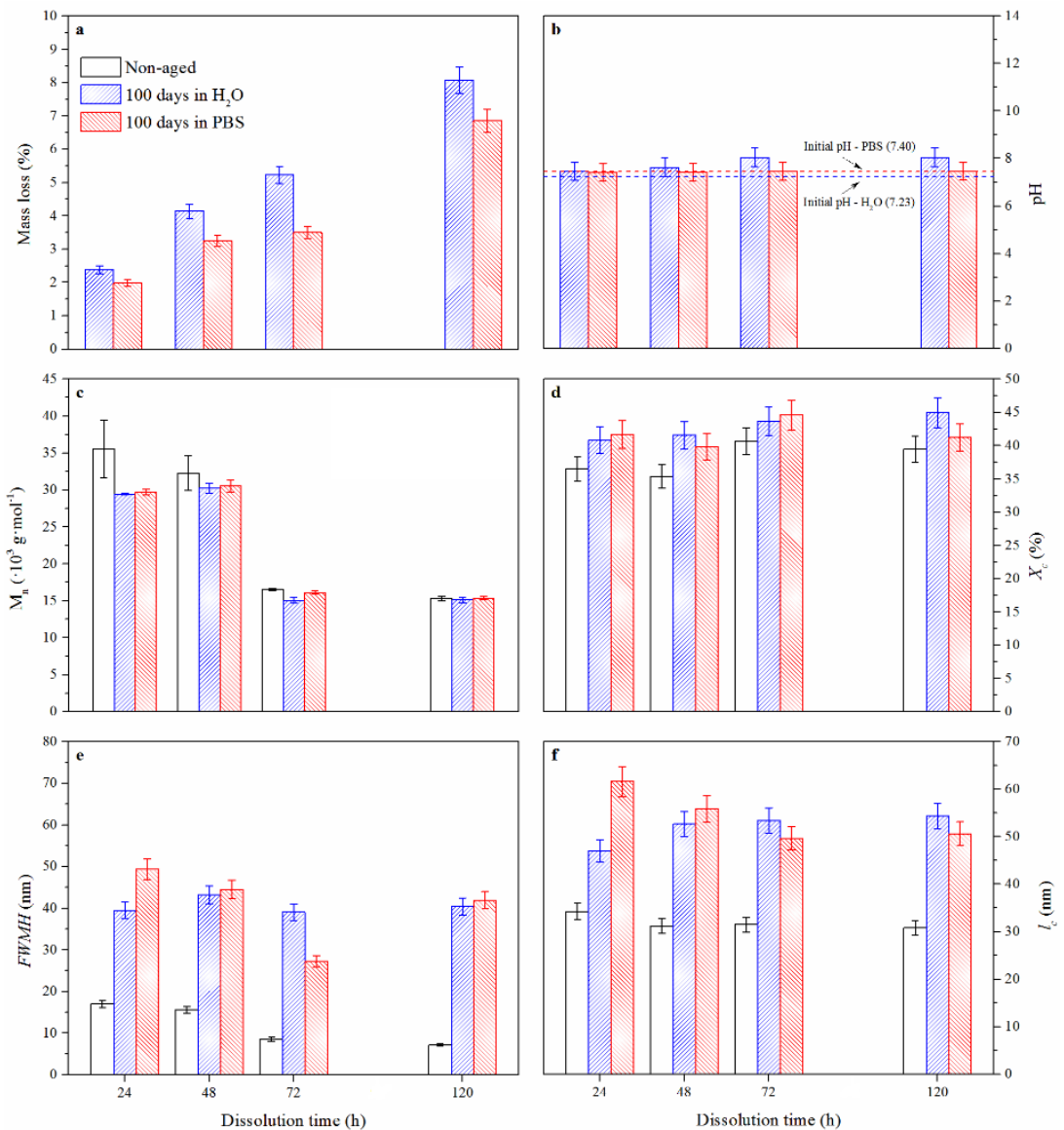

Figure 10. Evolution of several parameters selected as indicators for the assessment of the hydrolytic degradation after 100 days of immersion in aqueous and PBS media of the electrospun scaffolds processed after 24, 48, 72 and $120 \mathrm{~h}$ of dissolution time:

(a) Mass loss; (b) $\mathrm{pH}$ of the media; (c) Average molar mass in number $\left(M_{n}\right)$; (d)

Crystallinity degree $\left(X_{c}\right)$; (e) Full width at medium height of the lamellar thickness distribution $(F W M H)$; and (f) Peak of the lamellar thickness distribution $\left(l_{c}\right)$.

Erosion results as obtained by Equation 2 are plotted in Figure 10a. Greater mass loss was found as a function of dissolution time, which is related to the diffusion of higher amount of oligomeric species to the biodegradation media of greatly degraded scaffolds [75]. Slightly greater mass loss in water than in PBS for a given dissolution time was perceived. This difference can be ascribed to the capability of the PBS to buffer 
released acidic low molar mass compounds, avoiding autocatalytic degradation and thus, retarding the erosion process.

The changes on the molar mass and the fibre microstructure were subsequently assessed. Figure 10c shows the average molar mass in number $\left(M_{n}\right)$, which decreased more the lower the dissolution time was. Since the hydrolytic degradation is known to take place mainly in the amorphous regions of the samples, those with lower initial crystallinity degree showed higher molar mass reduction (scaffolds electrospun after 24 and 48 h) [76], [77]. Conversely, a greater initial crystallinity degree along with the growth of the lamellar thickness during immersion, prevented the scaffolds from hydrolytic degradation [78], [79] (scaffolds electrospun after 72 and $120 \mathrm{~h})$.

Interestingly, the effect of the in vitro validation procedure after 100 days was relevant in terms of development of chemically-induced crystallisation [62], [64], [80], as plotted in Figures 10d, 10e and 10f, but not in the molar mass which barely changed for all studied scaffolds. Indeed, crystallisation was driven by the combination of water and temperature. Water acted both as plasticizer to permit the mobility of polymer segments and promoted chain scission and mass loss. In addition, the temperature of the in vitro validation at $37{ }^{\circ} \mathrm{C}$ was close to the crystallisation temperature of PCL, as shown in Table 2. Therefore, there was a widening of the lamellar thickness distribution, an increase of its peak value and subsequent increase of the crystallinity degree, being more relevant the higher the dissolution time during the preparation of the scaffolds was.

Overall, the PCL based structure remained almost unaffected in the nanoscale range after the in vitro evaluation, which is essential for longterm biomedical applications, when no-collapsing structures are needed [81], [82], [83]. This behaviour was supported by the development of chemically-induced crystallisation, that reduced the amorphous/crystalline proportion and prevented the scaffold from hydrolytic degradation, as observed by the slightly modification of the molar mass.

\section{Conclusions}

Nanofibrous scaffolds were obtained by electrospinning of polycaprolactone (PCL) in 1:1 formic/acetic acid solvent. When viable, a non-significant influence of the voltage and feeding rate was found on the fibre diameters of scaffolds, while the influence of the dissolution time in the hydrolytic acid solvent was found to play a key role in the resultant physico-chemical properties, morphology and in vitro performance of the electrospun scaffolds.

The chain scission of PCL occurred through the hydrolytic degradation of the ester bonds along the dissolution preparation prior to electrospinning. 
The hydrolytic acid solvent reduced the molar mass of the electrospun scaffolds, increased the crystallinity degree and slightly lowered the lamellar thickness. Bead-free fibres were obtained after $24 \mathrm{~h}$ and $48 \mathrm{~h}$ of dissolution. Particularly at longer dissolution times (72 h and $120 \mathrm{~h}$ ), an intense reduction of molar mass and fibre diameter along with the apparition of beads was revealed.

The in vitro behaviour of the scaffolds after 100 days of immersion in water and PBS revealed some differences depending on the dissolution time prior to electrospinning. However, for all the scaffolds, the nanoscaled structure remained almost unaffected after the in vitro evaluation. This behaviour was supported by the development of chemically-induced crystallisation, that reduced the amorphous/crystalline proportion and prevented the scaffold from hydrolytic degradation, as observed by the slightly modification of the molar mass.

This tailoring procedure permitted to obtain scaffolds that maintained the nanoscaled structure after such long in vitro evaluation. This is essential for long-term PCL-based patches, when no-collapsing structures are needed. Future investigations will open up the possibility of functionalising this scaffolds with other components and studying the differentiation ability of cells onto these devices, as well as studying their biodegradation behaviour when implanted in vivo.

\section{Acknowledgements}

The Spanish Ministry of Economy and Competitiveness is acknowledged for the projects POLYCELL (ENE2014-53734-C2-1-R) and UPOV13-3E1947. The Spanish Ministry of Education, Culture and Sports is thanked for the pre-doctoral FPU grant of O. Gil-Castell (FPU13/01916) and the scholarship for a research stage of O. Gil-Castell in Kungliga Tekniska Högskolan (KTH). Generalitat Valenciana is thanked for the APOSTD/2014/041 for J.D. Badia. Universitat de València (UV) and IIS LaFe are acknowledged for the DERMASAFE project. The financial support given by the KTH Royal Institute of Technology is gratefully acknowledged. IESMAT S.A. and Malvern Instruments Ltd are recognised for their grateful collaboration.

\section{References}

[1] Coland ED, Matthews JA, Pawlowski KJ, Sompson DG, Wnek GE, Gary L. Electrospinning collagen and elastin: preliminary vascular tissue engineering. Frontiers in Bioscience 2004;9:1432-1442.

[2] Ma ZW, Kotaki M, Inai R, Ramakrishna S. Potential of nanofiber matrix as tissueengineering scaffolds. Tissue Engineering 2005;11(1-2):101-109.

[3] Agarwal S, Greiner A, Wendorff JH. Functional materials by electrospinning of polymers. Progress in Polymer Science 2013;38:963-991. 
[4] Xu CY, Inai R, Kotaki M, Ramakrishna S. Aligned biodegradable nanofibrous structure: a potential scaffold for blood vessel engineering. Biomaterials 2004;25:877-886.

[5] Ma PX. Scaffolds for tissue fabrication. Materials Today 2004;7:30-40.

[6] Smith LA, Ma PX. Nano-fibrous scaffolds for tissue engineering. Colloids and Surfaces B: Biointerfaces 2004;39:125-131.

[7] Buttafoco L, Kolkman NG, Engbers-Buijtenhuijs P, Poot AA, Dijkstra PJ, Vermes I, Feijen J. Electrospinning of collagen and elastin for tissue engineering applications. Biomaterials 2006;27: 724-734.

[8] Zhang Y, Ouyang H, Lim CT, Ramakrishna S, Huang ZM. Electrospinning of gelatin fibers and gelatin/PCL composite fibrous scaffolds. Journal of Biomedical Materials Research, Part B: Applied Biomaterials 2005;72B:156-165.

[9] Pham Q, Sharma U, Mikos A. Electrospinning of polymeric nanofibers for tissue engineering applications: a review. Tissue Engineering 2006;12:1197-1211.

[10] Zong X, Kim K, Fang D, Ran S, Hsiao B, Chu B. Structure and process relationship of electrospun bioabsorbable nanofiber membranes. Polymer 2002;43:4403-4412.

[11] Zeng J, Chen X, Xu X, Liang Q, Bian X, Yang L, et al. Ultrafine fibers electrospun from biodegradable polymers. Journal of Applied Polymer Science 2003;89:1085-1092.

[12] Yarin AL, Koombhongse S, Renrker DH. Bending instability in electrospinning of nanofibers. Journal of Applied Physics 2001;90:4836-4846.

[13] Deitzel JM, Kleinmeyer J, Harris D, Beck Tan NC. The effect of processing variables on the morphology of electrospun anofibers and textiles. Polymer 2001;42:261-272.

[14] Guarino V, Cirillo V, Taddei P, Alvarez-Perez MA, Ambrosio L. Tuning size scale and crystallinity of PCL electrospun fibres via solvent permittivity to address hMSC Response. Macromolecular Bioscience 2011;11:1694-1705.

[15] Chong EJ, Phan TT, Lim IJ, Zhang YZ, Bay BH, Ramakrishna S, et al. Evaluation of electrospun PCL/gelatin nanofibrous scaffold for wound healing and layered dermal reconstitution. Acta Biomaterialia 2007;3:321-330.

[16] Agarwal S, Wendorff JH, Greiner A. Use of electrospinning technique for biomedical applications. Polymer 2008; 49(26):5603-5621.

[17] Nepalli R, Marega, Margi A, Bajgai MP, Kim HY, Causin V. Poly(epsilon-caprolactone) filled with electrospun nylon fibres: a model for a facile composite fabrication. European Polymer Journal 2010;46(5):968-976.

[18] Venugopal J, Zhang YZ, Ramakrishna S. Fabrication of modified and functionalized polycaprolactone nanofiber scaffolds for vascular tissue engineering. Nanotechnology 2005;16(10);2138-2142.

[19] Wang X, Zhao H, Turng LS, Li Q. Crystalline morphology of electrospun poly( $\varepsilon$ caprolactone) (PCL) nanofibers. Industrial and Engineering Chemistry Research 2013;52:4939-4949.

[20] Jha BS, Colello RJ, Bowman JR, Sell SA, Lee KD, Bigbee JW, Bowlin GL, Chow WN, Mathern BE, Simpson DG. Two pole air gap electrospinning: fabrication of highly aligned, three-dimensional scaffolds for nerve reconstruction. Acta Biomaterialia 2011;, 7(1):203215.

[21] Ghasemi-Mobarakeh L, Prabhakaran MP, Morshed M, Nasr-Esfahani M-H, Ramakrishna S. Electrospun poly(e-caprolactone)/gelatin nanofibrous scaffolds for nerve tissue engineering. Biomaterials 2008;29(34):4532-4539.

[22] Bosworth L, Clegg P, Downes S. Electrospun nanofibres of polycaprolactone, and their use for tendon regeneration. International Journal of Nano and Biomaterials 2008;1(3):263279.

[23] Zamarripa N, Farboodmanesh S, Kuo CK. Novel biomimeticscaffold for tendon and ligament tissue engineering. Bioengineering conference, 2009 IEEE 35th annual northeast. 
[24] Powell HM, Boyce ST. Engineered human skin fabricated using electrospun collagen-PCL blends: morphogenesis and mechanical properties. Tissue Engineering Part A 2009;15(8):2177-2187.

[25] Chen H, Huang J, Yu J, Liu S, Gu P. Electrospun chitosangraft-poly (e-caprolactone)/poly (e-caprolactone) cationic nanofibrous mats as potential scaffolds for skin tissue engineering. International Journal of Biological Macromolecules 2011;48(1):13-19.

[26] Lee KH, Kim HY, Khil MS, Ra YM, Lee DR. Characterization of nanostructured poly(epsilon-caprolactone) nonwoven mats via electrospinning. Polymer 2003;44(4):12871294.

[27] Duan Y, Jia J, Wang S, Yan W, Jin L, Wang Z. Preparation of antimicrobial poly(epsiloncaprolactone) electrospun nanofibers containing silver-loaded zirconium phosphate nanoparticles. Journal of Applied Polymer Science 2007;106(2):1208-1214.

[28] Moghe AK, Hufenus R, Hudson SM, Gupta BS. Effect of the addition of a fugitive salt on electrospinnability of poly(epsilon-caprolactone). Polymer 2009;50(14):3311-8.

[29] Lowery JL, Datta N, Rutledge GC. Effect of fiber diameter, pore size and seeding method on growth of human dermal fibroblasts in electrospun poly(epsilon-caprolactone) fibrous mats. Biomaterials 2010;31(3):491-504.

[30] Del Gaudio C, Grigioni M, Bianco A, De Angelis G. Electrospun bioresorbable heart valve scaffold for tissue engineering. International Journal of Artificial Organs 2008;31(1):6875.

[31] Li W, Tuli R, Okafor C, Derfoul A, Danielson KG, Hall DJ, et al. A threedimensional nanofibrous scaffold for cartilage tissue engineering using human mesenchymal stem cells. Biomaterials 2005;26(6):599-609.

[32] Shin M, Ishii O, Sueda T, Vacanti JP. Contractile cardiac grafts using a novel nanofibrous mesh. Biomaterials 2004;25(17):3717-3723.

[33] Gaumer J, Prasad A, Lee D, Lannutti J. Structure-function relationships and source-toground distance in electrospun polycaprolactone. Acta Biomaterialia 2009;5(5):1552-1561.

[34] Del Gaudio C, Bianco A, Folin M, Baiguera S, Grigioni M. Structural characterization and cell response evaluation of electrospun PCL membranes: micrometric versus submicrometric fibers. Journal of Biomedical Materials Research A 2009;89A(4):10281039.

[35] Yu H, Jang J, Kim T, Lee H, Kim H. Apatite-mineralized polycaprolactone nanofibrous web as a bone tissue regeneration substrate. Journal of Biomedical Material Research A 2009;88A(3):747-754.

[36] Li X, Xie J, Yuan X, Xia Y. Coating electrospun poly(e-caprolactone) fibers with gelatin and calcium phosphate and their use as biomimetic scaffolds for bone tissue engineering. Langmuir 2008;24(24):14145-14150.

[37] Erisken C, Kalyon DM, Wang H. Functionally graded electrospun polycaprolactone and btricalciumphosphate nanocomposites for tissue engineering applications. Biomaterials 2008;29(30):4065-4073.

[38] Yang F, Wolke JGC, Jansen JA. Biomimetic calcium phosphate coating on electrospun poly(e-caprolactone) scaffolds for bone tissue engineering. Chemical Engineering Journal 2008;137(1):154-161.

[39] Nam J, Huang Y, Agarwal S, Lannutti J. Materials selection and residual solvent retention in biodegradable electrospun fibers. Journal of Applied Polymer Science 2008;107(3):1547-1554.

[40] Browning E. Toxic solvents: a review. British Journal of Industrial Medicine 1959;16(1):23-39.

[41] Bosworth LA, Downes S. Acetone, a sustainable solvent for electrospinning poly(ecaprolactone) fibres: effect of varying parameters and solution concentrations on fibre diameter. Journal of Polymers and the Environment 2012;20:879-886. 
[42] Bisnulal NS, Natarajan A, Menon D, Bhaskaran VK, Mony U, Nair SV. PCL-gelatin composite nanofibers electrospun using diluted acetic acid-ethyl acetate solvent system for stem cell-based bone tissue engineering. Journal of Biomaterials Science,, Polymer Edition, 2014;25(4):325-340.

[43] Van der Schueren L, De Schoenmaker B, Kalaoglu OI, De Clerck K. An alternative solvent system for the steady state electrospinning of polycaprolactone. European Polymer Journal 2011;47:1256-1263.

[44] Lavielle N, Popa AM, de Geus M, Hébraud A, Schlatter G, Thöny-Meyer L, Rossi RM. Controlled formation of poly( $\varepsilon$-caprolactone) ultrathin electrospun nanofibers in a hydrolytic degradation-assisted process. European Polymer Journal 2013;49:1331-1336.

[45] Pereira IH, Ayres E, Averous L, Schlatter G, Hebraud A, Mendes STOL, Oréfice RL. Elaboration and characterization of coaxial electrospun poly( $\varepsilon$-caprolactone)/gelatin nanofibers for biomedical applications. Advances in Polymer Technology, 2014;33:21475.

[46] Griffith LG. Polymeric biomaterials. Acta Materialia, 2000;48:263.

[47] Aharoni Sm. Increased glass transition temperature in motionally constrained semi crystalline polymers. Polmer for Advanced Technologies, 1998;9:169.

[48] Chen DR, Bei JZ, Wang SG. Polycaprolactone microparticles and their biodegradation. Journal of Polymer Degradation and Stability, 2000;67:455.

[49] Jenkins MJ, Harrison KL. The effect of crystalline morphology on the degradation of polycaprolactone in a solution of phosphate buffer and lipase. Polymers for Advanced Technologies, 2008;19:1901-1906.

[50] Mark JE. Physical Properties of Polymers Handbook, Springer, 2007. p 636.

[51] Hamley IW. Structure and flow behaviour of block copolymers. Journal of Physics: Condensed Matter, 2001;13:643-671.

[52] Thomas EL, Anderson DM, Henkee CS. Periodic area-minimizing surfaces in block copolymers. Nature, 1988;334:598-601.

[53] Suzuki Y, Duran H, Akram W, Steinhart M, Floudas G, Butt HJ. Multiple nucleation events and local dynamics of poly( $\varepsilon$-caprolactone) (PCL) confined to nanoporous alumina. Soft Matter 2013;9:9189-9198.

[54] ISO10993-13:2010 Biological evaluation of medical devices - Part 13: Identification and quantification of degradation products from polymeric medical devices.

[55] Fong H, Chun I, Reneker DH. Beaded nanofibers formed during electrospinning. Polymer 1999;40(16):4585-92.

[56] Yu H, Huang N, Wang C, Tang Z. Modeling of poly(L-lactide) thermal degradation: theoretical prediction of molecular weight and polydispersity index. Journal of Applied Polymer Science 2003;88(11):2557-2562.

[57] Snyder Rg, Maroncelli M, Strauss HL, Hallmark VL. Temperature and phase behaviour of infrared intensities: the poly(methylene) chain. The Journal of Physical Chemistry 1986;90:5263-5630.

[58] Coleman MM, Zarina J. Fourier-transform infrared studies of polymer blends. II. Poly( $\varepsilon$ caprolactone)-poly(vinyl chloride) system. Journal of Polymer Science: Polymer Physics Edition 1979;17(5):837-850.

[59] Badia JD, Vilaplana F, Karlsson S, Ribes-Greus A. Thermal analysis as a quality tool for assessing the influence of thermo-mechanical degradation on recycled poly(ethylene terephthalate). Polymer Testing 2009;28(2):169-75.

[60] Santonja-Blasco L, Moriana R, Badía JD, Ribes-Greus A. Thermal analysis applied to the characterization of degradation in soil of polylactide: I. calorimetric and viscoelastic analyses. Polymer Degradation and Stability 2010;95(11):2192-9.

[61] Badia JD, Strömberg E, Karlsson S, Ribes-Greus A. Material valorisation of amorphous polylactide. Influence of thermo-mechanical degradation on the morphology, segmental dynamics, thermal and mechanical performance. Polymer Degradation and Stability 2012; 97(4):670-8. 
[62] Badia JD, Santonja-Blasco L, Martínez-Felipe A, Ribes-Greus A. Hygrothermal ageing of reprocessed polylactide. Polymer Degradation and Stability 2012;97(10):1881-90.

[63] Badia JD, Strömberg E, Karlsson S, Ribes-Greus A. The role of crystalline, mobile amorphous and rigid amorphous fractions in the performance of recycled poly (ethylene terephthalate) (PET). Polymer Degradation and Stability 2012;97(1):98-107.

[64] Gil-Castell O, Badia JD, Kittikorn T, Strömberg E, Martínez-Felipe A, Ek M, Karlsson S, Ribes-Greus A. Hydrothermal ageing of polylactide/sisal biocomposites. Studies of water absorption behaviour and Physico-Chemical performance., Polymer Degradation and Stability 2014;108:212-222.

[65] Badia JD, Kittikorn T, Strömberg E, Santonja-Blasco L, Martínez-Felipe A, Ribes-Greus A, Ek M, Karlsson S. Water absorption and hydrothermal performance of PHBV/sisal biocomposites. Polymer Degradation and Stability 2014;108:166-174.

[66] Kimura N, Kim HK, Kim BS, Lee KH, Kim IS. Molecular orientation and crystalline structure of aligned electrospun nylon-6 nanofibers: Effect of gap size. Macromolecular Materials and Engineering 2010;295:1090-1096.

[67] Zhuravlev E, Schmelzer JWP, Wunderlich B, Schick C. Kinetics of nucleation and crystallization in poly(e-caprolactone) (PCL). Polymer 2011;52(9):1983-1997.

[68] Lauritzen JL, Hoffman JD. Theory of formation of polymer crystals with folded chains in dilute solution. Journal of Research of the National Bureau of Standards 1960;64:73-102.

[69] Lauritzen JL, Hoffman JD. Crystallization of bulk polymers with chain folding: theory of growth of lamellar spherulites. Journal of Research of the National Bureau of Standards 1961;65:297-336.

[70] Hoffman JD, Davis GT, Lauritzen JL. In: Hannay NB, editor. Crystalline and noncrystalline solids, vol. 3. New York: Plenum Press; 1976.

[71] Gil-Castell O, Badia JD, Teruel-Juanes R, Rodriguez I, Meseguer F, Ribes-Greus A. Novel Silicon microparticles to improve sunlight stability of raw polypropylene. European Polymer Journal 2015;70:247-261.

[72] Arinstein A, Burman M, Gendelman O, Zussman E. Effect of supramolecular structure on polymer nanofibre elasticity. Nature Nanotechnology 2007;2:59-62.

[73] Hohmann MM, Shin M, Rutledge G, Brenner MP. Electospinning and electrically forced jets I stability theory. Physics of fluids 2001;13(8):2201-2220.

[74] Kolbuk D, Sajkiewicz P, Maniura-Weber K, Fortunato G. Structure and morphology of electrospun polycaprolactone/gelatine nanofibers. European Polymer Journal 2013;49:2052-2061.

[75] Rutkowska M, Jasterzebska M, Janik H. Biodegradation of polycaprolactone in seawater. Reactive and Functional Polymers, 1998;38:27.

[76] Hakkarainen M, Albertsson AC, Karlsson S. Weight losses and molecular weight changes correlated with the evolution of hydroxyacids in simulated in vivo degradation of homoand copolymers of PLA and PGA. Polymer Degradation and Stability 1996, 52(3):283-291.

[77] Vert M, Li SM, Garreau H. Attempts to map the structure and degradation characteristics of aliphatic polyesters derived from lactic and glycolic acids. Journal of Biomaterial Science. Polymer Edition 1994;6(7):639-649.

[78] Li SM, Garreau H, Vert M. Structure-property relationships in the case of the degradation of massive aliphatic poly( $\alpha$-hydroxyacids) in aqueous media. Part 3: influence of the morphology of poly(L-lactic acid). Journal of Materials Science, Materials in Medicine 1990;1:198-206.

[79] Antheunis H, van der Meer JC, de Geus M, Kingma W, Koning CE. Improved mathematical model for the hydrolytic degradation of aliphatic polyesters. Macromolecules 2009;42:2462-2471.

[80] Gil-Castell O, Badia JD, Kittikorn T, Strömberg E, Ek M, Karlsson S, Ribes-Greus A. Impact of hydrothermal ageing on the thermal stability, morphology and viscoelastic 
performance of PLA/sisal biocomposites. Polymer Degradation and Stability 2016, 132:8796.

[81] Tillman BW, Yazdani SK, Lee SJ, Geary RL, Atala A, Yoo JJ. The in vivo stability of electrospun polycaprolactone-collagen scaffolds in vascular reconstruction. Biomaterials 2009;30(4):583-588.

[82] Hakimi O, Mouthuy PA, Carr A. Synthetic and degradable patches: an emerging solution for rotator cuff repair. International Journal of Experimental Pathology, 2013:94(4):287292.

[83] Fujimoto KL, Guan J, Oshima H, Sakai T, Wagner W. In vivo evaluation of a porous, elastic, biodegradable patch for reconstructive cardiac procedures. The annals of Thoracic Surgery, 2007;83(2):648-654. 


\section{Contribution 5.4 .}

Tailored electrospun nanofibrous

polycaprolactone/gelatin scaffolds into an acid hydrolytic solvent system

O. Gil-Castell, J. D. Badia, A. Ribes-Greus. Tailored electrospun nanofibrous polycaprolactone/gelatin scaffolds into an acid hydrolytic solvent system. European Polymer Journal 2018; 101:273-281

This is an open-access version, according to:

http://www.sherpa.ac.uk/romeo/issn/0014-3057/

Full text available at:

https://www.sciencedirect.com/science/article/pii/S001430571731889X

DOI:

https://doi.org/10.1016/j.eurpolymj.2018.02.030 


\title{
Tailored electrospun nanofibrous polycaprolactone/gelatin scaffolds into an acid hydrolytic solvent system
}

\author{
O. Gil-Castell ${ }^{1}$, J. D. Badia ${ }^{1,2}$, A. Ribes-Greus ${ }^{1, *}$ \\ ${ }^{1}$ Instituto de Tecnología de Materiales (ITM). Universitat Politècnica de València. Camino de \\ Vera s/n, 46022 Valencia, Spain. \\ ${ }^{2}$ Departament d'Enginyeria Química. Escola Tècnica Superior d’Enginyeria. Universitat de \\ València. Av. de la Universitat, s/n, 46100, Burjassot, Spain \\ ${ }^{*}$ Corresponding author:
}

A. Ribes-Greus aribes@ter.upv.es 


\title{
Tailored electrospun nanofibrous polycaprolactone/gelatin scaffolds into an acid hydrolytic solvent system
}

\author{
O. Gil-Castell, J. D. Badia, A. Ribes-Greus
}

\begin{abstract}
Blended nanofibrous scaffolds based on polycaprolactone (PCL) and gelatin (Ge) were successfully prepared. A formic/acetic acid (1:1) mixture was used to dissolve PCL/Ge blends from 100/0 to 20/80 \%wt in steps of $10 \%$ wt. The hydrolysis of the PCL diluted in the formic/acetic acid mixture was considered as a method for tailoring the surface morphology and physicochemical features of the nanofibrous PCL/Ge scaffolds as a function of the dissolution time. The fibre diameter remained in the nanoscale range for all the studied scaffolds, which is crucial to mimic the extra-cellular matrix size. The reduction of the intrinsic viscosity, molar mass and hydrodynamic radius found for the PCL molecules as a function of the dissolution time, consequently diminished the entanglement capability of the polymeric chains. Subsequently, the fibre diameter decreased as dissolution time increased, for all the studied compositions. While the crystallinity of the scaffolds with high PCL content increased as a function of the dissolution time, the scaffolds with high percentage of Ge showed the lowest crystallinity degree, which was ascribed to the hindering effect of the Ge diffused among the PCL segments. The wettability increased as a function of the Ge content due to the high hydrophilic behaviour of these molecules. It also increased as a function of the dissolution time, due to the more hydroxyl groups available in PCL segments to interact with water molecules. As a whole, the physicochemical assessment of the electrospun scaffolds revealed an effective tailoring procedure to obtain functionalised PCL/Ge scaffolds with specific properties as a function of the dissolution time before electrospinning.
\end{abstract}

\section{Keywords}

Electrospinning; scaffold; polycaprolactone (PCL); gelatin (Ge); tailoring; hydrolysis 


\section{Introduction}

Tissue engineering involves the combination of engineering, materials and cells to improve or replace biological tissues. One of the fundamental approaches of this field is the fabrication of biocompatible scaffolds that provide the optimum conditions for cell adhesion and proliferation along with tailored durability and performance. The development of synthetic nanoscaled fibrous scaffolds that structurally mimic extra-cellular matrix (ECM) in size and porosity has brought new possibilities in the field of tissue regeneration [1].

The processing techniques to obtain artificial tissues are in continuous development [2]. Electrospinning stands out as one of the most promising techniques for the preparation of polymeric nanofibrous devices [3]-[5]. This method offers non-woven nanofibrous scaffolds with large area-tosurface ratio and high porosity that have fulfilled novel biomedical requirements [6], [7].

A variety of natural and synthetic polymers have been used for nanofibrous scaffold fabrication, including polycaprolactone, poly(lactic acid), poly(glycolic acid) and their copolymers [8]-[11]. Among them, polycaprolactone (PCL) is a semicrystalline linear aliphatic polyester, widely applied in biomedicine due to its good mechanical properties, biocompatibility and slow biodegradability, being suitable for applications which require certain structural durability [12]-[17]. However, the lack of hydrophilic functional groups in the chemical structure of the PCL macromolecules have prevented this material from an extended application as an individual component. Several strategies such as coating, grafting or blending with other components have been suggested in order to improve the cell affinity of the scaffolds [18]. Actually, several hydrophilic biopolymers including collagen, gelatin, fibrinogen or elastin have been considered to improve the scaffold hydrophilicity and biocompatibility [19]. Gelatin $(\mathrm{Ge})$ is a natural biopolymer of excellent biocompatibility, biodegradability and low cost in comparison to collagen. It contains Arginyl-Glycyl-Aspartic amino acid sequence, which offers biochemical signals to promote cell adhesion, migration, proliferation and differentiation [20]. Thus, the combination of PCL and Ge into a nanofibrous scaffold would retain the mechanical properties of PCL with an improved cell affinity brought by the Ge. Actually, PCL/Ge nanofibrous scaffolds have been proposed as a versatile substrate for cell seeding of different tissues, including skin [21]-[26], muscle [27], cardiovascular [28], [29], nerve [30]-[32], bone [33]-[36] and cartilage [37], [38].

The suitability of the electrospinning process is known to depend on the synergistic effect of the solution and processing conditions [39]-[41]. Traditionally, highly toxic halogenated solvents such as chloroform, 
hexafluoroisopropanol, trifluoroethylene, dimethylformamide, methylene chloride or dichloroethane have been required for the effective electrospinning of PCL and Ge [40], [42], [43]. In the last years, some alternative solvents such as acetone [44], acetic acid [45], acetic acid/ethyl acetate [46], tetrahydrofuran/methanol [47], tetrahydrofuran [40] or formic/acetic acid mixture [48]-[50] have been proposed for the electrospinning of the PCL. These solvents allow minimizing the risk to health during manipulation [51] and reduce the toxicity of the scaffolds due to retained residual solvent [52]. For the electrospinning of Ge, low-toxic alternative solvents have also been considered, including acetic acid [53], [54] or ethyl-acetate/acetic acid in water [55]. Specifically, the formic/acetic mixture has been considered as a suitable candidate for the electrospinning of PCL/Ge scaffolds [56]-[59].

Some studies in the bibliography correlate the influence of several features of the scaffolds on their subsequent performance such as the composition, the fibre diameter, the scaffold porosity, the molar mass, the glass transition temperature or the crystallinity degree, among others [60]-[65]. The hydrolytic degradation of the PCL molecules in the formic/acetic mixture and results in the reduction of the polymer molar mass, and thus some of the physicochemical properties of the electrospun scaffolds could be expected to be altered as a function of the dissolution time [49]. Indeed, the physicochemical behaviour of PCL/Ge scaffolds has not been correlated to the dissolution time of the polymer in the formic/acetic acid solution before electrospinning, and therefore represents an interesting line of research for the tailoring of biomedical scaffolds.

The aim of this study was therefore to obtain tailored nanofibrous PCL/Ge scaffolds in terms of the blend composition and the dissolution time into a hydrolytic formic/acetic acid (1:1) solvent, and correlate them with the impact on the structure, morphology and performance of these scaffolds.

\section{Materials and methods}

\subsection{Materials}

Polycaprolactone (PCL) was supplied by Perstorp as $3 \mathrm{~mm}$ diameter pellets under the grade CAPA ${ }^{\mathrm{TM}} 6800\left(M_{n}=85000 \mathrm{~g} \cdot \mathrm{mol}^{-1}\right.$ and $\left.T_{m} 58-60{ }^{\circ} \mathrm{C}\right)$. Gelatin (Ge) from porcine skin Type A, gel strength 300, was supplied by Sigma-Aldrich. Formic acid and acetic acid ( $\geq 99 \%)$ were used as solvents for electrospinning. Tetrahydrofuran $(\geq 99.8 \%)$ was used for SEC sample preparation and analysis. All solvents were supplied by Sigma-Aldrich and were used without further purification.

\subsection{Polymer solution and electrospinning}

Nine blended compositions of PCL/Ge were prepared, ranging from 100/0 to $20 / 80$ by weight proportion, by steps of $10 \%$ wt. The solutions for 
electrospinning were prepared in a 1:1 formic/acetic acid mixture, with a total solid concentration of $15 \%$ wt and were electrospun after being subjected to $30{ }^{\circ} \mathrm{C}$ and magnetic stirring for 24, 48, 72, 96 and $120 \mathrm{~h}$. The dissolution time ranged between the minimum time to reach complete dissolution (24 h) and the time in which the viscosity of the solution still ensured stable electrospinning (120 h).

Nanofibrous scaffolds were obtained by means of a Bioinicia Fluidnatek ${ }^{\circledR}$ LE-10 electrospinning equipment, which contents a high voltage source, a programmable syringe pump, a HSW Norm-Ject 20 mL Luer Lock syringe, a Teflon ${ }^{\circledR}$ tubing, a gauge 21 metallic needle and a grounded flat collector. The tip-to-collector distance was maintained constant at $15 \mathrm{~cm}$. The feeding rate and voltage varied as dissolution time increased between 1 to $0.2 \mathrm{~mL} \cdot \mathrm{h}^{-1}$ and 25 to $19 \mathrm{kV}$, respectively. The working time was adjusted for each case as a function of the feeding rate in order to obtain nanofibrous structures with comparable surface density. The temperature and relative humidity (RH) were kept constant along electrospinning at $22^{\circ} \mathrm{C}$ and $35 \%$ $\mathrm{RH}$, respectively. The nanofibrous scaffolds were collected on waxed paper, dried and stored for further analyses.

\subsection{Scaffold characterization}

\subsubsection{Field-emission scanning electron microscopy (FE-SEM)}

The surface topology of the specimens was analysed by means of a Zeiss Ultra 55 field emission scanning electron microscope (FE-SEM). The samples were cut into small pieces and dried at $50{ }^{\circ} \mathrm{C}$ in a vacuum oven for $24 \mathrm{~h}$ and then kept in a desiccator during $48 \mathrm{~h}$. Afterwards, the specimens were mounted on metal studs and sputter-coated with a platinum layer during $10 \mathrm{~s}$ using a Leica EM MED020 sputter coater. FE-SEM images were taken at $22{ }^{\circ} \mathrm{C}$ with a $2 \mathrm{kV}$ voltage. The fibre diameters were measured from the scanning electronic microscope images $(10000 \times)$ at random locations $(n=100)$ with the aid of the Image $J ®$ software.

\subsubsection{Thermogravimetric analysis (TGA)}

The thermo-oxidative decomposition profiles were obtained by means of a Mettler-Toledo TGA 851 thermogravimetric analyser. The samples, with a mass of about $4 \mathrm{mg}$ were introduced in TGA Mettler-Toledo perforated alumina crucibles, with capacity of $70 \mu \mathrm{l}$. The samples were analysed in the temperature range of 25 to $800{ }^{\circ} \mathrm{C}$ with a heating rate of $10^{\circ} \mathrm{C} \cdot \mathrm{min}^{-1}$, under atmosphere of oxygen at a flow rate of $50 \mathrm{ml} \cdot \mathrm{min}^{-1}$. The experiments were performed in triplicates to ensure reproducibility.

\subsubsection{Size exclusion chromatography (SEC)}

Size exclusion chromatography (SEC) was carried out by means of a Malvern Instruments Omnisec Resolve chromatograph. It combined an 
integrated pump, a degasser, an autosampler and a column oven, along with a Malvern Instruments Omnisec Reveal multi-detector-Ultraviolet (UV), Refractive Index (RI), Low and Right Angle Light Scattering (LALS and RALS) and Viscosity (VISC)-. A monodisperse polystyrene standard with $\mathrm{dn} / \mathrm{dc}$ value of 0.185 was used for universal calibration. Two columns from Malvern Instruments (T2000 and T4000) were used $(300 \times 8 \mathrm{~mm})$. Tetrahydrofuran (THF) was used as mobile phase at a flow rate of 1 $\mathrm{mL} \cdot \mathrm{min}^{-1}$ and a column temperature of $35^{\circ} \mathrm{C}$. The samples were dissolved in THF with concentrations of around $2.0 \mathrm{mg} \cdot \mathrm{ml}^{-1}$ and filtered through 0.45 $\mu \mathrm{m}$ PTFE filters. Two specimens per sample were analysed and the obtained data were assessed in triplicates with the aid of the OMNISEC $\mathrm{V} 10^{\mathrm{TM}}$ software, and the averages were taken as representative values.

\subsubsection{Differential scanning calorimetry (DSC)}

The calorimetric data were obtained by means of a Mettler-Toledo DSC $820^{\mathrm{e}}$ differential scanning calorimeter, previously calibrated following the procedure of In and Zn standards. The samples, with a mass of about $4 \mathrm{mg}$, were analysed between 0 and $80^{\circ} \mathrm{C}$ with a heating/cooling/heating rate of $10^{\circ} \mathrm{C} \cdot \mathrm{min}^{-1}$. All the experiments were run under nitrogen atmosphere at 50 $\mathrm{mL} \cdot \mathrm{min}^{-1}$. The specimens were characterised at least by triplicate and the averages of temperatures and enthalpies were taken as representative values.

The crystallinity degree $\left(X_{c}\right)$ was evaluated from the melting enthalpy results, by means of the Equation 1,

$$
X_{c}(\%)=\frac{\Delta h_{m}}{w_{P C L} \cdot \Delta h_{m}^{0}} \cdot 100
$$

(Equation 1)

where $\Delta h_{m}$ is the melting enthalpy of the PCL melting, $w_{P C L}$ is the weight fraction of the PCL in the sample and $\Delta h_{m}{ }^{0}$ is the melting enthalpy of a perfect crystal of PCL $\left(148{\left.\mathrm{~J} \cdot \mathrm{g}^{-1}\right)}^{-1}\right.$ [66].

\subsubsection{Water contact angle}

The wettability of the scaffolds was characterized according to its water contact angle at $22^{\circ} \mathrm{C}$. The static contact angle was evaluated by means of a Theta Optical Tensiometer (KSV Instruments, Ltd) and a CCD (chargecoupled device) camera connected to a computer. $2 \mu \mathrm{L}$ of distilled water were dropped on the sample surface and, after $2 \mathrm{~s}$, the contact angle was measured. The assays were repeated at three different sites of a given sample to ensure reproducibility. 


\section{Results and discussion}

\subsection{Validation of the electrospinning strategy}

In order to validate the scaffold composition, the study of the thermooxidative decomposition behaviour was considered as an appropriate methodology, as proposed by Gautam et al. [67]. The thermo-oxidative decomposition profiles as a function of the scaffold composition are plotted in Figure 1.

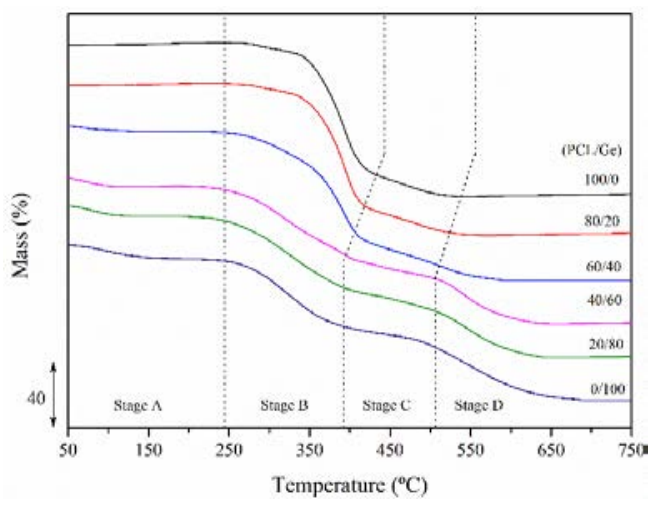

Figure 1. Thermo-oxidative decomposition profiles of electrospun scaffolds as a function of the scaffold composition (PCL/Ge) for a dissolution time of $24 \mathrm{~h}$.

Pure PCL (100/0) showed a multiple stage decomposition performance. Humidity loss was observed in stage A, and primarily decomposition was found in stage B, followed by a secondary decomposition in stage C, reaching complete decomposition between $350{ }^{\circ} \mathrm{C}$ and $520{ }^{\circ} \mathrm{C}$, as corroborated by literature [67], [68]. The decomposition profile of pure Ge $(0 / 100)$ consisted of multiple stages. The vaporization of moisture took place between 50 and $230^{\circ} \mathrm{C}$ in the stage $\mathrm{A}$, while the main decomposition stage occurred between $250^{\circ} \mathrm{C}$ and $400^{\circ} \mathrm{C}$ in the stage $\mathrm{B}$. Then the thermooxidative decomposition continued until $600{ }^{\circ} \mathrm{C}$ in the stages $\mathrm{C}$ and $\mathrm{D}$. This multiple stage behaviour was ascribed to a complex thermo-oxidative decomposition process that involves protein rupture and breakage of the peptide bond, in line with previous research [34], [69].The scaffolds showed an intermediate behaviour combining the thermo-oxidative decomposition stages of both pure components. The increase of the Ge content progressively displaced the onset of the decomposition towards lower temperatures as well as promoted the decomposition in stages A and $\mathrm{D}$ [26]. Although the main degradation stages of the PCL and Ge in the scaffolds were overlapped, the study of the horizontal step for each stage, especially for stages B and D, revealed a progressive behaviour as a function of the scaffold composition, as gathered in Table 1. According to bibliography, this phenomenon suggested a blending interaction between 
both components through hydrogen bonding between the ester group of the PCL and the amine group of Ge molecules within the scaffold [26], [67], [70].

Table 1. Mass loss (\%) in the different stages during thermo-oxidative decomposition of electrospun scaffolds for a dissolution time of $24 \mathrm{~h}$. Standard deviation between 3 and $5 \%$ omitted for the sake of clarity.

\begin{tabular}{cllll}
\hline $\begin{array}{c}\text { (PCL/Ge) } \\
(\% w t)\end{array}$ & Stage A & Stage B & Stage C & Stage D \\
\hline $100 / 0$ & - & 88.04 & 10.91 & - \\
\hline $80 / 20$ & - & 75.60 & 10.59 & 8.79 \\
\hline $60 / 40$ & 1.00 & 73.55 & 11.49 & 10.62 \\
\hline $40 / 60$ & 4.05 & 68.28 & 11.26 & 13.92 \\
\hline $20 / 80$ & 7.02 & 46.65 & 10.80 & 31.27 \\
\hline $0 / 100$ & 8.15 & 40.77 & 9.38 & 38.28 \\
\hline
\end{tabular}

The scanning electron microscope images of the electrospun scaffolds as a function of the PCL/Ge composition and dissolution time are shown in Figure 2. Practicable scaffolds ( $\star$ ), i.e, scaffolds which were adequately handled without mechanical disaggregation of fibres, were found after 24 $\mathrm{h}$ and $48 \mathrm{~h}$ of dissolution for all the studied compositions. However, as dissolution time increased, the scaffold usability was altered as perceived by the formation of ultra-thin fibres and micro-scaled beads. Nevertheless, the increase of the Ge content improved the electrospinning viability after high dissolution times, giving rise to more stable and practicable scaffolds.
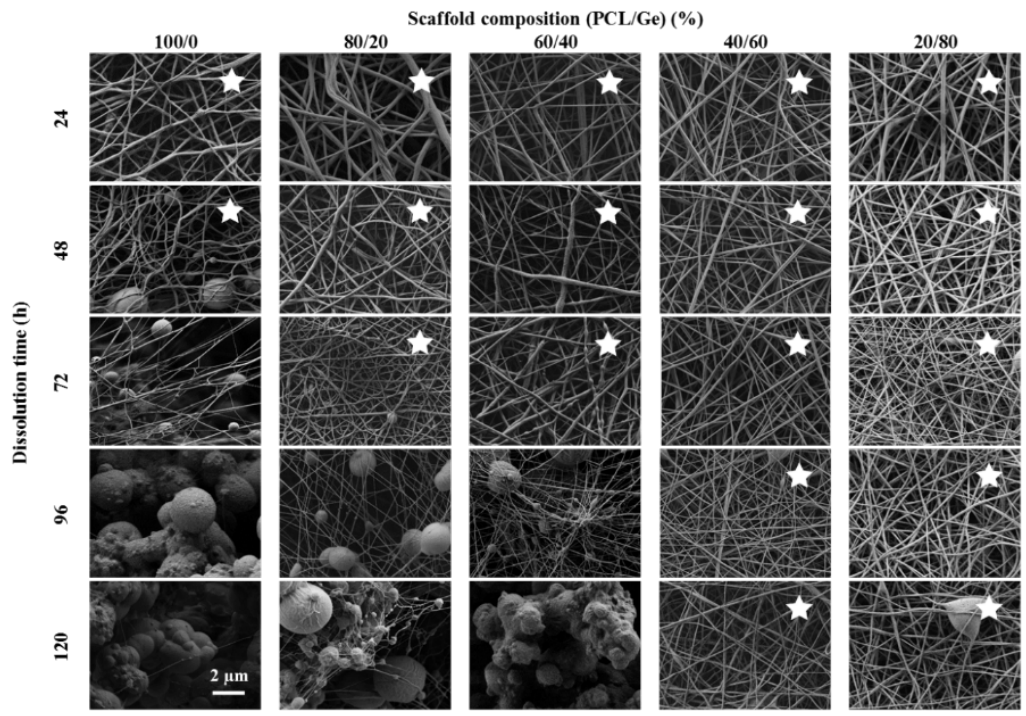

Figure 2. FE-SEM images (10 000×) of electrospun scaffolds as a function of the scaffold composition and the dissolution time. ( $\star$ ) Refer to the practicable scaffolds. 


\subsection{Hydrolytic degradation of the PCL fraction}

It is well known that suitable electrospinning depends on the confluence of several conditions and requirements [39]. Among them, one of the main factors is the solution viscosity, which is in turn affected by several elements such as the solution concentration, the polymer molar mass or the temperature [5]. Since the solid concentration (15\%wt) and the temperature remained constant, the hypothetic molar mass reduction due to the PCL chain scission may have resulted in excessively low viscosity for suitable electrospinning after high dissolution time. Although the hydrolysis and subsequent viscosity reduction of the $\mathrm{Ge}$ as a function of time when diluted in formic acid has been reported by Ki et al. [71], the addition of Ge to the blend may have contributed to retain enough viscosity for suitable electrospinning, particularly for high dissolution times, when the PCL molecules were severely hydrolytically degraded.

In order to evaluate the change in the molar mass of the PCL fraction of the scaffolds when diluted into the formic/acetic mixture, size exclusion chromatography (SEC) measurements were conducted regardless the formation of practicable electrospun scaffolds. The molar mass distributions are plotted in Figure 3a as a function of the dissolution time for all PCL/Ge compositions. When the dissolution time increased, a displacement of the molar mass distributions towards lower values was observed, due to hydrolytic degradation of the ester bond and subsequent chain scission [49], as visually suggested during the electrospinning solution preparation. The chain scission is frequently terminated by carboxylic acid end groups and hydroxyl end groups [72]. The hydrolytic reaction may occur as a depolymerisation process and random chain scission mechanism, highly catalysed by the formic/acetic acid solution.

Two different behaviours could be distinguished, depending on the prevalence of one component or the other in the scaffold. For scaffolds with high PCL content, a low molar mass peak (around $10000 \mathrm{~g} \cdot \mathrm{mol}^{-1}$ ) appeared and increased for high dissolution times, turning the original unimodal distribution into a bi-modal pattern. In contrast, for scaffolds with high Ge content, a complex multi-modal behaviour was found, attributed to the emulsion of PCL into the Ge matrix diluted in the formic/acetic acid mixture [57]. The dissimilar hydrolytic degradation of the PCL during dissolution in the acidic mixture may be ascribed to the formation of a disperse phase (PCL) into a continuous matrix (Ge), as reported by Kolbuk et al. [59].

The evolution of the average molar mass in number $\left(M_{n}\right)$, the intrinsic viscosity (IV) and the hydrodynamic radius $(R h)$, respectively, are shown in Figure 3b, 3c and 3d through 3D plots as a function of the blend composition and dissolution time. 
a)
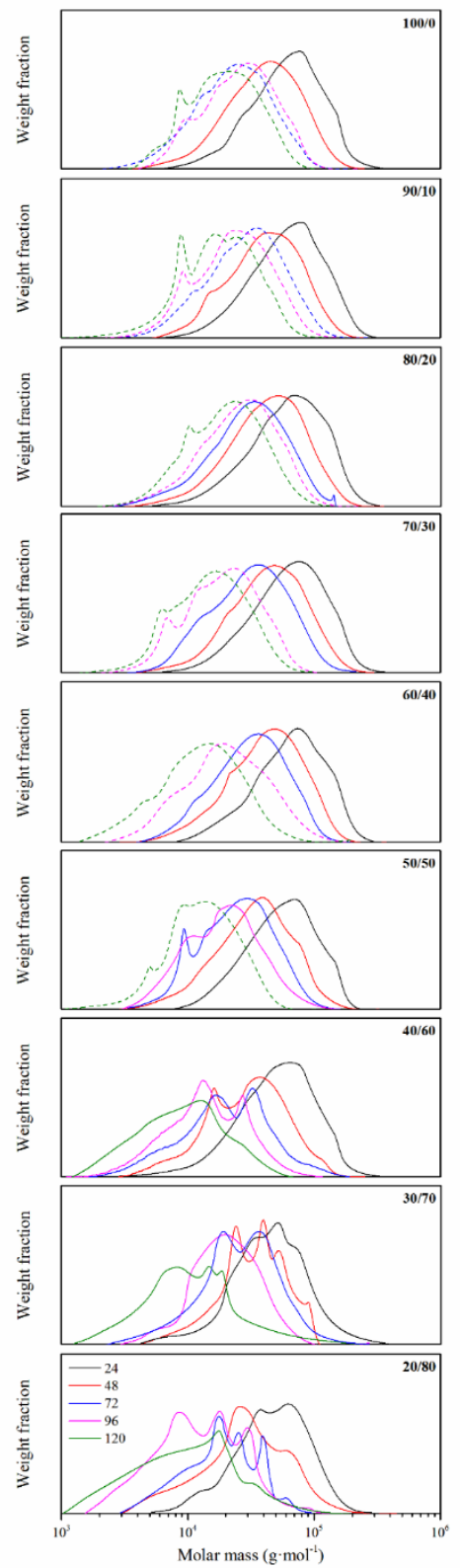

b)

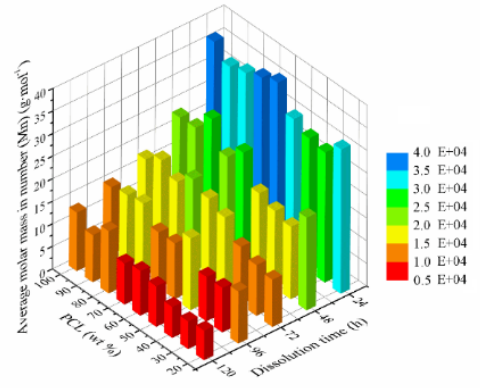

c)

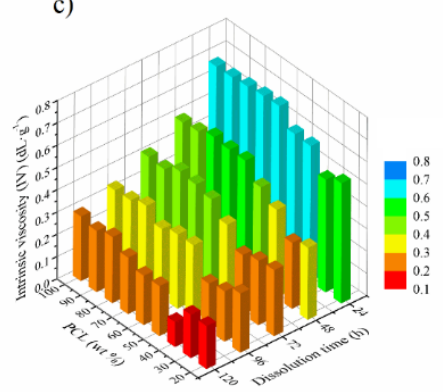

d)

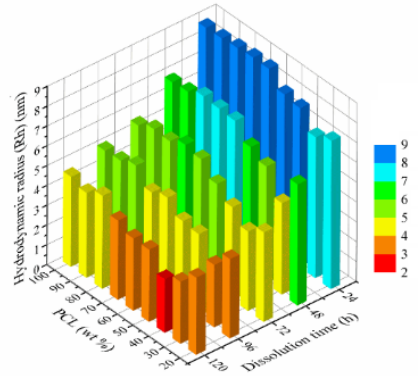

Figure 3. (a) Molar mass distributions as a function of the dissolution time for the different PCL:Ge compositions. Dash lines stand for non-practicable scaffolds; (b) Average molar mass; (c) Intrinsic viscosity; and (d) Hydrodynamic radius as a function of the scaffold composition and dissolution time. 
The analysis of the intrinsic viscosity (IV) and the hydrodynamic radius $(R h)$ of the PCL in the solvent used for the chromatographic analyses (THF) corroborated the hydrolytic degradation of the polymer. A reduction of the polymer chain length promoted lower number of macromolecular entanglements, which is closely related to the $I V$, and lower apparent size, associated to the $R h$. Shorter and smaller macromolecules exhibited lower equivalent radius as dissolution time increased.

The average molar mass in number $\left(M_{n}\right)$ values for the practicable and nonpracticable conditions are gathered in Table 2 . An estimation of the critical PCL molar mass to get suitable scaffolds for a given solution concentration can be thus established for the different scaffold compositions and dissolution times. The $M_{n}$ significantly decreased as a function of the dissolution time, especially after $24 \mathrm{~h}$ of dissolution. The lowest $M_{n}$ values were found for the scaffolds with high Ge percentage, electrospun after 120 $\mathrm{h}$ of dissolution.

Table 2. The average molar mass in number $\left(M_{n}, \mathrm{~g} \cdot \mathrm{mol}^{-1}\right)$ of the PCL fraction for the practicable and non-practicable (italics) conditions. Standard deviation between 2 and

$5 \%$ omitted in the table for the sake of clarity. D.T. stands for dissolution time.

\begin{tabular}{cccccccccc}
\hline \multirow{2}{*}{$\begin{array}{c}\text { D.T. } \\
\text { (h) }\end{array}$} & $\mathbf{1 0 0 / 0}$ & $\mathbf{9 0 / 1 0}$ & $\mathbf{8 0 / 2 0}$ & $\mathbf{7 0 / 3 0}$ & $\mathbf{6 0 / 4 0}$ & $\mathbf{5 0 / 5 0}$ & $\mathbf{4 0 / 6 0}$ & $\mathbf{3 0 / 7 0}$ & $\mathbf{2 0 / 8 0}$ \\
\hline 24 & 36000 & 33000 & 34000 & 35500 & 36900 & 31200 & 29400 & 28900 & 31900 \\
\hline 48 & 22900 & 23100 & 27500 & 21600 & 25000 & 18500 & 17000 & 16000 & 20500 \\
\hline 72 & 17700 & 19600 & 17300 & 19200 & 18500 & 16800 & 12100 & 11200 & 11500 \\
\hline 96 & 14800 & 15600 & 15100 & 13000 & 12300 & 12900 & 12800 & 9900 & 10500 \\
\hline 120 & 12900 & 11400 & 13400 & 9900 & 9100 & 8300 & 6900 & 6100 & 6600 \\
\hline
\end{tabular}

\subsection{Scaffold characterisation}

\subsubsection{Surface morphology}

The analysis of the morphology of the practicable electrospun scaffolds was performed in terms of the fibre diameter, from scanning electron microscope images. The fibre diameter distributions are represented in Box-Whisker plots in Figure 4 as a function of the scaffold composition and the dissolution time.

The fibre diameter remained in the nanoscale range for all the studied scaffolds, which is crucial to mimic the extra-cellular matrix size, an essential requirement for satisfactory cell attachment and proliferation [6]. Moreover, the fibre diameter obtained from the electrospinning of the formic/acetic acid solution was lower to that found by other authors that used traditional halogenated solvents [25], [26], [34], [36], [67], [73], [74]. Unimodal distributions were found regardless the composition with average values between 100 and $200 \mathrm{~nm}$ for scaffolds prepared after $24 \mathrm{~h}$ 
of dissolution. For a given composition, thinner fibres were observed with mean diameter with lower standard deviation as a function of the dissolution time. It is interesting to note that the fibre diameter of the scaffolds obtained after the longest practicable dissolution time decreased to about half of the initial value $(75-100 \mathrm{~nm})$. Although several factors such as temperature, feeding rate or voltage may influence the fibre diameter during electrospinning, the reduction in the solution viscosity can be ascribed as the main cause of the fibre diameter decrease. This fact revealed lower molar masses and smaller hydrodynamic radiuses, which produced the subsequent lower entanglement capability and resulted in nanostructured scaffolds with lower fibre diameter.

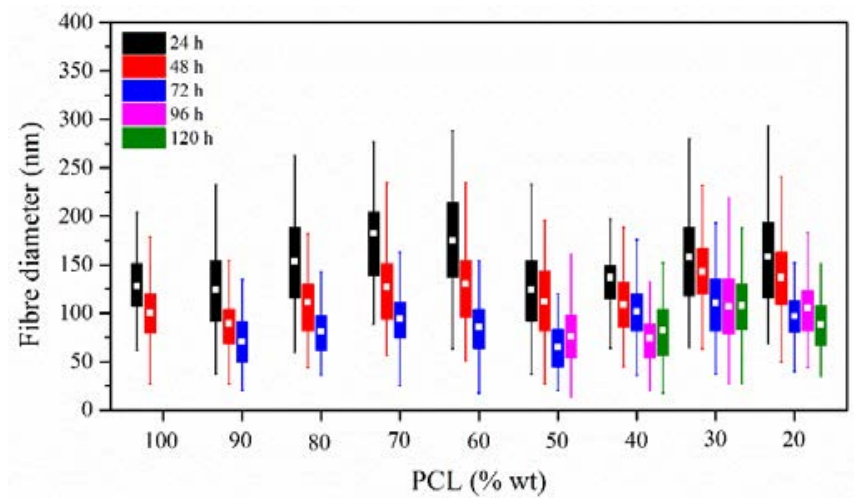

Figure 4. Fibre diameter distributions of the practicable electrospun scaffolds as a function of the scaffold composition and the dissolution time.

\subsubsection{Thermal properties}

Calorimetric analyses were conducted on the nanofibrous PCL/Ge scaffolds in order to study the fibre microstructure by the characterisation of the crystalline population, which is known to play a key role during the nanofibrous scaffold application [75]. The use of the differential scanning calorimetry (DSC) is essential to understand the thermal properties of the biopolymers subjected to different degrading conditions [76]-[80]. Indicators of the degradation such as the partial melting areas [77], the crystallinity degree [81], the relative partial crystallinity [82] or the balance among amorphous and rigid amorphous fractions [83] have been previously proposed for monitoring the degradation of some biopolymers. In this study, the balance between the evolution of the crystallinity degree and the lamellar thickness offers interesting discussion, as shown hereinafter. The calorimetric traces of the first heating scan for the different compositions and dissolution times are shown in Figure 5. 


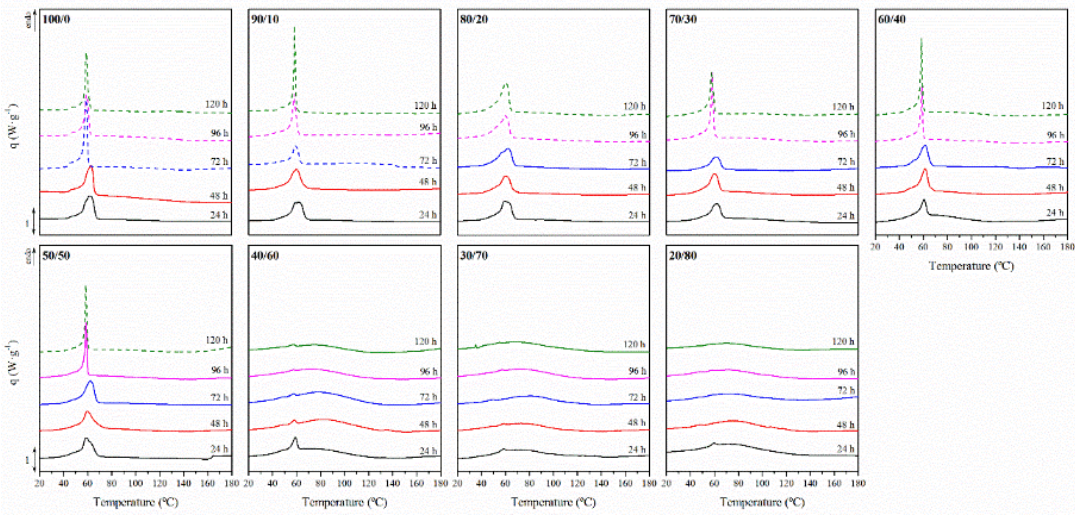

Figure 5. DSC first-heating traces of electrospun scaffolds as a function of the scaffold composition and the dissolution time. Dash lines are used for the nonpracticable scaffolds.

A general overview of the DSC thermograms showed different melting behaviours depending on the composition of the scaffolds, in line with the observation of Kolbuk et al. through polarized optical microscopy [59]. For the PCL/Ge scaffolds with compositions ranging from 100/0 to 50/50, a typical semicrystalline behaviour was perceived. They showed a melting transition associated to PCL $\left(\sim 62{ }^{\circ} \mathrm{C}\right)$ that moved towards lower values as the PCL content decreased [57]. Then, an almost negligible wide endotherm from 20 to $120{ }^{\circ} \mathrm{C}$ associated to the water release from Ge molecules was observed [57]. For the 40/60, 30/70 and 20/80 scaffolds, the melting behaviour associated to the PCL crystalline population moved towards lower temperatures until disappearance, while the wide endotherm from 20 to $120{ }^{\circ} \mathrm{C}$ gained importance. The melting temperatures $\left(T_{m}\right)$ for all compositions are gathered in Table 3. Since the characteristic peak of the helix to random coil transition of the Ge $\left(225^{\circ} \mathrm{C}\right)$ was not observed for these scaffolds, a random coil conformation of the Ge was expected [34]. Therefore, the formic/acetic acid mixture used as solvent for electrospinning may have denaturalised the helix conformation to random coil [45], [71].

As the dissolution time increased, the melting temperature of the PCL decreased for all compositions. The melting events were revealed sharper and displaced towards lower temperatures. Shorter PCL molecules caused by the advance of the hydrolytic degradation resulted in the formation of crystalline domains that melted at lower temperatures. This observation suggested that the hydrolytic degradation of the PCL molecules resulted in lower lamellar thickness and more concise crystalline populations, according to our previous results [49]. 
Table 3. PCL melting temperatures $\left(T m,{ }^{\circ} \mathrm{C}\right)$ as a function of the scaffold composition and the dissolution time. D.T. stands for dissolution time.

\begin{tabular}{cccccccccc}
\hline \multirow{2}{*}{$\begin{array}{c}\text { D.T. } \\
\text { (h) }\end{array}$} & $\mathbf{1 0 0 / 0}$ & $\mathbf{9 0 / 1 0}$ & $\mathbf{8 0 / 2 0}$ & $\mathbf{7 0 / 3 0}$ & $\mathbf{6 0 / 4 0}$ & $\mathbf{5 0 / 5 0}$ & $\mathbf{4 0 / 6 0}$ & $\mathbf{3 0 / 7 0}$ & $\mathbf{2 0 / 8 0}$ \\
\hline \multirow{2}{*}{24} & 61.6 & 61.7 & 60.5 & 61.0 & 60.8 & 59.0 & 59.6 & 58.9 & 59.7 \\
& \pm 0.4 & \pm 1.1 & \pm 1.2 & \pm 0.8 & \pm 0.4 & \pm 0.6 & \pm 0.1 & \pm 0.4 & \pm 0.1 \\
\hline \multirow{2}{*}{48} & 63.2 & 61.5 & 60.4 & 60.3 & 62.8 & 58.7 & 58.1 & 58.5 & 58.1 \\
& \pm 0.2 & \pm 0.1 & \pm 0.1 & \pm 0.1 & \pm 0.1 & \pm 0.0 & \pm 0.2 & \pm 0.1 & \pm 0.5 \\
\hline \multirow{2}{*}{72} & 58.4 & 58.6 & 62.0 & 61.1 & 61.3 & 62.1 & 57.3 & 59.2 & - \\
& \pm 0.1 & \pm 0.4 & \pm 0.1 & \pm 0.5 & \pm 0.1 & \pm 0.1 & \pm 0.4 & \pm 0.2 & - \\
\hline \multirow{2}{*}{96} & 59.1 & 58.3 & 60.8 & 58.5 & 58.8 & 58.0 & 57.6 & 58.6 & - \\
& \pm 0.1 & \pm 0.3 & \pm 0.5 & \pm 0.3 & \pm 0.1 & \pm 0.1 & \pm 0.2 & \pm 0.1 & - \\
\hline \multirow{2}{*}{120} & 58.8 & 58.5 & 60.3 & 57.7 & 58.3 & 58.2 & 57.3 & 55.1 & - \\
& \pm 0.1 & \pm 0.1 & \pm 0.2 & \pm 0.1 & \pm 0.1 & \pm 0.2 & \pm 0.0 & \pm 0.5 & - \\
\hline
\end{tabular}

The evolution of the crystallinity degree $\left(X_{c}\right)$ for practicable scaffolds is plotted in Figure 6. There, the influence of the PCL and Ge concentration was perceived. For the scaffolds with PCL/Ge compositions ranging from $100 / 0$ to 50/50, an increasing tendency of the $X_{c}$ was perceived, reaching the maximum for the 50/50 composition. Then, the increase in the Ge content lowered the $X_{c}$. According to bibliography, the high content of Ge allowed the diffusion of PCL molecules which hindered its crystallisation [59]. Therefore, a predominantly amorphous structure was expected for scaffolds with high Ge content.

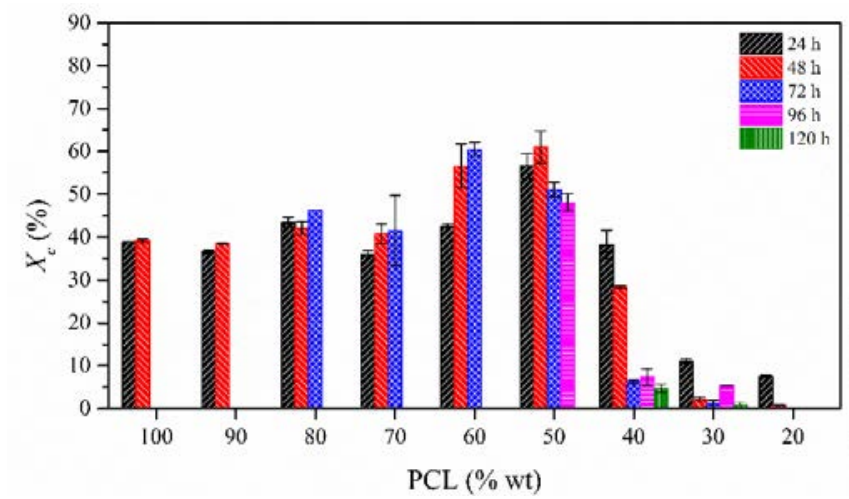

Figure 6. Crystallinity degree $\left(X_{c}\right)$ of the practicable electrospun scaffolds as a function of the scaffold composition and the dissolution time (D.T.).

The scaffolds with high PCL content, from 100/0 to 60/40, showed an increasing tendency of the $X_{c}$ as a function of the dissolution time, as a consequence of the hydrolytic degradation of the PCL chains. Shorter macromolecular segments with enhanced mobility were more capable of forming crystalline domains than longer segments. Shorter segments promoted enhanced crystallisation and orientation along the fibre axis [15]. However, scaffolds with high concentration of Ge, from 50/50 to 20/80, 
showed lower crystallinity degree as dissolution time increased. As observed in the previous section by the SEC analysis, the higher hydrolytic degradation of the PCL segments for these compositions seemed to result in too short PCL segments to develop substantial crystallisation. In addition, the lower molar mass and lower hydrodynamic radius found in previous sections corroborates the presumable diffusion of the PCL macromolecules into the Ge matrix, thus hindering the PCL crystallisation.

\subsubsection{Wettability}

Due to the biomedical purpose of these PCL/Ge scaffolds, an adequate wettability is of crucial importance, since it is related to the attachment, proliferation, migration and viability of cells [84], [85]. Therefore, the water contact angle of the practicable scaffolds is shown in Figure 7 as a function of the composition and the dissolution time.

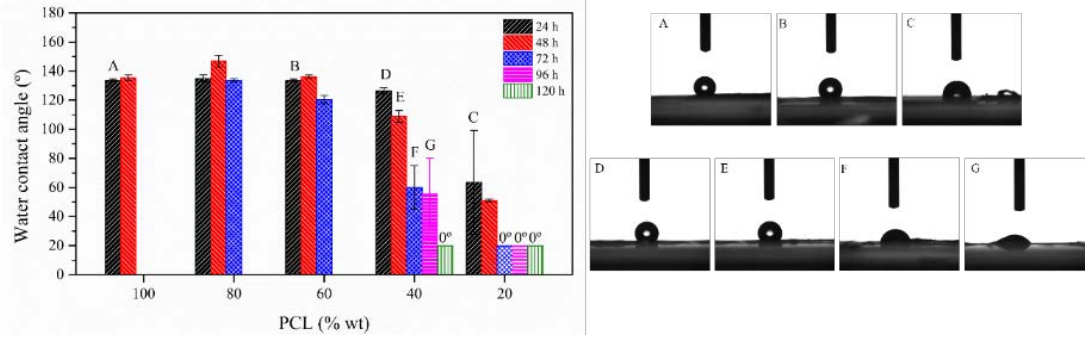

Figure 7. Water contact angle values (left) and selected drop pictures (right) of the practicable electrospun scaffolds as a function of the scaffold composition and the dissolution time (D.T.).

The pure PCL scaffold showed a contact angle of $134^{\circ}$, corroborating its hydrophobic behaviour [45]. A crystallised structure, along with the absence of available functional groups to interact with water molecules, reduced water affinity and resulted in high contact angles. On the one hand, PCL/Ge scaffolds with compositions ranging from 80/20 to 60/40 showed similar values than that of pure PCL. Although the Ge content increased, the PCL crystalline structure reduced the hydrophilic effect of the Ge. On the other hand, for PCL/Ge scaffolds with compositions between 40/60 and 20/80, the water contact angle decreased, suggesting higher wettability. This fact can be correlated with the highly hydrophilic nature of the Ge macromolecules containing amide, amine and carboxyl groups available to interact with water molecules [86].

Concerning the effect of the dissolution time, it promoted an increase of the wettability of scaffolds, especially for the PCL/Ge scaffolds with compositions between 40/60 and 20/80. The highly hydrolytically degraded PCL segments with new carboxyl groups available to interact with water molecules favoured the wettability of the scaffolds [32]. Indeed, 
the scaffolds with high content of Ge after long dissolution time showed complete water impregnation $\left(0^{\circ}\right)$.

\section{Conclusions}

Ultrathin nanofibrous scaffolds were successfully obtained by electrospinning of polycaprolactone (PCL) and gelatin (Ge) in a 1:1 formic/acetic acid solvent at PCL/Ge compositions ranging from 100/0 to 20/80 \%wt in steps of $10 \% w t$. The influence of the dissolution time in the hydrolytic acid solvent was found to play a key role in the resultant molar mass, fibre morphology, crystallinity and wettability of the electrospun scaffolds.

The hydrolytic degradation of the ester bond of PCL segments was corroborated by the reduction of the intrinsic viscosity, molar mass and hydrodynamic radius as a function of the dissolution time. It reduced the number of effective entanglements between PCL segments. Accordingly, the fibre diameter of the electrospun scaffolds decreased as a function of the dissolution time for all the studied compositions. The fibre diameter remained in the nanoscale range for all the studied scaffolds, which is crucial to mimic the extra-cellular matrix size.

An effective tailoring of the PCL/Ge scaffolds was achieved through the defined acidic solvent system. These tailored scaffolds will show dissimilar performance at service conditions, affecting to factors such as the scaffold degradability or cell culture viability, among others. Future investigations will open up the possibility of studying the differentiation ability of cells onto these devices and study their biodegradation behaviour when implanted in vivo.

\section{Acknowledgements}

The Spanish Ministry of Economy and Competitiveness is acknowledged for the projects POLYCELL (ENE2014-53734-C2-1-R), POLYDECARBOCELL (ENE2017-86711-C3-1-R) and UPOV13-3E1947. The Spanish Ministry of Education, Culture and Sports is thanked for the pre-doctoral FPU grant of O. Gil-Castell (FPU13/01916). Generalitat Valenciana is thanked for the APOSTD/2014/041 for J.D. Badia. S. Sánchez-Ballester is acknowledged for her kindness and aid with the wettability assays. IESMAT S.A. and Malvern Instruments Ltd. are recognised for their grateful collaboration.

\section{References}

[1] Z. Ma, M. Kotaki, R. Inai, and S. Ramakrishna, "Potential of nanofiber matrix as tissueengineering scaffolds,” Tissue Eng., vol. 11, no. 1, pp. 101-109, 2005.

[2] F. Khan, M. Tanaka, and S. R. Ahmad, "Fabrication of polymeric biomaterials: a strategy for tissue engineering and medical devices,” J. Mater. Chem. B, vol. 3, no. 42, pp. 8224-8249, Oct. 2015.

[3] A. Haider, S. Haider, and I. K. Kang, “A comprehensive review summarizing the effect 
of electrospinning parameters and potential applications of nanofibers in biomedical and biotechnology,” Arab. J. Chem., vol. In press, 2015.

[4] S. Agarwal, J. H. Wendorff, and A. Greiner, "Use of electrospinning technique for biomedical applications,” Polymer (Guildf)., vol. 49, no. 26, pp. 5603-5621, 2008.

[5] D. I. Braghirolli, D. Steffens, and P. Pranke, "Electrospinning for regenerative medicine: a review of the main topics,” Drug Discov. Today, vol. 19, no. 6, pp. 743-753, 2014.

[6] L. A. Smith and P. X. Ma, "Nano-fibrous scaffolds for tissue engineering," Colloids Surfaces B Biointerfaces, vol. 39, no. 3, pp. 125-131, 2004.

[7] S. Agarwal, A. Greiner, and J. H. Wendorff, "Functional materials by electrospinning of polymers,” Prog. Polym. Sci., vol. 38, no. 6, pp. 963-991, Jun. 2013.

[8] B. Dhandayuthapani, Y. Yoshida, T. Maekawa, and D. S. Kumar, "Polymeric scaffolds in tissue engineering application: A review,” Int. J. Polym. Sci., vol. 2011, no. ii, 2011.

[9] S. Stratton, N. B. Shelke, K. Hoshino, S. Rudraiah, and S. G. Kumbar, "Bioactive polymeric scaffolds for tissue engineering,” Bioact. Mater., vol. 1, no. 2, pp. 93-108, Dec. 2016.

[10] D. M. Yoon and J. P. Fisher, "Natural and Synthetic Polymeric Scaffolds," in Biomedical Materials, R. Narayan, Ed. Springer, 2009, pp. 415-442.

[11] A. Asti and L. Gioglio, "Natural and synthetic biodegradable polymers: Different scaffolds for cell expansion and tissue formation,” International Journal of Artificial Organs, vol. 37, no. 3. pp. 187-205, Mar-2014.

[12] M. A. Woodruff and D. W. Hutmacher, "The return of a forgotten polymerPolycaprolactone in the 21st century,” Prog. Polym. Sci., vol. 35, no. 10, pp. 1217-1256, Oct. 2010.

[13] V. Thomas, M. V Jose, S. Chowdhury, J. F. Sullivan, D. R. Dean, and Y. K. Vohra, "Mechano-morphological studies of aligned nanofibrous scaffolds of polycaprolactone fabricated by electrospinning,” J. Biomater. Sci. Polym. Ed., vol. 17, no. 9, pp. 969-984, Jan. 2006.

[14] A. Cipitria, A. Skelton, T. R. Dargaville, P. D. Dalton, and D. W. Hutmacher, "Design, fabrication and characterization of PCL electrospun scaffolds-a review," J. Mater. Chem., vol. 93, no. ii, pp. 1539-1550, 2011.

[15] X. Wang, H. Zhao, L. S. Turng, and Q. Li, "Crystalline morphology of electrospun poly(e-caprolactone) (PCL) nanofibers,” Ind. Eng. Chem. Res., vol. 52, no. 13, pp. 4939-4949, 2013.

[16] L. Bosworth, P. Clegg, and S. Downes, "Electrospun nanofibres of polycaprolactone, and their use for tendon regeneration,” Int. J. Nano Biomater., vol. 1, no. 3, p. 263, 2008.

[17] K. H. Lee, H. Y. Kim, M. S. Khil, Y. M. Ra, and D. R. Lee, "Characterization of nanostructured poly( $\varepsilon$-caprolactone) nonwoven mats via electrospinning,” Polymer (Guildf)., vol. 44, no. 4, pp. 1287-1294, Feb. 2003.

[18] W. Ji, Y. Sun, F. Yang, J. J. J. P. van den Beucken, M. Fan, Z. Chen, and J. A. Jansen, "Bioactive electrospun scaffolds delivering growth factors and genes for tissue engineering applications.,” Pharm. Res., vol. 28, no. 6, pp. 1259-72, Jun. 2011.

[19] N. Bhardwaj and S. C. Kundu, "Electrospinning: A fascinating fiber fabrication technique,” Biotechnol. Adv., vol. 28, no. 3, pp. 325-347, 2010.

[20] Q. Jiang, H. Xu, S. Cai, and Y. Yang, "Ultrafine fibrous gelatin scaffolds with deep cell infiltration mimicking 3D ECMs for soft tissue repair,” J. Mater. Sci. Mater. Med., vol. 25, no. 7, pp. 1789-1800, Jul. 2014.

[21] E. J. Chong, T. T. Phan, I. J. Lim, Y. Z. Zhang, B. H. Bay, S. Ramakrishna, and C. T. Lim, "Evaluation of electrospun PCL/gelatin nanofibrous scaffold for wound healing and layered dermal reconstitution,” Acta Biomater., vol. 3, no. 3 SPEC. ISS., pp. 321330, May 2007.

[22] H. M. Powell and S. T. Boyce, "Engineered Human Skin Fabricated Using Electrospun Collagen-PCL Blends: Morphogenesis and Mechanical Properties,” Tissue Eng. Part A, vol. 15, no. 8, pp. 2177-2187, Aug. 2009.

[23] R. S. Tığll, N. M. Kazaroğlu, B. Mavış, and M. Gümüşderelioğlu, "Cellular Behavior on Epidermal Growth Factor (EGF)-Immobilized PCL/Gelatin Nanofibrous Scaffolds,” J. Biomater. Sci. Polym. Ed., vol. 22, no. 1-3, pp. 207-223, Jan. 2011.

[24] L. H. Chong, M. M. Lim, and N. Sultana, "Fabrication and Evaluation of Polycaprolactone / Gelatin-Based Electrospun Nanofibers with Antibacterial 
Properties,” vol. 2015, 2015.

[25] H. Duan, B. Feng, X. Guo, J. Wang, L. Zhao, G. Zhou, W. Liu, Y. Cao, and W. J. Zhang, "Engineering of epidermis skin grafts using electrospun nanofibrous gelatin/polycaprolactone membranes,” Int. J. Nanomedicine, vol. 8, no. November, pp. 2077-2084, 2013.

[26] S. Gautam, C.-F. Chou, A. K. Dinda, P. D. Potdar, and N. C. Mishra, "Surface modification of nanofibrous polycaprolactone/gelatin composite scaffold by collagen type I grafting for skin tissue engineering,” Mater. Sci. Eng. C, vol. 34, pp. 402-409, 2014.

[27] M. S. Kim, I. Jun, Y. M. Shin, W. Jang, S. I. Kim, and H. Shin, “The Development of Genipin-Crosslinked Poly(caprolactone) (PCL)/Gelatin Nanofibers for Tissue Engineering Applications,” Macromol. Biosci., vol. 10, no. 1, pp. 91-100, Jan. 2010.

[28] S. Heydarkhan-Hagvall, K. Schenke-Layland, A. P. Dhanasopon, F. Rofail, H. Smith, B. M. Wu, R. Shemin, R. E. Beygui, and W. R. MacLellan, "Three-dimensional electrospun ECM-based hybrid scaffolds for cardiovascular tissue engineering," Biomaterials, vol. 29, no. 19, pp. 2907-2914, Jul. 2008.

[29] S. Pok, J. D. Myers, S. V. Madihally, and J. G. Jacot, "A multilayered scaffold of a chitosan and gelatin hydrogel supported by a PCL core for cardiac tissue engineering," Acta Biomater., vol. 9, no. 3, pp. 5630-5642, Mar. 2013.

[30] L. Ghasemi-Mobarakeh, M. P. Prabhakaran, M. Morshed, M.-H. Nasr-Esfahani, and S. Ramakrishna, "Electrospun poly( $\varepsilon$-caprolactone)/gelatin nanofibrous scaffolds for nerve tissue engineering,” Biomaterials, vol. 29, no. 34, pp. 4532-4539, Dec. 2008.

[31] M. A. Alvarez-Perez, V. Guarino, V. Cirillo, and L. Ambrosio, "Influence of Gelatin Cues in PCL Electrospun Membranes on Nerve Outgrowth,” Biomacromolecules, vol. 11, no. 9, pp. 2238-2246, Sep. 2010.

[32] D. Gupta, J. Venugopal, M. P. Prabhakaran, V. R. G. Dev, S. Low, A. T. Choon, and S. Ramakrishna, "Aligned and random nanofibrous substrate for the in vitro culture of Schwann cells for neural tissue engineering,” Acta Biomater., vol. 5, no. 7, pp. 25602569, 2009.

[33] Y. Zhang, H. Ouyang, C. T. Lim, S. Ramakrishna, and Z.-M. Huang, "Electrospinning of gelatin fibers and gelatin/PCL composite fibrous scaffolds," J. Biomed. Mater. Res., vol. 72B, no. 1, pp. 156-165, Jan. 2005.

[34] I. Rajzer, E. Menaszek, R. Kwiatkowski, J. A. Planell, and O. Castano, "Electrospun gelatin/poly( $\varepsilon$-caprolactone) fibrous scaffold modified with calcium phosphate for bone tissue engineering,” Mater. Sci. Eng. C, vol. 44, pp. 183-190, 2014.

[35] M. A. Alvarez Perez, V. Guarino, V. Cirillo, and L. Ambrosio, "In vitro mineralization and bone osteogenesis in poly( $\varepsilon$-caprolactone)/gelatin nanofibers,” J. Biomed. Mater. Res. Part A, vol. 100A, no. 11, pp. 3008-3019, Nov. 2012.

[36] A. K. Jaiswal, H. Chhabra, V. P. Soni, and J. R. Bellare, "Enhanced mechanical strength and biocompatibility of electrospun polycaprolactone-gelatin scaffold with surface deposited nano-hydroxyapatite,” Mater. Sci. Eng. C, vol. 33, no. 4, pp. 2376-2385, 2013.

[37] J. Huang, C. He, X. Liu, J. Xu, C. S. S. Tay, and S. Y. Chow, “Organic-inorganic nanocomposites from cubic silsesquioxane epoxides: direct characterization of interphase, and thermomechanical properties," Polymer (Guildf)., vol. 46, no. 18, pp. 7018-7027, Aug. 2005.

[38] R. Zheng, H. Duan, J. Xue, Y. Y. Liu, B. Feng, S. Zhao, Y. Zhu, Y. Y. Liu, A. He, W. Zhang, W. Liu, Y. Cao, and G. Zhou, "The influence of Gelatin/PCL ratio and 3-D construct shape of electrospun membranes on cartilage regeneration,” Biomaterials, vol. 35, no. 1, pp. 152-164, Jan. 2014.

[39] J. . Deitzel, J. Kleinmeyer, D. Harris, and N. . Beck Tan, "The effect of processing variables on the morphology of electrospun nanofibers and textiles," Polymer (Guildf)., vol. 42, no. 1, pp. 261-272, Jan. 2001.

[40] X. Qin and D. Wu, "Effect of different solvents on poly(caprolactone) (PCL) electrospun nonwoven membranes,” J. Therm. Anal. Calorim., vol. 107, no. 3, pp. 1007-1013, May 2012.

[41] P. Ginestra, E. Ceretti, and A. Fiorentino, "Electrospinning of Poly-caprolactone for Scaffold Manufacturing: Experimental Investigation on the Process Parameters 
Influence,” Procedia CIRP, vol. 49, pp. 8-13, 2016.

[42] C. Erisken, D. M. Kalyon, and H. Wang, "Functionally graded electrospun polycaprolactone and $\beta$-tricalcium phosphate nanocomposites for tissue engineering applications,” Biomaterials, vol. 29, no. 30, pp. 4065-4073, Oct. 2008.

[43] S. H. Bahrami and A. Gholipour Kanani, "Effect of changing solvents on poly( $\varepsilon$ Caprolactone) nanofibrous webs morphology,” J. Nanomater., vol. 2011, pp. 1-10, 2011.

[44] L. A. Bosworth and S. Downes, “Acetone, a Sustainable Solvent for Electrospinning Poly( $\varepsilon$-Caprolactone) Fibres: Effect of Varying Parameters and Solution Concentrations on Fibre Diameter,” J. Polym. Environ., vol. 20, no. 3, pp. 879-886, 2012.

[45] B. Feng, H. Tu, H. Yuan, H. Peng, and Y. Zhang, "Acetic-acid-mediated miscibility toward electrospinning homogeneous composite nanofibers of GT/PCL," Biomacromolecules, vol. 13, no. 12, pp. 3917-3925, Dec. 2012.

[46] N. S. Binulal, A. Natarajan, D. Menon, V. K. Bhaskaran, U. Mony, and S. V. Nair, "PCL-gelatin composite nanofibers electrospun using diluted acetic acid-ethyl acetate solvent system for stem cell-based bone tissue engineering,” J. Biomater. Sci. Polym. Ed., vol. 25, no. 4, pp. 325-340, Mar. 2014.

[47] S. Sarabi-maneji, J. Scott, and D. J. Y. S. Pagé, "Process Optimization for the Electrospinning of Polycaprolactone Nanofibers Using Non-halogenated Solvents,” no. 82, pp. 1-8, 2014.

[48] L. Van der Schueren, B. De Schoenmaker, Ö. I. Kalaoglu, and K. De Clerck, “An alternative solvent system for the steady state electrospinning of polycaprolactone,” Eur. Polym. J., vol. 47, no. 6, pp. 1256-1263, Jun. 2011.

[49] O. Gil-Castell, J. D. D. Badia, E. Strömberg, S. Karlsson, and A. Ribes-Greus, "Effect of the dissolution time into an acid hydrolytic solvent to tailor electrospun nanofibrous polycaprolactone scaffolds,” Eur. Polym. J., vol. 87, pp. 174-187, 2017.

[50] N. Lavielle, A. M. Popa, M. De Geus, A. Hébraud, G. Schlatter, L. Thöny-Meyer, and R. M. Rossi, "Controlled formation of poly( $\varepsilon$-caprolactone) ultrathin electrospun nanofibers in a hydrolytic degradation-assisted process,” Eur. Polym. J., vol. 49, no. 6, pp. 1331-1336, Jun. 2013.

[51] E. Browning, “Toxic solvents: a review,” Brit. J. Ind. Med, vol. 16, 1959.

[52] J. Nam, Y. Huang, S. Agarwal, and J. Lannutti, "Materials selection and residual solvent retention in biodegradable electrospun fibers,” J. Appl. Polym. Sci., vol. 107, no. 3, pp. 1547-1554, Feb. 2008.

[53] N. Choktaweesap, K. Arayanarakul, D. Aht-ong, C. Meechaisue, and P. Supaphol, "Electrospun Gelatin Fibers: Effect of Solvent System on Morphology and Fiber Diameters,” Polym. J., vol. 39, no. 6, pp. 622-631, Jun. 2007.

[54] S.-Y. Gu, Z.-M. Wang, J. Ren, and C.-Y. Zhang, "Electrospinning of gelatin and gelatin/poly(l-lactide) blend and its characteristics for wound dressing,” Mater. Sci. Eng. C, vol. 29, no. 6, pp. 1822-1828, Aug. 2009.

[55] J.-H. Song, H.-E. Kim, and H.-W. Kim, "Production of electrospun gelatin nanofiber by water-based co-solvent approach,” J. Mater. Sci. Mater. Med., vol. 19, no. 1, pp. 95102, Jan. 2008.

[56] I. H. L. Pereira, E. Ayres, L. Averous, G. Schlatter, A. Hebraud, S. T. O. L. Mendes, and R. L. Oréfice, "Elaboration and characterization of coaxial electrospun poly(??caprolactone)/gelatin nanofibers for biomedical applications,” Adv. Polym. Technol., vol. 33, no. S1, pp. 1-10, 2014.

[57] P. Denis, J. Dulnik, and P. Sajkiewicz, "Electrospinning and Structure of Bicomponent Polycaprolactone/Gelatin Nanofibers Obtained Using Alternative Solvent System,” Int. J. Polym. Mater. Polym. Biomater., vol. 64, no. 7, pp. 354-364, 2014.

[58] J. Dulnik, P. Denis, P. Sajkiewicz, D. Kołbuk, and E. Choińska, "Biodegradation of bicomponent PCL/gelatin and PCL/collagen nanofibers electrospun from alternative solvent system,” Polym. Degrad. Stab., vol. 130, no. November, pp. 10-21, 2016.

[59] D. Kolbuk, P. Sajkiewicz, P. Denis, and E. Choinska, "Investigations of polycaprolactone/gelatin blends in terms of their miscibility,” Bull. Polish Acad. Sci. Tech. Sci., vol. 61, no. 3, pp. 629-632, 2013.

[60] A. Arinstein, M. Burman, O. Gendelman, and E. Zussman, "Effect of supramolecular structure on polymer nanofibre elasticity,” Nat. Nanotechnol., vol. 2, no. 1, pp. 59-62, 
Jan. 2007.

[61] H. Cai, V. Dave, R. A. Gross, and S. P. McCarthy, "Effects of physical aging, crystallinity, and orientation on the enzymatic degradation of poly(lactic acid)," $J$. Polym. Sci. Part B Polym. Phys., vol. 34, no. 16, pp. 2701-2708, Nov. 1996.

[62] J. Gaumer, A. Prasad, D. Lee, and J. Lannutti, "Structure-function relationships and source-to-ground distance in electrospun polycaprolactone,” Acta Biomater., vol. 5, no. 5, pp. 1552-1561, Jun. 2009.

[63] V. Guarino, V. Cirillo, P. Taddei, M. A. Alvarez-Perez, and L. Ambrosio, "Tuning Size Scale and Crystallinity of PCL Electrospun Fibres via Solvent Permittivity to Address hMSC Response,” Macromol. Biosci., vol. 11, no. 12, pp. 1694-1705, Dec. 2011.

[64] M. J. Jenkins and K. L. Harrison, "The effect of crystalline morphology on the degradation of polycaprolactone in a solution of phosphate buffer and lipase," Polym. Adv. Technol., vol. 19, no. 12, pp. 1901-1906, Dec. 2008.

[65] J. L. Lowery, N. Datta, and G. C. Rutledge, "Effect of fiber diameter, pore size and seeding method on growth of human dermal fibroblasts in electrospun poly( $\varepsilon$ caprolactone) fibrous mats,” Biomaterials, vol. 31, no. 3, pp. 491-504, Jan. 2010.

[66] J. E. Mark, Properties of Polymers Handbook. Springer, 2007.

[67] S. Gautam, A. K. Dinda, and N. C. Mishra, "Fabrication and characterization of PCL/gelatin composite nanofibrous scaffold for tissue engineering applications by electrospinning method,” Mater. Sci. Eng. C, vol. 33, no. 3, pp. 1228-1235, 2013.

[68] Y. Wan, X. Lu, S. Dalai, and J. Zhang, "Thermophysical properties of polycaprolactone/chitosan blend membranes,” Thermochim. Acta, vol. 487, no. 1, pp. 33-38, 2009.

[69] C. Peña, K. de la Caba, A. Eceiza, R. Ruseckaite, and I. Mondragon, "Enhancing water repellence and mechanical properties of gelatin films by tannin addition,” Bioresour. Technol., vol. 101, no. 17, pp. 6836-6842, 2010.

[70] K. Lewandowska, "Miscibility and thermal stability of poly(vinyl alcohol)/chitosan mixtures,” Thermochim. Acta, vol. 493, no. 1, pp. 42-48, 2009.

[71] C. S. Ki, D. H. Baek, K. D. Gang, K. H. Lee, I. C. Um, and Y. H. Park, “Characterization of gelatin nanofiber prepared from gelatin-formic acid solution,” Polymer (Guildf)., vol. 46, no. 14, pp. 5094-5102, Jun. 2005.

[72] R. Muthuraj, M. Misra, and A. K. Mohanty, "Hydrolytic degradation of biodegradable polyesters under simulated environmental conditions,” J. Appl. Polym. Sci., vol. 132, no. 27, p. n/a-n/a, Jul. 2015.

[73] X. He, B. Feng, C. Huang, H. Wang, Y. Ge, R. Hu, M. Yin, Z. Xu, W. Wang, W. Fu, and J. Zheng, "Electrospun gelatin/polycaprolactone nanofibrous membranes combined with a coculture of bone marrow stromal cells and chondrocytes for cartilage engineering,” Int. J. Nanomedicine, vol. 10, pp. 2089-2099, 2015.

[74] J. Xue, B. Feng, R. Zheng, Y. Lu, G. Zhou, W. Liu, Y. Cao, Y. Zhang, and W. J. Zhang, "Engineering ear-shaped cartilage using electrospun fibrous membranes of gelatin/polycaprolactone,” Biomaterials, vol. 34, no. 11, pp. 2624-2631, 2013.

[75] D. . Chen, J. . Bei, and S. . Wang, "Polycaprolactone microparticles and their biodegradation,” Polym. Degrad. Stab., vol. 67, no. 3, pp. 455-459, 2000.

[76] L. Santonja-Blasco, R. Moriana, J. D. Badía, and A. Ribes-Greus, “Thermal analysis applied to the characterization of degradation in soil of polylactide: I. Calorimetric and viscoelastic analyses,” Polym. Degrad. Stab., vol. 95, no. 11, pp. 2185-2191, Nov. 2010.

[77] J. D. Badia, E. Strömberg, S. Karlsson, and A. Ribes-Greus, "Material valorisation of amorphous polylactide. Influence of thermo-mechanical degradation on the morphology, segmental dynamics, thermal and mechanical performance," Polym. Degrad. Stab., vol. 97, no. 4, pp. 670-678, Apr. 2012.

[78] O. Gil-Castell, J. D. D. Badia, T. Kittikorn, E. Strömberg, M. Ek, S. Karlsson, A. RibesGreus, E. Strömberg, M. Ek, S. Karlsson, and A. Ribes-Greus, "Impact of hydrothermal ageing on the thermal stability, morphology and viscoelastic performance of PLA/sisal biocomposites,” Polym. Degrad. Stab., vol. 132, pp. 87-96, Mar. 2016.

[79] J. D. Badia, T. Kittikorn, E. Strömberg, L. Santonja-Blasco, A. Martínez-Felipe, A. Ribes-Greus, M. Ek, and S. Karlsson, "Water absorption and hydrothermal performance of PHBV/sisal biocomposites,” Polym. Degrad. Stab., vol. 108, pp. 166-174, Oct. 2014.

[80] O. Gil-Castell, J. D. D. Badia, T. Kittikorn, E. Strömberg, A. Martínez-Felipe, M. Ek, 
S. Karlsson, and A. Ribes-Greus, "Hydrothermal ageing of polylactide/sisal biocomposites. Studies of water absorption behaviour and Physico-Chemical performance,” Polym. Degrad. Stab., vol. 108, pp. 212-222, Oct. 2014.

[81] J. D. Badia, L. Santonja-Blasco, A. Martínez-Felipe, and A. Ribes-Greus, “Hygrothermal ageing of reprocessed polylactide,” Polym. Degrad. Stab., vol. 97, no. 10, pp. 1881-1890, Oct. 2012.

[82] J. D. Badia, E. Strömberg, T. Kittikorn, M. Ek, S. Karlsson, and A. Ribes-Greus, "Relevant factors for the eco-design of polylactide/sisal biocomposites to control biodegradation in soil in an end-of-life scenario,” Polym. Degrad. Stab., vol. 143, pp. 919, Sep. 2017.

[83] J. D. Badia, E. Strömberg, S. Karlsson, and A. Ribes-Greus, “The role of crystalline, mobile amorphous and rigid amorphous fractions in the performance of recycled poly (ethylene terephthalate) (PET),” Polym. Degrad. Stab., vol. 97, no. 1, pp. 98-107, Jan. 2012.

[84] K. Zhang, H. Wang, C. Huang, Y. Su, X. Mo, and Y. Ikada, "Fabrication of silk fibroin blended P(LLA-CL) nanofibrous scaffolds for tissue engineering,” J. Biomed. Mater. Res. A, vol. 96, no. 3, pp. 984-993, 2010.

[85] A. Mikos, M. Lyman, L. Freed, and R. Langer, "Wetting of poly(L-lactic acid) and poly(DL-lactic-co-glycolic acid) foams for tissue culture,” Biomaterials, vol. 15, no. 1, pp. 55-58, 1994.

[86] W. Fu, Z. Liu, B. Feng, R. Hu, X. He, H. Wang, M. Yin, H. Huang, H. Zhang, and W. Wang, "Electrospun gelatin/PCL and collagen/PLCL scaffolds for vascular tissue engineering,” Int. J. Nanomedicine, vol. 9, no. 1, pp. 2335-2344, 2014. 
Contribution 5.5.

Validation of tailored electrospun nanofibrous

polycaprolactone/gelatin based scaffolds

O. Gil-Castell, J. D. Badia, I. Ontoria, D. Castellano, P. Sepúlveda, A. Ribes-Greus. Validation of tailored electrospun nanofibrous polycaprolactone/gelatin based scaffolds. Manuscript in preparation. 


\title{
Validation of tailored electrospun nanofibrous polycaprolactone/gelatin based scaffolds
}

\author{
O. Gil-Castell ${ }^{1}$, J. D. Badia ${ }^{1,2}$, I. Ontoria ${ }^{3}$, D. Castellano ${ }^{3}$, P. Sepúlveda ${ }^{3}$, \\ A. Ribes-Greus ${ }^{1, *}$
}
${ }^{1}$ Instituto de Tecnología de Materiales (ITM). Universitat Politècnica de València. Camino de Vera s/n, 46022 Valencia, Spain.
${ }^{2}$ Departament d’Enginyeria Química. Escola Tècnica Superior d’Enginyeria. Universitat de València. Av. de la Universitat s/n, 46100 Burjassot, Spain
${ }^{3}$ Unidad de Regeneración y Trasplante Cardíaco. Instituto de Investigación Sanitaria La Fe. Av. Fernando Abril Martorell Torre A, 46026 Valencia, Spain

\author{
*Corresponding author:
}

A. Ribes-Greus aribes@ter.upv.es 


\title{
Validation of tailored electrospun nanofibrous polycaprolactone/gelatin based scaffolds
}

\author{
O. Gil-Castell, J. D. Badia, I. Ontoria, D. Castellano, P. Sepúlveda, A. \\ Ribes-Greus
}

\begin{abstract}
Polycaprolactone (PCL) and gelatin (Ge) blended nanofibrous scaffolds were obtained by electrospinning as a function the PCL/Ge composition and the dissolution time into a 1:1 formic/acetic acid solvent. The influence of dissolution time in the hydrolytic acid solvent was found to play a key role in the resultant physicochemical properties and morphology of the electrospun scaffolds, as shown by the evaluation of the molar mass, crystalline structure, surface morphology and water contact angle. The cell adhesion and proliferation was found to be strongly influenced by the PCL/Ge composition, as corroborated by the MTT assay, the fluorescence analysis and the microscopy analyses. The effect of the dissolution time was studied for the most cell-compatible compositions $-60 / 40,50 / 50$ and $40 / 60 \mathrm{PCL} / \mathrm{Ge}-$, being less prominent for the last. The in vitro degradation in physiologic conditions was assessed on the selected 60/40, 50/50 and 40/60 PCL/Ge scaffolds, which revealed a progressive behaviour as a function of the composition and dissolution time. The release of the Ge fraction of the scaffolds during immersion was perceived in all cases. As well, the scaffolds electrospun after high dissolution time revealed a weakened structure, labile to degradation in physiologic conditions, more significant for the 40/60 PCL/Ge composition. The biocompatibility of the tailored 40/60 PCL/Ge scaffolds was corroborated by means of the pyrogen test, in which scaffolds were found to be non-inflammatory. Moreover, no inflammatory response was observed after a 15 day subcutaneous in vivo implantation in mice. The perceived in vivo progressive degradation behaviour as a function of the dissolution time, and the partial or complete assimilation during implantation corroborated the tailoring strategy to obtain highly biocompatible scaffolds with a controlled degradation rate.
\end{abstract}

\section{Keywords}

Scaffold, tailored, polycaprolactone (PCL), gelatin, degradation, in vitro, in vivo, biocompatibility 


\section{Introduction}

The regeneration of damaged and injured tissues is a field of great interest that has been the focus of numerous research along the last decade. The tissue engineering science involves the combination of engineering, materials and cells to replace or substitute biological tissues. In this sense, one of the main approaches of this field is the fabrication of biocompatible scaffolds that provide the optimum conditions for cell adhesion and proliferation along with tailored durability and performance. The development of synthetic nanoscaled fibrous scaffolds that structurally mimic extra-cellular matrix (ECM) in size and porosity has brought new possibilities in this field [1].

In recent years, the application of electrospinning to produce scaffolds with diameters in the nanometre scale that could mimic the natural extra-cellular matrix has gained great attention [2]-[4]. Among all the polymers considered for biodegradable scaffold fabrication, polyester based materials such as polycaprolactone (PCL), poly(lactic-co-glycolic acid) (PLGA) or polylactide (PLA) and their copolymers have been considered as promising candidates for tissue regeneration application. Their intrinsic structure with ester linkages labile to the hydrolytic degradation when implanted in physiological conditions allows disintegration and assimilation [5]-[8]. However, biocompatibility concerns such as inflammatory response, poor cell adhesion or loss of the nanostructured morphology have boosted the investigation of new candidates for scaffold production. Several strategies have been suggested such as coating, grafting or blending with other components in order to improve the scaffold cell affinity [9].

Blending biodegradable synthetic polymers and natural materials by electrospinning is a simple and cost-effective method to produce scaffolds, that would bring the advantages of both synthetic and natural materials, theoretically enhancing biocompatibility and offering the required mechanical integrity for application in the tissue engineering science [10]. Among other materials, the combination of polycaprolactone (PCL) and gelatin $(\mathrm{Ge})$ has been proposed as a resourceful substrate for scaffold fabrication in tissue engineering. Ge is a natural biopolymer with excellent biocompatibility, biodegradability and low cost that offers biochemical signals to promote cell adhesion, migration, proliferation and differentiation [11]. Blended PCL/Ge scaffolds have found application for regeneration of tissues such as skin [12]-[17], muscle [18], cardiovascular [19], [20], nerve [21]-[23], bone [24]-[27] and cartilage [28], [29]. However, depending on the use of these nanofibres, the physico-chemical properties and the usage duration of these materials needs to be taken into account. 
Some studies in the bibliography correlate the influence of the composition, the fibre diameter, the scaffold porosity, the molar mass, the glass transition temperature or the crystallinity degree on the subsequent performance of the scaffolds for tissue engineering [30]-[35]. Indeed, the change of these features during application would determine the satisfactory performance of these scaffolds. In this sense, some alternatives can be considered. The appropriate balance of the composition of the PCL/Ge blended nanofibres is crucial to promote the required cell affinity, given the hydrophobic nature of PCL and the hydrophilic performance of Ge [10]. Besides cytocompatibility and the affinity to the tissue to repair, the scaffold durability may be of high relevance for an adequate application. Therefore, the biodegradation rate of the scaffolds needs to be controlled to match the rate of tissue regeneration [36], [37]. Apart from adjusting scaffold composition, a promising alternative to tailor the durability of the scaffolds has been recently proposed [38]. Electrospinning PCL/Ge blend from a formic/acetic acid mixture has been proposed as an effective mode to satisfactorily produce nanofibres [39]-[41]. In addition, it can be considered as an effective method to tailor physico-chemical properties through the hydrolytic degradation of the PCL fraction as a function of the dissolution time prior to electrospinning [38]. Given the hydrolytic degradation of the PCL molecules in the formic/acetic mixture and the resulting reduction of the polymer molar mass, PCL/Ge scaffolds with different grade of hydrolysis would result in diverse performance [42].

The aim of this study was therefore to validate the tailored PCL/Ge scaffolds as a function of the composition and dissolution time prior to the electrospinning. For this purpose, the in vitro degradation behaviour in physiologic conditions needs to be deeply evaluated and correlated to the biocompatibility performance, signifying an interesting line of research for the development of tailored biomedical scaffolds.

\section{Materials and methods}

\subsection{Materials}

Polycaprolactone (PCL) was provided by Perstorp as $3 \mathrm{~mm}$ diameter pellets under the grade CAPA ${ }^{\mathrm{TM}} 6800\left(M_{n}=85000 \mathrm{~g} \cdot \mathrm{mol}^{-1}\right.$ and $T_{m}$ 58-60 ${ }^{\circ} \mathrm{C}$ ). Gelatin (Ge) from porcine skin Type A, gel strength 300, was supplied by Sigma-Aldrich. Formic acid and acetic acid $(\geq 99 \%)$ were used as solvents for electrospinning. Tetrahydrofuran ( $\geq 99.8 \%$ ) was used for SEC sample preparation and analysis. All solvents were supplied by SigmaAldrich and used without further purification.

\subsection{Polymer solution and electrospinning}

PCL/Ge nanofibres were obtained as reported in a previous study [42]. Briefly, PCL/Ge blended solutions were prepared ranging from 100/0 to 
20/80 by weight proportion, by steps of $10 \%$ wt, in 1:1 formic/acetic acid mixture, with a total solid concentration of $15 \%$ wt. and were electrospun after being subjected to $30{ }^{\circ} \mathrm{C}$ and magnetic stirring for 24, 48, 72, 96 and 120 h. Nanofibres were obtained by means of a Bioinicia Fluidnateek ${ }^{\circledR}$ LE-10 electrospinning equipment, which contents a high voltage source, a programmable syringe pump, a HSW Norm-Ject 20 mL Luer Lok syringe, a Teflon ${ }^{\circledR}$ tubing, a gauge 21 metallic needle and a grounded flat collector. The tip-to-collector distance, the feeding rate and the voltage were set at $15 \mathrm{~cm}, 0.2$ to $1 \mathrm{~mL} \cdot \mathrm{h}^{-1}$ and 19 to $25 \mathrm{kV}$, respectively. The process was performed at $22{ }^{\circ} \mathrm{C}$ and $35 \%$ of relative humidity. The nanofibrous scaffolds were collected on waxed paper, dried and stored for further analyses. They showed a smooth surface and were circle-shaped with 10 $\mathrm{cm}$ of diameter.

\subsection{Physico-chemical characterization}

\subsubsection{Field-emission scanning electron microscopy (FE-SEM)}

The surface topology of the specimens was analysed by means of a Zeiss Ultra 55 field emission scanning electron microscope (FE-SEM). The samples were cut into small pieces and dried at $50{ }^{\circ} \mathrm{C}$ in a vacuum oven for $24 \mathrm{~h}$ and then kept in a desiccator during $48 \mathrm{~h}$. Afterwards, the specimens were mounted on metal studs and sputter-coated with a platinum layer during $10 \mathrm{~s}$ using a Leica EM MED020 sputter coater. FE-SEM micrographs were taken at $22{ }^{\circ} \mathrm{C}$ with a $2 \mathrm{kV}$ voltage. The fibre diameters were measured from the electronic micrographs $(10$ 000×) at random locations $(n=100)$ with the aid of the Image $\mathrm{J} \AA$ software.

\subsubsection{Size exclusion chromatography (SEC)}

Size exclusion chromatography (SEC) was carried out by means of a Malvern Instruments Omnisec Resolve chromatograph. It combined an integrated pump, a degasser, an autosampler and a column oven, along with a Malvern Instruments Omnisec Reveal multi-detector -Ultraviolet (UV), Refractive Index (RI), Low and Right Angle Light Scattering (LALS and RALS) and Viscosity (VISC)-. A monodisperse polystyrene standard with $\mathrm{dn} / \mathrm{dc}$ value of 0.185 was used for previous calibration. Two columns from Malvern Instruments (T2000 and T4000) were used $(300 \times 8 \mathrm{~mm})$. Tetrahydrofuran (THF) was used as mobile phase at a flow rate of 1 $\mathrm{mL} \cdot \mathrm{min}^{-1}$ and a column temperature of $35^{\circ} \mathrm{C}$. The samples were dissolved in THF with concentrations of around $2.0 \mathrm{mg} \cdot \mathrm{ml}^{-1}$ and filtered through 0.45 $\mu \mathrm{m}$ PTFE filters. Two replicates per sample were performed and the obtained data were analysed with the aid of the Omnisec V10 ${ }^{\mathrm{TM}}$ software.

\subsubsection{Differential scanning calorimetry (DSC)}

The calorimetric data were obtained by means of a Mettler-Toledo DSC $820^{\mathrm{e}}$ differential scanning calorimeter (DSC), previously calibrated 
following the procedure of In and Zn standards. The samples, with a mass of about $4 \mathrm{mg}$ were analysed between 25 and $150{ }^{\circ} \mathrm{C}$ with a heating rate of $10{ }^{\circ} \mathrm{C} \cdot \mathrm{min}^{-1}$. All experiments were run under nitrogen atmosphere at 50 $\mathrm{mL} \cdot \mathrm{min}^{-1}$. The specimens were characterised at least by triplicate and the averages of temperatures and enthalpies were taken as representative values.

The crystallinity degree $\left(X_{c}\right)$ was evaluated from the melting enthalpy results, by means of the Equation 1,

$$
X_{c}(\%)=\frac{\Delta h_{m}}{\mathrm{w}_{P C L} \cdot \Delta h_{m}^{0}} \cdot 100 \quad \text { (Equation 1) }
$$

where $\Delta h_{m}$ is the melting enthalpy of the sample, $w_{P C L}$ is the weight fraction of the PCL in the sample and $\Delta h_{m}{ }^{0}$ is the melting enthalpy of a perfect crystal of PCL $\left(148 \mathrm{~J} \cdot \mathrm{g}^{-1}\right)$ [43].

With the purpose of deeply characterise the crystalline structure of the nanofibres, lamellar thickness distributions were calculated by applying the Thomson-Gibbs equation (Equation 2) [44], [45],

$$
l_{C}\left(T_{m}\right)=\left[\left(1-\frac{T_{m}}{T_{m}^{0}}\right) \cdot \frac{\Delta h_{m V}}{2 \cdot \sigma_{e}}\right]^{-1}
$$

where $T_{m}$ is the melting temperature; $T_{m}{ }^{0}$ is the equilibrium melting temperature of an infinite crystal (348 K); $\sigma_{e}$ is the surface free energy of the basal plane where the chains fold $\left(106 \cdot 10^{-3} \mathrm{~J} \cdot \mathrm{m}^{-2}\right)$; and $\Delta h_{m V}$ is the melting enthalpy per volume unit $\left(1.63 \cdot 10^{8} \mathrm{~J} \cdot \mathrm{m}^{-3}\right)$ [46].

\subsubsection{Water contact angle}

The wettability of the scaffolds was characterised according to its water contact angle at $22^{\circ} \mathrm{C}$. The static contact angle was evaluated by means of a KSV Instruments Theta Optical Tensiometer and a CCD (charge-coupled device) camera connected to a computer. $2 \mu \mathrm{L}$ of distilled water were dropped on the sample surface and, after $2 \mathrm{~s}$, the contact angle was measured. The assays were repeated at three different sites of a given sample to ensure reproducibility.

\subsection{In vitro hydrolytic degradation}

Scaffolds of PCL/Ge were subjected to hydrolytic degradation in phosphate buffer solution (PBS), according to international norm ISO 10993-13:2010, method 4.3 [47]. The initial scaffolds were cut into rectangular specimens with a mass around $10 \mathrm{mg}$. The specimens were weighed $\left(m_{0}\right)$ and placed in a previous weighed vial $\left(m_{\text {vial }}\right) .10 \mathrm{~mL}$ of degradation medium were introduced and then the vials were sealed with polytetrafluoroethylene (PTFE) threaded plugs and placed in a thermostatically controlled oven at $37^{\circ} \mathrm{C}$. The $\mathrm{pH}$ of the PBS solution was adjusted to 7.4 with $\mathrm{NaOH} 1 \mathrm{M}$. The effects of the hydrolytic degradation 
were evaluated along 180 days of immersion in three stages of 60 days. The liquid fraction was analysed immediately after extraction, while the solid fraction followed a washing-drying-keeping procedure before further analyses. Then, samples were dried under vacuum to constant mass into their degradation vials $\left(m_{d r y}\right)$ and saved for further analyses. The mass loss of the specimens was calculated according to the Equation 3.

$$
\operatorname{Mass} \operatorname{loss}(\%)=100-\frac{\left(m_{d r y}-m_{\text {vial }}\right)}{m_{0}} \cdot 100
$$

(Equation 3)

\subsection{Cell adhesion and proliferation}

HL-1 cells were plated at $4 \cdot 10^{4}$ cells $\mathrm{cm}^{2}$ onto scaffolds in Claycomb medium (Sigma-Aldrich) containing 10\% foetal bovine serum (Linus) and 1\% L-Glutamine (Millipore). Proliferation was measured after $48 \mathrm{~h}$ and 96 h by MTT assay. Absorbance was measured at $550 \mathrm{~nm}$ using a PerkinElmer Victor3 1420 Multilabel Counter microplate reader. To observe the cellular adhesion, cells were fixed with PFA $2 \%$ during $20 \mathrm{~min}$ at room temperature, washed twice and stained with 4',6-diamidino-2-phenylindole (DAPI) $48 \mathrm{~h}$ and $96 \mathrm{~h}$ after platting. Images were acquired by means of a Leica DM2500 microscope. Experiments were done in triplicates. As well, seeded scaffolds were fixed with $3 \%$ glutaraldehyde solution during $60 \mathrm{~min}$ at $37{ }^{\circ} \mathrm{C}$ and subsequently critical point dried (CPD). This procedure removed liquids from the specimen and avoids surface tension effects, by never allowing a liquid/gas interface to develop [48]. The CPD protocol consisted in dehydration through a graded series of ethanol $(10 \%, 20 \%$, $30 \%, 50 \%$ and $70 \%$, each step for $10 \mathrm{~min}$ ), and then immersed in $100 \%$ ethanol twice for $30 \mathrm{~min}$. The tissues were then transferred to a Leica CPD300 critical point dryer, using liquefied carbon dioxide as transitional fluid. Finally, samples were sputter-coated and analysed according to the protocol described in section 2.3.1.

\subsection{Pyrogen test and real-time polymerase chain reaction (RT-PCR)}

Blood samples were collected from healthy volunteers from the Valencian Blood Tissue Bank after informed consent and were processed as described previously [49]. For this purpose, $6 \cdot 10^{6}$ isolated peripheral blood mononuclear cells (PBMNC) were incubated with the corresponding scaffolds for $5 \mathrm{~h}$. Afterwards, RNA was obtained with the RNeasy Plus Mini Kit and quantified using a Nanodrop ND-2000 (NanoDrop Technologies). Then, $1 \mu$ g of total RNA was used for cDNA synthesis with the High-Capacity cDNA Reverse Transcription kit (Applied Biosystems). Equal amounts of cDNa were used for the RT-PCR with LightCycler FastStart DNA Master SYBR Green (Roche Life Science) according to the manufacturer's instructions. The following cytokines were analysed: IL$1 \beta$, IL-6, IL-10 and TNF- $\alpha$, gene expression levels were normalised to 
GAPDH and calculated using the comparative Ct method. Experiments were done in triplicates.

\subsection{In vivo subcutaneous implantation}

For the in vivo subcutaneous implantation, $1 \mathrm{~cm}^{2}$ of the corresponding scaffolds were implanted in adult C57BL6J mice $(n=18)$ provided by Charles River Laboratories, as described previously [50]. Briefly, a subcutaneous pocket was made at the dorsal region and the scaffolds were implanted on top of the muscular fascia. Afterwards, the skin was sutured with B/Braun Monosyn 3/0 and mice were sacrificed in the day 15 of implantation. 3 mice were used for each of the scaffold composition. Institutional ethical and animal care committees approved all these procedures.

\subsection{Histology}

Skin sections were fixed with ethanol, embedded in paraffin and 5-10 transverse sections of $5 \mu \mathrm{m}$ at the area of implantation were stained with haematoxylin/eosin (H/E). Images were acquired with a digital microimaging device Leica DMD108.

\section{Results and discussion}

\subsection{Tailored electrospun PCL/Ge based nanofibrous scaffolds}

The nanofibrous scaffolds, collected on a grounded flat collector, were smooth and circle-shaped about $10 \mathrm{~cm}$ in diameter. While practical scaffolds were found after $24 \mathrm{~h}$ and $48 \mathrm{~h}$ of dissolution for all the studied compositions, the scaffold viability was altered as dissolution time increased, as perceived by the formation of ultra-thin fibres and beads [42]. The surface morphology of the practical obtained scaffolds is shown in Figure 1. As well, the main physico-chemical properties of these scaffolds as a function of the composition and the dissolution time in terms of the average molar mass in number $\left(M_{n}\right)$, the average fibre diameter $(\varnothing)$, the melting temperature $\left(T_{m P C L}\right)$ and the crystallinity degree $\left(X_{C P C L}\right)$ of the PCL fraction as well as the water contact angle $(\theta)$ are gathered in Table 1.

The hydrolytic degradation of the ester bond of the PCL molecular chains when diluted in 1:1 formic/acetic acid mixture reduced the molar mass of the PCL chains [38]. Accordingly, a decrease of the average molar mass in number $\left(M_{n}\right)$ as a function of the dissolution time was observed in all cases that corroborated the hydrolytic degradation. Indeed, the lower molar mass, promoted lower intrinsic viscosity, which reduced their entanglement capability, essential for the production of nanofibres via electrospinning [4]. Nevertheless, the increase of the Ge content improved electrospinning viability after high dissolution times. Even though a reduction of the PCL 
molar mass occurred, the rich-Ge compositions maintained high enough viscosity to get practical scaffolds.

Although the fibre diameter $(\varnothing)$ remained in the nanoscale range for all the studied scaffolds, which is crucial to mimic the extra cellular matrix size, it decreased as a function of the dissolution time for all the studied compositions [51]. While scaffolds with high PCL content increased crystallinity $\left(X_{c}\right)$ as a function of the hydrolytic degradation, those compositions in which Ge predominated showed the lowest crystallinity degree. Ge diffused and interacted within the PCL molecules, hindering the PCL crystallisation, resulting in an amorphous structure. The wettability increased as a function of the Ge content due to the high hydrophilic behaviour of these molecules as well as increased as a function of the dissolution time, due to the more carboxyl groups available in PCL segments to interact with water molecules [52]. The physicochemical assessment of the electrospun scaffolds revealed an effective tailoring procedure to obtain functionalised blended PCL/Ge scaffolds with specific properties as a function of the dissolution preparation time prior to electrospinning. All these modifications are considered of great importance in the subsequent behaviour of the nanofibres [53]. 


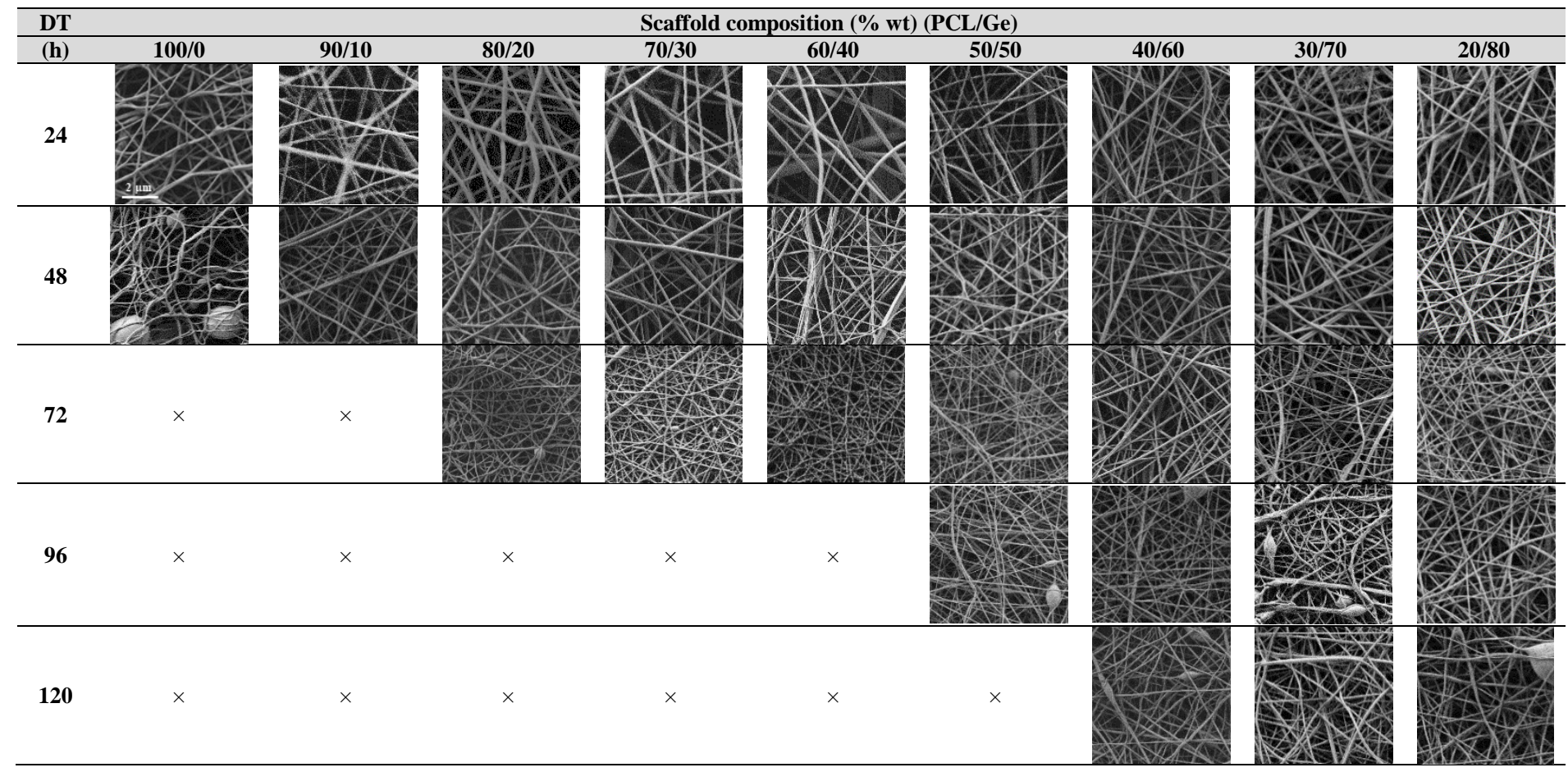

Figure 1. Surface micrographs $(10000 \times$, scale bar $2 \mu \mathrm{m})$ of the practical electrospun scaffolds as a function of the scaffold composition and the dissolution time (DT). 
Table 1. Physico-chemical properties of the scaffolds as a function of the composition and the dissolution time in terms of the average molar mass in number $\left(M_{n}\right)$, the average fibre diameter $(\varnothing)$, the melting temperature $\left(T_{m}\right)$ and the crystallinity degree $\left(X_{c}\right)$ of the PCL fraction as well as the water contact angle $(\theta)$. Standard deviation was omitted for the sake of clarity.

\begin{tabular}{|c|c|c|c|c|c|c|c|c|c|c|c|}
\hline \multirow{2}{*}{$\begin{array}{l}\text { DT } \\
\text { (h) } \\
\end{array}$} & & & \multicolumn{9}{|c|}{ Scaffold composition (\% wt) (PCL/Ge) } \\
\hline & & & $100 / 0$ & $90 / 10$ & $80 / 20$ & 70/30 & $60 / 40$ & $50 / 50$ & $40 / 60$ & $30 / 70$ & $20 / 80$ \\
\hline \multirow{5}{*}{24} & $M_{n}$ & $\left(\mathrm{~g} \cdot \mathrm{mol}^{-1}\right)$ & 42030 & 42970 & 40640 & 38540 & 38720 & 31235 & 29435 & 28870 & 28930 \\
\hline & $\varnothing$ & $(\mathrm{nm})$ & 128 & 125 & 154 & 182 & 168 & 120 & 137 & 158 & 159 \\
\hline & $T_{m}$ & $\left({ }^{\circ} \mathrm{C}\right)$ & 61.6 & 61.7 & 60.5 & 61.0 & 60.8 & 59.0 & 59.6 & 58.9 & - \\
\hline & $X_{c}$ & $(\%)$ & 38.9 & 36.5 & 34.8 & 36.0 & 42.7 & 56.6 & 38.3 & 7.5 & - \\
\hline & $\theta$ & $\left({ }^{\circ}\right)$ & 133.5 & 133.4 & 134.9 & 132.2 & 133.5 & 130.4 & 126.4 & 83.2 & 63.6 \\
\hline \multirow{4}{*}{48} & $M_{n}$ & $\left(\mathrm{~g} \cdot \mathrm{mol}^{-1}\right)$ & 25945 & 23115 & 27495 & 24300 & 26020 & 18510 & 17040 & 15990 & 18480 \\
\hline & $\varnothing$ & $(\mathrm{nm})$ & 101 & 99 & 111 & 126 & 131 & 112 & 109 & 133 & 137 \\
\hline & $X_{c}$ & (\%) & 39.2 & 38.6 & 33.7 & 40.9 & 56.6 & 60.9 & 28.3 & 2.2 & - \\
\hline & $\theta$ & $\left({ }^{\circ}\right)$ & 135.6 & 141.3 & 147.0 & 130.2 & 136.2 & 115.1 & 108.8 & 59.3 & 51.0 \\
\hline \multirow{5}{*}{72} & $M_{n}$ & $\left(\mathrm{~g} \cdot \mathrm{mol}^{-1}\right)$ & \multirow{5}{*}{$x$} & \multirow{5}{*}{$x$} & 19295 & 21630 & 18510 & 16820 & 12900 & 11232 & 11450 \\
\hline & $\varnothing$ & $(\mathrm{nm})$ & & & 81 & 98 & 86 & 75 & 102 & 111 & 97 \\
\hline & $T_{m}$ & $\left({ }^{\circ} \mathrm{C}\right)$ & & & 62.0 & 61.1 & 61.3 & 58.5 & 57.3 & 58.2 & - \\
\hline & $X_{c}$ & (\%) & & & 37.1 & 41.6 & 60.5 & 51.1 & 6.3 & 1.1 & - \\
\hline & $\theta$ & $\left({ }^{\circ}\right)$ & & & 133.7 & 126.5 & 120.4 & 109.2 & 60.1 & 44.2 & 0 \\
\hline \multirow{4}{*}{96} & $M_{n}$ & $\left(\mathrm{~g} \cdot \mathrm{mol}^{-1}\right)$ & \multirow{4}{*}{$x$} & \multirow{4}{*}{$x$} & \multirow{4}{*}{$x$} & \multirow{4}{*}{$x$} & \multirow{4}{*}{$x$} & 15870 & 12790 & 10874 & 10520 \\
\hline & $T_{m}$ & $\left({ }^{\circ} \mathrm{C}\right)$ & & & & & & 58.0 & 57.6 & 58.6 & - \\
\hline & $X_{c}$ & $(\%)$ & & & & & & 48.1 & 7.4 & 0.9 & - \\
\hline & $\theta$ & $\left({ }^{\circ}\right)$ & & & & & & 80.3 & 55.6 & 0 & 0 \\
\hline \multirow{5}{*}{120} & $M_{n}$ & $\left(\mathrm{~g} \cdot \mathrm{mol}^{-1}\right)$ & \multirow{5}{*}{$x$} & \multirow{5}{*}{$x$} & \multirow{5}{*}{$x$} & \multirow{5}{*}{$x$} & \multirow{5}{*}{$x$} & \multirow{5}{*}{$x$} & 6867 & 6132 & 6558 \\
\hline & $\varnothing$ & $(\mathrm{nm})$ & & & & & & & 82 & 98 & 88 \\
\hline & $T_{m}$ & $\left({ }^{\circ} \mathrm{C}\right)$ & & & & & & & 57.3 & 55.1 & - \\
\hline & $X_{c}$ & (\%) & & & & & & & 4.8 & 0.1 & - \\
\hline & $\theta$ & $\left({ }^{\circ}\right)$ & & & & & & & 0 & 0 & 0 \\
\hline
\end{tabular}


3.2. Cell adhesion and proliferation onto the PCL/Ge scaffolds as a function of the composition and the dissolution time

The cell adhesion and proliferation was assessed in the scaffolds by means of seeding HL-1 cells onto them. The cell viability was measured by MTT assay at 48 and $96 \mathrm{~h}$ after plating. As shown in Figure 2, HL-1 cells were able to adhere and proliferate over all the PCL/Ge scaffolds. No significant differences were found between the control cells and similar percentage of both PCL and Ge $-60 / 40,50 / 50,40 / 60$-, in terms of cell proliferation. In this context, excessive presence of PCL or Ge in the scaffold impaired the HL-1 cell growth.

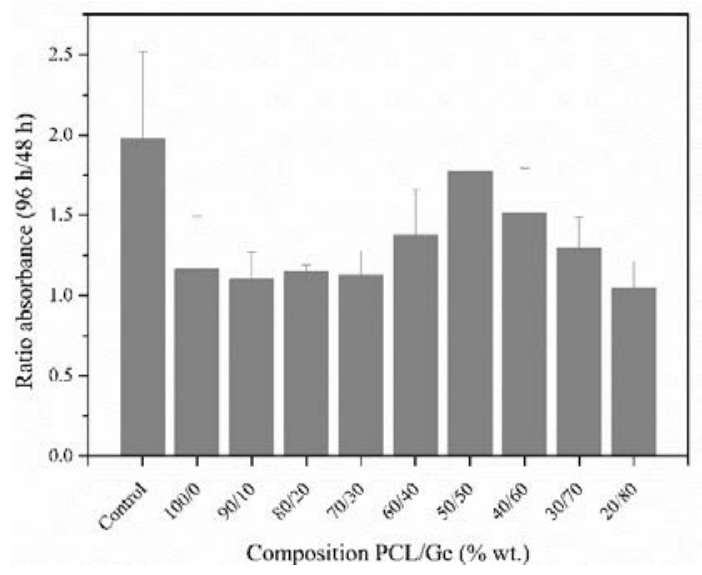

Figure 2. HL-1 cells viability as a function of the PCL/Ge scaffold composition determined by MTT assay. The graphic showed the ratio between the absorbance obtained at $550 \mathrm{~nm}$ measured at 96 and $48 \mathrm{~h}$. Scaffolds with similar percentage of PCL and Ge showed higher values of proliferation in comparison with the other scaffolds.

In order to visually corroborate the cell adhesion onto the scaffolds, cells were seeded, then fixed after 48 and $96 \mathrm{~h}$ and nuclear stained with DAPI. Similar results as obtained by MTT were found by fluorescence microscope images, as represented in Figure 3, for the different compositions in steps of $20 \% \mathrm{wt}$. Although cells were observed in all the PCL scaffolds, scaffolds with similar percentage of both PCL and Ge composition showed higher cellular adhesion than scaffolds with dissimilar composition of both compounds. 


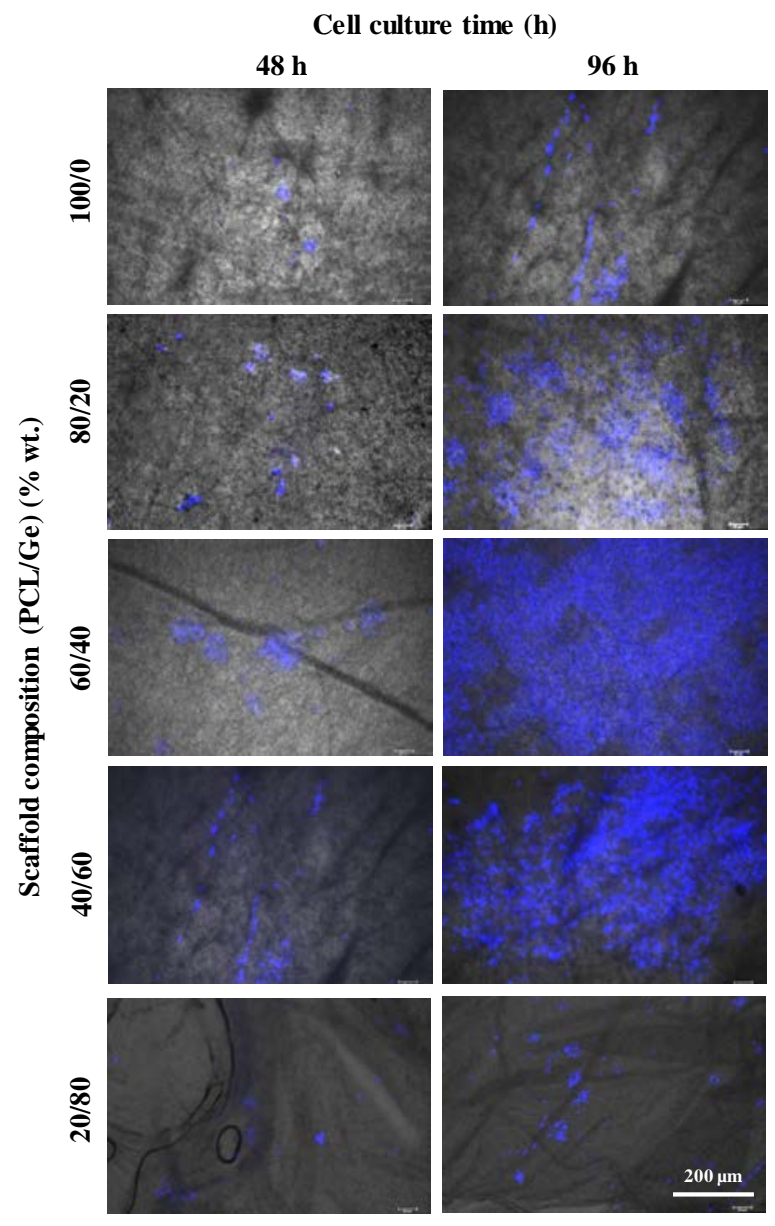

Figure 3. Representative overlapping images of nuclear staining with DAPI (blue) and transmitted light (grey) of HL-1 cells cultured on 100/0, 80/20, 60/40, 40/60 and 20/80 PCL/Ge \%wt. scaffolds for $48 \mathrm{~h}$ and $96 \mathrm{~h}$. Magnification 5×; scale bar $200 \mu \mathrm{m}$.

Along with cell survival, the cell distribution and morphology is also one of the parameters to take in account to evaluate the success of tissueengineering products as scaffolds [54], [55]. In this sense, cells were seeded onto the 60/40,50/50 and 40/60 PCL/Ge scaffolds for $96 \mathrm{~h}$, subsequently fixed, and microscopically observed by field-emission scanning electron microscopy (FE-SEM). As expected by the results obtained by MTT assay and fluorescence microscope, cells were completely attached to the scaffolds forming a continuous layer that covered the scaffold's surface regardless the composition, as shown in Figure 4. 


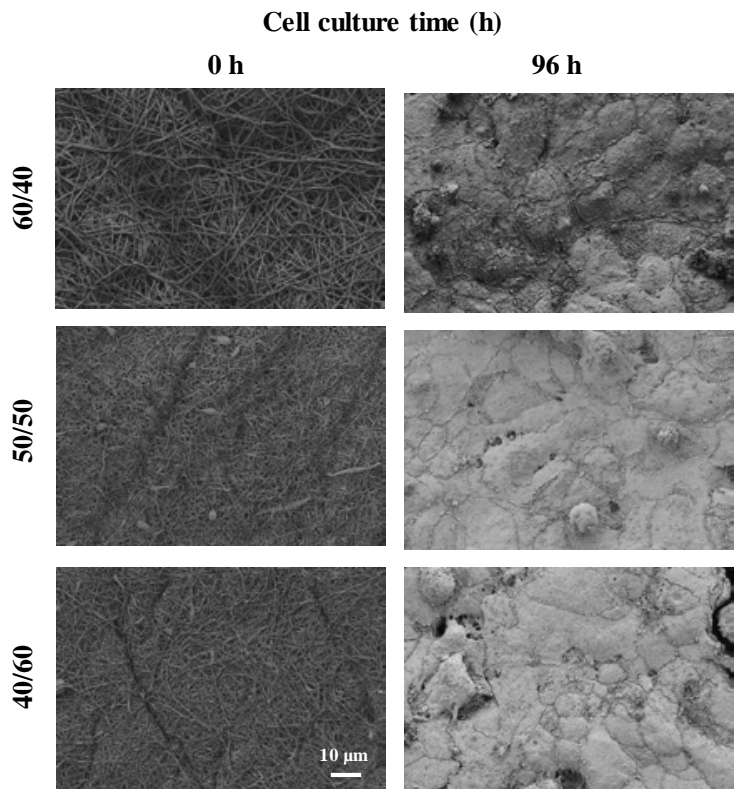

Figure 4. Scanning electronic microscope images of HL-1 cells cultured during $96 \mathrm{~h}$ in 60/40, 50/50 and 40/60 PCL/Ge scaffolds. Scaffolds surface in absence of cells (left) and scaffold's surface covered by cells (right). Magnification 1000×; scale bar $10 \mu \mathrm{m}$.

Once studied the cell adhesion and proliferation as a function of the scaffold composition, the 60/40, 50/50 and 40/60 PCL/Ge scaffolds were considered for studying the tailoring effect as a function of the dissolution time. As observed in section 3.1, the effect of the dissolution time was significantly perceived in the nanofibre diameter, the molar mass or the crystallinity, which are factors that can strongly define the cell adhesion and proliferation behaviour [33], [56]-[58]. The cell proliferation was studied in the selected compositions electrospun after 24, 48 and 72 h of dissolution time by MTT assay. Although higher dissolution times resulted into nanofibrous structures for rich-Ge compositions, they were not easy to manipulate and were not considered for further analyses. As well, the 50/50 PCL/Ge scaffold electrospun after $72 \mathrm{~h}$ of dissolution time could not be manipulated.

HL-1 cells were seeded onto the 60/40, 50/50 and 40/60 PCL/Ge scaffolds and absorbance at $550 \mathrm{~nm}$ was measured after 48 and $96 \mathrm{~h}$, which results are plotted in Figure 5. In all cases, absorbance values increased after $96 \mathrm{~h}$ of cell culture (ratio $>1$ ), indicating that cells were able to proliferate onto the scaffolds. In general, a similar tendency was perceived in all the compositions, in which proliferation decreased as dissolution time increased. Nevertheless, for the composition of 40/60 PCL/Ge, the effect 
of the dissolution time was less prominent, especially in the scaffolds electrospun after $72 \mathrm{~h}$, suggesting that the proliferation ratio was not altered by the dissolution time. The hydrolytic degradation of the PCL chains as a function of the dissolution time in the formic/acetic acid mixture may have generated new carboxyl groups in the PCL chain tails by the scission of the ester bonds [38], [41]. Low molar mass PCL chains with a marked acidic character may have decreased the $\mathrm{pH}$ in the surroundings of the scaffolds which, in turn, slightly reduced the cell proliferation. However, as the Ge content increased, this effect may have been buffered by the higher proportion of biocompatible molecules, as perceived in the 40/60 PCL/Ge scaffolds electrospun after $72 \mathrm{~h}$.

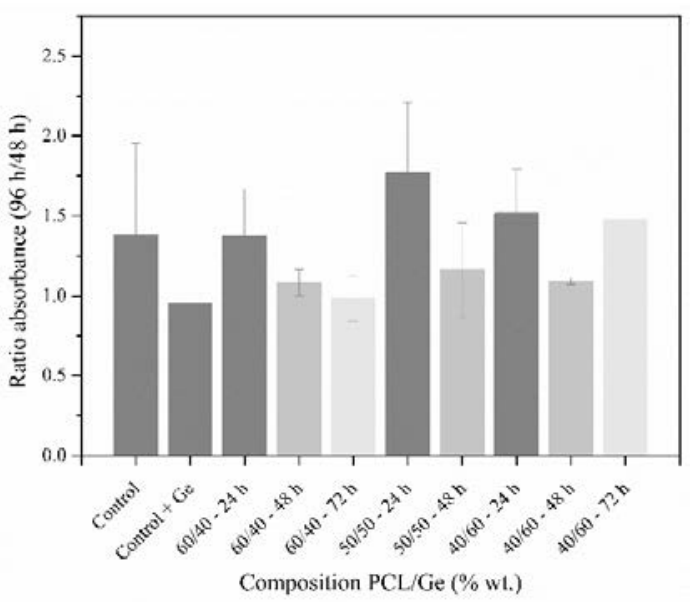

Figure 5. HL-1 cells viability for the 60/40, 50/50 and 40/60 PCL/Ge scaffold compositions as a function of the dissolution time determined by MTT assay. The graphic showed the ratio between the absorbance obtained at $550 \mathrm{~nm}$ and measured at 96 and 48 h. 60/40 and 50/50 scaffolds showed a proliferation decrease that depends on the dissolution time. Similar results were obtained for the 40/60 scaffold.

The cellular adhesion was also visually assessed in the 60/40, 50/50 and 40/60 PCL/Ge scaffolds as a function of the dissolution time, which representative images of cellular nuclear staining with DAPI are shown in Figure 6. The absorbance measured increased at $96 \mathrm{~h}$ in comparison to that measured after $48 \mathrm{~h}$ of cell culture, indicating that cells were able to proliferate onto the scaffolds. 
Cell culture time (h)

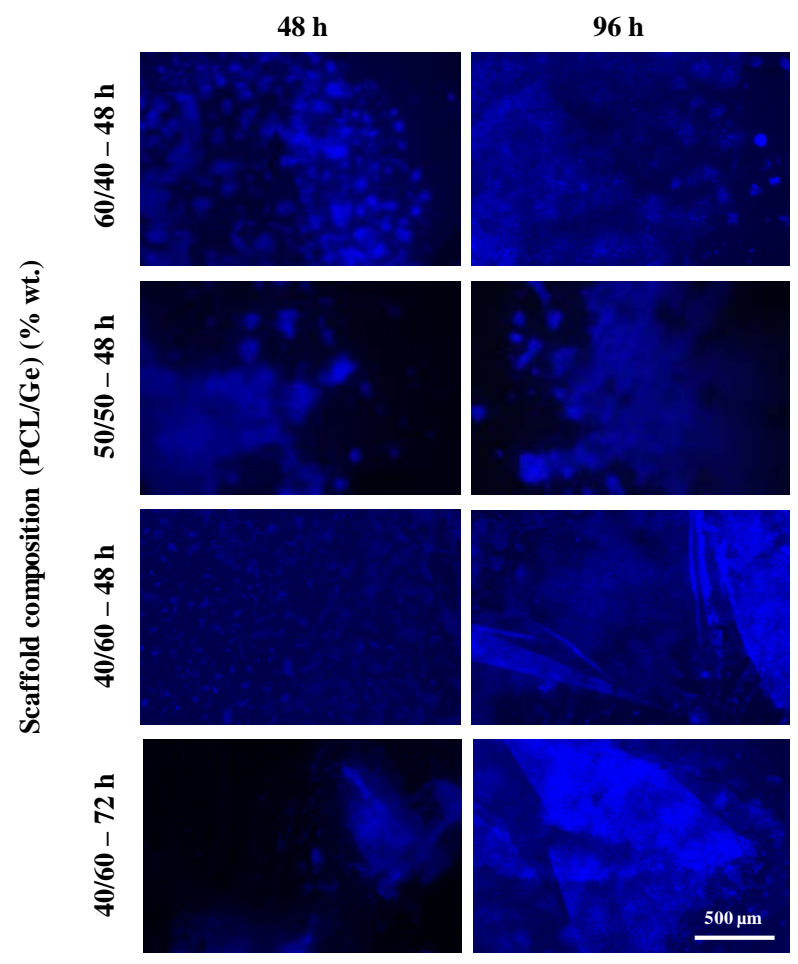

Figure 6. Representative images of cellular nuclear staining with DAPI (blue) of HL1 cells cultured on 60/40, 50/50 and 40/60 PCL/Ge scaffold compositions as a function of the dissolution time. Images were acquired with a $5 \times$ magnification. Scale bar $500 \mu \mathrm{m}$.

3.3. In vitro degradation in physiologic conditions of the 60/40, 50/50 and 40/60 PCL scaffolds as a function of the dissolution time

In this section, the in vitro degradation was assessed for the 60/40, 50/50 and the 40/60 PCL/Ge scaffolds as a function of the dissolution time after three stages of immersion -60, 120 and 180 days- in physiologic conditions (PBS, $37^{\circ} \mathrm{C}$ ). For this purpose, the changes of the mass, the surface morphology, the molar mass and the thermal properties and crystallinity of the scaffolds along immersion were evaluated.

\subsubsection{Mass}

The evaluation of the mass loss as a function of the immersion time is one the most established procedures to ascertain the degradation of nanofibrous scaffolds for biomedical applications [55]. For this reason, the mass loss evolution as a function of the composition, the dissolution time prior to the electrospinning and the immersion time in physiologic conditions was 
studied. The obtained results are plotted in Figure 7 by means of a 3D graph.
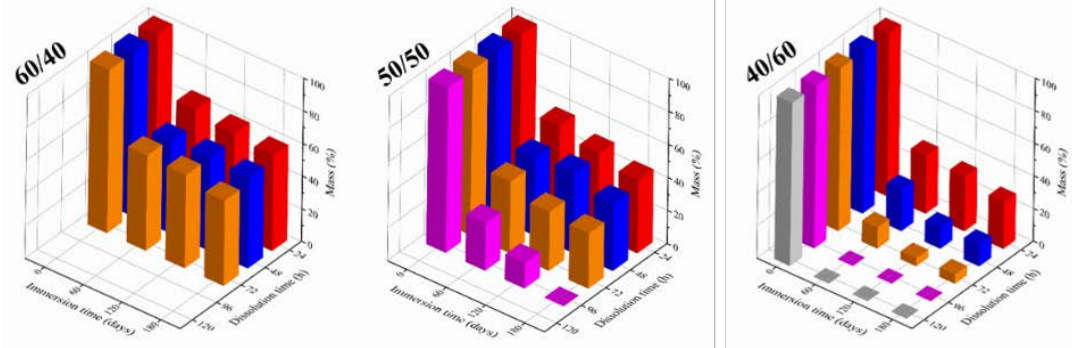

Figure 7. Mass loss evolution as a function of the immersion time for the 60/40, 50/50 and 40/60 PCL/Ge scaffolds electrospun after different dissolution time.

The effect of the composition in the scaffolds was assessed in those electrospun after $24 \mathrm{~h}$ of dissolution time. In general, the perceived mass loss after 60 days of immersion is closely related to the Ge release from the nanofibres, as it is highly soluble in aqueous environments [11]. In all the studied scaffolds, the mass reduction mainly corresponded to the loss of the percentage of Ge in the PCL/Ge blended nanofibres. Indeed, it has been reported that, the release of Ge fraction in PCL/Ge blended nanofibres may take place immediately after soaking nanofibres in physiologic conditions [59]. In particular, for high Ge content, it was found a mass loss even higher than that of the initial composition would suggest. It may be due to the release of individual PCL chains that diffused and interacted within the $\mathrm{Ge}$ molecules. Then, after the perceived mass loss in the first stage of immersion during 60 days, the remnant scaffold slightly decreased in mass after 120 and 180 days of soaking.

Regarding the effect of the dissolution time, dissimilar effect was found as a function of the scaffold composition. While the 60/40 PCL/Ge composition showed an almost identical behaviour for scaffolds electrospun after 24, 48 and 72 h of dissolution time, those of 50/50 and $40 / 60$, revealed a progressive higher degradation as dissolution time increased. As commented in previous sections, scaffolds electrospun after high dissolution time are composed of PCL chains with lower molar mass. This weakened structure would be more labile to mass loss and even resulted in complete disintegration along immersion for high dissolution time. Concretely, given the complete disintegration of the scaffolds of 40/60 PCL/Ge electrospun after 72, 96 and 120 h, they were not considered for further evaluation of the in vitro degradation in next sections. 


\subsubsection{Molar mass}

The in vitro hydrolytic degradation of the PCL fraction of the scaffolds was monitored in terms of the molar mass by means of size exclusion chromatography (SEC). This analysis brings valuable information of the size of the polymer chains and is widely considered as an essential technique to evaluate the degradation of polymeric materials [55].

The molar mass distributions for the 60/40, 50/50 and 40/60 PCL/Ge scaffolds as a function of the dissolution time for the different immersion stages are plotted in Figure 8. A slight displacement of the molar mass distributions towards lower values was perceived. The low molar mass tail slightly augmented as immersion time increased, that suggested hydrolytic degradation of the PCL polymeric chains after such long exposition time. As reported for PCL, slow hydrolytic degradation behaviour was expected [60].

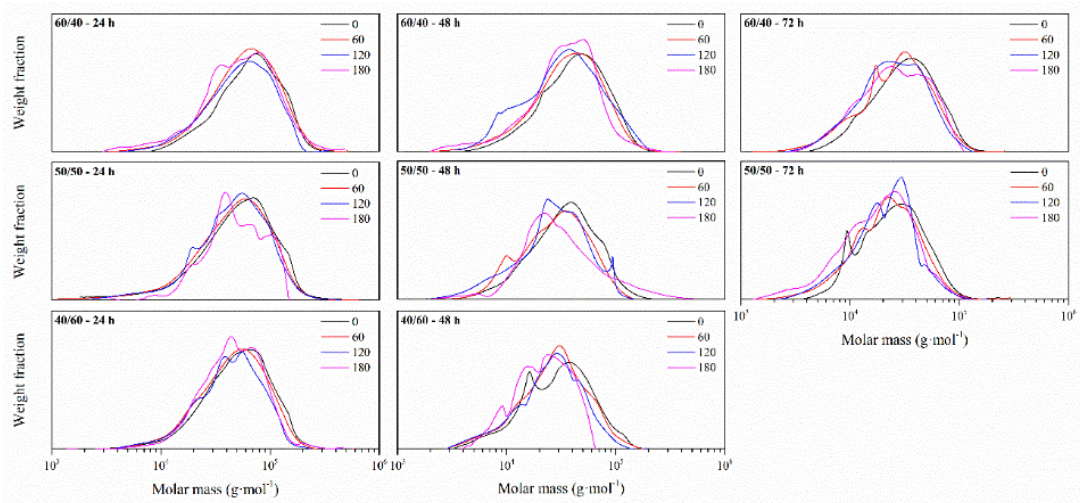

Figure 8. Molar mass distributions as a function of the immersion time for the $60 / 40$, 50/50 and 40/60 PCL/Ge scaffolds.

In order to deeply evaluate the molar mass evolution during immersion, some specific parameters such as the average molar mass in number $\left(M_{n}\right)$, the average molar mass in weight $\left(M_{w}\right)$, the polydispersity index $(P D I)$, the higher average molar mass $\left(M_{z}\right)$ the intrinsic viscosity $(I V)$ and the hydrodynamic radius $(R h)$ were assessed. The obtained results are gathered in Table 2 as a function of the composition, the dissolution time and the immersion time. Because of the hydrolytic degradation of the ester bond and the subsequent chain scission, all these parameters slightly decreased as immersion time increased. 
Table 2. Molar mass results, in terms of $M_{n}, M_{w}, P D I, M_{z}, I V$ and $R h$, as a function of the immersion time for the 60/40, 50/50 and 40/60 PCL/Ge scaffolds.

\begin{tabular}{|c|c|c|c|c|c|c|c|c|}
\hline PCL/Ge & $\begin{array}{l}\text { DT } \\
\text { (h) }\end{array}$ & $\begin{array}{c}\text { Immersion } \\
\text { (days) }\end{array}$ & $\begin{array}{c}M_{n} \\
\left(\mathrm{~g} \cdot \mathrm{mol}^{-1}\right)\end{array}$ & $\begin{array}{c}M_{w} \\
\left(\mathrm{~g} \cdot \mathrm{mol}^{-1}\right)\end{array}$ & PDI & $\begin{array}{c}M_{z} \\
\left(\mathrm{~g} \cdot \mathrm{mol}^{-1}\right)\end{array}$ & $\begin{array}{c}I V \\
\left(\mathrm{dL} \cdot \mathrm{g}^{-1}\right)\end{array}$ & $\begin{array}{c}R h \\
(\mathrm{~nm})\end{array}$ \\
\hline \multirow{12}{*}{$60 / 40$} & \multirow{4}{*}{24} & 0 & 38720 & 74230 & 1.92 & 114300 & 0.687 & 8.89 \\
\hline & & 60 & 38430 & 71380 & 1.86 & 109000 & 0.682 & 8.81 \\
\hline & & 120 & 36600 & 68770 & 1.88 & 105600 & 0.597 & 8.04 \\
\hline & & 180 & 32750 & 61150 & 1.87 & 86800 & 0.643 & 8.48 \\
\hline & \multirow{4}{*}{48} & $\mathbf{0}$ & 26020 & 49790 & 1.91 & 75700 & 0.516 & 7.09 \\
\hline & & 60 & 25840 & 45270 & 1.75 & 69670 & 0.489 & 6.75 \\
\hline & & 120 & 24820 & 44300 & 1.78 & 64010 & 0.463 & 6.48 \\
\hline & & 180 & 23650 & 42660 & 1.80 & 62730 & 0.482 & 6.72 \\
\hline & \multirow{4}{*}{72} & 0 & 18510 & 37030 & 2.00 & 57440 & 0.415 & 5.98 \\
\hline & & 60 & 15430 & 32090 & 2.08 & 49990 & 0.378 & 5.51 \\
\hline & & 120 & 17040 & 29910 & 1.76 & 45750 & 0.361 & 5.33 \\
\hline & & 180 & 15120 & 26640 & 1.76 & 36360 & 0.319 & 4.92 \\
\hline \multirow{12}{*}{$50 / 50$} & \multirow{4}{*}{24} & 0 & 34110 & 63930 & 1.87 & 98090 & 0.610 & 8.15 \\
\hline & & 60 & 31235 & 58830 & 1.88 & 88800 & 0.592 & 7.84 \\
\hline & & 120 & 30800 & 57420 & 1.86 & 86840 & 0.582 & 7.80 \\
\hline & & 180 & 27480 & 57500 & 2.09 & 79050 & 0.579 & 7.75 \\
\hline & \multirow{4}{*}{48} & 0 & 18510 & 41760 & 2.26 & 68620 & 0.445 & 6.32 \\
\hline & & 60 & 16570 & 35850 & 2.16 & 56050 & 0.393 & 5.75 \\
\hline & & 120 & 15370 & 34220 & 2.23 & 55790 & 0.388 & 5.66 \\
\hline & & 180 & 11730 & 32360 & 2.76 & 51740 & 0.378 & 5.49 \\
\hline & \multirow{4}{*}{72} & $\mathbf{0}$ & 16820 & 30130 & 1.79 & 50100 & 0.352 & 5.29 \\
\hline & & 60 & 13030 & 25920 & 1.99 & 40940 & 0.317 & 4.85 \\
\hline & & 120 & 12610 & 23680 & 1.88 & 35750 & 0.306 & 4.59 \\
\hline & & 180 & 12270 & 22890 & 1.87 & 36950 & 0.290 & 4.56 \\
\hline \multirow{8}{*}{$40 / 60$} & \multirow{4}{*}{24} & $\mathbf{0}$ & 30720 & 61780 & 2.01 & 97170 & 0.606 & 8.01 \\
\hline & & 60 & 29435 & 56390 & 1.92 & 84430 & 0.571 & 7.66 \\
\hline & & 120 & 26660 & 54980 & 2.06 & 78960 & 0.565 & 7.50 \\
\hline & & 180 & 25000 & 50830 & 2.03 & 77170 & 0.504 & 7.06 \\
\hline & \multirow{4}{*}{48} & 0 & 17040 & 54480 & 3.20 & 62480 & 0.394 & 5.90 \\
\hline & & 60 & 16810 & 32290 & 1.92 & 52970 & 0.383 & 5.51 \\
\hline & & 120 & 15030 & 29690 & 1.98 & 47470 & 0.355 & 5.24 \\
\hline & & 180 & 15230 & 26700 & 1.75 & 37670 & 0.328 & 4.97 \\
\hline
\end{tabular}

The advance of the hydrolysis promoted chain scission of the PCL molecules, as suggested by the $M_{n}, M_{w}$ and $M_{z}$ reduction. Moreover, the analysis of the $I V$ and $R h$ in the solvent used for the chromatographic analysis (THF) corroborated the hydrolytic degradation of the polymer. On the one hand, a reduction of the polymer chain length promoted lower number of molecule entanglements, which is closely related to the $I V$. On the other hand, smaller apparent size was found, associated to lower $R h$. Shorter and smaller molecules exhibited lower hydrodynamic radius as 
immersion time increased. Regarding the polydispersity index $(P D I)$, in general, it decreased along immersion, which suggested the predominant degradation of long PCL chains and resulted in more uniformity of the polymeric segment lengths. These observations were more pronounced for scaffolds with high Ge content and electrospun after high dissolution time. Feeble PCL chains seemed to be more labile to the hydrolytic degradation.

\subsubsection{Thermal properties and crystallinity}

Calorimetric analyses were conducted on the nanofibrous PCL/Ge scaffolds in order to study the changes in the fibre microstructure along immersion by the characterisation of the crystalline population, which is known to play a key role during the scaffold application [56]. The use of differential scanning calorimetry (DSC) is essential to understand the thermal properties of biopolymers subjected to degradation procedures [61]-[65]. Some parameters can bring valuable information of the degradation. The partial melting areas [62], the crystallinity degree [66], the relative partial crystallinity [67] or the balance among amorphous and rigid amorphous fractions [68] have been previously considered to evaluate the degradation behaviour of some biopolymers.

The first heating scan calorimetric thermograms are plotted in Figure $\mathbf{9}$ as a function of the immersion time. For all evaluated scaffolds, a typical semicrystalline melting behaviour of the PCL fraction was observed with a peak around $62{ }^{\circ} \mathrm{C}$ [38]. As Ge content increased, the melting peak of the PCL mowed towards lower temperatures. Moreover, a wide endotherm between 20 and $120^{\circ} \mathrm{C}$ was perceived, associated to the water release from Ge molecules [39].

As immersion time increased, the melting peak associated to the PCL moved towards higher temperatures and increased in area. These observations were corroborated from calorimetric results. The melting enthalpy $\left(\Delta h_{m}\right)$ and the melting peak temperature $\left(T_{m}\right)$ from the first heating scan were evaluated as a function of the immersion time. These parameters are closely related to the crystallinity degree $\left(X_{c}\right)$ and the lamellar thickness $\left(l_{c}\right)$, respectively. The calculated $\Delta h_{m}, X_{c}, T_{m}$ and $l_{c}$ are gathered in Table 3. Prior sections suggested that $\mathrm{Ge}$ was released in the first stages of immersion. Accordingly, results for the scaffolds after 60, 120 and 180 days of immersion were evaluated considering entirely PCL samples. 

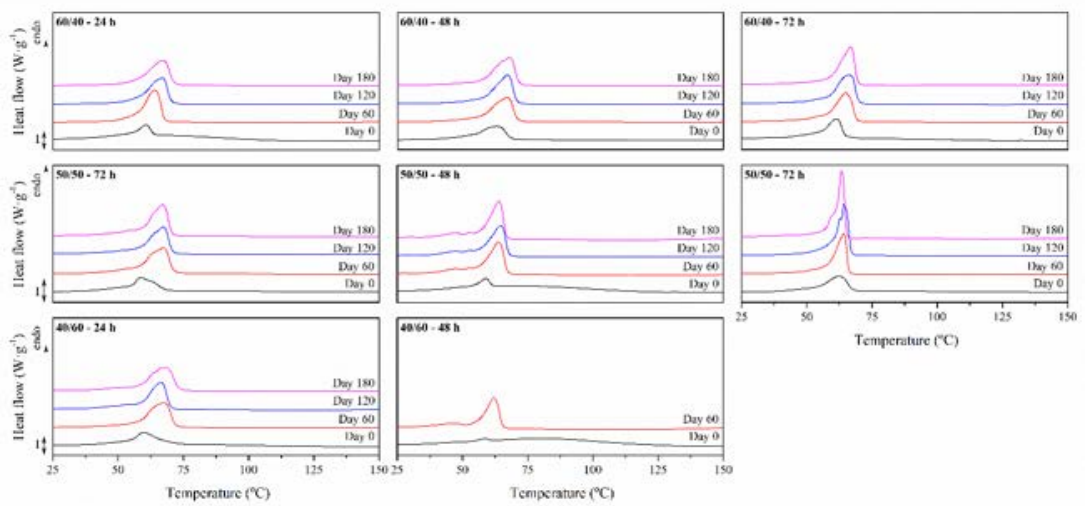

Figure 9. Calorimetric thermograms of the first heating scan as a function of the immersion time for the 60/40, 50/50 and 40/60 PCL/Ge scaffolds.

The $\Delta h_{m}$ augmented as immersion time in physiologic conditions increased, which suggested the crystallisation of the PCL molecules. Indeed, the $X_{c}$ moved from values around $30 \%$ to values around $60 \%$, which are close to the maximum crystallisation capacity of electrospun PCL-based nanofibres [69]. Along immersion, shorter macromolecular segments with enhanced mobility were more capable of forming crystalline domains than longer non-degraded segments [70]. Moreover, the plasticising effect of water absorbed by the nanofibres and the temperature above the glass transition of the PCL, may have promoted the rearrangement of polymer molecules into a crystalline structure, as suggested by the increase of the crystallinity degree [71].

Moreover, the $T_{m}$ shifted towards higher temperatures, approximately $10 \%$ increase after 180 days of immersion. Accordingly, the $l_{c}$ considerably increased from values around 35 to nearly $60 \mathrm{~nm}$, as calculated by applying the Thomson-Gibbs equation [44], [45]. This behaviour suggested that crystallisation during immersion was produced from the development and growth of the original crystalline structures.

The hydrolytically degraded scaffolds electrospun after several stages of dissolution time showed, in general, higher $X_{c}$ after 180 days of immersion. However, for high dissolution time, lower $l_{c}$ were found as dissolution time increased. Highly degraded short PCL segments rearranged and formed small crystalline domains that may have hindered and prevented the existing crystallites from growing. All these observations are in line with our previous results and literature and would support the superior hydrolytic stability of the PCL polymer [38], [59]. Moreover, amorphous fractions were found to be more labile to hydrolytic attack than crystalline domains, which confer high stability and resistance against degradation [72]. 
Table 3. Calorimetric results, in terms of the melting peak temperature $\left(T_{m}\right)$ and melting enthalpy $\left(\Delta h_{m}\right)$ from the first heating scan as a function of the immersion time for the $60 / 40,50 / 50$ and $40 / 60$ PCL/Ge scaffolds.

\begin{tabular}{|c|c|c|c|c|c|c|}
\hline PCL/Ge & $\begin{array}{l}\text { DT } \\
\text { (h) }\end{array}$ & $\begin{array}{c}\text { Immersion } \\
\text { (Days) }\end{array}$ & $\begin{array}{c}\Delta h_{m} \\
\left(J \cdot g^{-1}\right)\end{array}$ & $\begin{array}{c}X_{c} \\
(\%)\end{array}$ & $\begin{array}{c}T_{m} \\
\left({ }^{\circ} \mathrm{C}\right) \\
\end{array}$ & $\begin{array}{c}l_{c} \\
(\mathrm{~nm})\end{array}$ \\
\hline \multirow{12}{*}{$60 / 40$} & \multirow{4}{*}{24} & $\mathbf{0}$ & 30.98 & 22.56 & 60.42 & 31.04 \\
\hline & & 60 & 89.11 & 60.21 & 63.92 & 40.85 \\
\hline & & 120 & 84.42 & 57.04 & 66.74 & 54.80 \\
\hline & & 180 & 84.74 & 57.26 & 67.05 & 56.93 \\
\hline & \multirow{4}{*}{48} & $\mathbf{0}$ & 56.00 & 22.70 & 62.99 & 37.69 \\
\hline & & 60 & 85.57 & 57.82 & 67.05 & 56.93 \\
\hline & & 120 & 89.74 & 60.64 & 67.16 & 57.73 \\
\hline & & 180 & 95.39 & 64.45 & 68.01 & 64.75 \\
\hline & \multirow{4}{*}{72} & $\mathbf{0}$ & 52.90 & 21.45 & 61.42 & 33.33 \\
\hline & & 60 & 80.64 & 54.49 & 64.73 & 44.07 \\
\hline & & 120 & 86.82 & 58.66 & 66.24 & 51.67 \\
\hline & & 180 & 92.15 & 62.26 & 66.72 & 54.66 \\
\hline \multirow{12}{*}{$50 / 50$} & \multirow{4}{*}{24} & $\mathbf{0}$ & 52.79 & 17.83 & 58.38 & 27.23 \\
\hline & & 60 & 95.18 & 64.31 & 67.33 & 59.01 \\
\hline & & 120 & 86.69 & 58.57 & 67.36 & 59.24 \\
\hline & & 180 & 97.79 & 66.07 & 67.02 & 56.72 \\
\hline & \multirow{4}{*}{48} & 0 & 21.00 & 7.09 & 58.75 & 27.85 \\
\hline & & 60 & 92.38 & 62.42 & 63.75 & 40.23 \\
\hline & & 120 & 91.81 & 62.03 & 64.61 & 43.56 \\
\hline & & 180 & 96.05 & 64.90 & 63.94 & 40.92 \\
\hline & \multirow{4}{*}{72} & $\mathbf{0}$ & 54.87 & 18.54 & 62.25 & 35.50 \\
\hline & & 60 & 84.43 & 57.05 & 64.24 & 42.06 \\
\hline & & 120 & 101.13 & 68.33 & 64.30 & 42.30 \\
\hline & & 180 & 102.01 & 68.93 & 63.29 & 38.65 \\
\hline \multirow{8}{*}{$40 / 60$} & \multirow{4}{*}{24} & $\mathbf{0}$ & 52.69 & 14.84 & 59.72 & 29.62 \\
\hline & & 60 & 86.61 & 58.52 & 67.52 & 60.51 \\
\hline & & 120 & 84.24 & 56.92 & 66.42 & 52.75 \\
\hline & & 180 & 89.42 & 60.42 & 68.29 & 67.45 \\
\hline & \multirow{4}{*}{48} & 0 & 3.69 & 1.00 & 58.46 & 27.36 \\
\hline & & 60 & 78.74 & 53.20 & 61.79 & 34.26 \\
\hline & & 120 & - & - & - & - \\
\hline & & 180 & - & - & - & - \\
\hline
\end{tabular}




\subsubsection{Surface morphology}

The assessment of the surface morphology along immersion can visually represent the changes in the nanofibrous structure of the scaffolds. Degradation symptoms such as fibre conglutination, fibre breakage or erosion can be perceived from electronic micrographs as obtained by means of field-emission scanning electron microscopy (FE-SEM) [55]. Surface electronic micrographs of the of the $60 / 40,50 / 50$ and $40 / 60$ $\mathrm{PCL} / \mathrm{Ge}$ nanofibrous scaffolds as a function of the composition, the dissolution time prior to electrospinning and the immersion time in physiologic conditions are gathered in Figure 10. As well, the average fibre diameter $(\varnothing)$ of the scaffolds is included below the micrographs.

In general, the scaffolds retained the nanofibrous morphology along immersion. Although the fibre diameter slightly increased as a function of the immersion time, the porous structure remained almost unaffected for the scaffolds prepared after 24 of dissolution time. Even though the mass loss perceived in previous sections ascribed to the release of Ge would suggest a reduction in the diameters of the nanofibres, the fibres slightly swelled along immersion due to the penetration of the PBS solution.

However, if dissolution time (48 and $72 \mathrm{~h}$ ) is taken into account, the results revealed a slightly different behaviour. As the PCL chains were more hydrolysed during electrospinning, the entanglement capability of these molecules was considerably reduced, which resulted into a less compact structure. Accordingly, immersion in physiologic conditions resulted in higher swelling degree, reaching almost fibre conglutination in the case of scaffolds electrospun after $72 \mathrm{~h}$. From this observation, it can be deduced that the degradation pattern of these scaffolds would be a first stage of highly swelling degree along immersion until fibre conglutination and subsequent bulk disintegration due to extended hydrolysis of the ester bond of PCL molecules. 


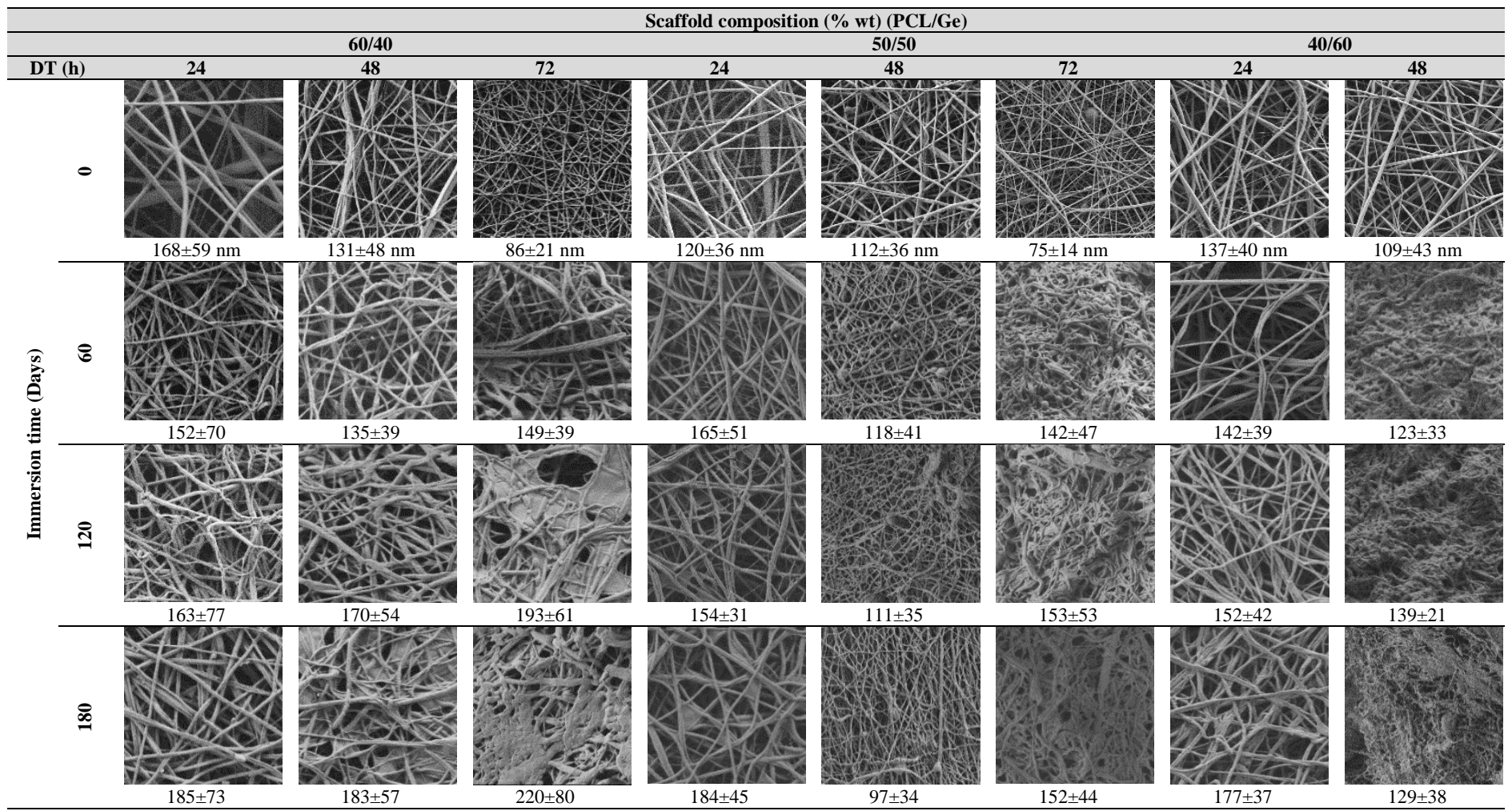

Figure 10. Surface micrographs (10 000×, scale bar $2 \mu \mathrm{m})$ as a function of the scaffold composition, the dissolution time (DT) and the immersion time in physiologic conditions (PBS, $37^{\circ} \mathrm{C}$ ). 
3.4. Biocompatibility of the 40/60 PCL/Ge scaffold as a function of the dissolution time

Once studied the cell adhesion and proliferation and the in vitro degradation in physiologic conditions for the different compositions, the scaffolds with the 40/60 PCL/Ge composition were selected for further analyses. This composition showed good cell proliferation and showed a progressive degradation behaviour as a function of the dissolution time. Due to these promising observations, the inflammatory response and the in vivo subcutaneous implantation was studied in the 40/60 PCL/Ge scaffolds electrospun after 24, 48 and $72 \mathrm{~h}$ of dissolution time.

\subsubsection{Inflammatory response}

In order to examine the acute inflammatory response induction, the quantification of gene expression levels of IL-1 $\beta$, IL-6, IL-10 and TNF was performed by means of a pyrogen test after being in contact during $5 \mathrm{~h}$ with the scaffolds. For this purpose, PBMNCs isolated from four different patients were incubated with PHB scaffolds as positive control, pure PCL and 40/60 PCL/Ge scaffolds electrospun after 24, 48 and $72 \mathrm{~h}$ of dissolution time. The obtained response in terms of fold change for the different expression of the cited proteins are plotted in Figure 11.

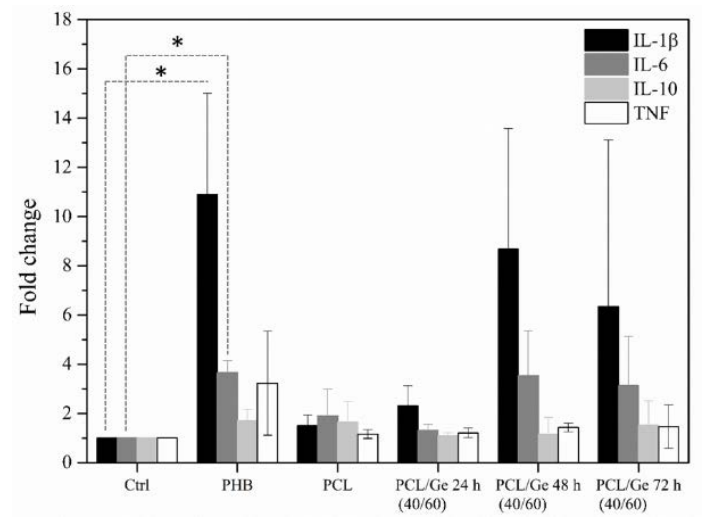

Figure 11. Quantification of gene expression levels of IL-1 $\beta$, IL-6, IL-10 and TNF of PBMNCs incubated with no scaffolds (Ctrl), PHB (positive control), pure PCL and the 40/60 PCL/Ge scaffolds electrospun after 24, 48 and $72 \mathrm{~h}$ of dissolution time.

Data are represented as mean \pm SD (standard deviation) of four independent experiments performed in triplicates, ${ }^{*} p<0.05$.

Results showed that the pure PCL and the 40/60 PCL/Ge $24 \mathrm{~h}$ induced similar expression levels in all the cytokines analysed and no significant differences were found between these two scaffolds and the control cells. However, the 40/60 PCL/Ge scaffolds prepared after 48 and $72 \mathrm{~h}$ of dissolution time induced similar cytokine expression levels than the PHB scaffold, which was used as a positive control given its well-known IL-1 $\beta$ 
and IL-6 expression in PBMNCs [49]. This effect may be ascribed to the increase in the carboxyl groups as a function of dissolution time that may reduce the $\mathrm{pH}$ in the surrounding of the scaffolds and could promote the increased expression of both cytokines. Nevertheless, this inflammatory reaction is not necessarily adverse, and needs to be further studied after longer time of interaction. For this reason, the in vivo implantation analysis was assessed in the next section.

\subsubsection{In vivo implantation}

As well as for the study of the inflammatory response, the 40/60 PCL/Ge scaffolds electrospun after 24, 48 and $72 \mathrm{~h}$ of dissolution time were considered to assess their in vivo implantation behaviour. Moreover, the pure PCL scaffold was also analysed as a reference to assess the effect of the gelatin during implantation. Therefore, the selected scaffolds were included in a subdermical pocket of healthy mice and evaluated after 15 days of implantation. Skin sections were obtained and the inflammation process along with the scaffold morphology were analysed by $\mathrm{H} / \mathrm{E}$ staining, which resulting images are shown in Figure 12.
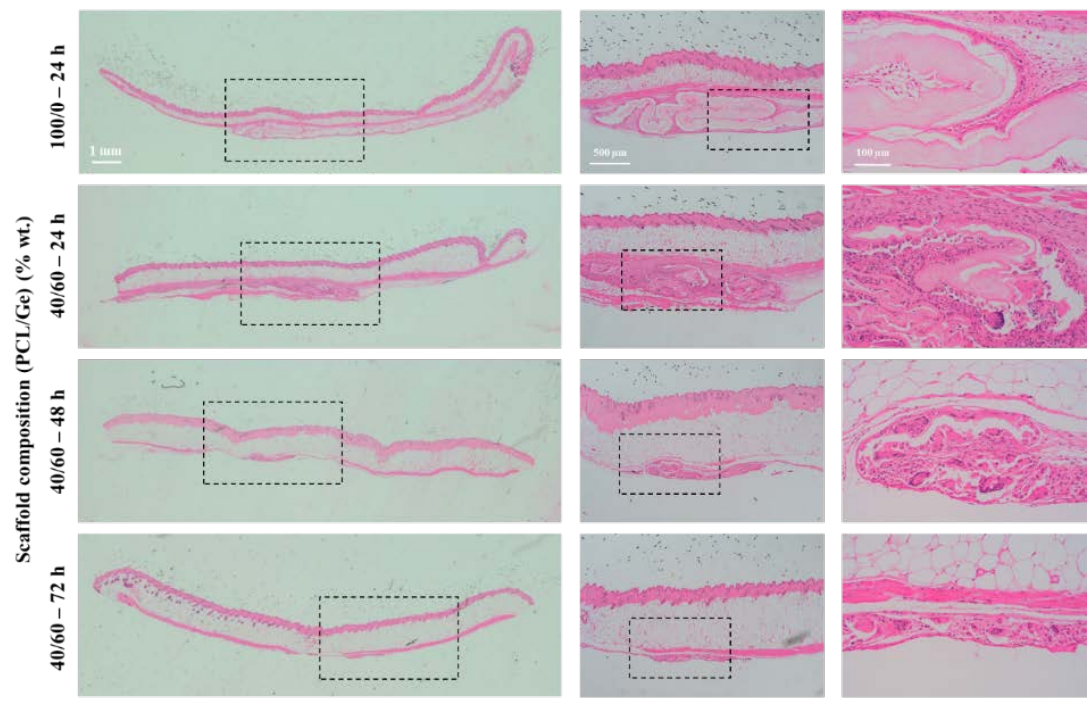

Figure 12. Representative images of the in vivo degradation of the scaffolds of pure PCL and 40/60 PCL/Ge electrospun after 24, 48 and $72 \mathrm{~h}$ of dissolution time, grafted in the dorsal region of C57BL6J mice. Skin sections taken from the grafted area after 15 days of implantation and stained with $\mathrm{H} / \mathrm{E}$. Black boxes indicate the amplified regions. Images were acquired with no magnification (left), magnification $4 \times$ (middle) and $20 \times$ (right). Scale bars are $1 \mathrm{~mm}, 100 \mu \mathrm{m}$ and $500 \mu \mathrm{m}$ from left to right, respectively.

In general, no chronic inflammation process was observed in any of the scaffolds after 15 days of implantation. The images of the pure PCL 
scaffold clearly showed that it remained almost unaffected, and subsequently it can be inferred that the complete degradation and assimilation of this scaffold would last more than 15 days [73].

Regarding the influence of the dissolution time for the 40/60 PCL/Ge scaffolds, noteworthy differences were observed. Whilst scaffold traces were visible at dissolution time of $24 \mathrm{~h}$, the scaffolds electrospun after 48 and $72 \mathrm{~h}$ almost disappeared during the 15 days of implantation. The perceived progressive behaviour as a function of the dissolution time, and the partial or complete assimilation during implantation confirmed and corroborated the tailoring strategy to obtain highly biocompatible scaffolds with a controlled degradation rate when implanted in vivo.

\section{Conclusions}

Polycaprolactone (PCL) and gelatin (Ge) blended nanofibrous scaffolds were obtained by electrospinning as a function the PCL/Ge composition and the dissolution time in the 1:1 formic/acetic acid solvent. The influence of the dissolution time in the hydrolytic acid solvent was found to play a key role in the resultant physicochemical properties and morphology of the electrospun scaffolds. The hydrolytic degradation during dissolution prior to electrospinning in the formic/acetic acid mixture reduced the molar mass of the PCL fraction, increased the crystallinity degree and slightly lowered the lamellar thickness. The increase in the Ge content in the blend resulted in higher electrospinning viability for high dissolution time.

The cell adhesion and proliferation was found to be strongly influenced by the PCL/Ge composition. In this context, the 60/40, 50/50 and 40/60 PCL/Ge compositions were found to be the most cell-compatible scaffolds, as corroborated by the MTT assay, the fluorescence analysis and the cellular layer covering the scaffold surface perceived in the microscopy analyses. As well, the effect of the dissolution time slightly decreased the cell-compatibility, being less prominent for the 40/60 PCL/Ge scaffolds.

The in vitro degradation in physiologic conditions of the 60/40, 50/50 and 40/60 PCL/Ge scaffolds revealed a progressive behaviour as a function of the composition and dissolution time. The release of the Ge fraction of the scaffolds during immersion was perceived in all cases. While the PCL molar mass was barely affected, the crystallinity degree and the lamellar thickness were developed during immersion. As well, scaffolds electrospun after high dissolution time revealed a weakened structure, more labile to degradation in physiologic conditions. This effect was more significant for the scaffold containing higher percentage of Ge, i.e. the 40/60 PCL/Ge composition.

The biocompatibility of the tailored 40/60 PCL/Ge scaffolds was corroborated by means of the pyrogen test, in which scaffolds obtained 
after $24 \mathrm{~h}$ of dissolution time were found to be non-inflammatory. Although the scaffolds electrospun after 48 and $72 \mathrm{~h}$ of dissolution time promoted an increase of the cytokines IL- $1 \beta$ and IL-6 expression levels, they were found to be similar to those of PHB in PBMNCs, which are considered suitable. This effect may be ascribed to the increase in the carboxyl groups as a function of dissolution time that may reduce the $\mathrm{pH}$ in the surrounding of the scaffolds and could promote the increased expression of both cytokines. Nevertheless, this was not a chronic effect, as no inflammatory response was observed after the 15 day subcutaneous in vivo implantation in mice. As well, the perceived progressive behaviour as a function of the dissolution time, and the partial or complete assimilation during implantation confirmed and corroborated the tailoring strategy to obtain highly biocompatible scaffolds with a controlled degradation rate when implanted in vivo.

\section{Acknowledgements}

The Spanish Ministry of Economy and Competitiveness is acknowledged for the projects POLYCELL (ENE2014-53734-C2-1-R) and UPOV13-3E1947. The Spanish Ministry of Education, Culture and Sports is thanked for the pre-doctoral FPU grant of O. Gil-Castell (FPU13/01916) and the scholarship for a research stage of O. Gil-Castell in Kungliga Tekniska Högskolan. Generalitat Valenciana is thanked for the APOSTD/2014/041 for J.D. Badia. Universitat Politècnica de València (UPV) and IIS LaFe are acknowledged for the SCARDIO project (2014_0460_CRC_COLAB_UPV-LAFE_SEPULVEDA). D. Castellano and I. Ontoria-Oviedo thanked RESOLTEX (Ministry of Economy, Industry and Competitiveness RETOS, RTC-2015-4185-1) and P. Sepúlveda acknowlewdges ISCIII for I3SNS Program.

\section{References}

[1] Z. Ma, M. Kotaki, R. Inai, and S. Ramakrishna, "Potential of nanofiber matrix as tissueengineering scaffolds,” Tissue Eng., vol. 11, no. 1, pp. 101-109, 2005.

[2] A. Haider, S. Haider, and I. K. Kang, “A comprehensive review summarizing the effect of electrospinning parameters and potential applications of nanofibers in biomedical and biotechnology,” Arab. J. Chem., vol. In press, 2015.

[3] S. Agarwal, J. H. Wendorff, and A. Greiner, "Use of electrospinning technique for biomedical applications,” Polymer (Guildf)., vol. 49, no. 26, pp. 5603-5621, 2008.

[4] D. I. Braghirolli, D. Steffens, and P. Pranke, "Electrospinning for regenerative medicine: a review of the main topics,” Drug Discov. Today, vol. 19, no. 6, pp. 743-753, 2014.

[5] B. Dhandayuthapani, Y. Yoshida, T. Maekawa, and D. S. Kumar, "Polymeric scaffolds in tissue engineering application: A review,” Int. J. Polym. Sci., vol. 2011, no. ii, 2011.

[6] S. Stratton, N. B. Shelke, K. Hoshino, S. Rudraiah, and S. G. Kumbar, "Bioactive polymeric scaffolds for tissue engineering,” Bioact. Mater., vol. 1, no. 2, pp. 93-108, Dec. 2016.

[7] D. M. Yoon and J. P. Fisher, "Natural and Synthetic Polymeric Scaffolds," in Biomedical Materials, R. Narayan, Ed. Springer, 2009, pp. 415-442.

[8] A. Asti and L. Gioglio, "Natural and synthetic biodegradable polymers: Different scaffolds for cell expansion and tissue formation," International Journal of Artificial Organs, vol. 37, no. 3. pp. 187-205, Mar-2014. 
[9] W. Ji, Y. Sun, F. Yang, J. J. J. P. van den Beucken, M. Fan, Z. Chen, and J. A. Jansen, "Bioactive electrospun scaffolds delivering growth factors and genes for tissue engineering applications.,” Pharm. Res., vol. 28, no. 6, pp. 1259-72, Jun. 2011.

[10] X. He, B. Feng, C. Huang, H. Wang, Y. Ge, R. Hu, M. Yin, Z. Xu, W. Wang, W. Fu, and J. Zheng, "Electrospun gelatin/polycaprolactone nanofibrous membranes combined with a coculture of bone marrow stromal cells and chondrocytes for cartilage engineering,” Int. J. Nanomedicine, vol. 10, pp. 2089-2099, 2015.

[11] Q. Jiang, H. Xu, S. Cai, and Y. Yang, "Ultrafine fibrous gelatin scaffolds with deep cell infiltration mimicking 3D ECMs for soft tissue repair,” J. Mater. Sci. Mater. Med., vol. 25, no. 7, pp. 1789-1800, Jul. 2014.

[12] E. J. Chong, T. T. Phan, I. J. Lim, Y. Z. Zhang, B. H. Bay, S. Ramakrishna, and C. T. Lim, "Evaluation of electrospun PCL/gelatin nanofibrous scaffold for wound healing and layered dermal reconstitution,” Acta Biomater., vol. 3, no. 3 SPEC. ISS., pp. 321330, May 2007.

[13] H. M. Powell and S. T. Boyce, "Engineered Human Skin Fabricated Using Electrospun Collagen-PCL Blends: Morphogenesis and Mechanical Properties,” Tissue Eng. Part A, vol. 15, no. 8, pp. 2177-2187, Aug. 2009.

[14] R. S. Tığglı, N. M. Kazaroğlu, B. Mavış, and M. Gümüşderelioğlu, "Cellular Behavior on Epidermal Growth Factor (EGF)-Immobilized PCL/Gelatin Nanofibrous Scaffolds,” J. Biomater. Sci. Polym. Ed., vol. 22, no. 1-3, pp. 207-223, Jan. 2011.

[15] L. H. Chong, M. M. Lim, and N. Sultana, "Fabrication and Evaluation of Polycaprolactone / Gelatin-Based Electrospun Nanofibers with Antibacterial Properties,” vol. 2015, 2015.

[16] H. Duan, B. Feng, X. Guo, J. Wang, L. Zhao, G. Zhou, W. Liu, Y. Cao, and W. J. Zhang, "Engineering of epidermis skin grafts using electrospun nanofibrous gelatin/polycaprolactone membranes,” Int. J. Nanomedicine, vol. 8, no. November, pp. 2077-2084, 2013.

[17] S. Gautam, C.-F. Chou, A. K. Dinda, P. D. Potdar, and N. C. Mishra, "Surface modification of nanofibrous polycaprolactone/gelatin composite scaffold by collagen type I grafting for skin tissue engineering,” Mater. Sci. Eng. C, vol. 34, pp. 402-409, 2014.

[18] M. S. Kim, I. Jun, Y. M. Shin, W. Jang, S. I. Kim, and H. Shin, "The Development of Genipin-Crosslinked Poly(caprolactone) (PCL)/Gelatin Nanofibers for Tissue Engineering Applications,” Macromol. Biosci., vol. 10, no. 1, pp. 91-100, Jan. 2010.

[19] S. Heydarkhan-Hagvall, K. Schenke-Layland, A. P. Dhanasopon, F. Rofail, H. Smith, B. M. Wu, R. Shemin, R. E. Beygui, and W. R. MacLellan, "Three-dimensional electrospun ECM-based hybrid scaffolds for cardiovascular tissue engineering," Biomaterials, vol. 29, no. 19, pp. 2907-2914, Jul. 2008.

[20] S. Pok, J. D. Myers, S. V. Madihally, and J. G. Jacot, "A multilayered scaffold of a chitosan and gelatin hydrogel supported by a PCL core for cardiac tissue engineering," Acta Biomater., vol. 9, no. 3, pp. 5630-5642, Mar. 2013.

[21] L. Ghasemi-Mobarakeh, M. P. Prabhakaran, M. Morshed, M.-H. Nasr-Esfahani, and S. Ramakrishna, "Electrospun poly( $\varepsilon$-caprolactone)/gelatin nanofibrous scaffolds for nerve tissue engineering,” Biomaterials, vol. 29, no. 34, pp. 4532-4539, Dec. 2008.

[22] M. A. Alvarez-Perez, V. Guarino, V. Cirillo, and L. Ambrosio, "Influence of Gelatin Cues in PCL Electrospun Membranes on Nerve Outgrowth,” Biomacromolecules, vol. 11, no. 9, pp. 2238-2246, Sep. 2010.

[23] D. Gupta, J. Venugopal, M. P. Prabhakaran, V. R. G. Dev, S. Low, A. T. Choon, and S. Ramakrishna, "Aligned and random nanofibrous substrate for the in vitro culture of Schwann cells for neural tissue engineering,” Acta Biomater., vol. 5, no. 7, pp. 25602569, 2009.

[24] Y. Zhang, H. Ouyang, C. T. Lim, S. Ramakrishna, and Z.-M. Huang, "Electrospinning of gelatin fibers and gelatin/PCL composite fibrous scaffolds," J. Biomed. Mater. Res., vol. 72B, no. 1, pp. 156-165, Jan. 2005.

[25] I. Rajzer, E. Menaszek, R. Kwiatkowski, J. A. Planell, and O. Castano, "Electrospun gelatin/poly(E-caprolactone) fibrous scaffold modified with calcium phosphate for bone tissue engineering,” Mater. Sci. Eng. C, vol. 44, pp. 183-190, 2014.

[26] M. A. Alvarez Perez, V. Guarino, V. Cirillo, and L. Ambrosio, "In vitro mineralization 
and bone osteogenesis in poly( $\varepsilon$-caprolactone)/gelatin nanofibers,” J. Biomed. Mater. Res. Part A, vol. 100A, no. 11, pp. 3008-3019, Nov. 2012.

[27] A. K. Jaiswal, H. Chhabra, V. P. Soni, and J. R. Bellare, "Enhanced mechanical strength and biocompatibility of electrospun polycaprolactone-gelatin scaffold with surface deposited nano-hydroxyapatite,” Mater. Sci. Eng. C, vol. 33, no. 4, pp. 2376-2385, 2013.

[28] J. Huang, C. He, X. Liu, J. Xu, C. S. S. Tay, and S. Y. Chow, “Organic-inorganic nanocomposites from cubic silsesquioxane epoxides: direct characterization of interphase, and thermomechanical properties," Polymer (Guildf)., vol. 46, no. 18, pp. 7018-7027, Aug. 2005.

[29] R. Zheng, H. Duan, J. Xue, Y. Y. Liu, B. Feng, S. Zhao, Y. Zhu, Y. Y. Liu, A. He, W. Zhang, W. Liu, Y. Cao, and G. Zhou, "The influence of Gelatin/PCL ratio and 3-D construct shape of electrospun membranes on cartilage regeneration,” Biomaterials, vol. 35, no. 1, pp. 152-164, Jan. 2014.

[30] A. Arinstein, M. Burman, O. Gendelman, and E. Zussman, "Effect of supramolecular structure on polymer nanofibre elasticity,” Nat. Nanotechnol., vol. 2, no. 1, pp. 59-62, Jan. 2007.

[31] H. Cai, V. Dave, R. A. Gross, and S. P. McCarthy, "Effects of physical aging, crystallinity, and orientation on the enzymatic degradation of poly(lactic acid)," $J$. Polym. Sci. Part B Polym. Phys., vol. 34, no. 16, pp. 2701-2708, Nov. 1996.

[32] J. Gaumer, A. Prasad, D. Lee, and J. Lannutti, "Structure-function relationships and source-to-ground distance in electrospun polycaprolactone,” Acta Biomater., vol. 5, no. 5, pp. 1552-1561, Jun. 2009.

[33] V. Guarino, V. Cirillo, P. Taddei, M. A. Alvarez-Perez, and L. Ambrosio, “Tuning Size Scale and Crystallinity of PCL Electrospun Fibres via Solvent Permittivity to Address hMSC Response,” Macromol. Biosci., vol. 11, no. 12, pp. 1694-1705, Dec. 2011.

[34] M. J. Jenkins and K. L. Harrison, "The effect of crystalline morphology on the degradation of polycaprolactone in a solution of phosphate buffer and lipase,” Polym. Adv. Technol., vol. 19, no. 12, pp. 1901-1906, Dec. 2008.

[35] J. L. Lowery, N. Datta, and G. C. Rutledge, "Effect of fiber diameter, pore size and seeding method on growth of human dermal fibroblasts in electrospun poly $(\varepsilon$ caprolactone) fibrous mats,” Biomaterials, vol. 31, no. 3, pp. 491-504, Jan. 2010.

[36] H.-J. Sung, C. Meredith, C. Johnson, and Z. S. Galis, "The effect of scaffold degradation rate on three-dimensional cell growth and angiogenesis,” Biomaterials, vol. 25, no. 26, pp. 5735-5742, Nov. 2004.

[37] E. Alsberg, H. J. Kong, Y. Hirano, M. K. Smith, A. Albeiruti, and D. J. Mooney, "Regulating Bone Formation via Controlled Scaffold Degradation,” J. Dent. Res., vol. 82, no. 11, pp. 903-908, Nov. 2003.

[38] O. Gil-Castell, J. D. D. Badia, E. Strömberg, S. Karlsson, and A. Ribes-Greus, "Effect of the dissolution time into an acid hydrolytic solvent to tailor electrospun nanofibrous polycaprolactone scaffolds,” Eur. Polym. J., vol. 87, pp. 174-187, 2017.

[39] P. Denis, J. Dulnik, and P. Sajkiewicz, "Electrospinning and Structure of Bicomponent Polycaprolactone/Gelatin Nanofibers Obtained Using Alternative Solvent System,” Int. J. Polym. Mater. Polym. Biomater., vol. 64, no. 7, pp. 354-364, 2014.

[40] L. Van der Schueren, B. De Schoenmaker, Ö. I. Kalaoglu, and K. De Clerck, “An alternative solvent system for the steady state electrospinning of polycaprolactone,” Eur. Polym. J., vol. 47, no. 6, pp. 1256-1263, Jun. 2011.

[41] N. Lavielle, A. M. Popa, M. De Geus, A. Hébraud, G. Schlatter, L. Thöny-Meyer, and R. M. Rossi, "Controlled formation of poly( $\varepsilon$-caprolactone) ultrathin electrospun nanofibers in a hydrolytic degradation-assisted process,” Eur. Polym. J., vol. 49, no. 6, pp. 1331-1336, Jun. 2013.

[42] O. Gil-Castell, J. D. D. Badia, and A. Ribes-Greus, "Tailored electrospun nanofibrous polycaprolactone/gelatin scaffolds into an acid hydrolytic solvent system,” Eur. Polym. J., vol. 101, pp. 273-281, Apr. 2018.

[43] J. E. Mark, Properties of Polymers Handbook. Springer, 2007.

[44] J. I. Lauritzen and J. D. Hoffman, "Formation of Polymer Crystals with Folded Chains from Dilute Solution,” J. Chem. Phys., vol. 31, no. 6, pp. 1680-1681, 1959.

[45] J. D. Hoffman and J. I. Lauritzen, "Crystallization of Bulk Polymers With Chain 
Folding : Theory of Growth of Lamellar Spherulites," J. Res. Natl. Bur. Stand. - A. Phys. Chem., vol. 65, no. August, p. 1961, 1961.

[46] Y. Suzuki, H. Duran, W. Akram, M. Steinhart, G. Floudas, and H.-J. Butt, "Multiple nucleation events and local dynamics of poly( $\varepsilon$-caprolactone) (PCL) confined to nanoporous alumina," Soft Matter, vol. 9, no. 38, p. 9189, 2013.

[47] "ISO 10993-13. Biological evaluation of medical devices.” 2010.

[48] A. K. Pathan, J. Bond, and R. E. Gaskin, "Sample preparation for SEM of plant surfaces,” Mater. Today, vol. 12, no. SUPPL., pp. 32-43, 2009.

[49] D. Castellano, M. Blanes, B. Marco, I. Cerrada, A. Ruiz-Saurí, B. Pelacho, M. Araña, J. A. Montero, V. Cambra, F. Prosper, and P. Sepúlveda, “A Comparison of Electrospun Polymers Reveals Poly(3-Hydroxybutyrate) Fiber as a Superior Scaffold for Cardiac Repair,” Stem Cells Dev., vol. 23, no. 13, pp. 1479-1490, Jul. 2014.

[50] D. Castellano, A. Sanchis, M. Blanes, M. D. M. D. Pérez del Caz, A. Ruiz-Saurí, M. Piquer-Gil, B. Pelacho, B. Marco, N. Garcia, I. Ontoria-Oviedo, V. Cambra, F. Prosper, and P. Sepúlveda, "Electrospun poly(hydroxybutyrate) scaffolds promote engraftment of human skin equivalents via macrophage M2 polarization and angiogenesis,” J. Tissue Eng. Regen. Med., vol. 12, no. 2, pp. e983-e994, Jan. 2017.

[51] L. A. Smith and P. X. Ma, "Nano-fibrous scaffolds for tissue engineering," Colloids Surfaces B Biointerfaces, vol. 39, no. 3, pp. 125-131, 2004.

[52] W. Fu, Z. Liu, B. Feng, R. Hu, X. He, H. Wang, M. Yin, H. Huang, H. Zhang, and W. Wang, "Electrospun gelatin/PCL and collagen/PLCL scaffolds for vascular tissue engineering,” Int. J. Nanomedicine, vol. 9, no. 1, pp. 2335-2344, 2014.

[53] F. Khan, M. Tanaka, and S. R. Ahmad, "Fabrication of polymeric biomaterials: a strategy for tissue engineering and medical devices,” J. Mater. Chem. B, vol. 3, no. 42, pp. 8224-8249, Oct. 2015.

[54] P. Thevenot, A. Nair, J. Dey, J. Yang, and L. Tang, "Method to analyze threedimensional cell distribution and infiltration in degradable scaffolds.," Tissue Eng. Part C. Methods, vol. 14, no. 4, pp. 319-31, Dec. 2008.

[55] O. Gil-Castell, J. D. Badia, I. Ontoria-Oviedo, D. Castellano, B. Marco, A. Rabal, J. J. Bou, A. Serra, L. Monreal, M. Blanes, P. Sepúlveda, and A. Ribes-Greus, "In vitro validation of biomedical polyester-based scaffolds: Poly(lactide-co-glycolide) as modelcase," Polym. Test., vol. 66, pp. 256-267, Apr. 2018.

[56] D. . Chen, J. . Bei, and S. . Wang, "Polycaprolactone microparticles and their biodegradation,” Polym. Degrad. Stab., vol. 67, no. 3, pp. 455-459, 2000.

[57] A. P. Bonartsev, A. P. Boskhomodgiev, A. L. Iordanskii, G. A. Bonartseva, A. V. Rebrov, T. K. Makhina, V. L. Myshkina, S. A. Yakovlev, E. A. Filatova, E. A. Ivanov, D. V. Bagrov, and G. E. Zaikov, "Hydrolytic Degradation of Poly(3-hydroxybutyrate), Polylactide and their Derivatives: Kinetics, Crystallinity, and Surface Morphology,” Mol. Cryst. Liq. Cryst., vol. 556, no. 1, pp. 288-300, May 2012.

[58] B. S. Kim and D. J. Mooney, "Development of biocompatible synthetic extracellular matrices for tissue engineering,” Trends Biotechnol., vol. 16, no. 5, pp. 224-229, Dec. 1998.

[59] J. Dulnik, P. Denis, P. Sajkiewicz, and D. Kołbuk, "Biodegradation of bicomponent PCL / Gelatin nanofibres electrospun from alternative solvent system . Structure and properties analysis .,” vol. 364, pp. 8-9, 2015.

[60] C. X. F. Lam, D. W. Hutmacher, J.-T. Schantz, M. A. Woodruff, and S. H. Teoh, "Evaluation of polycaprolactone scaffold degradation for 6 months in vitro and in vivo," J. Biomed. Mater. Res. Part A, vol. 90A, no. 3, pp. 906-919, Sep. 2009.

[61] L. Santonja-Blasco, R. Moriana, J. D. Badía, and A. Ribes-Greus, “Thermal analysis applied to the characterization of degradation in soil of polylactide: I. Calorimetric and viscoelastic analyses,” Polym. Degrad. Stab., vol. 95, no. 11, pp. 2185-2191, Nov. 2010.

[62] J. D. Badia, E. Strömberg, S. Karlsson, and A. Ribes-Greus, "Material valorisation of amorphous polylactide. Influence of thermo-mechanical degradation on the morphology, segmental dynamics, thermal and mechanical performance,” Polym. Degrad. Stab., vol. 97, no. 4, pp. 670-678, Apr. 2012.

[63] O. Gil-Castell, J. D. D. Badia, T. Kittikorn, E. Strömberg, M. Ek, S. Karlsson, A. RibesGreus, E. Strömberg, M. Ek, S. Karlsson, and A. Ribes-Greus, "Impact of hydrothermal ageing on the thermal stability, morphology and viscoelastic performance of PLA/sisal 
biocomposites,” Polym. Degrad. Stab., vol. 132, pp. 87-96, Mar. 2016.

[64] J. D. Badia, T. Kittikorn, E. Strömberg, L. Santonja-Blasco, A. Martínez-Felipe, A. Ribes-Greus, M. Ek, and S. Karlsson, "Water absorption and hydrothermal performance of PHBV/sisal biocomposites,” Polym. Degrad. Stab., vol. 108, pp. 166-174, Oct. 2014.

[65] O. Gil-Castell, J. D. D. Badia, T. Kittikorn, E. Strömberg, A. Martínez-Felipe, M. Ek, S. Karlsson, and A. Ribes-Greus, "Hydrothermal ageing of polylactide/sisal biocomposites. Studies of water absorption behaviour and Physico-Chemical performance,” Polym. Degrad. Stab., vol. 108, pp. 212-222, Oct. 2014.

[66] J. D. Badia, L. Santonja-Blasco, A. Martínez-Felipe, and A. Ribes-Greus, "Hygrothermal ageing of reprocessed polylactide," Polym. Degrad. Stab., vol. 97, no. 10, pp. 1881-1890, Oct. 2012.

[67] J. D. Badia, E. Strömberg, T. Kittikorn, M. Ek, S. Karlsson, and A. Ribes-Greus, "Relevant factors for the eco-design of polylactide/sisal biocomposites to control biodegradation in soil in an end-of-life scenario,” Polym. Degrad. Stab., vol. 143, pp. 919, Sep. 2017.

[68] J. D. Badia, E. Strömberg, S. Karlsson, and A. Ribes-Greus, "The role of crystalline, mobile amorphous and rigid amorphous fractions in the performance of recycled poly (ethylene terephthalate) (PET),” Polym. Degrad. Stab., vol. 97, no. 1, pp. 98-107, Jan. 2012.

[69] E. Kuzelova Kostakova, L. Meszaros, G. Maskova, L. Blazkova, T. Turcsan, and D. Lukas, "Crystallinity of Electrospun and Centrifugal Spun Polycaprolactone Fibers: A Comparative Study,” J. Nanomater., vol. 2017, pp. 1-9, Mar. 2017.

[70] X. Wang, H. Zhao, L. S. Turng, and Q. Li, "Crystalline morphology of electrospun poly(e-caprolactone) (PCL) nanofibers,” Ind. Eng. Chem. Res., vol. 52, no. 13, pp. 4939-4949, 2013.

[71] J. Dulnik, P. Denis, P. Sajkiewicz, D. Kołbuk, and E. Choińska, "Biodegradation of bicomponent PCL/gelatin and PCL/collagen nanofibers electrospun from alternative solvent system,” Polym. Degrad. Stab., vol. 130, no. November, pp. 10-21, 2016.

[72] V. Arias, P. Olsén, K. Odelius, A. Höglund, and A.-C. Albertsson, "Selective degradation in aliphatic block copolyesters by controlling the heterogeneity of the amorphous phase,” Polym. Chem., vol. 6, no. 17, pp. 3271-3282, Apr. 2015.

[73] G. L. Brode and J. V. Koleske, "Lactone Polymerization and Polymer Properties,” J. Macromol. Sci. Part A - Chem., vol. 6, no. 6, pp. 1109-1144, Oct. 1972. 


\section{CHAPTER 6 .}

\section{Conclusions and future}

\section{work}


The functionalisation of polymers was considered as a feasible strategy to achieve new requirements for smart applications, under a design-tovalidation research framework. This approach was based on a multi-stage scheme, involving the design, processing, characterisation and validation of the developed polymer-based materials to respond to the outcomeoriented needs for different applications.

The particular conclusions for the different application fields are summarised below.

\section{Photo-stabilisation of polyolefins for outdoor applications}

The photo-stabilisation of raw polypropylene was achieved by means of the incorporation by hot melt extrusion of silicon microparticles (Si) with maleic acid as coupling agent.

The incorporation of Si microparticles at 5 \%wt. into the PP matrix provided high photo-stabilisation and improved the performance of polypropylene at long-term simulated photo-oxidative conditions as demonstrated by the appearance, the crystalline morphology, the mechanical properties and the thermal stability.

\section{Polyelectrolyte membranes for fuel cells}

The functionalisation of poly(vinyl alcohol) (PVA)-based polyelectrolytes for direct ethanol fuel cells (DEFCs) was approached from different perspectives. The crosslinking, blending and combination with organic particles to induce stability and to tailor its electric and proton conductivity were considered.

\section{PVA/SSA/GO-based film membranes}

The cross-linking of poly(vinyl alcohol) (PVA) and sulfonated PVA (SPVA) with sulfosuccinic acid (SSA), along with the combination with 0.25 to $1.00 \%$ wt. of graphene oxide (GO) and SGO resulted in stable membranes after long-term evaluation subjected to service conditions.

The addition of GO and SGO particles allowed to keep proton conductivity and reduce the crossover of ethanol. Both effects were more relevant for membranes functionalised with SGO.

\section{PVA/SSA/GO-based electrospun membranes}

Electrospinning allowed obtaining functionalised nanofibrous PVA/SSA/GO-based and SPVA/SSA/GO-based membranes with controlled size and morphology. The GO contributed to retain humidity, which significantly influenced the proton conductivity. 
The crosslinked nanofibrous membranes were stable after an accelerated hydrothermal assay. The developed nanofibrous composite membranes can be considered as good candidates for being exploited as valuable components for the preparation of polyelectrolyte membranes.

PVA/SSA/CS-based film membranes

Functionalised chitosan (CS)/PVA blended membranes were obtained by means of the combination with sulfosuccinic acid (SSA) as crosslinking and sulfonating agent, and glycerol (GL) as plasticiser. The combination of solvent-casting and thermalcrosslinking permitted to obtain homogeneous membranes with controlled morphology.

All the crosslinked CS/PVA membranes showed a synergetic increase of the thermal stabilities and proton conductivity. However, the increase of CS in the CS/PVA membranes resulted in higher ethanol absorption capability, and showed maxima of diffusion coefficient and proton conductivity for membranes with a 20 and 40 \%wt. of CS. The addition of GL to the CS/PVA membranes reduced the ethanol absorption, the diffusion coefficient and the proton conductivity, and increased the ductile manageability of membranes to be mounted on Membrane Electrode Assembly (MEAs). The membrane 40CS/PVA/20GL showed the best behaviour in the DEFC test.

\section{Scaffolds for tissue engineering}

The functionalisation of electrospun scaffolds for tissue engineering was performed by means of the combination of polyester-based materials with natural polymers to induce biocompatibility, and the control of the molar mass by means of the use of an acid hydrolytic solvent system for the scaffold preparation.

Methodology for the in vitro validation of scaffolds: PLGA scaffolds as a model-case

A methodology for the validation of polyester-based scaffolds was defined by analysing and contrasting different analytical techniques to assess their in vitro hydrolytic degradation and in vitro biocompatibility. Poly(lactide-co-glycolide) (PLGA) scaffolds were considered as a model-case. The results revealed indications to set up an appropriate plan of analysis depending on the balance between the interest in ascertaining the trigger of degradation or deep into the knowledge of the causes and effects along validation. 


\section{Comparative behaviour of polyester-based scaffolds}

The comparison of the behaviour of poly(lactide-co-glycolide) (PLGA), polycaprolactone (PCL), polydioxanone (PDO) and polyhydroxybutyrate (PHB) scaffolds showed two different time lifespan of application. On the one hand, scaffolds for short-time applications were PLGA and PDO, and showed a fast disintegration rate and, subsequently, a pronounced acidification of the medium. On the other hand, scaffolds for long-term applications were PCL and PHB, which resistant pattern was mainly ascribed to the stability of the crystalline domains of the fibres.

\section{PCL-based tailored scaffolds}

Polycaprolactone (PCL) was selected as a promising candidate for scaffold development. In order to tailor the morphology and the future performance of these scaffolds, the control of the hydrolysis of the PCL was considered as a function of the dissolution time into a formic/acetic acid mixture prior to electrospinning.

Bead-free fibres were found for scaffolds electrospun after 24 and $48 \mathrm{~h}$ of dissolution time, with similar diameter. The decrease of the fibre diameter along with the apparition of beads was especially significant for scaffolds prepared after $72 \mathrm{~h}$ and $120 \mathrm{~h}$ of dissolution time. A reduction of the molar mass and the lamellar thickness as well as an increase of the crystallinity degree were observed as hydrolysis degree progressed in the PCL.

The service life of the obtained scaffolds, evaluated by means of in vitro assays under abiotic physiological conditions, revealed that, in general, the molar mass was barely affected and the crystallinity degree and the lamellar thickness increased along immersion, preventing scaffolds from degradation. Scaffolds prepared after 24 and $48 \mathrm{~h}$ kept their fibre diameters, whereas those prepared after 72 $\mathrm{h}$ and $120 \mathrm{~h}$ showed a significant reduction. This PCL tailoring procedure to obtain scaffolds that maintained the nanoscaled structure after such long in vitro evaluation will bring new opportunities in the design of long-term biomedical patches.

\section{PCL/Ge-based tailored scaffolds}

Nanofibrous scaffolds based on polycaprolactone (PCL) and gelatin (Ge) were prepared in several compositions ranging from 100/0 to 20/80 \%wt. to induce biocompatibility and degradability. The hydrolysis of the PCL in the formic/acetic acid mixture daily up to $120 \mathrm{~h}$ was also considered as a tailoring method for the PCL/Ge scaffolds. Although the fibre diameter remained in the nanoscale range for all the studied scaffolds, the reduction of the molar mass 
of the PCL molecules as a function of the dissolution time, diminished the entanglement capability of the polymeric chains, and reduced the fibre diameter. Whereas the crystallinity of the scaffolds with high PCL content increased as a function of the dissolution time, the scaffolds with high percentage of Ge showed the lowest crystallinity degree, which was ascribed to the hindering effect of the Ge diffused among the PCL segments. The wettability increased as a function of the Ge content due to its high hydrophilic behaviour. It also increased as a function of the dissolution time, due to the availability of more hydroxyl groups in the PCL segments to interact with water molecules.

The in vitro cell adhesion and proliferation was found to be strongly influenced by the PCL/Ge composition. In this context, the 60/40, 50/50 and 40/60 PCL/Ge compositions were the most cellcompatible scaffolds. The increase in the dissolution time slightly decreased the cell-compatibility, being less prominent for the 40/60 PCL/Ge scaffolds.

The in vitro degradation in physiologic conditions of the 60/40, 50/50 and 40/60 PCL/Ge scaffolds revealed a progressive behaviour as a function of the composition and dissolution time. In general, the release of the Ge fraction of the scaffolds during immersion was perceived. While the molar mass of PCL was barely affected, the crystallinity degree and the lamellar thickness developed during immersion. The scaffolds electrospun after high dissolution time revealed a weakened structure, more labile to in vitro degradation. This effect was more significant for the scaffold containing high percentage of Ge, i.e. the 40/60 PCL/Ge.

The in vitro biocompatibility of the 40/60 PCL/Ge scaffolds was corroborated by means of the absence of inflammatory reactions. The dissolution time promoted an increase of the cytokines IL- $1 \beta$ and IL-6 expression levels, within a suitable performance range. Indeed, this was not a chronic effect, as no inflammatory response was observed after the 15 day subcutaneous in vivo implantation in mice.

As a general conclusion, monitoring and understanding the in vitro behaviour of polymer scaffolds both comprising the study of the hydrolytic degradation and the cell seeding viability was essential to ensure the desired functionality, according to a given biomedical purpose. 


\section{Future work}

The field of polymer modification and functionalisation is in continuous expansion. The possibilities to deepen and develop the research lines proposed in this thesis are extensive. Figure 6.1 summarises the currently developed work in terms of materials, morphology and processing techniques. In this sense, the future work will involve the development of new materials and compositions but also the progress by alternative.

The future work is likewise open to new research lines in which the methodology proposed in this thesis could be applied following a designprocessing-characterisation-validation approach.

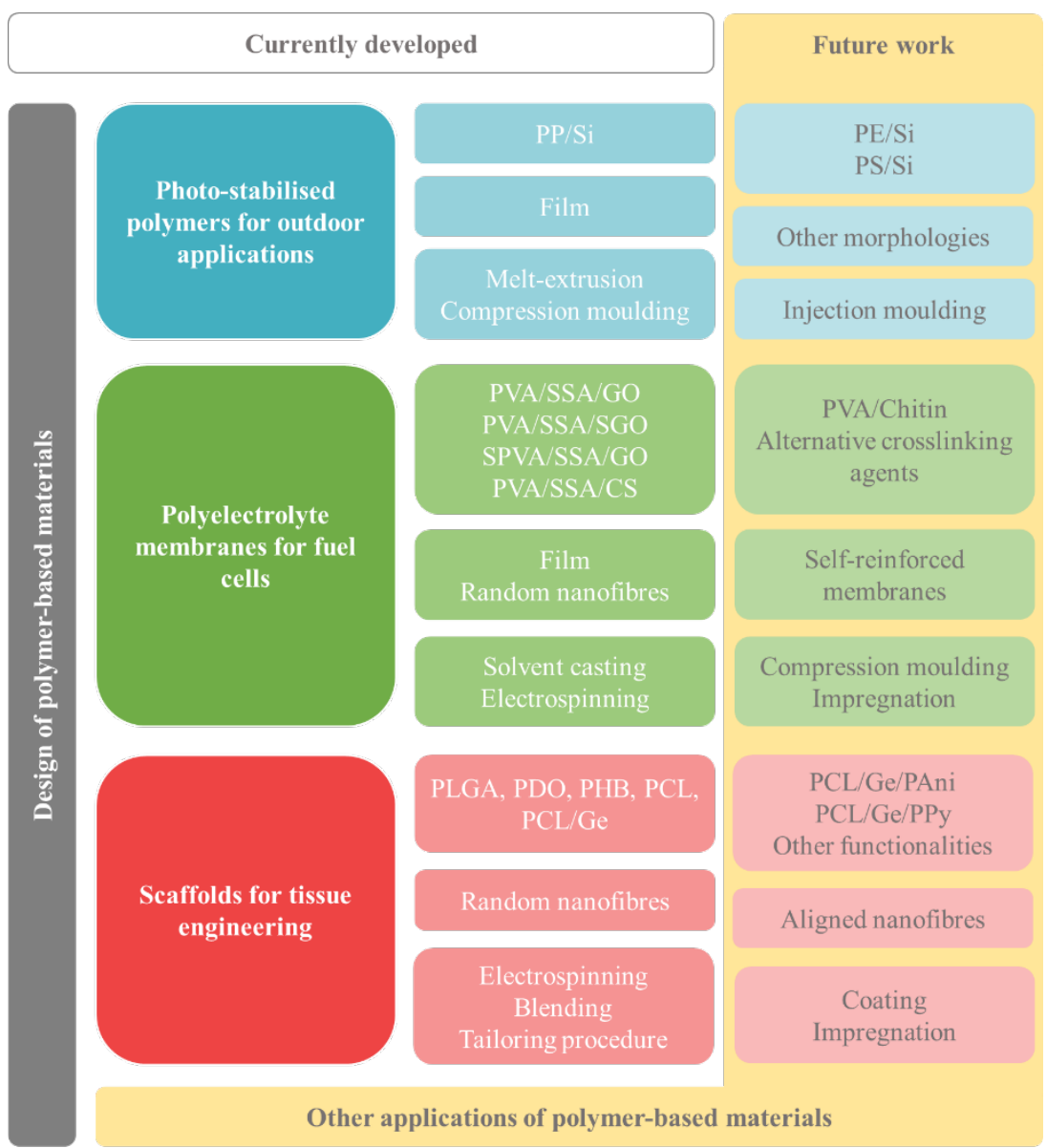

Figure 6.1. Correlation between current and future work. 


\section{Glossaries}




\section{ABbreviations}

AC

ACTB

AFM

AIDS

AITEX

ASTM

ATP

ATR

BDIS

CCD

$\mathrm{CH}$

CNT

CPD

CRU

CS

CSIC

Ctrl

DAFC

DAPI

DC

DETA

DLS

DMF

DMTA

DNA

DREMAP

DSC

DT

DTG

ECM

EN

FBS

FE-SEM

FR

FTIR
Alternating current

Human housekeeping actin-beta

Atomic force microscopy

Acquired immune deficiency syndrome

Textile Research Institute

American Society for Testing Materials

Adenosine triphosphate

Attenuated total reflectance

Broadband dielectric impedance spectrometer

Charge-coupled device

Chitin

Carbon nanotubes

Crytical point drying

Constitutional repeating unit

Chitosan

Consejo Superior de Investigaciones Científicas

Control

Direct alcohol fuel cell

4',6-diamidino-2-phenylindole

Direct current

Dielectric thermal analysis

Dynamic light scattering

Dimethylformamide

Dynamic mechanical-thermal analysis

desoxiribonucleic acid

Research Group of Functionalisation, Degradation and

Recycling of Polymer Materials

Differential scanning calorimetry

Dissolution time

Derivative thermogravimetric curve

Extra-cellular matrix

European Standards Organisation

Foetal bovine serum

Field-emission scanning electron microscopy

Feeding rate

Fourier transformed infrared spectroscopy 
FWMH Full width at medium height

GA Gluteraldehyde

GC Gas chromatography

Ge Gelatin

GL Glycerol

GO Graphene oxide

GPC Gel permeation chromatography

HA Hyaluronic acid

HaCaT Human keratinocites

HALS Hindered amine light stabiliser

HFIP Hexafluoroisopropanol

HL-1 Mice cardiomyocites

HPA Heteropolyacids

HV Hydroxyvalerate

ICTP Instute of Polymer Science and Technology

IIS La Fe Sanitary Investigation Institute $\mathrm{La} \mathrm{Fe}$

IR Infrared

ISO International Organisation for Standarisation

ITM Materials Technology Institute

IUPAC International Union of Pure and Applied Chemistry

IV Intrinsic viscosity

KTH Kungliga Tekniska Högskolan

LALS Low angle light scattering

LCA Life cycle assessments

LMWC Low molar mass compounds

M. Sc. Master of Science

MAH Maleic anhydride

MALDI- Matrix-assisted laser desorption-ionization time-of-flight

TOF-MS Mass spectrometry

MEA

Membrane-electrode assembly

MFI Melt flow index

MODA Microbial oxidative degradation analyser

MTT Methyl tetrazolium

MWD Molar mass distribution

NC Non-crosslinked

NMR Nuclear magnetic resonance

OIT Oxidation induction time

PAA Poly(acrylic acid)

PAni Polyanyline 


$\begin{array}{ll}\text { PBAT } & \text { Poly(butylene adipate terephthalate) } \\ \text { PBF } & \text { Poly(butylene fumarate) } \\ \text { PBMC } & \text { Peripheral blood mononuclear cell } \\ \text { PBMNC } & \text { Isolated peripheral blood mononuclear cells } \\ \text { PBS } & \text { Poly(butylene succinate) } \\ \text { PBS } & \text { Phosphate buffered saline } \\ \text { PCL } & \text { Polycaprolactone } \\ \text { PCL } & \text { Polycaprolactone } \\ \text { PDI } & \text { Polydispersity index } \\ \text { PDO } & \text { Polydioxanone } \\ \text { PDX } & \text { Polydioxanone } \\ \text { PE } & \text { Polyethylene } \\ \text { PEDOT } & \text { Poly(3,4-ethylenedioxythiophene) } \\ \text { PEM } & \text { Polyelectrolyte membrane } \\ \text { PEMFC } & \text { Proton exchange membrane fuel cell } \\ \text { PET } & \text { Poly(ethylene terephtalate) } \\ \text { PFA } & \text { Paraformaldehyde } \\ \text { PGA } & \text { Poly(glycolic acid) } \\ \text { PGS } & \text { Poly(glyceryl sebacate) } \\ \text { Ph. D. } & \text { Phylosophiæ Doctor } \\ \text { PHAs } & \text { Polyhydroxyalkanoates } \\ \text { PHB } & \text { Polyhydroxybutyrate } \\ \text { PHBV } & \text { Poly(hydroxybutyrate-co-valerate) } \\ \text { PHV } & \text { Polyhydroxyvalerate } \\ \text { PI } & \text { Polyimide } \\ \text { PLA } & \text { Poly(lactic acid) or poly(lactide) } \\ \text { PLGA } & \text { Poly(lactic-co-glycolic acid) or Poly(lactide-co-glycolide) } \\ \text { PP } & \text { Polypropylene } \\ \text { PPF } & \text { Poly(propylene fumarate) } \\ \text { PPG } & \text { Poly(propylene glycol) } \\ \text { PPy } & \text { Polypyrrole } \\ \text { PS } & \text { Polystyrene } \\ \text { PSSA } & \text { Polystyrene(sulfonic acid) } \\ \text { PSSA } & \text { Polystyrene(sulfonic acid-co-maleic acid) } \\ \text { PSU } & \text { Polysulfone } \\ \text { PSW } & \text { Plastic solid waste } \\ \text { PTFE } & \text { Polytetrafluoroethylene } \\ \text { PVA } & \text { Poly(vinyl alcohol) } \\ \text { PVB } & \text { Poly(vinyl butyral) } \\ & \end{array}$


PVC Poly(vinyl chloride)

PVDF Polyvinylidenefluoride

RALS Right angle light scattering

RETRACAR Cardiac Regeneration and Transplantation Group

$\mathrm{RH}$ Relative humidity

RI Refractive index

RNA Ribonucleic acid

RT-PCR Real-time polymerase chain reaction

SD Standard deviation

SDS Sodium dodecyl sulfate

SEA Sample-electrode assembly

SEC Size exclusion chromatography

SGO Sulfonated graphene oxide

SPEEK Sulfonated poly(ether-ether-ketone)

SPES Sulfonated poly(ether-sulfone)

SPVA Sulfonated poly(vinyl alcohol)

SSA Sulfosuccinic acid

TE-EC End-chain transesterifications

TEM Transmission electron microscopy

TE-MC Middle-chain transesterifications

TG Thermogravimetric curves

TGA Thermogravimetric analysis

THF Tetrahydrofuran

TPS Thermoplastic starch

UPV Universitat Politècnica de València

USA United States of America

UV Ultraviolet

VISC Viscosity 


\section{SYMBOLS}

A

C

C

D

$\Delta$

E

$E^{\prime}$

$E^{\prime \prime}$

$h_{c}$

$h_{m}$

I

In

L

l

$l_{c}$

$m$

$M_{n}$

$M_{w}$

$M_{z}$

$N$

$\varnothing$

$P_{\max }$

$R$

$\mathrm{Rg}$

$R h$

$\mathrm{Si}$

$T_{0}-T_{\text {onset }}$

$T_{c}$

$T_{d}$

$T_{e}-T_{\text {endset }}$

$T_{g}$

$T_{m}$

$T_{p}-T_{\text {peak }}$

V

$X$

$X_{c}$
Area

Capacitance

Crosslinked

Diffusion coefficient

Increment

Voltage

Storage modulus

Loss modulus

Crystallisation enthalpy

Melting enthalpy

Current

Indium

Inductance

Thickness

Lamellar thickness

Mass

Average molar mass in number

Average molar mass in weight

Higher average molar mass

Number

Average fibre diameter

Maximum power

Resistance

Radius of giration

Hydrodynamic radius

Silicon

Onset temperature

Crystallisation temperature

Degradation (decomposition) temperature

Endset temperature

Glass transition temperature

Melting temperature

Peak temperature

Voltage

Reactance

Crystallinity degree 


$\begin{array}{ll}Z & \text { Impedance } \\ \mathrm{Zn} & \text { Zinc } \\ \delta & \text { Phase angle } \\ \varepsilon & \text { Deformation } \\ \theta & \text { Contact angle } \\ \theta & \text { Phase angle } \\ \lambda & \text { Wavelength } \\ \rho & \text { Density } \\ \sigma & \text { Tension } \\ \sigma_{\text {elec }} & \text { Electric conductivity } \\ \sigma_{\text {prot }} & \text { Proton conductivity }\end{array}$


Other contributions 


\section{JOURNAL ARTICLES}

O. Gil-Castell, J.D. Badia, T. Kittikorn, E. Strömberg, A. Martínez-Felipe, M. Ek, S. Karlsson, A. Ribes-Greus. Hydrothermal ageing of polylactide/sisal biocomposites. Studies of water absorption behaviour and physico-chemical performance. Polymer Degradation and Stability, 2013;108:212-222

O. Gil-Castell, J.D. Badia, T. Kittikorn, E. Strömberg, M. Ek, S. Karlsson, A. Ribes-Greus. Impact of hydrothermal ageing on the thermal stability, morphology and viscoelastic performance of PLA/sisal biocomposites. Polymer Degradation and Stability, 2016;132:87-96

O. Gil-Castell, J.D. Badia, A. Ribes-Greus. Suitability of Blends from Virgin and Reprocessed Polylactide: Performance and Energy Valorization Kinetics. Accepted for publication in Journal of Renewable Materials, 2017

O. Gil-Castell, J.D. Badia, S. Inglés-Mascarós, R. Teruel-Juanes. A. Serra, A. Ribes-Greus. Polylactide-based self-reinforced composites biodegradation: individual and combined influence of temperature, water and compost. Accepted for publication in Polymer Degradation and Stability, 2018 


\section{CONFERENCE CONTRIBUTIONS}

J.D. Badia, E. Strömberg, T. Kittikorn, O. Gil-Castell, M. Ek, A. RibeGreus, S. Karlsson. Biodegradation in soil effects on PLA/sisal and PHBV/sisal biocomposites. 21 ${ }^{\text {st }}$ Bio-Environmental Polymer Society (BEPS 2013). Coventry, United Kingdom, 18/09/2013 - 20/09/2013

M. Bermejo, M. Schmitt, S. Sanchez-Ballester, O. Gil-Castell, R. TeruelJuanes, M. Rosado-Gil, L. Santonja-Blasco, A. Martínez-Felipe, I. Rodríguez, F. Meseguer, A. Ribes-Greus. Silicon colloids light-UV stabilisers of polystyrene and polypropylene. $13^{\text {th }}$ Baltic Polymer Symposium (BPS 2013). Vilnius, Lietuva, 19/09/2013 - 21/09/2013

P. Fernandez, T. Lamberty, S. Sánchez-Ballester, O. Gil-Castell, R. TeruelJuanes, M. Rosado-Gil, A. Martínez-Felipe, V. Soria, A. Ribes-Greus. Blends of PAA and ionomers LC copolymers for electrolytes in DMFC and DEFC. $13^{\text {th }}$ Baltic Polymer Symposium (BPS 2013). Vilnius, Lietuva, 19/09/2013 - 21/09/2013

O. Gil-Castell, S. Sánchez-Ballester, R. Teruel-Juanes, M. Rosado-Gil, J.D. Badia, A. Martínez-Felipe, A. Ribes-Greus. Influence of maleic anhydride as coupling agent in PLA/sisal biocomposites under hydrothermal degrading conditions. $13^{\text {th }}$ Baltic Polymer Symposium (BPS 2013). Vilnius, Lietuva, 19/09/2013 - 21/09/2013

O. Gil-Castell, M. Rosado-Gil, S. Sánchez-Ballester, R. Teruel-Juanes, C. Moliner, A. Martínez-Felipe, J.D. Badia, A. Ribes-Greus. Influence of sisal fibers on thermal decomposition of poly(hydroxibutyrate-co-valerate) biocomposites. $13^{\text {th }}$ Baltic Polymer Symposium (BPS 2013). Vilnius, Lietuva, 19/09/2013 - 21/09/2013

O. Gil-Castell, J.D. Badia, T. Kittikorn, E. Strömberg, A. Martínez-Felipe, M. Ek, S. Karlsson, A. Ribes-Greus. Hydrothermal ageing of polylactide/sisal biocomposites. studies of water absorption behaviour and phisico-chemical performance. $4^{\text {th }}$ International Conference on Biodegradable and Biobased Polymers (BIOPOL 2013). Roma, Italy 01/10/2013 - 03/10/2013

A. Salvador-Andreu, O. Gil-Castell, J.D. Badia, A. Ribes-Greus. Recycled polylactide blends as an alternative to polyolefin in disposable applications. $5^{\text {th }}$ International Conference on Polyolefin Characterization (ICPC 2014) Valencia, Spain, 21/09/2014 - 23/09/2014

A. Montesinos, O. Gil-Castell, J.D. Badia, I. Rodríguez, F. Meseguer, A. Ribes-Greus. Thermal characterisation of non-additivated raw polypropylene/Silicon colloidal composites. $5^{\text {th }}$ International Conference 
on Polyolefin Characterization (ICPC 2014) Valencia, Spain, 21/09/2014 23/09/2014

O. Gil-Castell, J.D. Badia, A. Ribes-Greus. Monitorización de la degradación in vitro de un scaffold de PLGA de elevada porosidad. Comparación del proceso de hidrólisis en agua y en PBS. I Congreso Biomedicina Predocs Valencia (CONBIOPREVAL 2014). Valencia, Spain, 27/11/2014 - 28/11/2014

O. Gil-Castell, J.D. Badia, R. Teruel-Juanes, T. Kittikorn, E. Strömberg, M. Ek, S. Karlsson, A. Ribes-Greus. Influence of combined water and temperature on the morphology, thermal and viscoelastic performance of polylactide/sisal biocomposites. $5^{\text {th }}$ International Conference on Biobased and Biodegradable Polymers (BIOPOL 2015); San Sebastián, Spain, 06/10/2015 - 09/10/2015

O. Gil-Castell, J.D. Badia, A. Ribes-Greus. Tailoring the morphology of nanofibrous poly( $\varepsilon$-caprolactone) scaffolds for biomedical applications. II Congreso Biomedicina Predocs Valencia (CONBIOPREVAL 2015). Valencia, Spain, 26/11/2015 - 27/11/2015

O. Gil Castell, M. Gómez, J.D. Badia, D. Castellano, P Sepúlveda, A. Ribes-Greus. Development and validation of tailored electrospun nanofibrous poly(caprolactone)/gelatin based scaffolds. I Congreso Nacional de Jóvenes Investigadores en Biomedicina - III Congreso Biomedicina Predocs Valencia (CONBIOPREVAL 2016); Valencia, Spain, 28/11/2016 - 29/11/2016

S. Ingles-Mascaros, O. Gil-Castell, J.D. Badia, A. Ribes-Greus. Performance of self-reinforced composites based on polylactide subjected to biodegradation in soil. $6^{\text {th }}$ International Conference on Biodegradable and Biobased Polymers (BIOPOL 2017). Mons, Belgium, 11/09/2017 13/09/2017

D. Galindo-Alfaro, O. Gil-Castell, J.D. Badia, A. Ribes-Greus. Development of functionalised PVA-based mixed matrix membranes as proton exchange polymer electrolytes. $6^{\text {th }}$ International Conference on Biodegradable and Biobased Polymers (BIOPOL 2017). Mons, Belgium, 11/09/2017 - 13/09/2017

O. Gil-Castell, R. Cerveró, R. Teruel-Juanes, J.D. Badia, A. Ribes-Greus. Obtaining, characterisation and preliminary validation of functionalised poly (vinyl alcohol)/graphene oxide membranes for energy applications. International Conference on Materials \& Energy (ICOME 2018). San Sebastian, Spain, 30/04/2018 - 04/05/2018

R. Teruel-Juanes, C. Del Rio, O. García, O. Gil-Castell, J.D. Badia, A. Ribes-Greus. Correlation between dielectric analysis and monocell 
performance for photocrosslinked and post-sulfonated sebs-based membranes. International Conference on Materials \& Energy (ICOME 2018). San Sebastian, Spain, 30/04/2018 - 04/05/2018

O. Gil-Castell, R. Cerveró, R. Teruel-Juanes, J.D. Badia, A. Ribes-Greus. Poly(vinyl alcohol) based membranes with sulfonated graphene oxide and graphene oxide particles for fuel cell applications. Euromembrane 2018, Valencia, Spain, 09/07/2018 - 13/07/2018

O. Gil-Castell, J.D. Badia, I. Ontoria, D. Castellano, P. Sepúlveda, A. Ribes-Greus. In vitro evaluation of tailored nanofibrous polycaprolactone/gelatin membranes for biomedical applications. Euromembrane 2018. Valencia, Spain, 09/07/2018 - 13/07/2018 


\section{SCIENTIFIC DIVULGATION ARTICLES}

O. Gil-Castell, J.D. Badia, A. Ribes-Greus. Recuperación de bioplásticos: presente y futuro. Plásticos Modernos. 107-686:15-20. Focitec, 01/01/2014

J.D. Badia, O. Gil-Castell, R. Teruel-Juanes, A. Ribes-Greus. La falsa dicotomía del diseño para la sostenibilidad. Revista AVEP. 101:18-21. Asociación Valenciana de Empresarios del Plástico, 03/01/2017 


\section{Acknowledgements}




\section{Gràcies.}

Gràcies és la primera paraula que em ve a la ment, ara que és l'hora de fer balanç d'aquestos últims anys. Tot i que els que em conegueu sabeu que manque de romanceria, vaig a tractar d'obrir el meu pensament i compartir amb vosaltres la meua experiència. Això sí, serè breu i concís.

Tractant de remuntar-me en el temps, he d'anar fins al segon quadrimestre del segon curs d'Enginyeria, on va començar tot. Dintre del maremàgnum enginyeril, vaig trobar una llum, el reclam d'una matèria interessant, plena de nous reptes i problemes reals que afrontar, els polímers. Vosaltres Amparo i José, plantàreu en mi la llavor, no només del meu interès en la ciència de materials plàstics, sinó que a més em sembrareu la motivació per seguir, pas a pas, el camí de la recerca, de la constància, de l'aprenentatge continu i de la superació diària. He crescut. Molt. Gràcies al vostre recolzament incondicional, ara sóc millor persona, company, investigador, orientador, docent i estic segur que amic també.

Ara, després d'assolir les fites del treball de fi de carrera i treball de fi de màster, hem aconseguit vèncer el llarg camí de la tesi doctoral. I no només l'hem vençut, sinó que hem superat totes les expectatives. Hem batut moments d'incertesa, a nivell personal i professional, hem gestionat la motivació i hem augmentat l'exigència en nosaltres mateixos per tal d'assolir tots i cadascun dels objectius marcats. Ara és el moment d'assaborir i mirar amb perspectiva allò que hem aconseguit, que no és poc.

De nou, Amparo, gràcies per la teua completa disposició i per la teua admirable tenacitat. El teu exemple de resiliència i de lluita ens demostra que no hi ha res impossible. Simplement es tracta de trobar la manera alternativa de superar els obstacles. La teua devoció per la feina ben feta i el segell de qualitat són dos de les teues virtuts més valuoses, i que estic segur que m'ajudaran en aquesta nova i successives etapes. Gràcies per donar-me la oportunitat de formar part de la història del Grup.

José, director, company i amic, has sigut, eres i seràs un mirall al qual veure's reflectit. No només a nivell professional, que també, sinó millor encara amb totes les diverses facetes en que m'has oferit la teua valuosa perspectiva. Més que l'immens coneixement que m’has transmès, em quede amb la teua genial visió de la vida, eixa amb la qual tot canvia de color i que tracte de fer meua sempre que puc. Gràcies per la teua incondicionalitat, paciència i innombrables consells.

El Grup, quin Grup! Un Grup en continua evolució, amb alts i baixos, com a totes les cases, però amb un innegable sentiment d'unitat, de tots a una, de respecte i d'amistat. Em sent afortunat i estic segur que no hi ha millor grup que aquest, el que em va escollir per dur a terme aquesta gran tasca. 
Som multidisciplinars, multiculturals, multilingües, multinacionals, multitasca, transversals, politècnics, polivalents, polifacètics, ...polí-mers? Per suposat, we can do it! Però we couldn't have done it sense tu, Roberto, Soraia, Carlos, Carmem, Borja, Vicent, Víctor, Llúcia, Ma Ángeles, Laura i Cristina. Hem compartit infinites hores de feina, viatges, risses, discussions, alegries i decepcions, però sobretot d'amistat i d'harmonia.

No voldria oblidar-me de tots els qui han fet possible de forma directa o indirecta, que aquesta aventura arribara a tan bon port com així ha sigut. Des del nord d'Europa fins al sud d'Amèrica, m'agradaria recordar el les aportacions de tots els qui han sigut partícips d'aquest procés.

A tots els que han passat pel nostre laboratori, per aportar noves experiències i perspectives en aquest món de la recerca, especialment a Eva, Janise, Javiera, Daniel i Silvia.

Gràcies a les professores Sigbritt Karlsson i Emma Strömberg per la seua supervisió a les meues estades a Estocolm. D’allà també vull recordar als meus benvolguts companys i amics Antonio i Ana Isabel, per fer-me sentir com a casa a més de 3000 quilòmetres de la meua llar. Gràcies també a Hajar, Husam, Thibaut, Dani i Laura, per fer les estades més entretingudes.

Voldria agrair als docents Vicent Amigó, Alfonso Cárcel, Oscar Sahuquillo, David Busquets, Francisco Segovia, Amparo Broseta, Alejandro Sanchez i Vicente Climent per haver-me recolzat al llarg de les meues primeres experiències amb la docència. Ha sigut una vivència apassionant. Així mateix, una menció especial per als tècnics de laboratori Inmaculada, $\mathrm{M}^{\mathrm{a}}$ Carmen i Fidel, per facilitar sempre que han pogut aquesta tasca com a docent. En aquesta línia, moltes gràcies a Toni, Adrian, Diana, Sara, Karla, Raquel, Francesca i Giovanni. Gràcies per donar-me la oportunitat d’aportar el millor de mi a la vostra formació.

Recordar també la col·laboració especial, sempre amable i disposta, dels integrants del Servei de Microscopia Electrònica de la UPV, concretament, Merche, Ximo, Alicia, José Luís i Manolo.

Per descomptat, agrair la col·laboració fonamental del grup de Regeneració i Transplantament Cardíac (RETRACAR) de l'Institut d'Investigació Sanitaria La Fe, dirigit per la Dra. Pilar Sepúlveda. Ha sigut magnífic i enormement enriquidor treballar amb vosaltres, Pilar, Imelda, Delia i Marta. M'heu aportat noves visions i perspectives de la ciència de materials per aplicacions biomèdiques. Espere que aquesta col-laboració siga ben fructífera i prolongada.

Gràcies Eva i Marga per les vostres valuoses gestions al llarg d'aquest camí. Heu sigut de gran ajuda amb tots els tràmits i burocràcia propis de la realització d'aquesta tesi doctoral. 
Per últim, i no menys important, voldria agrair-vos a vosaltres, els de casa, que heu estat amb mi des del principi.

Papà i mamà, heu aconseguit forjar-me com a persona, en aspectes tan importants com la responsabilitat, el seny, l'esforç i la constància. De vosaltres he aprés el significat de l'ordre, la perseverança i la sensatesa, així com també de l'empatia i simpatia, del bon tracte i del respecte per tot el qui ens envolta. M'heu donat tot. Heu estat a les dures i a les madures. Ara, només espere estar a l'altura de les circumstàncies i que el tancament d'aquesta etapa vos plene d’orgull i satisfacció. Va per vosaltres!

Cosins, cosines, tios, ties, iaios i iaies, els qui esteu i els qui ja no, tots heu aportat el vostre granet d'arena en mi i en la construcció de la meua persona. Vicente, Consue, Pepe, Consue, Josele, Jordi, Emilio, Amalia, Pepita, Emilio, Ricardo, Eva, Ausias, Alba, Carlos, Rosaura, Carlos, Sonia, Pepe i Amparo. Gràcies família.

Maru i Pedro, gràcies a vosaltres he conegut noves perspectives de la vida. No penseu que la vostra col·laboració ha sigut baladí. Heu fet que em senta sempre com a casa, valorat, comprés i apreciat. M’heu acollit com un més de la família i m’heu recolzat sempre que ho he necessitat. Gràcies de tot cor! També a vosaltres, Erica i Toni per formar part d’aquesta família, la que un es troba, i amb la qual pot comptar sempre que ho necessita. Paula, la meua nineta, que encara que tots pensen que eres menudeta, res més lluny de la realitat, eres molt gran i estic segur que aconseguiràs tot allò que et proposes.

I tu, Maria, mereixes una menció especial. Quan menys t’esperava, aparegueres per convertir-te en companya inseparable de viatge i aventures. Junts hem crescut, hem lluitat, hem plorat i hem rigut també. Has estat sempre a l'altura de les situacions i has aportat en mi grans dosis d'estima i serenitat. Estic convençut que formem un gran equip i, per descomptat, que serem grans i triomfarem. Gràcies per donar-me la oportunitat de formar part del teu passat, present i futur. T’estime.

Amb tot, espere no haver-me oblidat de tu, en aquests moments de nerviosisme, retocs, anades i tornades. Si així ha sigut, et demane disculpes i et done les gràcies.

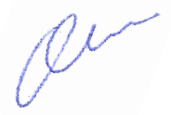

Óscar Gil. 
